\title{
ESTRUTURAS DE PISOS DE EDIFÍCIOS COM A UTILIZAÇÃO DE CORDOALHAS ENGRAXADAS
}

\author{
Fernando Menezes de Almeida Filho
}

Dissertação apresentada à Escola de Engenharia de São Carlos, da Universidade de São Paulo, como parte integrante dos requisitos para obtenção do Título de Mestre em Engenharia de Estruturas.

ORIENTADOR: Prof. Dr. Márcio Roberto Silva Corrêa

São Carlos

2002 
FOLHA DE JULGAMENTO

Candidato: Engenheiro FERNANDO MENEZES DE ALMEIDA FILHO

Dissertação defendida e julgada em 15-07-2002 perante a Comissåo Julgadora:

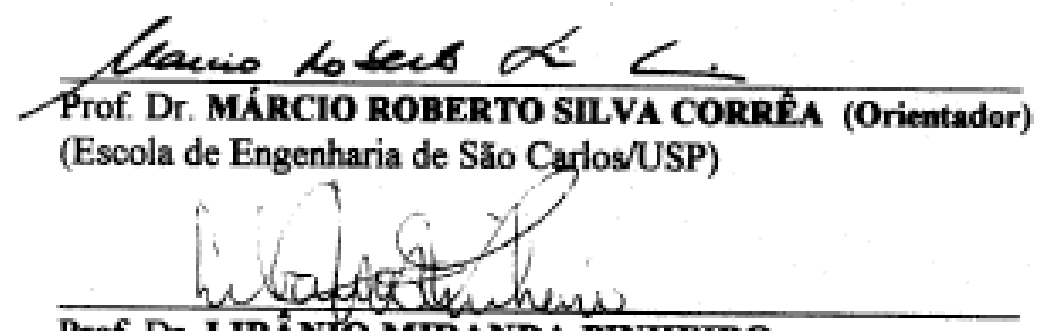

Aprovato

Prof. Dr. LIBÁNIÓ MIRANDA PINHEIRO

APRCVADO

(Escola de Engenharia de Săo Carlos/USP)

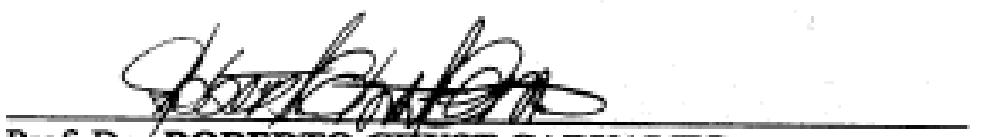

Prof. Dr. ROBERTO CHUST CARVALHO

(Universidade Federal de São Carlos/UFSCar)

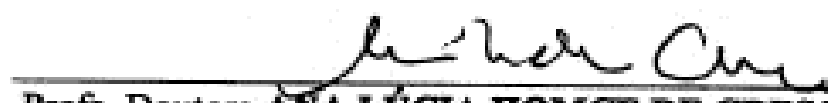

Profa. Doutora ANA LÚCIA HOMCE DE CRESCEEL DEBS

Coordenadora do Programa de Pós-Graduaçăo em

Engenharia Civil (Engenharia de Estruturas)

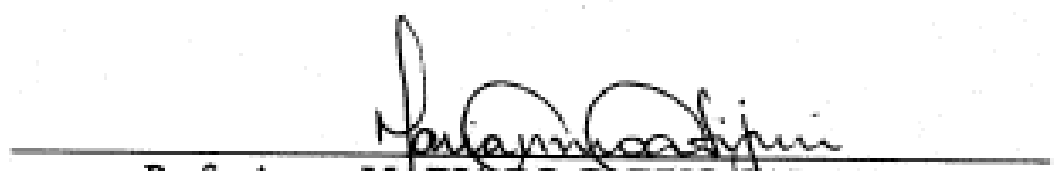

Profa. Assoc. MARIA Do CARMO CALIJURI

Presidente da Comissão de Pós-Graduaçăo 
A Deus e aos meus pais, que sempre acreditaram e me apoiaram em tudo. 


\section{AGRADECIMENTOS}

A Deus, por iluminar minha trilha com minha Familia e meus Amigos.

A toda a minha Família, em especial, à memória de minha querida avó, que sempre nos educou com alegria e sabedoria.

A minha querida Ana Cláudia, uma pessoa muito especial, que pelo enorme carinho, presença e sabedoria, propiciaram grandes momentos de amor, alegria e paz.

Ao Prof. Márcio Corrêa, pela excelente orientação, amizade e confiança que, mesmo à distância, foram sempre presentes.

Aos Professores João Bento de Hanai e Roberto Chust de Carvalho, pelas contribuições no Exame de Qualificação.

Aos meus grandes amigos de Fortaleza, em especial, Ednardo e Daniel, que, mesmo tão longe, sempre lembraram de nossa amizade.

Aos Professores Joaquim Mota e Magnólia, que foram fontes de minha inspiração para a engenharia de estruturas e aos Engenheiros Hélder Martins, Marcelo Silveira e Ricardo Brígido, pela contribuição no desenvolvimento desta pesquisa.

À TQS Informática pela ajuda no desenvolvimento dos modelos protendidos, em especial, ao eng. Nelson Covas pela confiança e ao eng. Luiz Aurélio pela paciência e amizade.

A todos os meus amigos do mestrado que, direta ou indiretamente, contribuíram para a conclusão desta pesquisa, em especial, Rodrigo Delalibera, Ricardo Dias, Ricardo Carrazedo, André Luís, Gustavo Tristão, Ângela, Fábio, Clayton, Andrei, Ricardo Rizzo, Johnny, Malton e João de Deus.

Ao CNPq, pela bolsa de estudos para o mestrado.

Aos demais professores e funcionários do Departamento de Engenharia de Estruturas que colaboram para o desenvolvimento do trabalho. 


\section{SUMÁRIO}

RESUMO

$\mathrm{V}$

ABSTRACT

vi

$\begin{array}{ll}\text { 1. INTRODUÇÃO } & 01\end{array}$

$\begin{array}{ll}1.1 \text { OBJETIVOS } & 02\end{array}$

$\begin{array}{ll}1.2 \text { JUSTIFICATIVA } & 02\end{array}$

$\begin{array}{ll}1.3 \text { METODOLOGIA } & 03\end{array}$

1.4 APRESENTAÇÃO DO TRABALHO 04

2. CONSIDERAÇÕES GERAIS 05

2.1 HISTÓRICO DO CONCRETO PROTENDIDO 05

2.2 PROTENSÃO NÃO ADERENTE 08

$\begin{array}{ll}2.3 \text { REVISÃO BIBLIOGRÁFICA } & 10\end{array}$

2.4 VANTAGENS E DESVANTAGENS 33

2.5 SISTEMAS UNIDIRECIONAIS E BIDIRECIONAIS 34

2.6 UTILIZAÇÃO - SISTEMAS ESTRUTURAIS 36

2.7 PROCESSO CONSTRUTIVO 45

2.7.1 Materiais $\quad 45$

i) Cordoalhas Engraxadas 45

ii) Ancoragens 47

iii) Macaco Hidráulico 49

2.7.2 Resumo do Processo Construtivo 49

2.8 EXEMPLOS DE APLICAÇÃO DA PROTENSÃO NÃO

ADERENTE 54

3. ASPECTOS DO CONCRETO PROTENDIDO 57

3.1 ANÁLISE DAS TENSÕES $\quad 57$

3.2 PROCESSOS DE CÁLCULO DA FORÇA DE PROTENSÃO 60

Método do Balanceamento de Carga 60

3.3 PERDAS DE PROTENSÃO 63

3.3.1 Perdas Imediatas 63

i) Perdas por Atrito 64

ii) Perdas por acomodação das cunhas $\begin{array}{ll}\text { de ancoragem } & 67\end{array}$

iii) Perdas por encurtamento elástico do concreto 
3.3.2 Perdas Progressivas

i) Perdas devido à deformação por fluência do concreto

ii) Perdas devido à deformação por retração do concreto

iii) Perdas devido à relaxação da armadura ativa

iv) Perdas Totais Progressivas

3.3.3 Perda e ganho de tensão no cabo devido à flexão da peça

3.4 CARACTERÍSTICAS DOS MOMENTOS DAS PEÇAS PROTENDIDAS

\section{MOdelos DE CÁlCULO DE PAVIMENTOS DE CONCRETO} PROTENDIDO

4.1 ANÁLISE DOS PAVIMENTOS PARA OS ESTADOS LIMITES

4.2 MÉTODO DOS PÓRTICOS EQUIVALENTES

4.3 MÉTODO DA ANÁLISE POR GRELHA

4.4 MÉTODO DOS ELEMENTOS FINITOS

4.5 ANÁLISE NUMÉRICA DE MODELO EXPERIMENTAL PELO

MÉTODO DOS ELEMENTOS FINITOS

4.5.1 Programa Utilizado

4.5.2 Influência da Protensão

4.5.3 Conclusões sobre a Modelagem

4.6 ANÁLISE NUMÉRICA DE MODELO EXPERIMENTAL

ATRAVÉS DA ANALOGIA POR GRELHA

4.6.1 Conclusões sobre a Modelagem

4.7 CONCLUSÕES SOBRE A ANÁLISE NUMÉRICA DO MODELO EXPERIMENTAL

\section{ESTUDO COMPARATIVO E ANÁLISE DOS RESULTADOS}

5.1 CONSIDERAÇÕES GERAIS

5.2 PROGRAMA DE CÁLCULO ESTRUTURAL TQS®

5.3 CARREGAMENTOS NA ESTRUTURA

5.4 RECOMENDAÇÕES SOBRE O PRÉ-DIMENSIONAMENTO DOS ELEMENTOS 
5.4.2 Vigas 138

5.4.3 Lajes 139

5.5 MATERIAIS 139

5.5.1 Concreto 139

5.5.2 Armadura Ativa 140

5.5.3 Armadura Passiva 140

5.5.4 Fôrmas 141

5.5.5 Escoramentos 142

5.6 EFEITOS DE SEGUNDA ORDEM EM EDIFÍCIOS ALTOS 142

5.6.1 Parâmetro de Instabilidade $\alpha \quad 143$

$\begin{array}{ll}\text { 5.6.2 O Coeficiente } \gamma_{z} & 145\end{array}$

5.7 PAVIMENTO A SER ESTUDADO 146

5.8 RESULTADOS DA PESQUISA DE ALBUQUERQUE 148

5.9 RESULTADOS DA PESQUISA ATUAL 152

5.9.1 Lajes planas maciças apoiadas sobre pilares 153

5.9.2 Lajes planas nervuradas apoiadas sobre pilares 156

5.9.3 Lajes nervuradas armadas apoiadas em vigas faixa protendidas sobre pilares 159

5.10 COMPARAÇÃO DOS RESULTADOS 162

5.10.1 Volume de Concreto 162

5.10.2 Quantidade de Armadura Passiva 162

5.10.3 Quantidade de Armadura Ativa 163

5.10.4 Quantidade de Área de Fôrmas 163

5.11 ANÁLISE DOS RESULTADOS 164

5.12 TEMPO DE EXECUÇÃO 172

5.12.1 Protensão Aderente x Protensão Não Aderente 172

5.12.2 Concreto Armado x Protensão Aderente e Não Aderente 174

5.13 COMENTÁRIOS FINAIS 175

6. CONCLUSÕES 179

REFERÊNCIAS BIBLIOGRÁFICAS

APÊNDICE A - CRITÉRIOS DE PROJETO ADOTADOS PARA O PROGRAMA DE CÁLCULO ESTRUTURAL TQS ${ }^{\circledR}$

APÊNDICE B - DIAGRAMAS DE MOMENTO FLETOR E 
DESLOCAMENTOS DOS PAVIMENTOS

APÊNDICE C - ANÁLISE DOS PÓRTICOS TRIDIMENSIONAIS DOS MODELOS

ANEXO A - PRESCRIÇÕES DO PROJETO DE REVISÃO DA NBR 6118-2001

ANEXO B - PRESCIÇÕES DO ACI 423-89 E ACI 318-99 


\section{RESUMO}

ALMEIDA FILHO, F. M. [2002]. Estruturas de Pisos de Edifícios com a Utilização de Cordoalhas Engraxadas. Dissertação de Mestrado, 284 p., Departamento de Engenharia de Estruturas, Escola de Engenharia de São Carlos, Universidade de São Paulo.

O presente trabalho aborda a utilização da protensão não aderente em edificios residenciais e comerciais de concreto, focando os aspectos referentes às soluções com protensão aderente e não aderente e em concreto armado, para o consumo de materiais, notadamente: concreto, fôrmas e armaduras. São considerados três diferentes sistemas estruturais, sendo estes: laje plana maciça apoiada sobre pilares; laje plana nervurada apoiada sobre pilares e laje nervurada apoiada em vigas faixa protendidas sobre pilares. São apresentados estudos destes casos com a utilização da ferramenta computacional de análise estrutural TQS ${ }^{\circledR}$, a qual é baseada na análise por grelha. São comparados os índices de consumo de materiais para os dois referidos sistemas de protensão, discutindo os limites de sua utilização. Como resultados, o estudo fornece conclusões satisfatórias para utilização da protensão, tanto aderente quanto não aderente, em relação ao concreto armado. Ainda, o sistema de protensão aderente mostrou-se ligeiramente mais econômico, do ponto de vista de consumo de materiais, porém, é um sistema com produtividade inferior às soluções com protensão não aderente, tornando esta última solução, a mais adotada no cotidiano dos escritórios de cálculo de engenharia civil dentre as citadas.

Palavras-chave: Concreto protendido; Protensão não aderente; Consumo de materiais. 


\begin{abstract}
ALMEIDA FILHO, F. M. [2002]. Building Floors Using Prestressed Unbonded Tendons. Dissertação de Mestrado, 284 p., Departamento de Engenharia de Estruturas, Escola de Engenharia de São Carlos, Universidade de São Paulo.

The present work deals the use of the prestressed unbonded tendons in residential and commercial concrete buildings, pointing out aspects to the application with bonded and unbonded prestressing and reinforced concrete, regarding the consumption such as concrete, molds and reinforcing steel. Three different structural systems are considered: flat plate and columns; waffle slab and columns and waffle slab (non prestressed) in prestressed strip beams supported by columns. Case studies are presented with the use of the software of structural analysis TQS ${ }^{\circ}$, which is based on the grillage analogy method. The consumption of materials is compared for the two referred prestressing systems, discussing the limits of their application. Based on the developed analyses, the study supplies satisfactory conclusions for use of the prestressing systems (bonded and unbonded), compared to reinforced concrete systems. With relation to the consumption of materials, the use of bonded tendons is a bit more cost effective, however, with smaller productivity than tendons with prestressed unbonded tendons, being the last one the more usual prestressing systems. Still, the system of prestressed bonded tendons was shown more economical, of the point of view of materials consumption, however, it is a system with inferior productivity to the solutions with prestressed unbonded tendons adopted in civil engineering offices nowadays.
\end{abstract}

Keywords: Prestressed concrete, prestressed unbonded tendons, materials consumption. 
1

\section{INTRODUÇÃO}

O concreto, desde sua criação, tem sido amplamente utilizado na construção civil. O advento da protensão tem tornado o concreto cada vez mais atraente como solução para sistemas estruturais, devido às suas vantagens técnicas e econômicas, dentre as quais, pode-se destacar:

- Possibilidade de utilização de grandes vãos e estruturas esbeltas, portanto, estruturas mais leves, aliviando assim o carregamento total aplicado à fundação;

- Melhoria das condições de utilização da estrutura, devido à redução de fissuras no concreto ou limitação de suas aberturas, aumentando assim a resistência da estrutura à agressividade do meio ambiente;

- Construções mais rápidas;

- Facilidade de recuperação da estrutura após um supercarregamento, pois, eventuais fissuras se fecham após o descarregamento;

- A estrutura permanece praticamente no Estádio I ao longo de sua vida útil, pois, ocorre controle da formação de fissuras.

Com o aumento da quantidade das construções, houve a necessidade de se desenvolver um sistema de protensão que atendesse a esta demanda com estruturas mais "leves", com maiores vãos e menores custos. 
Surgiu, então, nos anos 50, a primeira patente de protensão que utilizava bainhas individuais de plástico extrudadas. Com isso, deu-se um grande salto nas soluções de projeto estrutural, com a redução na espessura média dos pavimentos e produção de estruturas mais leves; redução da altura total da edificação; rapidez no processo de execução e outras promoveram reduções no custo total da obra, tornando este tipo de solução estrutural uma das escolhas iniciais para o projeto de edificios.

\section{1 - Objetivos}

O presente trabalho consiste em um estudo da utilização da protensão não aderente em pavimentos de edifícios quanto ao seu aspecto estrutural.

Pretende-se abordar a análise estrutural do pavimento utilizando o Método da Análise por Grelha. Serão analisados os pisos de edificios em três arranjos estruturais:

- Laje plana maciça apoiada sobre pilares;

- Laje nervurada sobre vigas faixa apoiadas em pilares;

- Laje plana nervurada apoiada em pilares.

Será abordada, em sua análise, a adequação do sistema à geometria do pavimento. Serão incluídas comparações de soluções com e sem o emprego da protensão não aderente.

\section{2 - Justificativa}

Em função do crescimento da utilização da protensão não aderente em pavimentos de edificios e, ainda, devido à pouca divulgação do assunto no país, justifica-se esta pesquisa que procura reunir informações sobre o tema, focalizando os aspectos estruturais voltados à aplicação em pisos de edificios de concreto. Ainda, devido à falta de informações com relação aos pavimentos de edificios com a utilização de protensão aderente comparados à soluções com protensão não aderente, esta pesquisa procura mostrar as diferenças existentes e comprovar as vantagens econômicas da protensão não aderente. 


\section{3 - Metodologia}

A presente pesquisa é baseada em um estudo teórico de pavimentos de edificios com protensão não aderente.

Foi realizada ampla revisão bibliográfica com o objetivo de analisar os trabalhos mais importantes sob a utilização de protensão não aderente, e, dentre estes, priorizou-se:

- Procedimentos para a análise estrutural, dimensionamento e normatização;

- Características dos processos de execução;

- Estudos comparativos de pavimentos com e sem protensão não aderente.

A análise numérica dos modelos, com protensão não aderente, será realizada com o Método da Análise por Grelha (MAG), adotado no programa de cálculo estrutural TQS ${ }^{\circledR}$ que será utilizado para quantificar os consumos de materiais, que é um dos objetivos desta pesquisa. A modelagem será do tipo elástico-linear, não se considerando as não linearidades físicas e geométricas.

Será também desenvolvida uma análise a respeito do tempo de execução dos pavimentos de concreto armado e protendido, com e sem aderência, ressaltando qual pavimento é mais produtivo.

Com isso, será feita uma investigação de soluções estruturais de pavimentos de edificios com e sem a utilização do sistema de protensão não aderente.

Como resultados da pesquisa, serão fornecidos índices de consumo de fôrmas, concreto e aço e os aspectos executivos, em especial a rapidez de execução da obra.

\section{4 - Apresentação do Trabalho}

O presente trabalho está dividido em seis capítulos.

O Capítulo 1 consiste na introdução ao tema de pavimentos de edifício de concreto com protensão não aderente, bem como na descrição dos objetivos, a justificativa, metodologia e apresentação da pesquisa. 
O capítulo 2 mostra breve histórico sobre o desenvolvimento e a utilização da protensão não aderente, a revisão bibliográfica pesquisada e uma descrição dos pavimentos que utilizam a protensão não aderente. Ainda, são apresentadas as vantagens e desvantagens do sistema, uma descrição sucinta do processo de execução e exemplos de pavimentos de edificios executados com o sistema de cordoalhas engraxadas.

O Capítulo 3 faz um estudo sobre os aspectos do concreto protendido e um estudo sobre perdas de protensão.

O capítulo 4 descreve os modelos de cálculo usuais de pavimentos de concreto protendido com monocordoalhas engraxadas, tais como o Método dos Pórticos Equivalentes, o Método de Análise por Grelha e o Método dos Elementos Finitos (MEF). Ainda, é feita uma modelagem numérica de um modelo experimental tanto para elementos finitos quanto para grelha.

No Capítulo 5 são desenvolvidas as análises de pavimentos pelo MAG, comparando-se as soluções estruturais com e sem protensão não aderente. Neste capítulo serão comparados os valores dos índices de consumo de materiais dos modelos em concreto protendido com os das soluções em concreto armado.

No Capítulo 6 serão apresentados os comentários finais sobre os resultados obtidos no Capítulo 5 e as conclusões do trabalho.

$\mathrm{O}$ apêndice $\mathrm{A}$ traz os critérios adotados para a utilização do programa de cálculo estrutural TQS® .

$\mathrm{O}$ apêndice $\mathrm{B}$ mostra os diagramas de momentos fletores e as isolinhas de deslocamento para os modelos estudados.

$\mathrm{O}$ apêndice $\mathrm{C}$ traz as deformadas dos pórticos tridimensionais dos modelos estudados e uma análise a respeito dos deslocamentos encontrados nos exemplos e uma comparação da variação do momento fletor na viga de um pórtico e do esforço cortante em um pilar dos modelos protendidos.

Os Anexos A e B trazem as prescrições do Projeto de Revisão da Norma Brasileira NBR 6118-2001 e do Código do ACI 318-99 e ACI 423-89, respectivamente, para os Estados Limites de Serviço e Último, tanto para as solicitações normais quanto para as tangenciais. 


\section{CONSIDERAÇÕES GERAIS}

\section{1 - Histórico do Concreto Protendido}

$\mathrm{O}$ início dos trabalhos em concreto protendido datam de meados do ano de 1872, quando P.H. Jackson, engenheiro do estado da Califórnia, E.U.A., patenteou um sistema o qual utilizou um tirante de união para construir vigas ou arcos com blocos individuais.

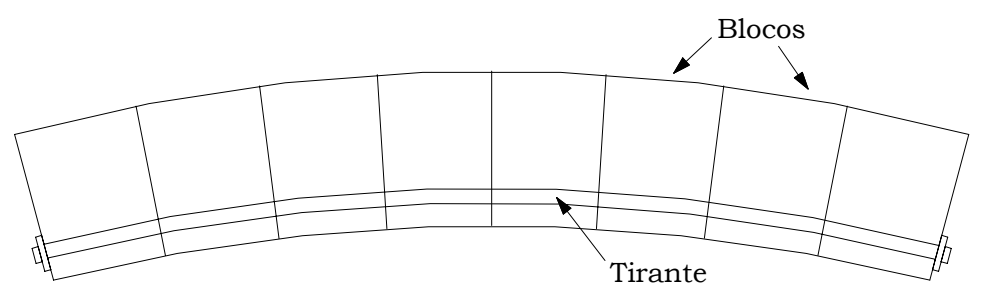

Figura 2.1 - Modelo de P.H. Jackson

Em 1888, na Alemanha, C. W. Doehring obteve a patente para lajes protendidas com fios metálicos.

Contudo, vale ressaltar que, estas atitudes pioneiras não tiveram sucesso devido às perdas de protensão com o tempo.

R.E. Drill of Alexandria, de Nebraska, E.U.A., desenvolveu vários trabalhos no que se refere ao concreto protendido, entre eles, estudou a 
influência da resistência do concreto para a fissuração e a deformação lenta e desenvolveu ainda a protensão não aderente de tirantes de união com a idéia que esta falta de aderência compensaria as perdas de tensão com o tempo por causa da diminuição do comprimento do elemento por causa da fissuração e da deformação lenta.

No início da década de 20, em Mineápolis, E.U.A., W. H. Hewlett desenvolveu o princípio da protensão circular. Ele fez uma armadura horizontal de barril tracionada em tornos dos muros de concreto para prevenir a fissuração deste devido à pressão interna do líquido.

Na Europa, em particular, na França, houve o desenvolvimento do concreto protendido através da engenhosidade de Eugene Freyssinet, o qual, em 1926-28, propôs métodos para se estimar as perdas de protensão no uso de aços de alta-resistência e alta-ductilidade. Em 1940 ele desenvolveu o sistema Freyssinet de ancoragem em cunha cônica de 12 cabos.

Em 1934, F. Dischinger desenvolveu a utilização de protensão externa sem aderência. Logo, em 1936, ocorreu a construção da primeira ponte utilizando a protensão sem aderência (Dischinger).

Após a Segunda Guerra Mundial, com a destruição arrasadora pelo qual a Europa passou, era necessário reconstruir de maneira rápida as pontes destruídas, então, G. Magnel of Ghent, Bélgica e Y. Guyon, França, desenvolveram métodos e conceitos de protensão para o projeto e construção de pontes na Europa Ocidental e Central.

$\mathrm{Na}$ Inglaterra, o conceito de protensão parcial foi desenvolvido por P.W. Abeles, entre as décadas de 30 e 60. F. Leonhardt, Alemanha, V. Mikhailov, Rússia, e T.Y. Lin, E.U.A., contribuíram em muito para o desenvolvimento e aperfeiçoamento do concreto protendido.

Em 1949, a construção da Ponte do Galeão foi realizada utilizando-se a protensão não aderente, sendo na época a maior ponte em concreto protendido do mundo com $380 \mathrm{~m}$ de comprimento. Foi uma das primeiras realizações da patente Freyssinet no mundo, com o próprio Eugene Freyssinet orientando o projeto. Vale ressaltar que, houve a injeção de pasta de cimento nos cabos, porém a sua finalidade era a de promover uma melhor proteção contra corrosão dos cabos. 
O início da construção das lajes protendidas sem aderência ocorreu nos E.U.A., em meados de 1956-57, com a construção de escolas em Nevada, E.U.A..

$\mathrm{Na}$ década de 60, foi quando houve o maior desenvolvimento na utilização de lajes protendidas, como falado anteriormente, devido às enormes contribuições de. F. Leonhardt, Alemanha, V. Mikhailov, Rússia, e T.Y. Lin, E.U.A., sendo que estes desmistificaram as dúvidas inerentes ao comportamento do concreto protendido, realizaram melhorias e simplificações nos processos construtivos de protensão, a utilização do método do balanceamento de cargas, o qual simplificou bastante o cálculo de elementos protendidos e a utilização de materiais mais eficientes para a utilização da protensão.

Devemos ressaltar a utilização do concreto protendido no Brasil com a grande colaboração de José E. Rufloff Manns e do Eng. José Carlos de Figueiredo Ferraz que, entre 1953-73, desenvolveu um sistema de protensão que, dentre suas obras, podemos destacar o Museu de Arte de São Paulo MASP, a ponte da Cidade Universitária e o Viaduto da Beneficência Portuguesa.

Com o desenvolvimento computacional, foi permitido associar a aplicação de métodos numéricos à informática, promovendo assim, uma facilidade maior em analisar resultados cada vez mais precisos.

Atualmente, a utilização de protensão não aderente vem sendo feita de uma maneira modesta, talvez devido ao conceito do concreto protendido ter custo mais elevado, o que é um conceito falho, pois a protensão com monocordoalha engraxada (protensão não-aderente) constitui um sistema altamente competitivo para com o concreto armado convencional.

A maior utilização deste sistema se dá, por enquanto, no Nordeste, onde o seu emprego se estende desde a construção de pavimentos protendidos, até a construção de fundações tipo radier, tanto para casas quanto para edifícios de médio ou grande porte. 


\section{2 - Protensão não aderente}

O início da construção de lajes protendidas, utilizando monocordoalhas engraxadas, data de meados de 1956-57, quando foi construída a primeira estrutura, uma escola no E.U.A., utilizando este sistema.

O sistema recebe o nome de monocordoalha devido à presença de uma única cordoalha por cabo. A presença da graxa entre a cordoalha e a bainha plástica, permite ao cabo deslizar sem problemas no ato da protensão, reduzindo substancialmente as perdas por atrito.

A protensão não aderente segue os mesmos processos de cálculo da protensão convencional, com a particularidade que os cabos já vêm isolados com uma capa plástica de polietileno que serve de bainha. Esta bainha possui em seu interior uma camada de graxa que se interpõe entre ela e o cabo, propiciando uma proteção permanente contra corrosão.

$\mathrm{Na}$ figura 2.2, pode-se ver o detalhe de como a graxa envolve por completo a cordoalha.

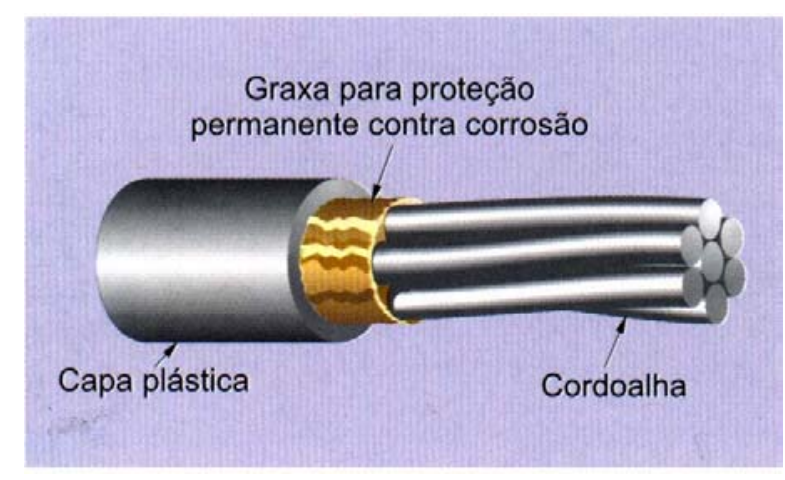

Figura 2.2 - Composição da monocordoalha engraxada

As deformações por flexão em peças com protensão não aderente submetido a ações são desiguais para o concreto e para o cabo, este que assume uma deformação uniforme. As deformações no concreto, devido às tensões impostas pelo carregamento, no nível do cabo, variam de acordo com o diagrama de momento. A compatibilidade de deformações requer um alongamento da cordoalha igual à deformação no concreto na extensão da cordoalha, resultando no aumento da deformação do cabo e, este incremento será uniforme sobre toda a extensão da cordoalha, desde que não haja atrito entre o cabo e a bainha. 
O comportamento da protensão não aderente pouco difere da protensão aderente (NAAMAN [1991a]), porém para o Estado Limite Último da peça, essa afirmativa não é verdadeira. Entretanto, ensaios realizados por LEONHARDT [1983], provam que a influência da aderência é de grande importância no comportamento resistente tanto para o Estado Limite Último quanto com relação à fissuração em serviço.

De acordo com LEONHARDT [1983], em ensaios de vigas com protensão com aderência e sem aderência, a viga com aderência sofreu menores deslocamentos para grandes cargas de ruptura $(900 \mathrm{kN})$, enquanto, a viga protendida sem aderência rompeu na zona comprimida sobre uma carga de $600 \mathrm{kN}$ (ver figura 2.3). Pode-se ver com isso que a falta de aderência provoca uma diminuição da carga limite em 30\%. Logo, para o caso de protensão sem aderência, que é objeto de nosso estudo, deve-se promover um acréscimo de armadura passiva que seja o suficiente para dar segurança à estrutura, impedindo a progressão das fissuras, uma vez que não existe a parcela de deformação conjunta da armadura protendida com o concreto.

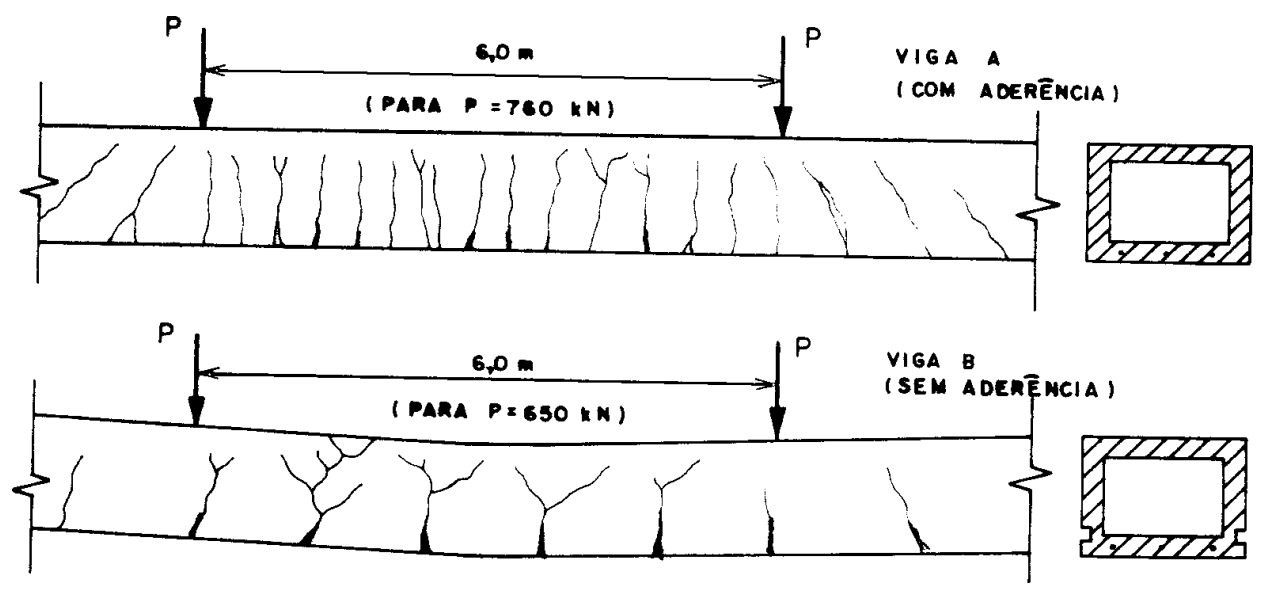

Figura 2.3 - Configuração das fissuras para as vigas (adaptado de LEONHARDT [1983])

A figura 2.4 ilustra um diagrama de força vs. deslocamento onde são mostradas as curvas para protensão aderente (A) e protensão não aderente (B), onde pode-se observar a verificação dos experimentos de Leonhardt de 1950 com os modelos ensaiados por ROZVANY \& WOODS [1969]. Quando ocorre a fissuração, as vigas com protensão aderente apresentam uma ductilidade elevada, levando a peça ao colapso posteriormente. Já para a protensão não aderente, após a fissuração da peça, esta perde rapidamente 
muita resistência necessitando assim, de uma quantidade de armadura passiva para garantir a segurança da estrutura.

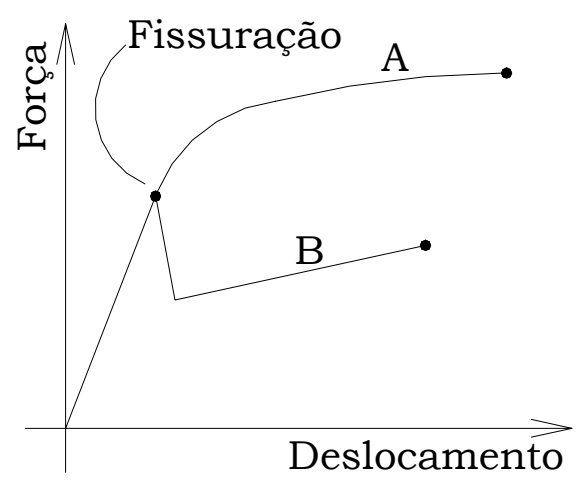

Figura 2.4 - Diagrama de força $\mathrm{x}$ deslocamento para vigas com protensão aderente

(A) e não aderente (B) (adaptado de ROZVANY \& WOODS [1969])

A crescente utilização de estruturas com monocordoalhas engraxadas deve-se à simplicidade de operação e ao seu baixo custo unitário, se comparado ao sistema de protensão aderente e a sua pequena dimensão.

O sistema de protensão não aderente é muito útil para protensão de grande e de baixa intensidade, sendo muito utilizado em construções de prédios, pontes, centros comerciais, silos e fundações.

\section{3 - Revisão Bibliográfica}

Com base nos estudos de diversos autores, observou-se que a protensão não aderente é um sistema seguro, eficaz e econômico.

Este sistema teve seu início em 1956, quando foi construída a primeira estrutura utilizando a protensão não aderente.

No Brasil, iniciaram-se as primeiras utilizações em 1997 quando a Belgo-Mineira começou a produzir as cordoalhas engraxadas.

A seguir, serão vistas as principais publicações a respeito do sistema de protensão não aderente aplicado a pavimentos de edificios de concreto.

Em 1954, LEONHARDT realizou inúmeros estudos sobre casos de protensão, bem como ensaios para se verificar a otimização do concreto protendido para o meio técnico. Pode-se destacar os estudos sobre aderência e aços para protensão, tipos de ancoragens e emendas para a armadura ativa, 
sistemas e equipamentos de protensão, avaliando tanto o estado limite de serviço como o estado limite último. Os estudos de LEONHARDT embora tenham maior ênfase na protensão aderente é de grande relevância para o desenvolvimento da protensão.

Na década de 50, SCORDELIS et al. [1956] realizaram ensaios em uma laje com protensão não aderente simplesmente apoiada em pilares nas duas direções (ver figura 2.5). O propósito do trabalho era avaliar seu comportamento durante e após a fase elástica e comparar esses resultados experimentais com a teoria elástica clássica (MARCUS ${ }^{1}$ [1932]).

Segundo os autores, antes da fissuração da laje, a teoria elástica clássica pode ser utilizada para determinar os deslocamentos, tensões, momentos e deformações; a carga de fissuração pode ser obtida com uma precisão de $10 \%$ pela teoria elástica clássica utilizando o módulo de ruptura do concreto. Ainda, os autores recomendaram maiores estudos com cabos não aderentes com perfis curvos e em lajes contínuas.

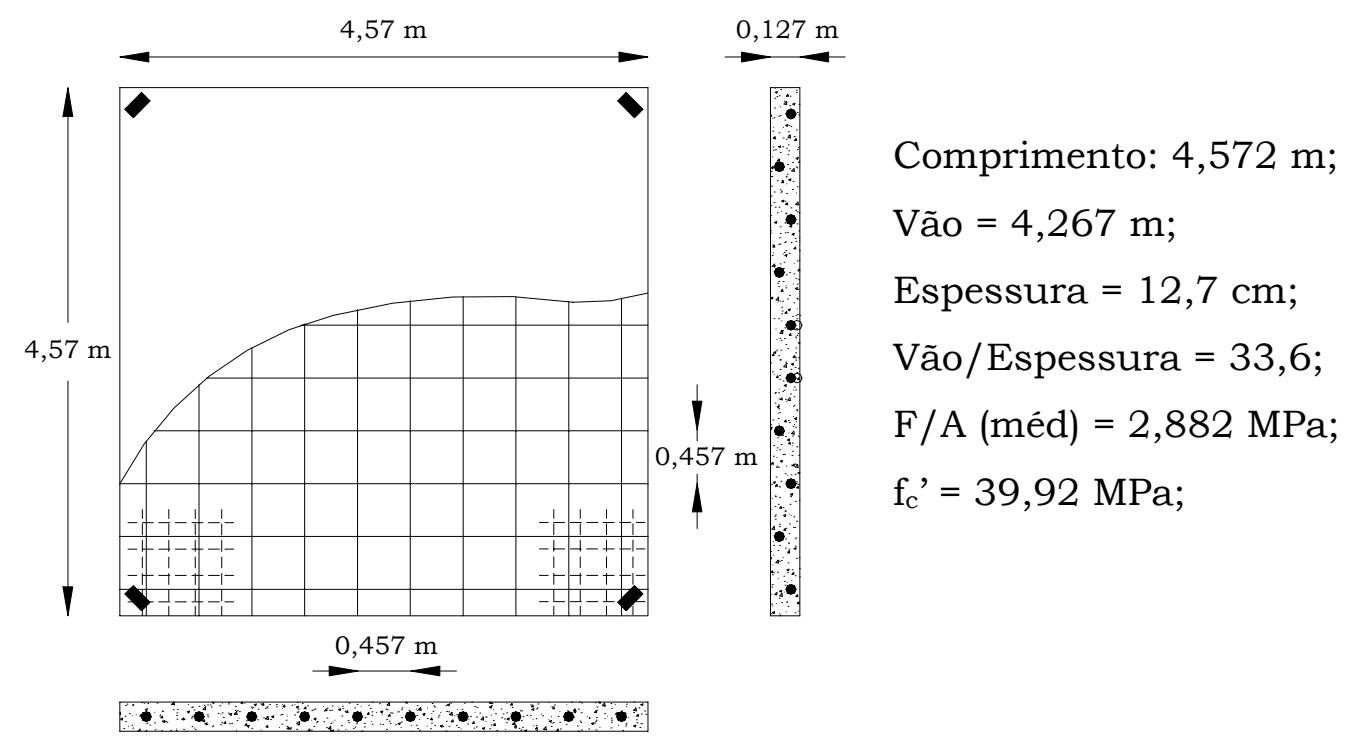

Figura 2.5 - Modelo adaptado do ensaio de SCORDELIS et al. [1956]

Em 1959, SCORDELIS et al. realizaram ensaios em uma laje continua com protensão não aderente nas duas direções com cabos parabólicos (ver figura 2.6). O objetivo, semelhante ao desenvolvido em 1956, era verificar o comportamento durante e após a fase elástica para a estrutura. Realizaram

${ }_{1}^{1}$ MARCUS, H. [1932]. Die Theorie Elastisher Gewebe und Thre Andwendung auf die Berechnung Biegsamer Platten. Julius Springer, Berlin, 1932, pp. 173-184. 
uma comparação do modelo experimental com os modelos teóricos correspondentes à teoria de placas e de barras. Foi verificado que a teoria elástica de placas pode ser utilizada de maneira satisfatória para se avaliar o comportamento de lajes protendidas na sua fase elástica; a formação inicial de fissuras ocorreu em locais de picos de momento e o modelo suportou grandes incrementos de carga antes da difusão das fissuras.

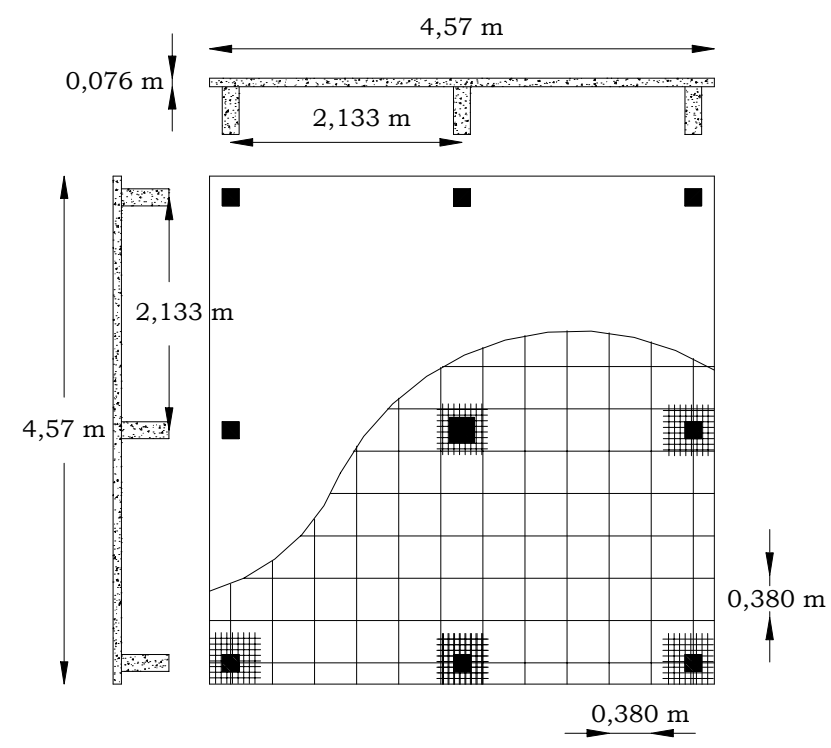

Vão $=2,133 \mathrm{~m}$;

Espessura $=7,62 \mathrm{~cm}$;

Vão/Espessura = 28;

$\mathrm{F} / \mathrm{A}$ (méd) $=1,034 \mathrm{MPa}$;

$\mathrm{F}=30,425 \mathrm{kN}$;

$\mathrm{f}_{\mathrm{c}}{ }^{\prime}=37,61 \mathrm{MPa}$;

Figura 2.6 - Modelo adaptado do ensaio de SCORDELIS et al. [1959]

Na década de 60, LIN [1963] desenvolveu um método para calcular de maneira eficaz, segura e simples, a força de protensão. Este foi chamado de "Método do Balanceamento de Carga". Este método, extremamente vantajoso no cálculo de estruturas estaticamente indeterminadas (lajes planas e algumas cascas delgadas) está baseado no princípio de que a força de protensão equilibra uma parcela da carga aplicada na estrutura tal que a estrutura não estaria sujeita a tensões de tração.

$$
\begin{aligned}
& \mathrm{w}_{\mathrm{x}}=\frac{8 \cdot \mathrm{P}_{\mathrm{x}} \cdot \delta_{\mathrm{x}}}{\mathrm{L}_{\mathrm{x}}^{2}} \\
& \mathrm{w}_{\mathrm{y}}=\frac{8 \cdot \mathrm{P}_{\mathrm{y}} \cdot \delta_{\mathrm{y}}}{\mathrm{L}_{\mathrm{y}}^{2}}
\end{aligned}
$$

Onde,

$\mathrm{P}_{\mathrm{x}}$ e $\mathrm{P}_{\mathrm{y}} \quad$ são as forças de protensão aplicadas ao pavimento nas direções $\mathrm{X}$ e Y, respectivamente; 
$\delta_{\mathrm{x}}$ e $\delta_{\mathrm{y}} \quad$ são as flechas dos perfis dos cabos com relação ao centróide da seção transversal nas direções X e Y, respectivamente;

$\mathrm{L}_{\mathrm{x}}$ e $\mathrm{L}_{\mathrm{y}} \quad$ são os comprimentos das parábolas dos cabos nas direções $\mathrm{X}$ e $\mathrm{Y}$, respectivamente;

$\mathrm{w}_{\mathrm{x}}$ e $\mathrm{w}_{\mathrm{y}} \quad$ são as cargas balanceadas pelas forças de protensão $\mathrm{P}_{\mathrm{x}}$ e $\mathrm{P}_{\mathrm{y}}$, respectivamente, por unidade de comprimento.

ROZVANY \& WOODS [1969] realizaram um estudo teórico-experimental avaliando o comportamento de vigas e lajes, com protensão não aderente, submetidas à flexão na fase de fissuração. A figura 2.4, mostra a diferença entre vigas com protensão aderente (A) e protensão não aderente (B), demonstrando que a protensão convencional apresenta um crescimento menor da resistência com a fissuração, ao contrário da protensão sem aderência, que apresentam uma súbita redução da capacidade de carga na fissuração.

Os autores propuseram uma teoria (admitindo que a distribuição de fissuras é linear), para seções retangulares e não retangulares, para o cálculo do comportamento após o início da fissuração. Pode-se ver com isso que, é admitido que a fissuração continua propagando até que a máxima tensão de tração seja maior que o módulo de ruptura.

$$
\frac{P}{b_{w} \cdot d} \geq f_{r}
$$

Onde,

$\mathrm{P}$ é força de protensão aplicada;

$\mathrm{b}_{\mathrm{w}}$ é a largura da viga;

d é a altura útil da seção transversal;

$\mathrm{f}_{\mathrm{r}}$ é o módulo de ruptura do concreto.

Foi verificado que este fenômeno, causado por excessivas cargas acidentais ou terremotos, provoca uma instabilidade na estrutura podendo levá-la ao colapso. Assim, esta instabilidade pode ser evitada, desde que a tensão devida à protensão seja superior ao módulo de ruptura do concreto.

Ainda em 1969, MUSPRATT realizou ensaio em uma laje nervurada com protensão não aderente simplesmente apoiada em suas quatro extremidades 
(ver figura 2.7). O objetivo do autor era verificar as deformações para longos períodos de vida útil da laje e verificar a validade da teoria de ROZVANY2.

Segundo o autor, não houve a ocorrência da teoria de ROZVANY, pois aparentemente, foi visto que tal teoria não é facilmente estendida para casos bidirecionais (lajes); a ruptura do modelo se deu por torção nas nervuras, pois a formação das linhas de ruptura ocorreu nas diagonais da estrutura, mostrando assim, que seriam necessários maiores estudos para avaliar a tensão de torção nas diagonais (charneiras); a protensão não aderente, aparentemente, não apresenta grandes desvantagens estruturais para lajes, e ainda, sua utilização promove a economia da injeção de pasta de cimento na bainha metálica e das perdas de protensão por atrito; o Método do Balanceamento de Carga (LIN[1963]) pode ser utilizado para equilibrar uma parte da carga acidental.

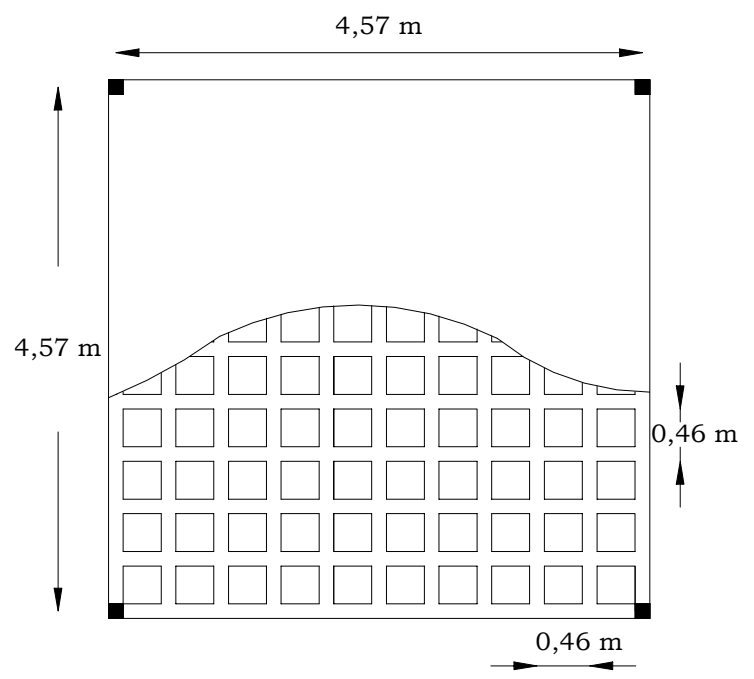

Vão $=4,572 \mathrm{~m}$;

Espaçamento $=0,457 \mathrm{~m}$;

$\mathrm{F}$ (méd.) $=31,577 \mathrm{kN}$;

$\mathrm{F}$ (ruptura) $=31,969 \mathrm{kN}$.

Figura 2.7 - Modelo da laje nervurada (adaptado de MUSPRATT [1969])

No início da década de 70, MATTOCK et al. [1971] realizaram ensaios em vigas de concreto com e sem protensão não aderente (ver figura 2.8). O objetivo do trabalho era verificar o comportamento das peças com a presença ou falta de aderência da armadura ativa e a quantidade de armadura passiva; a utilização de cordoalha aderente como armadura passiva e a ductilidade das vigas com protensão aderente e não aderente.

2 Elementos protendidos com cordoalhas não aderentes são sujeitos ao súbito colapso devido à fissuração, a menos que, a protensão média seja de pelo menos 1,5 vezes o módulo de ruptura. 


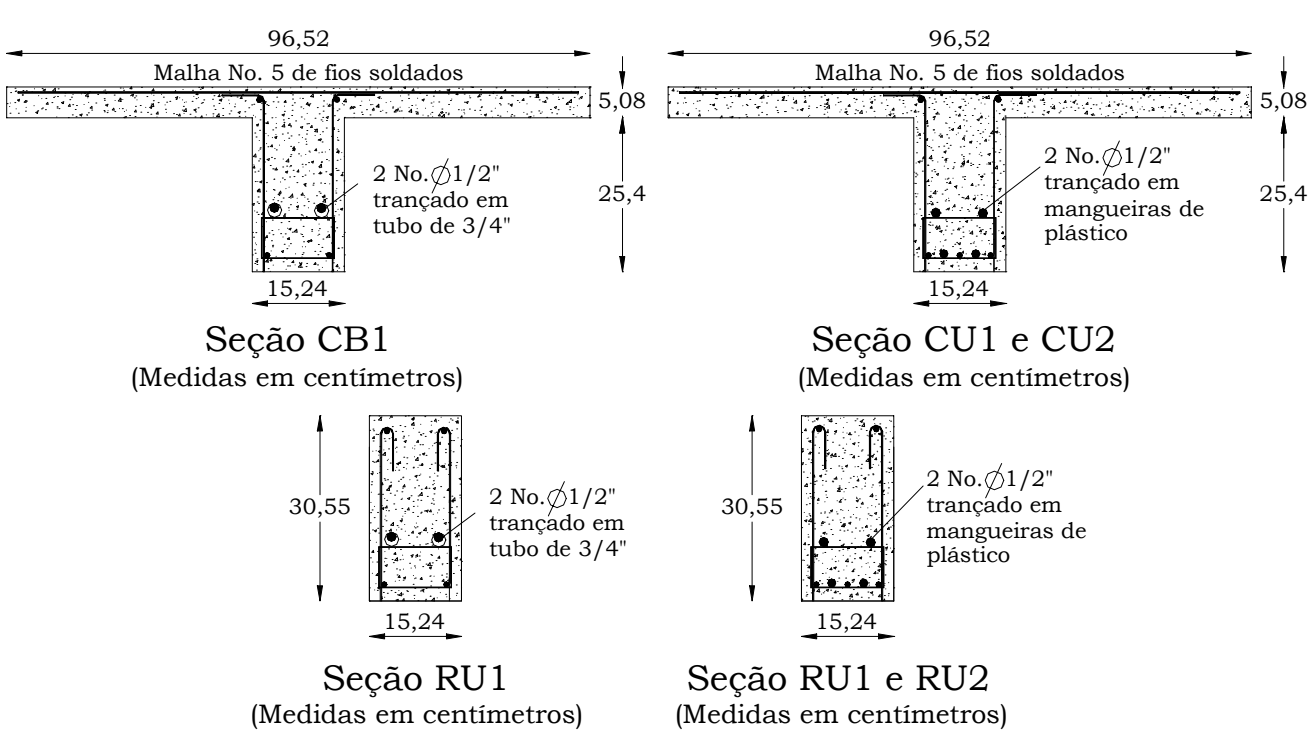

Seção CU - Viga-T contínua com cabos não aderentes

Seção CB - Viga-T contínua com cabos aderentes

Seção RU - Viga de seção retangular com cabos não aderentes

Seção RB - Viga de seção retangular com cabos aderentes

Figura 2.8 - Seções das vigas (adaptado de MATTOCK et al. [1971])

Os autores propuseram uma equação para determinar a tensão última $\left(f_{\text {su }}\right)$ em cordoalhas não aderentes.

$$
\mathrm{f}_{\mathrm{su}}=\mathrm{f}_{\mathrm{se}}+\frac{1,4 \cdot \mathrm{f}_{\mathrm{c}}{ }^{\prime}}{100 \cdot \mathrm{p}}+700\left(\mathrm{kgf} / \mathrm{cm}^{2}\right)
$$

Onde,

$\mathrm{f}_{\mathrm{su}}$ é a tensão na armadura ativa na resistência última do cabo;

$\mathrm{f}_{\mathrm{c}}$ ' é a resistência à compressão do concreto;

$\mathrm{f}_{\mathrm{se}}$ é a tensão na armadura ativa após as perdas de protensão;

p é a razão de protensão.

Nos resultados obtidos, as vigas simplesmente apoiadas e com protensão não aderente apresentaram alta ductilidade. Para as vigas contínuas, a ductilidade foi menor, devido ao rompimento da seção do apoio central. A utilização de armadura passiva em conjunto com as cordoalhas não aderentes garante um estado de serviço, ductilidade e resistências iguais ou melhores que uma viga com protensão aderente, tendo sido constatado que fios trançados podem ser utilizados satisfatoriamente como armadura passiva aderente. Ainda, determinou-se uma quantidade mínima de armadura passiva 
em uma viga com protensão não aderente de 0,4 \% da área compreendida entre a face tracionada e a linha neutra da seção bruta.

Ainda na mesma década, BURNS \& HEMAKOM [1977], desenvolveram um estudo em laje plana com protensão não aderente (ver figura 2.9). Os objetivos eram verificar o comportamento da laje submetida a um carregamento superior ao carregamento último; as propagações de fissuras; a contribuição da armadura passiva; o aumento da tensão nos cabos no carregamento último e sua utilização em projeto.

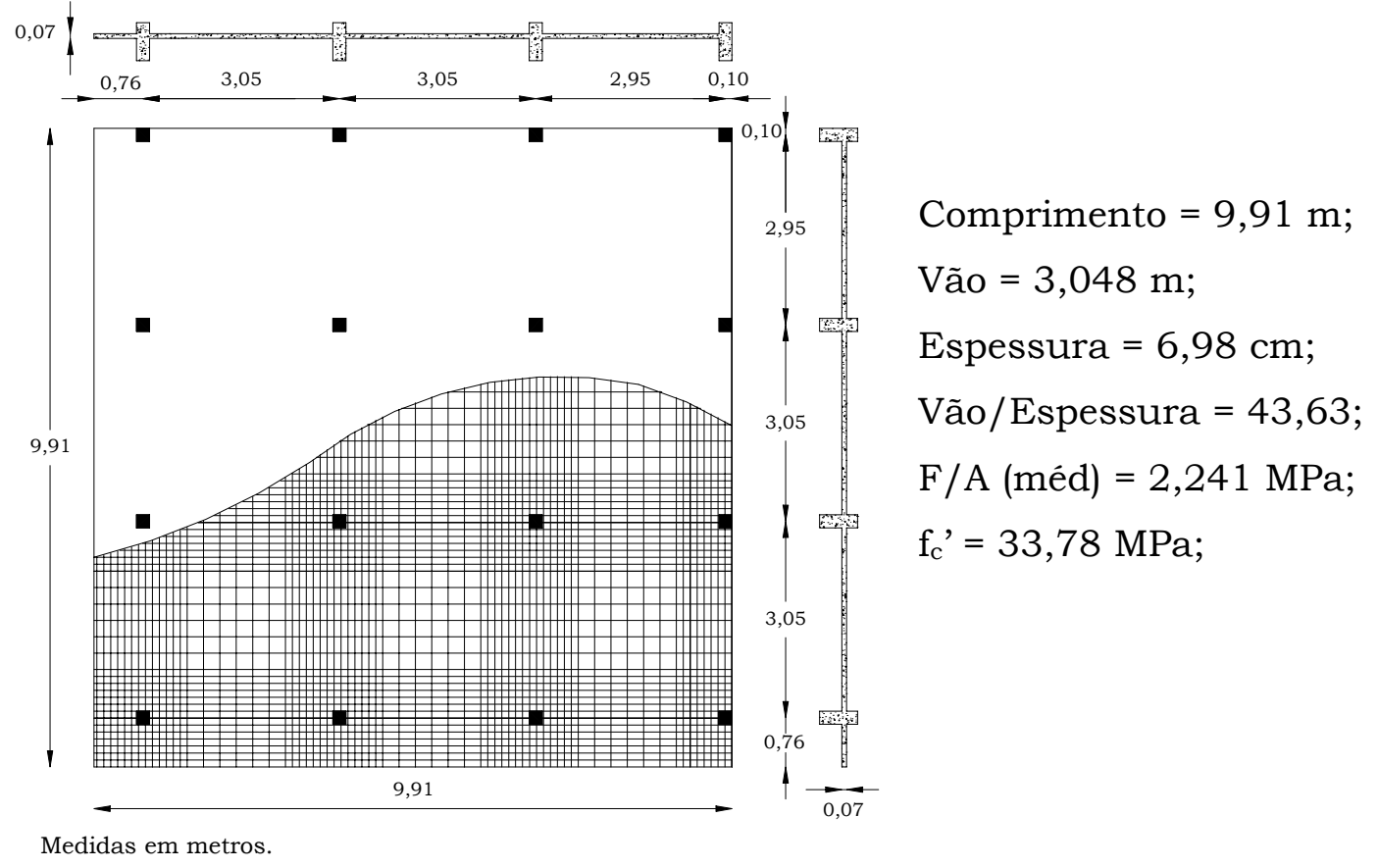

Figura 2.9 - Modelo de laje plana (adaptado de BURNS \& HEMAKOM [1977])

De acordo com os autores, a utilização de $0,15 \%$ da área da seção transversal de concreto de armadura passiva controlou a distribuição das fissuras e contribuiu ainda para aumentar a resistência a laje; o posicionamento de armadura passiva no topo nas vizinhanças dos pilares produziu excelentes resultados; as tensões medidas nos cabos nos carregamentos últimos foram $2 \%-13 \%$ inferiores aos valores determinados pelo ACI 318-71; a resistência ao esforço cortante do modelo foi maior que a resistência calculada pelas equações do ACI 423, devido aos fatores resistência à compressão do concreto, quantidade de armadura passiva e perfil dos cabos. 
De acordo com as recomendações dos autores, deve sempre ser colocada armadura passiva em locais de picos de momento negativo (ao redor dos pilares) e posicionada a uma distância de 1,5 vezes a espessura da laje das faces do pilar; a utilização de faixas protendidas com $70 \%$ dos cabos distribuídos na faixa dos pilares e o restante, $30 \%$ distribuído nas faixas centrais em cada direção, fornece excelente comportamento a laje; quanto maior o valor de $\mathrm{P} / \mathrm{A}$, maior será a resistência à fissuração e a resistência ao esforço cortante.

No início da década de 80, HAWKINS [1981] fez um estudo experimental em seis modelos em escala real de ligações laje-pilar. O principal objetivo era determinar a resistência e a rigidez das conexões laje-pilar na transferência dos momentos.

O autor verificou que as equações do ACI 318-77 são satisfatórias para calcular a capacidade de transferência de momento da laje; a disposição dos cabos ao redor do pilar foi eficiente para melhorar a transferência de momentos e a quantidade de armadura passiva, determinada pelo ACI 318-77, foi satisfatória para os pilares internos. Para os pilares externos, a armadura passiva colocada deve poder reagir à torção quando a tensão produzida pelo esforço cortante exceder $0,17 \cdot \sqrt{\mathrm{f}_{\mathrm{c}}{ }^{\prime}}(\mathrm{em} \mathrm{MPa})$. Ainda, concluiu que devem ser feitas maiores investigações com relação ao controle de fissuração das ligações laje-pilar internos; que a rigidez ao carregamento lateral depende da fissuração e, ocorrendo a fissuração, deve-se reduzir a rigidez à torção a $1 / 10$ dos valores propostos pelo ACI 318-77.

A seguir, de acordo com o Design of Post-Tensioned Slabs - PTI [1983], seguem as referências de GAMBLE [1964], ODELLO \& MEHTA [1967], BROTCHIE \& BERESFORD [1967], HEMAKOM \& GERBRE-MICHAEL [1970] e VINES \& CHARNEY [1975], com relação aos estudos de flexão e GROW \& VANDERBILT [1967], BURNS \& GERBER [1971], BURNS \& SMITH [1973] e HAWKINS \& TRONGTHAM [1976], com relação aos estudos de verificação da punção em lajes com protensão não aderente. 
GAMBLE [1964]33 , apud PTI [1983], realizou ensaios em uma laje plana contínua com protensão não aderente (ver figura 2.10). A protensão foi do tipo pós-tração com cabos retos. Como resultado, o autor citou que este arranjo de cabo reto não é eficiente para lajes bidirecionais, entretanto, conseguiu dados relevantes sobre o comportamento da laje relacionados ao esforço cortante.

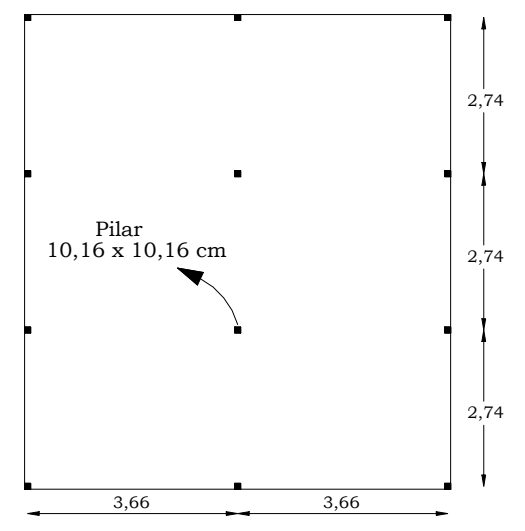

$$
\begin{array}{lc}
\text { Espessura: } & 7,62 \mathrm{~cm} ; \\
\mathrm{f}_{\mathrm{c}}{ }^{\prime}: & 31,03 \mathrm{MPa} ;
\end{array}
$$

\begin{tabular}{c|c|c} 
Relações & Em X: & Em Y: \\
\hline Vão: & $3,66 \mathrm{~m}$ & $2,74 \mathrm{~m}$ \\
1/h $:$ & 48 & 36 \\
F/A (MPa): & 3,447 & 2,689
\end{tabular}

Figura 2.10 - Modelo de laje plana de Gamble (adaptado do PTI [1983])

BROTCHIE \& BERESFORD [1967]4, apud PTI [1983], ensaiaram um modelo de laje plana protendida submetida à carregamentos de longa duração e de ruptura (ver figura 2.11). A distribuição dos cabos foi feita de maneira variada em cada vão. De acordo com os autores, não foi necessária a utilização de armadura passiva, porém, é recomendada, pois esta aumenta a rigidez da laje. Foi observado que a relação vão/espessura de 48 foi aparentemente satisfatória tanto para o comportamento de curta como de longa duração.

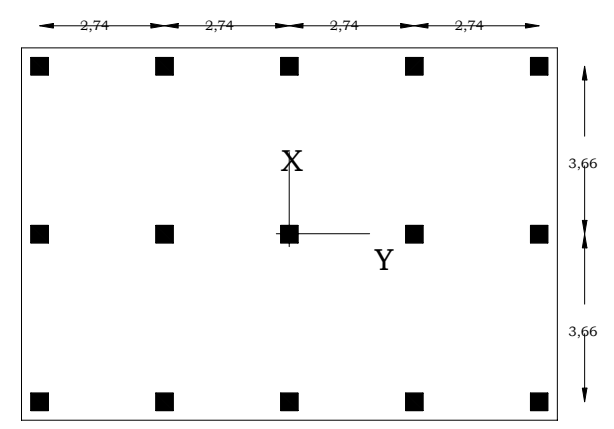

\begin{tabular}{c|c|c} 
Relações & Em X: & Em Y: \\
\hline Vão: & $3,66 \mathrm{~m}$ & $2,74 \mathrm{~m}$ \\
$1 / \mathrm{h}:$ & 48 & 36 \\
F/A (MPa): & 1,206 & 2,330
\end{tabular}

Figura 2.11 - Modelo de Brotchie \& Beresford (adaptado do PTI [1983])

3 GAMBLE, W. L. [1964]. An Experimental Investigation of the Strength of a Prestressed Concrete Flat Plate Structure. Report T80-9, Division of Building Research, Commonwealth (of Australia) Scientific and Industrial Research Organization, Melbourne, 1964.

${ }^{4}$ BROTCHIE, J. F.; BERESFORD, F. D. [1967]. Experimental Study of a Prestressed Concrete Flat Plate Structure. Civil Engineering Transactions, Institute of Engineers, Sydney, Australia, October 1967, pp. 276282. 
ODELLO \& MEHTA [1967]5, apud PTI [1983], realizaram um ensaio similar ao feito por SCORDELIS et al [1959], sendo que este modelo apresentava drop panels em seu arranjo estrutural (ver figura 2.12). O objetivo seria comparar o comportamento da laje com e sem drop panels verificando a viabilidade da utilização deste sistema.

Segundo os autores, este tipo de arranjo estrutural seria ideal para o uso prático sendo que a laje ensaiada apresentou uma carga de ruína 169\% maior que a da laje sem a utilização de drop panels.

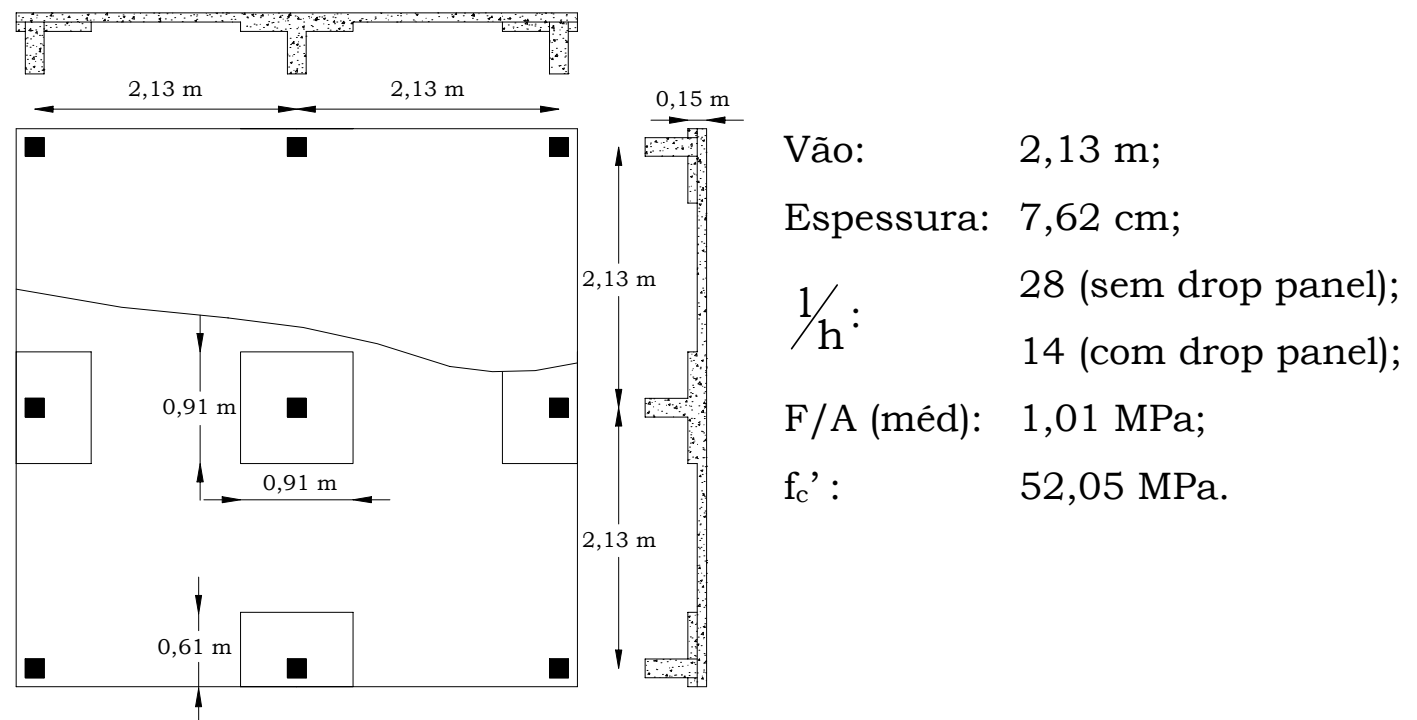

Figura 2.12 - Modelo de laje plana de Odello \& Mehta (adaptado do PTI [1983])

HEMAKOM \& GERBRE-MICHAEL [1970]6,7, apud PTI [1983], realizaram ensaios em cinco modelos de laje contínua com protensão não aderente. A quantidade de armadura passiva era variável em cada modelo, em todos, superior aos requisitos do ACI 318-77.

Segundo os autores, quando ocorria o descarregamento, as fissuras fechavam-se quase que completamente (mesmo para uma carga de 50\% da carga de ruína) e na ruptura por flexão, foi verificado que a resistência era maior que a calculada pelo ACI 318-77.

5 ODELLO, R. J.; MEHTA, B. M. [1967]. Behavior of a Continuous Prestressed Concrete Slab with Drop Panels. Thesis, Division of Structural Engineering and Structural Mechanics, Univesity of California, Berkeley, 1967.

6 HEMAKOM, R. [1970]. Behavior of Post-Tensioned Concrete Slabs with Unbonded Reinforcement. Thesis, The University of Texas at Austin, Austin, Texas, 1970.

7 GERBRE-MICHAEL, Z. [1970]. Behavior of Post-Tensioned Concrete Slabs with Unbonded Reinforcement. Thesis, The University of Texas at Austin, Austin, Texas, 1970. 
VINES \& CHARNEY [1975] $]^{8,9}$, apud PTI [1983], ensaiaram dois modelos de lajes protendidas contínuas unidirecionais com cabos não aderentes. As lajes foram divididas de acordo com as tensões de serviço de $6 \cdot \sqrt{\mathrm{f}_{\mathrm{C}}{ }^{\prime}}$ e de 9. $\sqrt{f_{\mathrm{C}^{\prime}}}$ (ambas em psi). As características das lajes estão na Tabela 1.

De acordo com os autores, tanto a laje $A\left(6 \cdot \sqrt{f_{c}{ }^{\prime}}\right)$ quanto a laje $B$ $\left(9 \cdot \sqrt{\mathrm{f}_{\mathrm{C}}{ }^{\prime}}\right)$, apresentaram comportamento satisfatório (elástico-linear); a quantidade de armadura passiva foi suficiente para controlar a fissuração e a ruptura se deu com um valor maior que o calculado, porém, na laje B, houve ruptura prematura em um dos vãos. As tensões nos cabos permaneceram abaixo das tensões limites estabelecidas no ACI 318-77.

Tabela 2.1 - Características das lajes de VINES \& CHARNEY [1975]

\begin{tabular}{||l|c|c||}
\hline \hline & Laje A $\left(6 \cdot \sqrt{\mathrm{f}_{\mathrm{c}}{ }^{\prime}}\right)$ & Laje B $\left(9 \cdot \sqrt{\mathrm{f}_{\mathrm{c}}{ }^{\prime}}\right)$ \\
\hline \hline Vãos $=$ & $3 \times 3,048 \mathrm{~m}$ & $3 \times 3,048 \mathrm{~m}$ \\
\hline Espessura $=$ & $7,43 \mathrm{~cm}$ & $6,93 \mathrm{~cm}$ \\
\hline Vão / Espessura $=$ & 41 & 44 \\
\hline $\mathrm{F} / \mathrm{A}$ (médio) $=$ & $1,185 \mathrm{MPa}$ & $0,965 \mathrm{MPa}$ \\
\hline $\mathrm{f}_{\mathrm{c}}{ }^{\prime}=$ & $35,51 \mathrm{MPa}$ & $32,75 \mathrm{Mpa}$ \\
\hline
\end{tabular}

GROW \& VANDERBUILT [1967] ${ }^{10}$, apud PTI [1983], realizaram ensaios em doze modelos de ligações laje-pilar cujo objetivo, era estabelecer uma relação da resistência à punção no Estado Limite Último. A tensão de protensão variou de 0 a 650 psi (4,48 MPa). De acordo com os autores, foi estabelecida a seguinte expressão:

$$
\mathrm{V}_{\mathrm{u}}=\left(360+0,3 \cdot \mathrm{f}_{\mathrm{ec}}\right) \cdot \mathrm{b} \cdot \mathrm{d}, \mathrm{em} \mathrm{lb}
$$

Onde:

$f_{\text {ec }} \quad$ é a pré-compressão média (em psi);

d é a altura útil da laje (em polegadas);

b é o perímetro da face da coluna (em polegadas).

\footnotetext{
8 VINES, W. R. [1976]. Strength and Behavior of a Post-Tensioned Concrete Slab with Unbonded Tendons. Thesis, The University of Texas at Austin, Austin, Texas, 1976.

9 CHARNEY, F. A. [1976]. Strength and Behavior of a Partially Post-Tensioned Concrete Slab with Unbonded Tendons. Thesis, The University of Texas at Austin, Austin, Texas, 1976.

10 GROW, J. B.; VANDERBILT, M. D. [1967]. Shear Strength of a Prestressed Lightweight Aggregate Flat Plates. Journal of Prestressed Concrete Institute. Vol. 12, No. 4, August 1967, pp. 18-28.
} 
BURNS \& GERBER [1971]11, apud PTI [1983], realizaram ensaios em ligações laje-pilar. A idéia dos autores não foi propor equações para determinação da resistência da ligação ao esforço cortante, e sim, fornecer dados para as recomendações do ACI 318-77 para cálculo da resistência ao esforço cortante em lajes planas.

BURNS \& SMITH [1973]12, apud PTI [1983], estudaram o efeito da punção em ligações laje-pilar. O objetivo foi avaliar o efeito da adição de armadura passiva na zona de puncionamento. Foi determinada uma equação, que posteriormente foi incorporada ao ACI 318, para o cálculo da armadura mínima.

$$
\mathrm{A}_{\mathrm{S}}=0,00075 . \mathrm{h} .1
$$

Onde,

h é a espessura da laje (em polegadas);

1 é o vão médio (em polegadas) na direção do momento.

HAWKINS \& TRONGTHAM [1976]13, apud PTI [1983], estudaram o esforço cortante e torçor em ligações laje-pilar de estruturas protendidas. Segundo os autores, a armadura de protensão e a passiva foram efetivas para transferência do momento devido ao esforço cortante; $80 \%$ da armadura passiva prescrita pelo ACI 318-77, foi suficiente para suportar as tensões de serviço e de fissuração em ligações laje-pilar internas, entretanto, para as demais ligações esta quantidade não seria satisfatória e a armadura passiva inferior deveria ser igual à armadura de combate à retração e à variação de temperatura sendo que esta deve atravessar toda a ligação até além da seção crítica quando houver um esforço cortante superior a $0,7 \cdot \sqrt{f_{c}{ }^{\prime}}$ (em psi). Foi verificado que uma armadura passiva bem detalhada pode trabalhar no combate ao esforço torçor quando o esforço cortante exceder $2 . \sqrt{\mathrm{f}_{\mathrm{c}}}$ (em psi).

\footnotetext{
11 BURNS, N. H.; GERBER, L. L. [1971]. Ultimate Strength Tests of Post-Tensioned Flat Plates. Journal of Prestressed Concrete Institute. Vol. 16, No. 6, November - December 1971, pp. 40-58.

12 SMITH, S. W.; BURNS, N. H. [1974]. Post-Tensioned Flat Plate to Column Connection Behavior. Journal of Prestressed Concrete Institute. Vol. 19, No. 3, May-June 1974, pp. 74-91.

13 HAWKInS, N. M.; TRONGTHAM, N. [1976]. Moment Transfer between Unbonded Post-Tensioned Concrete Slabs and Columns. Progress Report to the Post-Tensioning Institute and Reinforced Concrete Research Council on Project \#39, Structures and Mechanics Division, Departmente of Civil Engineering, University of Washington, Seattle, November 1976.
} 
Os autores chegaram à conclusão que as ligações laje-pilar internas protendidas são mais rígidas quando comparadas com lajes de concreto armado com mesma capacidade de flexão e que, a ductilidade das lajes protendidas para carregamentos unidirecionais, são iguais se comparados com lajes de concreto armado com armadura de punção.

MORDECAI [1984] fez alusão à economia provocada pela utilização da protensão com monocordoalhas engraxadas na Grã-Bretanha. As causas de sua pouca utilização eram devidas à falta de normatização, à escassez de dados relacionados com custos e à mão-de-obra muito especializada. Apresentou a parte construtiva de lajes protendidas onde ressalta a importância da utilização da mesma equipe de montagem para armadura aderente e a não aderente. Dentre suas comparações, o autor citou que a utilização da protensão aderente é feita para grandes carregamentos aplicados e a protensão não aderente para menores carregamentos onde a tensão de protensão varia de 1,0 a 2,5 $\mathrm{MPa}$.

Segundo o autor, foi possivel atingir uma economia de 10,67\% na estrutura, ao se utilizar a protensão não aderente em comparação com concreto armado.

Em 1985, BURNS \& HEMAKOM [1985] novamente utilizaram o mesmo modelo de laje plana de 1977, mas com os cabos distribuídos de maneira diferente (ver figura 2.13). Os objetivos eram semelhantes, mas o modelo apresentava baixos níveis de protensão, onde se pretendia avaliar o desempenho do concreto com baixas tensões de compressão e do arranjo de cabos em faixas.

Segundo os autores, o comportamento do modelo em serviço foi elástico-linear com ductilidade elevada. O arranjo em faixas promove uma rigidez maior que o arranjo distribuído. Com relação à punção, sua resistência foi muito baixa em virtude do modo de ruína apresentado. 


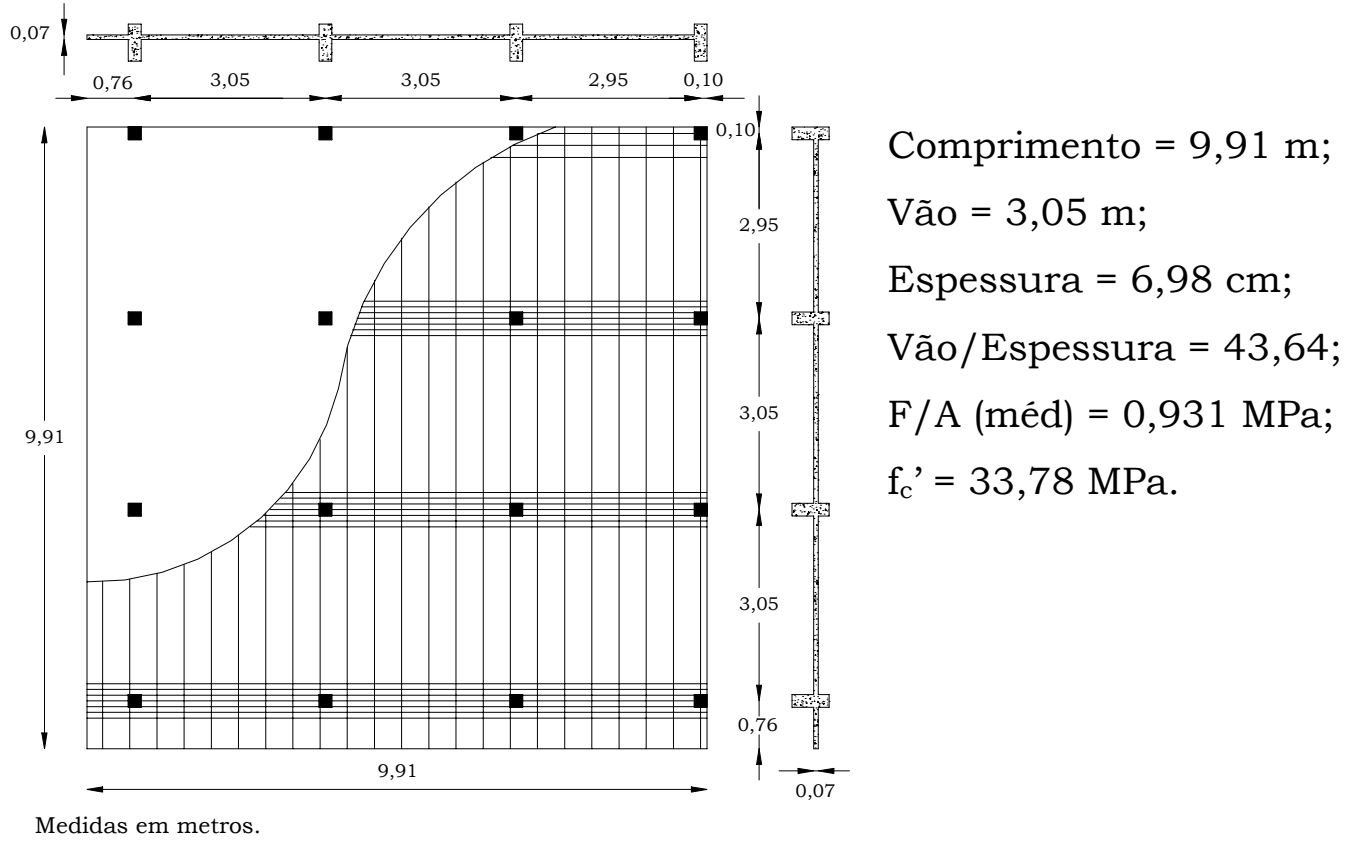

Figura 2.13 - Modelo de laje plana (adaptado de BURNS \& HEMAKOM [1985])

Para projeto, reforçando as mesmas recomendações de BURNS \& HEMAKOM [1977], deve-se colocar pelo menos $0,15 \%$ da área da seção transversal em zonas de ligação laje-pilar com armadura passiva, pois esta aumenta sua capacidade resistente e estendê-la até uma distância de 1,5 vezes a face do pilar e, quanto maior o valor de P/A, maior será a resistência à fissuração e a resistência ao esforço cortante. Foi verificado que os pilares externos foram beneficiados pelo posicionamento das ancoragens aumentando a tensão no concreto e assim, favorecendo a resistência ao esforço cortante.

KOSUT et al. [1985] fizeram um estudo semelhante aos trabalhos de BURNS \& HEMAKOM [1985] em lajes planas com protensão sem aderência (ver figura 2.14). Os objetivos eram confirmar o comportamento da estrutura na sua fase elástica e inelástica até o colapso; verificar a distribuição de fissuras; averiguar as resistências nas armaduras aderentes e não aderentes; verificar a resistência à punção e procedimentos mais adequados para o cálculo de lajes planas com armadura de protensão não aderente. 


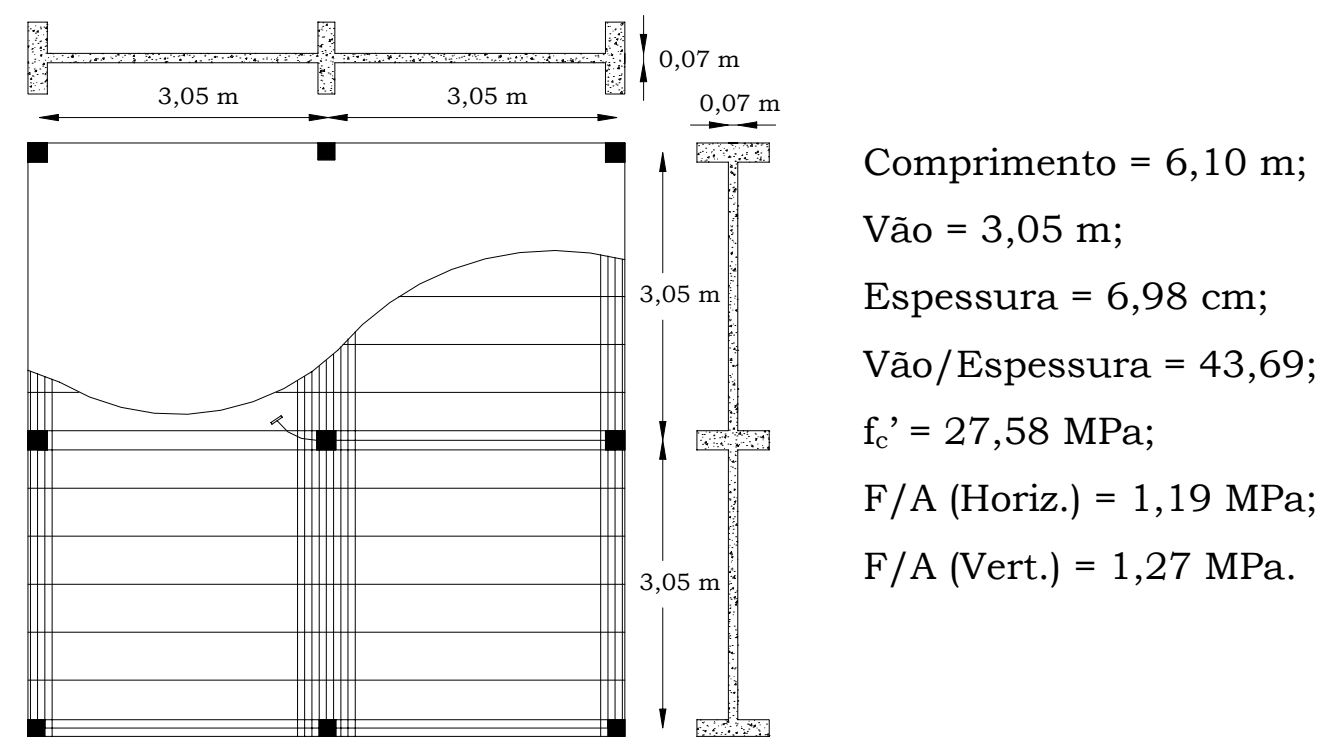

Figura 2.14 - Modelo de laje plana (adaptado de KOSUT et al. [1985])

De acordo com os autores, a armadura calculada pelo ACI 318-77 foi suficiente para o controle da fissuração; a distribuição em faixas foi eficaz na resistência a cargas maiores que aquelas calculadas e o método dos pórticos equivalentes foi muito eficaz na determinação dos momentos atuantes; a tensão nos cabos foi inferior àquela estimada pelo ACI 318-77; a rigidez de cada ligação laje-pilar excedeu os valores estimados pelo ACI 318-77 e ainda, a adoção de estribos verticais nos pilares de extremidade não aumentou sua resistência ao colapso pela punção. Os autores ainda sugeriram equações para as tensões últimas para armadura não aderente:

$$
\begin{aligned}
& \mathrm{f}_{\mathrm{ps}}=\mathrm{f}_{\mathrm{se}}+\frac{10000 \cdot \mathrm{f}_{\mathrm{c}^{\prime}}}{100 \cdot \rho_{\mathrm{p}}} \quad\left(\text { para: } \frac{1}{\mathrm{~h}} \leq 28\right) \\
& \mathrm{f}_{\mathrm{ps}}=\left(1,265-9,375 \cdot 10^{-3} \frac{1}{\mathrm{~h}}\right) \cdot\left(\mathrm{f}_{\mathrm{se}}+10000+\frac{\mathrm{f}_{\mathrm{c}}{ }^{\prime}}{100 \cdot \rho_{\mathrm{p}}}\right)
\end{aligned}
$$

Sendo esta última válida somente para $\frac{1}{h}>28$.

$\mathrm{f}_{\mathrm{ps}} \quad$ é a tensão na armadura ativa para a carga de serviço aplicada (em psi);

$\mathrm{f}_{\mathrm{se}} \quad$ é a tensão na armadura ativa após as perdas de protensão (em psi);

$1 / \mathrm{h}$ a relação do vão pela espessura da laje. 
Onde $f_{p s}$ não deve ser maior que $f_{p y}$ ou $\left(f_{s e}+60000\right)$. Estas equações promovem uma redução linear de 100 a 85\% na tensão última do cabo para relações vão-espessura variando de 28 a 44, respectivamente.

Em 1987, COLLINS \& MITCHELL apresentaram texto bastante amplo a respeito do concreto protendido, citando critérios para o dimensionamento à flexão, ao esforço cortante, ao momento torçor e recomendações para o projeto de edificios e pontes. Ainda, deram ênfase às lajes com protensão não aderente, com critérios e recomendações para projeto.

Segundo os autores, a simplicidade da protensão não aderente somada com a eliminação da injeção de pasta de cimento, permite ao sistema, uma construção mais econômica (ver figura 2.15).

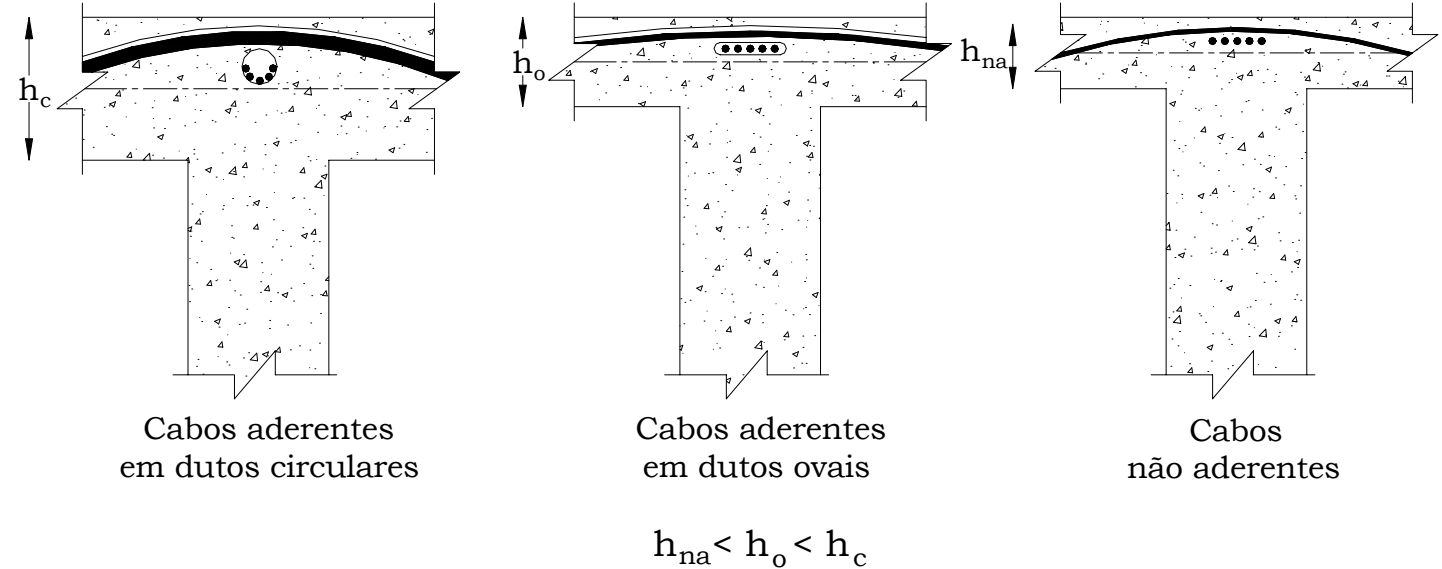

Figura 2.15 - Efeito do tipo de protensão (aderente e não aderente) na altura da laje. (Adaptado de COLLINS \& MITCHELL [1987])

Onde,

$h_{c} \quad$ é a espessura da laje com cabos aderentes em dutos circulares;

$h_{0} \quad$ é a espessura da laje com cabos aderentes em dutos ovais;

$\mathrm{h}_{\text {na }}$ é a espessura da laje com cabos não aderentes.

Em 1988, CHACOS descreveu os materiais utilizados na protensão não aderente e os principais problemas que podem ocorrer, desde a manufatura até a fase final de inspeção do pavimento protendido. Segundo o autor, o sistema de protensão não aderente é seguro, eficaz, econômico e que, a resolução de pequenos problemas poderiam evitar reparos desnecessários que atrasariam o andamento da obra. 
Ainda em 1988, FALCONER realizou um estudo sobre a durabilidade em pavimentos, com protensão não aderente, de edificios garagem com a resolução de alguns detalhes construtivos. Segundo o autor, para se realizar um projeto e detalhamento satisfatórios, seria necessário primeiramente entender como a protensão atua no pavimento. Em seu estudo, mostrou dados referentes ao posicionamento de armaduras passivas para combater a retração e outras ações.

FALCONER \& WILSON [1988], do mesmo modo que CHACOS [1988], realizaram um estudo sobre a qualidade da protensão não aderente. Em seu trabalho estudaram os procedimentos para inspeção de uma estrutura protendida como o posicionamento das ancoragens e dos perfis dos cabos, de acordo com o projeto. Discutiram o sistema de laje plana, mostrando as distribuições de cabos em faixas e uniforme; os sistemas de laje-viga, e ainda, o sistema de fundação tipo radier.

No final da década de 80 e durante a década de 90, AALAMI [1988 2000] realizou abrangentes estudos com relação à protensão não aderente. Desenvolveu técnicas de modelagem de pavimentos; observou a importância do perfil e da distribuição dos cabos de protensão e disposição da armadura passiva, bem como sua quantidade; larguras efetivas de faixas para protensão; configurações para pavimentos de edificios moldados no local (pós-tração) e, além disso, ressaltou sua aplicação a projetos, bem como suas limitações e materiais necessários para uma boa qualidade da estrutura. Observou ainda, os vãos e espessuras mais adequadas para sistemas estruturais de pavimentos protendidos.

Em 1990, FOUTCH et al. realizaram estudos em lajes planas com protensão não aderente (ver figura 2.16) e priorizaram o efeito do momento fletor e do esforço cortante nas ligações laje-pilar; estudaram o mecanismo de falha das ligações e desenvolveram um procedimento simples para avaliar a rigidez de uma ligação.

De acordo com os autores, o sistema de lajes planas com protensão não aderente é muito econômico, pois, apresenta várias características 
interessantes como a mínima obstrução para a utilização e passagem das canalizações; peso reduzido por pavimento; boas propriedades com relação à resistência ao fogo, entre outras.

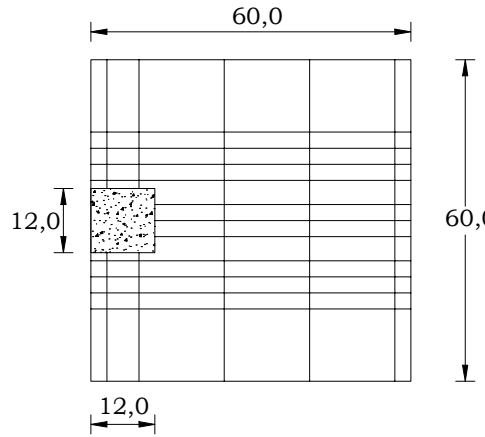

Modelos S1 e S2 (medidas em centimetros)

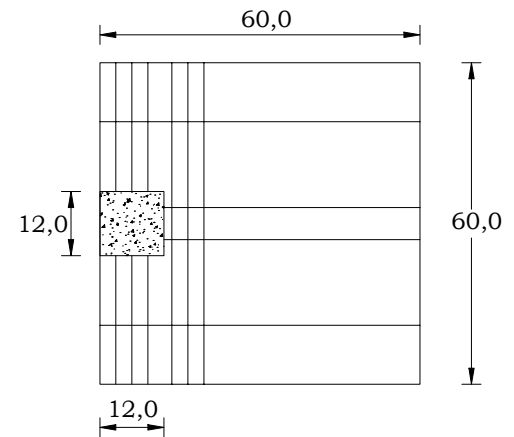

Modelos S3 e S4 (medidas em centímetros)

Figura 2.16 - Distribuição dos cabos nos modelos (adaptado de FOUTCH et al. [1990])

$\mathrm{Na}$ análise dos resultados, foi verificada uma boa concordância entre os momentos calculados e os medidos nos modelos, porém, não existia um método adequado para determinar a tensão final em cordoalhas não aderentes. Para a análise do esforço cortante, no caso, punção, a equação proposta pelo ACI admite que existe uma força cortante aplicada diretamente, em termos de $\mathrm{F} / \mathrm{A}$, mais uma segunda componente relacionada com $\mathrm{o}$ momento não balanceado que deve ser transferido para o pilar (neste caso, uma parte é transferida diretamente por momento fletor e o resto é transferido pelo esforço cortante distribuído de maneira não uniforme ao redor do perímetro crítico do pilar). Os modelos apresentaram valores iguais ou superiores aos valores limites estabelecidos pelo ACI 318.

Concluindo, os autores recomendaram maiores estudos com materiais com resistências variadas, outras geometrias e diferentes condições de contorno seriam necessárias para determinar aproximações empíricas para este problema.

Em 1992, MATTACCHIONE desenvolveu um estudo sobre lajes com protensão não aderente objetivando suas vantagens com relação ao sistema de protensão aderente. Fez uma comparação entre as lajes de concreto protendido e de concreto armado e verificou que a economia na utilização da 
protensão não aderente em sistemas unidirecionais de aproximadamente $17,80 \%$ e para sistemas bidirecionais de aproximadamente $9,37 \%$.

Em 1993, LONG \& CLELAND realizaram estudos experimentais sobre o comportamento de lajes planas com protensão não aderente (ver figura 2.17). Foram ensaiados cinco modelos simulando o comportamento da estrutura em três etapas: durante a transferência da protensão; com cargas de serviço e com a aplicação da carga de ruptura, variando o nível de protensão; a distribuição e o perfil dos cabos na estrutura.
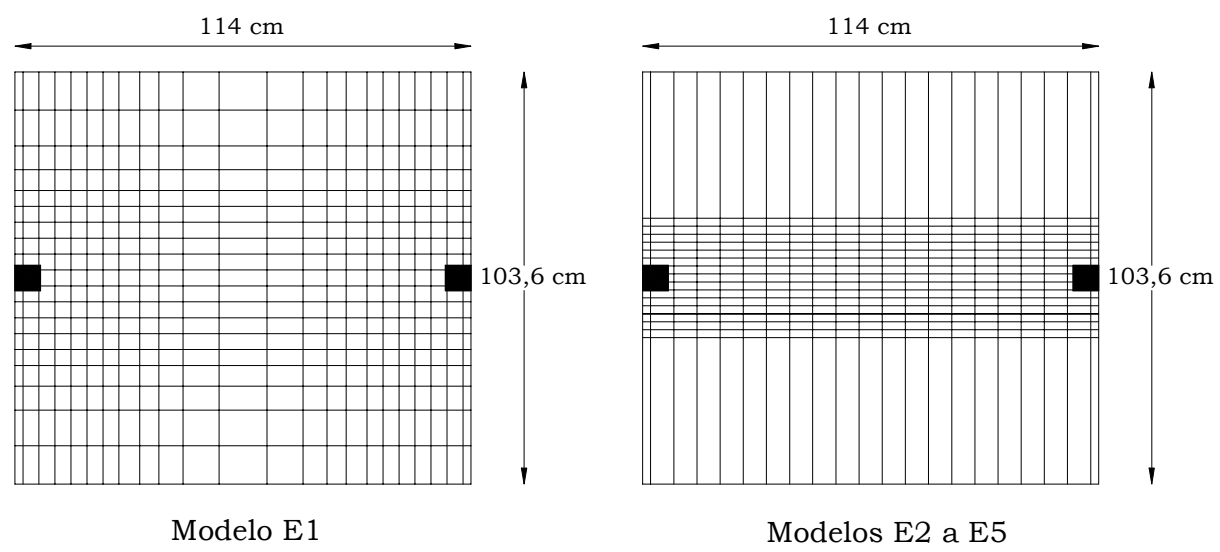

Figura 2.17 - Distribuição dos cabos (adaptado de LONG \& CLELAND [1993])

Segundo os autores, foi novamente verificado que a utilização de armadura passiva nas regiões críticas controla a fissuração e aumenta a ductilidade da estrutura; verificou-se que as equações do ACI 423-89 são extremamente conservadoras para o cálculo da punção; o arranjo de cabos em faixas, quando perpendicular à bordas livres, acarretam apenas um pequeno aumento na resistência da ligação; a tensão na cordoalha aumenta a resistência à ruptura de 5 a $10 \%$.

Em 1993, SCHMID publicou um texto referente ao cálculo de lajes planas protendidas onde procurou mostrar aspectos de projeto como o dimensionamento à flexão e à punção; vãos livres e arranjos para os cabos. Fez uma comparação econômica entre os sistemas de laje de concreto armado e protendido, com ou sem vigas, e constatou que as soluções com protensão são mais econômicas, chegando a $18,5 \%$ de economia em relação ao concreto armado. 
DUARTE [1995], fez um estudo semelhante ao de SCHMID [1993] onde tentou, segundo ele mesmo, "fazer uma literatura técnica mais abrangente para os profissionais". Em seu trabalho, fez cálculos manuais utilizando a teria de grelhas para duas lajes comparando-as com um programa de cálculo de lajes protendidas.

NAWY [1996], publicou extenso trabalho sobre o concreto protendido, citando critérios e recomendações de projeto. $O$ texto inclui interessante cálculo de uma laje com protensão não aderente, mostrando passo-a-passo o seu dimensionamento.

ALBUQUERQUE [1998], analisou sistemas estruturais de concreto armado e protendido. Foi visto que o sistema protendido é bastante promissor, devido à possibilidade de aplicação em uma grande variedade de pavimentos e pelo número reduzido de pilares. Em seu estudo, foi observado que o sistema protendido, com o tempo, deverá ser bastante competitivo com os demais sistemas estruturais de concreto armado.

GARDNER \& KALLAGE [1998], estudaram o comportamento da punção em lajes planas com protensão não aderente (ver figura 2.18). Objetivava-se estudar o mecanismo de ruptura das ligações, porém, sem armadura suplementar passiva, e, desenvolver equações que representassem, de acordo com os resultados do modelo experimental, os parâmetros que controlavam a capacidade de resistência à punção, comparando-as com o Código do ACI 31895, BS $8110-85$ e um novo método proposto pelos autores. 


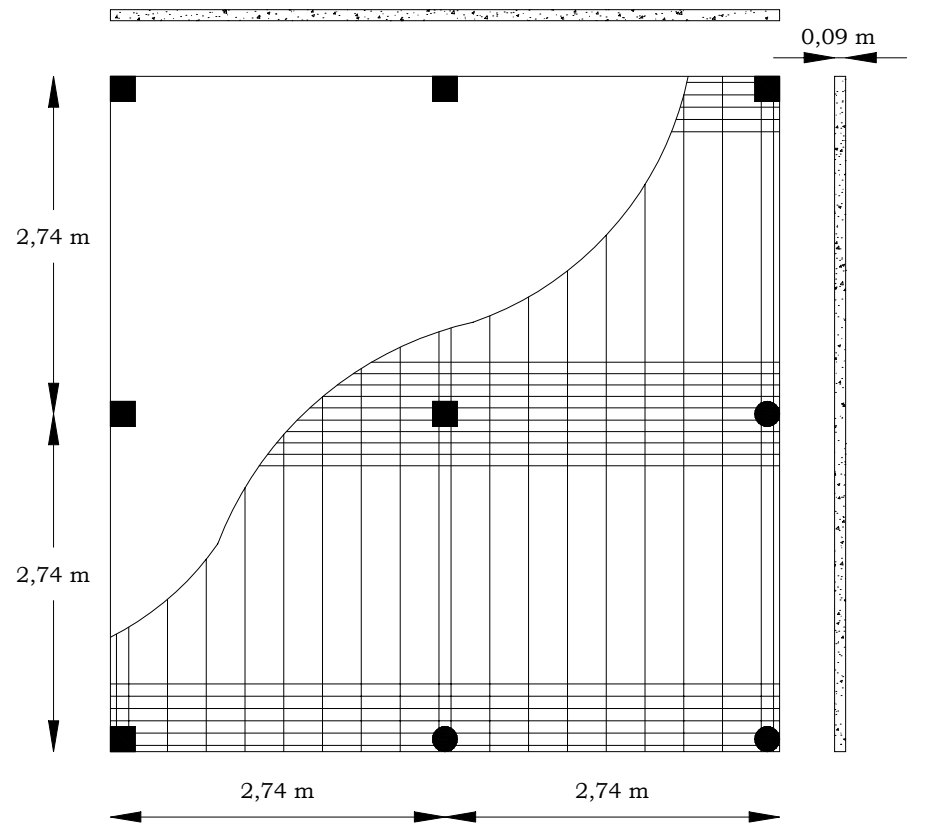

Comprimento $=5,48 \mathrm{~m}$;

Vão $=2,74 \mathrm{~m}$;

Espessura $=9,00 \mathrm{~cm}$;

Vão/Espessura $=30,44$;

$\mathrm{f}^{\prime}{ }_{\mathrm{c}}=44,0 \mathrm{MPa}$;

$\mathrm{P}=89,0 \mathrm{kN}$ (por cabo);

Pilares quadrados $=$

$$
20,3 \times 20,3 \mathrm{~cm}
$$

Pilares circulares $=$

20,3 cm de diâmetro

Figura 2.18 - Modelo de laje plana (adaptado de GARDNER \& KALLAGE [1998])

Segundo os autores, o comportamento à flexão das lajes planas com protensão não aderente era excelente, desde que não ocorresse a formação de fissuras, pois estas apresentavam picos de momento elevado. Foi visto que a capacidade resistente última do modelo é determinada pela sua resistência à punção e que, de acordo com os estudos, a ruptura por punção é violenta e súbita, devendo-se, portanto, utilizar minoradores de resistência.

Os autores também citaram recomendações para as ligações laje-pilar de canto e de borda.

SILVA [1998] estudou conceitos relevantes de projeto lajes planas maciças protendidas. Segundo a autora, o projeto de lajes, com protensão não aderente, foi muito prejudicado devido às restrições impostas pela NBR 7197, pois, estabelecia que a protensão não aderente somente poderia ser utilizada no regime de protensão completa; recomendou cuidados na escolha correta da espessura da laje e, do mesmo modo que AALAMI, sugeriu aproximar ao máximo o comportamento da laje de sua resposta natural.

CARDOSO [2001] abordou a fase de projeto e dimensionamento de lajes com protensão não aderente. Verificou os procedimentos de cálculo, dimensionamento e segurança adotados pela Norma do ACI 423.3R e ACI 318- 
95, a Norma Britânica BS 8110-97 e pela Norma Brasileira NBR 7197, NBR 6118-78 e o Projeto de Revisão da Norma NBR 6118-2000. Segundo o autor, deve-se levar em consideração, para o dimensionamento de estruturas com protensão não aderente, vários fatores como: o grau de protensão, o nível de carregamento, vãos dentre outras. Apresentou, ainda, outros fatores importantes, do mesmo modo que CAUDURO e GRAZIANO, que são as vantagens construtivas que a protensão não aderente apresenta, como, por exemplo, a rapidez de execução.

Ainda em 2001, MELGES realizou um estudo semelhante ao desenvolvido por FOUTCH et al. [1990]. Verificou o comportamento à punção de lajes planas de concreto armado e protendido (sem aderência), sendo que, neste último, além de analisar a influência da protensão na ligação laje-pilar, também analisou a influência da presença ou não de armadura de punção (ver figura 2.19). Segundo o autor, a presença da armadura de punção aumentou a resistência da ligação.

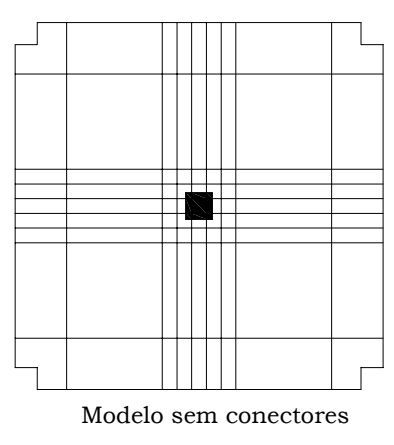

Figura 2.19 - Distribuição dos cabos nos modelos (adaptado de MELGES [2001])

Do mesmo modo que MELGES [2001], CORREA et al. [2001] apresentou um trabalho referente ao comportamento ao puncionamento de lajes planas com protensão não aderente (ver figura 2.20). Comparou os resultados experimentais de seis modelos com os Códigos em vigência, tais como, ACI 318-95, o EC2/98, o FIP/98, a NB1-78 e a Proposta de Revisão de Norma NBR 6118-2000. 


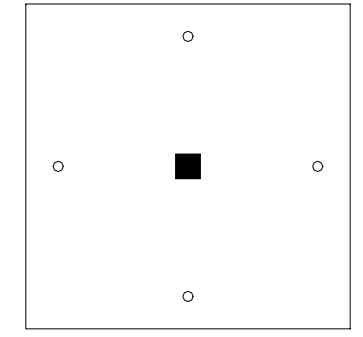

LP1

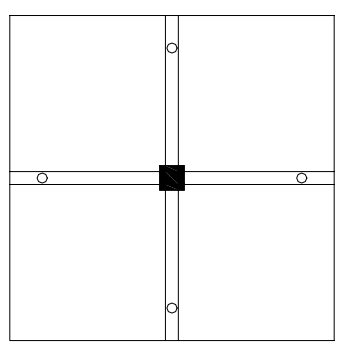

LP4

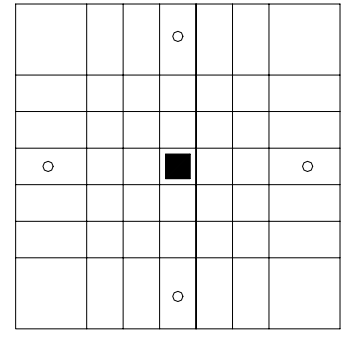

LP2

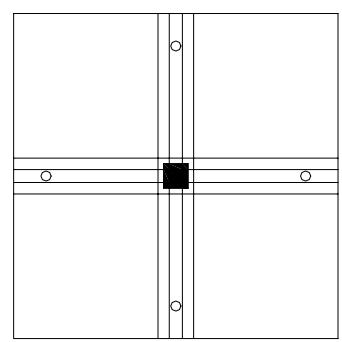

LP5

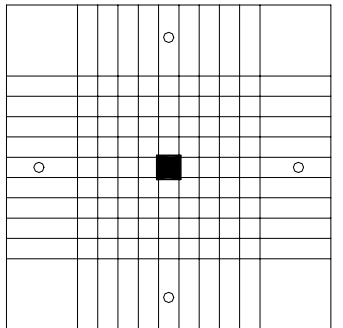

LP3

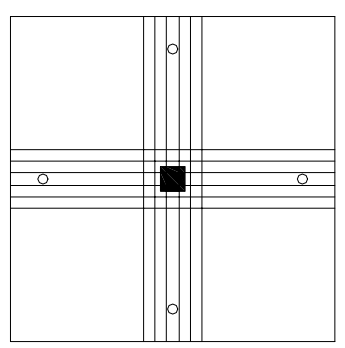

LP6

Figura 2.20 - Distribuição dos cabos (adaptado de CORRÊA et al. [2001])

Segundo os autores, o efeito da carga equilibrante aumentou a resistência da ligação laje-pilar à punção; o Código do FIP/98 forneceu as melhores estimativas para a carga de ruptura; os modelos com distribuição das cordoalhas em faixas apresentaram grandes deslocamentos, mostrando assim, grande ductilidade, e por último, os autores sugeriram a adoção de expressões, utilizadas no Código do FIP/98 e pelo MC/90, que quantificariam o efeito da protensão.

Os trabalhos citados se referem, em sua maioria, a experimentos e modelagens em diversos sistemas estruturais com os sistemas de cálculo existentes, sempre comparando com os parâmetros normatizados. Foram realizados muitos ensaios referentes ao comportamento à flexão e ao esforço cortante (punção). Embora, muitas vezes repetitivo, isso demonstrou a grande preocupação dos pesquisadores em avaliar de maneira correta o desempenho de estruturas de edifícios com a protensão não aderente.

Pode-se ver ainda que, nos últimos anos, houve um desenvolvimento nos trabalhos com monocordoalhas engraxadas no Brasil, isso, pois o sistema somente começou a ser adotado a partir de 1997. 
Somente a partir da década de 80 , foi que as primeiras publicações que destacavam a idéia da protensão não aderente divulgando suas vantagens, econômicas e construtivas, em relação ao concreto armado e ao concreto com protensão aderente surgiram, tentando assim, vencer a barreira que separa a protensão não aderente da utilização comum nas obras de engenharia.

Esses estudos continuam em avanço, mostrando assim, a necessidade de maiores investigações, o que justifica a importância deste trabalho.

\section{4 - Vantagens e Desvantagens}

O sistema de protensão com monocordoalhas engraxadas apresenta várias vantagens com relação a protensão tradicional (aderente). Dentre elas, pode-se destacar:

- Maior praticidade do posicionamento das cordoalhas nas fôrmas, pois, o manuseio é feito com uma cordoalha por vez, sendo que esta apresenta um peso de $0,89 \mathrm{~kg} / \mathrm{m}$;

- Ausência da bainha metálica, tornando assim reduzidos, aqueles excessivos cuidados com a disposição e transporte na fôrma, pois a cordoalha possui uma capa plástica protetora PEAD resistente aos trabalhos na obra;

- O macaco hidráulico de dois cilindros é leve e pode ser manuseado por um único operário;

- Inexistência da operação de injeção de pasta de cimento nos cabos;

- Como as cordoalhas se apresentam em bainhas individuais de plástico, estas podem se espalhar na laje em movimentos horizontais, permitindo assim, que as cordoalhas passem através dos pilares, mesmo estes estando desalinhados;

- Como as cordoalhas podem se espalhar, é facilitada a passagem das instalações através da laje;

- As ancoragens são pequenas e práticas, vindas em uma única peça e já vem acompanhadas de uma forma plástica para nicho; 
- Devido ao perfil delgado da cordoalha engraxada, é possivel utilizar maiores excentricidades que no caso da protensão tradicional com bainhas metálicas;

- Devido à presença da graxa na bainha de plástico, ocorre o escorregamento do cabo, reduzindo assim, as perdas por atrito;

- A bainha e a graxa promovem a proteção contra a corrosão da cordoalha;

- Rapidez na execução da protensão, mesmo com o fato da operação do macaco hidráulico ser feito em uma cordoalha por vez, pois esta é muito rápida, sendo feita em uma só elevação de pressão, levando menos de 20 segundos para o término da aplicação da força de protensão.

Como desvantagens, o sistema de protensão não aderente apresenta deficiências com relação ao comportamento da estrutura, quando sujeita à carregamentos de serviço e de ruptura.

Dentre elas, pode-se destacar:

- A seção transversal do elemento apresenta capacidade resistente inferior ao da protensão tradicional (aderente) na ruptura, suportando menores carregamentos;

- A distribuição de fissuras na protensão por aderência é melhor que na protensão não aderente;

- Apresenta o fato de que a força de protensão é garantida apenas por meio das ancoragens, necessitando, portanto, de atenção especial na região de concretagem das ancoragens.

Para se aumentar a capacidade resistente da seção transversal, é necessário, de acordo com várias publicações de ensaios realizados, o posicionamento de armadura complementar passiva aderente na seção, para com isso, aumentar esta capacidade e, em alguns casos, pode-se ter comportamento superior a elementos com protensão aderente.

\section{5 - Sistemas Unidirecionais e Bidirecionais}

O comportamento das lajes de concreto, tanto armado quanto protendido, se baseia em dois sistemas: unidirecionais e bidirecionais. 
Estes sistemas se caracterizam pelo caminho que a carga seguirá desde o local de sua aplicação até o apoio da laje, sendo que, este caminho pode variar dependendo da geometria da laje, disposição da armadura, força de protensão aplicada, disposição dos pilares, distribuição do carregamento e sua intensidade.

De acordo com AALAMI, estes sistemas têm origem na resposta natural da estrutura aos carregamentos aplicados com as condições de contorno da estrutura, e o projetista, deve ter isto em mente quando fizer a disposição de cordoalhas e armaduras complementares para transferir de maneira satisfatória os carregamentos aplicados na estrutura.

Os sistemas unidirecionais se caracterizam pela transferência de cargas se dar por um único caminho para os apoios (ver figura 2.21).
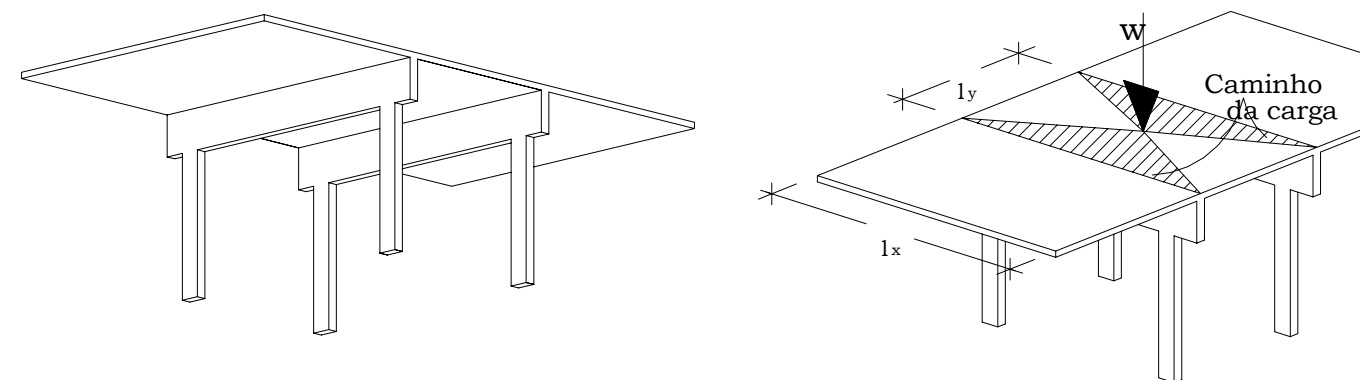

Figura 2.21 - Sistema unidirecional de lajes

Já os sistemas bidirecionais, se caracterizam pela transferência de cargas se dar por dois caminhos distintos (ver figura 2.22).

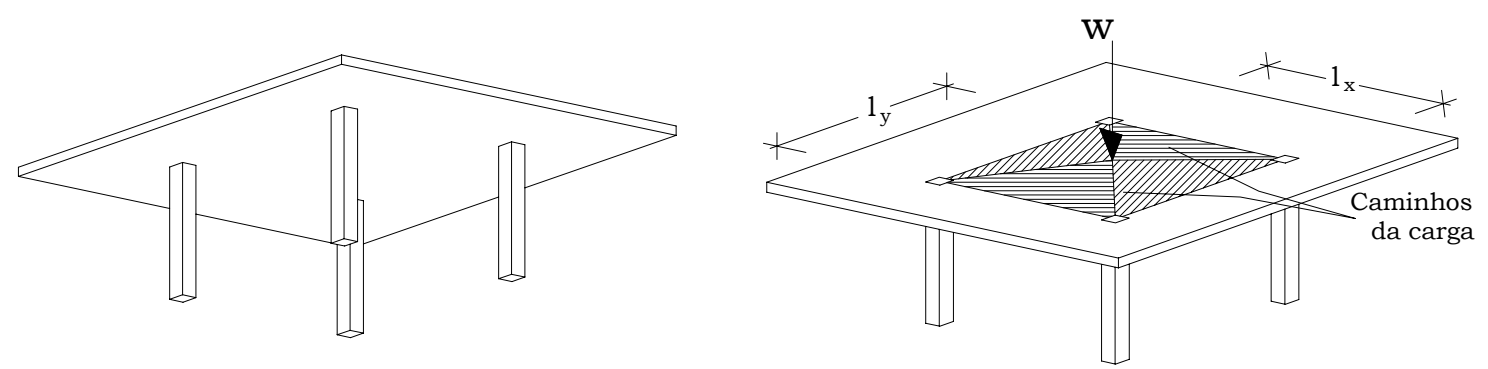

Figura 2.22 - Sistema bidirecional de lajes

A experiência tem mostrado que o sistema bidirecional leva a um dimensionamento significativamente mais econômico, chegando a reduções de $20 \%$ ou mais no consumo de cabos e de armadura passiva. 


\section{6 - Utilização - Sistemas Estruturais}

A utilização da protensão com monocordoalhas engraxadas é feita da mesma maneira na construção de pavimentos de edificios de concreto armado.

Tem-se que, na concepção estrutural de um pavimento, levar em consideração para o projeto, fatores como: os vãos a serem vencidos e disposição dos pilares; espessura da laje para suportar os esforços devidos às cargas aplicadas e a quantidade de armadura e seu arranjo. Deve-se, portanto, fazer uma boa escolha do sistema estrutural, para evitar custos acentuados devidos a uma má escolha nos critérios acima descritos.

Pode-se verificar alguns critérios adotados em projeto:

- Dispor os pilares no perímetro do pavimento, desde que não haja restrição arquitetônica, para assim limitar os balanços em dimensões econômicas para o projeto;

- Reduzir a seção dos pilares para assim minimizar as perdas de protensão devidas à restrição ao encurtamento da laje;

- Sempre que possivel, ajustar o arranjo e o traçado dos cabos de maneira a otimizar o balanceamento de cargas para cada vão;

- Dimensionar traçados de cabos para que se possa obter um bom nível de flecha para os cabos de maneira a propiciar a sua melhor utilização (para tal, é necessário dimensionar uma altura satisfatória para a laje em seu pré-dimensionamento pelas relações vão/espessura).

A distribuição dos cabos é muito importante para se obter um comportamento mais eficiente. Segundo as recomendações na literatura técnica, pode-se chegar a um arranjo de cabos que propicie mais economia, que, é a disposição das cordoalhas em faixas, embora isto dependa de cada caso.

Na figura 2.23, têm-se as disposições possiveis de serem utilizadas em pavimentos de edificios. 


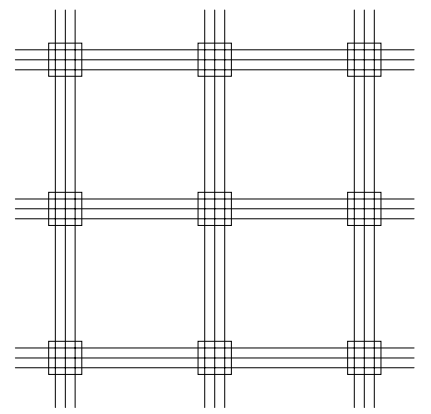

(a)

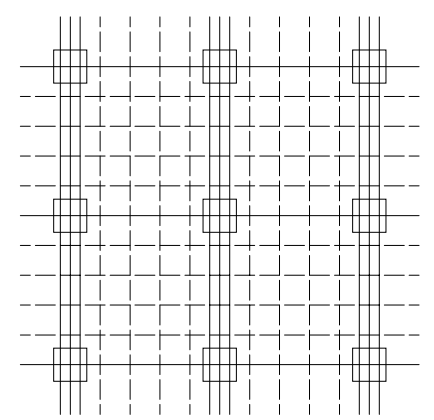

(d)

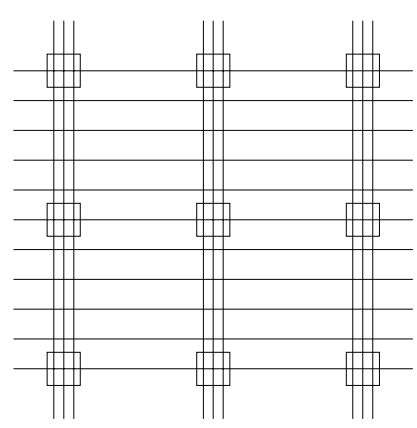

(b)

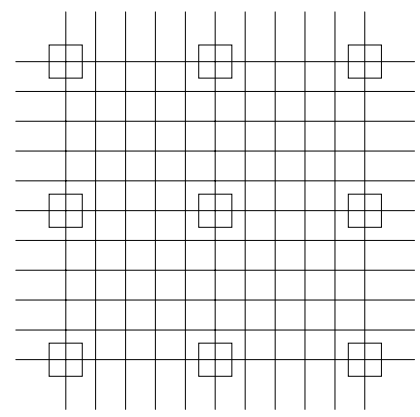

(e)

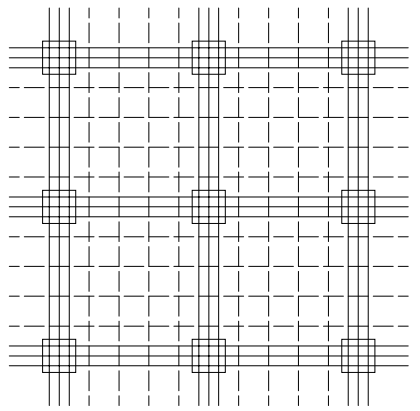

(c)

Figura 2.23 - Exemplos de distribuição de cabos

A figura 2.23 (a) mostra uma disposição com $100 \%$ dos cabos passando pelas faixas dos pilares nas duas direções; a figura 2.23 (b) mostra uma disposição com 100\% dos cabos passando pelas faixas dos pilares em uma direção e na outra, uma distribuição uniforme; a figura 2.23 (c) mostra uma concentração de $75 \%$ de cabos nas faixas dos pilares e de $25 \%$ nas faixas centrais, em ambas as direções; a figura 2.23 (d) é similar à figura 2.23 (b), uniforme em uma direção, e, na outra direção existe uma disposição igual a $75 \%$ de cabos nas faixas dos pilares e de $25 \%$ nas faixas centrais; e a figura 2.23 (e), que ilustra a disposição uniforme dos cabos nas duas direções.

A utilização das faixas de cordoalhas traz muitas vantagens, dentre as quais pode-se citar:

- Melhor uniformidade no balanceamento de carga;

- A concentração de cabos nas regiões dos pilares aumenta a resistência à punção da laje e, também, incrementa a transferência do momento na ligação laje-pilar;

- O posicionamento de cabos em faixas permite uma maior rapidez de execução na obra do que a distribuição uniforme na laje. 
Para o pré-dimensionamento de lajes protendidas, pode-se utilizar as recomendações do PTI [1983] e AALAMI [1989] (Ver Tabela 2.2).

Tabela 2.2 - Relações de $1 / \mathrm{h}$ para pré-dimensionamento

\begin{tabular}{||l|l|c|c|c|c||}
\hline \multirow{2}{*}{ Sistema } & \multicolumn{2}{c|}{$1 / \mathrm{h}$ (Vão Continuo) } & \multicolumn{2}{c|}{$1 / \mathrm{h}$ (Vão Simples) } \\
\cline { 3 - 6 } & & Teto & Piso & Teto & Piso \\
\hline \hline \multirow{3}{*}{ Unidirecional } & Lajes & 50 & 45 & 45 & 40 \\
\cline { 2 - 6 } & Vigas & 35 & 30 & 30 & 26 \\
\hline \multirow{5}{*}{ Bidirecional } & Laje Plana & $45-48$ & $40-45$ & - & - \\
\cline { 2 - 6 } & Laje Nervurada & 40 & 35 & 35 & 30 \\
\cline { 2 - 6 } & $\begin{array}{l}\text { Laje Plana } \\
\text { com capitéis }\end{array}$ & - & $\begin{array}{c}58^{*} \\
\text { (AALAMI) }\end{array}$ & - & - \\
\cline { 2 - 6 } & $\begin{array}{l}\text { Laje Plana } \\
\text { com drop panels }\end{array}$ & - & $\begin{array}{c}60^{*} \\
\text { (AALAMI) }\end{array}$ & - & - \\
\hline
\end{tabular}

* Essas razões baseiam-se em exemplos com a espessura da laje igual a $20,3 \mathrm{~cm}$.

Admiti-se para os casos da tabela 2.2, uma ação variável até 10,0 $\mathrm{kN} / \mathrm{m}^{2}$.

O Código do FIP recomenda que, para lajes contínuas, com dois ou mais vãos, a relação vão-espessura não deve exceder 48 para lajes de teto e 42 para pavimentos planos.

Segundo GILBERT [1989], a avaliação da relação vão-espessura para lajes planas deve ser feita na direção do maior vão. O limite da razão vãoespessura pode ser aumentado para 48 (laje de teto) e 42 (pavimento), desde que as flechas, curvaturas e vibrações estejam em limites aceitáveis.

$\mathrm{Na}$ presente pesquisa será dada ênfase aos arranjos de laje - viga pilar, laje nervurada - pilar e laje lisa - pilar, onde serão vistas suas principais características como limitação de vãos, espessuras mínimas, cargas admissiveis e critérios limitadores.

Como ilustração são apresentadas as armaduras determinadas nas figuras (ver figuras 2.25, 2.26, 2.27, 2.28, 2.30, 2.31, 2.33). Os exemplos são submetidos a uma ação variável de $2,40 \mathrm{kN} / \mathrm{m}^{2}$ e a uma ação permanente de $1,44 \mathrm{kN} / \mathrm{m}^{2}$ com uma resistência à compressão do concreto de $28 \mathrm{MPa}$.

As lajes sem vigas apresentam configurações variadas em que o modelo estrutural pode apresentar quatro concepções (ver figura 2.24), que são a laje plana, a laje plana com capitéis, laje plana com drop panels e laje plana com 
drop panels e capitéis, sendo este último não muito utilizada, por não ser vantajosa para edificios comerciais e residenciais submetidos a ações variáveis superiores a $3,60 \mathrm{kN} / \mathrm{m}^{2}$, devido às dificuldades de execução das fôrmas e ao congestionamento das armaduras.

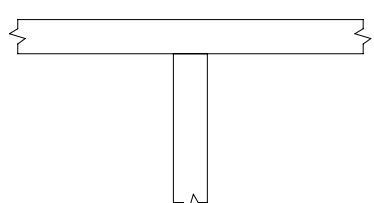

Laje Plana

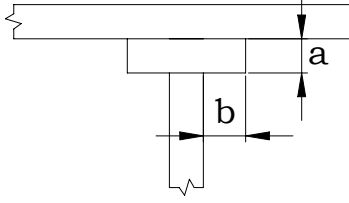

Laje Plana com capitel

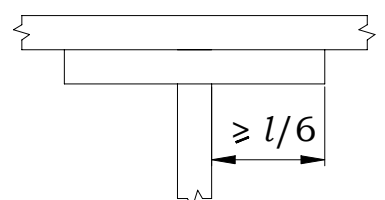

Laje Plana com drop panel

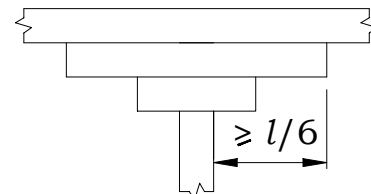

Laje Plana com drop panel e capitel

Onde $l$ é o vão livre entre apoios

Figura 2.24 - Ligações laje-pilar para lajes planas (AALAMI [1999])

A seguir, são vistos os modelos estruturais utilizados, bem como suas limitações e consumos médios de armaduras.

\section{- Laje lisa}

A figura 2.25 ilustra o modelo de laje plana apoiada sobre pilares.

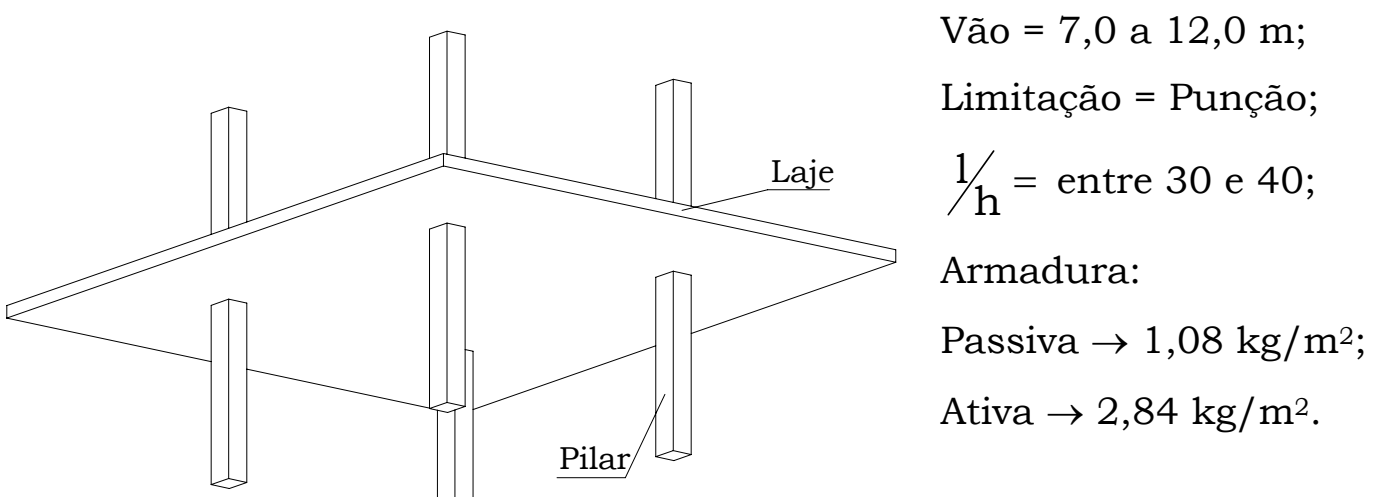

Figura 2.25 - Laje lisa maciça com suas características (AALAMI) 


\section{- Laje lisa com capitéis}

A utilização dos capitéis limita-se em aumentar a capacidade resistente da ligação laje-pilar à punção (vide figura 2.26).

O capitel é definido como um engrossamento da laje na região do apoio sobre o pilar, onde suas dimensões, de acordo com o Código do ACI, não podem ser superiores a $1 / 6$ do vão livre entre apoios.

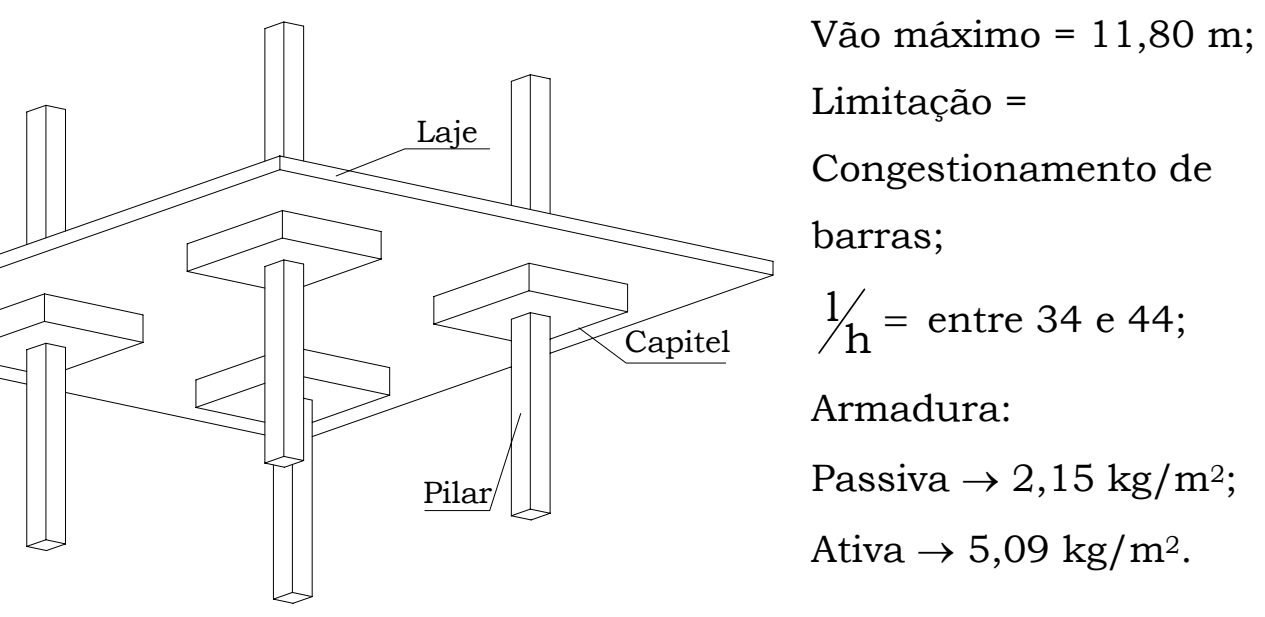

Figura 2.26 - Laje lisa maciça com capitéis e suas características (AALAMI)

\section{- Laje lisa com drop panels}

O drop panel é definido, do mesmo modo que o capitel, como um engrossamento da laje na região do apoio sobre o pilar, onde suas dimensões, de acordo com o Código do ACI, são superiores a 1/6 do vão livre entre apoios (ver figuras 2.24 e 2.27).

As funções principais do drop panel são: aumentar a capacidade resistente à flexão da laje na ligação laje-pilar, aumentar a rigidez do vão livre e aumentar a resistência à punção. 


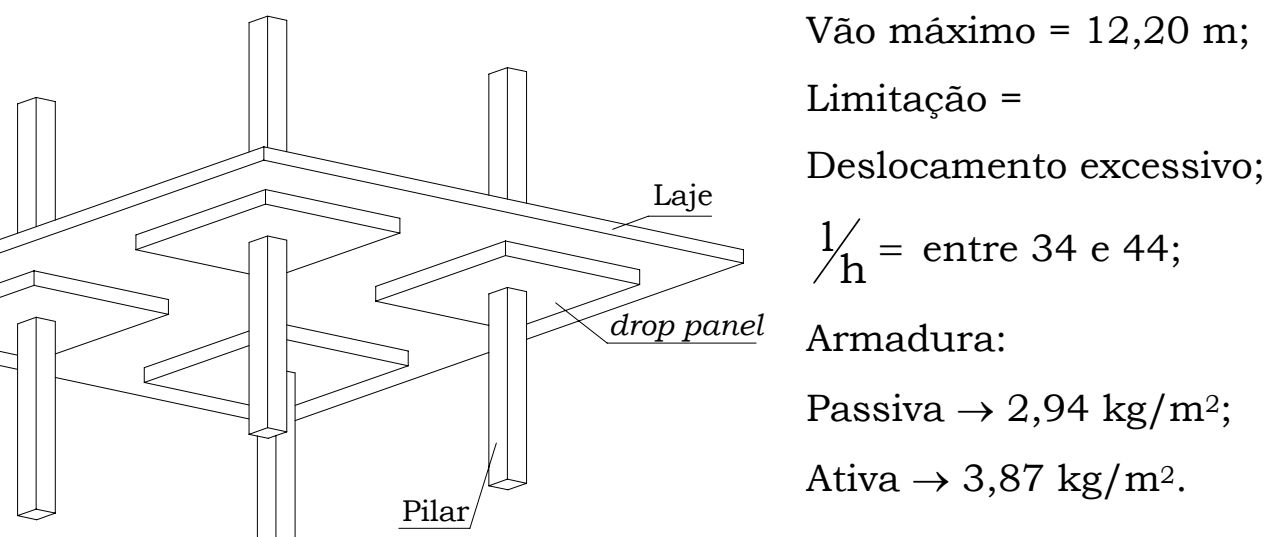

Figura 2.27 - Laje lisa maciça com drop panel e suas características (AALAMI)

\section{- Laje nervurada}

Este tipo de estrutura é muito utilizado em função da economia no consumo de concreto da obra (ver figura 2.28).

Além da laje nervurada propriamente dita, pode-se ainda utilizar o sistema de grelha (ver exemplo 01 do item 2.8). É possivel realizar a protensão na grelha com espaçamentos variados e obter uma relação vão/espessura econômica e ainda, obter grandes vãos livres.

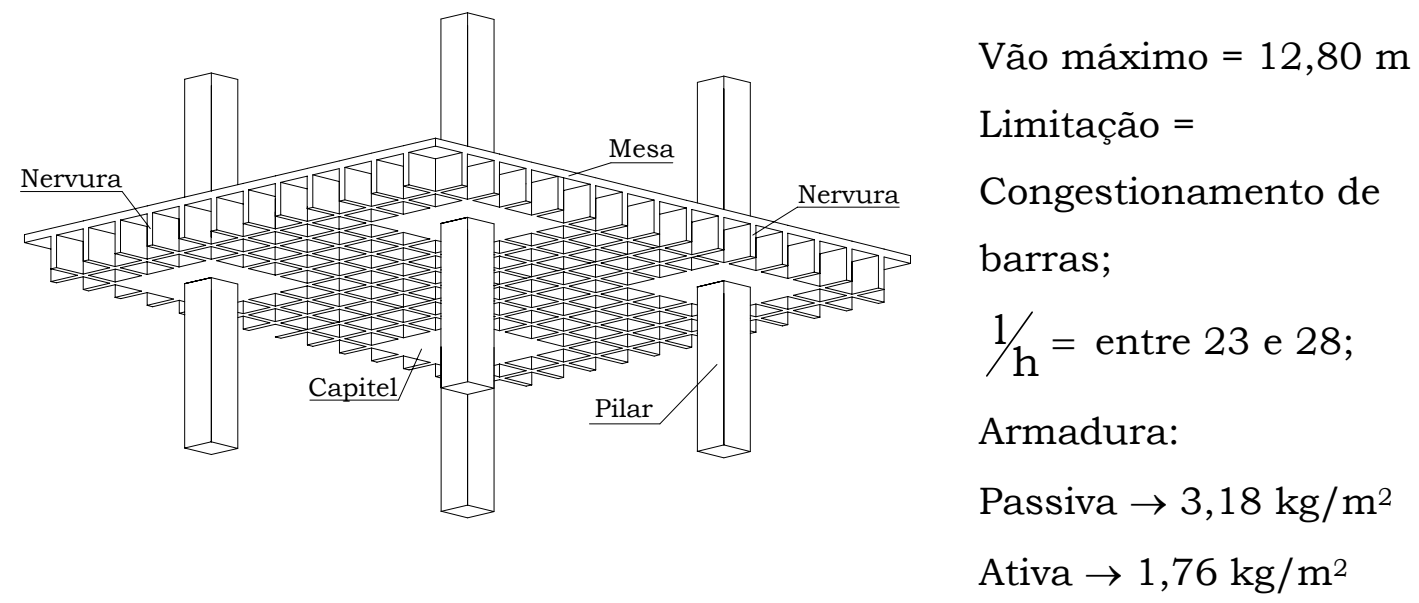

Figura 2.28 - Laje nervurada com características (AALAMI)

Deve-se observar, para a laje nervurada, composições estruturais variadas (Ver figura 2.29). 


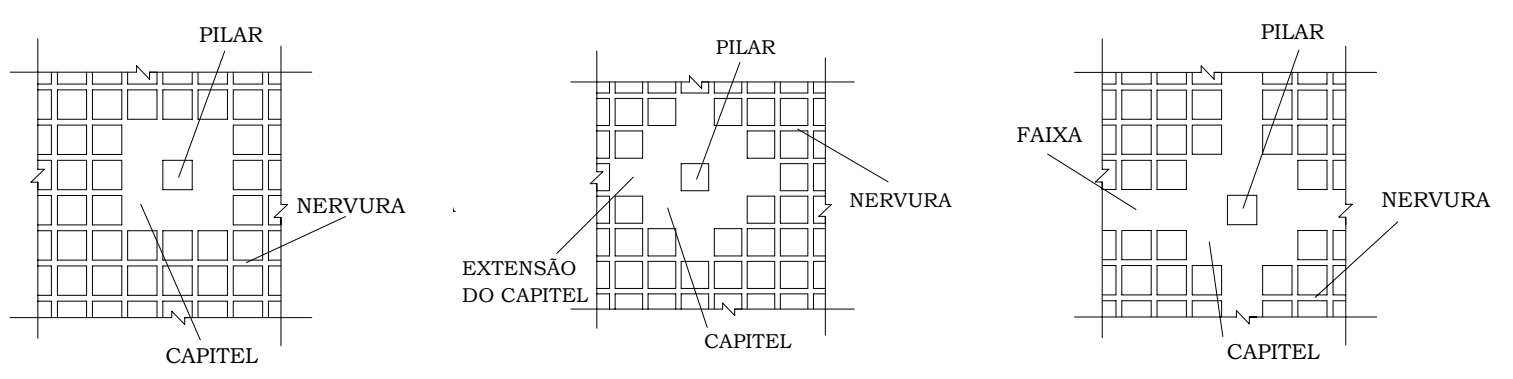

Figura 2.29 - Arranjos para pavimentos com lajes nervuradas (AALAMI)

\section{- Laje maciça - viga - pilar bidirecional}

A figura 2.30 ilustra o arranjo laje apoiada em vigas sobre pilares.

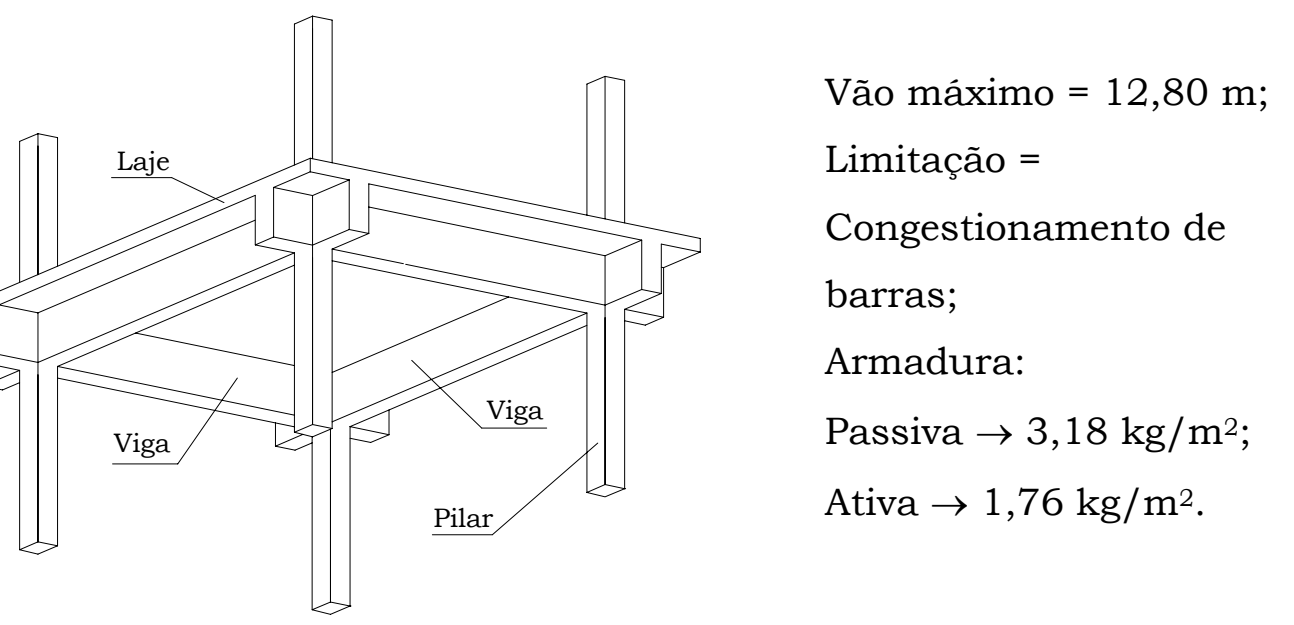

Figura 2.30 - Laje maciça - viga - pilar bidirecional e suas características (AALAMI)

\section{- Laje maciça - viga - pilar unidirecional}

A figura 2.31 mostra o arranjo de laje maciça apoiada em vigas sobre pilares. Este tipo de estrutura é muito utilizado em estacionamentos de veículos (edifícios garagem). 


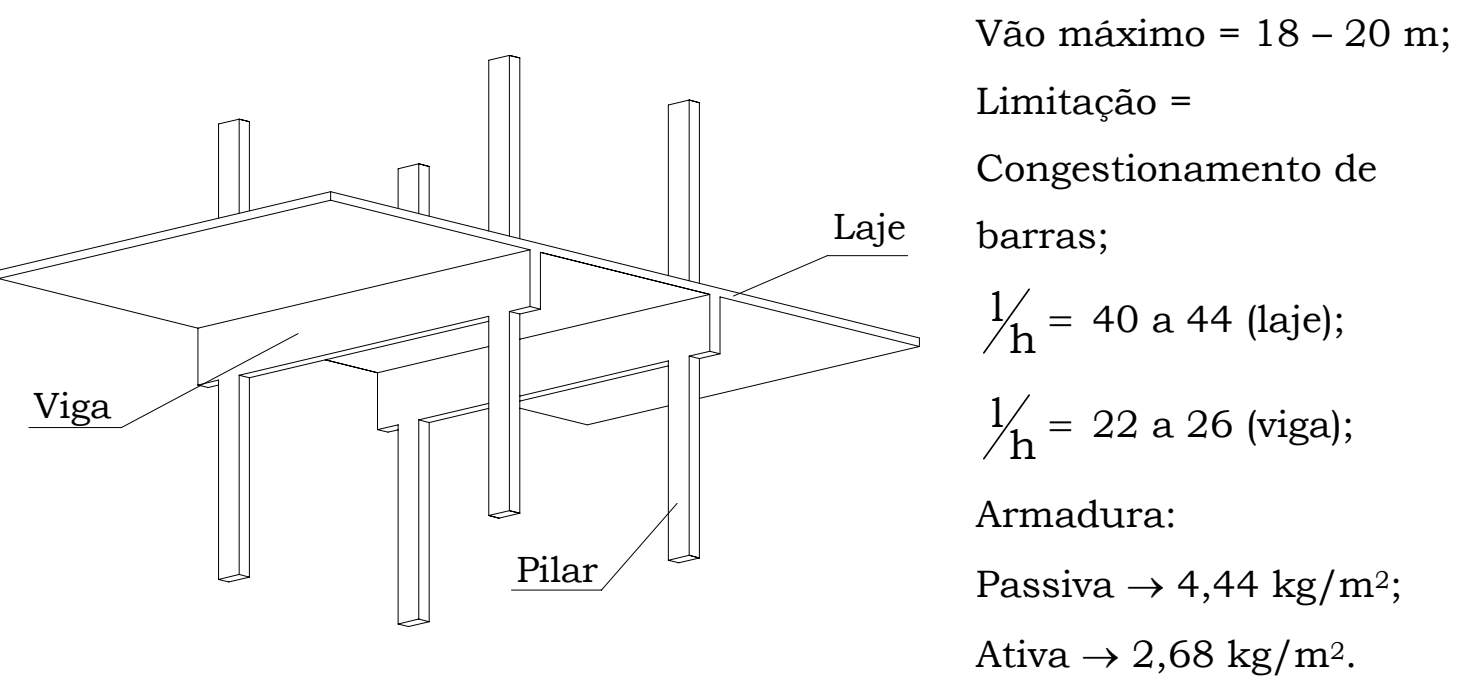

Figura 2.31 - Laje maciça - viga - pilar unidirecional e suas características (AALAMI)

\section{- Laje maciça com vigas faixa protendidas}

Este tipo de estrutura é utilizado quando um dos vãos da laje é substancialmente maior que o vão que lhe é perpendicular, sendo a espessura da viga faixa definida a partir do vão maior.

Neste caso, utiliza-se a disposição de faixas protendidas em vigas de baixa altura (vigas faixa) para poder aumentar a flecha do perfil do cabo e com isso, eficiência da protensão (ver figura 2.33).

Na figura 2.32, pode-se ver a seção transversal de uma viga faixa com suas recomendações de pré-dimensionamento.

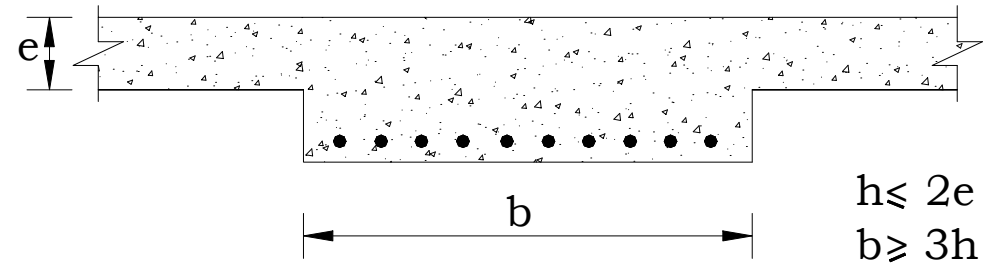

Figura 2.32 - Recomendações de projeto para vigas-faixa (AALAMI)

Onde:

b é a largura da viga-faixa;

h é a altura total da viga-faixa;

e é a espessura da laje. 


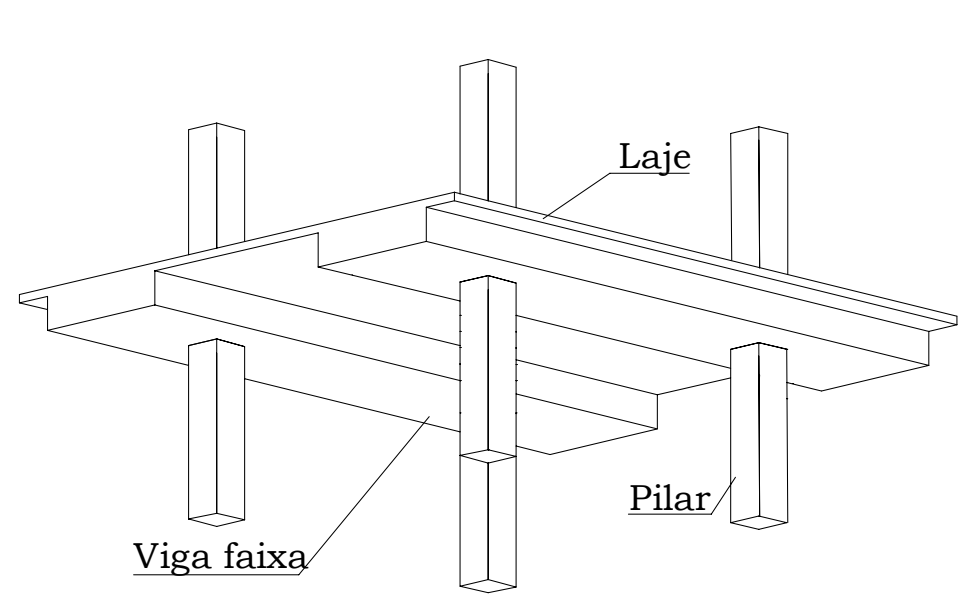

Vão máximo $=13,40 \mathrm{~m}$;

Limitação $=$

Congestionamento de barras;

$1 / \mathrm{h}=35$ a 45 (laje);

$1 / \mathrm{h}=18$ a 25 (faixa);

Armadura:

Passiva $\rightarrow 2,01 \mathrm{~kg} / \mathrm{m}^{2}$;

Ativa $\rightarrow 4,16 \mathrm{~kg} / \mathrm{m}^{2}$.

Figura 2.33 - Laje maciça com vigas faixas protendidas em uma direção e suas características (AALAMI)

Pode-se ainda utilizar, ao invés de lajes maciças no projeto, lajes nervuradas armadas e com isso, promover uma economia no consumo de concreto na obra.

As figuras 2.34 e 2.35, ilustram os arranjos com vigas faixa utilizando lajes nervuradas.

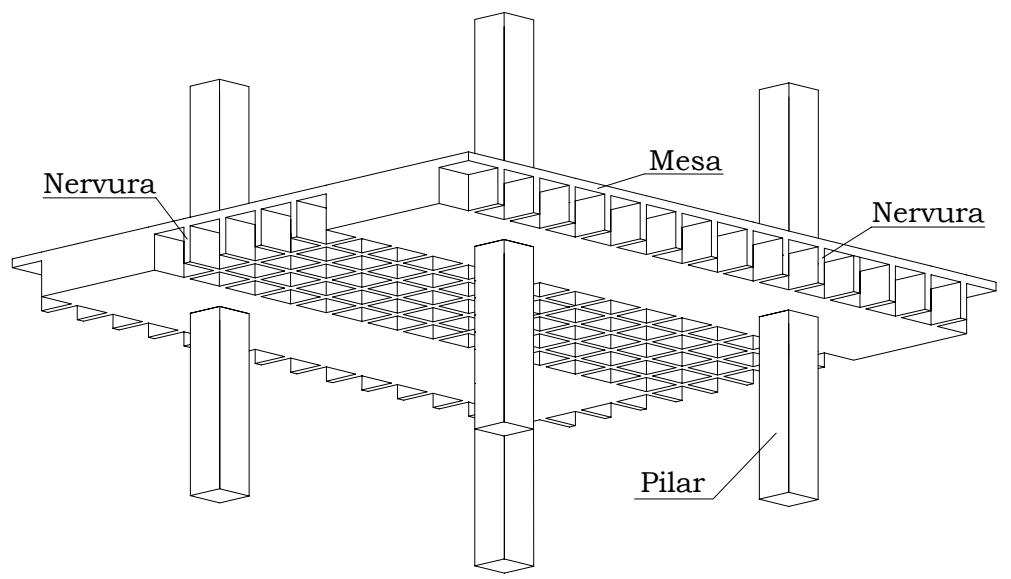

Figura 2.34 - Laje nervurada com vigas faixas protendidas em uma direção 


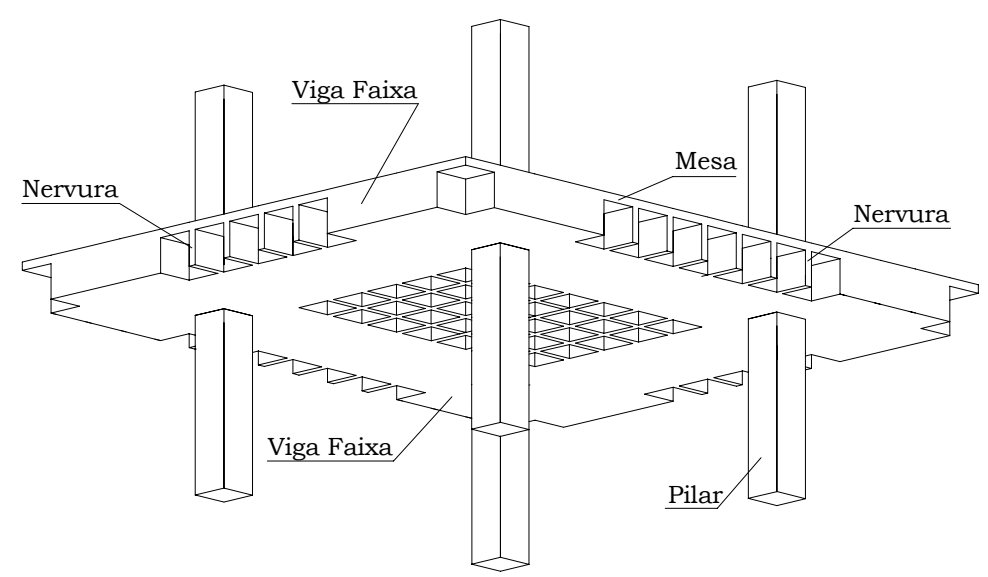

Figura 2.35 - Laje nervurada com vigas faixas protendidas nas duas direções

\section{7 - Processo Construtivo}

Neste segmento, dá-se um pequeno enfoque sobre a execução, ou seja, o processo construtivo para estruturas protendidas com cordoalhas engraxadas. Serão vistos os equipamentos e materiais utilizados, bem como ilustrações de sua aplicação.

\subsection{1. - Materiais}

\section{i) Cordoalhas engraxadas}

Fornecidas pela Indústria Belgo-Mineira desde 1997 apresentam bainha plástica extrudada sobre a própria cordoalha (figura 2.36). São produzidas em rolos de até 12.000 metros. Apresentam em sua composição, além da bainha plástica PEAD, graxa com massa linear variando de $37 \mathrm{~g} / \mathrm{m}$ a $44 \mathrm{~g} / \mathrm{m}$ para cordoalhas de diâmetro $12,7 \mathrm{~mm}$ a 15,2 $\mathrm{mm}$, respectivamente. Possui ainda, o coeficiente de atrito entre o aço e o plástico da bainha com graxa variando de 0,05 a 0,07 . Seu acondicionamento é feito em rolos de 1,4 a 2,8 t (ver figura 2.37). 


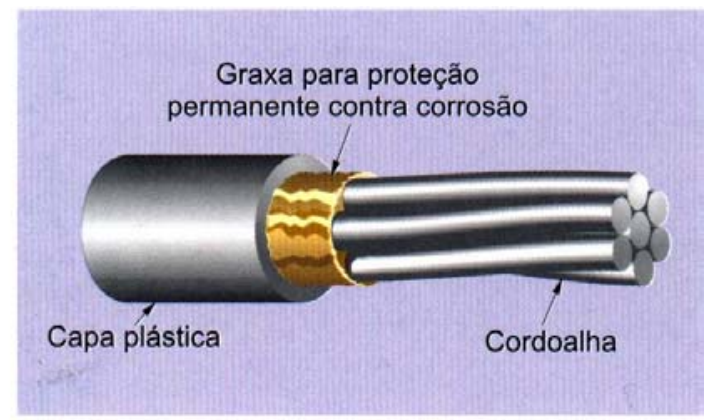

Figura 2.36 - Detalhe da cordoalha engraxada (Indústria Belgo-Mineira)

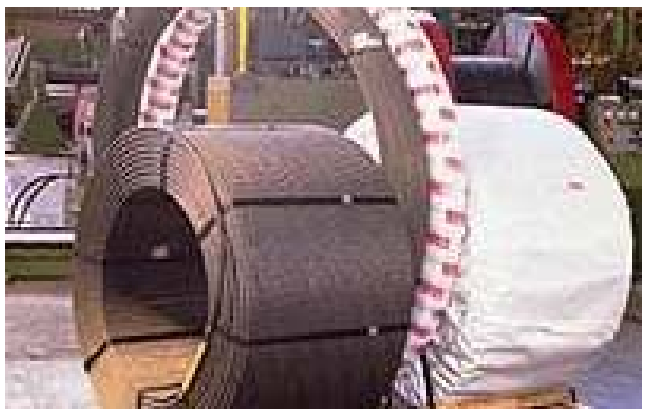

Figura 2.37 - Acondicionamento de cordoalhas em rolos (Indústria Belgo-

Mineira)

Tabela 2.3 - Especificação das cordoalhas

\begin{tabular}{|c|c|c|c|c|c|c|c|c|c|}
\hline \multirow[t]{2}{*}{$\begin{array}{l}\text { Cordoalha } \\
\text { (CP 190 RB) }\end{array}$} & \multirow{2}{*}{$\frac{\phi}{(\mathrm{mm})}$} & \multirow{2}{*}{$\frac{\text { A }_{\text {aprox. }}}{\left(\mathrm{mm}^{2}\right)}$} & \multirow{2}{*}{$\begin{array}{l}\mathbf{A}_{\text {minima }} \\
\left(\mathrm{mm}^{2}\right)\end{array}$} & \multirow{2}{*}{$\begin{array}{l}\begin{array}{c}\text { Massa } \\
\text { aprox. }\end{array} \\
(\mathrm{kg} / \mathrm{km})\end{array}$} & \multicolumn{2}{|c|}{$\begin{array}{l}\text { Carga min. } \\
\text { de ruptura }\end{array}$} & \multicolumn{2}{|c|}{$\begin{array}{l}\text { Carga min. } \\
\text { com } 1 \% \\
\text { alongamento }\end{array}$} & \multirow{2}{*}{$\begin{array}{c}\begin{array}{c}\text { Along. } \\
\text { após } \\
\text { ruptura }\end{array} \\
(\%)\end{array}$} \\
\hline & & & & & $(\mathrm{kN})$ & (kgf) & $(\mathrm{kN})$ & (kgf) & \\
\hline $3 \times 3,0$ & 6,5 & 21,8 & 21,5 & 171 & 40,8 & 4080 & 36,7 & 3670 & 3,5 \\
\hline $3 \times 3,5$ & 7,6 & 30,3 & 30,0 & 238 & 57 & 5700 & 51,3 & 5130 & 3,5 \\
\hline $3 \times 4,0$ & 8,8 & 39,6 & 39,4 & 312 & 74,8 & 7480 & 67,3 & 6730 & 3,5 \\
\hline $3 \times 4,5$ & 9,6 & 46,5 & 46,2 & 366 & \begin{tabular}{|l|}
87,7 \\
\end{tabular} & 8770 & 78,9 & 7890 & 3,5 \\
\hline $3 \times 5,0$ & 11,1 & 66,5 & 65,7 & 520 & 124,8 & 12480 & 112,3 & 11230 & 3,5 \\
\hline \multirow[t]{6}{*}{ 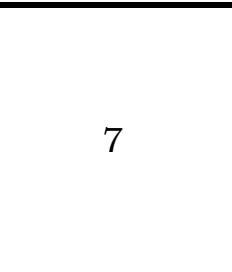 } & 6,4 & 26,5 & 26,2 & 210 & 49,7 & 4970 & 44,7 & 4470 & 3,5 \\
\hline & 7,9 & 39,6 & 39,3 & 313 & 74,6 & 7460 & 67,1 & 6710 & 3,5 \\
\hline & 9,5 & 55,5 & 54,8 & 441 & 104,3 & 10430 & 93,9 & 9390 & 3,5 \\
\hline & 11,0 & 75,5 & 74,2 & 590 & 140,6 & 14060 & 126,4 & 12640 & 3,5 \\
\hline & 12,7 & 101,4 & 98,7 & 792 & $\begin{array}{l}187,3 \\
\end{array}$ & 18730 & 168,6 & 16860 & 3,5 \\
\hline & 15,2 & 143,5 & 140,0 & 1126 & 265,8 & 26580 & 239,2 & 23920 & 3,5 \\
\hline
\end{tabular}

Fonte: Indústria Belgo-Mineira

Tabela 2.4 - Acondicionamento das cordoalhas

\begin{tabular}{|c|c|c|c|c|}
\hline Cordoalha & $\begin{array}{c}\text { Peso Nominal } \\
\text { (kg) }\end{array}$ & $\begin{array}{c}\text { Diâmetro Ext. } \\
\text { (cm) }\end{array}$ & $\begin{array}{c}\text { Diâmetro Int. } \\
\text { (cm) }\end{array}$ & $\begin{array}{c}\text { Altura do rolo } \\
\text { (cm) }\end{array}$ \\
\hline 3 fios & 2800 & 76,2 & 139 & 76,2 \\
\hline 7 fios & 2800 & 76,2 & 127 & 76,2 \\
\hline
\end{tabular}

Fonte: Indústria Belgo-Mineira

A bainha plástica deve apresentar as seguintes características:

- Ser impermeável à água;

- Apresentar capa plástica composta de polietileno de alta densidade;

- Apresentar espessura mínima de 1,00 mm;

- Ter resistência e durabilidade para suportar o arraste por entre as ferragens soltas da obra; 
- Formar uma barreira, juntamente com a graxa, contra a passagem de umidade e de agentes químicos;

- Não reagir com o concreto ou com as armaduras ativas e passivas e nem com o material inibidor da corrosão (graxa).

A graxa deve apresentar as seguintes características:

- Agir como um redutor do atrito entre a cordoalha e a bainha;

- Funcionar como um elemento de proteção e inibição da corrosão para a armadura ativa.

\section{ii) Ancoragens}

As ancoragens (vide figura 2.38), na protensão sem aderência, são as responsáveis pela integridade da protensão, pois, como fora dito anteriormente, não existe aderência entre o concreto e a armadura ativa, logo, o único fator que promove a interação da protensão com o concreto, são as ancoragens.

Daí vem a preocupação na obra em se ter um cuidado maior no momento da concretagem dos locais onde se encontram as ancoragens.

Elas podem ser utilizadas tanto como ancoragem ativa (onde é aplicado o alongamento do cabo) quanto ancoragem passiva (onde o cabo está fixado).

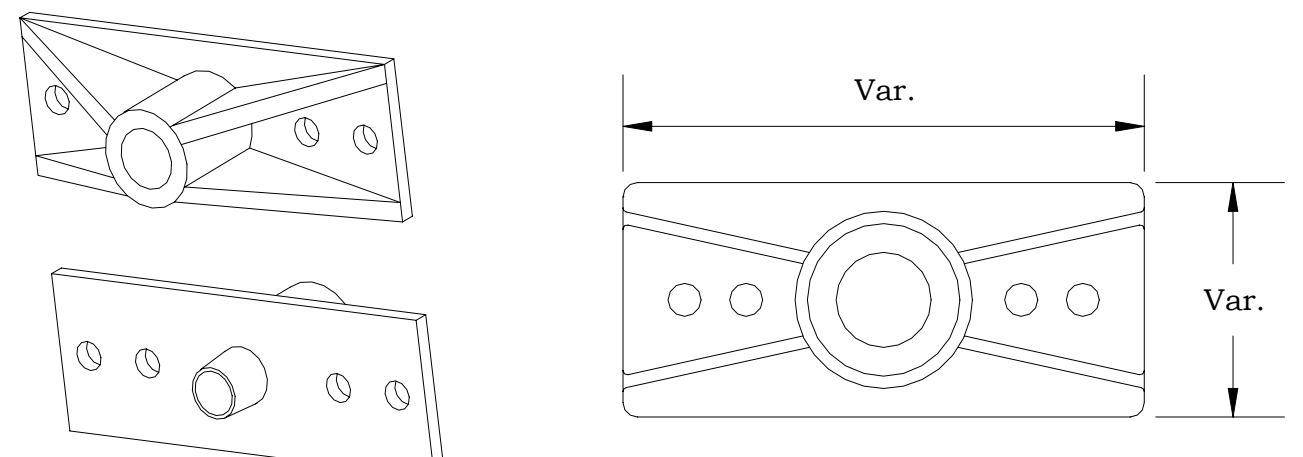

Figura 2.38 - Detalhe da ancoragem

De acordo com GRAZIANO [2001] as ancoragens são submetidas a forças de tração paralelas ao seu plano, de intensidade até quatro vezes a 
força de protensão. Essas peças devem resistir a pelo menos 1,2 vezes a solicitação de Estado Limite Último, segundo o referido autor.

De acordo com as recomendações do PTI [1985], as ancoragens devem prover, pelo menos, $95 \%$ da resistência última da cordoalha, o que garante condição suficiente de segurança.

Na figura 2.39 ilustra-se o arranjo das ancoragens ativas e passivas.

Ancoragem ativa

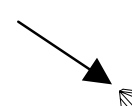

580

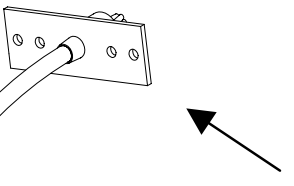

Ancoragem passiva

Figura 2.39 - Detalhe dos tipos de ancoragens (ativa e passiva)

Segundo as recomendações do PTI [1994], deve-se tomar cuidado na execução das ancoragens, atentando-se para o seu posicionamento, que deve estar bem ligada e perpendicular à fôrma para não permitir vazamentos durante a concretagem (ver figura 2.40).

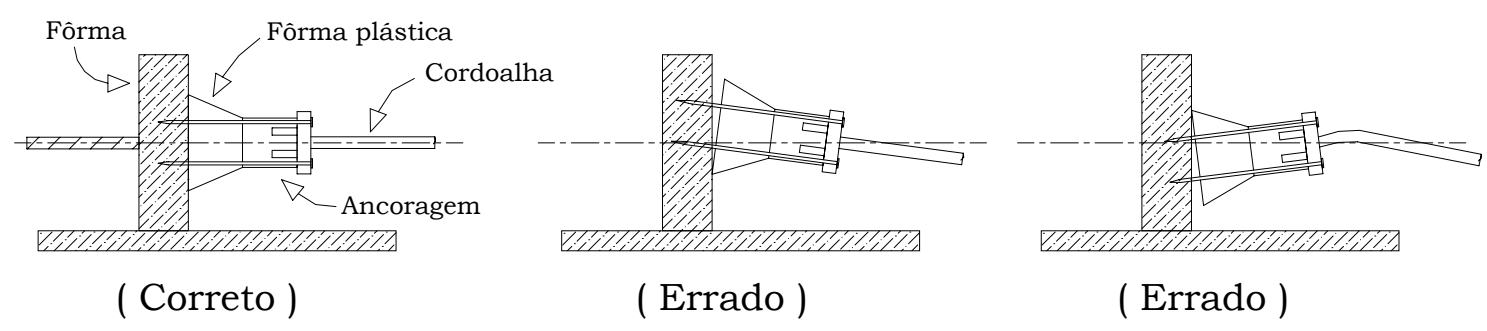

Figura 2.40 - Posicionamento da ancoragem na fôrma (PTI [1994])

Deve-se observar que a fôrma plástica tem como função impedir a passagem da pasta de cimento para a cavidade da ancoragem. 
iii) Macaco Hidráulico

O macaco hidráulico, utilizado para realizar a protensão das cordoalhas engraxadas, apresenta dois modelos: o automático (figura 2.41) e o manual (figura 2.42).

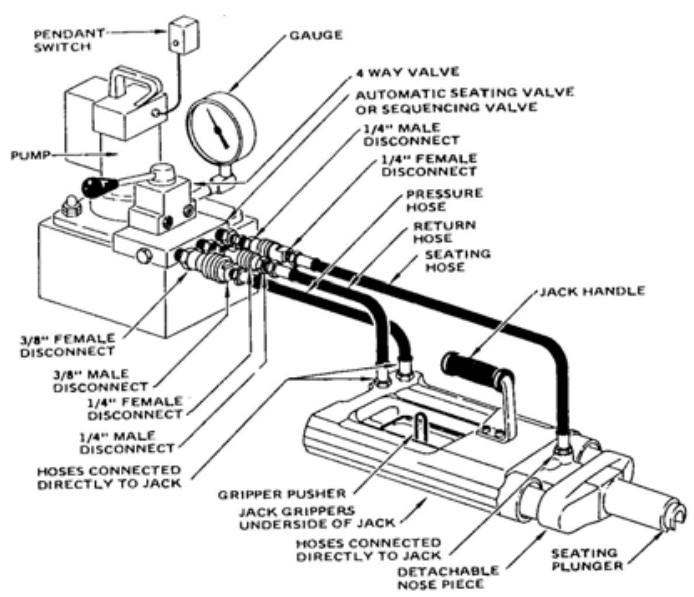

Figura 2.41 - Macaco hidráulico de regulagem automática (PTI [1994])

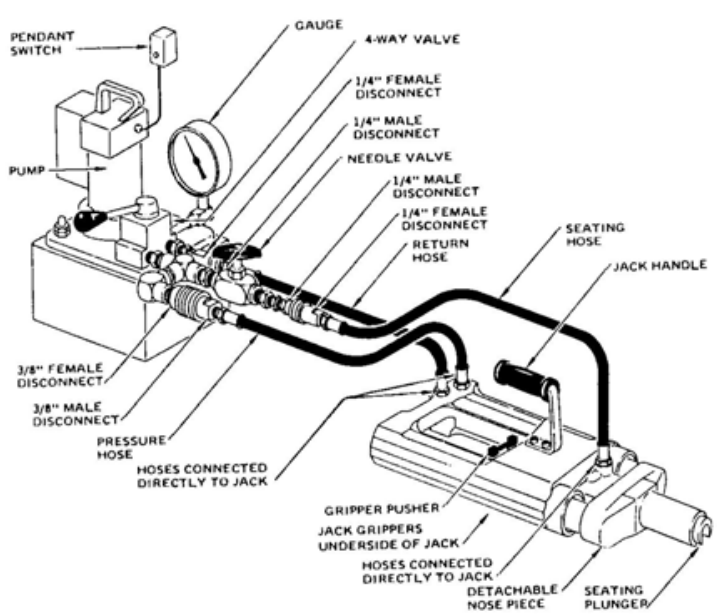

Figura 2.42 - Macaco hidráulico de regulagem manual (PTI [1994])

Durante a protensão dos cabos, cada cordoalha é acondicionada individualmente, e posteriormente alongada, sendo este processo extremamente rápido.

\subsection{2 - Resumo do Processo Construtivo}

Agora, faz-se uma pequena explicação do procedimento de execução da protensão sem aderência.

- Após o posicionamento das fôrmas e da armadura frouxa (passiva), deve-se colocar a armadura ativa não aderente e, de preferência, a mesma equipe que posicionou a armadura frouxa deve colocar a armadura de protensão;

- Durante o posicionamento da armadura ativa não é necessário cuidado especial com os cabos, pois a bainha plástica é resistente ao contato com a fôrma e com a armadura frouxa durante o seu arrastamento. Deve-se, porém, ter cuidado no instante do posicionamento das ancoragens junto às armaduras de fretagem; 
- Os cabos podem deslizar livremente pelas fôrmas, podendo fazer curvas para interceptar pilares que estejam um pouco fora da linha dos demais;

- Deve ser colocada uma luva plástica na zona de intersecção entre a ancoragem e o cabo (ver figura 2.43), para evitar a passagem de pasta de cimento para a ancoragem;

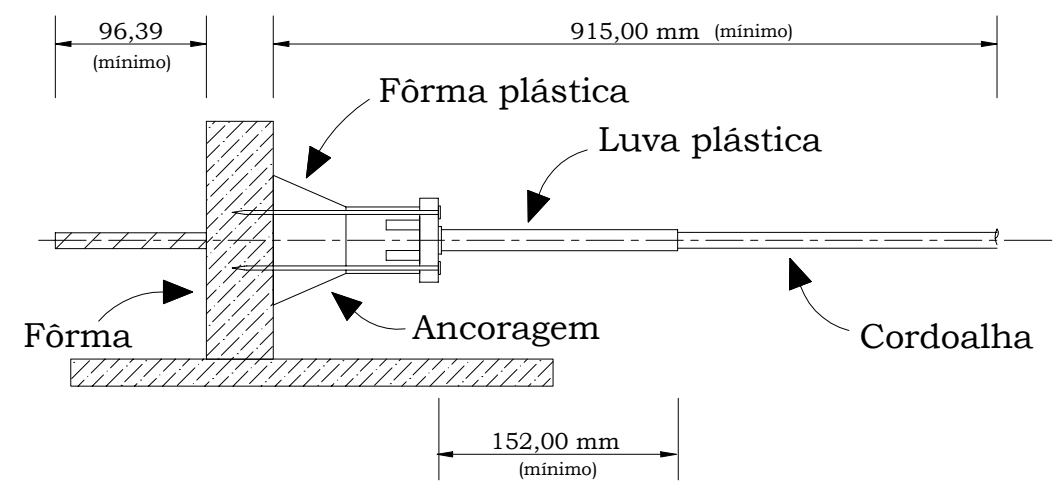

Figura 2.43 - Dimensões da luva plástica aplicada na junção da ancoragem com a cordoalha (Adaptado do PTI [1994])

- Nas ancoragens passivas devem ser assegurados o seu cobrimento e o seu posicionamento por meio de suportes (figura 2.44);

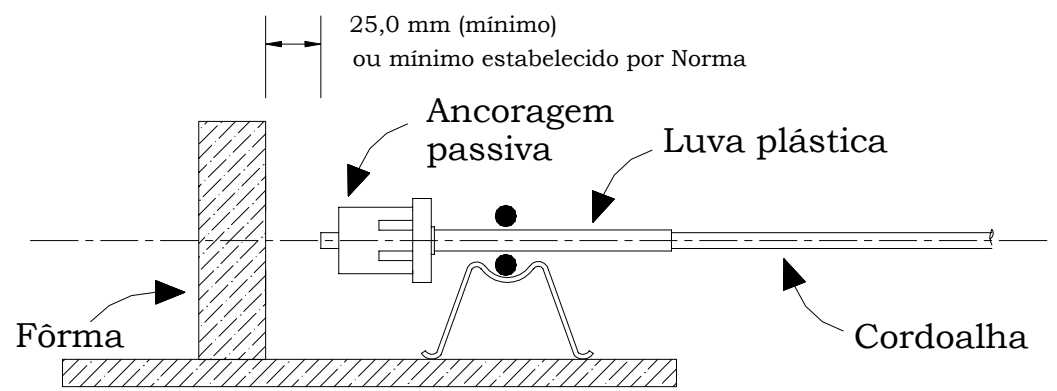

Figura 2.44 - Detalhe da ancoragem passiva (Adaptado do PTI [1994])

- Os cabos devem, em regiões onde há a presença de aberturas, contorná-las seguindo a recomendação da figura 2.45, colocando um reforço no topo e na face inferior da laje; 


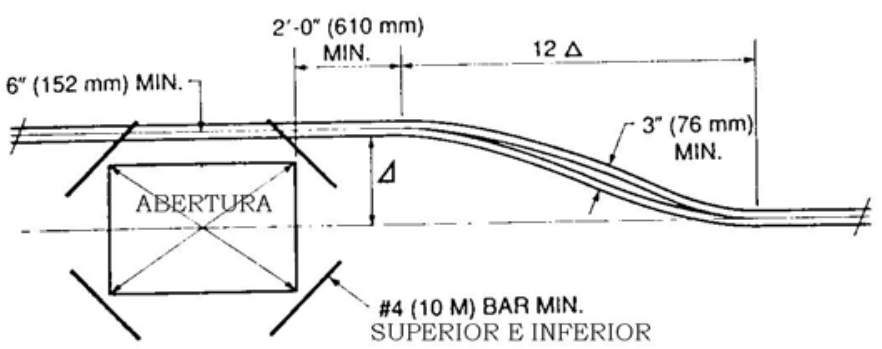

Figura 2.45 - Procedimento da passagem dos cabos com abertura na laje (Adaptado do PTI [1994])

- Após o lançamento das armaduras ativa e frouxa, deve ser feita uma inspeção para assegurar a correta localização das ferragens (ver figura $2.46,2.47,2.48,2.49$ e 2.51), o diâmetro da armadura, tanto ativa quanto passiva e ainda, se o perfil do cabo atende ao projeto;

- Com isso, pode ser iniciada a concretagem do pavimento do edifício, sempre tomando muito cuidado para não atingir nenhum cabo durante este processo, pois a vibração pode provocar o afastamento de algum cabo de sua posição original (mudança do seu perfil);

- A protensão dos cabos deve ser realizada somente quando o concreto atingir a resistência mínima estabelecida em projeto;

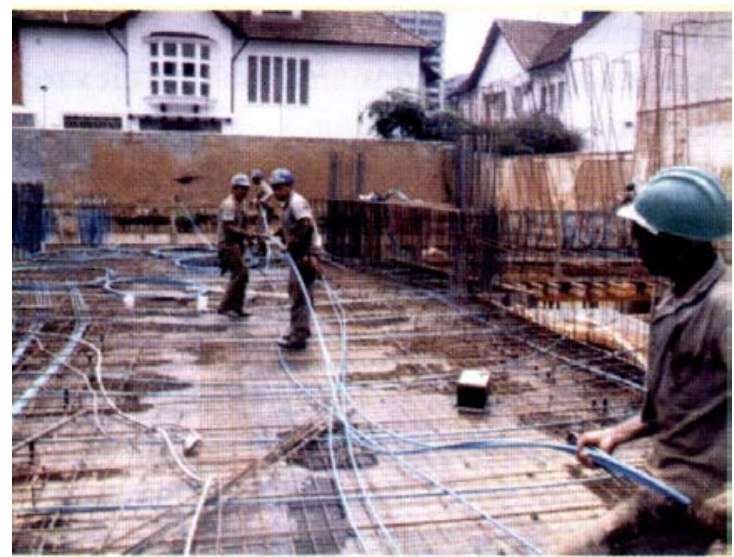

Figura 2.46 - Lançamento das armaduras ativa e frouxa (GRAZIANO [2000])

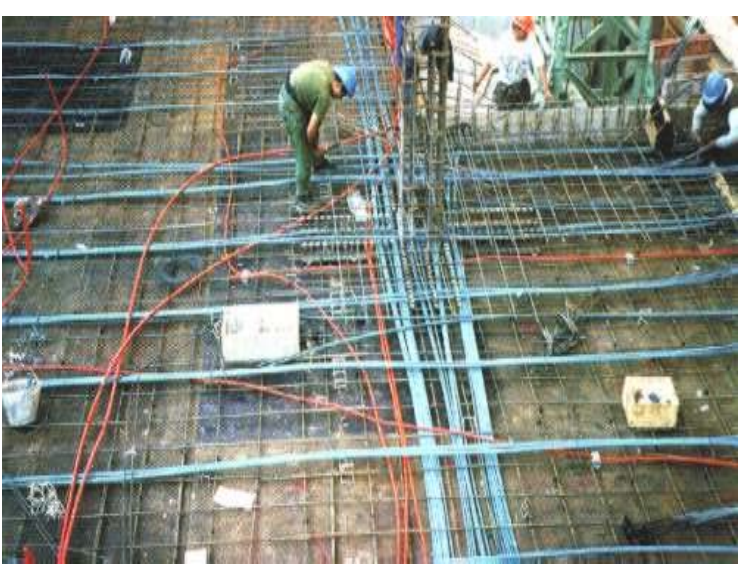

Figura 2.47 - Inspeção da passagem de armadura ativa pelo pilar (GRAZIANO [2000]) 


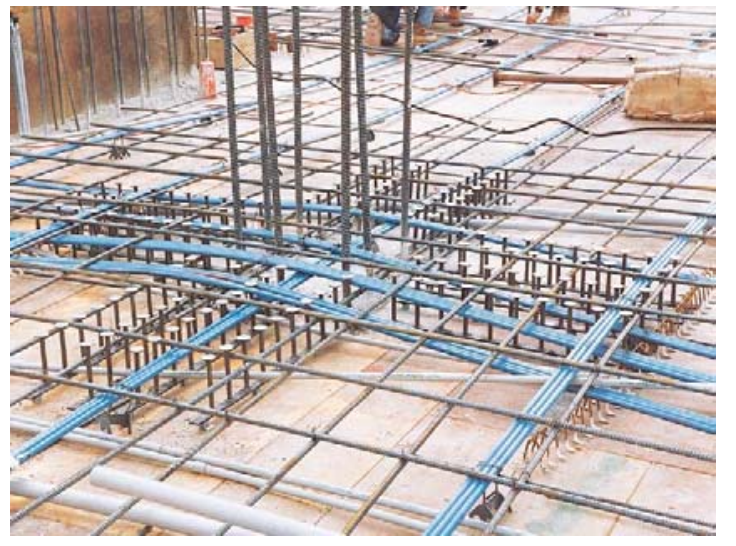

Figura 2.48 - Detalhe da passagem de armadura ativa por ligação laje-pilar

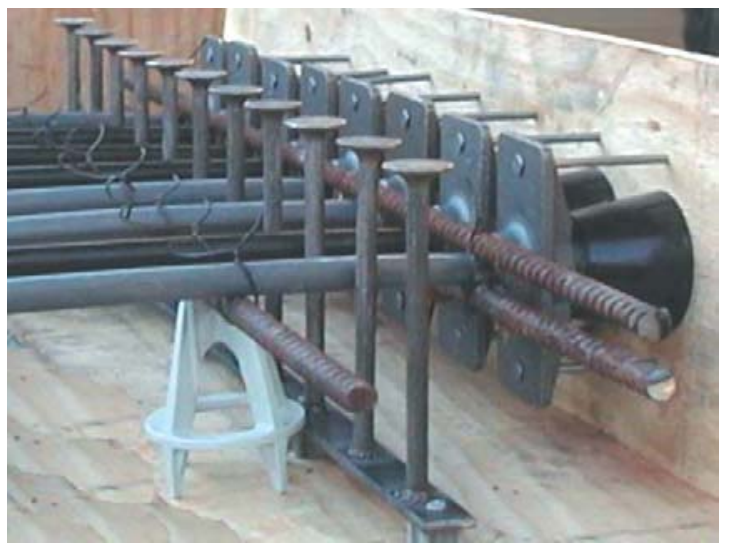

Figura 2.49 - Posicionamento de ancoragens na fôrma

- Durante a protensão dos cabos, deve-se tomar cuidado com o alongamento das cordoalhas, marcando-as com tinta, com o intuito de ter uma referência de alongamento da cordoalha;

- Com isso, pode-se realizar a protensão com o macaco hidráulico (ver figura 2.50), posicionando-se as cunhas e alongando um cabo por vez, sendo esta tarefa realizada por pessoal devidamente treinado;

- Logo após, deve-se proceder ao corte das pontas dos cabos e executar o preenchimento do nicho de protensão, o que deve ser feito com material cimentício e de baixa retração, de modo a proteger as ancoragens de agentes agressivos do meio ambiente;

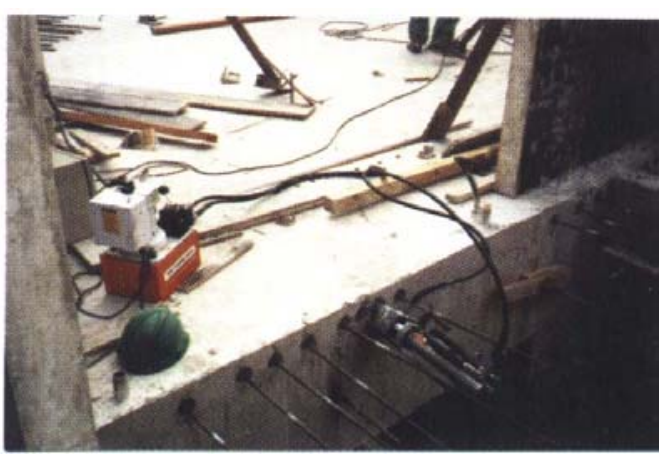

Figura 2.50 - Protensão de cordoalha com macaco hidráulico (GRAZIANO [2000])

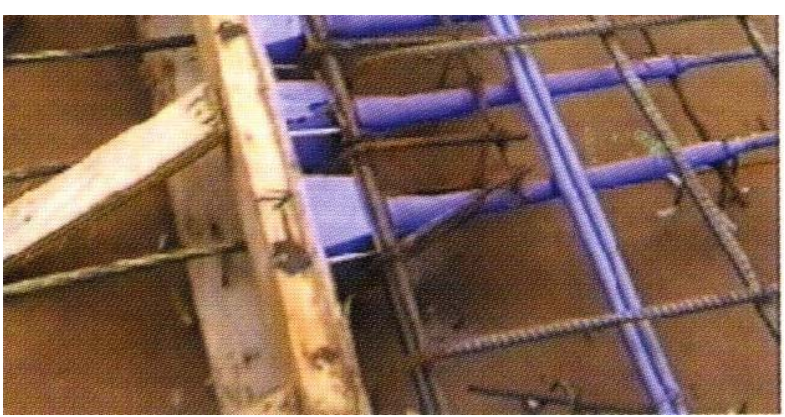

Figura 2.51 - Detalhe construtivo mostrando a ancoragem posicionada (GRAZIANO [2000])

Na figura 2.52 pode-se ver os equipamentos que compõem o sistema de protensão não aderente. 


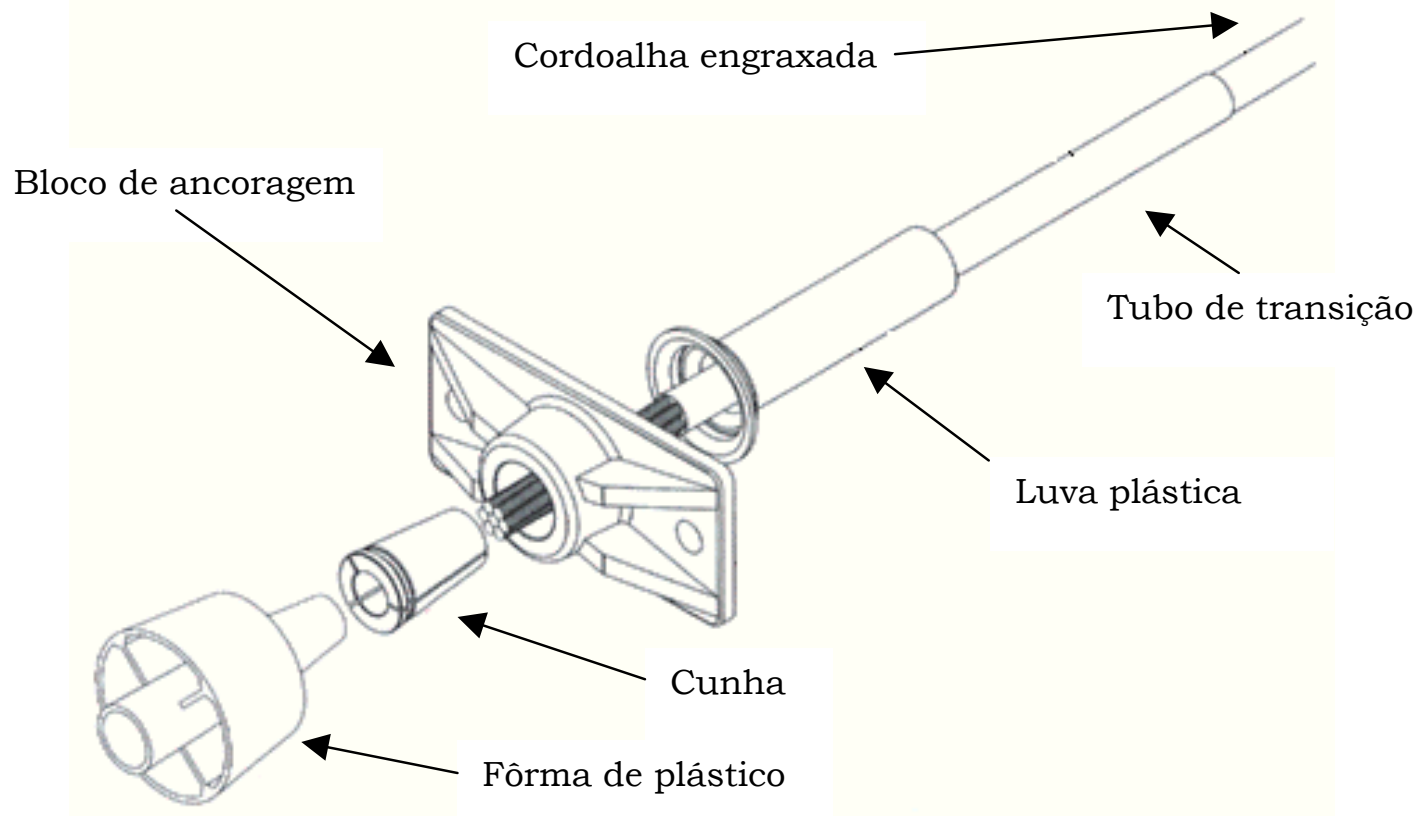

Figura 2.52 - Sistema de ancoragem e cordoalha

A seguir, na figura 2.53, pode-se ver um esquema simplificado da protensão de cordoalhas não aderentes.

Ancoragem passiva com armadura de fretagem

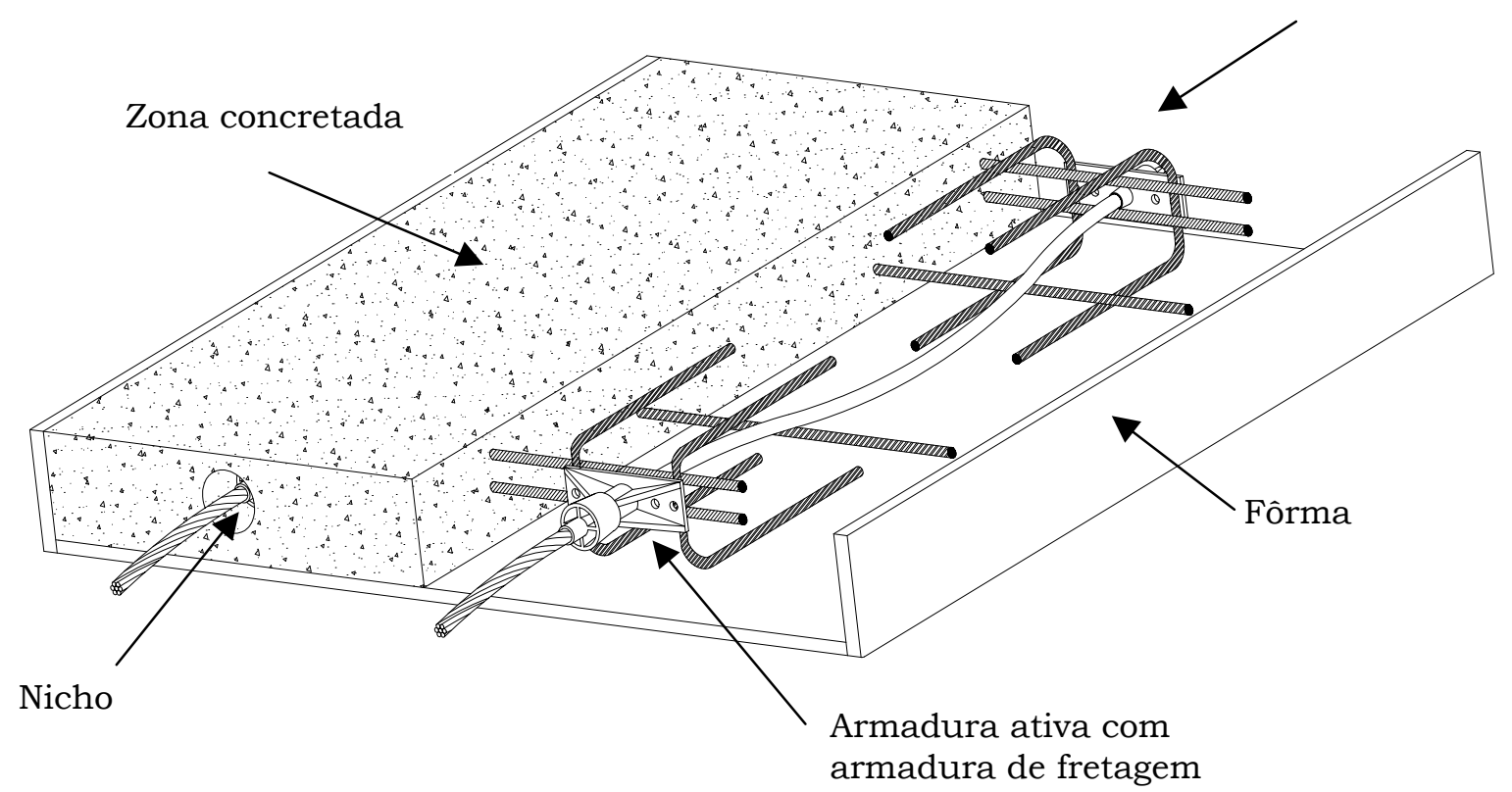

Figura 2.53 - Esquema simplificado de protensão não aderente 


\section{8 - Exemplos de Aplicação da Protensão Não Aderente}

Neste segmento serão ilustradas algumas aplicações bem sucedidas do sistema de protensão de monocordoalhas engraxadas de estruturas de edificios, comerciais e residenciais no Brasil.

- Exemplo 01 - Edificio Comercial Miguel Dias (figuras 2.54 a 2.56)

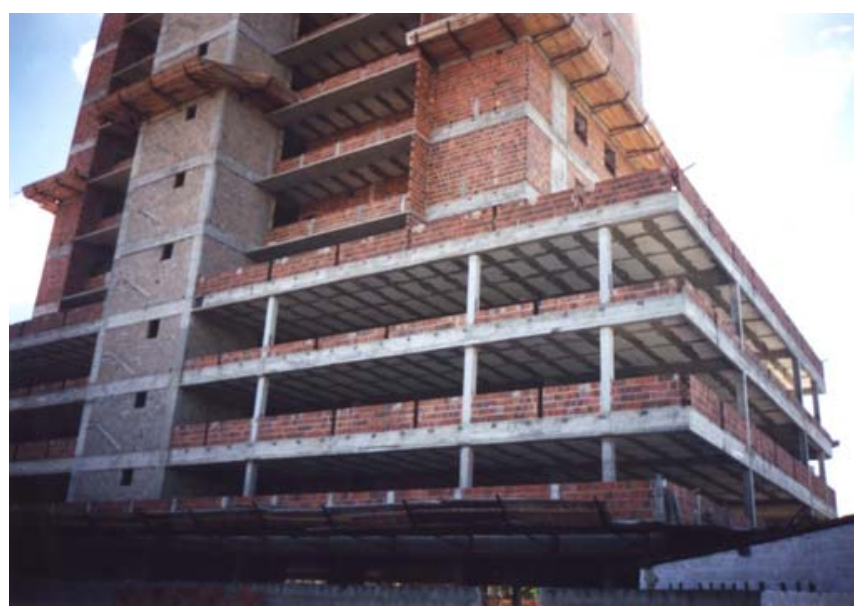

Construtora:

J. Amaral Construções

Cálculo Estrutural:

HM Engenharia Estrutural

S/C Ltda.

Local:

Fortaleza-CE

Figura 2.54 - Edificio Comercial Miguel Dias

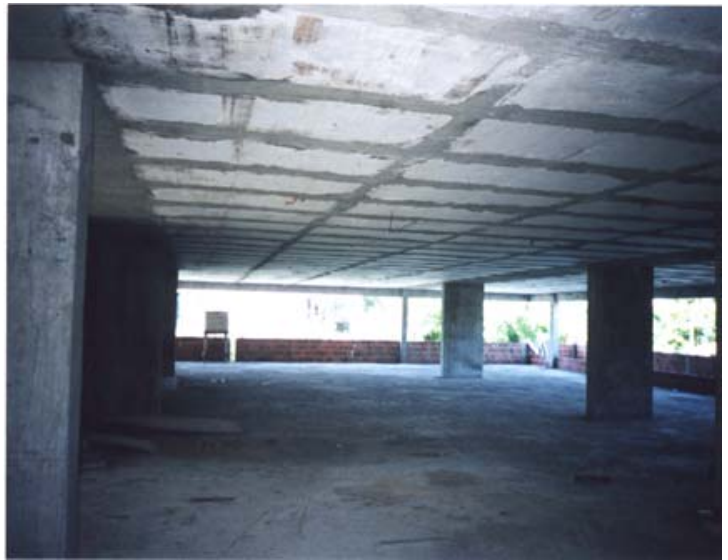

Figura 2.55 - Vão livre no estacionamento

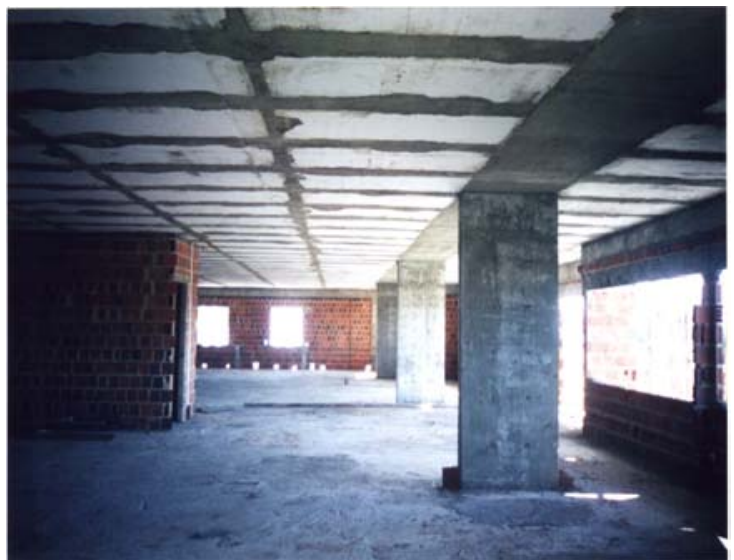

Figura 2.56 - Vão livre dos escritórios 
- Exemplo 02 - Edificio Villa de Huesca (figuras 2.57 a 2.59)

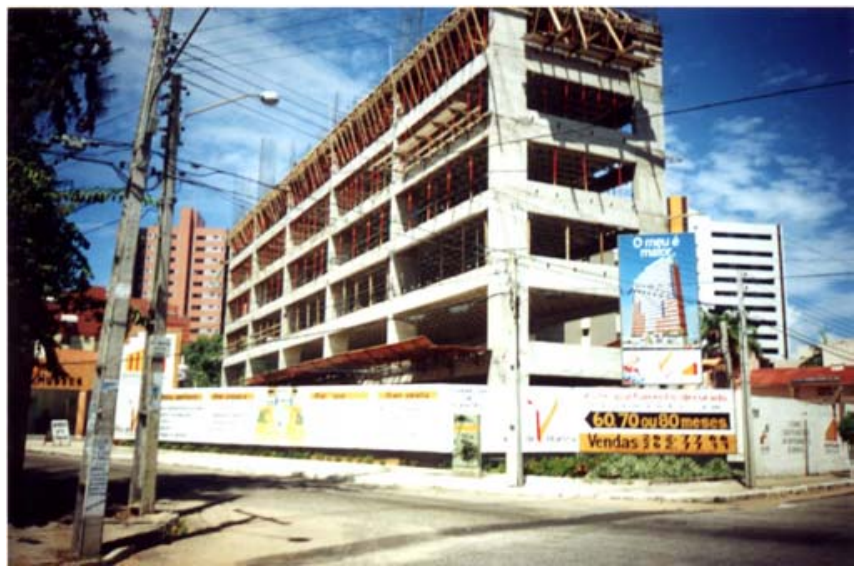

Construtora:

Barcelona Construções

Cálculo Estrutural:

J. R. Medeiros Engenheiros Associados S/A.

Local:

Fortaleza - CE

Figura 2.57 - Edificio Villa de Huesca

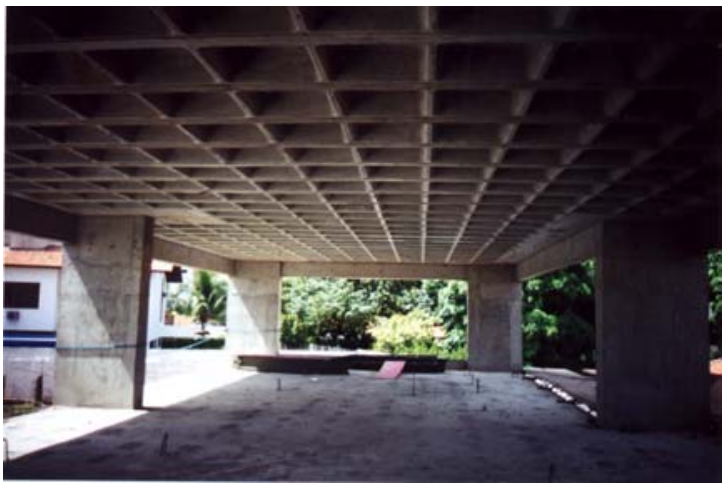

Figura 2.58 - Vão livre da laje

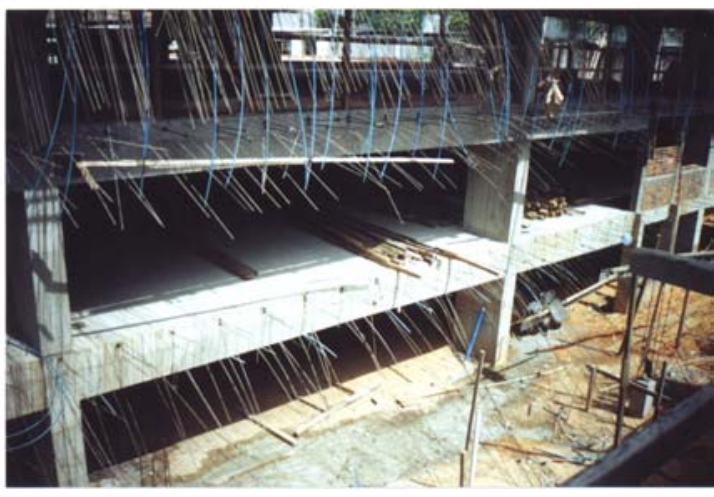

Figura 2.59 - Ancoragens no pavimento

- Exemplo 03 - Igreja de Nossa Senhora de Lourdes (figuras 2.60 a 2.62)

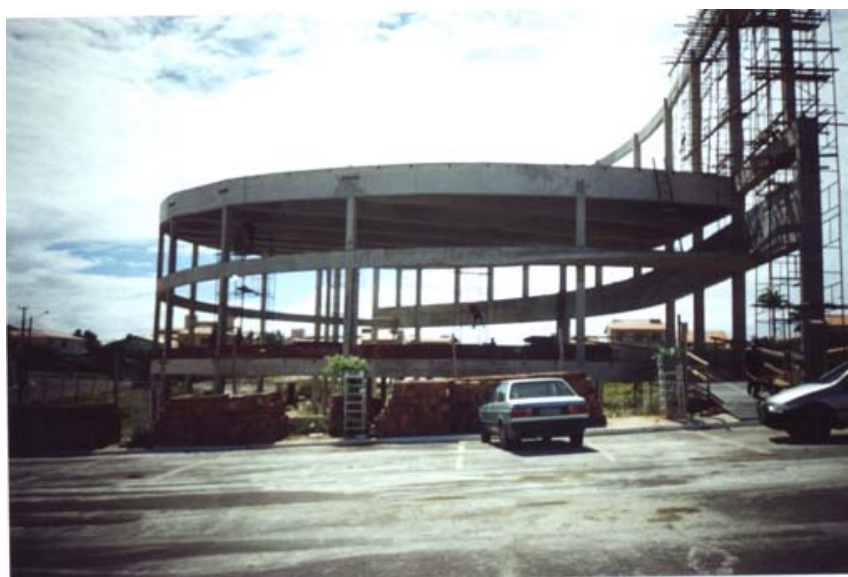

Figura 2.60 - Vista geral
Construtora:

J. Simões

Engenharia Ltda.

Cálculo Estrutural:

MD Engenheiros

Associados S/A

Local:

Fortaleza - CE 


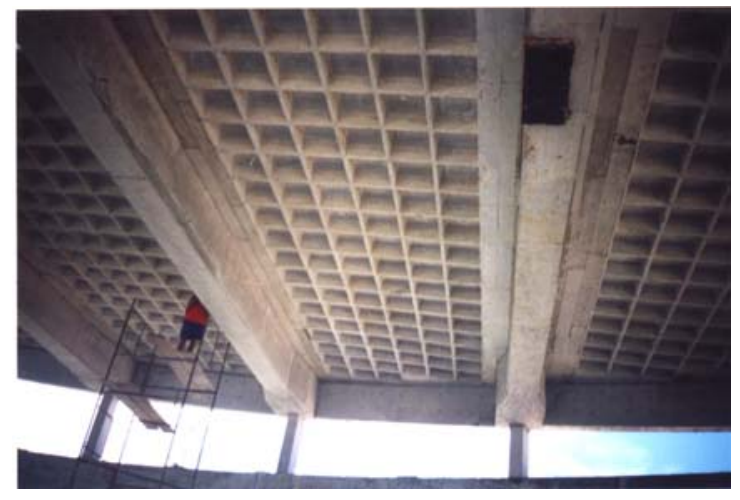

Figura 2.61 - Detalhe da viga protendida e da laje nervurada

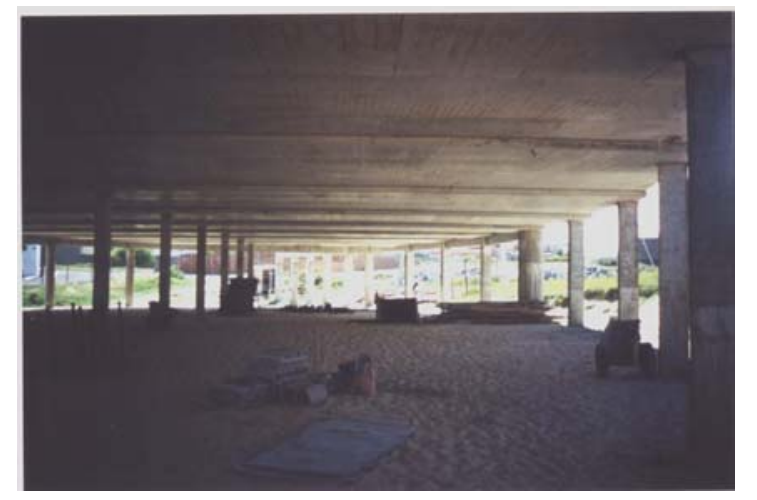

Figura 2.62 - Vão livre do pavimento térreo da estrutura 


\section{ASPECTOS TEÓRICOS DO CONCRETO PROTENDIDO}

\section{1 - Análise das tensões}

Vai-se analisar as tensões limites para os estados limites estabelecidos de acordo com as limitações de resistência à tração e à compressão do concreto.

A análise da seção transversal será feita divido-a em duas regiões (figura 3.1): a das fibras inferiores, aqui caracterizada pelo índice 1 e a região das fibras superiores, caracterizada pelo índice 2.

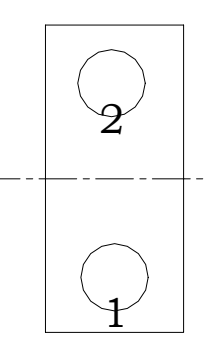

Borda Superior

Borda Inferior

Figura 3.1 - Seção transversal de uma viga mostrando as regiões para as fibras inferiores (1) e superiores (2) 
Pode-se ver na figura 3.2 um esquema de uma viga simplesmente apoiada submetida a um carregamento de intensidade $w$ distribuido uniformemente e uma força de protensão de intensidade $P$ aplicada à peça ${ }^{1}$.

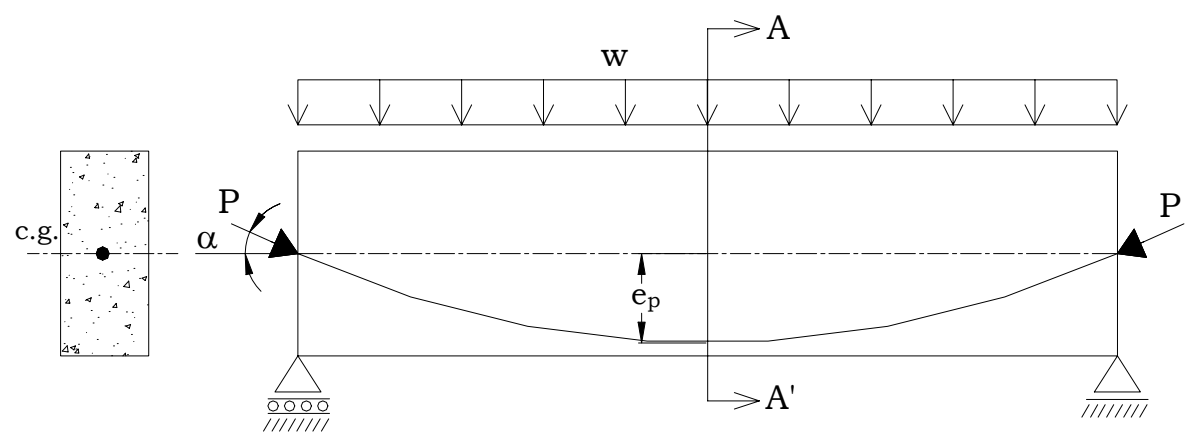

Figura 3.2 - Esquema de viga simplesmente apoiada com cabo parabólico

Aplicando-se a força de protensão $P$ na seção transversal da viga, com a adição do momento correspondente, tem-se um diagrama de tensões como o ilustrado na figura 3.3.

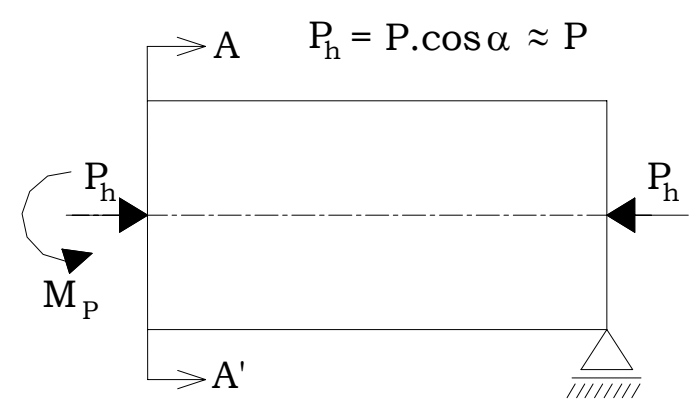

$$
-\frac{P}{A_{c}} \quad \frac{P \cdot e_{p}}{W_{2}} \quad \sigma_{c p 2}=-\frac{P}{A_{c}}+\frac{P \cdot e_{F}}{W_{2}}
$$

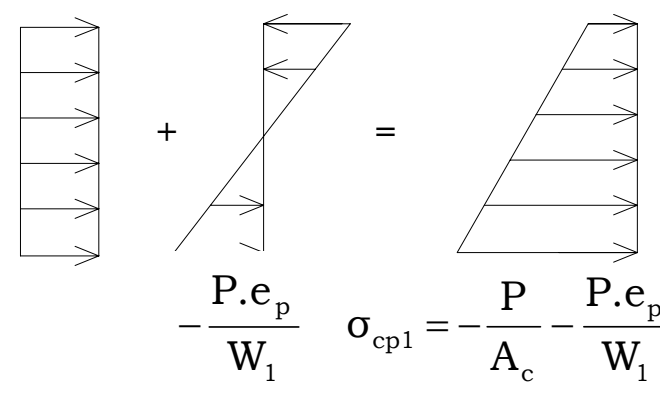

Figura 3.3 - Diagramas de tensão, para a seção transversal central da viga, referentes à força de protensão $P$ aplicada

\footnotetext{
1 A ilustração é feita a forças uniformemente distribuídas, embora as idéias apresentadas sejam iguais
} 


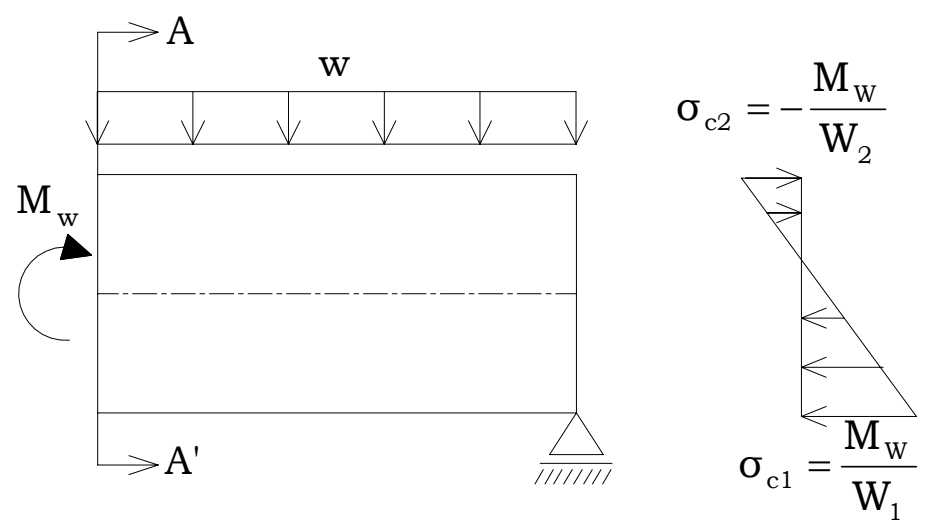

Figura 3.4 - Diagrama de tensões, para a seção transversal central da viga, referente à aplicação da força $w$

Com a aplicação da carga $w$ à viga (figura 3.4), vê-se que ocorre um incremento nas tensões de tração e compressão nas regiões 1 e 2, fazendo o equilíbrio com as tensões de protensão já impostas, tem-se:

$$
\begin{aligned}
& \sigma_{\mathrm{cp} 1}=-\frac{P}{A_{c}}-\frac{P \cdot e_{p}}{W_{1}}+\frac{M_{w}}{W_{1}} \\
& \sigma_{c p 2}=-\frac{P}{A_{c}}+\frac{P \cdot e_{p}}{W_{2}}-\frac{M_{W}}{W_{2}}
\end{aligned}
$$

Onde,

$\sigma_{\mathrm{cp} 1}$ é a tensão devida à protensão e a carga $w$ aplicada na peça na região 1 da seção transversal;

$\sigma_{\mathrm{cp} 2}$ é a tensão devida à protensão e a carga $w$ aplicada na peça na região 2 da seção transversal;

$e_{P}$ é a excentricidade do perfil do cabo com relação ao centro de gravidade da seção transversal da peça;

$\mathrm{P} \quad$ é a força de protensão aplicada à peça;

$\mathrm{A}_{\mathrm{c}} \quad$ é a área da seção transversal de concreto;

$\mathrm{W}_{1}$ é o módulo resistente para as região 1 ;

$\mathrm{W}_{2} \quad$ é o módulo resistente para as região 2; 


\section{2 - Método de Cálculo da Força de Protensão}

\section{Método do Balanceamento de Carga}

Foi introduzido por LIN [1963] como um método de análise de peças protendidas e, devido a sua enorme simplicidade, foi largamente difundido e atualmente é o método predominante de cálculo de peças protendidas.

Baseia-se no princípio de que a protensão é vista, principalmente, como uma tentativa de balancear uma parte da carga da estrutura, o que explica o nome do método. A protensão equilibra parte da carga, ou combinação de carga, de tal maneira que a peça não fique sujeita a tensões de tração. Pode-se assim, controlar a formação de fissuras e o desempenho da estrutura ao longo de sua vida útil.

De acordo com AALAMI [1989], o balanceamento de carga é o principal método de análise de estruturas de concreto protendido. Quando aplicado em estruturas complexas, necessitam de uma abordagem em seus conceitos com um contexto mais ampla não incluída no presente texto. Este método é extremamente vantajoso no cálculo de sistemas estaticamente indeterminados, pois mesmo neste caso mantém a sua simplicidade. Uma estrutura com sua carga balanceada pode ser considerada como não protendida, com uma redução de carregamento transversal, devida à uma pré-compressão aplicada pela força de protensão.

Em sua publicação, AALAMI [1989], realiza um amplo estudo teórico.

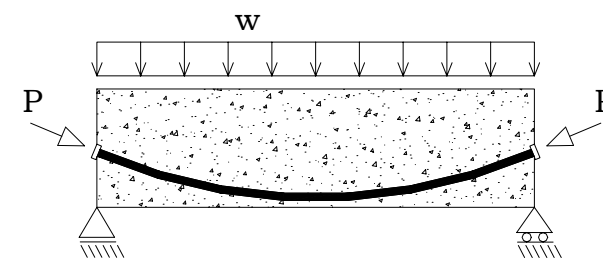

Viga protendida simplesmente apoiada
$\mathrm{P} \quad \mathrm{P}$

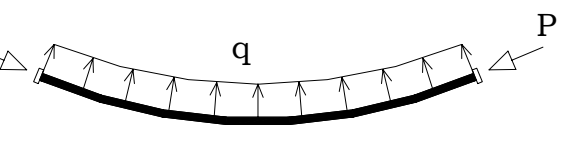

Esquema de corpo-livre do cabo

$\mathrm{w}-\mathrm{q}$

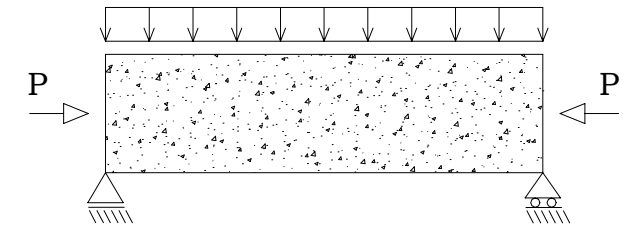

Esquema da estrutura com a carga equivalente aplicada

Figura 3.5 - Aplicação do Método do Balanceamento de Cargas 
Segundo LIN [1963], as forças do balanceamento de carga são produzidas pela componente transversal devida à protensão longitudinal (ver figura 3.5). O carregamento aplicado ao pavimento $w$ é equilibrado pelo carregamento de sentido contrário q, proveniente da protensão. Esta carga $q$ pode equilibrar totalmente a carga $w$ ou apenas parte dela.

A determinação da força de protensão necessária, para equilibrar a carga w aplicada à estrutura, pode ser determinada utilizando-se a seguinte expressão, válida para um cabo com perfil parabólico:

$$
\mathrm{w}=\frac{8 \cdot \mathrm{P} \cdot \mathrm{h}}{\mathrm{L}^{2}}
$$

Onde,

P é a força de protensão aplicada na seção transversal da peça;

h é a altura do cabo em relação a linha média da seção transversal da peça;

L é o comprimento da parábola que o cabo faz no trecho da peça;

w é o carregamento aplicado à estrutura.

O balanceamento de cargas para o sistema bidirecional é diferente do unidirecional, pois, naquele ocorre tanto o acréscimo quanto o decréscimo da carga balanceada devido à componente transversal dos cabos posicionados na direção perpendicular. Conseqüentemente, pode-se observar que, as forças de protensão e os perfis dos cabos nas duas direções ortogonais são totalmente inter-relacionados.

$\mathrm{Na}$ figura 3.6, vê-se a esquematização das componentes das cargas balanceadas em um sistema bidirecional. 


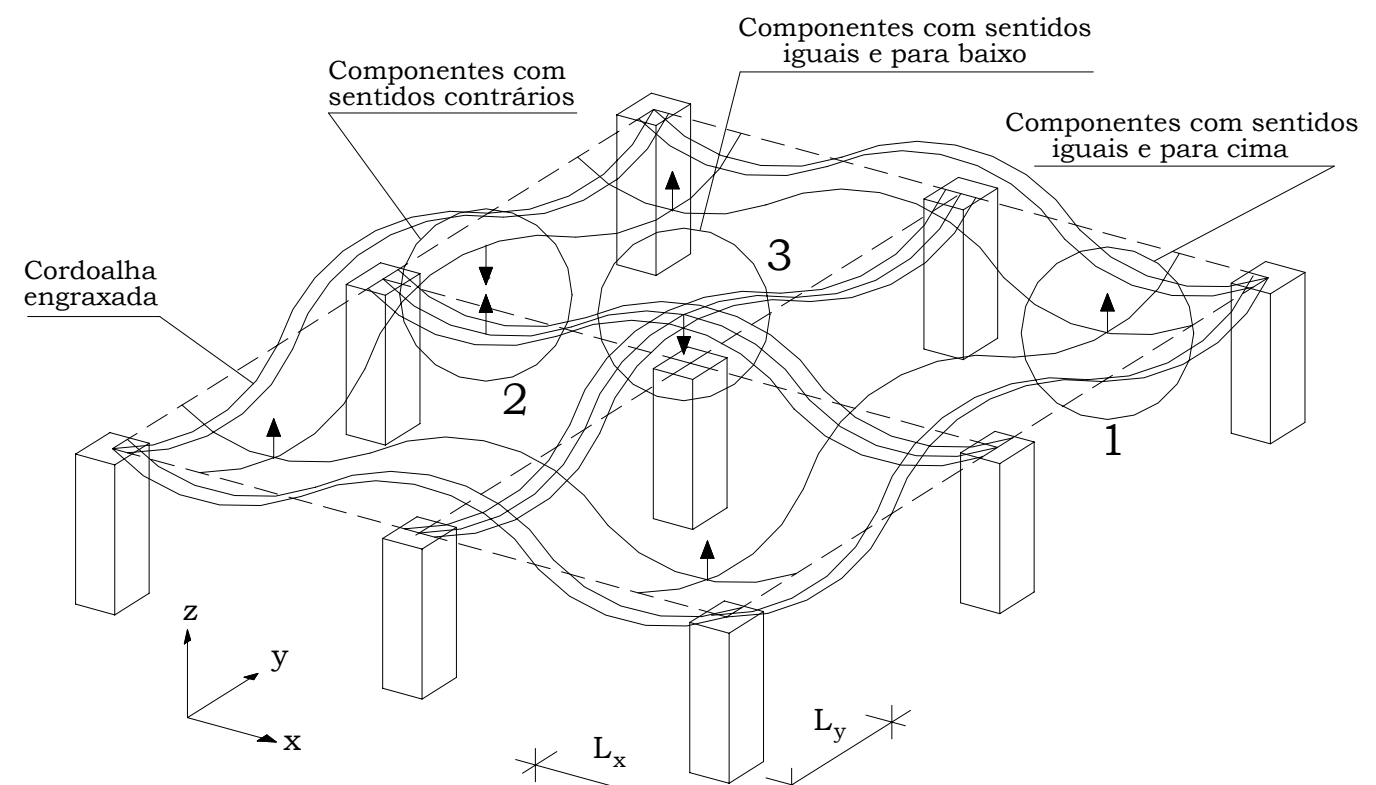

Figura 3.6 - Perfis de cabos parabólicos em lajes protendidas contínuas

Pode-se ver na figura 3.6 que os cabos apresentam perfis diferentes nas duas direções e, em algumas situações, estes coincidem seu perfil, gerando componentes da força de protensão em sentidos iguais.

$\mathrm{Na}$ região 1, pode-se ver que as componentes de protensão apresentam a mesma direção e sentido, para os cabos ortogonais, gerando um alivio na carga aplicada ao pavimento.

Na região 2, tem-se a componente na direção $X$ no sentido contrário ao da força aplicada no pavimento e na direção ortogonal, $Y$, a componente apresenta o mesmo sentido da força aplicada ao pavimento. Neste caso, deve-se, antes de realizar o equilíbrio entre as componentes da força de protensão e a força aplicada ao pavimento, equilibrar as duas componentes dos cabos nas direções ortogonais.

A região 3, apresenta o mesmo princípio da região 1, porém, apresenta as componentes da força de protensão têm o mesmo sentido da força aplicada ao pavimento.

A equação a seguir, incorpora as forças de protensão nas duas direções para equilibrar a ação $w$.

$$
w=\frac{8 \cdot P_{x} \cdot e_{x}}{L_{x}{ }^{2}}+\frac{8 \cdot P_{y} \cdot e_{y}}{L_{y}{ }^{2}}
$$


Onde,

$\mathrm{P}_{\mathrm{x}} \quad$ é a força de protensão na direção $\mathrm{X}$ por unidade de comprimento;

$\mathrm{P}_{\mathrm{y}} \quad$ é a força de protensão na direção $\mathrm{Y}$ por unidade de comprimento;

$e_{x} \quad$ é a altura do cabo em relação a linha média da seção transversal da laje nas direção X;

e é a altura do cabo em relação a linha média da seção transversal da laje nas direção Y;

$\mathrm{L}_{\mathrm{x}}$ é o comprimento do trecho do cabo de onde começa e termina a parábola do cabo na laje na direção X;

$\mathrm{L}_{\mathrm{y}}$ é o comprimento do trecho do cabo de onde começa e termina a parábola do cabo na laje na direção Y;

w é a parcela do carregamento aplicado por unidade de área a ser equilibrada.

De acordo com LIN, muitas combinações de $\mathrm{P}_{\mathrm{x}}$ e $\mathrm{P}_{\mathrm{y}}$ satisfazem a equação (3.4).

\section{3 - Perdas de Protensão}

As perdas de protensão dividem-se em dois tipos, sendo esta divisão de caráter temporal, pois as perdas variam com o tempo, sendo estes no ato da protensão ao longo do tempo. Outro tipo de perda, em menor escala, refere-se à flexão da peça, ou seja, a mudança da geometria da peça.

- Perdas Imediatas - que ocorrem durante a protensão da peça;

- Perdas Progressivas - que ocorrem ao longo do tempo, após a protensão;

- Efeito da curvatura na força de protensão produzido pela flexão da peça.

\subsection{1 - Perdas Imediatas}

As perdas imediatas se manifestam exatamente durante e imediatamente após o ato da protensão.

São subdivididas em três tipos: 


\section{i) Perdas por atrito}

Quando um cabo é submetido a uma força de alongamento, esta força não fica constante ao longo do seu comprimento, pois existe atrito entre a superficie do duto ou bainha e a superficie do próprio cabo.

As perdas por atrito são causadas por duas componentes de atrito:

- Efeito da curvatura do perfil;

- Efeito da mudança do perfil do cabo ao longo dele (ondulações acidentais ou parasitas).

Para um trecho elementar de cabo, mostrado na figura 3.7, vêem-se as componentes de fricção entre a superficie do cabo e a superfície da bainha. Os ângulos de desvio da são considerados suficientemente pequenos, podendo-se considerar $\operatorname{sen}(d \alpha)=\operatorname{tg}(d \alpha)=d \alpha$.

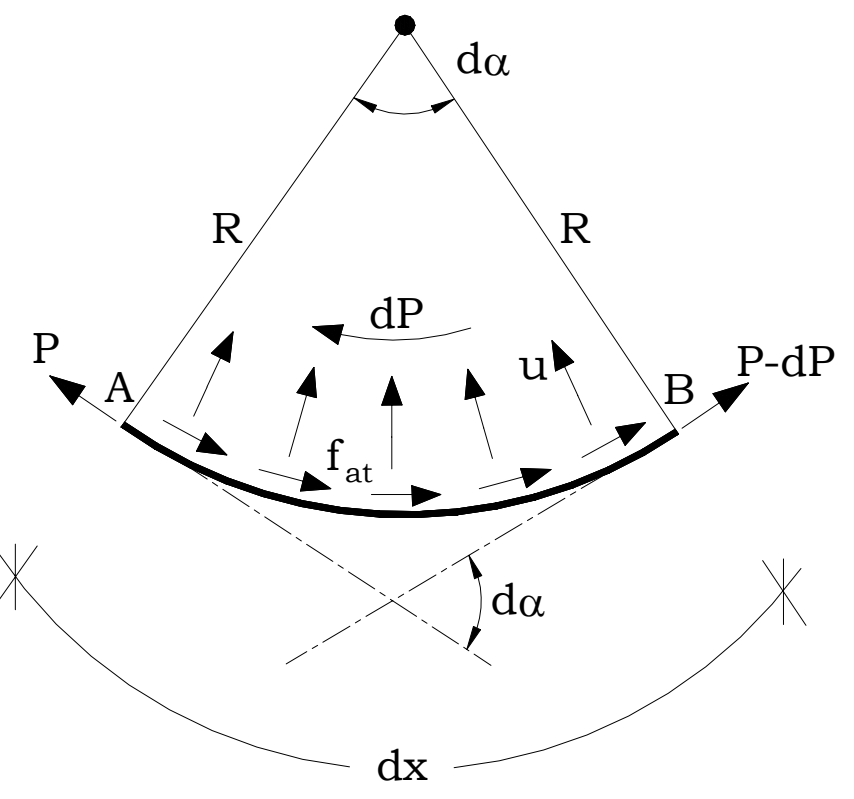

Figura 3.7 - Perdas de protensão por atrito devido à curvatura do cabo Onde,

$\mathrm{R}$ é o raio de curvatura do cabo no trecho $\mathrm{AB}$;

$\mathrm{d} \alpha$ é o ângulo de desvio do cabo no trecho $\mathrm{AB}$ (em radianos);

$\mathrm{u}$ é a força equilibrante distribuída ao longo do cabo no trecho $\mathrm{AB}$, $\left(\mathrm{u}=\frac{\mathrm{P}}{\mathrm{R}}\right)$

dP é a componente de perda da força de protensão no trecho AB;

$\mathrm{P} \quad$ é a força de protensão aplicada no ponto A; 
P-dP é a força de protensão resultante após as perdas por atrito no trecho; $\mathrm{dx}$ é o comprimento do cabo no trecho $\mathrm{AB}, \mathrm{dx}=\mathrm{R} . \mathrm{d} \alpha$;

$\mathrm{f}_{\mathrm{at}} \quad$ é a força de atrito distribuída no trecho $\mathrm{AB}$;

$\mathrm{f}_{\mathrm{at}}=\mu . \mathrm{u}$, onde $\mu$, é o coeficiente de atrito de Coulomb.

Com isso, a perda devida à força de atrito $\left(\mathrm{f}_{\mathrm{at}}\right)$, para um comprimento do cabo igual a $d x$, pode ser expressa por:

$$
\mathrm{dP}=\mu . \mathrm{P} \cdot \mathrm{d} \alpha
$$

As oscilações acidentais (vide figura 3.8) ocorrem em virtude de imperfeições no posicionamento dos cabos, que são desvios angulares não intencionais que provocam perdas por atrito.
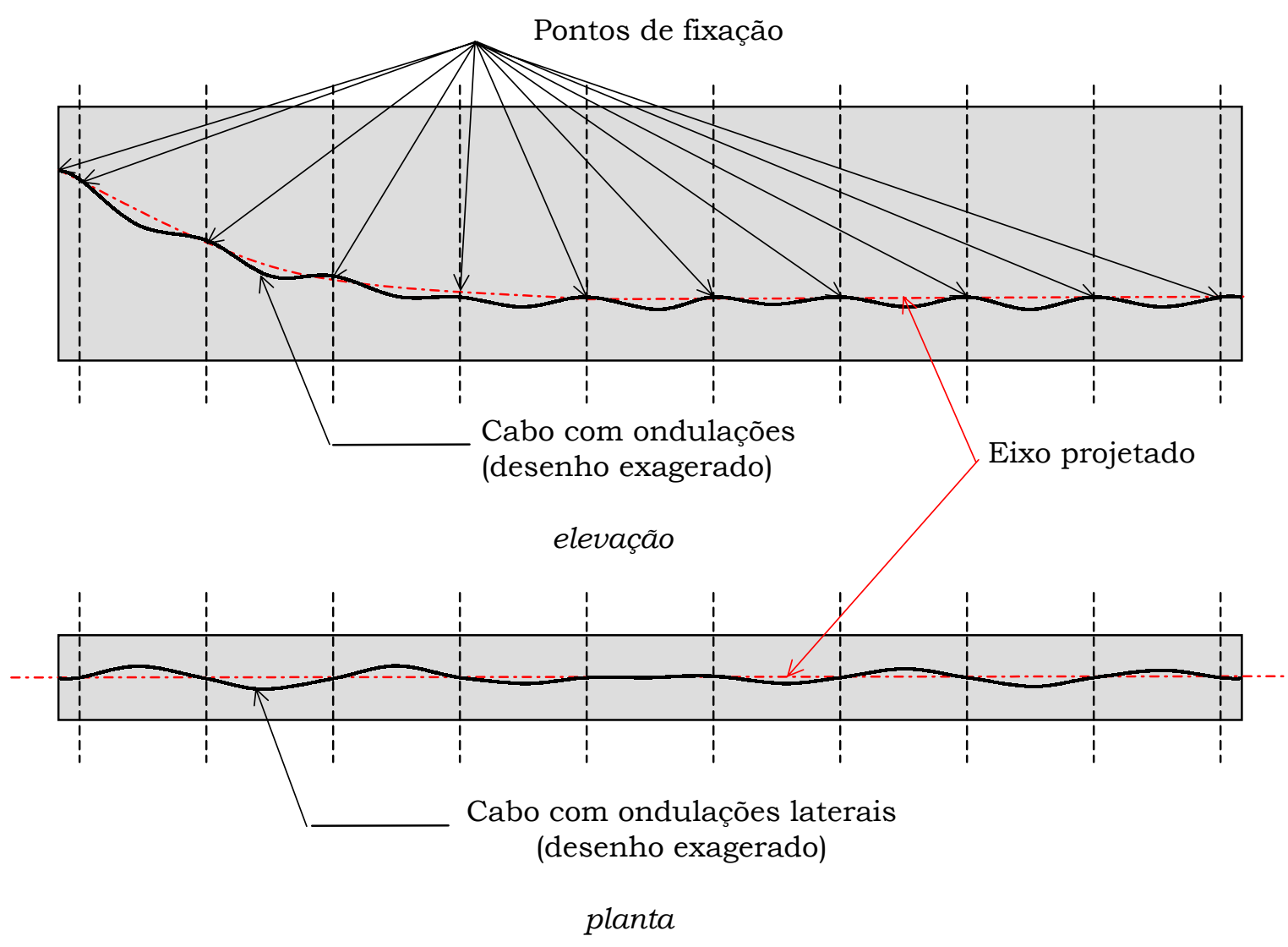

Figura 3.8 - Esquema das oscilações acidentais ou parasitas nos cabos (Adaptado de HANAI [2000]) 
As perdas devidas a essas oscilações acidentais ao longo do comprimento $d x$ (ver figura 3.6) são usualmente expressas como K.P.dx, onde $K$ é um coeficiente empírico de oscilações acidentais por metro do cabo (conforme no Código do CEB-FIP [1984], na falta de dados experimentais adota-se $\mathrm{K}=0,01 \mu)$.

$$
\mathrm{dP}=\mathrm{K} \cdot \mathrm{P} \cdot \mathrm{dx}
$$

Somando as duas parcelas, tem-se:

$$
\mathrm{dP}=\mu . P \cdot d \alpha+K \cdot P \cdot d x
$$

Assim, para se determinar o total de perdas para o cabo no trecho $\mathrm{AB}$, tem-se:

$$
\int_{P_{B}}^{P_{A}} \frac{d P}{P}=\mu \cdot \int_{0}^{a} d \alpha+K \cdot \int_{0}^{x} d x
$$

Resolvendo, chega-se a um resultado final igual a:

$$
\mathrm{P}_{\mathrm{B}}=\mathrm{P}_{\mathrm{A}} \cdot \mathrm{e}^{-(\mu \cdot \alpha+\mathrm{K} \cdot \mathrm{x})}
$$

Onde,

$\mathrm{P}_{\mathrm{A}} \quad$ é a força de protensão no ponto $\mathrm{A}$;

$\mathrm{P}_{\mathrm{B}} \quad$ é a força de protensão no ponto $\mathrm{B}$;

Estendendo para o caso do cabo inteiro, tem-se que a equação toma a seguinte forma:

$$
\Delta \mathrm{P}(\mathrm{x})=\mathrm{P}_{\mathrm{i}} \cdot\left[1-\mathrm{e}^{-(\mu \cdot \Sigma \alpha+\mathrm{K} \cdot \mathrm{x})}\right]
$$

Com,

$\Delta \mathrm{P}(\mathrm{x})$ é a perda de protensão no cabo na seção de abscissa $\mathrm{x}$;

$\mathrm{P}_{\mathrm{i}} \quad$ é a força de protensão aplicada na armadura pelo equipamento de tração;

$\Sigma \alpha$ é a soma dos ângulos de desvios previstos (em radianos) no trecho compreendido entre 0 e $\mathrm{x}$;

Na tabela 3.1, vê-se os valores para $\mu$ de acordo com o Projeto de Revisão da NBR 6118-2001. 
Tabela 3.1 - Coeficientes de atrito $\mu$, de acordo

com o Projeto de Revisão da NBR 6118-2001

\begin{tabular}{||l|c|}
\hline \multicolumn{1}{|c|}{ Tipo de superficies de atrito } & $\mu$ \\
\hline \hline Entre o cabo e concreto & 0,50 \\
\hline Entre barras ou fios com mossas ou saliências e bainha metálica & 0,30 \\
\hline Entre fios lisos ou cordoalhas e bainha metálica & 0,20 \\
\hline Entre fios lisos ou cordoalhas e bainha metálica lubrificada & 0,10 \\
\hline Entre cordoalha e bainha de polipropileno lubrificada & 0,05 \\
\hline
\end{tabular}

\section{ii) Perdas por acomodação das cunhas de ancoragem}

Quanto uma cordoalha é tensionada e o macaco hidráulico é liberado, a força de protensão é transferida para as cunhas. Essas cunhas estão sujeitas a tensões que provocam uma deformação junto às ancoragens, na forma de uma fricção entre a superficie das duas peças. A acomodação da ancoragem consiste em um recuo da cunha. Esta acomodação acarreta uma redução da força de protensão no trecho inicial da cordoalha, sendo o recuo da ordem de 2,54 mm (LIN \& BURNS [1981]), para os cabos de múltiplas cordoalhas.

De acordo com o Projeto de Revisão da NBR 6118-2001, o valor desta perda deve ser determinado experimentalmente ou adotado segundo as indicações dos fabricantes dos dispositivos de ancoragem.

Segundo LIN \& BURNS [1981], as cunhas deslizam na ancoragem até que esta esteja firmemente posicionada. A acomodação depende do tipo de cunha, da ancoragem e da intensidade da força de protensão utilizadas. Segundo os referidos autores, um valor igual a $0,254 \mathrm{~cm}(0,1$ in.) pode ser adotado como o valor da acomodação da cunha na ancoragem.

A Empresa MAC fornece um valor entre 6,0 e 14,0 $\mathrm{mm}$, para ancoragens de cordoalhas engraxadas e de 6,0 $\mathrm{mm}$ para ancoragens de armaduras ativas aderentes.

As perdas geradas por esta acomodação são maiores nas cordoalhas de pequena extensão do que para cordoalhas de maior comprimento.

$\mathrm{Na}$ expressão 3.10, pode-se ver que o alongamento da cordoalha é diretamente proporcional ao comprimento do cabo. 


$$
\Delta_{\mathrm{a}}=\frac{\sigma_{\mathrm{Pi}} \cdot \mathrm{L}}{\mathrm{E}_{\mathrm{P}}}
$$

Onde,

$\Delta_{\mathrm{a}} \quad$ é o alongamento da cordoalha;

L é o comprimento da cordoalha afetado por esta perda;

$\mathrm{E}_{\mathrm{p}} \quad$ é o módulo de elasticidade do aço protendido;

$\sigma_{\mathrm{pi}}$ é a de tensão na armadura ativa imediatamente após a aplicação da força de protensão.

Relacionando esta equação com a acomodação da cunha na ancoragem para o valor de LIN \& BURNS $(2,54 \mathrm{~mm})$ e para o valor fornecido pela Empresa MAC de protensão $(10,0 \mathrm{~mm})$, a figura 3.9 mostra um exemplo com cabos protendidos com a mesma intensidade de força $\left(\sigma_{\mathrm{pi}}=103,40 \mathrm{kN} / \mathrm{cm}^{2}\right)$ e módulo de elasticidade do aço de protensão $\left(E_{p}=20.694,27 \mathrm{kN} / \mathrm{cm}^{2}\right)$, porém, com comprimentos de cabo diferente.

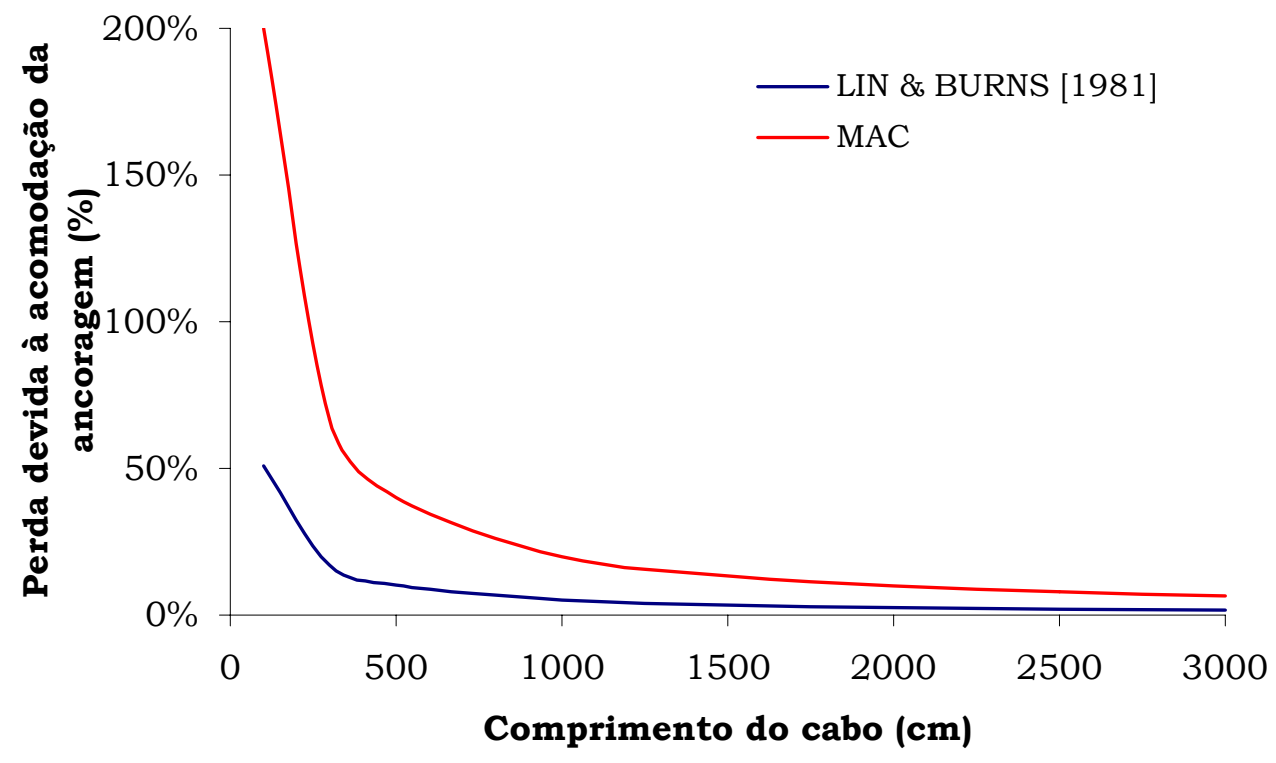

Figura 3.9 - Variação da perda por acomodação da ancoragem para uma cordoalha com diferentes comprimentos

\section{iii) Perdas por encurtamento elástico do concreto.}

Quando um cabo é alongado, ou seja, submetido a uma força de protensão, ele provoca um encurtamento elástico no concreto, gerando, 
como conseqüência, uma perda de força de protensão (ou relaxação) dos demais cabos já protendidos.

De acordo com o Projeto de Revisão da NBR 6118-2001, a perda de tensão média de protensão, devida à relaxação do aço de protensão, pode ser obtida pela seguinte expressão:

$$
\Delta \sigma_{\mathrm{P}}=\frac{\alpha_{\mathrm{P}}\left(\sigma_{\mathrm{CP}}+\sigma_{\mathrm{CG}}\right) \cdot(\mathrm{n}-1)}{2 \cdot \mathrm{n}}
$$

Onde,

$\sigma_{\mathrm{cp}}$ é a tensão inicial no concreto no nível do baricentro da armadura de protensão, devida à protensão simultânea dos n cabos;

$\sigma_{c g}$ é a tensão no concreto no nível do baricentro da armadura de protensão, devida à carga permanente modificada pela protensão ou simultaneamente aplicada com a protensão;

$\alpha_{\mathrm{p}}$ é a relação entre os módulos de elasticidade da armadura ativa e do concreto, na data do ato da protensão.

Vale salientar que o número de cabos (n) na expressão depende do projetista.

\subsection{2 - Perdas Progressivas}

As perdas progressivas consistem nas perdas que a peça e o cabo sofrem ao longo do tempo.

$\mathrm{Na}$ literatura, foram publicados muitos trabalhos na tentativa de determinar este comportamento, onde se pode destacar o trabalho de MEYERS et al. [1970], ZIA et al. [1979] e o PCI [1975].

De acordo com SILVA [1998], uma vez que os fenômenos de retração e fluência do concreto e relaxação do aço da armadura ativa são dependentes do tempo, os aspectos construtivos, que consistem nas fases de concretagem e aplicação de carregamentos, tornam-se relevantes na estimativa destas perdas.

Segundo o Projeto de Revisão da NRB 6118-2001, deve-se levar em conta, na sua determinação, a interação destes fenômenos utilizando os processos indicados, com as hipóteses de que são que a peça esteja no Estádio I e que exista aderência entre o aço e o concreto. 
A cordoalha engraxada não apresenta aderência com o concreto, e o Projeto de Revisão da NRB 6118-2001 não comenta nada com relação às perdas progressivas para a protensão do tipo não aderente.

Segundo LIN \& BURNS [1981], as perdas diferidas são interdependentes. Os materiais concreto e aço apresentam características próprias para o comportamento ao longo do tempo, mas, ao se aplicar uma força de protensão, essas propriedades são inter-relacionadas.

\section{i) Perdas devido à deformação por fluência do concreto}

A deformação por fluência consiste em um acréscimo nas deformações do concreto devido à manutenção de um carregamento à peça.

$\mathrm{Na}$ figura 3.10, tem-se a variação da fluência em função tempo, dando uma idéia de suas propriedades. Embora, esta curva apresente muita variação entre estruturas diferentes, os limites superiores e inferiores na figura 3.10, mostram esta variação e servem para demonstrar que é simples estimar as perdas no cabo devido à fluência.

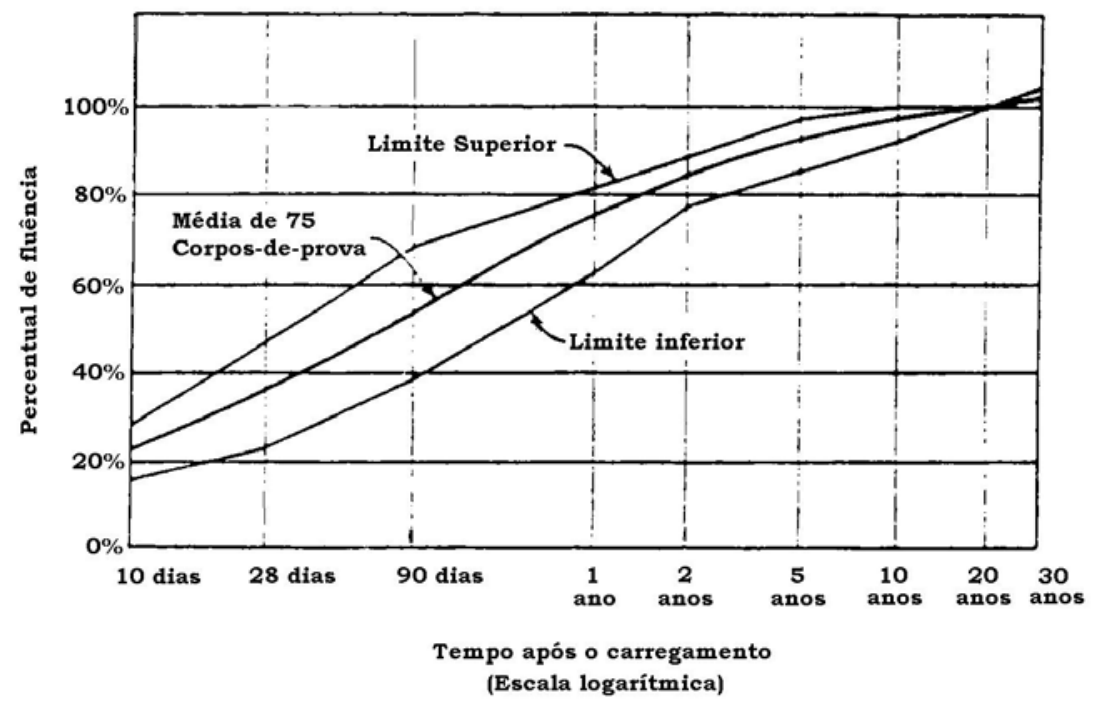

Figura 3.10 - Relação entre a porcentagem de ação da fluência com o tempo (adaptado de LIN \& BURNS [1981])

Para a protensão não aderente, a compressão média na peça é utilizada para se estimar as perdas devidas ao encurtamento elástico e a deformação por fluência do concreto. 
De acordo com a publicação de LIN \& BURNS, a perda de tensão na cordoalha pode ser obtida pela seguinte expressão:

$$
\Delta \sigma_{\mathrm{PC}}=\varphi\left(t, \mathrm{t}_{0}\right) \cdot \sigma_{\mathrm{CG}} \cdot \frac{\mathrm{E}_{\mathrm{P}}}{\mathrm{E}_{\mathrm{C}}}
$$

Onde,

$\Delta \sigma_{\mathrm{pc}}$ é a perda de tensão de protensão na cordoalha devida à fluência;

$\mathrm{E}_{\mathrm{p}} \quad$ é o módulo de elasticidade da armadura ativa;

$\mathrm{E}_{\mathrm{c}} \quad$ é o módulo de elasticidade do concreto aos 28 dias;

$\sigma_{c g}$ é a tensão no concreto no nível do baricentro da armadura de protensão, devida à carga permanente modificada pela protensão ou simultaneamente aplicada com a protensão.

$\varphi\left(t, t_{0}\right)$ é o coeficiente de fluência, estabelecido de acordo com o Projeto de Revisão da NRB 6118-2001, no instante t para a protensão e carga permanentes aplicadas no instante $t_{0}$;

Segundo LIN \& BURNS, o valor do coeficiente de fluência $\varphi\left(t, t_{0}\right)$, deve ser igual a 1,6 para peças com pós-tração e igual a 2,0 para peças com prétração.

Vale observar que, o Projeto de Revisão da NBR 6118-2001 não faz qualquer alusão à protensão não aderente, mostrando que a equação 3.12 é para o caso com protensão aderente. Entretanto, a equação fica a favor da segurança para o caso do cálculo para protensão não aderente.

\section{ii) Perdas devidas à deformação por retração do concreto}

A deformação por retração consiste em um encurtamento da peça, provocando assim, um afrouxamento na armadura ativa, o que promove uma redução na força de protensão.

De acordo com LIN \& BURNS [1981], a deformação por retração varia em função da relação volume-superficie externa, da umidade relativa e do tempo de final da cura e aplicação da força de protensão.

Os autores acima citados permitem uma estimativa para a deformação por retração do concreto com a seguinte expressão: 


$$
\varepsilon_{\mathrm{CS}}=8,2 \cdot 10^{-6} \cdot\left(1-0,06 \cdot \frac{\mathrm{V}}{\mathrm{S}}\right) \cdot(100-\mathrm{UR})
$$

Onde,

V/S é a relação volume-superfície da peça (em polegadas);

UR é a umidade relativa do ar (em porcentagem);

$\varepsilon_{c s} \quad$ é a deformação por retração do concreto;

Para a estimativa da perda de protensão devida ao encurtamento da peça, pode-se utilizar a equação 3.13 .

$$
\Delta \sigma_{\mathrm{PS}}=8,2 \cdot 10^{-6} \cdot \mathrm{K}_{\mathrm{S}} \cdot \mathrm{E}_{\mathrm{P}} \cdot\left(1-0,06 \cdot \frac{\mathrm{V}}{\mathrm{S}}\right) \cdot(100-\mathrm{UR})
$$

Com,

$\Delta \sigma_{\mathrm{ps}}$ é a perda da tensão na força de protensão aplicada na cordoalha devido à retração do concreto;

$\mathrm{E}_{\mathrm{p}} \quad$ é o módulo de elasticidade da armadura ativa;

$\mathrm{K}_{\mathrm{s}}$ é o coeficiente que leva em consideração o instante do início da retração e a aplicação da força de protensão.

Na tabela 3.2, vê-se a variação do coeficiente $K_{S}$ para diversas idades do concreto entre o fim do período de cura da peça e a aplicação da força de protensão.

Tabela 3.2 - Valores do coeficiente $\mathrm{K}_{\mathrm{S}}$ para idades variadas entre o tempo de final de cura e da aplicação da força de protensão

\begin{tabular}{||c|c|c|c|c|c|c|c|c||}
\hline $\begin{array}{c}\text { Tempo } \\
\text { (em dias) }\end{array}$ & $\mathbf{1}$ & $\mathbf{3}$ & $\mathbf{5}$ & $\mathbf{7}$ & $\mathbf{1 0}$ & $\mathbf{2 0}$ & $\mathbf{3 0}$ & $\mathbf{6 0}$ \\
\hline \hline $\mathbf{K}_{\mathbf{s}}$ & 0,92 & 0,85 & 0,80 & 0,77 & 0,73 & 0,64 & 0,58 & 0,45 \\
\hline
\end{tabular}

Fonte: LIN \& BURNS [1981]

Para o Projeto de Revisão da NBR 6118-2001, a deformação por retração provoca um encurtamento da peça, resultando em uma perda de protensão no cabo. Do mesmo modo LIN \& BURNS [1981] ressaltam que o valor da retração varia conforme a umidade relativa do ambiente, a consistência do concreto no lançamento e a espessura fictícia da peça. 
A perda de tensão na cordoalha referente ao encurtamento da peça pode ser obtida pela equação 3.15 .

$$
\Delta \sigma_{\mathrm{PS}}=\varepsilon_{\mathrm{CS}}\left(\mathrm{t}, \mathrm{t}_{0}\right) \cdot \mathrm{E}_{\mathrm{P}}
$$

A deformação devida à retração para os instantes to e t, é:

$$
\varepsilon_{\mathrm{CS}}\left(\mathrm{t}, \mathrm{t}_{0}\right)=\varepsilon_{\mathrm{CS}}{ }^{\infty} \cdot\left[\beta_{\mathrm{S}}(\mathrm{t})-\beta_{\mathrm{S}}\left(\mathrm{t}_{0}\right)\right]
$$

Onde,

$\beta_{\mathrm{S}}(\mathrm{t})$ e $\beta_{\mathrm{S}}\left(\mathrm{t}_{0}\right)$ são os coeficientes relativos à retração, no instante $\mathrm{t}$ e $\mathrm{t}_{0}$, respectivamente (Eq. 3.16)-(Ver figura 3.11);

$$
\beta_{S}(t)=\frac{\left(\frac{t}{100}\right)^{3}+A \cdot\left(\frac{t}{100}\right)^{2}+B \cdot\left(\frac{t}{100}\right)}{\left(\frac{t}{100}\right)^{3}+C \cdot\left(\frac{t}{100}\right)^{2}+D \cdot\left(\frac{t}{100}\right)+E}
$$

Onde,

$$
\begin{aligned}
& A=40 \\
& B=116 \cdot h^{3}-282 \cdot h^{2}+220 \cdot h-4,8 \\
& C=2,5 \cdot h^{3}-8,8 \cdot h+40,7 \\
& D=-75 \cdot h^{3}+585 \cdot h^{2}+496 \cdot h-6,8 \\
& E=-169 \cdot h^{4}+88 \cdot h^{3}+584 \cdot h^{2}-39 \cdot h+0,8
\end{aligned}
$$

$\mathrm{t} \quad$ é o tempo em dias ( $\mathrm{t} \geq 3$ dias);

h é a espessura fictícia em metros, com $0,05 \leq \mathrm{h} \leq 1,6$;

$\varepsilon_{c s}^{\infty} \quad$ é o valor final da retração, definido pela equação 3.23;

$\varepsilon_{\mathrm{CS}}{ }^{\infty}=\varepsilon_{1 \mathrm{~S}} \cdot \varepsilon_{2 \mathrm{~S}}$

Com,

$\varepsilon_{1 \mathrm{~s}} \quad$ é o coeficiente dependente da umidade relativa do ambiente e da consistência do concreto (ver tabela 3.3);

$\varepsilon_{1 \mathrm{~s}}=\left(-6,16-\frac{\mathrm{UR}}{484}+\frac{\mathrm{UR}^{2}}{1590}\right) \cdot 10^{-4}$

A equação 3.24 somente é válida para abatimentos de $5-9 \mathrm{~cm} \mathrm{e}$ $\mathrm{UR}<90 \%$.

$\varepsilon_{2 \mathrm{~s}} \quad$ é o coeficiente dependente da espessura fictícia da peça; 
$\varepsilon_{2 \mathrm{~S}}=\frac{33+2 \cdot \mathrm{h}_{\mathrm{fic}}}{20,8+3 \cdot \mathrm{h}_{\mathrm{fic}}}$

A espessura fictícia $\left(h_{\text {fic }}\right)$ é dada pela seguinte expressão:

$\mathrm{h}_{\text {fic }}=\left[1+\mathrm{e}^{(-7,8+0,1 \cdot \mathrm{UR})}\right] \cdot \frac{2 \cdot \mathrm{A}_{\mathrm{C}}}{\mathrm{u}_{\mathrm{ar}}} \quad($ para $\mathrm{UR}<90 \%)$

$\mathrm{A}_{\mathrm{c}} \quad$ é a área da seção transversal de concreto da peça;

$\mathrm{u}_{\mathrm{ar}}$ é a parte do perímetro externo da seção transversal da peça em contato com o ar.

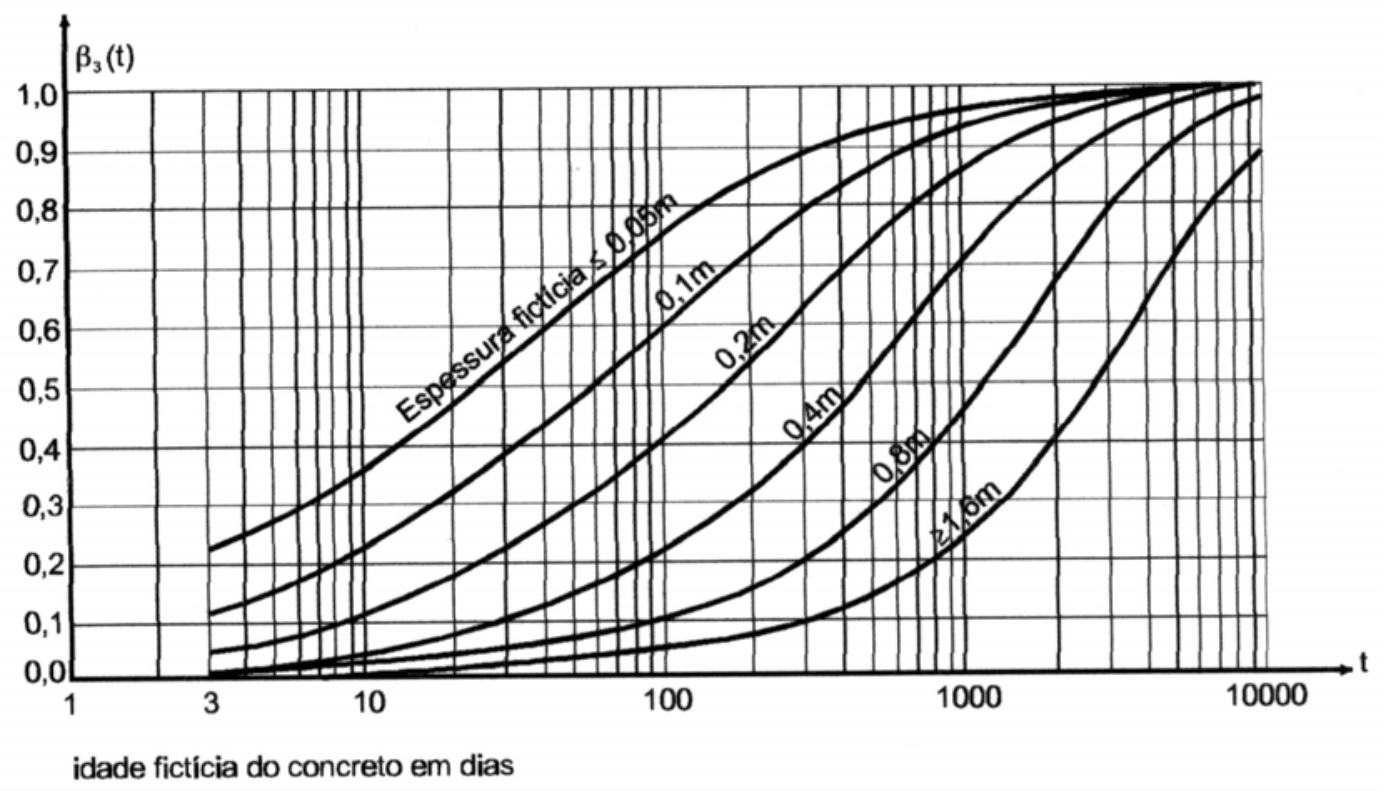

Figura 3.11 - Variação de $\beta_{\mathrm{s}}$ para o tempo t (adaptado do Projeto de Revisão da NBR 6118-2001)

Tabela 3.3 - Valores numéricos usuais para determinação de $\varepsilon_{1 \mathrm{~S}}$

\begin{tabular}{||c|c|c|c||}
\hline \multirow{2}{*}{$\begin{array}{l}\text { Umidade } \\
\text { Relativa }\end{array}$} & \multicolumn{3}{|c||}{ Retração (104. 1 1s) } \\
\cline { 2 - 4 } (UR) - \% & \multicolumn{2}{|c||}{ Abatimento de acordo com a NBR 7223 } \\
\cline { 2 - 4 } & $\mathbf{0 - 4} \mathbf{~ c m}$ & $\mathbf{5 - 9} \mathbf{~ c m}$ & $\mathbf{1 0 - 1 5} \mathbf{~ c m}$ \\
\hline \hline $100 \%$ & 1,0 & 1,0 & 1,0 \\
\hline $90 \%$ & $-1,0$ & $-1,3$ & $-1,6$ \\
\hline $70 \%$ & $-2,5$ & $-3,2$ & $-4,0$ \\
\hline $40 \%$ & $-4,0$ & $-5,2$ & $-6,5$ \\
\hline
\end{tabular}

Fonte: Projeto de Revisão da NBR 6118-2001 


\section{iii) Perdas devidas à relaxação da armadura ativa}

A relaxação do aço consiste na perda de tensão que a cordoalha sofre ao longo do tempo, sob deformação constante. De acordo com ensaios em aços para protensão submetidos a alongamento constante em um determinado período de tempo, é visto que, ocorre uma redução gradual na força de protensão, como pode ser visto na figura 3.12. Nessa figura $f_{p i} / f_{p y}$ é a razão entre a tensão de protensão aplicada e a tensão de escoamento do aço de protensão.

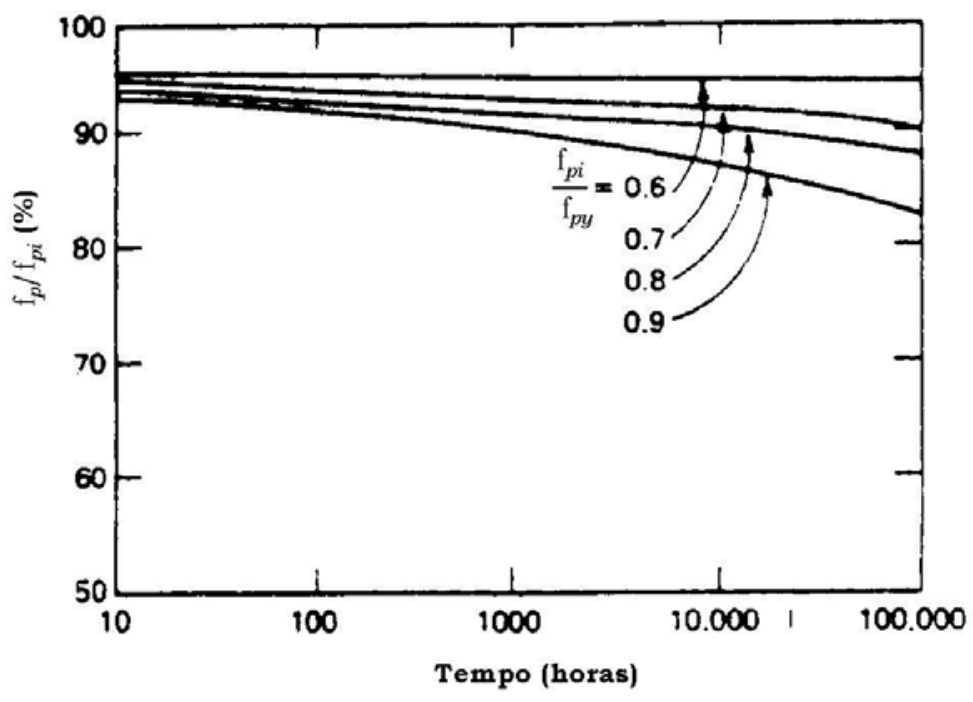

Figura 3.12 - Diagrama de perda de tensão nos cabos ao longo do tempo (adaptado de LIN \& BURNS [1981])

A perda de tensão da força de protensão pode ser obtida com a seguinte equação 3.27 .

$$
\Delta \sigma_{\mathrm{PR}}=\psi\left(\mathrm{t}, \mathrm{t}_{0}\right) \cdot \sigma_{\mathrm{Pi}}
$$

Com,

$\Delta \sigma_{\mathrm{pr}}\left(\mathrm{t}, \mathrm{t}_{\mathrm{o}}\right) \quad$ é a perda de tensão por relaxação pura (com comprimento constante) desde o instante $t_{0}$ do estiramento da armadura até o instante t considerado;

$\sigma_{\mathrm{pi}} \quad$ é a tensão da armadura de protensão no instante de seu estiramento;

$\psi\left(t, t_{0}\right) \quad$ é a intensidade da relaxação do aço. 
$\mathrm{Na}$ tabela 3.4 , tem-se os valores para $\psi\left(\mathrm{t}, \mathrm{t}_{0}\right)$, em porcentagem, para valores médios da relaxação, medidos após 1000 h a uma temperatura de $20^{\circ} \mathrm{C}\left(\psi_{1000}\right)$.

Tabela 3.4 - Valores de $\psi_{1000}$ em porcentagem (\%)

\begin{tabular}{||c|c|c|c|c|c||}
\hline \multirow{2}{*}{$\sigma_{\mathbf{P o}}$} & \multicolumn{2}{|c|}{ Cordoalhas } & \multicolumn{2}{|c|}{ Fios } & \multirow{2}{*}{ Barras } \\
\cline { 2 - 5 } & $\mathbf{R N}^{*}$ & $\mathbf{R B}^{* *}$ & $\mathbf{R N}^{*}$ & $\mathbf{R B}^{* *}$ & \\
\hline \hline $\mathbf{0 , 5 . f _ { \text { ptk } }}$ & 0 & 0 & 0 & 0 & 0 \\
\hline $\mathbf{0 , 6 . f _ { \text { ptk } }}$ & 3,5 & 1,3 & 2,5 & 1,0 & 1,5 \\
\hline $\mathbf{0 , 7 . f _ { \text { ptk } }}$ & 7,0 & 2,5 & 5,0 & 2,0 & 4,0 \\
\hline $\mathbf{0 , 8 . f _ { \text { ptk } }}$ & 12,0 & 3,5 & 8,5 & 3,0 & 7,0 \\
\hline
\end{tabular}

Fonte: Projeto de Revisão da NBR 6118-2001

* RN - Relaxação Normal

** RB - Relaxação Baixa

Com $\mathrm{f}_{\mathrm{ptk}}$ sendo igual ao valor característico da resistência à tração do aço de protensão.

De acordo com o Projeto de Revisão da NBR 6118-2001, para valores diferentes de $1000 \mathrm{~h}$, sempre a $20^{\circ} \mathrm{C}$, pode-se utilizar a seguinte expressão:

$$
\psi\left(t, t_{0}\right)=\psi_{1000} \cdot\left(\frac{t-t_{0}}{41,67}\right)^{0,15}
$$

Onde, $\mathrm{t}$ e to são dados em dias.

Ainda, é admitido que, para tensões inferiores a $0,5 . f_{\text {ptk }}$ não existam perdas por relaxação do aço de protensão e que, para o tempo infinito, o valor de $\psi\left(t, t_{0}\right)$ seja aproximadamente igual a 2,5. $\psi_{1000}$.

\section{iv) Perdas Totais Progressivas}

Para a determinação das perdas totais progressivas, deve ser feita simplesmente a soma das perdas calculadas, de acordo com a expressão a seguir: 


$$
\Delta \sigma_{\mathrm{p}, \mathrm{c}+\mathrm{r}+\mathrm{s}}=\Delta \sigma_{\mathrm{pc}}+\Delta \sigma_{\mathrm{pr}}+\Delta \sigma_{\mathrm{ps}}
$$

Onde,

$\Delta \sigma_{\mathrm{p}, \mathrm{c}+\mathrm{s}+\mathrm{r}} \quad$ é a perda de tensão no aço de protensão devido à deformação por fluência e retração do concreto e por relaxação do aço.

De acordo com o ACI 423-89, para estruturas típicas, os valores para as perdas de protensão podem ser adotados na falta de cálculo mais detalhado. Na tabela 3.5, essas estimativas são apresentadas baseados em concreto normal com valores médios para a resistência à compressão do concreto, nível de protensão (completa ou parcial) e condições de exposição ao meio ambiente.

Vale ressaltar que a tabela 3.5 não inclui as perdas relacionadas ao atrito e à acomodação da ancoragem, que devem ser adicionadas aos valores tabelados.

Tabela 3.5 - Perdas de protensão aproximadas

\begin{tabular}{||l|c|c|}
\hline \multicolumn{1}{|c|}{ Tipo de cabo } & \multicolumn{2}{c|}{ Perda de protensão (MPa) } \\
\cline { 2 - 3 } & Lajes & Vigas \\
\hline $\begin{array}{l}\text { Cordoalhas }\left(\mathrm{f}_{\mathrm{ptk}}=1860 \mathrm{MPa}\right) \\
\text { fios }\left(\mathrm{f}_{\mathrm{ptk}}=1655 \mathrm{MPa}\right)\end{array}$ & 207 & 241 \\
\hline Barras & 138 & 172 \\
\hline $\begin{array}{l}\text { Cordoalhas de baixa relaxação } \\
\left(\mathrm{f}_{\mathrm{ptk}}=1860 \mathrm{MPa}\right)\end{array}$ & 103 & 138 \\
\hline
\end{tabular}

Fonte: ACI 423-89.

\subsection{3 - Perda e ganho de tensão no cabo devido à flexão da peça}

Este tipo de perda ou ganho se encontra tanto na fase inicial da protensão da peça, quanto ao longo do tempo.

Quando uma peça está sujeita à flexão, a tensão devida à força de protensão no cabo pode reduzir ou aumentar, dependendo da curvatura de flexão (concavidade da peça) e da localização do cabo.

O projeto de Revisão da NBR 6118-2001 não faz qualquer alusão a este fenômeno que ocorre em peças de concreto protendido. 
De acordo com LIN \& BURNS [1981], a mudança da curvatura da peça depende do tipo de protensão (pré ou pós-tração) e do tipo de cordoalha utilizada (aderente ou não aderente).

No presente estudo admite-se que a protensão não aderente pode apresentar uma perda de sua tensão, devida à contra-flecha ocasionada pela protensão, ou, um ganho de tensão, quando a peça estiver completamente solicitada (ver figura 3.13). Se os cabos possuírem liberdade para se deslocar na bainha, estes irão aumentar ou diminuir seu comprimento conforme a flexão que ocorrerá na peça.
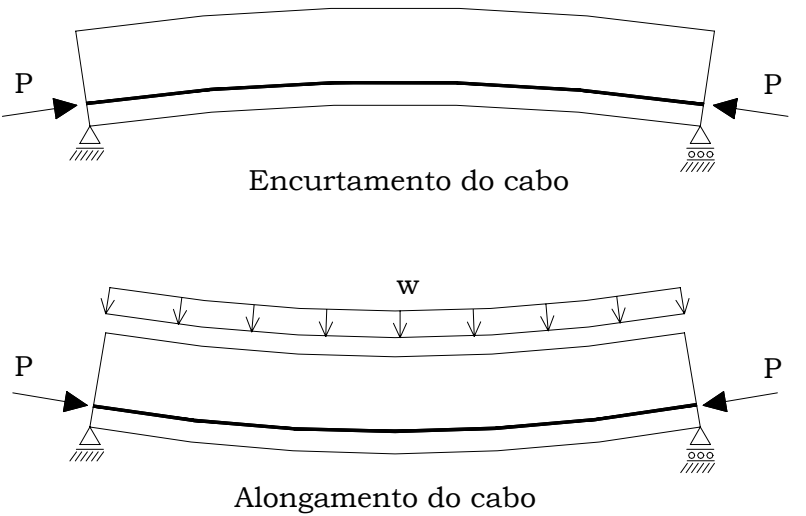

Figura 3.13 - Variação do comprimento do cabo (adaptado de LIN \& BURNS [1981])

Embora seja um efeito difícil de se avaliar, de acordo com os referidos autores, a perda ou o ganho de tensão na cordoalha são da ordem de 2 ou $3 \%$.

\section{4 - Características dos Momentos das Peças Protendidas}

Os momentos induzidos pela protensão são diretamente proporcionais à excentricidade dos cabos com relação à linha neutra da peça. Em vãos contínuos, ou estruturas protendidas indeterminadas, os momentos não são usualmente diretamente proporcionais à excentricidade do cabo. Esta diferença ocorre por causa das deformações impostas pela protensão que são resistidas onde existe a continuidade com outros elementos da estrutura (apoio). Estas restrições modificam as reações e 
conseqüentemente afetam os momentos fletores e as cortantes resultantes da protensão.

De acordo com a literatura mundial, os momentos das peças protendidas são divididos em duas categorias:

- Momentos Primários ou de Primeira Ordem;

- Momentos Secundários ou de Segunda Ordem ou Momentos Hiperestáticos.

Os momentos resultantes das restrições para as deformações oriundas da protensão são normalmente chamadas de momentos secundários ou de segunda ordem. Este termo é usualmente empregado por serem induzidos pelos momentos primários da protensão, $\mathrm{P} * \mathrm{e}_{\mathrm{p}}$, onde $P$ é a força de protensão e $e_{p}$ a excentricidade, e não por que o momento secundário seja desprezivel, nem necessariamente menor que o primário (momento de primeira ordem).

Momentos secundários devidos à protensão têm um significado muito importante no projeto de estruturas contínuas pois modificam significativamente as tensões $\mathrm{e}$ as forças calculadas. $\mathrm{Na}$ maioria das estruturas contínuas, os momentos secundários aumentam o valor do momento positivo relativo à protensão nos apoios internos e reduzem o valor do momento negativo relativo à protensão entre os apoios. 


\section{MODELOS DE CÁlCULO DE PAVIMENTOS DE CONCRETO PROTENDIDO}

Neste capitulo serão vistos os métodos mais empregados no cálculo de pavimentos de concreto protendido, com o objetivo de mostrar, de modo sucinto, seu funcionamento, limitações e campo de aplicação.

De acordo com CORREA [1991], existem dois grandes grupos de métodos para análise estrutural. O primeiro, consiste no modelo onde os elementos do pavimento, incluindo as lajes, são substituídos por conjunto de barras com características equivalentes à estrutural real. Pode-se citar o Método dos Pórticos Equivalentes e a Analogia por Grelha como exemplos. Segundo o autor, a desvantagem de sua utilização está na dificuldade de se definirem as propriedades das barras equivalentes, assim como suas vinculações e a geometria do pavimento quando este apresenta irregularidades em sua forma.

O segundo grupo consiste no modelo onde o pavimento é tratado como um meio contínuo. Inclui procedimentos numéricos que permitem resolver as equações diferenciais que regem o comportamento da estrutura do piso do edifício. Pode-se citar como exemplos o Método dos Elementos Finitos, o Método dos Elementos de Contorno e o Método das Diferenças Finitas.

Dentre os métodos supracitados, dar-se-á atenção ao Método dos Elementos Finitos, o Método dos Pórticos Equivalentes e o Método da 
Análise por Grelha, pois são os processos mais utilizados para a análise e determinação dos esforços por pesquisadores e engenheiros de cálculo estrutural.

$\mathrm{Na}$ análise estrutural, somente serão tratados os carregamentos estáticos e considerando apenas o comportamento elástico-linear do pavimento.

\section{1- Análise dos Pavimentos para os Estados Limites}

Quando uma estrutura se torna inapta à função para qual foi dimensionada, entende-se que ela atingiu um estado limite.

Estes estados limites são divididos em duas categorias:

- Estado Limite Último (E.L.U.) - envolve o colapso da estrutura em parte ou como um todo;

- Estado Limite de Serviço (E.L.S.) - envolve a perda de funcionabilidade para a qual a estrutura foi projetada.

O projeto estrutural envolve a identificação dos possiveis modos de ruptura (E.L.U.) e dos níveis de aceitabilidade de utilização do sistema estrutural (E.L.S.).

Os elementos de barra a serem utilizados têm como finalidade simular as vigas e pilares dos pavimentos a serem modelados. Com isso, os elementos de barra irão trabalhar em conjunto com os elementos de placa para simular o pavimento.

Uma placa é um corpo contornado por duas superficies de pequena curvatura, sendo que a distância entre elas, no caso chamada de espessura, é muito pequena em relação às dimensões da superfície (onde é aplicado o carregamento).

Neste texto será considerado que:

- A placa apresenta espessura uniforme;

- O material da placa é linear-elástico (Lei de HOOKE), isótropo e homogêneo;

- A placa apresenta linearidade geométrica, com deslocamentos muito menores que a sua espessura; 
- As tensões aplicadas nas superficies limites são muito pequenas quando comparadas com as tensões de flexão ( $\sigma_{\mathrm{Z}}<<\sigma_{\mathrm{X}}$ ou $\left.\sigma_{\mathrm{Y}}\right)$;

- É válida a Hipótese de Bernouille, que as seções planas permanecem planas $^{1}$.

A solução clássica, para o cálculo de lajes bidirecionais, utiliza a teoria de placas elásticas delgadas. Tem-se que a equação de equilíbrio:

$$
\frac{\partial^{4} \delta}{\partial \mathrm{x}^{4}}+2 \cdot \frac{\partial^{4} \delta}{\partial \mathrm{x}^{2} \partial \mathrm{y}^{2}}+\frac{\partial^{4} \delta}{\partial \mathrm{y}^{4}}=\frac{\mathrm{w}}{\mathrm{D}}
$$

Onde,

$\delta \quad \quad$ é a flecha da placa (laje);

w é o carregamento aplicado à placa (laje);

D é a rigidez à flexão da placa (laje);

$$
\mathrm{D}=\frac{\mathrm{E} \cdot \mathrm{h}^{3}}{12 \cdot\left(1-\mathrm{v}^{2}\right)}
$$

E é o módulo de elasticidade do material;

h é a espessura da placa (laje);

$v \quad$ é o Coeficiente de Poisson do material.

A relação entre os momentos fletores existentes, devidos à aplicação dos carregamentos na laje, e suas respectivas curvaturas é dada por:

$$
\left\{\begin{array}{l}
M_{x} \\
M_{y} \\
M_{x y}
\end{array}\right\}=\frac{E \cdot h^{3}}{12 \cdot\left(1-v^{2}\right)} \cdot\left[\begin{array}{ccc}
1 & v & 0 \\
v & 1 & 0 \\
0 & 0 & 2 \cdot(1+v)
\end{array}\right] \cdot\left\{\begin{array}{c}
\varphi_{x} \\
\varphi_{y} \\
\varphi_{x y}
\end{array}\right\}
$$

Onde,

$\mathrm{M}_{\mathrm{X}} \quad$ é o momento atuante no eixo X;

$\mathrm{M}_{\mathrm{Y}} \quad$ é o momento atuante no eixo $\mathrm{Y}$;

$\mathrm{M}_{\mathrm{XY}}$ é o momento volvente;

$\varphi_{\mathrm{x}} \quad$ é a curvatura no eixo $\mathrm{X}$;

$\varphi_{y} \quad$ é a curvatura no eixo $\mathrm{Y}$;

$\varphi_{\mathrm{xy}} \quad$ é a curvatura devido ao momento volvente.

1 Toda linha perpendicular à superfície média, antes do carregamento, permanecerá perpendicular a superficie média deformada após o carregamento. 
De acordo com as recomendações do ACI 435.9R, embora a influência do Coeficiente de Poisson seja pequena, a ausência de tal valor provocaria um erro de 2 a $6 \%$ no cálculo das flechas da estrutura.

TIMOSHENKO \& WOINOWSKY-KRIEGER ${ }^{2}$ [1959] e JENSEN ${ }^{3}$ [1938] citam maiores detalhes com relação ao cálculo de placas com várias geometrias e condições de contorno.

$\mathrm{Na}$ aplicação do carregamento são considerados os efeitos da fissuração da seção e das deformações por fluência e por retração do concreto, de acordo com as recomendações do ACI 435R-95 e do Projeto de Revisão da Norma NBR 6118-2001.

Para simular o efeito da fissuração da seção transversal de concreto, o Projeto de Revisão da Norma NBR 6118-2001 adota o modelo de BRANSON ${ }^{4}$ [1963].

Este modelo é suficientemente preciso na determinação das flechas de elementos de concreto armado e protendido (ACI 435R-95).

$$
I_{e f}=\left(\frac{M_{c r}}{M_{a}}\right)^{3} \cdot I_{g}+\left[1-\left(\frac{M_{c r}}{M_{a}}\right)^{3}\right] \cdot I_{c r}
$$

$\mathrm{Ou}$

$$
I_{e f}=\left(\frac{M_{c r}}{M_{a}}\right)^{3} \cdot\left(I_{g}-I_{c r}\right)+I_{c r}
$$

Onde,

$\mathrm{I}_{\mathrm{ef}} \quad$ é o momento de inércia efetivo da seção de concreto;

Ig é o momento de inércia da seção bruta de concreto;

$\mathrm{I}_{\mathrm{cr}} \quad$ é o momento de inércia da seção fissurada de concreto;

$\mathrm{M}_{\mathrm{cr}} \quad$ é o momento de fissuração da seção de concreto;

$\mathrm{M}_{\mathrm{a}} \quad$ é o momento fletor máximo atuante na seção de concreto referente à carga acidental.

\footnotetext{
2 TIMOSHENKO, S. \& WOINOWSKY-KRIEGER, S. [1959]. Theory of Plates and Shells. $2^{\text {nd }}$ Edition, McGraw-Hill Book Co., New York, NY, 580 pp.

3 JENSEN, V. P. [1938]. Solutions for Certain Rectangular Slabs Continuous Over Flexible Supports. Bulletin No. 303, University of Illinois Engineering Experimentation Station.

4 BRANSON, D. E. [1963]. Instantaneous and Time-Dependent Deflections of Simple and Continuous Reinforced Concrete Beams. HPR Publication No. 7, Part 1, Alabama Highway Department, Bureau of Public Roads, 1963, pp. 1-78;
} 
De acordo com o Projeto de Revisão da Norma NBR 6118-2001, $\mathrm{M}_{\mathrm{cr}}$ é determinado pela seguinte expressão:

$$
M_{c r}=\frac{f_{c t m} \cdot I_{g}}{y_{t}}=\frac{f_{c t m} \cdot b_{w} \cdot h^{2}}{6}
$$

Com,

yt é distância do centro de gravidade da seção à fibra mais tracionada.

$\mathrm{f}_{\mathrm{ctm}} \quad$ é a resistência média à tração do concreto;

$\mathrm{f}_{\mathrm{ctm}}=0,3 \cdot\left(\mathrm{f}_{\mathrm{ck}}\right)^{2 / 3}(\mathrm{em} \mathrm{MPa})$

Porém, deve-se utilizar a expressão do item 17.2.3 do Projeto de Revisão da Norma NBR 6118-2001, que estabelece que a resistência à tração na flexão do concreto tem o valor de $1,2 . f_{\mathrm{ct}, \mathrm{k}}$ para peças de seção $\mathrm{T}$ ou duplo $\mathrm{T}$ e $1,5 . \mathrm{f}_{\mathrm{ct}, \mathrm{k}}$ para peças de seção retangular.

$O$ valor de $f_{c t, k}$ a ser utilizado deve ser igual ao valor de $f_{c t k, \text { inf. }}$

$\mathrm{f}_{\mathrm{ctk}, \text { inf }}=0,7 . \mathrm{f}_{\mathrm{ctm}}$

A relação entre o momento crítico e o aplicado pode ser substituída pela seguinte expressão (NAWY [1996] e ACI 435R-95):

$$
\left(\frac{\mathrm{M}_{\mathrm{cr}}}{\mathrm{M}_{\mathrm{a}}}\right)=\left(1-\frac{\mathrm{f}_{\mathrm{TL}}-\mathrm{f}_{\mathrm{r}}}{\mathrm{f}_{\mathrm{L}}}\right)
$$

Onde,

$\mathrm{f}_{\mathrm{TL}} \quad$ é a tensão calculada na peça;

$\mathrm{f}_{\mathrm{r}} \quad$ é o módulo de ruptura do concreto $\left(\mathrm{f}_{\mathrm{r}}=7,5 \cdot \sqrt{\mathrm{f}^{\prime}{ }_{\mathrm{c}}}\right.$ em psi);

$\mathrm{f}_{\mathrm{L}} \quad$ é a tensão calculada devida à carga acidental;

$\mathrm{Na}$ Tabela 4.1, pode-se ver as relações de $\mathrm{I}_{\mathrm{ef}}$ para peças contínuas e simplesmente apoiadas. 
Tabela 4.1 - Equações de $I_{\text {ef }}$ para diferentes condições de contorno.

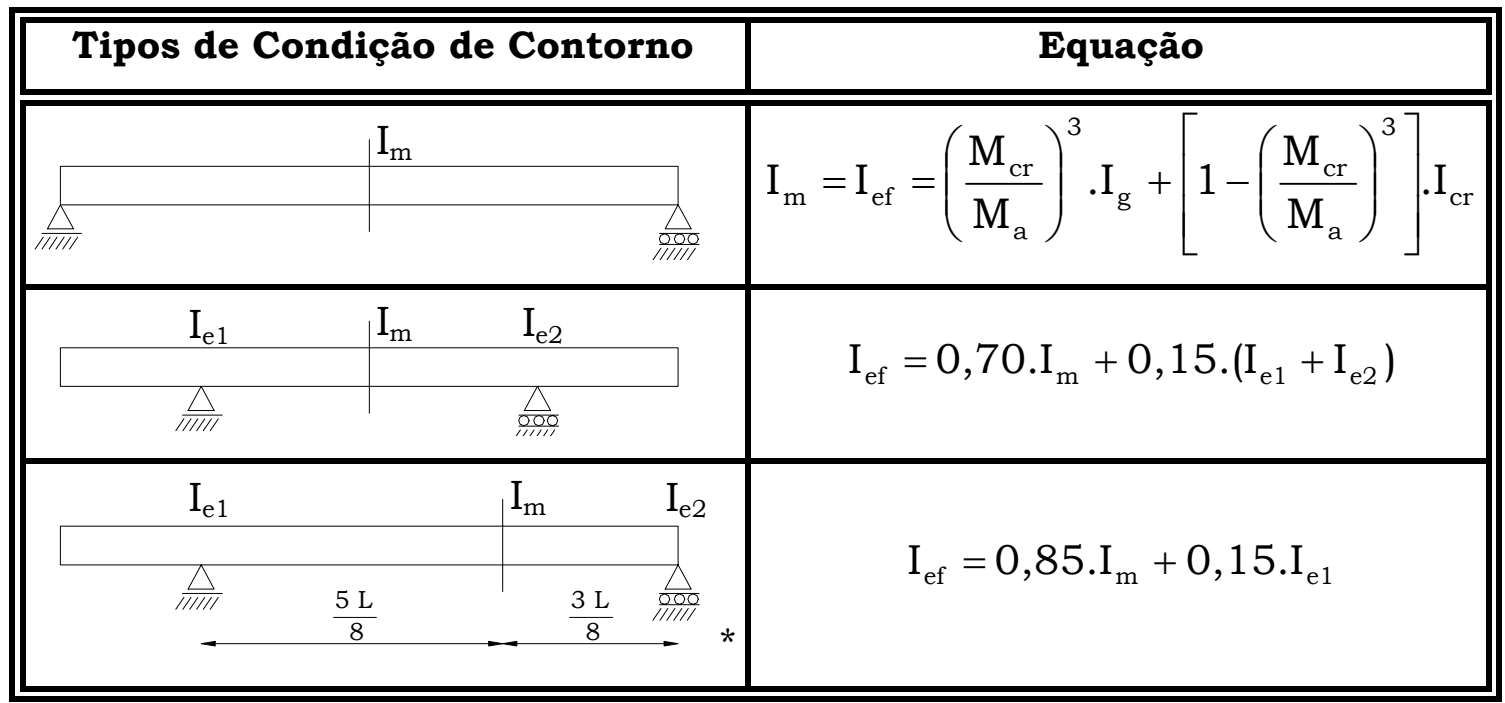

Fonte: ACI 435R-95

* Os limites colocados são válidos somente para cargas distribuídas.

Onde,

L é o comprimento do vão;

$\mathrm{I}_{\mathrm{m}} \quad$ é o momento de inércia efetivo para o meio do vão;

$\mathrm{I}_{\mathrm{e} 1} \quad$ é o momento de inércia efetivo da extremidade do vão (ponto 1);

$\mathrm{I}_{\mathrm{e} 2} \quad$ é o momento de inércia efetivo da extremidade do vão (ponto 2).

Segundo o ACI 435R-95, os dois momentos de inércia calculados, Ig e $\mathrm{I}_{\mathrm{cr}}$, são baseados na condição do comportamento bilinear da relação momento-deslocamento da seção fissurada.

Para o cálculo do momento de inércia da seção fissurada de concreto, tem-se as seguintes expressões:

$$
\begin{gathered}
I_{c r}=n_{p} \cdot A_{p s} \cdot d_{p}{ }^{2} \cdot\left(1-1,6 \cdot \sqrt{n_{p} \cdot \rho_{p}}\right) \\
I_{c r}=\left(n_{p} \cdot A_{p s} \cdot d_{p}{ }^{2}+n_{s} \cdot A_{s} \cdot d_{s}{ }^{2}\right) \cdot\left(1-1,6 \cdot \sqrt{n_{p} \cdot \rho_{p}+n_{s} \cdot \rho_{s}}\right)
\end{gathered}
$$

Onde,

$\mathrm{n}_{\mathrm{p}}=\frac{\mathrm{E}_{\mathrm{ps}}}{\mathrm{E}_{\mathrm{c}}}$

$\mathrm{n}_{\mathrm{s}}=\frac{\mathrm{E}_{\mathrm{s}}}{\mathrm{E}_{\mathrm{c}}}$

$\rho_{p}=\frac{A_{p s}}{b_{w} \cdot d}$ 
$\rho_{\mathrm{s}}=\frac{\mathrm{A}_{\mathrm{s}}}{\mathrm{b}_{\mathrm{w}} \cdot \mathrm{d}}$

Onde,

$\mathrm{A}_{\mathrm{ps}} \quad$ é a área de armadura ativa;

$\mathrm{A}_{\mathrm{s}} \quad$ é a área de armadura passiva de tração;

$\mathrm{d}_{\mathrm{p}} \quad$ é a altura útil da armadura ativa;

$\mathrm{d}_{\mathrm{s}} \quad$ é a altura útil da armadura passiva de tração;

$\rho_{\mathrm{p}} \quad$ é a taxa de armadura ativa;

$\rho_{\mathrm{s}} \quad$ é a taxa de armadura passiva.

A equação (4.10) é utilizada para determinar o momento de inércia da seção fissurada, quando a protensão for "completa" (ausência de armadura passiva tracionada) e a equação (4.11), quando a protensão for do tipo "parcial” (presença de armadura passiva trabalhando à tração).

Quanto ao valor do módulo de elasticidade transversal $\left(\mathrm{G}_{\mathrm{xy}}=\mathrm{G}\right)$, de acordo com o ACI 435.9R-91, o valor integral pode ser utilizado como uma simplificação do cálculo, tanto antes como após a fissuração da seção transversal, pois, análises realizadas mostraram que as flechas calculadas não são sensiveis às variações do módulo $\mathrm{G}_{\mathrm{xy}}$.

\section{2 - Método dos Pórticos Equivalentes}

A proposta de cálculo pelo método dos pórticos equivalentes data de meados da década de 30 na Alemanha e nos Estados Unidos. Em 1948, Peabody apresentou um detalhado método para a análise dos pórticos equivalentes que foi incorporado na edição subseqüente do ACI da época como "Projeto por Análise Elástica".

É Um processo atualmente bastante utilizado por ser simples e eficiente na análise e cálculo de pavimentos de concreto protendido. É um processo tridimensional que consiste em dividir o pavimento em duas estruturas que são analisadas independentemente uma da outra, ou seja, consiste em representar a estrutura, no caso um pavimento protendido, composta de lajes e pilares através de uma série de pórticos tomados nas 
direções dos planos ortogonais às bordas da laje. Admite-se que a estrutura, em cada uma das direções, seja uma série de pórticos múltiplos.

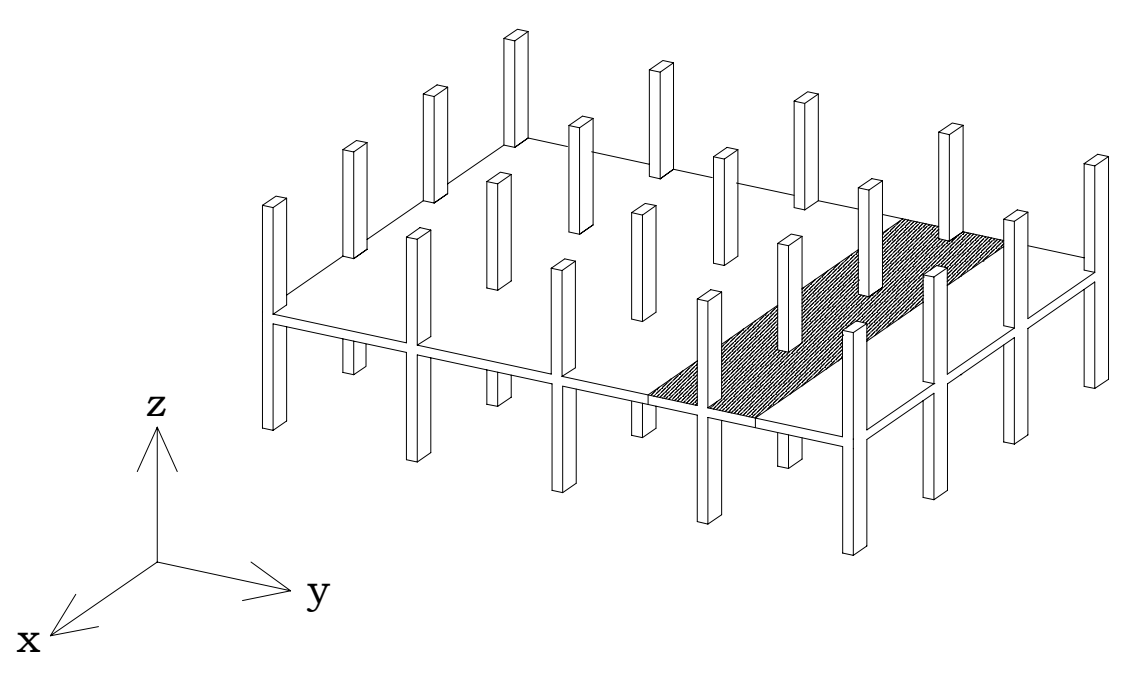

Figura 4.1 - Distribuição dos pórticos equivalentes na direção X

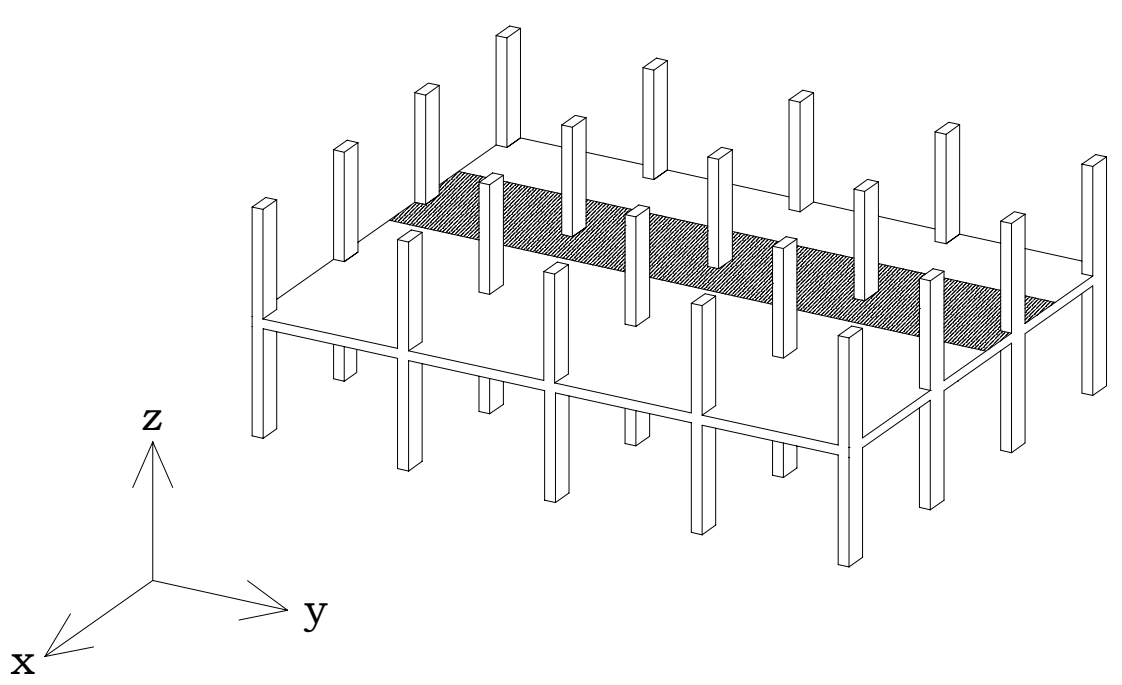

Figura 4.2 - Distribuição dos pórticos equivalentes na direção Y

Nas figuras 4.1, 4.2 e 4.3, pode-se ver a distribuição no pavimento dos pórticos equivalentes.

Nesse sistema os pórticos são constituídos por um conjunto de colunas e barras horizontais, cujas inércias são iguais às da região da laje limitada pela metade da distância entre as duas linhas adjacentes de pilares. Os pórticos criados são, então, calculados independentemente um 
dos outros, com a carga total aplicada e suas combinações de carga (caso mais desfavorável).

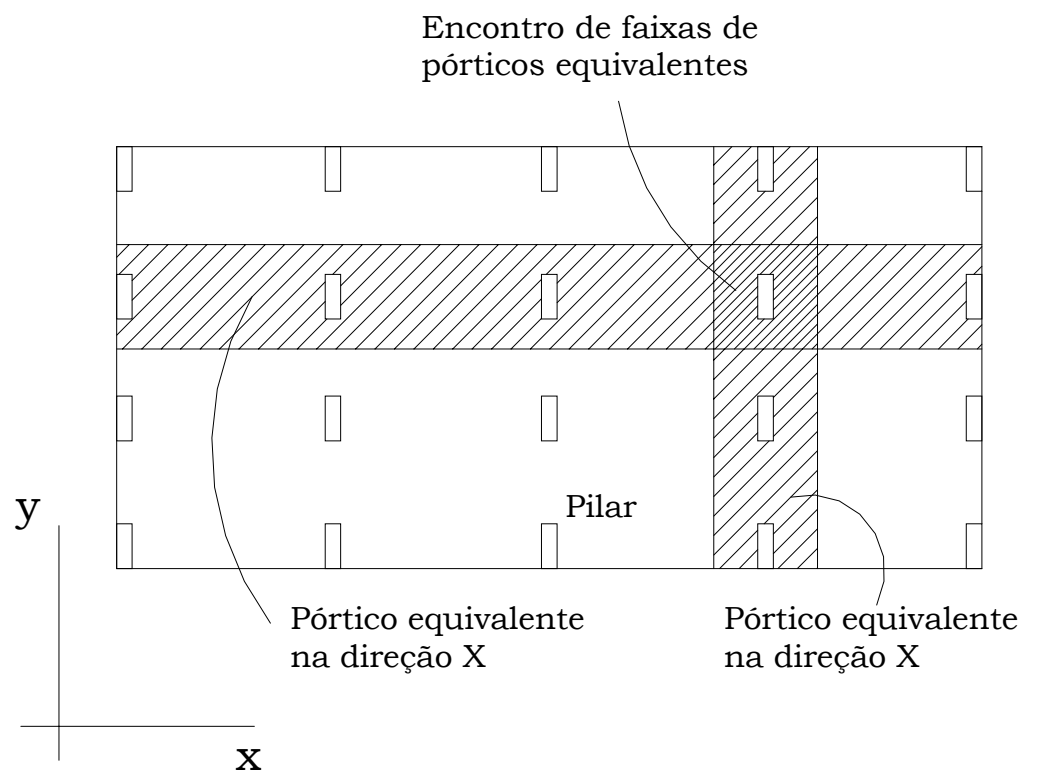

Figura 4.3 -Divisão típica de pavimento em pórticos equivalentes

Para o cálculo de esforços, é necessário fazer-se uma diferenciação quanto à posição do pórtico (interno ou externo).

A proposta de revisão da Norma, a NBR 6118-2001, comenta que a análise estrutural de pavimentos do tipo plano pode ser realizada mediante o emprego de procedimento numérico adequado, como diferenças finitas, elementos finitos e elementos de contorno.

O Projeto de revisão da NBR 6118-2001 também adota o processo de cálculo de pórticos equivalentes, porém, somente para o caso em que os pilares estiverem dispostos em filas ortogonais, de maneira regular e com vãos pouco diferentes.

Segundo o Código do ACI 318-99, as faixas são subdivididas para a distribuição dos esforços calculados através do pórtico equivalente, de acordo com o ilustrado na figura 4.4. 


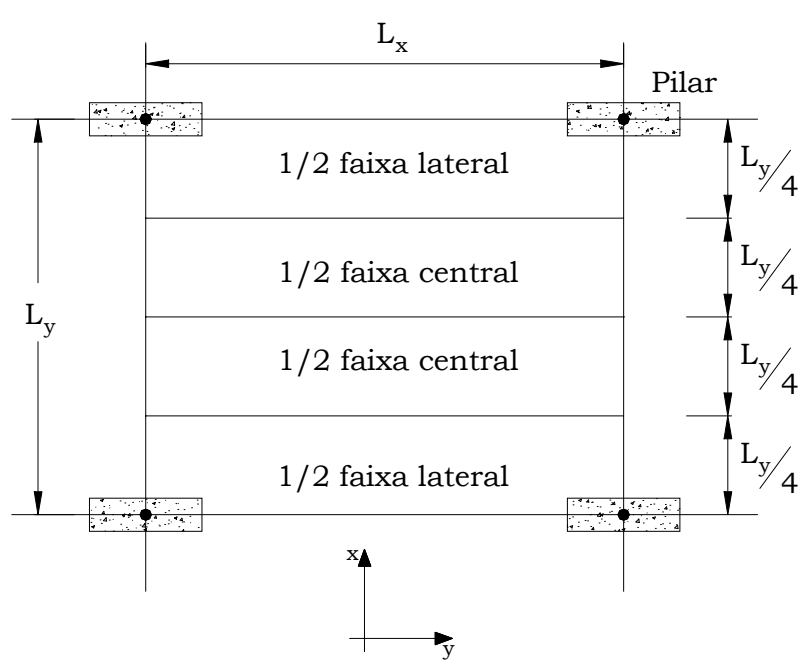

Figura 4.4 - Faixas centrais e laterais de um painel de laje

De acordo com NAWY [1996], o método dos pórticos equivalentes apresenta uma série de características interessantes:

- As variações no momento de inércia ao longo dos eixos dos pórticos podem ser consideradas, como por exemplo, o efeito da utilização de drop panels e de capitéis (ver figura 4.5);

- Os efeitos de forças laterais podem ser analisados, desde que se façam considerações necessárias nas rigidezes das peças com o objetivo de se determinar eficazmente o efeito da fissuração;

- Este método é de fácil implementação computacional.

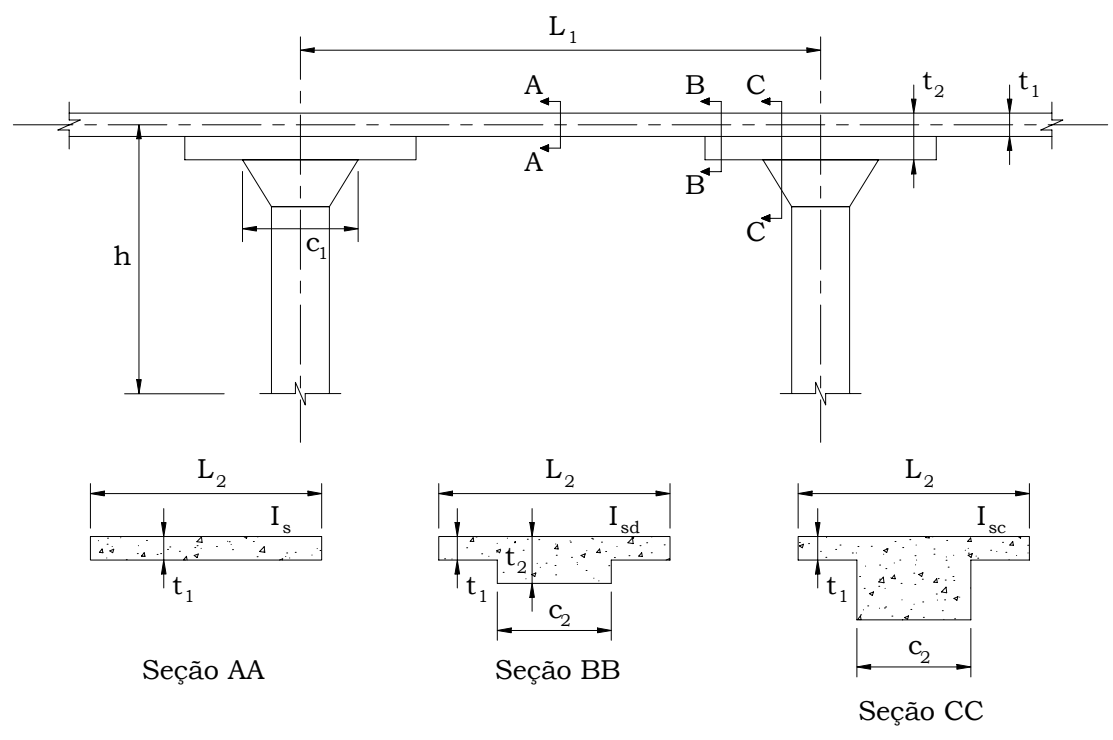

Figura 4.5 - Variações do momento de inércia para o cálculo das rigidezes do pórtico equivalente (Adaptado de CORLEY \& JIRSA [1970]) 
Com,

$\mathrm{I}_{\mathrm{s}} \quad$ sendo o momento de inércia da faixa de laje longe do apoio;

$\mathrm{I}_{\mathrm{sd}} \quad$ sendo o momento de inércia da faixa da laje imediatamente ao redor do apoio;

$\mathrm{I}_{\mathrm{sc}} \quad$ sendo o momento de inércia da faixa desde a face do pilar (apoio) ou capitel, até o centro do apoio.

Onde,

$$
I_{s c}=\frac{I_{s d}}{\left(1-\frac{c_{2}}{L_{2}}\right)^{2}}
$$

$\mathrm{c}_{1} \quad$ sendo a dimensão do pilar, capitel ou parede na direção dos momentos a serem determinados;

$\mathrm{c}_{2}$ sendo a dimensão do pilar, capitel ou parede na direção transversal dos momentos a serem determinados;

$t_{1} \quad$ sendo a espessura da laje;

$t_{2} \quad$ sendo a espessura do drop panel;

$\mathrm{L}_{1} \quad$ sendo o comprimento do vão na direção em que os momentos estão sendo determinados, medido a partir do centro dos apoios;

$\mathrm{L}_{2}$ sendo o comprimento do vão transversal à $\mathrm{L}_{1}$ medido a partir do centro dos apoios;

Os pilares internos estão sujeitos à flexão, a menos que, os momentos fletores dos dois lados sejam exatamente iguais. Os pilares externos sempre apresentarão flexão, a não ser que esta ligação apresente rotação intencional livre. Considerando a figura 4.6, o equilíbrio requer que o momento no pilar seja igual ao momento total da laje, fazendo com que as rotações existentes tanto no pilar quanto na laje sejam iguais. 


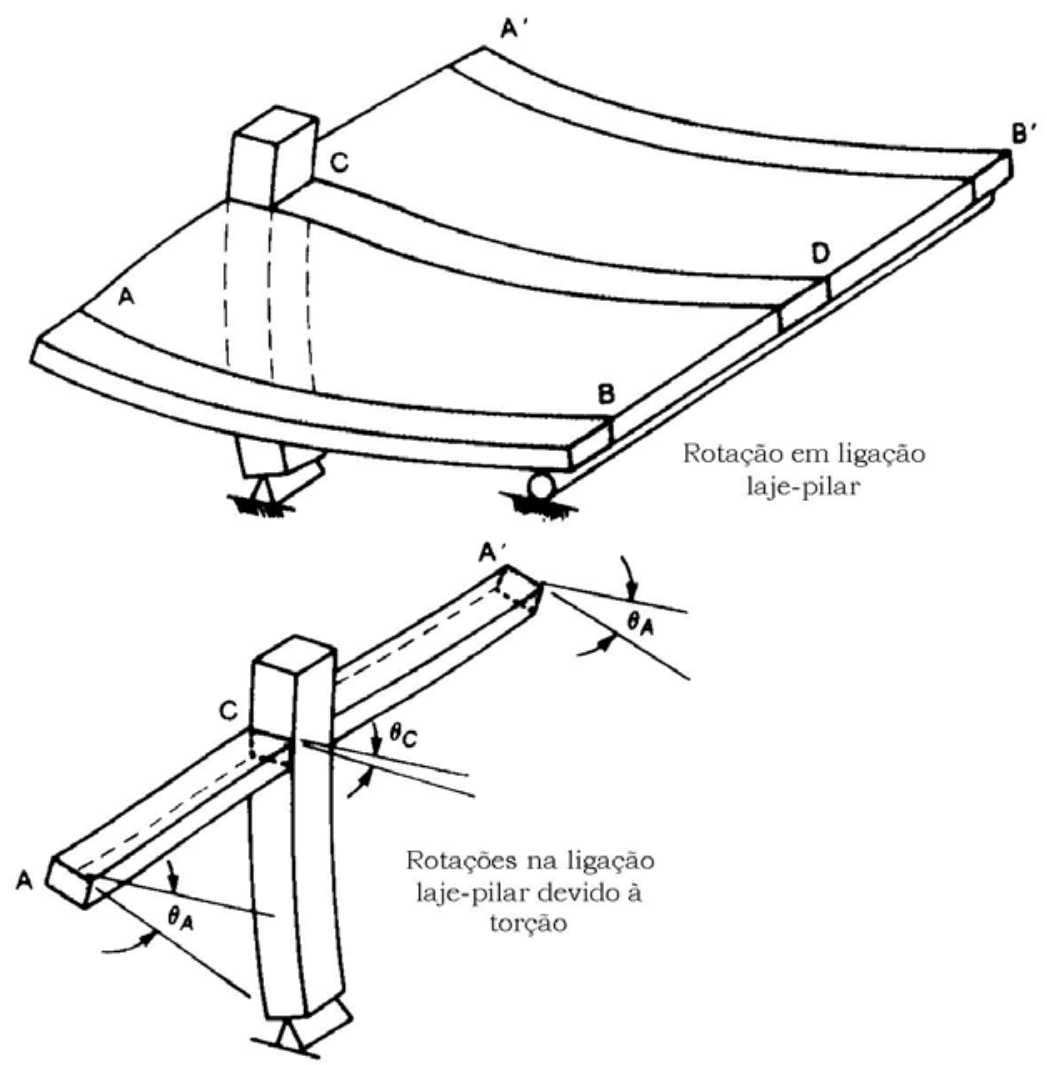

Figura 4.6 - Rotações em ligações laje-pilar

Segundo MACGREGOR [1992], a extremidade da laje e da parede, onde se conectam, apresentam as mesmas rotações quando a laje estiver solicitada por cargas verticais. Quanto a uma ligação de laje-pilar de um piso do tipo laje plana maciça, a rotação do pilar é igual a rotação da extremidade da faixa de laje $\mathrm{CD}$ que se liga ao pilar. A rotação no ponto $\mathrm{A}$ da faixa $A B$ é maior que a rotação no ponto $C$, pois, no ponto $C$ existe mais restrição a essa rotação. Com isso, tem-se a ocorrência do momento volvente (twist moment).

CORLEY \& JIRSA [1970], desenvolveram o conceito de pilar equivalente, que transforma a análise que seria tridimensional em plana, pois esta já engloba no plano as rigidezes à torção nas ligações laje-pilar. Assim, o Código do ACI 318-95 comenta que os pórticos devem ser compostos de três partes, sendo:

- Faixas horizontais da laje;

- Pilares ou outros elementos estruturais verticais de apoio, considerados tanto acima quanto abaixo do piso a ser analisado; 
- Elementos estruturais que possibilitam a transferência de momentos entre os elementos verticais e horizontais, para assim considerar o efeito da torção na laje.

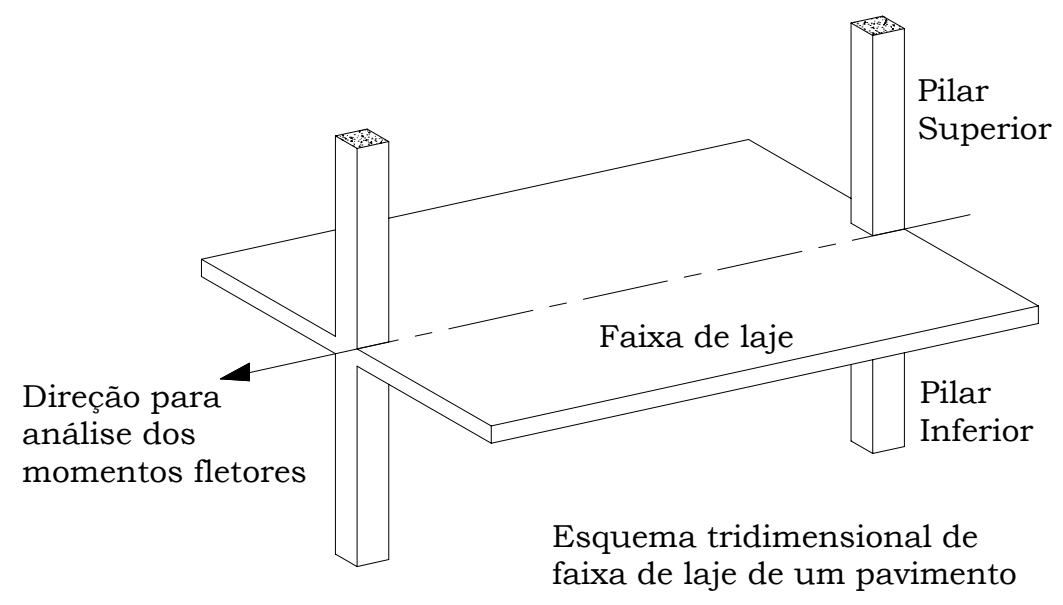

Figura 4.7 - Esquema tridimensional de faixa de laje de pórtico equivalente, localizado no caminho dos pilares

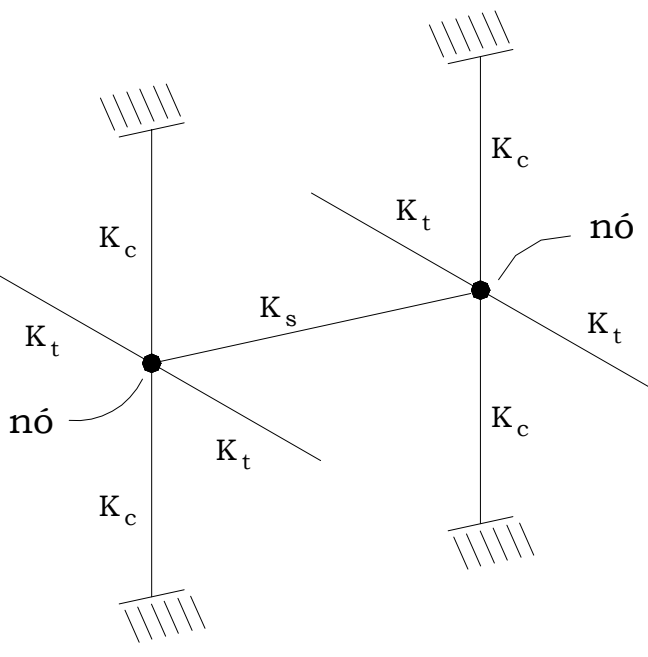

a) Esquema do modelo analítico tridimensional

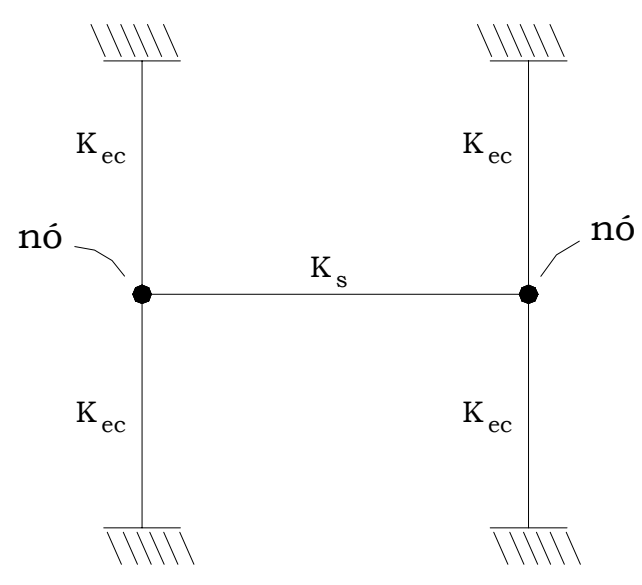

b) Esquema do modelo de pórtico plano

Figura 4.8 - Configurações para os modelos tridimensional (a) e plano (b) (Adaptado de CANO \& KLINGNER [1988])

Onde,

$\mathrm{K}_{\mathrm{c}} \quad$ é a rigidez à flexão do pilar, em momento por rotação unitária;

$\mathrm{K}_{\mathrm{s}} \quad$ é a rigidez à flexão da laje, em momento por rotação unitária; 
$\mathrm{K}_{\mathrm{t}}$ é a rigidez à torção devida aos elementos transversais, em momento por rotação unitária;

$\mathrm{K}_{\mathrm{ec}}$ é a rigidez à flexão do pilar equivalente, em momento por rotação unitária.

$\mathrm{Na}$ figura 4.8, pode-se observar a diferença da utilização da análise tridimensional com as variáveis $K_{s}, K_{t}$ e $K_{c}$ e da análise plana, que, conforme descrito anteriormente, a parcela de torção é somada a uma parcela da rigidez dos pilares, acima e abaixo do nó e posteriormente inserida em uma variável $\mathrm{K}_{\mathrm{ec}}$.

A rigidez de cada elemento estrutural é considerada para que se tenha o valor dos momentos atuantes no pavimento. Tem-se que a restrição à rotação da laje é devida tanto à rigidez do pilar à flexão quanto à rigidez à torção da faixa transversal.

O pilar equivalente pode ser tomado como a soma da rigidez do pilar (acima e abaixo do pavimento) com a rigidez à torção da faixa transversal, logo:

$\frac{1}{\mathrm{~K}_{\mathrm{ec}}}=\frac{1}{\sum \mathrm{K}_{\mathrm{c}}}+\frac{1}{\mathrm{~K}_{\mathrm{t}}} \quad$ (em termos da flexibilidade)

$\mathrm{K}_{\mathrm{ec}}=\frac{\sum \mathrm{K}_{\mathrm{C}}}{\left(1+\frac{\sum \mathrm{K}_{\mathrm{C}}}{\mathrm{K}_{\mathrm{t}}}\right)} \quad$ (em termos diretamente da rigidez)

Tem-se que a rigidez à flexão do pilar é dada por:

$$
\mathrm{K}_{\mathrm{C}}=\frac{4 . \mathrm{E} \cdot \mathrm{I}}{\mathrm{L}}
$$

Ainda, de acordo com NAWY [1996], a equação da rigidez à flexão do pilar pode ser escrita em função do engastamento dos pilares abaixo e acima do nó e de suas inércias.

$$
\sum \mathrm{K}_{\mathrm{c}}=\frac{4 \cdot \mathrm{E} \cdot \mathrm{I}_{\mathrm{pi}}}{\mathrm{L}_{\mathrm{i}}-2 \cdot \mathrm{h}_{\mathrm{eq}}}+\frac{4 \cdot \mathrm{E} \cdot \mathrm{I}_{\mathrm{ps}}}{\mathrm{L}_{\mathrm{s}}-2 \cdot \mathrm{h}_{\mathrm{eq}}}
$$

Onde, 
$\mathrm{I}_{\mathrm{pi}} \quad$ é o momento de inércia à flexão do pilar inferior à laje;

$\mathrm{I}_{\mathrm{ps}} \quad$ é o momento de inércia à flexão do pilar superior à laje;

$\mathrm{L}_{\mathrm{i}} \quad$ é a comprimento do pilar (pé-direito) inferior à laje;

$\mathrm{L}_{\mathrm{i}} \quad$ é a comprimento do pilar (pé-direito) superior à laje;

$h_{\text {eq }} \quad$ é a espessura da laje maciça equivalente.

A rigidez à torção da faixa transversal é dada por:

$$
\mathrm{K}_{\mathrm{t}}=\sum\left\{\frac{\text { 9.E.C }}{\left[\mathrm{L}_{2} \cdot\left(1-\frac{\mathrm{c}_{2}}{\mathrm{~L}_{2}}\right)^{3}\right]}\right\}
$$

Onde,

C é a constante da seção transversal da faixa da laje transversal corresponde a:

$$
C=\frac{x^{3} \cdot y}{3} \cdot\left(1-0,63 \cdot \frac{x}{y}\right)
$$

Onde,

$\mathrm{x}, \mathrm{y}$ correspondem, respectivamente, à menor e à maior dimensão da seção transversal da faixa da laje.

Para a análise de cada pórtico é considerado o carregamento total. A distribuição dos momentos é deita da seguinte forma:

- $45 \%$ de momentos positivos para as duas faixas internas;

- $27,5 \%$ dos momentos positivos para cada uma das faixas externas;

- $25 \%$ dos momentos negativos para as duas faixas internas;

- $37,5 \%$ dos momentos negativos para cada uma das faixas externas.

De acordo com o ACI 318-99, quando a sobrecarga for superir a $75 \%$ da carga permanente, tem-se:

- Carga permanente atuando em todos os vãos e $75 \%$ da carga acidental atuando em vãos alternados para determinarem-se os momentos positivos;

- Carga permanente atuando em todos os vãos e $75 \%$ da carga acidental atuando em vãos adjacentes ao apoio onde se quer determinar o valor do momento negativo. 


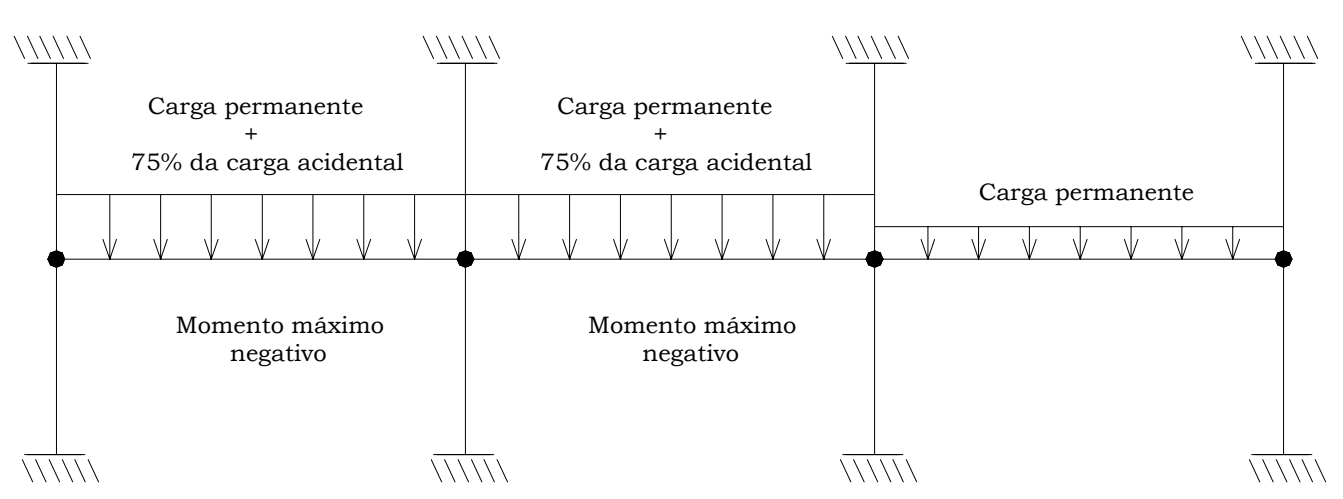

Figura 4.9 - Combinações de carregamento no pórtico para determinação dos momentos máximos negativos

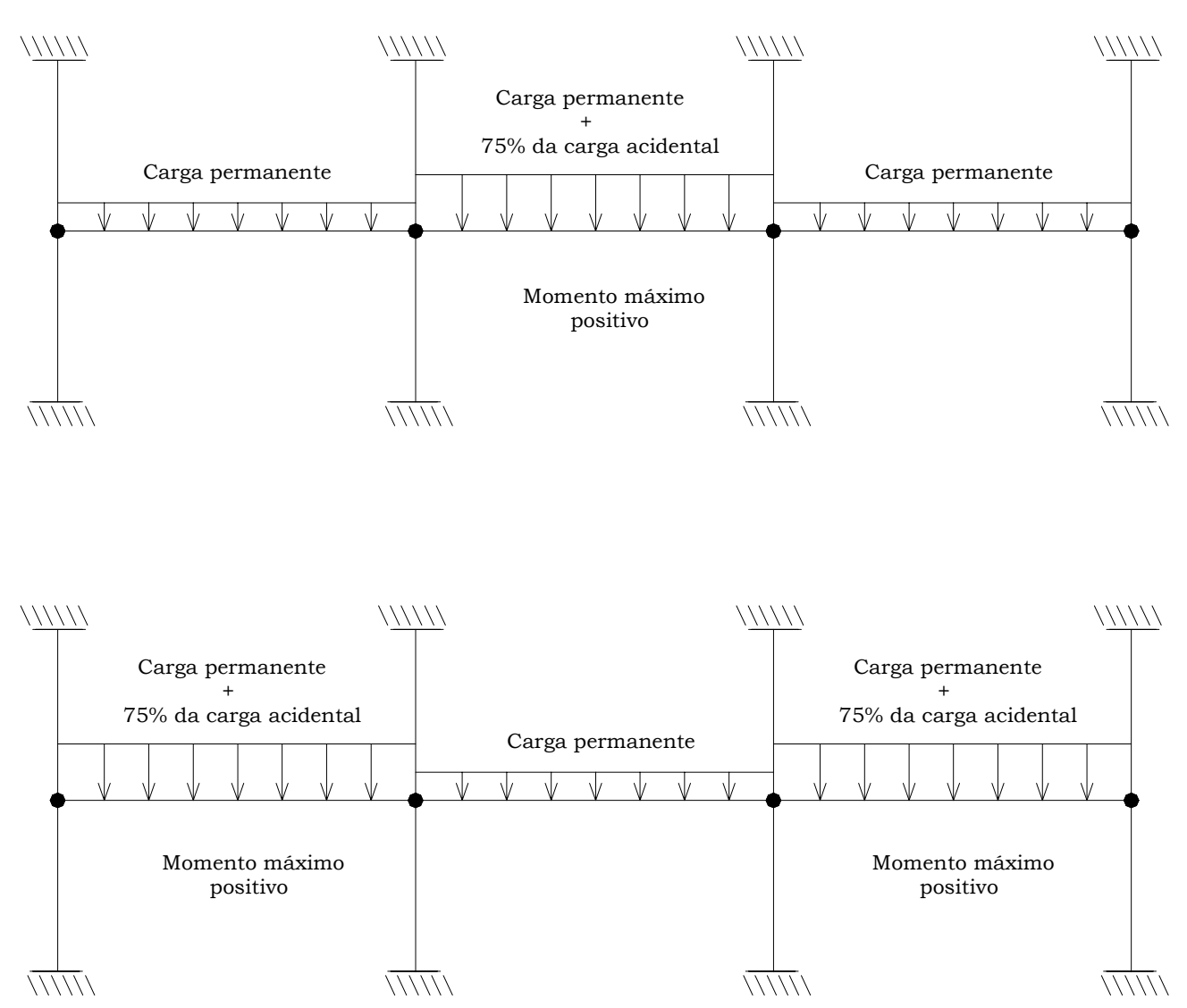

Figura 4.10 - Combinações de carregamento no pórtico para determinação dos momentos máximos positivos

A força axial exercida sobre os pilares deve ter atenção especial, pois para o cálculo de cada pórtico, é adotado o carregamento total, o que significa que o pavimento está sendo duas vezes carregado na análise dos pórticos, recomenda-se então que seja tomada a média das forças obtidas 
em cada pilar pertencente a dois pórticos distintos (VANDERBILT \& CORLEY [1983]).

Vale ressaltar que, em nenhum instante, qualquer seção deve ter esforços inferiores àqueles causados pelo carregamento total que atua em todos os vãos da laje simultaneamente.

Os momentos positivos e negativos nas seções críticas, obtidos no cálculo dos pórticos, devem ser distribuídos para as faixas dos pilares e faixas centrais com os mesmos coeficientes do método direto.

Embora seja um método muito utilizado, ele apresenta algumas desvantagens, sob o ponto de vista dos projetistas (CANO \& KLINGNER [1988]):

- Necessidade de estimar as rigidezes $K_{t}, K_{s}, K_{c}$ e $K_{e c}$, que mesmo calculadas por computador, consomem tempo;

- O método é aplicável apenas a subestruturas de um pavimento.

\section{3 - Método da Análise por Grelha}

A análise por grelha é um procedimento simples que pode ser usado de maneira satisfatória para o cálculo dos esforços e de deslocamentos decorrentes da aplicação de carregamentos no pavimento de edifícios. No caso de lajes sem vigas (lajes cogumelo ou lisas), este método apresenta resultados coerentes com os demais métodos.

O método consiste em substituir a placa (laje) por uma grelha equivalente de elementos do tipo barra onde cada uma representa uma faixa determinada da laje conforme a abertura escolhida para a malha (no caso da protensão, nestas barras estarão compreendidas as cordoalhas na faixa escolhida). Na figura 4.11, pode-se ver um pavimento com a representação da analogia de grelha. 


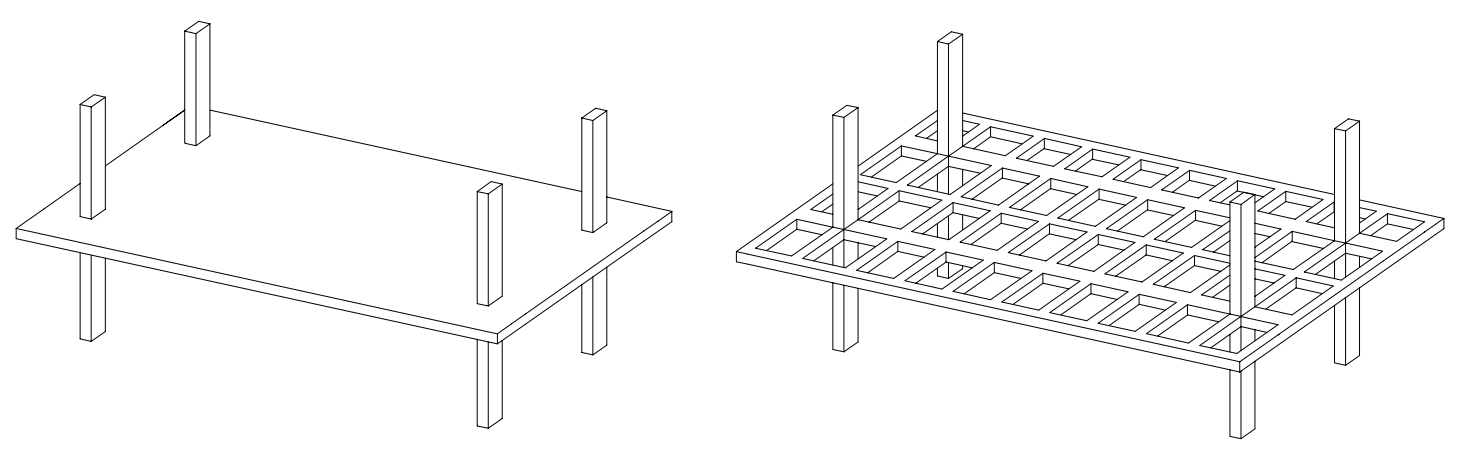

Figura 4.11 - Laje genérica e grelha respectiva

Segundo HAMBLY [1976], a analogia de estruturas por grelha é a mais popular, por ser de fácil compreensão e utilização, e, além disso, este processo proporciona excelentes resultados, muito próximos da resposta natural da estrutura.

Este método foi inicialmente utilizado em computadores por LIGHTFOOT \& SAWKO [1959]. A idéia é que a rigidez longitudinal da laje é concentrada em barras longitudinais da peça, enquanto a rigidez transversal é concentrada nas barras transversais. Segundo os autores, "a rigidez da barra tem de ser tal que quando a laje maciça e a grelha equivalente estão sujeitas a ações idênticas, as duas estruturas deverão deslocar identicamente, e os momentos fletores, momentos torçores e forças cortantes em qualquer que seja a malha da grelha, sejam iguais as resultantes de tensão na seção transversal da parte da laje representada pela barra".

De acordo com HAMBLY [1976], o equilíbrio de qualquer elemento da laje requer que os momentos volventes sejam iguais nas direções ortogonais, pois $\tau_{\mathrm{xy}}=\tau_{\mathrm{yx}}$.

Os deslocamentos na malha da grelha são melhor aproximados com o refinamento da malha, ou seja, quanto maior a discretização da grelha em barras, mais regular será a superficie deslocada (figura 4.12a), com as torções sendo praticamente iguais (isso se as rigidezes à torção forem as mesmas nas duas direções). Se o refinamento da malha for pequeno, isso resultará em deslocamentos com uma superficie não regular (figura 4.12b) e com momentos torçores não necessariamente iguais nas duas direções. Mas, ainda assim, geralmente uma discretização sem muito refinamento é 
suficiente para o projeto estrutural (HAMBLY [1976]), sob o ponto de vista prático.

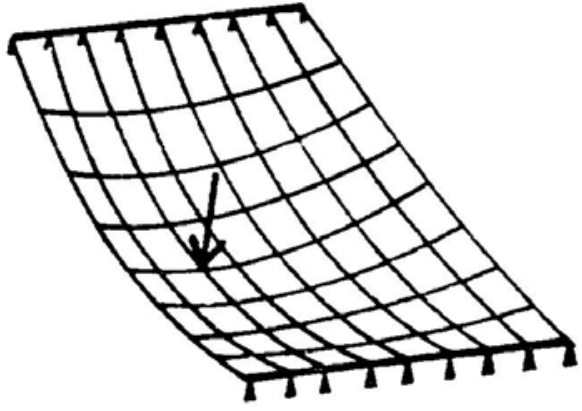

(a)

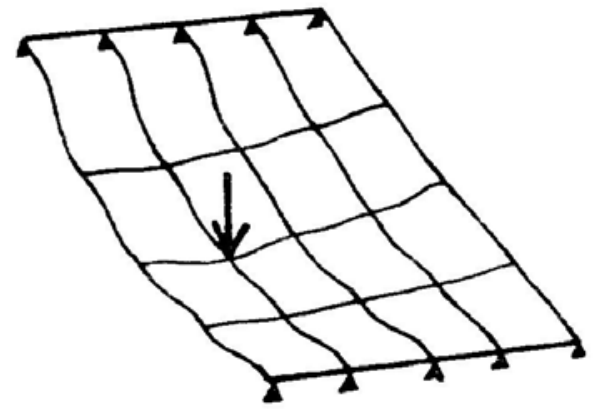

(b)

Figura 4.12 - Variação da superficie dos deslocamentos nas grelhas (HAMBLY [1976])

Um problema que ocorre é que o momento fletor, em qualquer barra, é somente proporcional à sua curvatura, enquanto que, na laje, o momento em qualquer direção depende tanto da curvatura nessa direção quanto da curvatura na direção ortogonal. Contudo, comparando-se os resultados obtidos com essa analogia e com o método dos elementos finitos, pode-se afirmar que a analogia de grelha fornece resultados satisfatórios (BARBOZA [1992]).

A vinculação das barras permite a interação de forças ortogonais ao plano da grelha e de dois momentos em torno dos eixos pertencentes a esse plano por nó da barra. Cada nó apresenta três graus de liberdade, sendo uma translação ortogonal e duas rotações no plano do pavimento.

As cargas aplicadas na placa são distribuídas entre os elementos de grelha equivalente, de acordo com a área de influência de cada uma, utilizando para a distribuição, por exemplo, o critério das linhas de plastificação ou charneiras plásticas. Podem ser consideradas uniformemente distribuídas ao longo dos elementos, ou dentro de um certo grau de aproximação, concentradas nos nós quando há grande refinamento da discretização. Neste caso, pode-se utilizar o processo de áreas de influência (figura 4.13) onde, cada carga, a uma distância menor ou igual a metade do comprimento da barra, em ambas as direções, é levada diretamente ao nó, ou seja: 


$$
\mathrm{Q}_{\mathrm{i}}=(\mathrm{g}+\mathrm{q}) \cdot \mathrm{A}_{\mathrm{i}}
$$

Onde,

g é a carga permanente aplicada na laje, por metro quadrado;

q é a carga acidental aplicada na laje, por metro quadrado;

$\mathrm{A}_{\mathrm{i}} \quad$ é a área de influência do nó $\mathrm{i}$;

$\mathrm{Q}_{\mathrm{i}} \quad$ é a carga aplicada no nó i da grelha.

No caso das cargas concentradas, elas devem ser aplicadas diretamente sobre os nós.
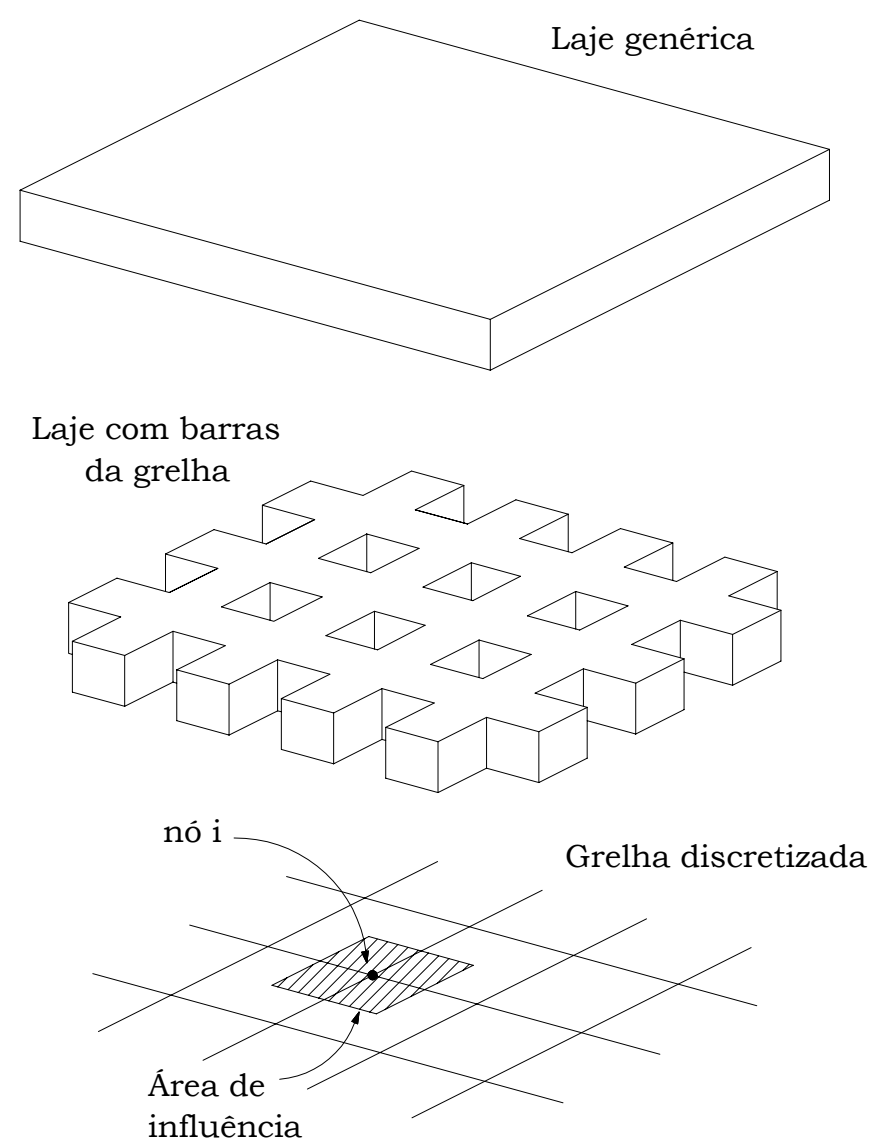

Figura 4.13 - Área de influência para cada faixa na analogia por grelha

A rigidez à torção e à flexão nas duas direções é tratada como concentradas nos elementos (barras) da grelha equivalente. Devem ser adotados valores tais que a placa e a grelha equivalente, submetida ao mesmo carregamento, possuam deslocamentos de modo idêntico e os mesmos esforços internos. 
$\mathrm{Na}$ definição da malha, não existe um processo determinístico que conduza sempre à malha adequada, havendo então algumas regras que devem ser obedecidas e adaptadas para cada situação (TAKEYA [1985]).

- Para placas isótropas, cada barra deve ter largura de no máximo igual a $1 / 4$ do vão transversal ao seu eixo (vide figura 4.15);

$$
\mathrm{b}_{\mathrm{x}}=1 \mathrm{x} / 4 \quad \mathrm{~b}_{\mathrm{y}}=1 \mathrm{y} / 4
$$

- Para placas ortótropas, na direção da menor inércia, deve-se considerar a largura das barras no máximo igual a 40\% do vão transversal ao seu eixo;

- Quanto menores forem a largura e o comprimento da barra, isto é, quanto mais densa a malha, melhores serão os resultados. Entretanto, essa melhora acontece quando a largura das barras for menor que 2 ou 3 vezes a espessura da placa;

- Para a parte da laje em balanço é necessário alocar pelo menos duas barras transversais em seu vão (ver figura 4.14);

- Para locais onde a concentração de esforços é muito grande, tais como apoios ou junto a cargas concentradas, é recomendável dispor uma malha cuja largura das barras não seja superior a 3 ou 4 vezes a espessura da placa;

- Orifícios na laje cuja maior dimensão não seja superior a 3 vezes a espessura da laje (h), não precisam ser discretizados, salvo no caso de se encontrarem muito próximos dos pilares, interrompendo assim o fluxo de cargas para os apoios (para o caso de se ter abertura superior a 3 vezes a espessura da laje, deve-se considera-la esta como borda livre).

- Deve-se colocar uma linha de barras no contorno livre da laje, cuja largura para o cálculo do momento de inércia à torção seja diminuído de $0,3 . h$, onde $h$ é a espessura da laje, por se tratar da região por onde passa a resultante das tensões de cisalhamento devidas à torção; 


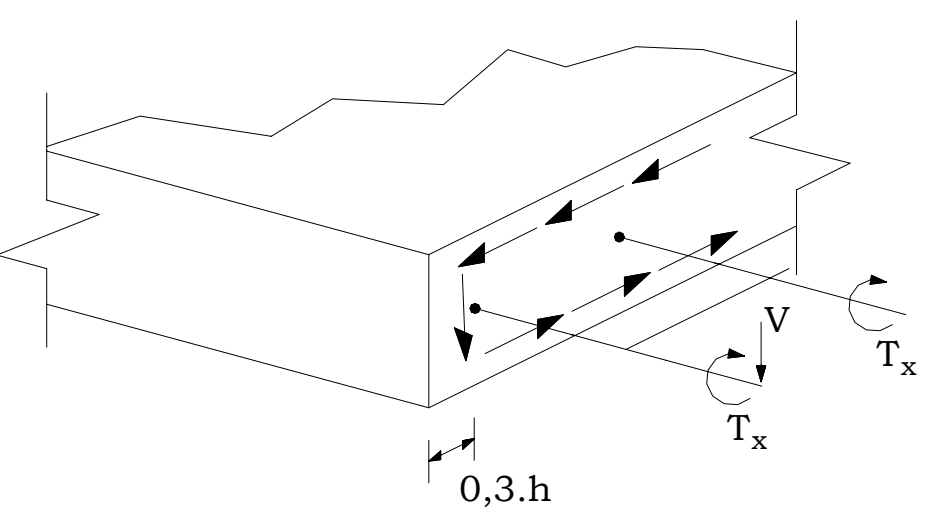

Figura 4.14 - Detalhe da barra de extremidade, adaptado de HAMBLY [1976]

As propriedades geométricas dos elementos da grelha podem ser consideradas a partir de uma faixa de largura b, igual à soma da metade dos espaços dos elementos vizinhos, e da espessura h da laje. Logo:

- $\quad$ Momento de inércia à flexão:

$$
I=\frac{b \cdot h^{3}}{12}
$$

- Momento de inércia à torção

Para um retângulo com dimensões $b$ e $h$ (base $e$ altura, respectivamente), o momento de inércia à torção é dado por:

$$
C=\frac{3 \cdot b^{3} \cdot h^{3}}{10 \cdot\left(b^{2}+h^{2}\right)}
$$

Para uma barra de grelha que representa uma largura b de uma laje isótropa, tem-se:

$$
C=\frac{b \cdot h^{3}}{6}
$$

Mas, esse valor é o dobro do momento de inércia à flexão, logo, usase:

$$
\mathrm{C}=2 . \mathrm{I}
$$

Eq. (4.26) 
Nas lajes ortótropas, o momento de inércia à torção, por unidade de largura, deve ser igual em ambas as direções, logo:

$$
\mathrm{C}=2 \cdot \sqrt{\mathrm{I}_{\mathrm{x}}{ }^{\mathrm{I}} \mathrm{y}}
$$

Onde,

$\mathrm{I}_{\mathrm{x}} \quad$ é o momento de inércia à flexão, por unidade de largura, das barras na direção x;

$\mathrm{I}_{\mathrm{y}}$ é o momento de inércia à flexão, por unidade de largura, das barras na direção y;

Para uma linha de barras paralelas ao eixo x e com largura $b_{y}$, o valor de $\mathrm{C}_{\mathrm{x}}$ é dado por:

$$
C_{x}=b_{y} \cdot C
$$

$E$, para barras paralelas ao eixo y e com largura $b_{x}$, o valor de $C_{y}$ vale:

$$
\mathrm{C}_{\mathrm{y}}=\mathrm{b}_{\mathrm{x}} \cdot \mathrm{C}
$$

Para o caso das barras junto ao contorno livre da laje, que deve apresentar a largura da barra subtraída de 0,3.h, para as barras paralelas aos eixos $\mathrm{x}$ e $\mathrm{y}$, respectivamente, tem-se:

$$
\begin{gathered}
C_{x}=\left(b_{y}-0,3 \cdot h\right) \cdot C \\
e, \\
C_{y}=\left(b_{x}-0,3 \cdot h\right) \cdot C
\end{gathered}
$$




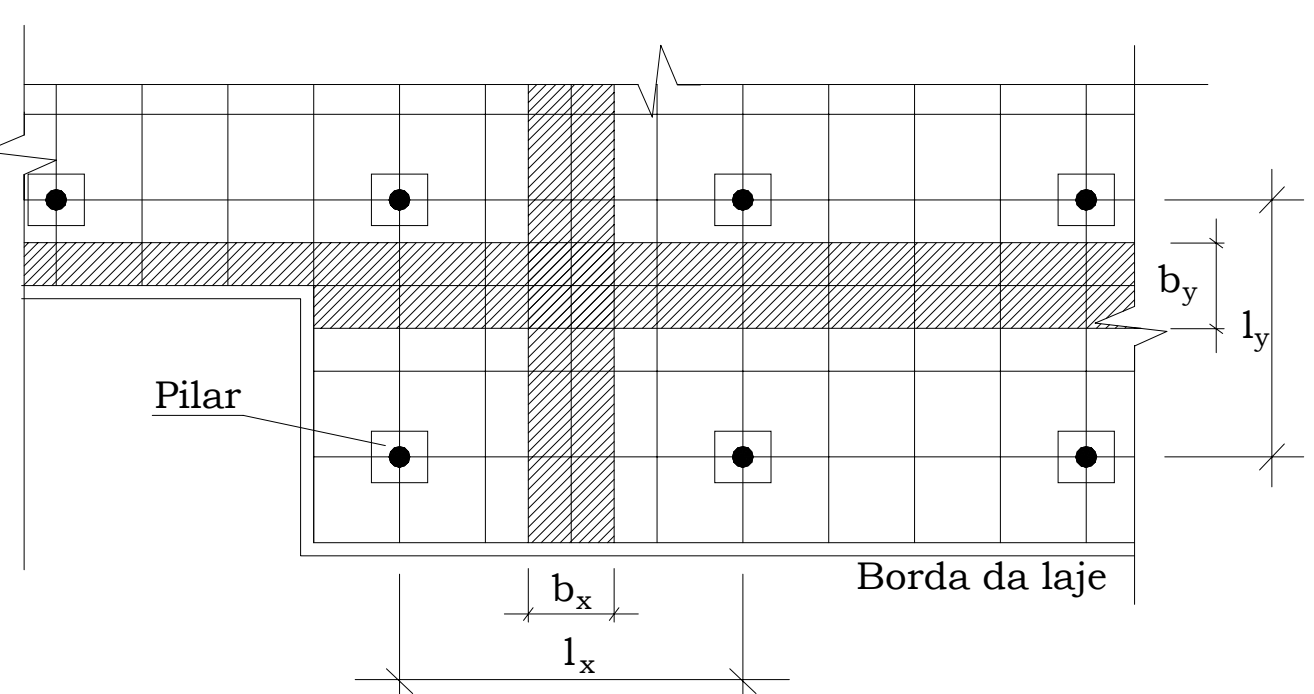

Figura 4.15 - Laje representada pela analogia de grelha

Quanto às características elásticas do concreto, deve-se fixar parâmetros que permitam avaliar com boa aproximação os deslocamentos que ocorrem na laje, bem como os esforços atuantes. De acordo com TAKEYA (1985), esta tarefa é muito dificil, uma vez que uma parte da laje está trabalhando no Estádio I e outra parte no Estádio II, somando-se a isso o efeito da retração e da deformação lenta do concreto. Mas, para um nível de pré-dimensionamento, após inúmeras observações, verificou-se que se pode ter uma avaliação razoavelmente segura das flechas. Associado a isso, a protensão fornece um estado de tensões prévio ao concreto fazendo com que a laje trabalhe no Estádio I com poucos trechos no Estádio II.

Para a determinação do módulo de deformação transversal do concreto $\left(\mathrm{G}_{\mathrm{c}}\right)$, TAKEYA (1985) adota uma redução de $85 \%$ em relação ao valor do módulo de elasticidade longitudinal do concreto $\left(\mathrm{E}_{\mathrm{c}}\right)$.

$$
\mathrm{G}_{\mathrm{C}}=0,15 \cdot \mathrm{E}_{\mathrm{C}}
$$

LEONHARDT (1978), adota uma redução de 95 \% em relação ao valor do módulo de elasticidade longitudinal do concreto $\left(E_{c}\right)$ para a inércia à torção.

Para a consideração da colaboração da laje na rigidez da viga, as deformações tanto na mesa quanto na viga, em sua intersecção (figura 4.16), devem ser as mesmas. Com isso, aparece uma força de intensidade $\mathrm{T}$ 
ao longo da ligação entre a laje e a viga, solicitando a laje como uma chapa e faz com que uma parte da laje contribua na rigidez da viga.

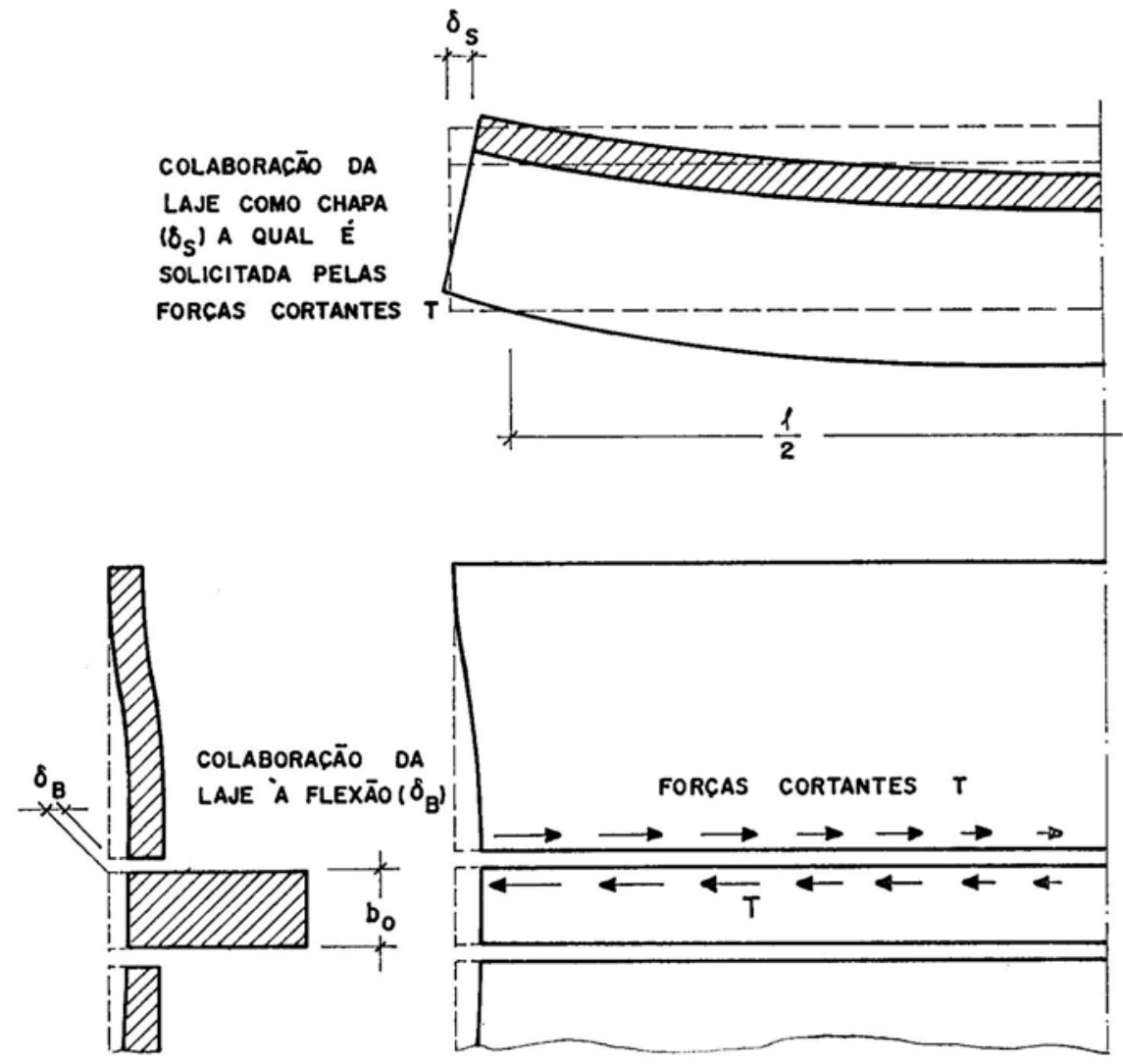

Figura 4.16 - Colaboração da laje na rigidez da viga (BARBOZA [1992])

Segundo LEONHARDT [1982], como a laje deforma menos que a viga, a linha neutra na seção transversal não é mais uma reta e sim, uma curva (figura 4.17), e, para a determinação exata da distribuição de tensões, é necessário que se solucione uma equação diferencial para a chapa formada na laje. 


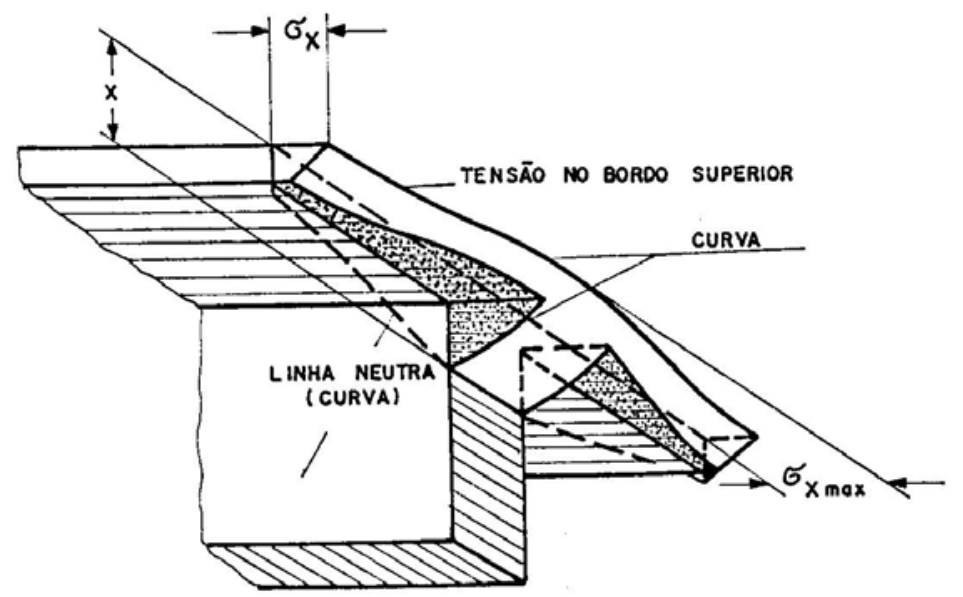

Figura 4.17 - Posição da linha neutra e das tensões de compressão (LEONHARDT [1982])

Porém, na prática, ao invés de um cálculo exato, adota-se uma distribuição das tensões (figura 4.18) de modo que a fibra superior da viga tenha deformação aproximadamente igual à força de compressão total da laje.

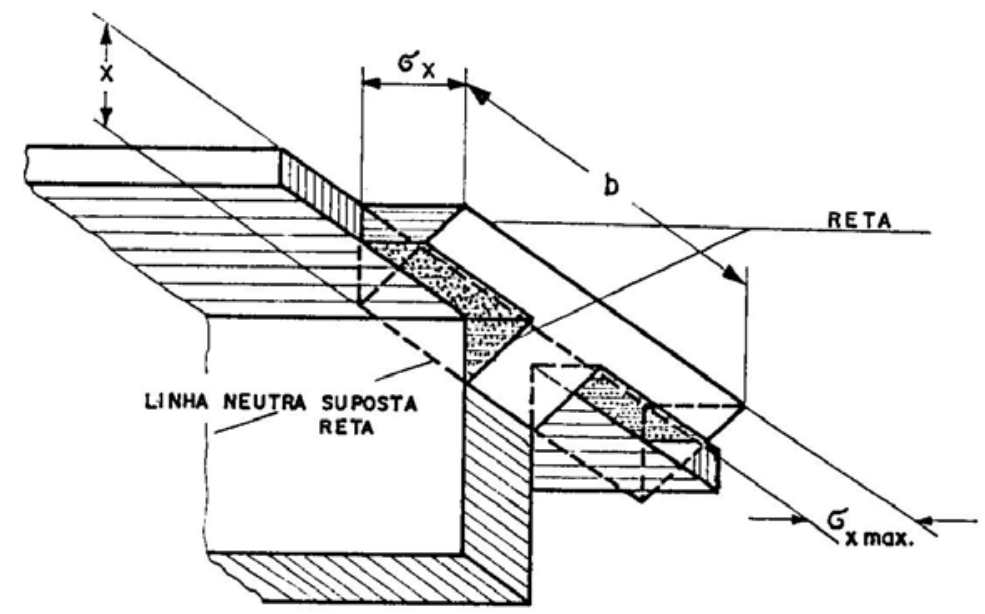

Figura 4.18 - Distribuição das tensões na largura colaborante b (LEONHARDT [1982])

\section{4 - Método dos Elementos Finitos}

O Método dos Elementos Finitos (MEF) consiste em uma subdivisão de uma estrutura, seja simples ou complexa, em uma série de elementos 
(ver figura 4.19) que, quando submetidos a ações horizontais e/ou verticais, apresentará uma resposta o mais próximo possivel do comportamento real da estrutura.
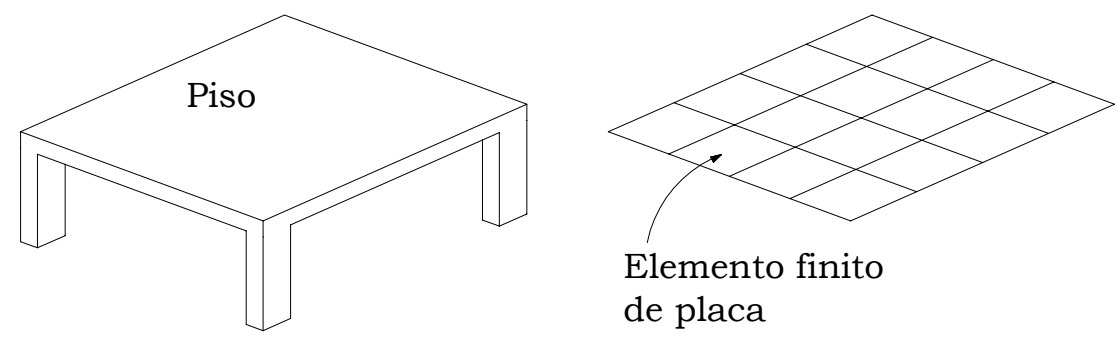

Elemento finito de placa

Figura 4.19 - Subdivisão de placa em elementos finitos

Na divisão da estrutura em elementos, cada um deles é formulado com o intuito de ser obter o comportamento da estrutura neste local, baseado em fatores tais como: as propriedades dos materiais, geometria, localização na estrutura e o seu relacionamento com os demais elementos que o circundam. A montagem do modelo matemático destes elementos em estruturas complexas permite então a resolução automática do comportamento da estrutura inteira de uma vez só. Este método possui larga aplicação e tem promovido a recriação da resposta natural de estruturas reais, se o modelo estrutural for bem formulado e a rede de elementos finitos for suficientemente densa. Pode ser matematicamente mostrado que uma solução bem refinada pelo MEF converge para uma solução exata com o aumento do número de elementos na malha (AALAMI \& BOMMER [1999]).

A maioria dos elementos finitos é baseado em campos de deslocamentos e campos de tensões definidos ou a combinação de ambos (método híbrido de tensões). Quase todas as recentes formulações do MEF para programas de análise de lajes (AALAMI \& BOMMER [1999]), usam o método híbrido de tensões, pois este conduz a resultados geralmente melhores na análise da flexão em lajes.

O Método dos Elementos Finitos apresenta uma série de vantagens com relação aos demais métodos de cálculo (CORRÊA [1991]), dentre os quais, pode-se citar: 
- Tratamento mais realista do pavimento, pois os carregamentos referentes a outros elementos constituintes do piso podem ser considerandos em sua posição real, sem necessitar, assim, de uma uniformização das cargas no painel;

- Facilidade de se modelarem aberturas em lajes e de formatos irregulares;

- Simulação automática da continuidade dos painéis;

- Grande saída de dados com informações sobre deslocamentos e esforços solicitantes de todo o sistema estrutural;

- Possibilidade de se trabalhar com elementos com espessuras e características variadas;

- Representação da rigidez relativa laje-viga-pilar, com influência significativa no fluxo de cargas pelo sistema estrutural, onde cargas oriundas das lajes são transferidas para as regiões mais rígidas das vigas, com uma parte sendo lançada diretamente sobre os pilares.

Vê-se na figura 4.20, um sistema estrutural em laje plana.

$\mathrm{Na}$ figura 4.21 pode-se ver os passos para a discretização de um pavimento em elementos finitos. O primeiro passo corresponde a adotar um pavimento genérico para a análise devida às ações verticais; o segundo consiste em separá-lo da estrutura para uma análise específica; o terceiro incorpora a determinação de suas características geométricas, suas condições de contorno e as características de carregamento, do perfil dos cabos (no caso de haver protensão) e os materiais utilizados; o quarto envolve a descrição da malha de elementos finitos para a análise do pavimento sob a ação das cargas verticais. 


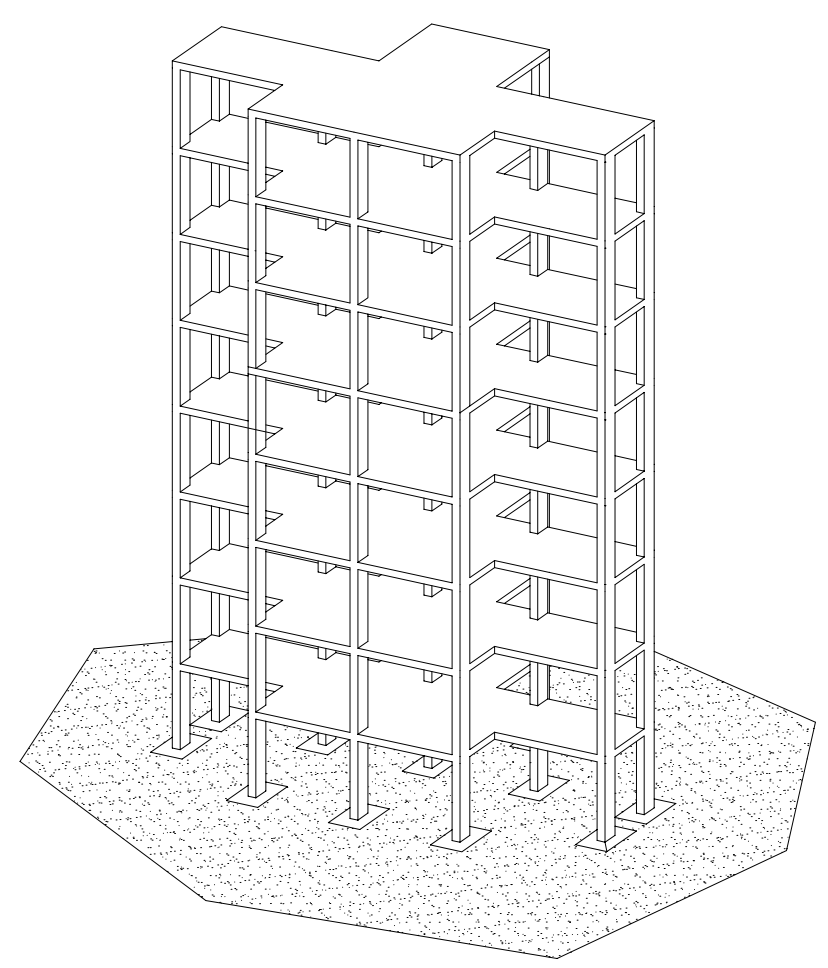

Figura 4.20 - Exemplo de modelo de edificio

O Método dos Elementos Finitos é uma ferramenta poderosa para a análise de elementos de concreto armado e protendido. Na literatura mundial, existem extensas pesquisas para a análise deste método em duas (2D) e três dimensões (3D). Para sistemas homogêneos elásticos envolvendo tensões e deformações planas, flexões de placas, cascas e sólidos podem ser bem vistos em ZIENKIEWICZ [1991] e TIMOSHENKO \& WOINOWSKYKRIEGER [1959]. 


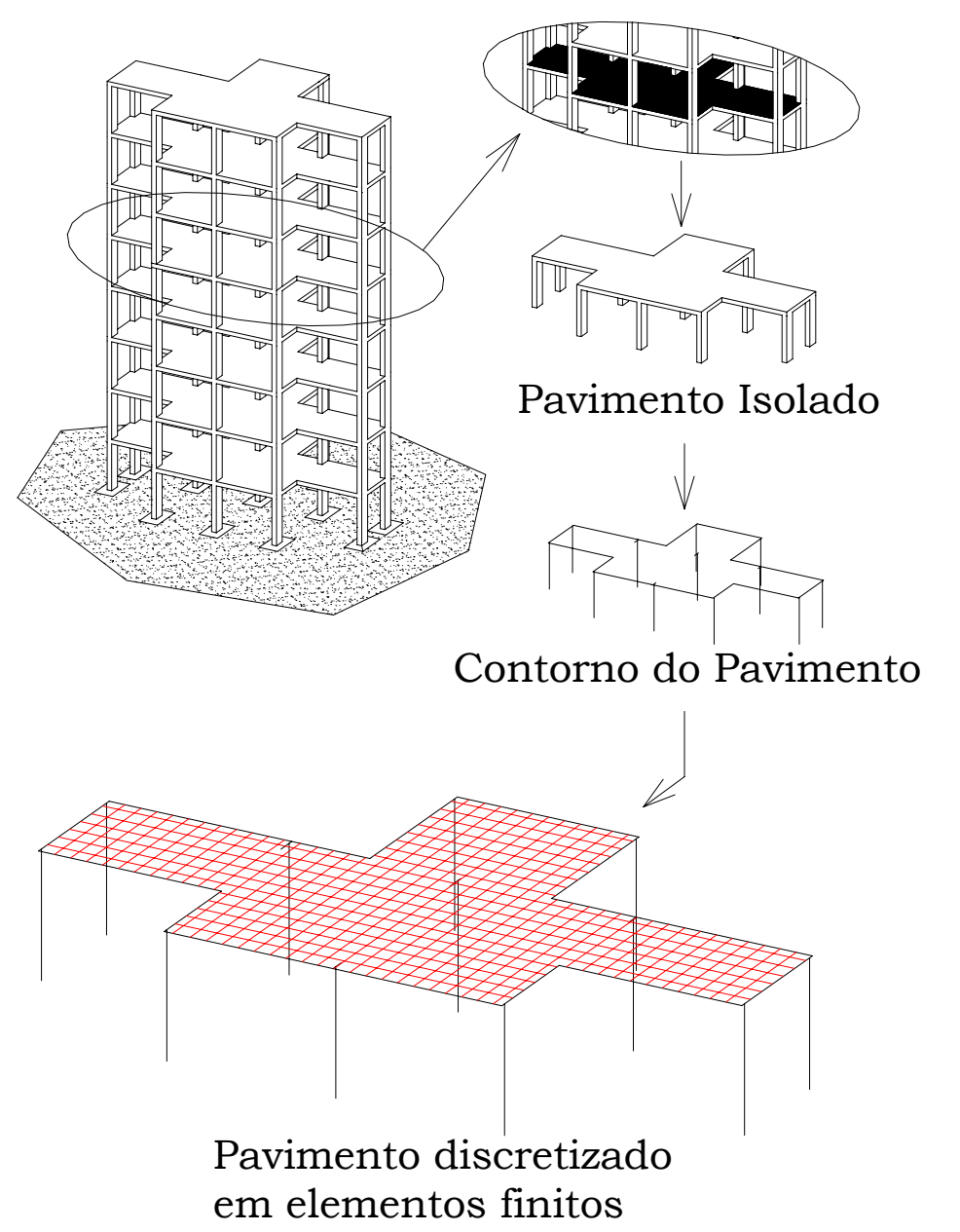

Figura 4.21 - Passos da discretização de um pavimento

\section{5 - Análise numérica de modelo experimental pelo Método dos Elementos Finitos}

Neste segmento, será mostrado um exemplo de laje com protensão não aderente ensaiada em laboratório.

O motivo desta análise é obter correlação entre resultados numéricos e experimentais.

\subsection{1 - Programa Utilizado}

O programa de elementos finitos a ser utilizado é o ANSYS 5.5.1® tendo sido adotados os seguintes elementos de placa, de casca e de barra de sua biblioteca de elementos. 
- SHELL63

- SHELL43

- BEAM4

\section{i) SHELL63}

Consiste em um elemento tridimensional quadrilateral ou triangular linear de placa.

Ele possui seis graus de liberdade em cada nó: translações e rotações nodais nos eixos $\mathrm{X}, \mathrm{Y}$ e $\mathrm{Z}$.

A figura 4.22 ilustra as coordenadas locais do elemento.

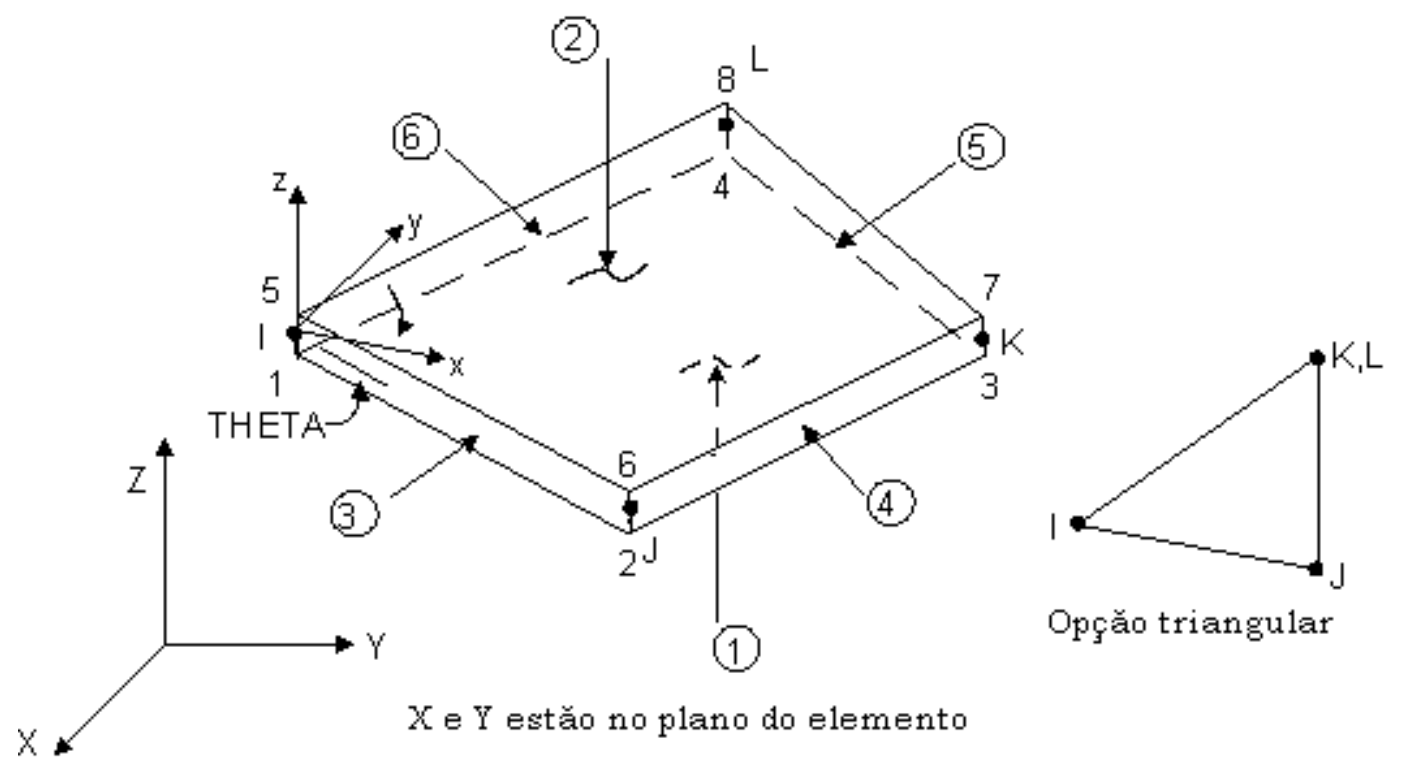

Figura 4.22 - Características geométricas do elemento SHELL63 (ANSYS®)

Este elemento apresenta as seguintes caracteristicas:

- O elemento se ajusta exatamente a uma laje lisa, porém, não é calculada nenhuma deformação devida ao esforço cortante, pois o elemento apresenta pequena espessura, com isso, a consideração da deformação devida ao esforço cortante não é significativa;

- Fornece como resultados, tensões, momentos $\mathrm{X}, \mathrm{Y}$ e XY, forças paralelas aos eixos $\mathrm{X}, \mathrm{Y}$ e $Z$, deslocamentos e deformações nos eixos X, Y e $Z$. 


\section{ii) SHELL43}

Semelhante ao SHELL63, este elemento de casca tridimensional pode assumir a forma quadrilateral ou triangular, linear ou não-linear. A maior diferença é que o SHELL43 incorpora deformações devidas ao esforço cortante.

Apresenta seis graus de liberdade em cada nó: translações e rotações nodais nos eixos $\mathrm{X}, \mathrm{Y}$ e $\mathrm{Z}$.

Pode incluir grandes deslocamentos, plasticidade, fluência e fissuração.

A figura 4.23 ilustra as características deste elemento.

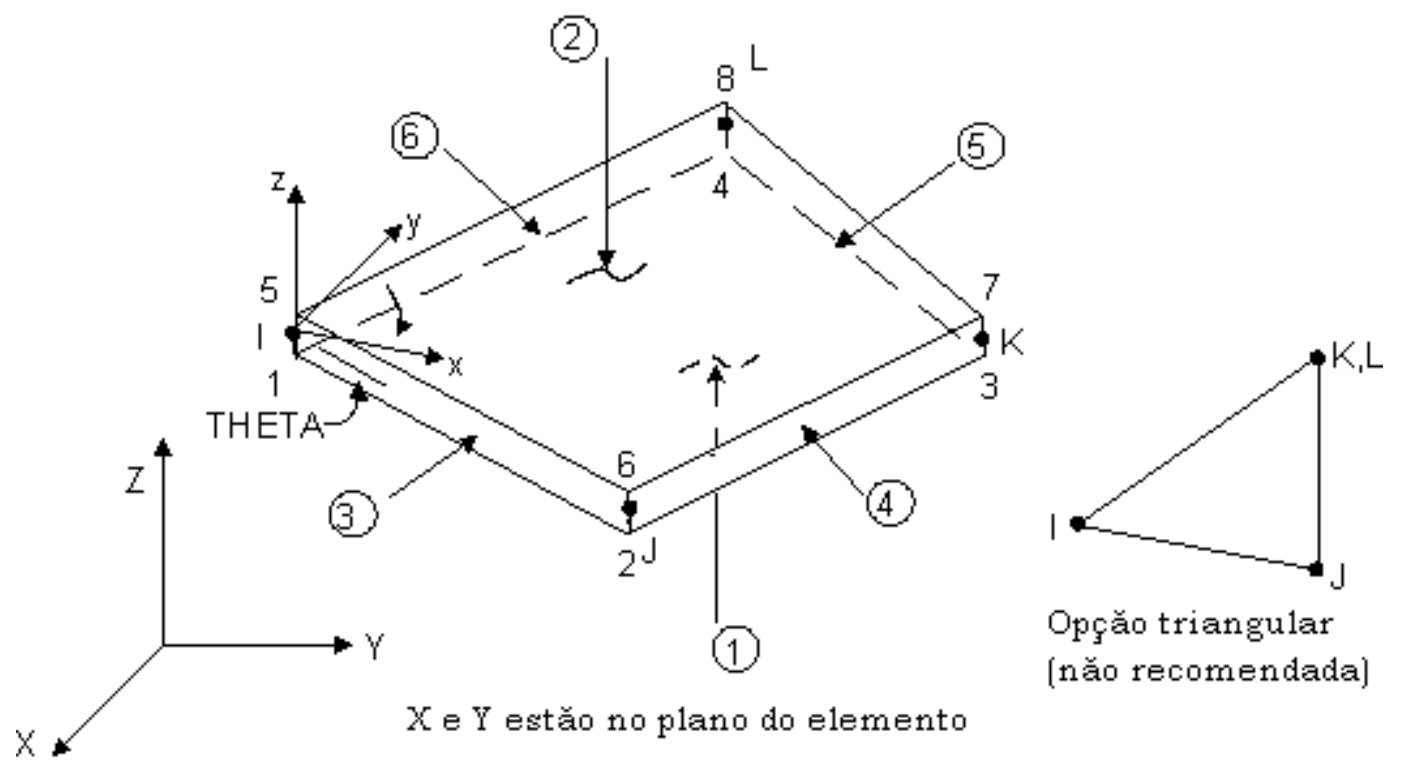

Figura 4.23 - Características geométricas do elemento SHELL43 (ANSYS®)

Este elemento apresenta as seguintes características:

- Elementos de forma triangular produzem resultados de qualidade inferior aos elementos de forma quadrilateral;

- As tensões normais variam linearmente ao longo da espessura do elemento;

- Os esforços cortantes são constantes ao longo da espessura do elemento;

- Fornece como resultados: tensões, momentos X, Y e XY, forças paralelas aos eixos X, Y e $Z$, esforços cortantes nas direções X e Y, deslocamentos e deformações nos eixos X, Y e Z. 


\section{iii) BEAM4}

É um elemento de barra uniaxial tridimensional que incorpora as análises de força normal, força cortante, momento fletor e torçor. Apresenta seis graus de liberdade em cada um dos nós de extremidade: translações e rotações nodais nos eixos $\mathrm{X}, \mathrm{Y}$ e $\mathrm{Z}$.

A figura 4.24 ilustra as características deste elemento.

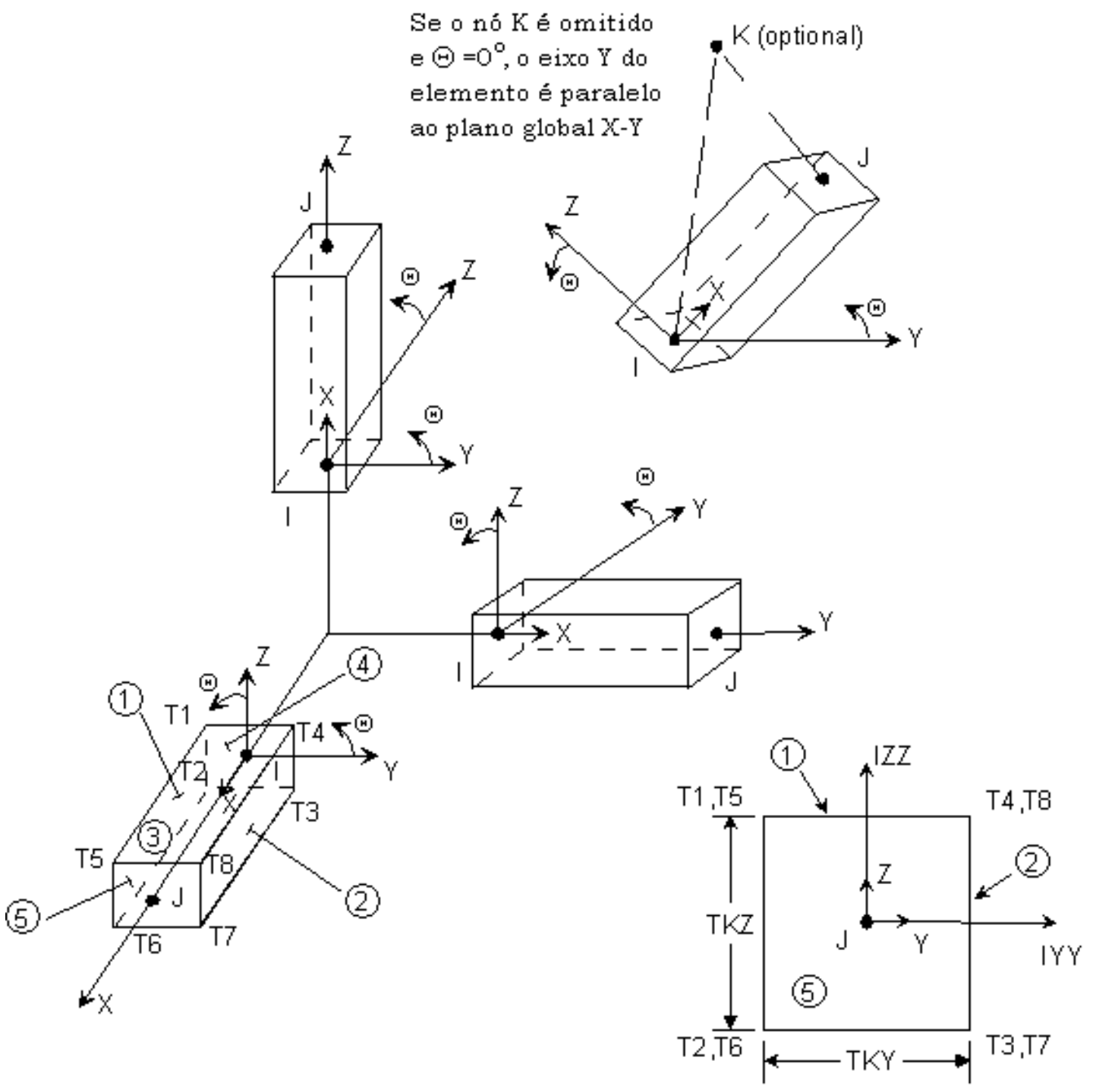

Figura 4.24 - Características geométricas do elemento BEAM4 (ANSYS®)

Apresenta as seguintes características:

- A altura e a largura do elemento somente são utilizadas para o cálculo das tensões devidas ao momento fletor e tensões devidas à temperatura; 


\subsection{2 - Influência da Protensão}

Foram utilizados dois processos para a verificação da influência da protensão no pavimento: o balanceamento de carga por área de influência de cordoalha, isto é, a força de protensão para o equilíbrio aplicado por unidade de área (ver figura 4.30) e o balanceamento por reação da componente de protensão nas intersecções dos cabos, ou seja, para a carga balanceada $q$ ao longo da cordoalha serão calculadas suas reações nas intersecções das cordoalhas, obtendo uma força resultante vertical (ver figura 4.29).

SCORDELIS et al. [1959] realizaram ensaios em uma laje plana com protensão não aderente. Foram feitas diversas verificações em seus ensaios, sendo elas baseadas em combinações de carga até a ruptura. Nestas verificações, o objetivo era o de estudar a distribuição dos momentos e flechas, além de observar o comportamento da laje sob uma série de carregamentos variados.

Pode-se ver na figura 4.25 um esquema do modelo ensaiado pelos autores.

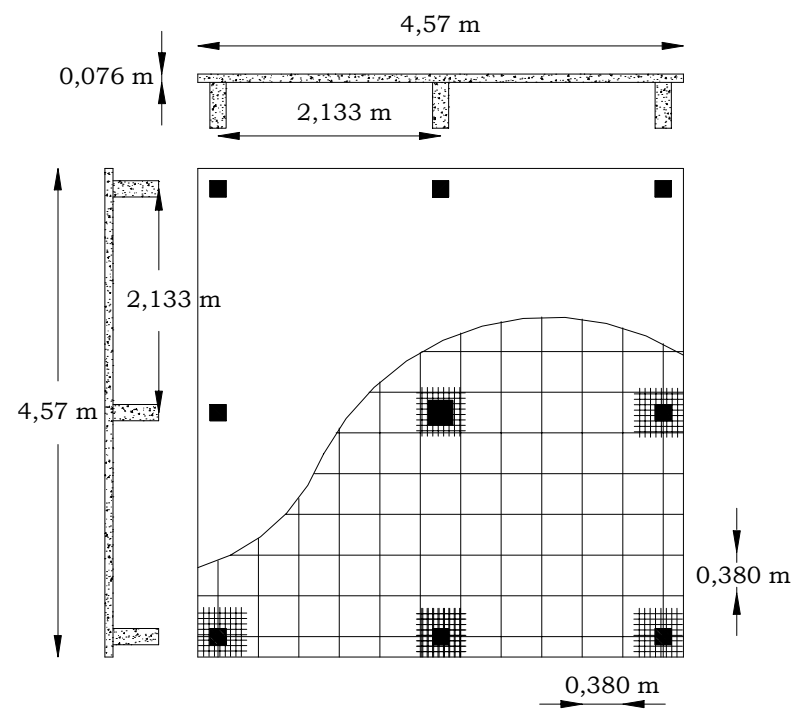

Figura 4.25 - Modelo de SCORDELIS et al. [1959]

Para a modelagem, foram adotados os mesmos carregamentos utilizados pelos autores, bem como as forças de protensão e as características do concreto. 
A carga equivalente de protensão foi calculada segundo o método de LIN [1963] para balanceamento de carga. Foram aplicadas forças nas intersecções das cordoalhas, referente ao carregamento equivalente distribuído no cabo, que será chamado de modelo 1. Adicionalmente foi realizado um segundo processamento, a aplicação da carga equivalente por área de influência da cordoalha, aqui chamado de modelo 2 .

O equilíbrio de cargas do pavimento foi dividido em três regiões, pois, o cabo possuía perfil parabólico e era distribuído nas duas direções, como mostrado na figura 4.26.

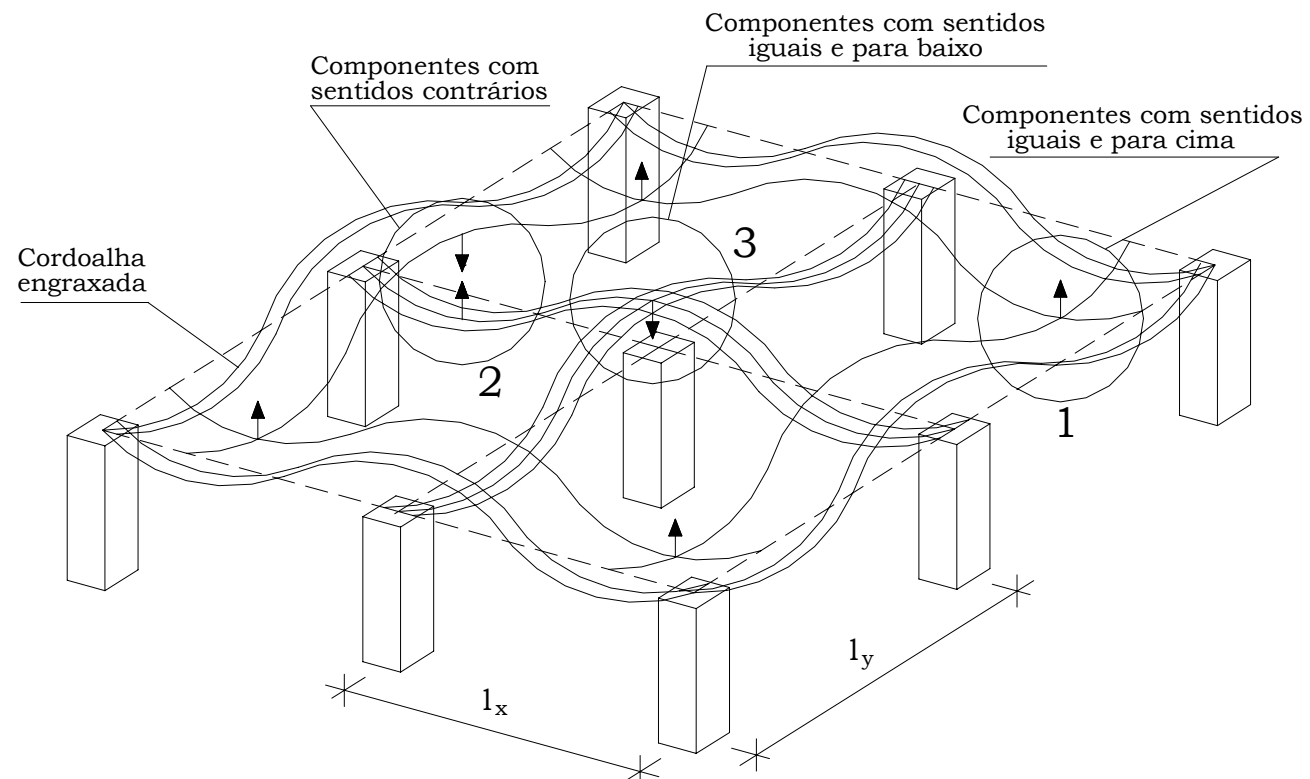

Figura 4.26 - Perfis de cabos parabólicos em lajes protendidas contínuas

A modelagem feita pode ser vista na figura 4.27 e 4.28 . 


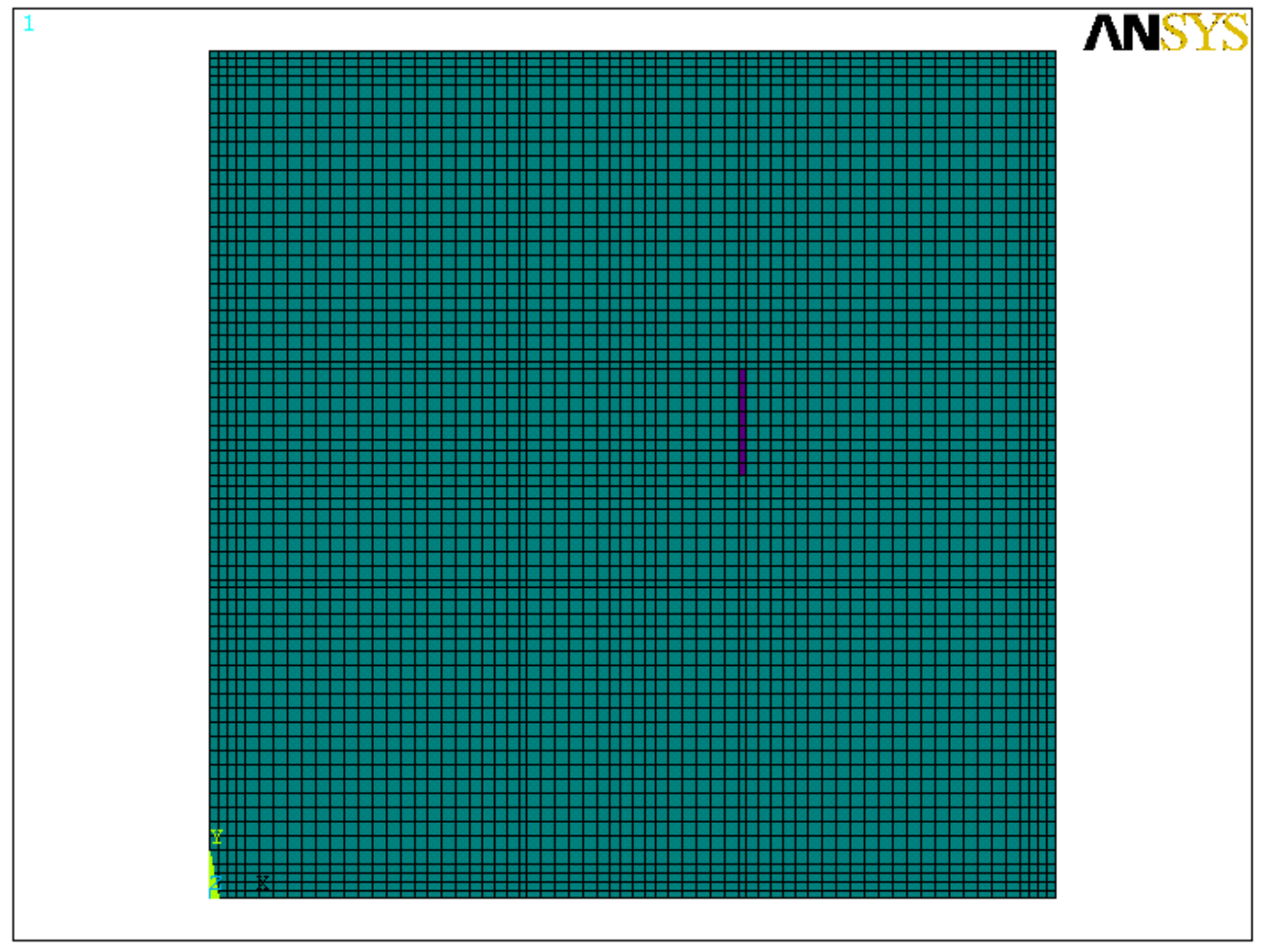

Figura 4.27 - Discretização em elementos finitos para o modelo de SCORDELIS et al. [1959]

É necessário calcular o valor das componentes referentes à protensão, para poder determinar o valor da forças nas intersecções dos cabos e nas suas áreas de influência (Ver figura 4.29).

\section{Dados:}

$\mathrm{P}=6840 \mathrm{lb} ; \mathrm{e}=1$ in.;

$\mathrm{s}=15$ in. (espaçamento das cordoalhas);

$1_{1}=66$ in. (comprimento do perfil com componente de protensão ascendente);

$1_{2}=48$ in. (comprimento do perfil com componente de protensão descendente);

Logo:

$\mathrm{W}_{\text {bal1 }}=\frac{8 . P . e}{1_{1}^{2}} \rightarrow \mathrm{W}_{\text {bal1 }}=\frac{8.6840(\mathrm{lb}) .1(\mathrm{in} .)}{66^{2}\left(\mathrm{in}^{2}\right)} \rightarrow \mathrm{W}_{\text {bal1 }}=12,562 \mathrm{lb} / \mathrm{in}$.

$\mathrm{W}_{\mathrm{bal} 2}=\frac{8 . \mathrm{P} . \mathrm{e}}{1_{2}^{2}} \rightarrow \mathrm{W}_{\mathrm{bal} 1}=-\frac{8.6840(\mathrm{lb}) \cdot 1 \text { (in.) }}{48^{2}\left(\mathrm{in}^{2}\right)} \rightarrow \mathrm{W}_{\mathrm{bal} 1}=-23,75 \mathrm{lb} / \mathrm{in}$.

Onde, 
$\mathrm{W}_{\text {bal1 é a componente de protensão ascendente; }}$

$\mathrm{W}_{\mathrm{bal} 2}$ é a componente de protensão descendente.

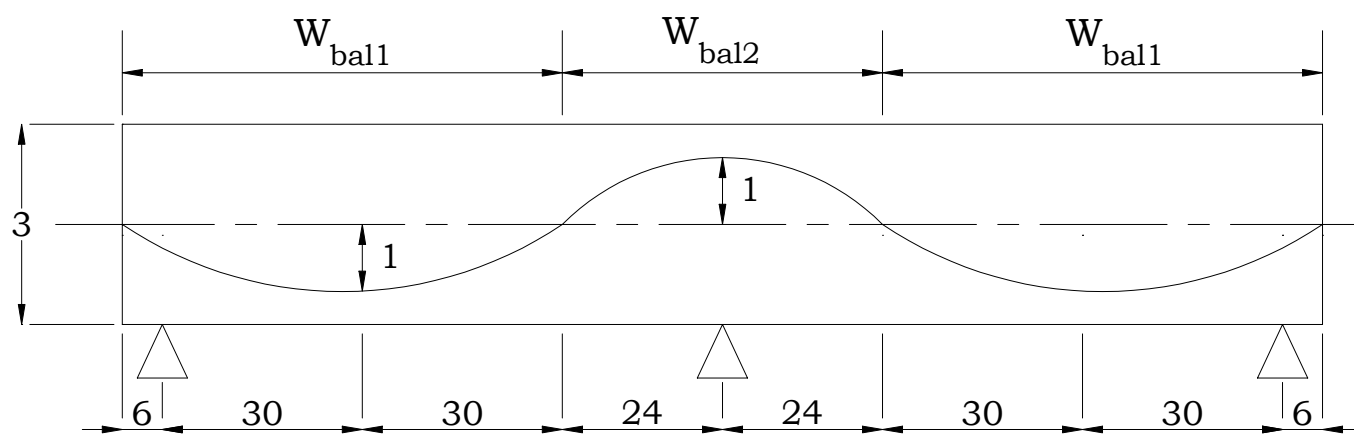

Medidas em polegadas $(1$ in. $=2,54 \mathrm{~cm})$

Figura 4.28 - Perfil da cordoalha adotado para as direções X e Y (adaptado de SCORDELIS et al. [1959])

$\mathrm{Na}$ figura 4.29, mostra-se o sistema de reações nodais aplicado ao pavimento, para simular o efeito da protensão ao longo da cordoalha.

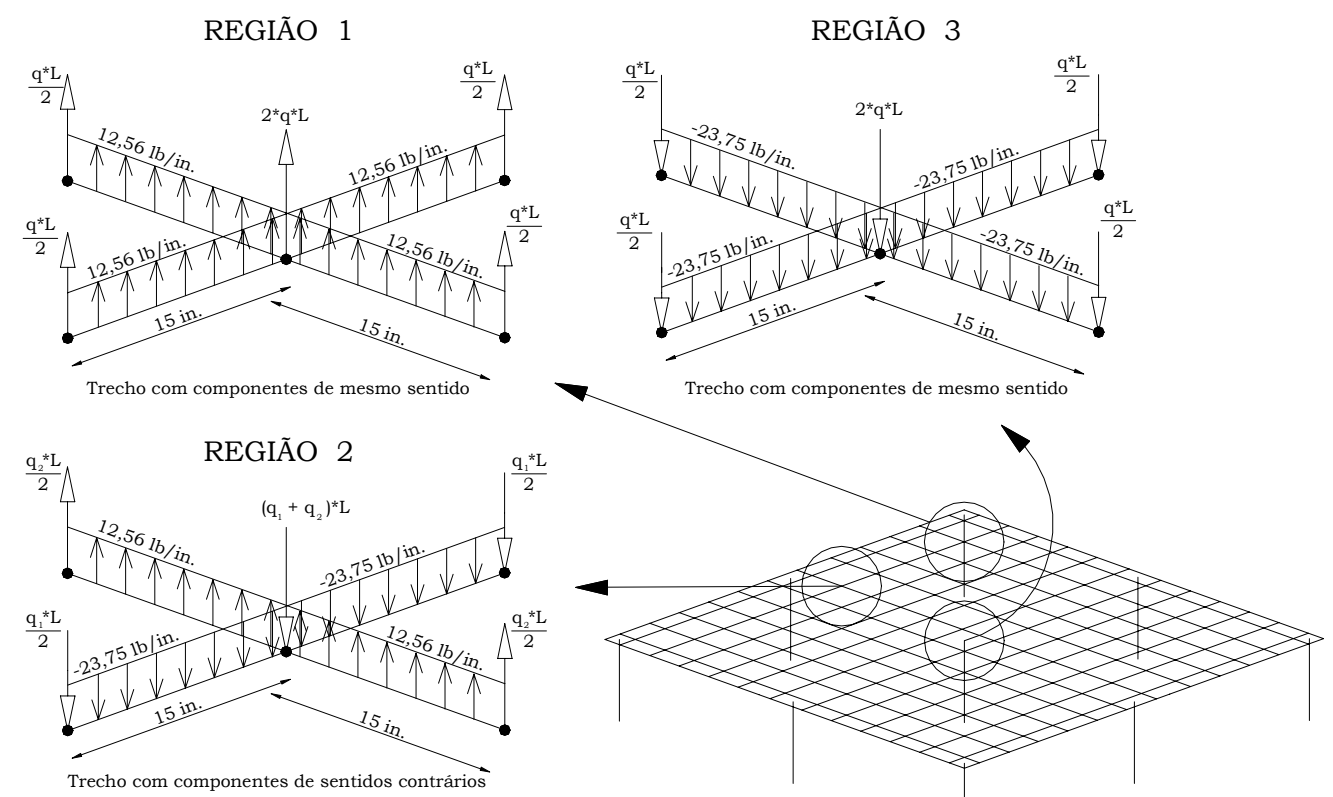

Figura 4.29 - Esquema de forças nodais nas intersecções dos cabos (Modelo 1)

Com isso, as forças nas intersecções dos cabos, ou seja, as componentes para o modelo 1 , serão iguais a: 


\section{Região 1:}

$$
\begin{aligned}
& \mathrm{W}_{1}=\mathrm{W}_{\text {bal }}(\mathrm{x}) \cdot \mathrm{s}_{\mathrm{x}}+\mathrm{W}_{\mathrm{bal}}(\mathrm{x}) \cdot \mathrm{s}_{\mathrm{x}}+\mathrm{W}_{\mathrm{bal}}(\mathrm{y}) \cdot \mathrm{s}_{\mathrm{y}}+\mathrm{W}_{\mathrm{bal}}(\mathrm{y}) \cdot \mathrm{s}_{\mathrm{y}} \rightarrow \mathrm{W}_{1}=\frac{12,56}{2}\left(\frac{\mathrm{lb}}{\mathrm{in} \cdot}\right) \cdot 15(\text { in. }) \\
& +\frac{12,56}{2}\left(\frac{\mathrm{lb}}{\text { in. }}\right) \cdot 15 \text { (in.) }+\frac{12,56}{2}\left(\frac{\mathrm{lb}}{\text { in. }}\right) \cdot 15(\text { in. })+\frac{12,56}{2}\left(\frac{\mathrm{lb}}{\text { in. }}\right) \cdot 15(\text { in. }) \rightarrow \mathrm{W}_{1}=376,86 \mathrm{lb}
\end{aligned}
$$

\section{Região 2:}

$\mathrm{W}_{2}=\mathrm{W}_{\text {bal }}(\mathrm{x}) \cdot \mathrm{s}_{\mathrm{x}}+\mathrm{W}_{\text {bal }}(\mathrm{x}) \cdot \mathrm{s}_{\mathrm{x}}+\mathrm{W}_{\text {bal }}(\mathrm{y}) \cdot \mathrm{s}_{\mathrm{y}}+\mathrm{W}_{\text {bal }}(\mathrm{y}) \cdot \mathrm{s}_{\mathrm{y}} \rightarrow \mathrm{W}_{2}=\frac{12,56}{2}\left(\frac{1 \mathrm{~b}}{\text { in. }}\right) \cdot 15$ (in.)

$+\frac{12,56}{2}\left(\frac{1 \mathrm{~b}}{\text { in. }}\right) \cdot 15($ in. $)-\frac{23,75}{2}\left(\frac{1 \mathrm{~b}}{\text { in. }}\right) \cdot 15($ in. $)-\frac{23,75}{2}\left(\frac{\mathrm{lb}}{\text { in. }}\right) \cdot 15($ in. $) \rightarrow \mathrm{W}_{2}=-167,82 \mathrm{lb}$

\section{Região 3:}

$$
\begin{aligned}
& \mathrm{W}_{3}=\mathrm{W}_{\text {bal }}(\mathrm{x}) \cdot \mathrm{s}_{\mathrm{x}}+\mathrm{W}_{\text {bal }}(\mathrm{x}) \cdot \mathrm{s}_{\mathrm{x}}+\mathrm{W}_{\mathrm{bal}}(\mathrm{y}) \cdot \mathrm{s}_{\mathrm{y}}+\mathrm{W}_{\mathrm{bal}}(\mathrm{y}) \cdot \mathrm{s}_{\mathrm{y}} \rightarrow \mathrm{W}_{3}=-\frac{23,75}{2}\left(\frac{\mathrm{lb}}{\mathrm{in} .}\right) \cdot 15(\mathrm{in} .) \\
& -\frac{23,75}{2}\left(\frac{1 \mathrm{~b}}{\text { in. }}\right) \cdot 15(\text { in. })-\frac{23,75}{2}\left(\frac{1 \mathrm{~b}}{\text { in. }}\right) \cdot 15(\text { in. })-\frac{23,75}{2}\left(\frac{\mathrm{lb}}{\text { in. }}\right) \cdot 15(\text { in. }) \rightarrow \mathrm{W}_{3}=-712,50 \mathrm{lb}
\end{aligned}
$$

Nas expressões anteriores, o sinal negativo indica componente com sentido igual ao da força da gravidade.

$\mathrm{Na}$ figura 4.30, mostra-se o sistema de forças por unidade área, referente à influência de cada cordoalha (modelo2).

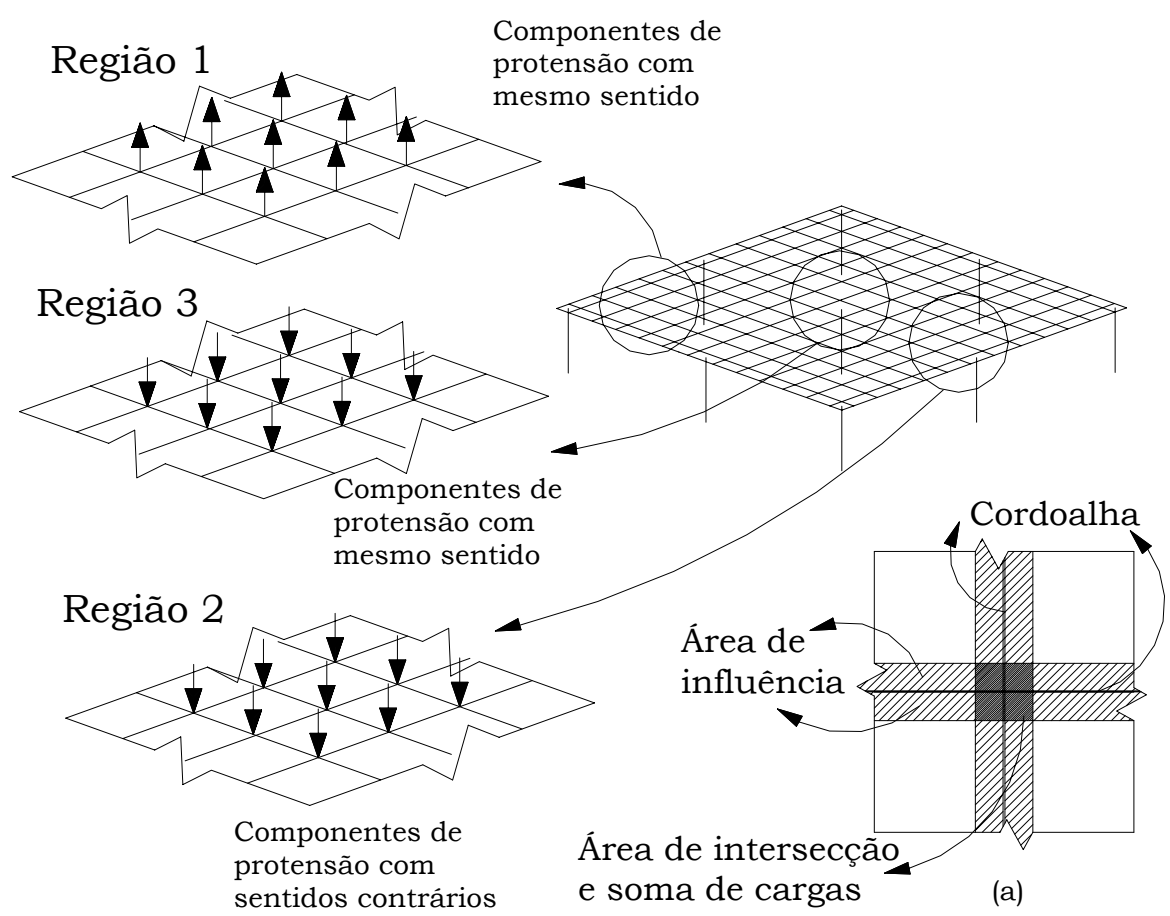

Figura 4.30 - Esquema de carregamento equivalente de protensão por unidade de área (Modelo 2) 
Com isso, os valores referentes a cada região, são:

\section{Região 1:}

$$
\begin{aligned}
& \mathrm{W}_{1}=\mathrm{W}_{\text {bal }}(\mathrm{x}) \cdot\left(\frac{1}{\mathrm{~s}_{\mathrm{y}}}\right)+\mathrm{W}_{\text {bal }}(\mathrm{y}) \cdot\left(\frac{1}{\mathrm{~s}_{\mathrm{x}}}\right) \rightarrow \mathrm{W}_{1}=12,56\left(\frac{\mathrm{lb}}{\mathrm{in}}\right) \cdot\left(\frac{1}{15(\text { in. })}\right)+12,56\left(\frac{\mathrm{lb}}{\text { in }}\right) \cdot\left(\frac{1}{15(\text { in. })}\right) \rightarrow \\
& \mathrm{W}_{1}=0,84+0,84 \rightarrow \mathrm{W}_{1}=1,66 \mathrm{psi}
\end{aligned}
$$

\section{Região 2:}

$\mathrm{W}_{2}=\mathrm{W}_{\text {bal }}(\mathrm{x}) \cdot\left(\frac{1}{\mathrm{~s}_{\mathrm{y}}}\right)+\mathrm{W}_{\text {bal }}(\mathrm{y}) \cdot\left(\frac{1}{\mathrm{~s}_{\mathrm{x}}}\right) \rightarrow \mathrm{W}_{2}=12,56\left(\frac{\mathrm{lb}}{\text { in }}\right) \cdot\left(\frac{1}{15(\text { in. })}\right)-23,75\left(\frac{\mathrm{lb}}{\text { in }}\right) \cdot\left(\frac{1}{15(\text { in. })}\right) \rightarrow$

$\mathrm{W}_{2}=0,84-1,58 \rightarrow \mathrm{W}_{2}=-0,74 \mathrm{psi}$

\section{Região 3:}

$\mathrm{W}_{3}=\mathrm{W}_{\text {bal }}(\mathrm{x}) \cdot\left(\frac{1}{\mathrm{~s}_{\mathrm{y}}}\right)+\mathrm{W}_{\text {bal }}(\mathrm{y}) \cdot\left(\frac{1}{\mathrm{~s}_{\mathrm{x}}}\right) \rightarrow \mathrm{W}_{3}=-23,75\left(\frac{1 \mathrm{~b}}{\text { in }}\right) \cdot\left(\frac{1}{15(\text { in. })}\right)-23,75\left(\frac{1 \mathrm{~b}}{\text { in }}\right) \cdot\left(\frac{1}{15(\text { in. })}\right) \rightarrow$

$\mathrm{W}_{3}=-1,58-1,58 \rightarrow \mathrm{W}_{3}=-3,16 \mathrm{psi}$

Para os resultados teóricos para a flecha do pavimento devido à protensão, sem a aplicação de qualquer outro carregamento, que não seja o de protensão, tem-se os seguintes diagramas de deslocamentos ortogonais à laje:
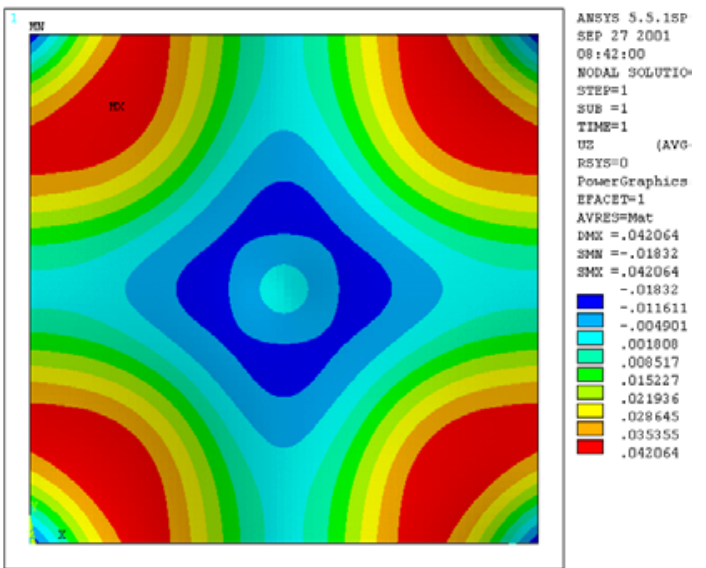

Modelo 1 com elemento SHELL63

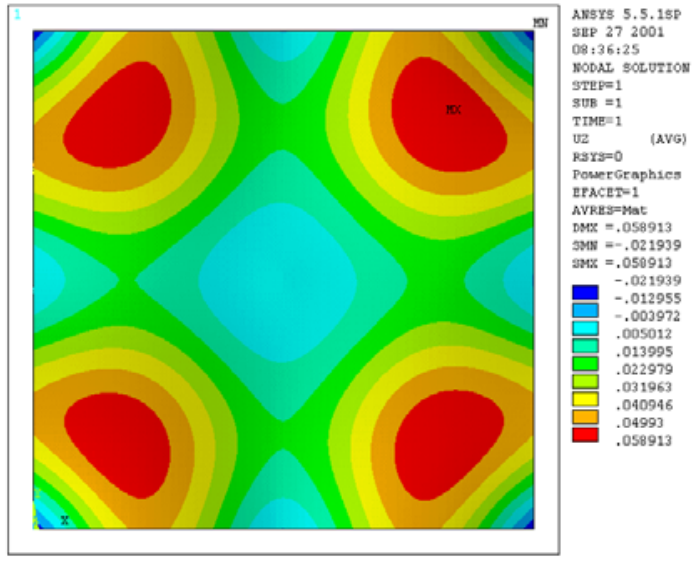

Modelo 2 com elemento SHELL63 


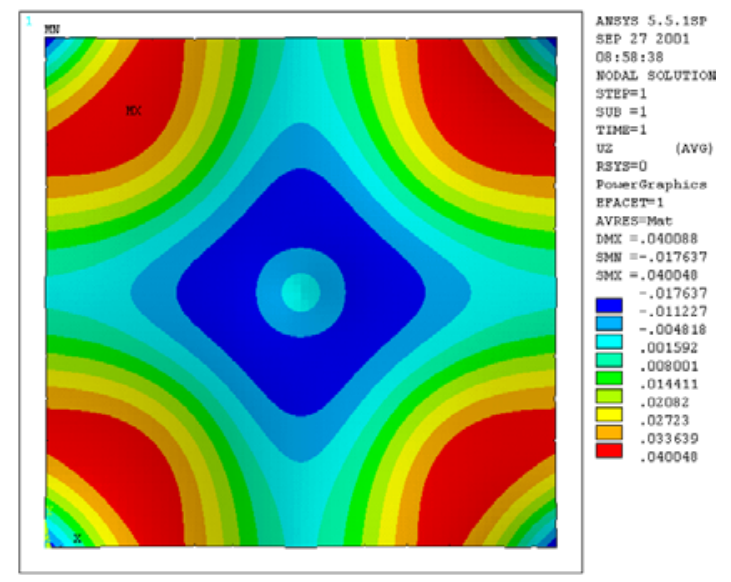

Modelo 1 com elemento SHELL43

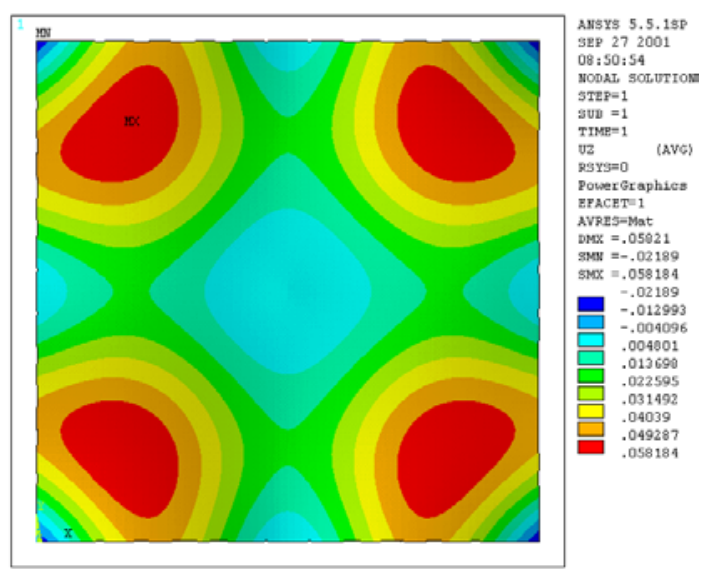

Modelo 2 com elemento SHELL43

Figura 4.31 - Deslocamentos para o pavimento devido à carga de protensão (unidades em libras e polegadas)

O modelo experimental produziu um valor de 0,045 in. $(0,114 \mathrm{~cm}) \mathrm{de}$ flecha.

$\mathrm{Na}$ Tabela 4.2, pode-se ver as diferenças entre os resultados experimentais e os numéricos.

Tabela 4.2 -Deslocamento entre modelos numérico e experimental com a aplicação somente da carga de protensão $(\mathrm{em} \mathrm{cm})$

\begin{tabular}{||c|c|c|c||}
\hline & Experimental & SHELL63 & SHELL43 \\
\hline \hline Modelo 1 & \multirow{2}{*}{$\approx 0,114$} & 0,101 & 0,102 \\
\cline { 3 - 4 } Modelo 2 & & 0,150 & 0,148 \\
\hline
\end{tabular}

Nesta análise, o modelo1 foi o que mais se aproximou dos resultados experimentais, com uma diferença de 10,53\%.

Para as condições de pré-fissuração, foi aplicada uma carga (permanente + acidental) de 200 psf $\left(9,576 \cdot 10^{-4} \mathrm{kN} / \mathrm{cm}^{2}\right)$. Os resultados de deslocamentos nos modelos numéricos são mostrados na figura 4.32. 


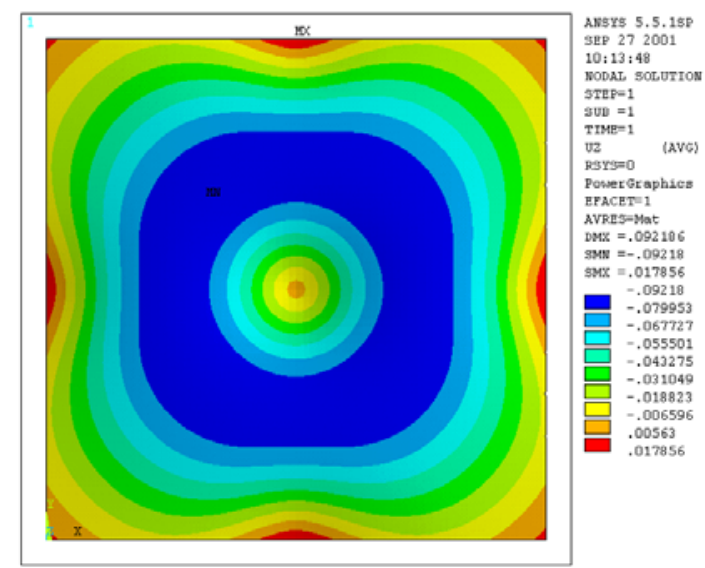

Modelo 1 com elemento SHELL63

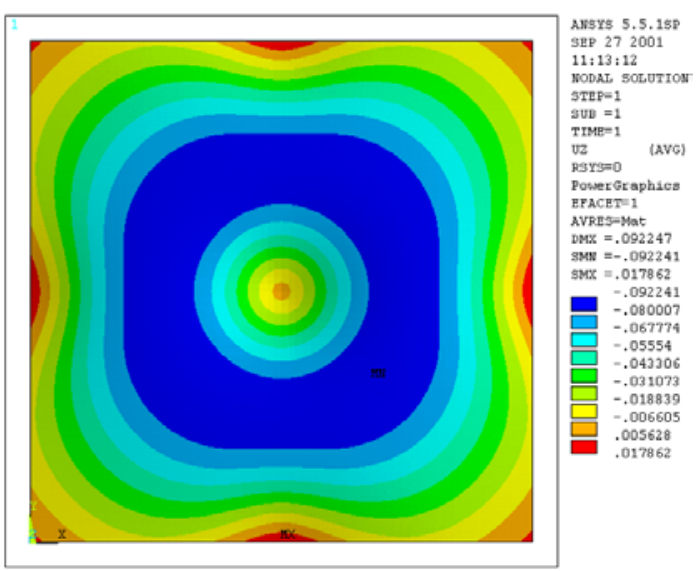

Modelo 1 com elemento SHELL43

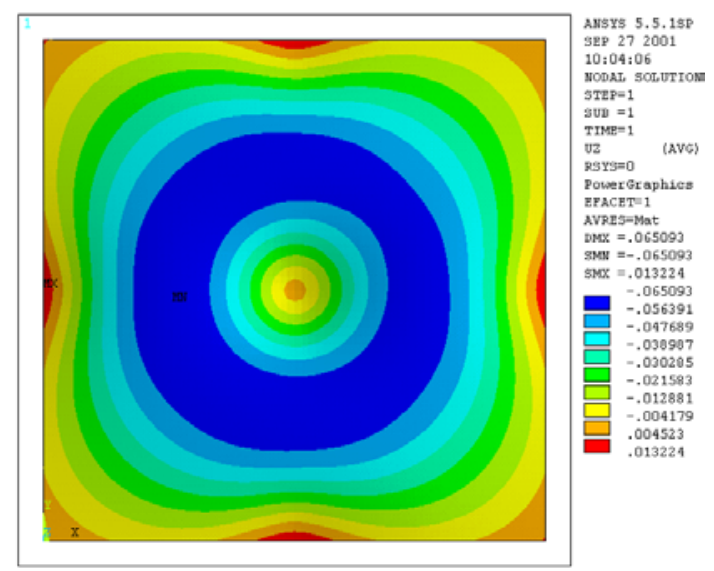

Modelo 2 com elemento SHELL63

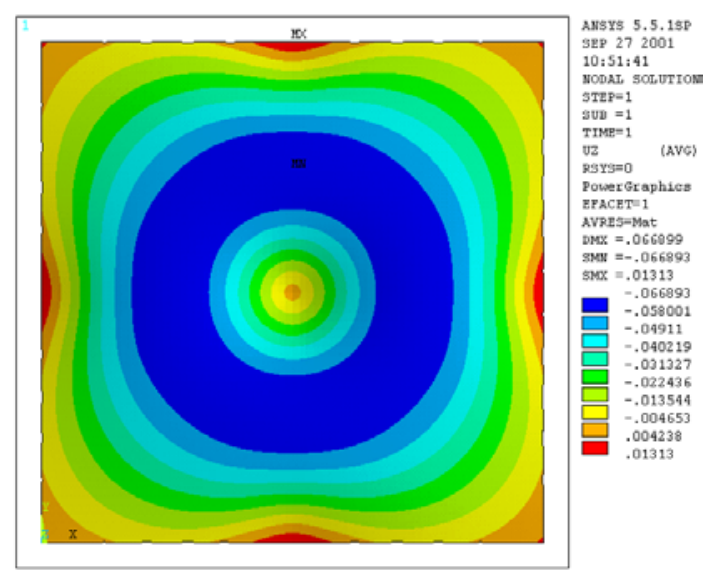

Modelo 2 com elemento SHELL43

Figura 4.32 - Deslocamentos para carregamento antes da fissuração

Os modelos numéricos produziram resultados muito próximos do experimental, como se pode ver, na tabela 4.3.

Tabela 4.3 - Valores dos deslocamentos (em $\mathrm{cm})$, numéricos e experimental com a aplicação da protensão e carga de serviço de 200 psf.

\begin{tabular}{||c|c|c|c|}
\hline \hline & Experimental & SHELL63 & SHELL43 \\
\hline \hline Modelo 1 & \multirow{2}{*}{$\approx 0,120$} & 0,133 & 0,132 \\
\cline { 3 - 4 } & & 0,015 & 0,022 \\
\hline
\end{tabular}

Pode-se observar, novamente, que o modelo 1 forneceu melhores resultados, com uma diferença de 9,09\% em relação ao experimental.

Para o Estado Limite Último, o carregamento de ruptura de acordo com o ensaio foi $347 \mathrm{psf}\left(1,66 \cdot 10^{-3} \mathrm{kN} / \mathrm{cm}^{2}\right)$. Os deslocamentos calculados 
podem ser encontrados na tabela 4.4. A figura 4.33 ilustra as isolinhas de deslocamento.

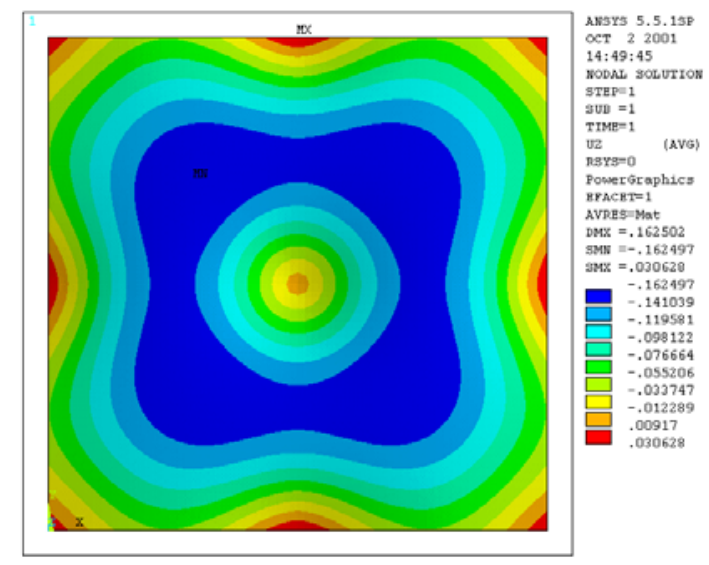

Modelo 1 com elemento SHELL63
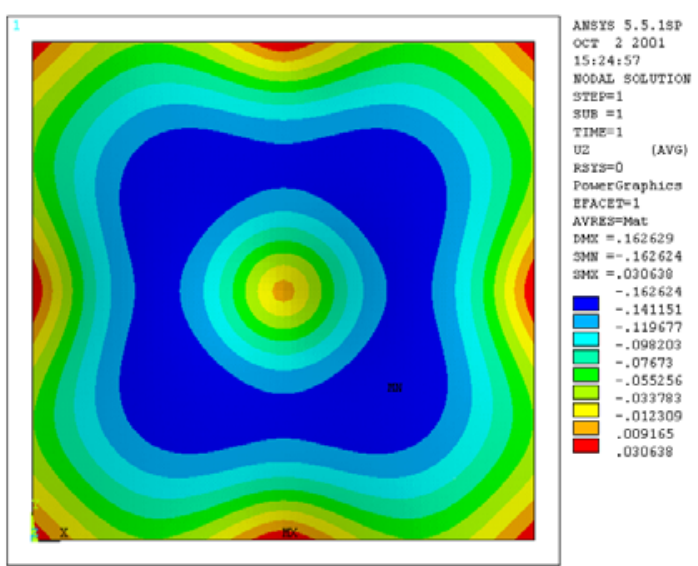

Modelo 1 com elemento SHELL43

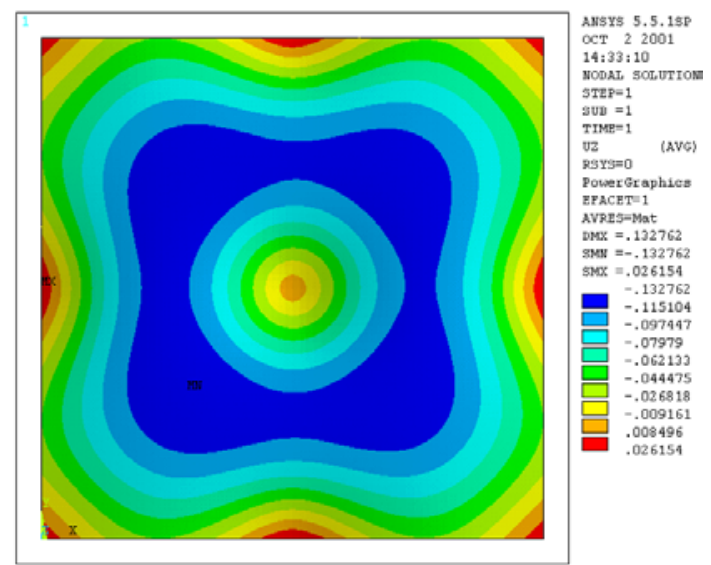

Modelo 2 com elemento SHELL63

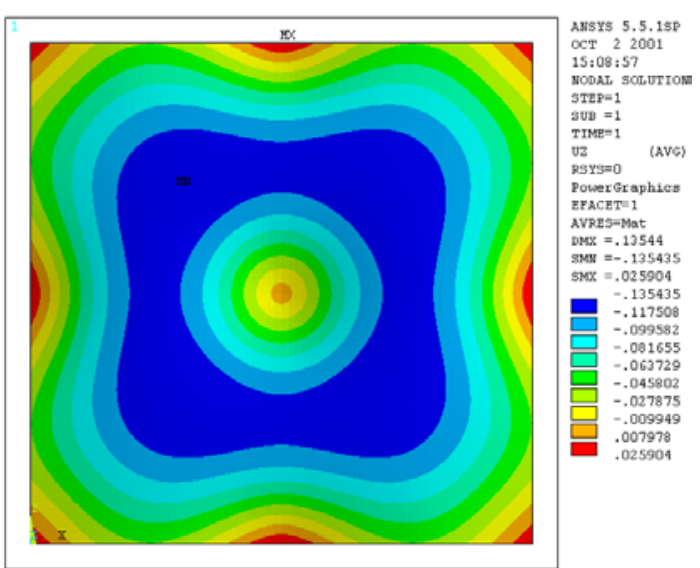

Modelo 2 com elemento SHELL43

Figura 4.33 - Deslocamentos para carregamento de ruptura.

Tabela 4.4 - Valores dos deslocamentos (em $\mathrm{cm}$ ) dos modelos numéricos e experimental, com a aplicação da protensão e carga de ruptura de 347 psf.

\begin{tabular}{||c|c|c|c|}
\hline \hline & Experimental & SHELL63 & SHELL43 \\
\hline \hline Modelo 1 & \multirow{2}{*}{$\approx 0,394$} & 0,312 & 0,311 \\
\cline { 3 - 4 } Modelo 2 & & 0,236 & 0,242 \\
\hline
\end{tabular}

Novamente, o modelo 1 forneceu resultados melhores, apresentando uma diferença de 20,81\% com relação ao modelo experimental. Já o modelo 2 apresentou resultados 39,09\% abaixo do modelo experimental. 


\subsection{3 - Conclusões sobre a modelagem}

$\mathrm{Na}$ análise do modelo em elementos finitos, foram utilizados dois métodos para se determinarem os deslocamentos do pavimento, quando submetido aos carregamentos de serviço e de ruína.

Com base na análise numérica, pode-se constatar que o modelo 1 foi o que apresentou melhores resultados.

Com isso, foi eleito como modelo numérico o modelo 1 , que considera forças aplicadas nas intersecções das cordoalhas, referentes à carga equilibrante $q$ aplicada ao longo do cabo.

Deve-se, agora, determinar qual elemento melhor aproxima o comportamento do modelo numérico ao modelo experimental.

$\mathrm{Na}$ figura 4.34 vê-se o comportamento do modelo numérico (modelo 1) com o elemento SHELL43, em relação aos resultados do modelo experimental.

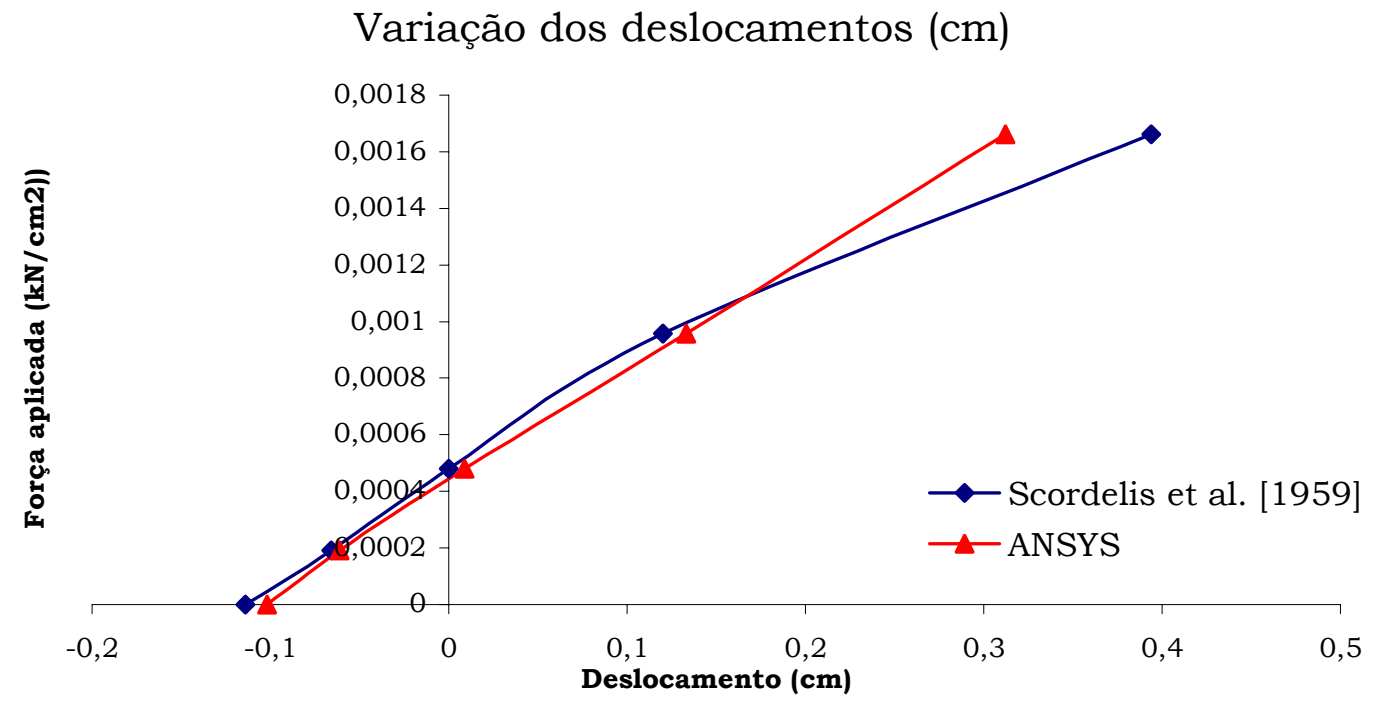

Figura 4.34 - Deslocamentos dos modelos numérico e experimental

Foram ilustradas apenas as curvas referentes ao modelo 1 em virtude de apresentar melhores resultados. Pode-se ver que ambos os elementos obtiveram resultados, no trecho elástico-linear, praticamente iguais aos encontrados no modelo experimental.

Vale salientar que, no gráfico, o deslocamento das curvas foi subtraído da contra-flecha existente, pois no artigo dos referidos autores, 
para a força de protensão igual a zero, tem-se deslocamento do pavimento igual a zero, o que é incorreto. Logo, observou-se que deveria ser feita a redução referente à elevação que o modelo apresenta devido apenas à força de protensão.

$\mathrm{Na}$ Tabela 4.5, tem-se o valor das diferenças obtidas pela modelagem numérica e pelo modelo ensaiado pelos autores e um resumo das propriedades da laje modelada, utilizando o modelo1 com o elemento SHELL43.

Foram adotados os seguintes critérios:

- $\quad$ Coeficiente de Poisson = 0,14;

- Módulo de Elasticidade Longitudinal $\left(\mathrm{E}_{\mathrm{c}}\right)=2413,16 \mathrm{kN} / \mathrm{cm}^{2}$;

- Módulo de Elasticidade Tangencial $\left(\mathrm{G}_{\mathrm{c}}\right)=965,26 \mathrm{kN} / \mathrm{cm}^{2}$.

Tabela 4.5 - Características do modelo numérico (SHELL43) e experimental

\begin{tabular}{|c|c|c|}
\hline & Trecho elástico & Ruptura \\
\hline Carregamento $\left(\mathrm{kN} / \mathrm{cm}^{2}\right)$ & $9,57.10^{-4}$ & $1,66.10^{-3}$ \\
\hline Experimental (cm) & $\approx 0,120$ & $\approx 0,394$ \\
\hline Modelo Numérico (cm) & $\approx 0,133$ & $\approx 0,312$ \\
\hline Diferença & $9,77 \%$ & $20,81 \%$ \\
\hline
\end{tabular}

A modelagem desenvolvida no ANSYS 5.5.1® apresentou resultados com diferenças da ordem de 9,80 \% com relação ao modelo experimental na fase elástica, mostrando uma boa precisão. Com relação ao carregamento de ruptura, a diferença foi de $20,81 \%$, pois a modelagem foi do tipo elástico-linear, ou seja, não se esperava uma aproximação no trecho não linear.

Essa diferença nos deslocamentos do modelo numérico (modelo 1) para com o modelo experimental, na carga de ruptura, se deve à fissuração da peça quando o carregamento supera $200 \mathrm{psf}\left(9,576 \cdot 10^{-4} \mathrm{kN} / \mathrm{cm}^{2}\right)$.

$\mathrm{Na}$ figura 4.35, tem-se os valores dos momentos fletores nas duas direções, $\mathrm{x}$ e y, tanto para a modelagem em elementos finitos quanto para os valores experimentais, para a posição igual a $1,14 \mathrm{~m}(3,5 \mathrm{ft})$ de distância da extremidade da laje. 
Diagramas de momentos fletores do modelo experimental e do modelo numérico (ANSYS)

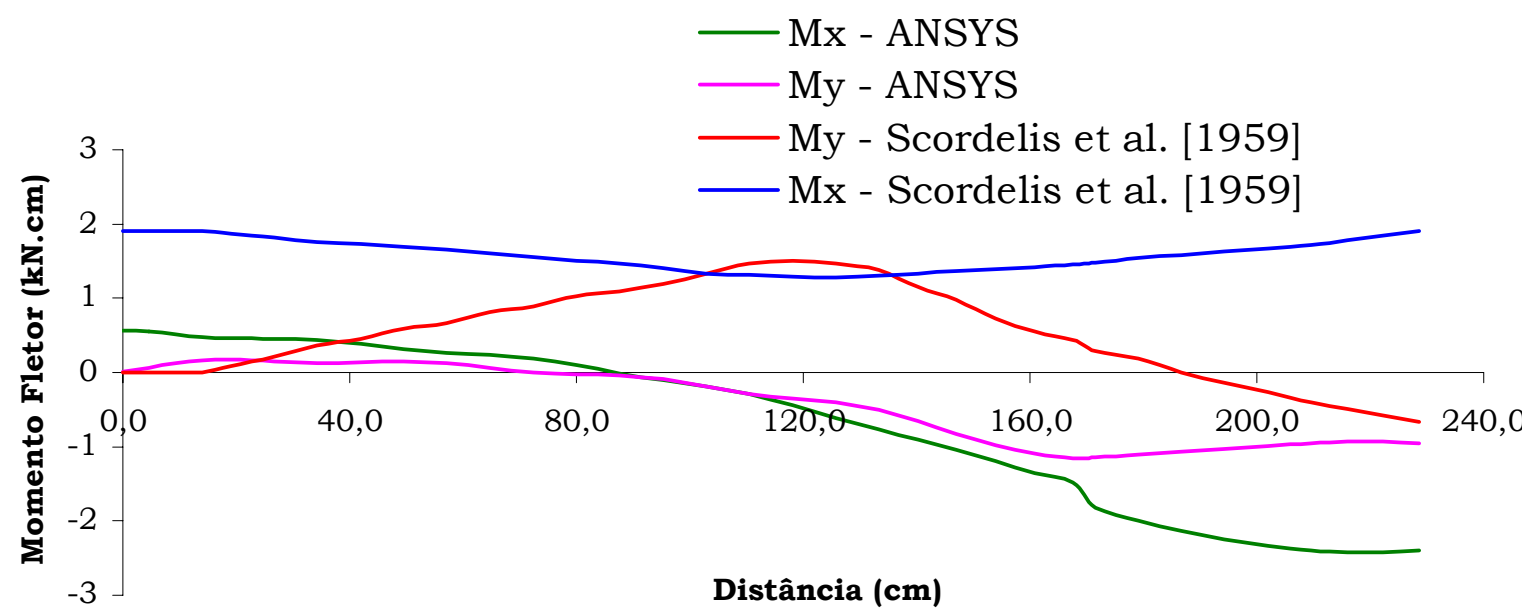

Figura 4.35 - Diagramas de momentos fletores para carga igual a $4,78.10^{-4} \mathrm{kN} / \mathrm{cm}^{2}$

Pode-se ver uma grande discrepância nos resultados produzida por algum problema no pós-processador do programa do ANSYS 5.5.1®, pois, a apresentação dos resultados referentes ao momento fletor nas duas direções, é muito diferente, principalmente para o caso do momento fletor na direção $\mathrm{X}$, mesmo com os deslocamentos obtidos pelo programa muito próximos aos do modelo experimental.

Como os momentos fletores são muito importantes para se fazer o dimensionamento da estrutura, e, após inúmeras tentativas de se obter esses valores, descartou-se a utilização deste software e optou-se pela utilização do programa de cálculo estrutural TQS® que utiliza para análise estrutural o método da analogia de grelha.

\section{6 - Análise numérica de modelo experimental através da Analogia por Grelha}

O programa TQS ${ }^{\circledR}$, além de calcular a estrutura por grelha e incluir em seus resultados os quantitativos dos materiais utilizados, insere a influência da protensão (tanto para o sistema com aderência quanto para o 
sistema sem aderência), realiza o detalhamento e ainda requer um esforço computacional inferior ao programa de elementos finitos ANSYS $®$.

A análise por grelha é muito eficaz e produz resultados satisfatórios para estruturas, mesmo as protendidas, o que será visto a seguir.

$\mathrm{Na}$ figura 4.36, ilustra-se a grelha modelada para o estudo do modelo experimental.

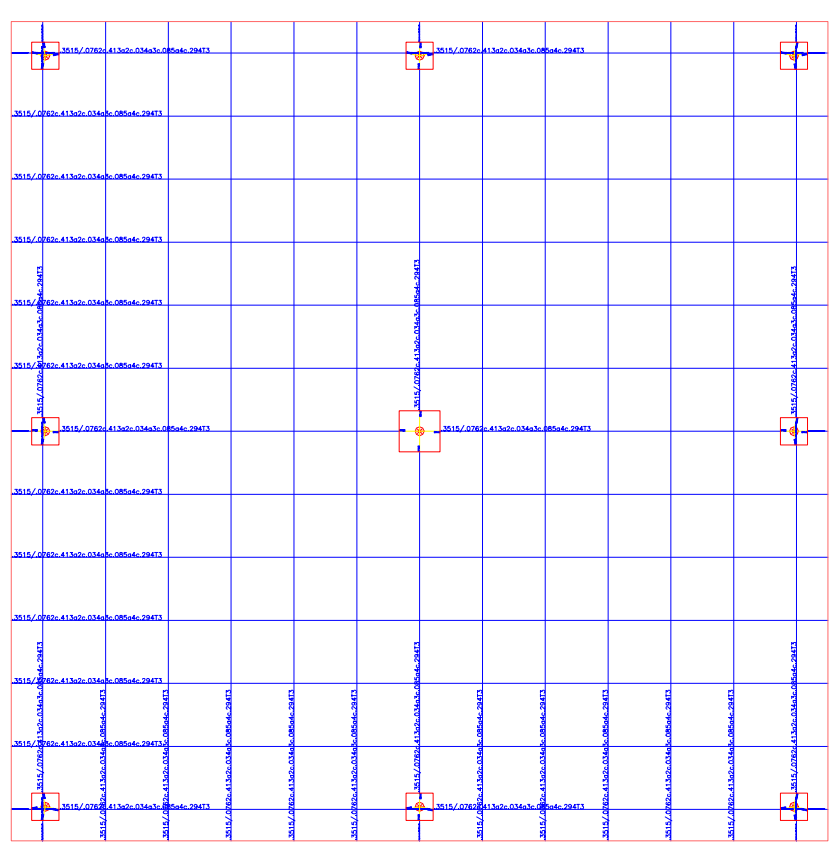

Figura 4.36 - Modelo de grelha de barras para a análise do modelo experimental de SCORDELIS et al. [1959]

Na figura 4.37, pode-se ver a distribuição dos cabos no modelo. 


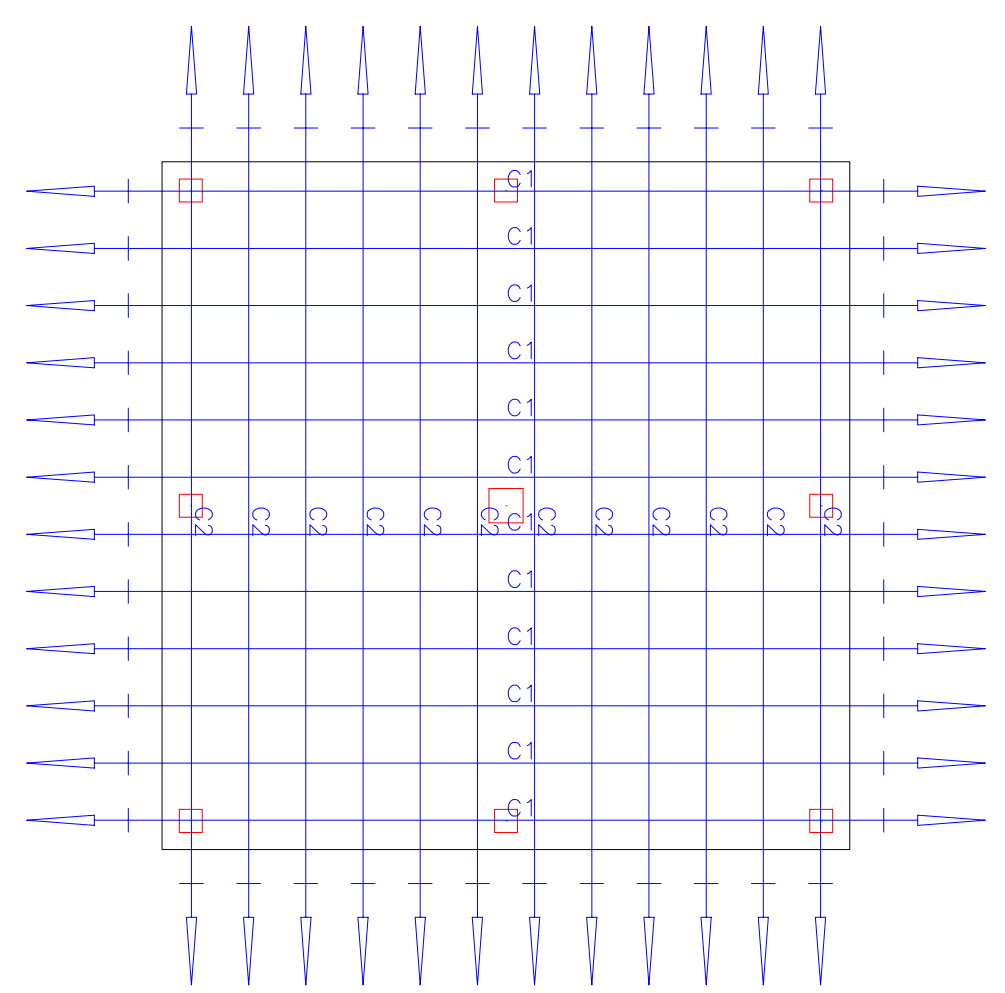

Figura 4.37 - Disposição dos cabos para o modelo de SCORDELIS et al. [1959]

$\mathrm{Na}$ figura 4.37, pode-se ver que houve a preocupação em dispor os cabos do mesmo modo que o modelo de Scordelis e colaboradores.

Os cabos no modelo experimental consistiam em cordoalhas engraxadas em tubos plásticos com diâmetro de $6,35 \mathrm{~mm}$, onde esta apresentava as seguintes características:

Limite de proporcionalidade: $170 \mathrm{ksi}$

$119,52 \mathrm{kN} / \mathrm{cm}^{2}$

Limite de escoamento:

$218 \mathrm{ksi}$

$1.532,69 \mathrm{kN} / \mathrm{cm}^{2}$

Limite de ruptura:

$253 \mathrm{ksi}$

$1.744,37 \mathrm{kN} / \mathrm{cm}^{2}$

Módulo de elasticidade $\mathrm{E}_{\mathrm{p}}$ :

$29.400 \mathrm{ksi}$

$20.670,03 \mathrm{kN} / \mathrm{cm}^{2}$

Área do cabo:

0,05 sq.in.

$0,32 \mathrm{~cm}^{2}$

De posse destes valores, foram extraidos os diagramas de isolinhas de deslocamento e de momentos fletores para os casos a serem comparados com o modelo experimental, do mesmo modo que foi realizado no item 4.5.

$\mathrm{Na}$ figura 4.38, vê-se o diagrama de isolinhas de deslocamento para o caso de apenas haver a força de protensão. 


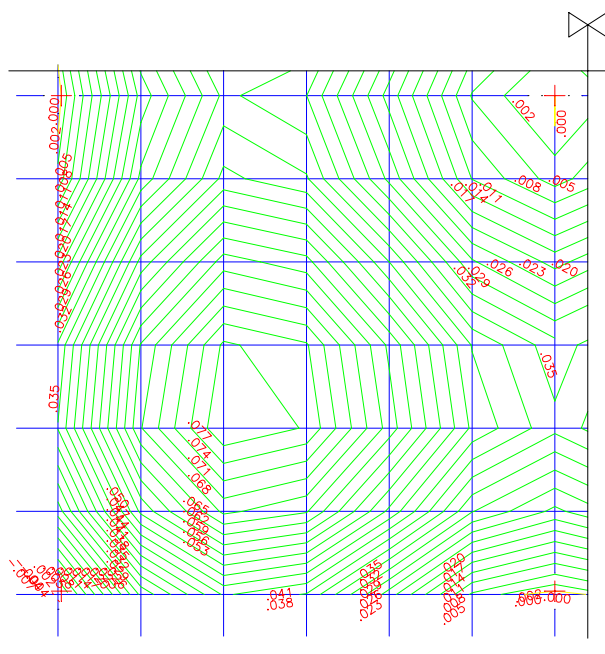

Figura 4.38 - Diagrama de isolinhas de deslocamento para o caso de haver somente a força de protensão

Tabela 4.7 -Deslocamento entre modelos numérico e experimental com a aplicação somente da força de protensão $(\mathrm{em} \mathrm{cm})$

\begin{tabular}{||c|c|c||}
\hline \hline & Experimental & TQS \\
\hline \hline Deslocamento & 0,114 & 0,077 \\
\hline
\end{tabular}

Pode-se ver que o deslocamento obtido foi de 0,077 $\mathrm{cm}$ de contraflecha no modelo numérico. Nesta análise, o modelo do TQS apresentou uma de diferença de $32,46 \%$ com relação ao modelo experimental.

$\mathrm{Na}$ figura 4.39 ilustram-se os deslocamentos referentes ao carregamento de 200 psf $\left(9,576 \cdot 10^{-4} \mathrm{kN} / \mathrm{cm}^{2}\right)$. 


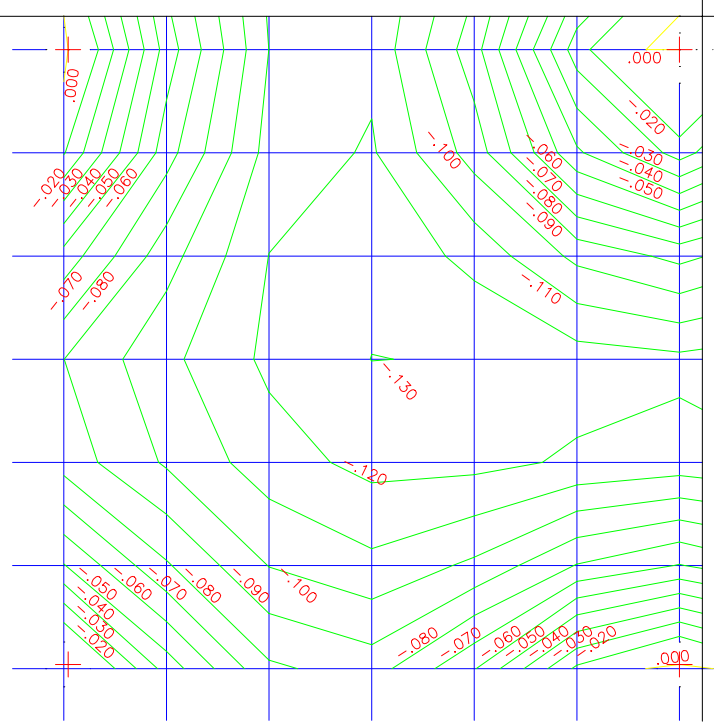

Figura 4.39 - Diagrama de isolinhas de deslocamento para o caso aplicação de carga de $200 \mathrm{psf}\left(9,576 \cdot 10^{-4} \mathrm{kN} / \mathrm{cm}^{2}\right)$

A tabela 4.8 mostra as diferenças de deslocamento entre os modelos experimental e numérico para o caso de força aplicada de 200 psf.

Tabela 4.8 -Deslocamento $(\mathrm{em} \mathrm{cm}$ ) entre modelos numérico e experimental com a aplicação da força de 200 psf $\left(9,576.10^{-4} \mathrm{kN} / \mathrm{cm}^{2}\right)$

\begin{tabular}{||c|c|c|}
\hline \hline & Experimental & TQS \\
\hline \hline Deslocamento & 0,120 & 0,130 \\
\hline
\end{tabular}

Nesta análise, o modelo do TQS apresentou uma diferença de 7,69\% com relação ao modelo experimental.

Para a força de ruptura do modelo experimental, o diagrama da figura 4.40 ilustra os deslocamentos do modelo numérico. Vale salientar que esta comparação, do mesmo modo que no caso da modelagem em elementos finitos, não foi eficaz para a presente pesquisa, pois a análise da grelha foi do tipo elástico-linear. 


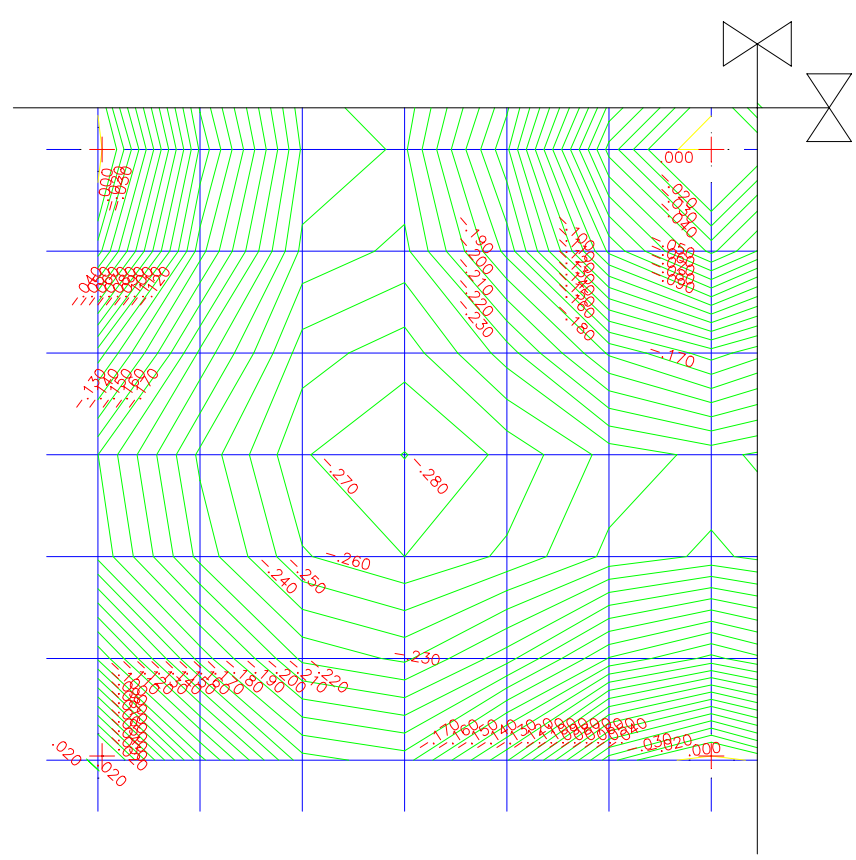

Figura 4.40 - Diagrama de isolinhas de deslocamento para a carga de ruptura de $347 \mathrm{psf}\left(1,661.10^{-3} \mathrm{kN} / \mathrm{cm}^{2}\right)$

A tabela 4.9 mostra as diferenças de deslocamento entre os modelos experimental e numérico para o caso de força aplicada de 347 psf.

Tabela 4.9 -Deslocamento (em $\mathrm{cm}$ ) entre modelos numérico e experimental com a aplicação da força de $347 \mathrm{psf}\left(1,661.10^{-3} \mathrm{kN} / \mathrm{cm}^{2}\right)$

\begin{tabular}{||c|c|c|}
\hline \hline & Experimental & TQS \\
\hline \hline Deslocamento & 0,394 & 0,280 \\
\hline
\end{tabular}

Nesta análise, o modelo do TQS apresentou uma de diferença de $28,93 \%$ com relação ao modelo experimental.

\subsection{1 - Conclusões sobre a modelagem}

O gráfico da figura 4.41 ilustra a variação de deslocamento do modelo experimental com relação ao modelo numérico. 


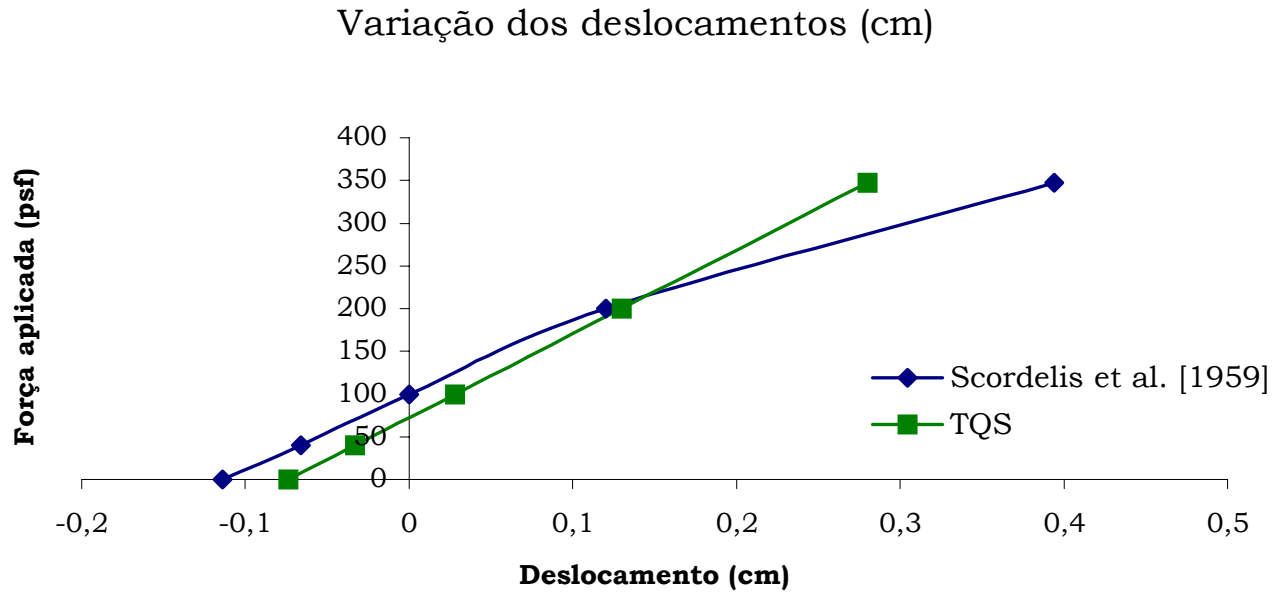

Figura 4.41 - Variação dos deslocamentos para o modelo numérico e experimental

Na tabela 4.10, tem-se um resumo dos valores encontrados.

Foram adotados os seguintes critérios:

- $\quad$ Coeficiente de Poisson = 0,14;

- Módulo de Elasticidade Longitudinal $\left(\mathrm{E}_{\mathrm{c}}\right)=2413,16 \mathrm{kN} / \mathrm{cm}^{2}$;

- Módulo de Elasticidade Tangencial $\left(\mathrm{G}_{\mathrm{c}}\right)=965,26 \mathrm{kN} / \mathrm{cm}^{2}$.

Tabela 4.10 - Características do modelo numérico TQS ${ }^{\circledR}$ e experimental

\begin{tabular}{||l|c|c|}
\hline & Trecho elástico & Ruptura \\
\hline \hline Carregamento (kN/cm $\mathbf{~})$ & $9,57.10^{-4}$ & $1,66.10^{-3}$ \\
\hline Experimental $\mathbf{( c m )}$ & $\approx 0,120$ & $\approx 0,394$ \\
\hline Modelo Numérico $\mathbf{( c m )}$ & $\approx 0,130$ & $\approx 0,280$ \\
\hline
\end{tabular}

A modelagem desenvolvida no programa TQS $\AA$ apresentou resultados com diferenças da ordem de 9,23 \% com relação ao modelo experimental na fase elástica, mostrando uma boa precisão. Com relação ao carregamento de ruptura, a diferença foi de $28,93 \%$, pois a modelagem foi do tipo elástico-linear, ou seja, não se esperava uma aproximação no trecho não linear, pois não estão incluídas as não linearidades físicas ou geométricas no modelo.

$\mathrm{Na}$ verificação dos momentos fletores, foi observado que houve um comportamento similar ao modelo dos referidos autores, porém com magnitudes inferiores aos encontrados no experimento. 
A figura 4.42 mostra o local de aferição dos momentos fletores.

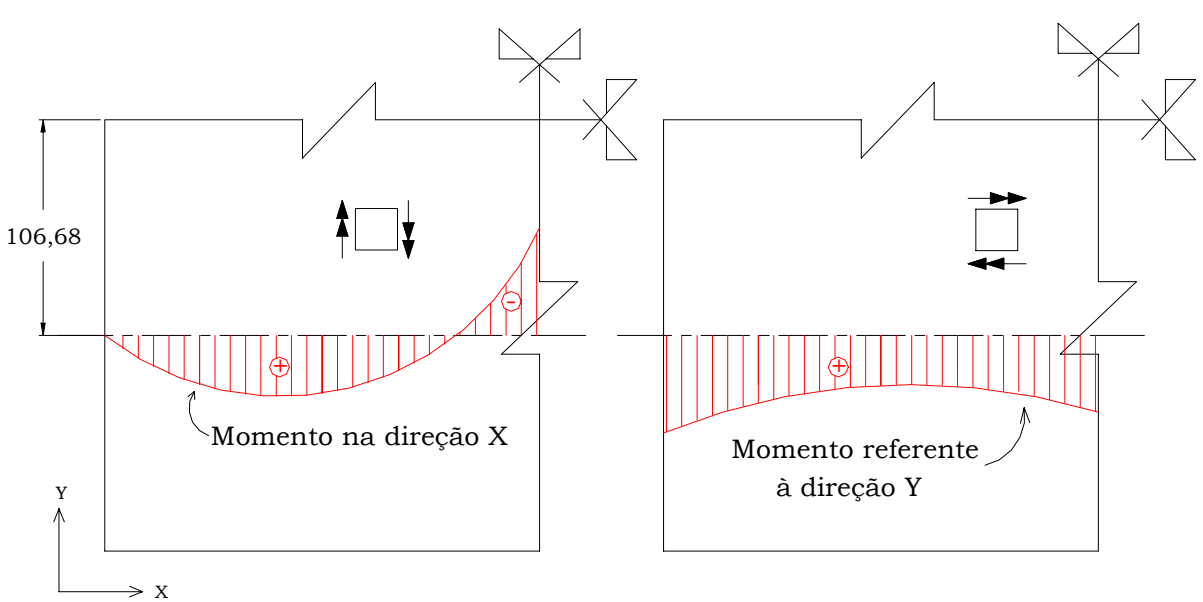

Figura 4.42 - Localização dos valores encontrados para os momentos fletores

A figura 4.43 ilustra os diagramas de momentos fletores do modelo experimental e do modelo numérico do programa TQS ${ }^{\circledR}$.

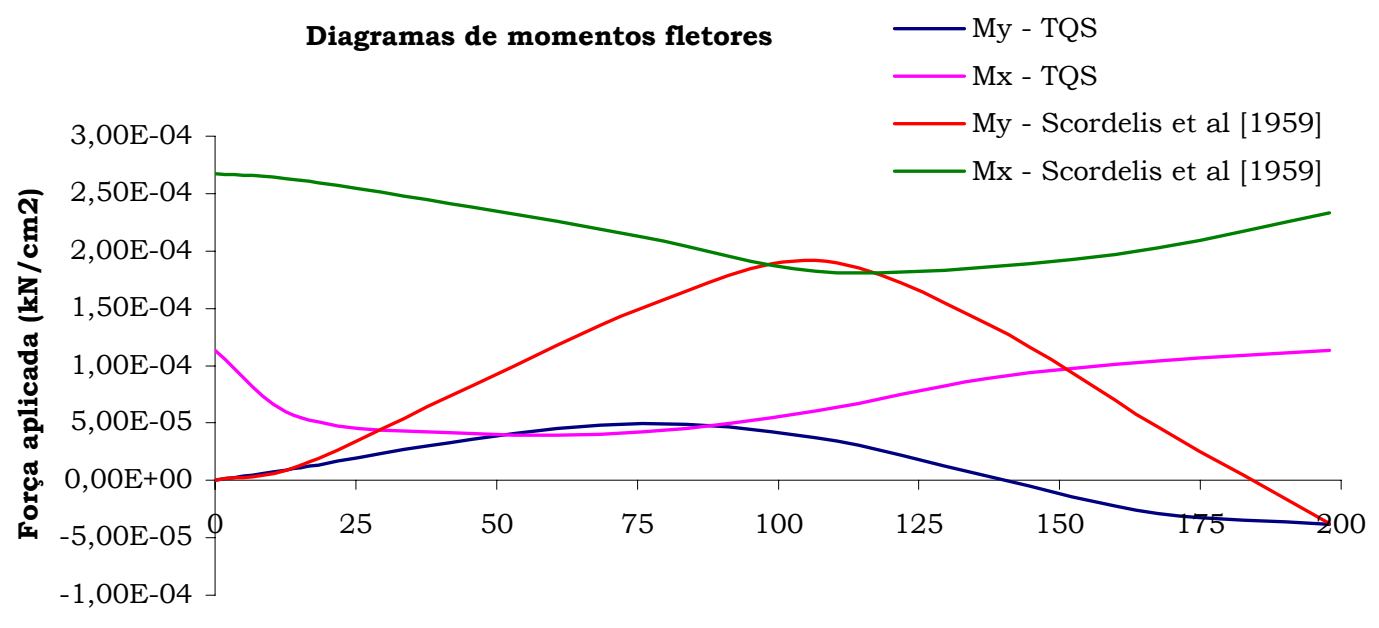

Distância (cm)

Figura 4.43 - Diagramas de momentos fletores para o modelo experimental e modelo numérico

$\mathrm{Na}$ análise dos momentos fletores, o modelo experimental obteve um valor de momento máximo positivo, na direção $\mathrm{Y}$, igual a 1,92.10-4 $\mathrm{kN} . \mathrm{cm} / \mathrm{cm}$, na posição igual a 106,5 cm, enquanto, no modelo numérico, o valor encontrado, para o momento máximo positivo na direção $\mathrm{X}$, foi de 4,93.10-5 kN.cm/cm para a posição $75,97 \mathrm{~cm}$. Tem-se aí uma diferença de $74,29 \%$, mostrando que não há uma boa correlação com os momentos 
fletores positivos. Porém os momentos fletores negativos máximos apresentaram uma boa precisão, onde, para o modelo experimental o valor encontrado foi de $-3,73.10^{-5} \mathrm{kN} . \mathrm{cm} / \mathrm{cm}$ e para o modelo numérico $-3,84.10^{-5}$ $\mathrm{kN} . \mathrm{cm} / \mathrm{cm}$, mostrando uma diferença de $2,82 \%$.

Com relação aos momentos fletores referentes à direção X, para o modelo experimental, o valor máximo de momento encontrado foi de 2,67.10-4 kN.cm/cm e para modelo numérico de $1,14 \cdot 10^{-4} \mathrm{kN} . \mathrm{cm} / \mathrm{cm}$, dando uma diferença de $57,44 \%$.

\section{7 - Conclusões sobre a análise numérica do modelo experimental}

A análise desenvolvida tinha por objetivo avaliar a precisão do modelo numérico com o modelo experimental. Para isso, foram utilizadas duas ferramentas computacionais, sendo elas o programa de elementos finitos ANSYS ${ }^{\circledR}$ e o programa de cálculo estrutural TQS®, que utiliza a modelagem por grelha linear.

O modelo experimental estudado foi o ensaio de uma laje plana maciça com cabos não aderentes de SCORDELIS et al. [1959].

Observando os valores extraídos da publicação dos referidos autores com relação aos modelos numéricos, constatou-se que a análise de deslocamentos apresentou resultados satisfatórios onde, para o trecho linear houve boa concordância. A figura 4.44 ilustra a variação do deslocamento para os modelos numérico e experimental. 


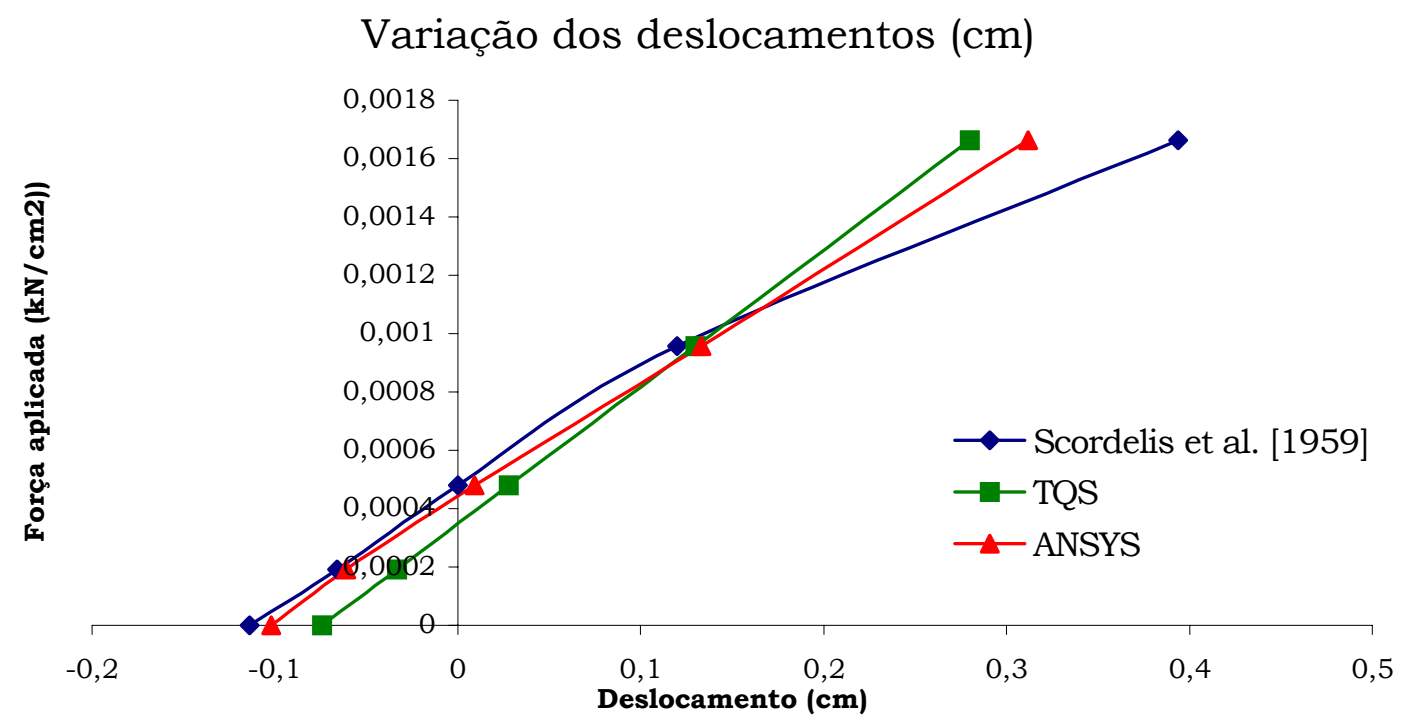

Figura 4.44 - Variação de deslocamento para os modelos numérico e experimental

$\mathrm{Na}$ tabela 4.11, tem-se os valores encontrados para a modelagem desenvolvida no ANSYS ${ }^{\circledR}$ (Modelo 1 - elemento SHELL43), no TQS ${ }$ e no modelo experimental dos referidos autores.

Tabela 4.11 - Características do modelo numérico, ANSYS ${ }^{\circledR}$ e TQS $®$ e modelo experimental

\begin{tabular}{|c|c|c|c|}
\hline & $\begin{array}{c}\text { Somente } \\
\text { protensão }\end{array}$ & $\begin{array}{c}\text { Limite do } \\
\text { Trecho Elástico }\end{array}$ & Ruptura \\
\hline Carregamento $\left(\mathrm{kN} / \mathrm{cm}^{2}\right)$ & 0,00 & $9,57 \cdot 10^{-4}$ & $1,66.10^{-3}$ \\
\hline Modelo Experimental & 0,114 & 0,120 & 0,394 \\
\hline Modelo Numérico TQS $\mathbb{R}$ & 0,077 & 0,130 & 0,280 \\
\hline 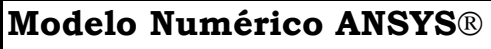 & 0,102 & 0,133 & 0,312 \\
\hline
\end{tabular}

De acordo com a tabela 4.11, verifica-se que há um bom comportamento dos modelos numéricos com relação ao modelo experimental até o limite do trecho elástico, isto é, até a aplicação da força de $9,57 \cdot 10^{-4} \mathrm{kN} / \mathrm{cm}^{2}$ à laje.

Quando há o início do trecho não-linear, força aplicada à laje superior a $9,57.10^{-4} \mathrm{kN} / \mathrm{cm}^{2}$, os comportamentos dos modelos experimental e numérico se diferenciam até chegar ao limite de ruptura, quando a 
diferença entre os modelos experimental e numérico (ANSYS ${ }^{\circledR}$ ) chega a $20,81 \%$.

O modelo em elementos finitos apresentou em seu pósprocessamento uma variação de momentos fletores peculiar, onde o momento fletor, aproximadamente, no centro do painel da laje foi igual a zero, enquanto, o modelo experimental e o modelo numérico do TQS ${ }^{\circ}$ (ver figura 4.43) apresentaram distribuições semelhantes. A figura 4.46 ilustra os diagramas de momento fletor para as direções X e Y para lados paralelos aos lados da laje, distantes $1 / 4$ do vão.

Diagrama de momento fletor - direções X e Y (ANSYS)

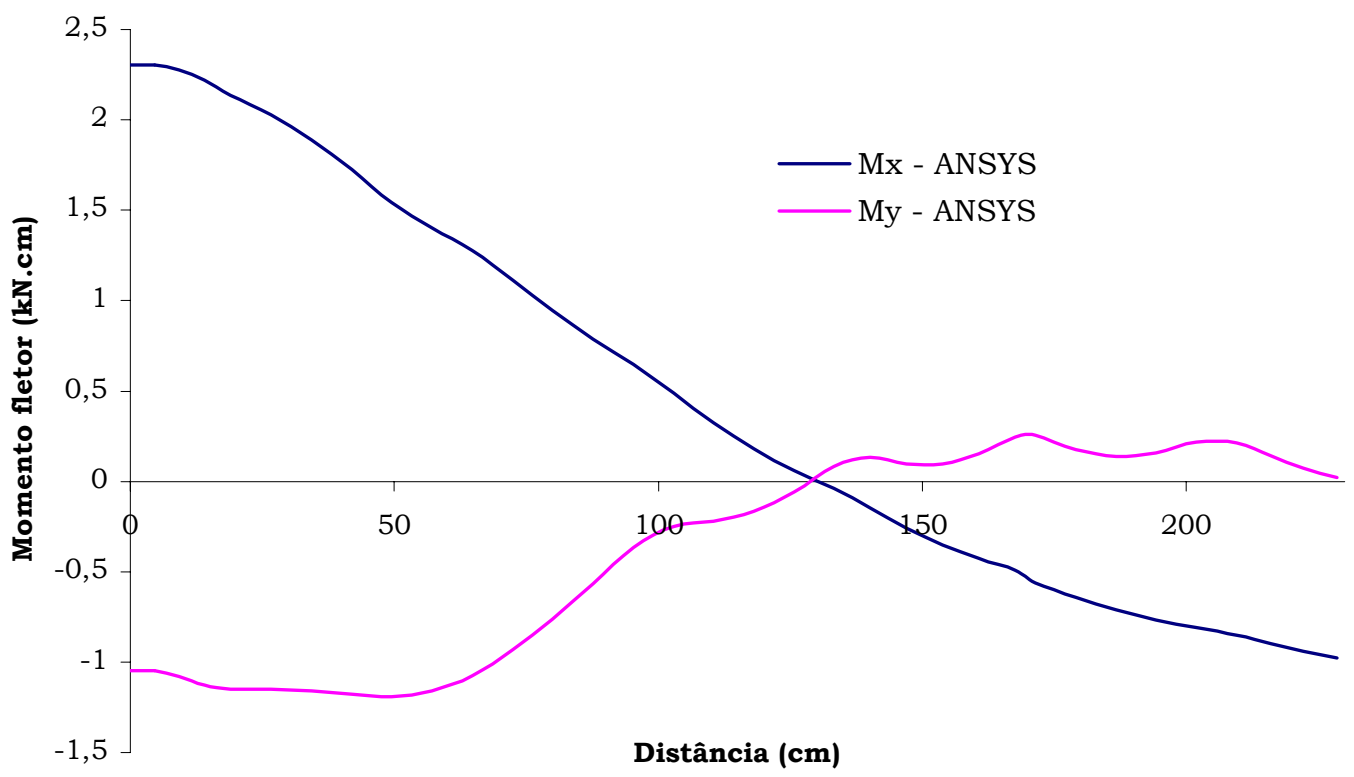

Figura 4.46 - Diagrama de momento fletor para a modelagem em elementos finitos para as direções $\mathrm{X}$ e $\mathrm{Y}$

Esses resultados fizeram com que fosse abandonada a modelagem em elementos finitos e fosse adotado o programa de cálculo estrutural TQS®.

Com relação ao programa do TQS $\AA$, o diagrama de momentos fletores para ambas direções, $\mathrm{X}$ e $\mathrm{Y}$, apresentaram um aspecto semelhante aos observados pelo modelo experimental, porém, com magnitudes diferentes, como pode ser observado na figura 4.43. Além disso, o programa permite o detalhamento da estrutura protendida, tornando-se assim, adequado para esta pesquisa. 


\section{ESTUDO COMPARATIVO E} ANÁLISE DOS RESULTADOS

\section{1 - Considerações Gerais}

Com o modelo arquitetônico definido, pode-se dar início ao estudo dos arranjos estruturais a serem adotados, que, no presente caso, envolverão a utilização da protensão aderente e não aderente.

De acordo com CORREAA [1991], "O problema tem como característica fundamental a complexidade, por causa do número de variáveis e da multiplicidade de soluções possíveis".

$\mathrm{Na}$ análise estrutural para do pavimento serão analisados os arranjos para laje plana maciça apoiada sobre pilares; laje plana nervurada apoiada sobre pilares e laje apoiada em vigas faixa sobre pilares, onde, serão adequadas as geometrias do pavimento, no que se refere às suas aberturas para passagens das instalações.

Para se determinar a disposição dos elementos estruturais (lajes, vigas e pilares) é recomendável seguir um roteiro para se conseguir um projeto estrutural mais eficaz. Para isso, de acordo com ALBUQUERQUE [1998], devese:

- Fazer a locação dos pilares de canto no pavimento; 
- Locação dos pilares de extremidade e internos;

- Determinar, de acordo com o arranjo estrutural e os carregamentos determinados, a posição de vigas e das lajes.

É claro que um projeto envolve uma enormidade de variáveis (CORRÊA [1991]), e estas necessitam de um estudo cuidadoso e hierárquico.

Após a locação dos elementos estruturais passa-se ao prédimensionamento dos elementos estruturais existentes.

\section{2 - Programa de Cálculo Estrutural TQS $\AA$}

A análise dos pavimentos será realizada com a utilização do programa de cálculo estrutural TQS $\AA$, versão 9.0.

O programa adota, para a determinação das solicitações do pavimento, o modelo de grelha. Neste, é feita a determinação de esforços, deslocamentos, tensões e reações resultantes das combinações de carregamento impostas ao pavimento.

O processo de grelha pode ser utilizado tanto para estruturas de concreto armado quanto para estruturas de concreto protendido. Segundo o Eng. Marcelo Silveira ${ }^{1}$, não se deve interpretar a estrutura de concreto protendido como uma estrutura especial, e sim, como uma estrutura comum submetida a esforços aplicados através dos cabos.

O modelo de grelha é elástico linear, portanto, não consideram os efeitos das não-linearidades físicas e geométricas. Este modelo assume uma série de carregamentos e combinações para o dimensionamento e detalhamento de uma laje protendida.

As barras ou elementos da grelha, conforme explicado no capítulo 4, não admitem componentes de forças normais em sua seção transversal. $O$ programa adota regiões de protensão uniforme e regiões de transferência de esforços. Nessas regiões são colocadas as tensões referentes à força de protensão que são sobrepostas às tensões oriundas das solicitações da laje.

A região de protensão uniforme, ou RPU, é definida como uma região poligonal da laje onde são adotados os mesmos espaçamentos, diâmetros,

1 SILVEIRA, M. [2002]. Mensagens eletrônicas. 2001-2002, Fortaleza-CE 
forças de protensão e perfis para todos os cabos. A região de transferência de esforços, ou RTE é definida como uma região poligonal da laje, que contém uma ou diversas RPU's e que determinam a região para extração das solicitações (momentos fletores) para as RPU's e as dimensões da seção transversal que serão empregadas no dimensionamento. Resumindo, a RPU determina a região para o perfil dos cabos e a RTE determina a região de influência da protensão, podendo conter uma ou mais RPU's.

\section{3 - Carregamentos na Estrutura}

$\mathrm{Na}$ aplicação das forças ao piso do edificio, serão consideradas cargas usuais aplicadas a pavimentos de edificios residenciais. Pode-se exemplificar as cargas utilizadas:

- Carga permanente devida ao revestimento $(2,0 \mathrm{~cm}$ de espessura) e sua regularização $\left(2,5 \mathrm{~cm}\right.$ de espessura), igual a $0,615 \mathrm{kN} / \mathrm{m}^{2}$;

- Carga permanente devida à presença do forro (1,5 $\mathrm{cm}$ de espessura), igual a $0,285 \mathrm{kN} / \mathrm{m}^{2}$;

- Carga permanente devida ao peso próprio do concreto;

- Carga permanente devida ao peso das alvenarias cerâmicas $(15 \mathrm{~cm}$ de espessura) no pavimento, igual a $2,5 \mathrm{kN} / \mathrm{m}^{2}$;

- Carga acidental, de acordo com a NBR-6120/78 - "Cargas para cálculo de estruturas de edificações - Procedimento" e a NBR-8681/84 - "Ações e segurança nas estruturas - Procedimento", igual a $2,0 \mathrm{kN} / \mathrm{m}^{2}$, para edifícios comerciais (escritórios) e residenciais.

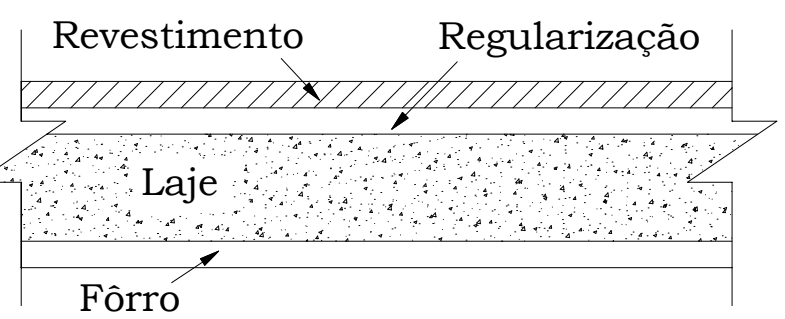

Figura 5.1 - Dimensões para o cálculo dos pesos próprios de uma laje 


\section{4 - Recomendações sobre o Pré-Dimensionamento dos Elementos}

Serão utilizadas as recomendações de ALBURQUERQUE [1998] sobre a estruturação do pavimento, com a padronização das fôrmas, dimensão e geometria das seções transversais das peças.

\subsubsection{Pilares}

Os pilares devem apresentar pouca variação nas dimensões de sua seção transversal, para evitar a utilização de fôrmas de diversos tamanhos. De acordo com ALBURQUERQUE [1998], a utilização de cinco seções transversais por pavimento é um número razoável e, quando possível, deve-se manter um valor não inferior a $20 \mathrm{~cm}$ para o menor lado do pilar, para não sobressair muito da arquitetura e para facilitar as operações de concretagem.

Quanto à geometria, deve-se procurar utilizar seções transversais retangulares ou quadradas, por serem de execução mais fácil e rápida. Assim, deve-se evitar, desde que não existam imposições arquitetônicas, a utilização de pilares de formas variadas com seções transversais em $\mathrm{T}, \mathrm{L}$ ou $\mathrm{U}$, pois apresentam uma execução mais complicada, prejudicando o andamento da obra.

\subsubsection{Vigas}

Os tipos de seção transversal das vigas protendidas a serem utilizadas no trabalho são do tipo faixa, apresentando, de acordo com AALAMI [1999] as dimensões mostradas na figura abaixo.

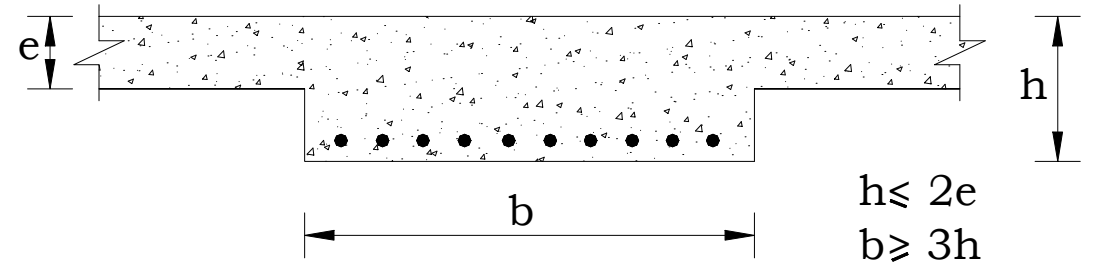

Figura 5.2 - Recomendações de projeto para vigas-faixa (AALAMI [1999]) 
Onde:

b é a largura da viga faixa;

h é a altura total da viga faixa;

e é a espessura da laje.

Segundo as recomendações de Albuquerque, a utilização de dois ou três tipos de seção transversal de concreto armado por pavimento é ideal, porém, para vigas faixa protendidas com cordoalhas engraxadas, deve-se utilizar, quando possivel, apenas uma seção transversal, para o caso de pavimentos usuais de edifícios de concreto. Porém, a utilização de até duas seções transversais é aceitável.

\subsubsection{Lajes}

Para as lajes planas, geralmente se adota a mesma espessura para todo o pavimento, em se tratando de um pavimento usual de edificio comercial ou residencial.

De acordo com o Projeto de Revisão da NBR 6118-2001, a espessura mínima a ser respeitada para o caso de se utilizar a protensão é de $16 \mathrm{~cm}$.

\section{5 - Materiais}

Os materiais a serem utilizados na análise apresentarão resistências características usuais dos edificios comerciais e residenciais construídos no País.

\subsubsection{Concreto}

De acordo com o Projeto de Revisão da NBR 6118-2001, a resistência mínima à compressão que o concreto pode apresentar é de $20 \mathrm{MPa}$ para construções em concreto armado e de $25 \mathrm{MPa}$ para obras com concreto protendido, sendo que estes valores podem variar dependendo da classe de agressividade ambiental do local da obra. 
$\mathrm{Na}$ análise dos pisos, foi estabelecida a resistência à compressão do concreto de $35 \mathrm{MPa}$, por ser um valor já empregado atualmente na construção civil.

\subsubsection{Armadura Ativa}

Para a armadura ativa, tanto a aderente quanto a não aderente, serão utilizadas as bitolas mais comuns, sendo que, os diâmetros a serem adotados são os de 12,7 e 15,2 mm, e com utilização de somente um tipo de bitola. As cordoalhas deverão ser do tipo $\mathrm{RB}$, isto é, de relaxação baixa, para evitar maiores perdas de protensão.

Tabela 5.2 - Características das cordoalhas a serem utilizadas nos modelos.

\begin{tabular}{|c|c|c|c|c|c|c|c|c|c|}
\hline Cordoalha & $\begin{array}{c}\phi \\
(\mathrm{mm})\end{array}$ & $\begin{array}{l}\mathbf{A}_{\text {aprox. }} \\
\left(\mathrm{mm}^{2}\right)\end{array}$ & $\begin{array}{l}A_{\text {minima }} \\
\left(\mathrm{mm}^{2}\right)\end{array}$ & $\begin{array}{c}\text { Massa } \\
\text { aprox. } \\
(\mathrm{kg} / \mathrm{km})\end{array}$ & $\begin{array}{l}\text { Carge } \\
\text { de ru } \\
(\mathrm{kN})\end{array}$ & $\begin{array}{c}\min . \\
\text { ptura } \\
(\mathrm{kgf})\end{array}$ & $\begin{array}{r}\text { Carg } \\
\text { con } \\
\text { along } \\
(\mathrm{kN})\end{array}$ & $\begin{array}{l}\text { min. } \\
1 \% \\
\text { imento } \\
(\mathrm{kgf})\end{array}$ & $\begin{array}{c}\text { Along. } \\
\text { Após } \\
\text { ruptura } \\
(\%)\end{array}$ \\
\hline \multirow{2}{*}{ CP 190 RB 7} & $\begin{array}{l}12,7 \\
\end{array}$ & 101,4 & $\begin{array}{l}98,7 \\
\end{array}$ & 792 & 187,3 & 18730 & 168,6 & 16860 & 3,5 \\
\hline & 15,2 & 143,5 & 140,0 & 1126 & 265,8 & 26580 & 239,2 & 23920 & 3,5 \\
\hline
\end{tabular}

Fonte: Indústria Belgo-Mineira

\subsubsection{Armadura Passiva}

A armadura passiva será do tipo CA-50, obedecendo as especificações da NBR 7480.

Tabela 5.3 - Características da armadura passiva

\begin{tabular}{||c|c|c|}
\hline $\begin{array}{c}\phi \\
(\mathrm{mm})\end{array}$ & $\begin{array}{c}\text { Massa aprox. } \\
(\mathrm{kg} / \mathrm{m})\end{array}$ & $\begin{array}{c}\text { Seção Nominal } \\
\left(\mathrm{mm}^{2}\right)\end{array}$ \\
\hline \hline 6,3 & 0,245 & 31,2 \\
\hline 8,0 & 0,395 & 50,3 \\
\hline 10,0 & 0,617 & 78,5 \\
\hline 12,5 & 0,963 & 122,7 \\
\hline 16,0 & 1,578 & 201,1 \\
\hline
\end{tabular}

Fonte: Indústria Belgo-Mineira 


\subsection{4 - Fôrmas}

As fôrmas geralmente se dividem em: placas de madeira de compensado resinada e placas de madeira de compensado plastificadas, que podem ser manuseadas por um ou mais operários (dependendo das dimensões da placa).

São utilizados, também, os blocos de EPS (Poliestireno Expandido). São constituídos de $98 \%$ de ar e $2 \%$ de poliestireno, possuindo grande praticidade (além de leves podem ser moldados em várias formas) e economia.

Os blocos de EPS são extremamente leves, reduzindo, portanto, o peso total da estrutura e, além disso, apresentam uma série de vantagens descritas abaixo (ALBUQUERQUE [1998]).

- É ótimo isolante térmico;

- Apresenta baixa absorção de água;

- Possui facilidade de transporte, manuseio e execução no canteiro de obras;

- O sistema permite a passagem de instalações através do bloco.

Ainda, este sistema permite várias alturas para as lajes, mostrando, assim, grande versatilidade e aproveitamento na obra.

Este sistema é bastante utilizado na construção de lajes em grelha, como pode ser visto na figura 5.3.

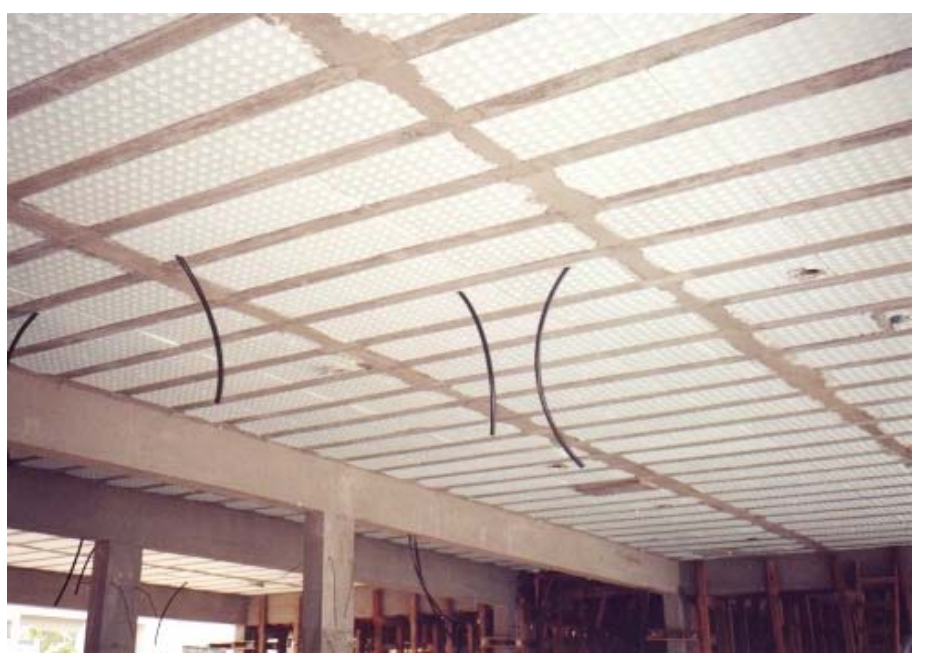

Figura 5.3 - Esquema da utilização de EPS em pavimentos de edifícios

Um outro sistema de fôrmas é o de caixotes plásticos de polietileno injetado. Este sistema traz muitas vantagens, como:

- Rapidez de execução; 
- Os caixotes não introduzem carregamentos à laje;

- Permitem a passagem de dutos para as instalações;

- A fôrma pode ser reutilizada várias vezes;

- Economia de madeira e aço;

- Reutilização em curto prazo de tempo;

- Fácil montagem e redução de escoramento.

\subsection{5 - Escoramentos}

De acordo com a tecnologia atual, o emprego de escoramento metálico permite maior precisão no escoramento dos elementos estruturais e de um maior reaproveitamento da peça. Os escoramentos apresentam as mais variadas formas, sendo distribuídos conforme o elemento estrutural a ser escorado.

Os escoramentos, assim como as fôrmas, se destacam por sua praticidade e economia (reutilizações e rapidez de posicionamento).

\section{6 - Efeitos de Segunda Ordem em Edificios Altos}

A existência de deslocamentos expressivos pode propiciar o surgimento de efeitos de segunda ordem que, somados ao estado de solicitação original da estrutura, pode conduzi-la a instabilidade.

A análise de segunda ordem considera a estrutura deformada na formulação de suas equações de equilíbrio, e esta análise é feita em todo o edificio, podendo o projetista controlar a rigidez global do edificio.

De acordo com CARMO [1995], "assume-se que os esforços obtidos nas análises de primeira ordem são suficientemente precisos para o projeto da estrutura se não forem excedidos em mais de $10 \%$ pelos esforços finais, isto é, os momentos de segunda ordem poderão ser ignorados se o momento de final, incluindo os efeitos de segunda ordem da estrutura, for menor ou igual a 1,1 vezes o momento de primeira ordem".

Neste segmento, pretende-se estudar os parâmetros verificadores da instabilidade da estrutura, que são os parâmetros $\alpha$ e $\gamma_{z}$. 


\subsection{1 - Parâmetro de instabilidade $\alpha$}

Segundo LIMA [2001], BECK \& KÖNING¹ [1966] utilizaram a teoria de Eüler para desenvolver um parâmetro avaliador dos efeitos de segunda ordem, em um regime elástico-linear, em função do carregamento aplicado e das características geométricas do pilar.

Segundo os referidos autores, o edificio era considerado como um pilar equivalente, que tinha rigidez igual à soma das rigidezes de todos os pilares isolados que participavam do contraventamento da estrutura, engastado na base e livre no topo, apresentando seção transversal constante e submetida a uma ação vertical uniformemente distribuída ao longo de seu comprimento.

$$
\alpha=H \cdot \sqrt{\frac{N}{E . I}}
$$

Onde,

$\mathrm{H}$ é a altura total da estrutura;

$\mathrm{N} \quad$ é a somatória das ações verticais;

EI é módulo de rigidez de flexão da estrutura.

De acordo com os autores, o valor de $\alpha$ para que os efeitos de segunda ordem permanecessem inferiores a $10 \%$ dos efeitos de primeira ordem, deveria ser menor ou igual a 0,6 .

Segundo VASCONCELOS ${ }^{2}$ [1985], o valor do módulo de rigidez EI, proposto por BECK \& KÖNING [1966], só é representativo para o caso de estruturas pré-moldadas. Logo, a não consideração do acréscimo de rigidez, em estruturas moldadas no local, acarretará valores de $\alpha$ muito conservadores.

De acordo com LIMA [1998], o valor do módulo de rigidez equivalente $(\mathrm{EI})_{\text {eq }}$ da estrutura pode ser obtido em função da altura da edificação, da força aplicada na estrutura (concentrada no topo ou como uma força $q$ uniformemente distribuída ao longo da altura da edificação) e do deslocamento

\footnotetext{
${ }^{1}$ BECK, H.;KÖNING, G. [1966]. Restraining Forces (Festhaltekräfte) in the Analysis of Tall Buildings. In: Symposium of Tall Buildings, Oxford, Proceedings, pp. 513-536;

${ }^{2}$ VASCONCELOS, A. C. [1985]. Critérios para Dispensa de Consideração do Efeito de $2^{a}$ Ordem. In: Reunião Anual do Ibracon: Colóquio Sobre Estabilidade Global das Estruturas de Concreto Armado, São Paulo, Anais;
} 
que a estrutura sofre devido às ações horizontais (ver figura 5.7), para este último caso.

$$
(\mathrm{EI})_{\mathrm{eq}}=\frac{\mathrm{q} \cdot \mathrm{H}^{4}}{8 \cdot \mathrm{a}}
$$

Onde,

q é a ação horizontal uniformemente distribuída;

a é o deslocamento horizontal no topo da estrutura devido a ação horizontal q;

H é a altura total da edificação.

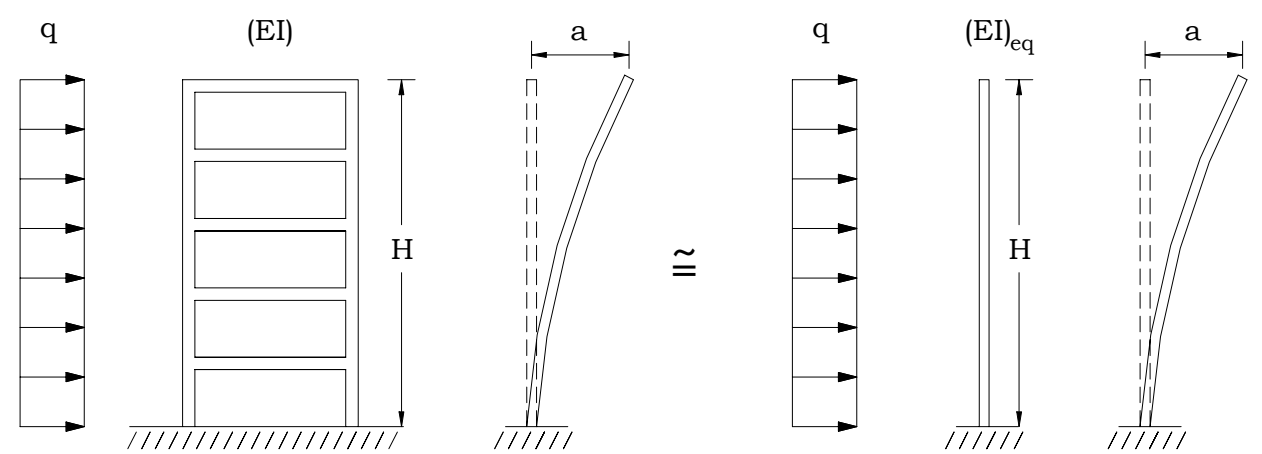

Figura 5.7 - Módulo de rigidez equivalente

Na figura 5.8, ilustra-se a variação da linha elástica da estrutura, que depende do tipo de sistema de contraventamento, podendo ser: pilar-parede, pórtico e associação de pórtico-parede.

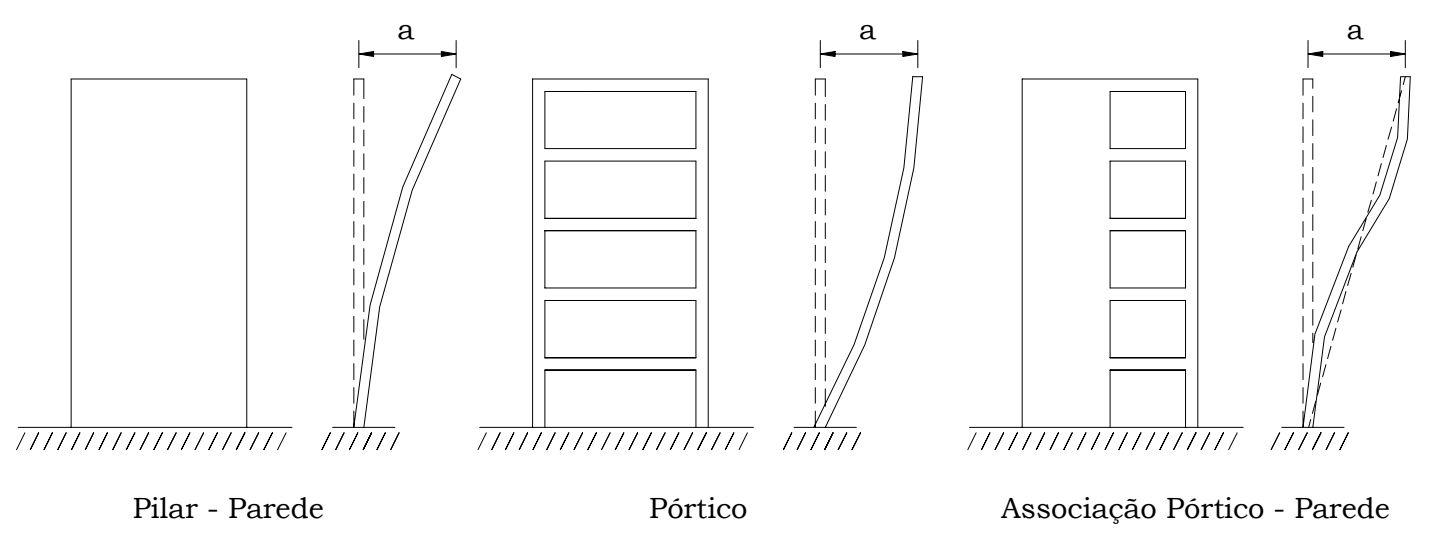

Figura 5.8 - Variação da deformada da estrutura

Segundo LIMA [2001], no caso de pilares-parede, a variação dos deslocamentos é maior à medida que se aproxima do topo. No caso dos pórticos, a deformada apresenta um comportamento contrário ao caso de 
pilar-parede, ou seja, a variação dos deslocamentos é maior junto à base. No caso da associação de ambos, ou seja, a utilização da combinação de pórticos e paredes, existe uma compensação tal que aparece um ponto de inflexão na deformada.

LIMA [2001], apud $\mathrm{FRANCO}^{3}$, mostrou em sua pesquisa que as diferenças entre as deformadas nos sistemas de contraventamento resultam em diferentes respostas nos efeitos de segunda ordem e nos valores de $\alpha$.

$\mathrm{Na}$ tabela 5.4 , tem-se os valores limites de $\alpha$.

TABELA 5.4 - Valores de $\alpha_{\lim }$ para os diferentes sistemas de contraventamento.

\begin{tabular}{|c|c|}
\hline Tipo de Estrutura de Contraventamento & $\alpha_{\lim }$ \\
\hline \hline Sistema Pilar-Parede & 0,7 \\
\hline Sistema de Pórticos & 0,5 \\
\hline Associação Pórtico-Parede & 0,6 \\
\hline
\end{tabular}

Fonte: LIMA [2001]

VASCONCELOS [1987] sugeriu uma outra abordagem do problema, estabelecendo que o valor de $\alpha_{\lim }$ seja calculado pela expressão:

$$
\alpha_{\lim }=\frac{1}{\sqrt{1,2}} \cdot\left(0,88-0,44 \cdot 10^{-0,144 . n}\right)
$$

Com,

n número de pavimentos da edificação.

$\mathrm{Na}$ utilização da equação 5.3 , para valores de $\mathrm{n} \geq 13$, o resultado do parâmetro de instabilidade $\alpha_{\lim }$ converge para um valor igual 0,8 .

\subsection{2 - O Coeficiente $\gamma_{z}$}

Desenvolvido por FRANCO \& VASCONCELOS [1991], este processo baseia-se na razão existente entre os acréscimos de deslocamentos referentes a duas iterações, que apresentam praticamente o mesmo valor e, assumindose que esta hipótese, ou seja, que a razão permaneça constante ao longo de todas as demais iterações, pode-se, com isso, aproximar os deslocamentos horizontais por uma progressão geométrica decrescente, sendo que o mesmo

${ }^{3}$ FRANCO, M. [1985b]. O Parâmetro de Instabilidade de Edifícios Altos. Revista Portuguesa de Engenharia de Estruturas, Lisboa, No. 23, pp. 69-72; 
ocorre com os momentos fletores (LIMA [2001], apud FRANCO \& VASCONCELOS [1997]).

Com isso, o valor de $\gamma_{z}$ pode ser escrito como:

$$
\gamma_{z}=\frac{1}{1-\frac{\Delta \mathrm{M}_{\mathrm{d}}}{\mathrm{M}_{1 \mathrm{~d}}}}
$$

Onde,

$\Delta \mathrm{M}_{\mathrm{d}} \quad$ acréscimo de momentos após a análise de primeira ordem;

$\mathrm{M}_{1 \mathrm{~d}} \quad$ corresponde ao momento de primeira ordem.

Segundo LIMA [2001], o $\gamma_{z}$ pode ser calculado com as ações verticais e horizontais de serviço, nos casos usuais de edificios.

O critério para dispensa do acréscimo dos efeitos de segunda ordem na edificação é que o valor do efeito de segunda ordem seja menor ou igual ao momento de primeira ordem mais $10 \%$ deste valor, ou seja, o valor de $\gamma_{z}$ deverá ser menor ou igual a 1,1 .

Segundo LIMA [1998], o valor do coeficiente $\gamma_{z}$ pode ser utilizado como majorador dos efeitos de primeira ordem, porém, FRANCO \& VASCONCELOS [1991] mostraram que este valor, majorador dos momentos de primeira ordem, é bem aplicado até o valor de $\gamma_{z} \leq 1,2$.

\section{7 - Pavimento a ser Estudado}

Para o estudo, foi tomado como exemplo o pavimento estudado por ALBUQUERQUE [1998], que realizou um estudo semelhante, porém, com ênfase em estruturas de concreto armado.

O objetivo é avaliar os índices de consumo de materiais entre os exemplos e eleger o que apresenta melhores resultados e analisar o desempenho estrutural dos exemplos, que no caso, será determinado pelos deslocamentos máximos encontrados no pavimento e no pórtico tridimensional.

Não serão avaliados os momentos fletores, pois os exemplos apresentam arranjos estruturais diferenciados, portanto, comportamentos diferentes.

A figura 5.9 ilustra o pavimento a ser estudado. 


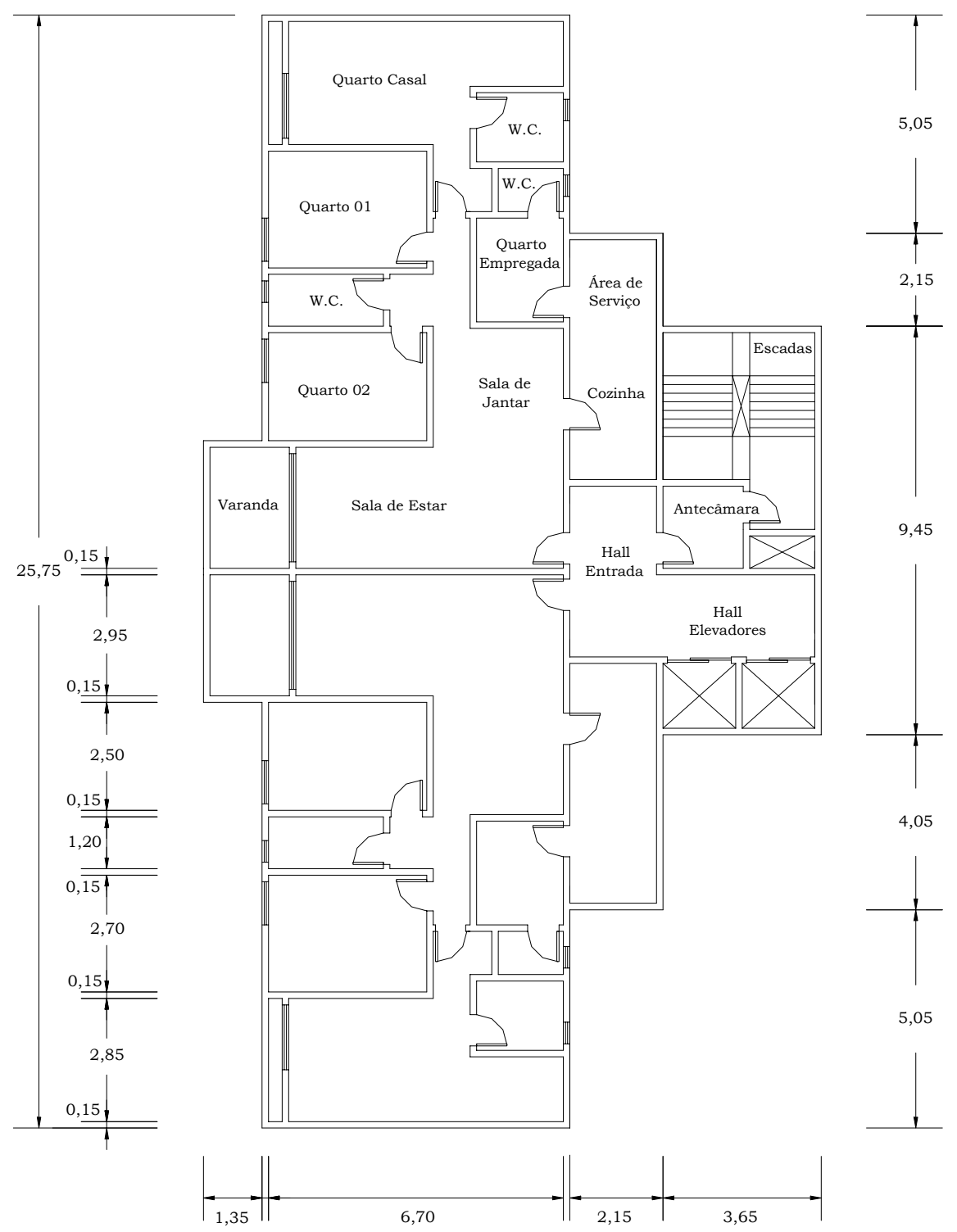

Figura 5.9 - Pavimento-tipo do trabalho de ALBUQUERQUE [1998] (medidas em metros)

$\mathrm{Na}$ figura 5.9, ilustra-se o pavimento analisado por Albuquerque. Consiste em um piso de edificio residencial com $254 \mathrm{~m}^{2}$ de área com altura de 20 andares. O autor desenvolveu a modelagem utilizando o programa TQS ${ }^{\circ}$, adotando a análise por grelha. 


\section{8 - Resultados da Pesquisa de ALBUQUERQUE [1998]}

$\mathrm{Na}$ figura 5.10, são ilustrados os arranjos estruturais em concreto armado, sendo eles, laje apoiada em vigas sobre pilares (A01); laje nervurada apoiada em vigas sobre pilares (A02) e laje plana nervurada apoiada sobre pilares (A03).
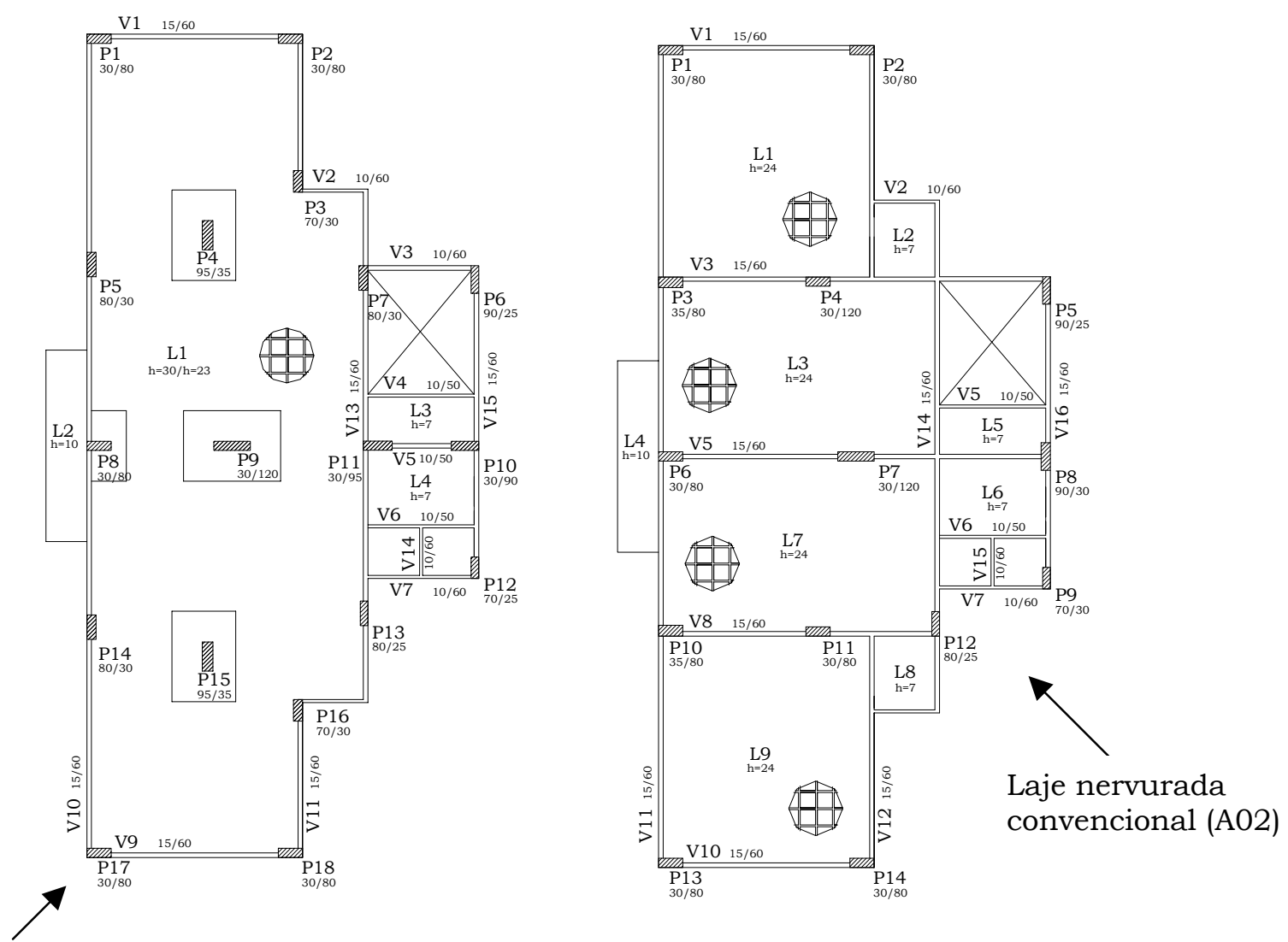

Laje plana nervuradapilar (A03)

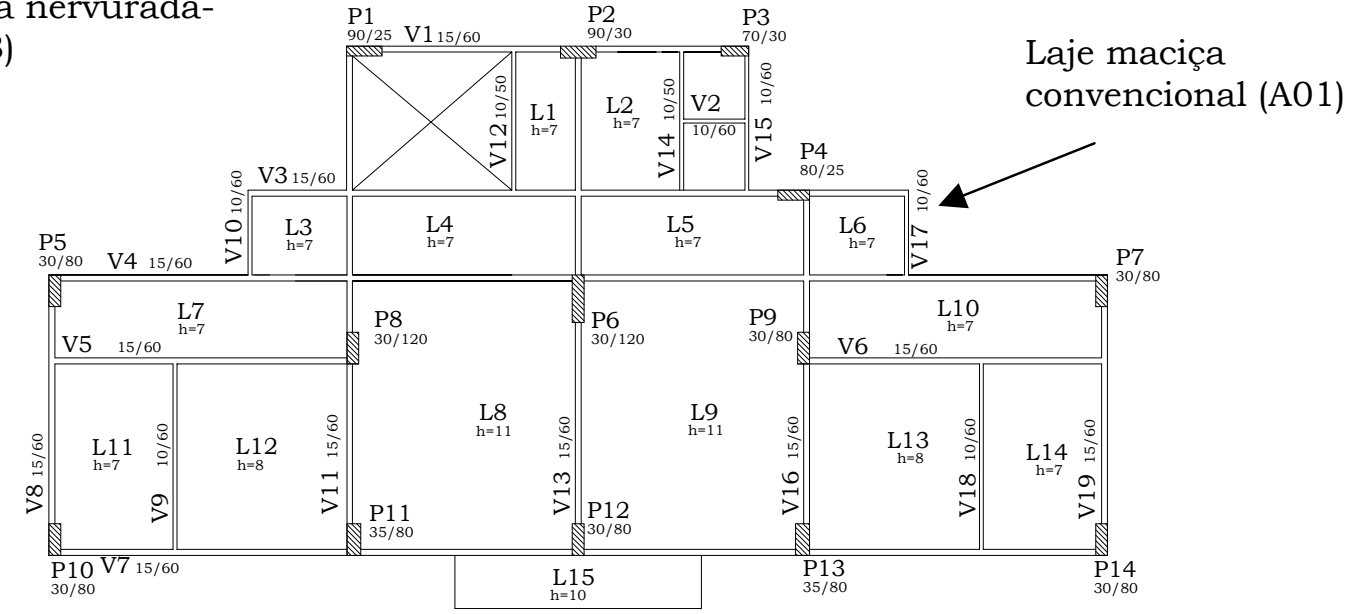

Figura 5.10 - Esquemas estruturais adotados por ALBUQUERQUE [1998] 
Nas tabelas 5.5 a 5.14 , tem-se as características dos modelos de Albuquerque. Nos gráficos 5.1, 5.2 e 5.3, tem-se a comparação dos valores dos consumos de materiais para os exemplos A01, A02 e A03.

Vale salientar que a seção transversal dos pilares não varia ao longo do edificio.

Para o modelo A01, tem-se:

Tabela 5.5 - Consumos de materiais (globais) para o modelo A01

\begin{tabular}{|c|c|c|c|c||}
\hline \multirow{2}{*}{ Exemplo } & Elemento & $\begin{array}{c}\text { Vol. de } \\
\text { Concreto } \\
\left.\mathbf{( m}^{\mathbf{3}}\right)\end{array}$ & $\begin{array}{c}\text { Armadura } \\
\text { passiva } \\
\mathbf{( k g )}\end{array}$ & $\begin{array}{c}\text { Área de } \\
\text { Fôrmas } \\
\left.\mathbf{( m}^{\mathbf{2}}\right)\end{array}$ \\
\hline \hline \multirow{3}{*}{ A01 } & LAJE & 366,0 & $18.389,0$ & $4.234,6$ \\
\cline { 2 - 5 } & VIGA & 244,6 & $36.888,0$ & $3.535,0$ \\
\cline { 2 - 5 } & PILAR & 206,8 & $21.277,0$ & $1.872,0$ \\
\cline { 2 - 6 } & TOTAL: & $\mathbf{8 1 7 , 4}$ & $\mathbf{7 6 . 5 5 4 , 0}$ & $\mathbf{9 . 6 4 1 , 6}$ \\
\hline
\end{tabular}

Tabela 5.6 - Taxas de consumo de materiais para o modelo A01

\begin{tabular}{|c|c|c|c|c|c|}
\hline Elemento & $\begin{array}{c}\text { Taxa de } \\
\text { Armadura } \\
\left(\mathrm{kg} / \mathrm{m}^{3}\right)\end{array}$ & $\begin{array}{c}\text { Taxa de } \\
\text { Armadura } \\
\left(\mathbf{k g} / \mathrm{m}^{3}\right)\end{array}$ & $\begin{array}{l}\text { Taxa de } \\
\text { Fôrmas } \\
\left(\mathrm{m}^{2} / \mathrm{m}^{2}\right)\end{array}$ & $\begin{array}{c}\text { Taxa de } \\
\text { Pilares } \\
\text { (m²/pilar) }\end{array}$ & $\begin{array}{c}\text { Espes. } \\
\text { Média } \\
(\mathrm{cm})\end{array}$ \\
\hline$\overline{\text { LAJE }}$ & $\overline{50,24}$ & \multirow{3}{*}{93,66} & \multirow{3}{*}{1,90} & \multirow{3}{*}{18,14} & \multirow{3}{*}{16,1} \\
\hline VIGA & 150,81 & & & & \\
\hline PILAR & 102,89 & & & & \\
\hline
\end{tabular}

Tabela 5.7 - Parâmetros de Instabilidade para o modelo A01

\begin{tabular}{||c|c|c|}
\hline Direção & $\gamma_{\mathbf{z}}$ & $\alpha$ \\
\hline \hline Direção X - Face Lateral & 1,07 & 0,64 \\
\hline Direção Y - Face Frontal & 1,06 & 0,57 \\
\hline
\end{tabular}


Para o modelo A02, tem-se:

Tabela 5.8 - Consumos de materiais (globais) para o modelo A02

\begin{tabular}{|c|c|c|c|c||}
\hline \multirow{2}{*}{ Exemplo } & Elemento & $\begin{array}{c}\text { Vol. de } \\
\text { Concreto } \\
\left(\mathbf{m}^{\mathbf{3}}\right)\end{array}$ & $\begin{array}{c}\text { Armadura } \\
\text { passiva } \\
\mathbf{( k g )}\end{array}$ & $\begin{array}{c}\text { Área de } \\
\text { Fôrmas } \\
\mathbf{( m}^{\mathbf{2}} \mathbf{)}\end{array}$ \\
\hline \hline \multirow{3}{*}{$\mathbf{A 0 2}$} & LAJE & 326,6 & $14.704,0$ & $4.237,4$ \\
\cline { 2 - 5 } & VIGA & 190,8 & $30.253,0$ & $2.773,8$ \\
\cline { 2 - 5 } & PILAR & 206,8 & $19.384,0$ & $1.872,0$ \\
\cline { 2 - 5 } & TOTAL: & $\mathbf{7 2 4 , 2}$ & $\mathbf{6 4 . 3 4 1 , 0}$ & $\mathbf{8 . 9 7 3 , 2}$ \\
\hline
\end{tabular}

Tabela 5.9 - Taxas de consumo de materiais para o modelo A02

\begin{tabular}{|c|c|c|c|c|c|}
\hline Elemento & $\begin{array}{c}\text { Taxa de } \\
\text { Armadura } \\
\left(\mathbf{k g} / \mathbf{m}^{3}\right)\end{array}$ & $\begin{array}{c}\text { Taxa de } \\
\text { Armadura } \\
\left(\mathbf{k g} / \mathrm{m}^{3}\right)\end{array}$ & $\begin{array}{l}\text { Taxa de } \\
\text { Fôrmas } \\
\left(\mathrm{m}^{2} / \mathrm{m}^{2}\right)\end{array}$ & $\begin{array}{c}\text { Taxa de } \\
\text { Pilares } \\
\text { (m²/pilar) }\end{array}$ & $\begin{array}{c}\text { Espes. } \\
\text { Média } \\
(\mathrm{cm})\end{array}$ \\
\hline$\overline{\text { LAJE }}$ & 45,02 & \multirow{3}{*}{88,84} & \multirow{3}{*}{1,77} & \multirow{3}{*}{18,14} & \multirow{3}{*}{14,25} \\
\hline VIGA & 158,55 & & & & \\
\hline PILAR & 93,73 & & & & \\
\hline
\end{tabular}

Tabela 5.10 - Parâmetros de Instabilidade para o modelo A02

\begin{tabular}{|c|c|c||}
\hline Direção & $\gamma_{\mathbf{z}}$ & $\alpha$ \\
\hline \hline Direção X - Face Lateral & 1,08 & 0,66 \\
\hline Direção Y - Face Frontal & 1,05 & 0,56 \\
\hline
\end{tabular}

Para o modelo A03, tem-se:

Tabela 5.11 - Consumos de materiais (global) para o modelo A03

\begin{tabular}{|c|c|c|c|c|}
\hline Exemplo & Elemento & $\begin{array}{c}\text { Vol. de } \\
\text { Concreto } \\
\left(\mathrm{m}^{3}\right)\end{array}$ & $\begin{array}{c}\text { Armadura } \\
\text { passiva } \\
\text { (kg) }\end{array}$ & $\begin{array}{c}\text { Área de } \\
\text { Fôrmas } \\
\left(\mathbf{m}^{2}\right)\end{array}$ \\
\hline \multirow{4}{*}{ A02 } & LAJE & 483,4 & $20.112,0$ & $4.415,0$ \\
\hline & VIGA & 138,2 & $23.364,0$ & $2.162,8$ \\
\hline & PILAR & 260,4 & $26.910,0$ & $2.361,6$ \\
\hline & TOTAL: & 882,0 & $70.386,0$ & $8.939,4$ \\
\hline
\end{tabular}


Tabela 5.12 - Taxas de consumo de materiais para o modelo A03

\begin{tabular}{|c|c|c|c|c|c|}
\hline Elemento & $\begin{array}{c}\text { Taxa de } \\
\text { Armadura } \\
\left(\mathrm{kg} / \mathrm{m}^{3}\right)\end{array}$ & $\begin{array}{c}\text { Taxa de } \\
\text { Armadura } \\
\left(\mathrm{kg} / \mathrm{m}^{3}\right)\end{array}$ & $\begin{array}{l}\text { Taxa de } \\
\text { Fôrmas } \\
\left(\mathrm{m}^{2} / \mathrm{m}^{2}\right)\end{array}$ & $\begin{array}{c}\text { Taxa de } \\
\text { Pilares } \\
\text { (m²/pilar) }\end{array}$ & $\begin{array}{c}\text { Espes. } \\
\text { Média } \\
(\mathrm{cm})\end{array}$ \\
\hline$\overline{\text { LAJE }}$ & 41,61 & \multirow{3}{*}{79,80} & \multirow{3}{*}{1,76} & \multirow{3}{*}{14,11} & \multirow{3}{*}{17,36} \\
\hline$\overline{\text { VIGA }}$ & 169,06 & & & & \\
\hline PILAR & 103,34 & & & & \\
\hline
\end{tabular}

Tabela 5.13 - Parâmetros de Instabilidade para o modelo A03

\begin{tabular}{|c|c|c||}
\hline Direção & $\gamma_{\mathbf{z}}$ & $\alpha$ \\
\hline \hline Direção X - Face Lateral & 1,05 & 0,55 \\
\hline Direção Y - Face Frontal & 1,09 & 0,75 \\
\hline
\end{tabular}

Volume total de concreto (m3)

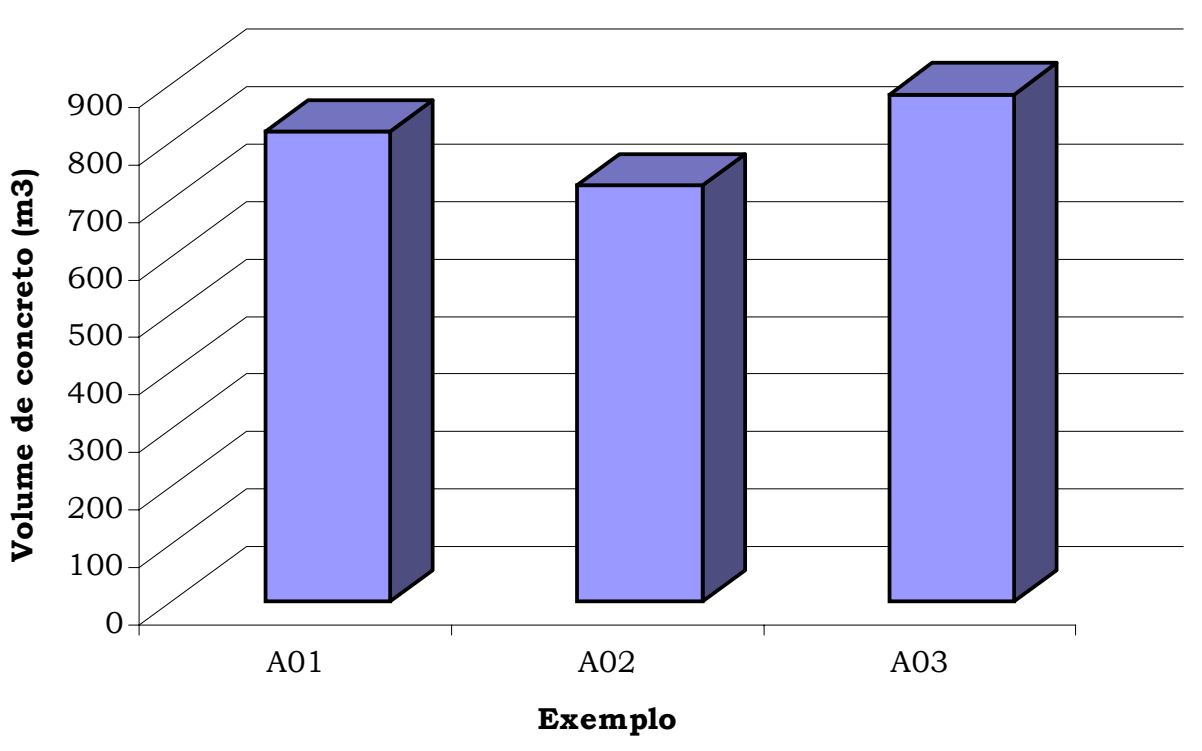

Gráfico 5.1 - Consumo de concreto 
Quantidade total de armadura passiva (kg)

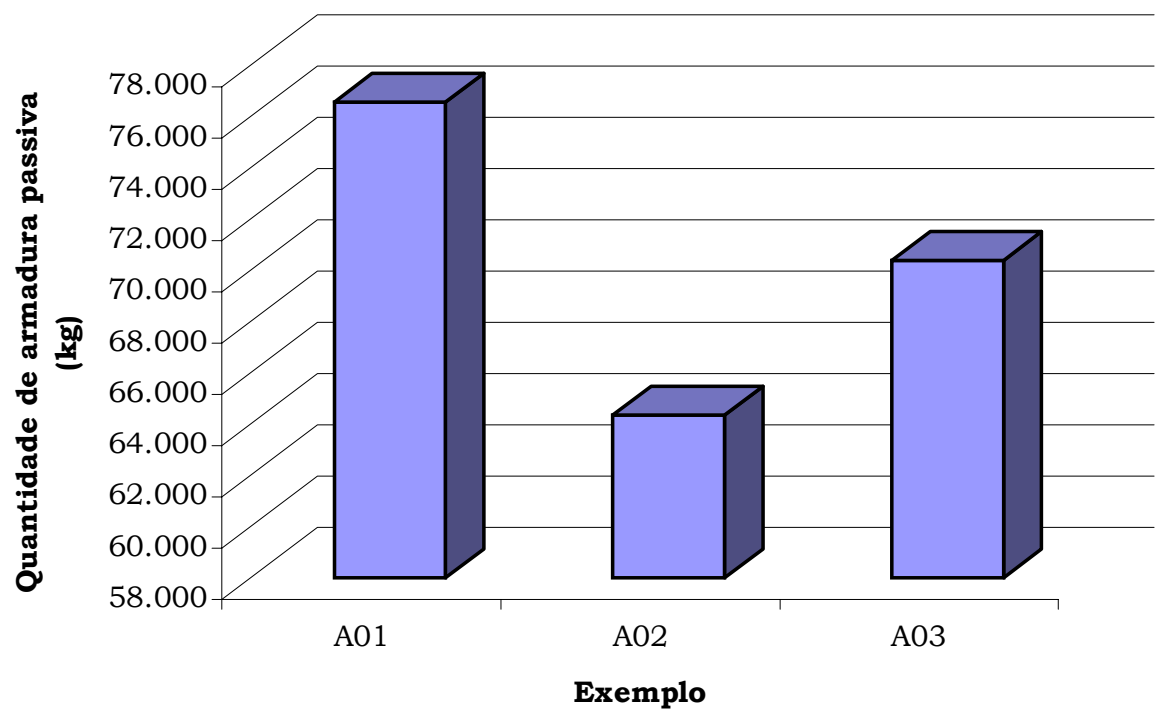

Gráfico 5.2 - Consumo de armadura passiva

Quantidade total de área de fôrmas (m2)

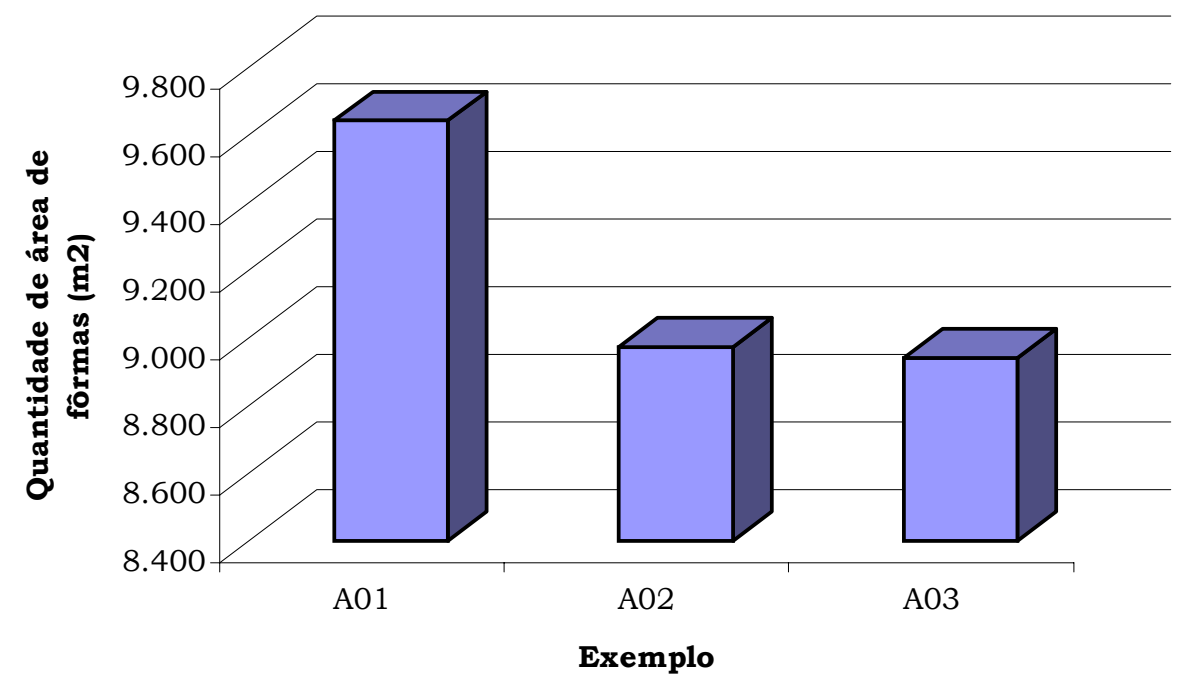

Gráfico 5.3 - Consumo de fôrmas

\section{9 - Resultados da Pesquisa Atual}

Agora, terá início a análise dos pavimentos utilizando a protensão não aderente e a aderente. Nos apêndices A, B e C, encontram-se os critérios adotados no programa de cálculo Estrutural TQS $®$, os resultados referentes aos deslocamentos e diagramas de momento fletor para os exemplos 
protendidos $\mathrm{e}$ as considerações sobre os pórticos tridimensionais dos exemplos, respectivamente.

Vale salientar que o edificio é composto de 20 pavimentos.

Na Tabela 5.14, tem-se um comparativo das resistências à compressão do concreto da presente pesquisa em relação ao trabalho de ALBUQUERQUE [1998].

Tabela 5.14 - Resistências à compressão do concreto para os modelos a serem analisados

\begin{tabular}{||c|c|c||}
\hline & ALBURQUERQUE [1998] & Atual Pesquisa \\
\hline \hline Lajes & $20 \mathrm{MPa}$ & $35 \mathrm{MPa}$ \\
\hline Vigas & $35 \mathrm{MPa}$ & $35 \mathrm{MPa}$ \\
\hline Pilares & $35 \mathrm{MPa}$ & $35 \mathrm{MPa}$ \\
\hline
\end{tabular}

Foram dimensionados seis modelos da seguinte forma:

E01 - Modelo de laje plana maciça sobre pilares com protensão não aderente;

E02 - Modelo de laje plana maciça sobre pilares com protensão aderente;

E03 - Modelo de laje plana nervurada sobre pilares com protensão não aderente;

E04 - Modelo de laje plana nervurada sobre pilares com protensão aderente;

E05 - Modelo de laje nervurada sobre vigas faixa com protensão não aderente em pilares;

E06 - Modelo de laje nervurada sobre vigas faixa com protensão aderente em pilares.

\subsection{1 - Lajes planas maciças apoiadas sobre pilares}

Na figura 5.11 pode-se ver os arranjos estruturais para o pavimento da figura 5.9. Em ambos os casos, isto é, para a protensão aderente e não aderente, foram utilizadas espessuras da laje de $16,0 \mathrm{~cm}$, ou seja, o mínimo estabelecido pelo Projeto de Revisão da NBR 6118-2001. 


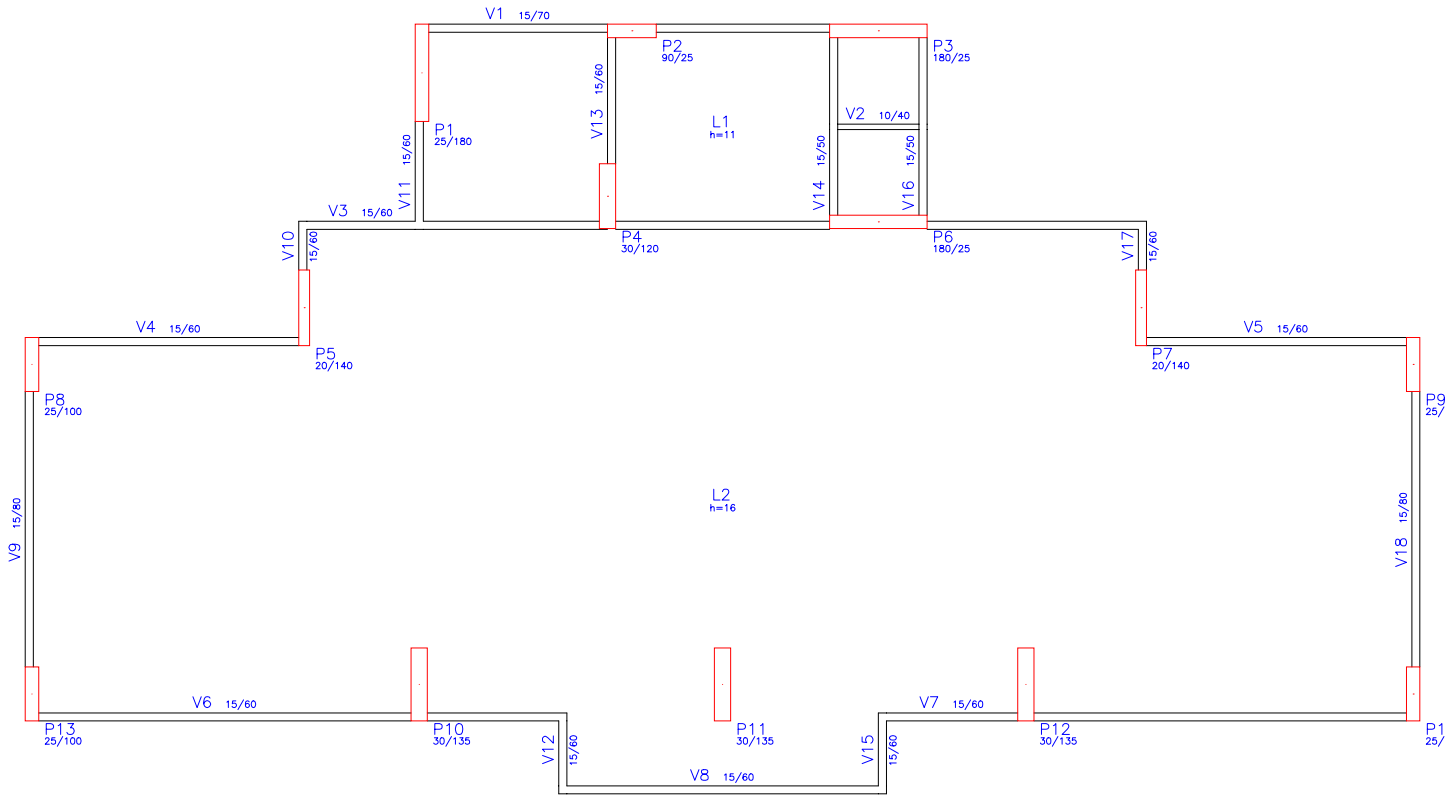

Figura 5.11 - Arranjo estrutural para o sistema de laje plana maciça apoiada sobre pilares

Na figura 5.12, pode-se ver o tipo de ancoragem ativa padrão utilizado no dimensionamento do modelo com protensão aderente.

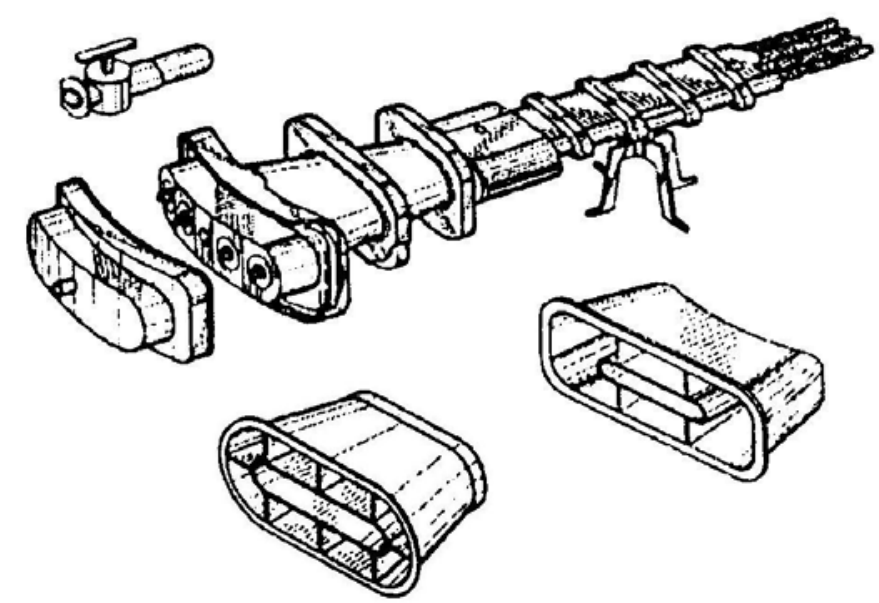

Figura 5.12 - Ancoragem ativa para sistema de protensão aderente com quatro cordoalhas (AALAMI [1999])

Para a laje plana com protensão não aderente, as tabelas 5.15 a 5.17 mostram suas características de consumo de materiais e de seu comportamento estrutural. 
Tabela 5.15 - Consumos de materiais (globais) para o modelo E01

\begin{tabular}{||c|c|c|c|c|c||}
\hline \multirow{2}{*}{ Exemplo } & Elemento & $\begin{array}{c}\text { Vol. de } \\
\text { Concreto } \\
\mathbf{( m}^{\mathbf{3}} \mathbf{n}\end{array}$ & $\begin{array}{c}\text { Armadura } \\
\text { passiva } \\
\mathbf{( k g})\end{array}$ & $\begin{array}{c}\text { Armadura } \\
\text { Ativa } \mathbf{( k g})\end{array}$ & $\begin{array}{c}\text { Área de } \\
\text { Fôrmas } \\
\left.\mathbf{( m}^{\mathbf{2}}\right)\end{array}$ \\
\hline \hline \multirow{3}{*}{ E01 } & LAJE & 714,7 & $29.554,0$ & $19.800,0$ & $4.554,0$ \\
\cline { 2 - 6 } & VIGA & 148,2 & $19.342,0$ & - & $1.998,0$ \\
\cline { 2 - 7 } & PILAR & 271,3 & $24.910,0$ & - & $2.528,0$ \\
\cline { 2 - 7 } & TOTAL: & $\mathbf{1 . 1 3 4 , 2}$ & $\mathbf{7 3 . 8 0 6 , 0}$ & $\mathbf{1 9 . 8 0 0 , 0}$ & $\mathbf{9 . 0 8 0 , 0}$ \\
\hline
\end{tabular}

Tabela 5.16 - Taxas de consumo de materiais para o modelo E01

\begin{tabular}{|c|c|c|c|c|c|c|}
\hline Elemento & $\begin{array}{c}\text { Taxa de } \\
\text { Armadura } \\
\left(\mathrm{kg} / \mathrm{m}^{3}\right)\end{array}$ & $\begin{array}{c}\text { Taxa de } \\
\text { Protensão } \\
\left(\mathbf{k g} / \mathrm{m}^{3}\right)\end{array}$ & $\begin{array}{c}\text { Taxa de } \\
\text { Armadura } \\
\left(\mathbf{k g} / \mathbf{m}^{3}\right)\end{array}$ & $\begin{array}{l}\text { Taxa de } \\
\text { Fôrmas } \\
\left(\mathrm{m}^{2} / \mathrm{m}^{2}\right)\end{array}$ & $\begin{array}{c}\text { Taxa de } \\
\text { Pilares } \\
\text { (m²/pilar) }\end{array}$ & $\begin{array}{c}\text { Espes } \\
\text { Média } \\
(\mathrm{cm})\end{array}$ \\
\hline$\overline{\text { LAJE }}$ & 41,35 & 27,70 & \multirow{3}{*}{65,07} & \multirow{3}{*}{1,91} & \multirow{3}{*}{17,11} & \multirow{3}{*}{24,0} \\
\hline VIGA & 130,51 & - & & & & \\
\hline PILAR & 91,82 & - & & & & \\
\hline
\end{tabular}

Tabela 5.17 - Parâmetros de Instabilidade para o modelo E01

\begin{tabular}{||c|c|c||}
\hline Direção & $\gamma_{\mathbf{z}}$ & $\alpha$ \\
\hline \hline Direção X - Face Lateral & 1,17 & 0,83 \\
\hline Direção Y - Face Frontal & 1,12 & 0,77 \\
\hline
\end{tabular}

O deslocamento máximo encontrado no pavimento foi de 2,20 cm (ver apêndice B).

Para o exemplo 2, que utiliza a protensão aderente, tem-se (tabelas 5.18 a 5.20): 
Tabela 5.18 - Consumos de materiais (globais) para o modelo E02

\begin{tabular}{|c|c|c|c|c|c||}
\hline \multirow{2}{*}{ Exemplo } & Elemento & $\begin{array}{c}\text { Vol. de } \\
\text { Concreto } \\
\left.\mathbf{( m}^{\mathbf{3}}\right)\end{array}$ & $\begin{array}{c}\text { Armadura } \\
\text { passiva } \\
\mathbf{( k g )}\end{array}$ & $\begin{array}{c}\text { Armadura } \\
\text { Ativa (kg) }\end{array}$ & $\begin{array}{c}\text { Área de } \\
\text { Fôrmas } \\
\left.\mathbf{( m}^{2}\right)\end{array}$ \\
\hline \hline \multirow{3}{*}{ E02 } & LAJE & 714,7 & $28.696,0$ & $17.700,0$ & $4.554,0$ \\
\cline { 2 - 6 } & VIGA & 148,2 & $18.267,0$ & - & $1.998,0$ \\
\cline { 2 - 7 } & PILAR & 271,3 & $24.893,0$ & - & $2.528,0$ \\
\cline { 2 - 7 } & TOTAL: & $\mathbf{1 . 1 3 4 , 2}$ & $\mathbf{7 1 . 8 5 6 , 0}$ & $\mathbf{1 7 . 7 0 0 , 0}$ & $\mathbf{9 . 0 8 0 , 0}$ \\
\hline
\end{tabular}

Tabela 5.19 - Taxas de consumo de materiais para o modelo E02

\begin{tabular}{|c|c|c|c|c|c|c|}
\hline Elemento & $\begin{array}{c}\text { Taxa de } \\
\text { Armadura } \\
\left(\mathrm{kg} / \mathrm{m}^{3}\right)\end{array}$ & $\begin{array}{c}\text { Taxa de } \\
\text { Protensão } \\
\left(\mathrm{kg} / \mathrm{m}^{3}\right)\end{array}$ & $\begin{array}{c}\text { Taxa de } \\
\text { Armadura } \\
\left(\mathrm{kg} / \mathrm{m}^{3}\right)\end{array}$ & $\begin{array}{l}\text { Taxa de } \\
\text { Fôrmas } \\
\left(\mathrm{m}^{2} / \mathrm{m}^{2}\right)\end{array}$ & $\begin{array}{c}\text { Taxa de } \\
\text { Pilares } \\
\text { (m²/pilar) }\end{array}$ & $\begin{array}{c}\text { Espes. } \\
\text { Média } \\
(\mathrm{cm})\end{array}$ \\
\hline$\overline{\text { LAJE }}$ & 40,15 & 24,76 & \multirow{3}{*}{63,35} & \multirow{3}{*}{1,91} & \multirow{3}{*}{17,11} & \multirow{3}{*}{24,0} \\
\hline$\overline{\text { VIGA }}$ & 123,34 & - & & & & \\
\hline PILAR & 91,75 & - & & & & \\
\hline
\end{tabular}

Tabela 5.20 - Parâmetros de Instabilidade para o modelo E02

\begin{tabular}{||c|c|c||}
\hline Direção & $\gamma_{\mathbf{z}}$ & $\alpha$ \\
\hline \hline Direção X - Face Lateral & 1,17 & 0,83 \\
\hline Direção Y - Face Frontal & 1,12 & 0,77 \\
\hline
\end{tabular}

O deslocamento máximo encontrado no pavimento foi de $1,90 \mathrm{~cm}$ (ver apêndice B).

\subsection{2 - Lajes planas nervuradas apoiadas sobre pilares}

Na figura 5.13 pode-se ver o segundo arranjo estrutural adotado para o pavimento da figura 5.9 . 


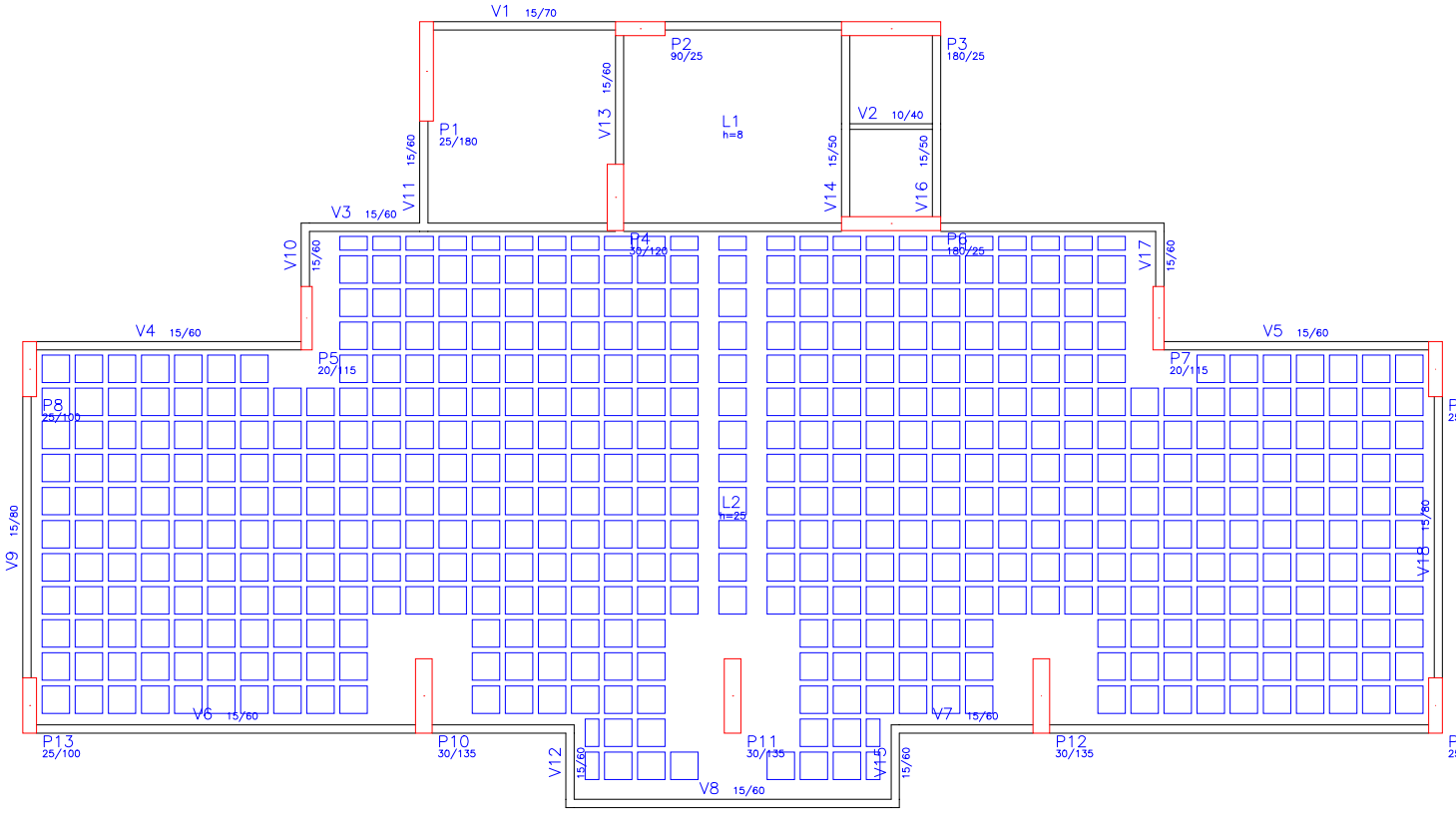

Figura 5.13 - Arranjo estrutural para o sistema de laje plana nervurada apoiada sobre pilares

$\mathrm{Na}$ figura 5.14, tem-se o tipo de bainha utilizada para o caso da protensão aderente posicionado nas nervuras.

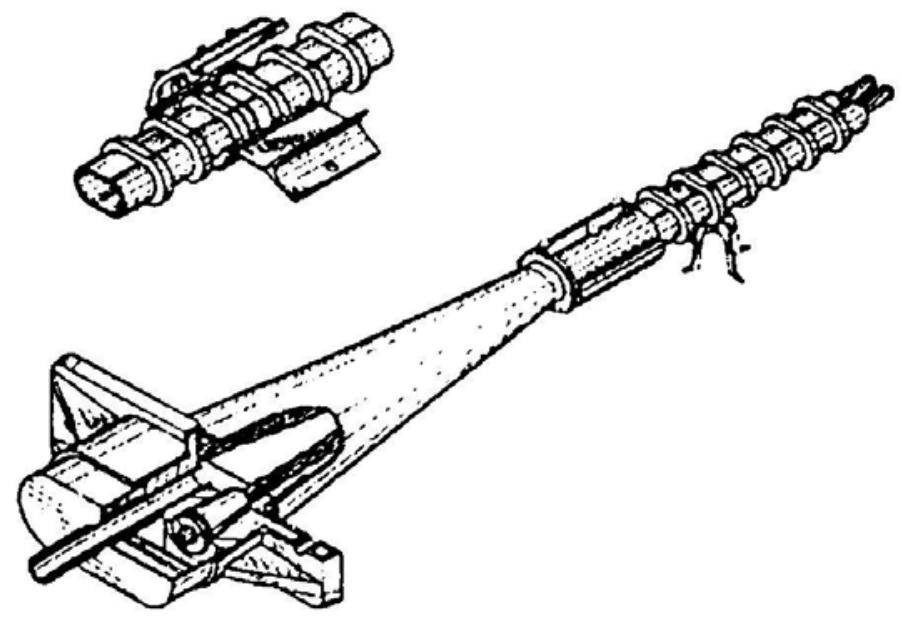

Figura 5.14 - Ancoragem ativa para sistema de protensão aderente com duas cordoalhas (AALAMI [1999])

Partindo para o consumo de materiais, vai-se iniciar com os índices do sistema de protensão não aderente (tabelas 5.21 a 5.23). 
Tabela 5.21 - Consumos de materiais (globais) para o modelo E03

\begin{tabular}{||c|c|c|c|c|c||}
\hline \multirow{2}{*}{ Exemplo } & Elemento & $\begin{array}{c}\text { Vol. de } \\
\text { Concreto } \\
\left(\mathbf{m}^{\mathbf{3}}\right)\end{array}$ & $\begin{array}{c}\text { Armadura } \\
\mathbf{p a s s i v a} \\
\mathbf{( k g )}\end{array}$ & $\begin{array}{c}\text { Armadura } \\
\text { Ativa (kg) }\end{array}$ & $\begin{array}{c}\text { Área de } \\
\text { Fôrmas } \\
\left(\mathbf{m}^{2}\right)\end{array}$ \\
\hline \hline \multirow{3}{*}{ E03 } & LAJE & 473,8 & $17.502,0$ & $10.240,0$ & $4.554,0$ \\
\cline { 2 - 6 } & VIGA & 149,0 & $17.118,0$ & - & $1.906,0$ \\
\cline { 2 - 7 } & PILAR & 265,5 & $24.117,0$ & - & $2.472,0$ \\
\cline { 2 - 7 } & TOTAL: & $\mathbf{8 8 8 , 3}$ & $\mathbf{5 8 . 7 3 7 , 0}$ & $\mathbf{1 0 . 2 4 0 , 0}$ & $\mathbf{8 . 9 3 2 , 0}$ \\
\hline
\end{tabular}

Tabela 5.22 - Taxas de consumo de materiais para o modelo E03

\begin{tabular}{|c|c|c|c|c|c|c|}
\hline Elemento & $\begin{array}{c}\text { Taxa de } \\
\text { Armadura } \\
\left(\mathbf{k g} / \mathbf{m}^{3}\right)\end{array}$ & $\begin{array}{c}\text { Taxa de } \\
\text { Protensão } \\
\left(\mathrm{kg} / \mathrm{m}^{3}\right)\end{array}$ & $\begin{array}{c}\text { Taxa de } \\
\text { Armadura } \\
\left(\mathbf{k g} / \mathbf{m}^{3}\right)\end{array}$ & $\begin{array}{l}\text { Taxa de } \\
\text { Fôrmas } \\
\left(\mathrm{m}^{2} / \mathrm{m}^{2}\right)\end{array}$ & $\begin{array}{c}\text { Taxa de } \\
\text { Pilares } \\
\text { (m²/pilar) }\end{array}$ & $\begin{array}{c}\text { Espes. } \\
\text { Média } \\
(\mathrm{cm})\end{array}$ \\
\hline$\overline{\text { LAJE }}$ & 36,94 & 21,61 & \multirow{3}{*}{66,12} & \multirow{3}{*}{1,88} & \multirow{3}{*}{17,11} & \multirow{3}{*}{19,0} \\
\hline VIGA & 114,88 & - & & & & \\
\hline PILAR & 90,83 & - & & & & \\
\hline
\end{tabular}

Tabela 5.23 - Parâmetros de Instabilidade para o modelo E03

\begin{tabular}{||c|c|c||}
\hline Direção & $\gamma_{\mathbf{z}}$ & $\alpha$ \\
\hline \hline Direção X - Face Lateral & 1,17 & 0,83 \\
\hline Direção Y - Face Frontal & 1,13 & 0,78 \\
\hline
\end{tabular}

O deslocamento máximo encontrado no pavimento foi de $1,10 \mathrm{~cm}$ (ver apêndice B).

Para o caso da protensão aderente, tem-se (tabelas 5.24 a 5.26):

Tabela 5.24 - Consumos de materiais (globais) para o modelo E04

\begin{tabular}{||c|c|c|c|c|c||}
\hline \multirow{2}{*}{ Exemplo } & Elemento & $\begin{array}{c}\text { Vol. de } \\
\text { Concreto } \\
\left(\mathbf{m}^{\mathbf{3}}\right)\end{array}$ & $\begin{array}{c}\text { Armadura } \\
\text { passiva } \\
\mathbf{( k g )}\end{array}$ & $\begin{array}{c}\text { Armadura } \\
\text { Ativa (kg) }\end{array}$ & $\begin{array}{c}\text { Área de } \\
\text { Fôrmas } \\
\mathbf{( m}^{\mathbf{2}}\end{array}$ \\
\hline \hline \multirow{3}{*}{ E04 } & LAJE & 473,8 & $15.236,0$ & $9.860,0$ & $4.554,0$ \\
\cline { 2 - 6 } & VIGA & 149,0 & $17.118,0$ & - & $1.906,0$ \\
\cline { 2 - 7 } & PILAR & 265,5 & $24.117,0$ & - & $2.472,0$ \\
\cline { 2 - 7 } & TOTAL: & $\mathbf{8 8 8 , 3}$ & $\mathbf{5 6 . 4 7 1 , 0}$ & $\mathbf{9 . 8 6 0 , 0}$ & $\mathbf{8 . 9 3 2 , 0}$ \\
\hline
\end{tabular}


Tabela 5.25 - Taxas de consumo de materiais para o modelo E04

\begin{tabular}{|c|c|c|c|c|c|c|}
\hline Elemento & $\begin{array}{c}\text { Taxa de } \\
\text { Armadura } \\
\left(\mathrm{kg} / \mathrm{m}^{3}\right)\end{array}$ & $\begin{array}{c}\text { Taxa de } \\
\text { Protensão } \\
\left(\mathrm{kg} / \mathrm{m}^{3}\right)\end{array}$ & $\begin{array}{c}\text { Taxa de } \\
\text { Armadura } \\
\left(\mathrm{kg} / \mathrm{m}^{3}\right)\end{array}$ & $\begin{array}{l}\text { Taxa de } \\
\text { Fôrmas } \\
\left(\mathrm{m}^{2} / \mathrm{m}^{2}\right)\end{array}$ & $\begin{array}{c}\text { Taxa de } \\
\text { Pilares } \\
\text { (m²/pilar) }\end{array}$ & $\begin{array}{c}\text { Espes. } \\
\text { Média } \\
\text { (cm) }\end{array}$ \\
\hline LAJE & 32.16 & 20,21 & \multirow{3}{*}{63,57} & \multirow{3}{*}{1,86} & \multirow{3}{*}{17,11} & \multirow{3}{*}{19,0} \\
\hline VIGA & 114,88 & - & & & & \\
\hline PILAR & 90,83 & - & & & & \\
\hline
\end{tabular}

Tabela 5.26 - Parâmetros de Instabilidade para o modelo E04

\begin{tabular}{|c|c|c|}
\hline Direção & $\gamma_{\mathbf{z}}$ & $\alpha$ \\
\hline \hline Direção X - Face Lateral & 1,17 & 0,83 \\
\hline Direção Y - Face Frontal & 1,13 & 0,78 \\
\hline
\end{tabular}

O deslocamento máximo encontrado no pavimento foi de $0,80 \mathrm{~cm}$ (ver apêndice $\mathrm{B})$.

\subsection{3 - Lajes nervuradas armadas apoiadas em vigas faixa protendidas sobre pilares}

A relação vão/espessura utilizada foi 30, levando a uma espessura da viga faixa igual a 27,0 cm. Foi adotada uma espessura igual a 25,0 cm, como tentativa inicial de pré-dimensionamento.

As lajes nervuradas apresentam 25,0 cm de altura. A figura 5.15 traz detalhes de sua geometria.

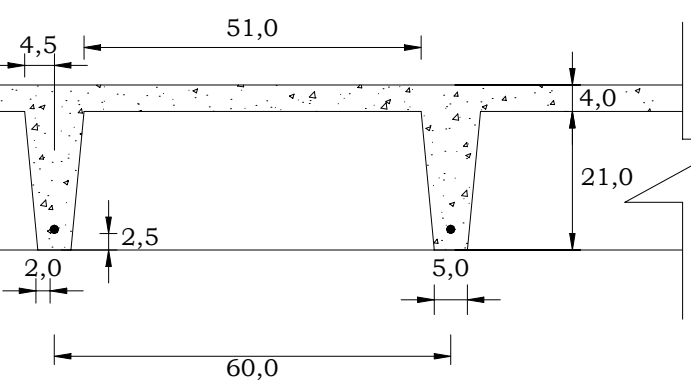

Figura 5.15 - Detalhe das nervuras de concreto armado (medidas em centímetros) 
Na figura 5.16, pode-se ver os arranjos estruturais para o caso de laje apoiada sobre vigas faixa.

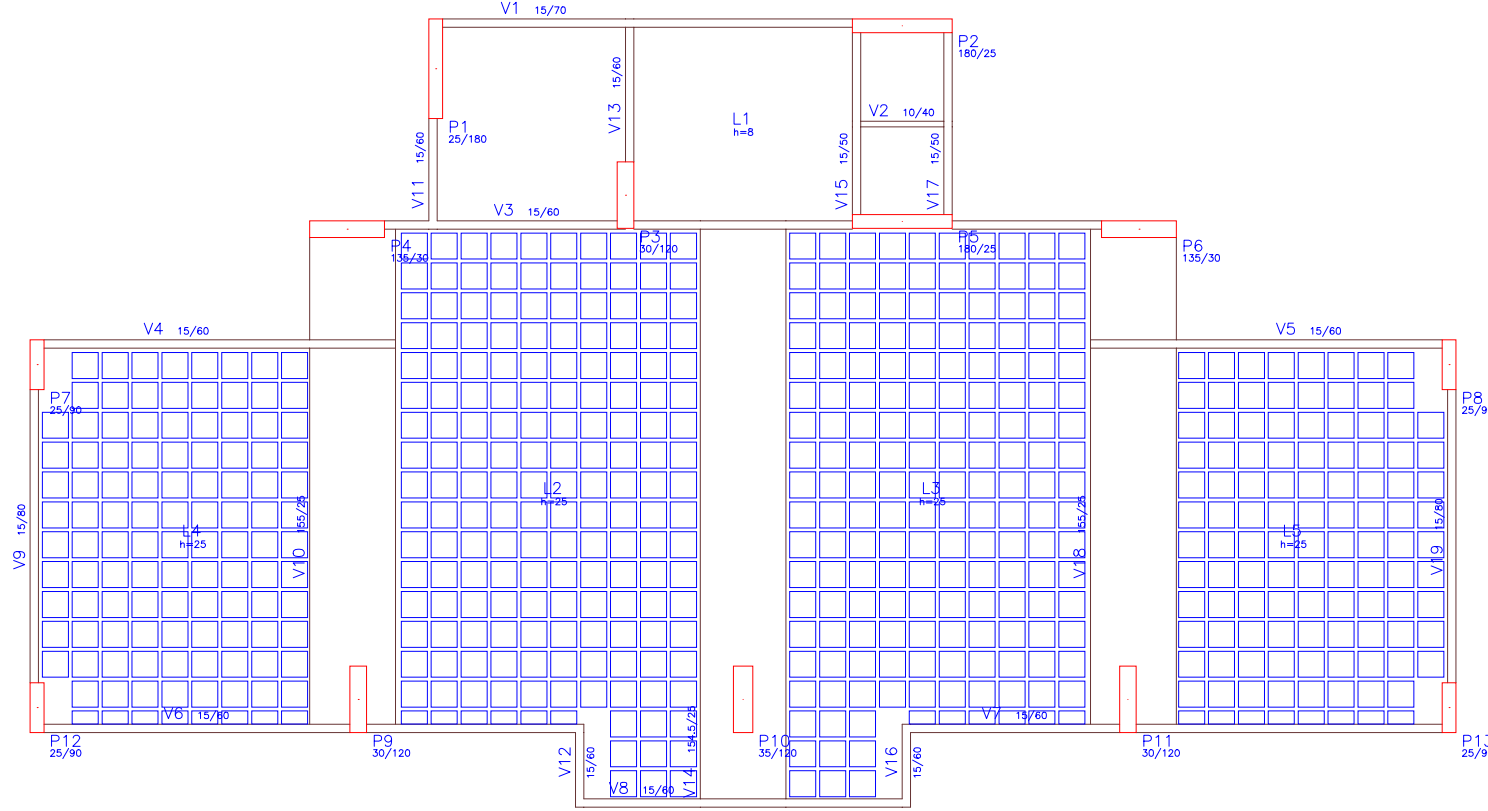

Figura 5.16 - Arranjo estrutural para o sistema de laje nervurada armada apoiada em vigas faixa protendidas sobre pilares

As tabelas 5.26 a 5.28 referem-se aos índices da protensão não aderente. Já as tabelas 5.29 a 5.31 referem-se aos consumos para a protensão aderente.

Tabela 5.26 - Consumos de materiais (globais) para o modelo E05

\begin{tabular}{||c|c|c|c|c|c||}
\hline \multirow{3}{*}{ Exemplo } & Elemento & $\begin{array}{c}\text { Vol. de } \\
\text { Concreto } \\
\left(\mathbf{m}^{\mathbf{3}}\right)\end{array}$ & $\begin{array}{c}\text { Armadura } \\
\text { passiva } \\
\mathbf{( k g )}\end{array}$ & $\begin{array}{c}\text { Armadura } \\
\text { Ativa } \mathbf{( k g})\end{array}$ & $\begin{array}{c}\text { Área de } \\
\text { Fôrmas } \\
\mathbf{( m}^{\mathbf{2}}\end{array}$ \\
\hline \hline \multirow{3}{*}{ E05 } & LAJE & 332,7 & $31.662,0$ & - & $3.692,0$ \\
\cline { 2 - 6 } & VIGA & 326,4 & $31.418,0$ & $8.060,0$ & $2.482,0$ \\
\cline { 2 - 7 } & PILAR & 262,7 & $26.665,0$ & - & $2.316,0$ \\
\cline { 2 - 7 } & TOTAL: & $\mathbf{9 2 1 , 7}$ & $\mathbf{8 9 . 7 4 5 , 0}$ & $\mathbf{8 . 0 6 0 , 0}$ & $\mathbf{8 . 4 9 0 , 0}$ \\
\hline
\end{tabular}


Tabela 5.27 - Taxas de consumo de materiais para o modelo E05

\begin{tabular}{|c|c|c|c|c|c|c|}
\hline Elemento & $\begin{array}{c}\text { Taxa de } \\
\text { Armadura } \\
\left(\mathrm{kg} / \mathrm{m}^{3}\right)\end{array}$ & $\begin{array}{c}\text { Taxa de } \\
\text { Protensão } \\
\left(\mathrm{kg} / \mathrm{m}^{3}\right)\end{array}$ & $\begin{array}{c}\text { Taxa de } \\
\text { Armadura } \\
\left(\mathrm{kg} / \mathrm{m}^{3}\right)\end{array}$ & $\begin{array}{l}\text { Taxa de } \\
\text { Fôrmas } \\
\left(\mathrm{m}^{2} / \mathrm{m}^{2}\right)\end{array}$ & $\begin{array}{c}\text { Taxa de } \\
\text { Pilares } \\
\text { (m²/pilar) }\end{array}$ & $\begin{array}{c}\text { Espes. } \\
\text { Média } \\
\text { (cm) }\end{array}$ \\
\hline LAJE & 95,16 & - & \multirow{3}{*}{97,37} & \multirow{3}{*}{1,86} & \multirow{3}{*}{17,94} & \multirow{3}{*}{21,0} \\
\hline VIGA & 96,26 & 24,69 & & & & \\
\hline PILAR & 101,50 & - & & & & \\
\hline
\end{tabular}

Tabela 5.28 - Parâmetros de Instabilidade para o modelo E05

\begin{tabular}{|c|c|c|}
\hline Direção & $\gamma_{\mathbf{z}}$ & $\alpha$ \\
\hline \hline Direção X - Face Lateral & 1,14 & 0,76 \\
\hline Direção Y - Face Frontal & 1,12 & 0,75 \\
\hline
\end{tabular}

O deslocamento máximo encontrado no pavimento foi de 1,80 cm (ver apêndice $\mathrm{B})$.

Para o modelo com protensão aderente (E06), tem-se:

Tabela 5.29 - Consumos de materiais (globais) para o modelo E06

\begin{tabular}{||c|c|c|c|c|c||}
\hline \multirow{2}{*}{ Exemplo } & Elemento & $\begin{array}{c}\text { Vol. de } \\
\text { Concreto } \\
\left(\mathbf{m}^{\mathbf{3}}\right)\end{array}$ & $\begin{array}{c}\text { Armadura } \\
\text { passiva } \\
(\mathbf{k g})\end{array}$ & $\begin{array}{c}\text { Armadura } \\
\text { Ativa (kg) }\end{array}$ & $\begin{array}{c}\text { Área de } \\
\text { Fôrmas } \\
\left.\mathbf{( m}^{\mathbf{2}}\right)\end{array}$ \\
\hline \multirow{3}{*}{ E06 } & LAJE & 332,7 & $33.634,0$ & - & $3.692,0$ \\
\cline { 2 - 6 } & VIGA & 326,4 & $30.035,0$ & $7.300,0$ & $2.482,0$ \\
\cline { 2 - 7 } & PILAR & 262,7 & $25.073,0$ & - & $2.316,0$ \\
\cline { 2 - 7 } & TOTAL: & $\mathbf{9 2 1 , 7}$ & $\mathbf{8 8 . 7 4 2 , 0}$ & $\mathbf{7 . 3 0 0 , 0}$ & $\mathbf{8 . 4 9 0 , 0}$ \\
\hline
\end{tabular}

Tabela 5.30 - Taxas de consumo de materiais para o modelo E06

\begin{tabular}{|c|c|c|c|c|c|c|}
\hline Elemento & $\begin{array}{c}\text { Taxa de } \\
\text { Armadura } \\
\left(\mathrm{kg} / \mathrm{m}^{3}\right)\end{array}$ & $\begin{array}{c}\text { Taxa de } \\
\text { Protensão } \\
\left(\mathrm{kg} / \mathrm{m}^{3}\right)\end{array}$ & $\begin{array}{c}\text { Taxa de } \\
\text { Armadura } \\
\left(\mathbf{k g} / \mathbf{m}^{3}\right)\end{array}$ & $\begin{array}{l}\text { Taxa de } \\
\text { Fôrmas } \\
\left(\mathrm{m}^{2} / \mathrm{m}^{2}\right)\end{array}$ & $\begin{array}{c}\text { Taxa de } \\
\text { Pilares } \\
\text { (m²/pilar) }\end{array}$ & $\begin{array}{c}\text { Espes. } \\
\text { Média } \\
\text { (cm) }\end{array}$ \\
\hline LAJE & 101,09 & - & \multirow{3}{*}{96,28} & \multirow{3}{*}{1,84} & \multirow{3}{*}{17,94} & \multirow{3}{*}{21,0} \\
\hline VIGA & 92,02 & 21,82 & & & & \\
\hline PILAR & 95,44 & - & & & & \\
\hline
\end{tabular}


Tabela 5.31 - Parâmetros de Instabilidade para o modelo E06

\begin{tabular}{|c|c|c||}
\hline Direção & $\gamma_{\mathbf{z}}$ & $\alpha$ \\
\hline \hline Direção X - Face Lateral & 1,14 & 0,77 \\
\hline Direção Y - Face Frontal & 1,12 & 0,72 \\
\hline
\end{tabular}

O deslocamento máximo encontrado no pavimento foi de 1,60 $\mathrm{cm}$ (ver apêndice B).

\subsection{0 - Comparação dos Resultados}

\subsection{1 - Volume de Concreto}

O gráfico 5.4 mostra a variação de consumo de concreto.

Volume total de concreto (m3)

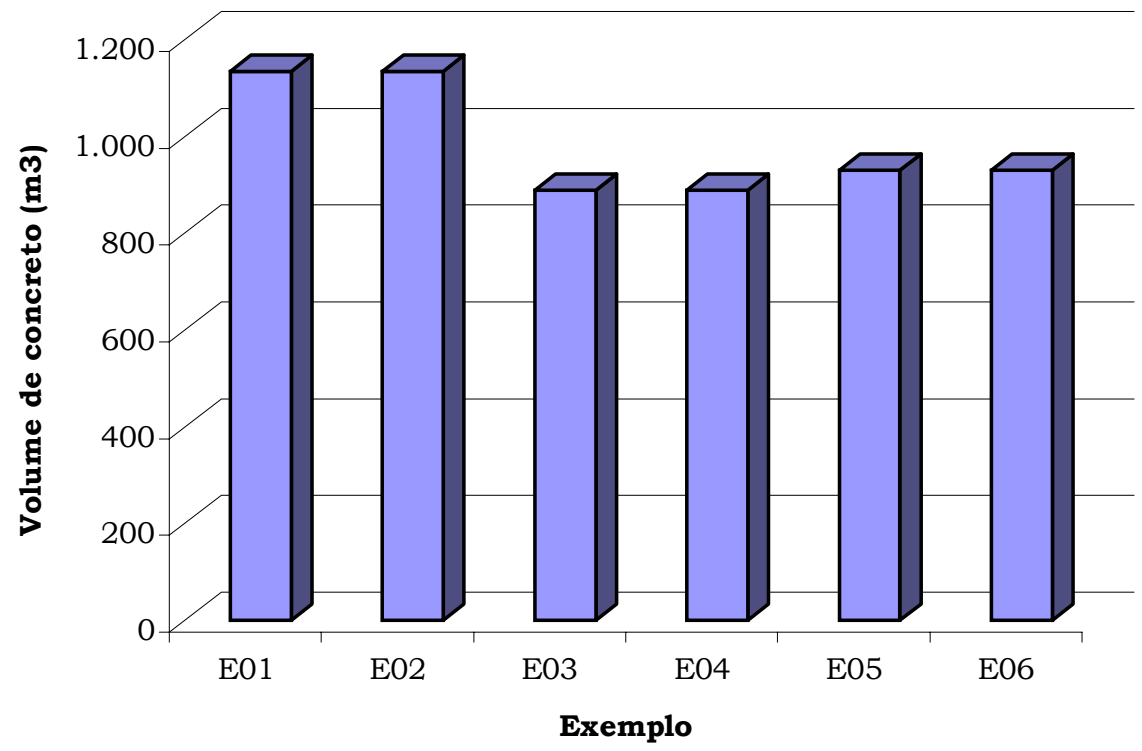

Gráfico 5.4 - Variação do volume de concreto nos exemplos

\subsection{2 - Quantidade de Armadura Passiva}

Vê-se no gráfico 5.5 a variação de armadura passiva para os modelos. 
Quantidade total de armadura passiva (kg)

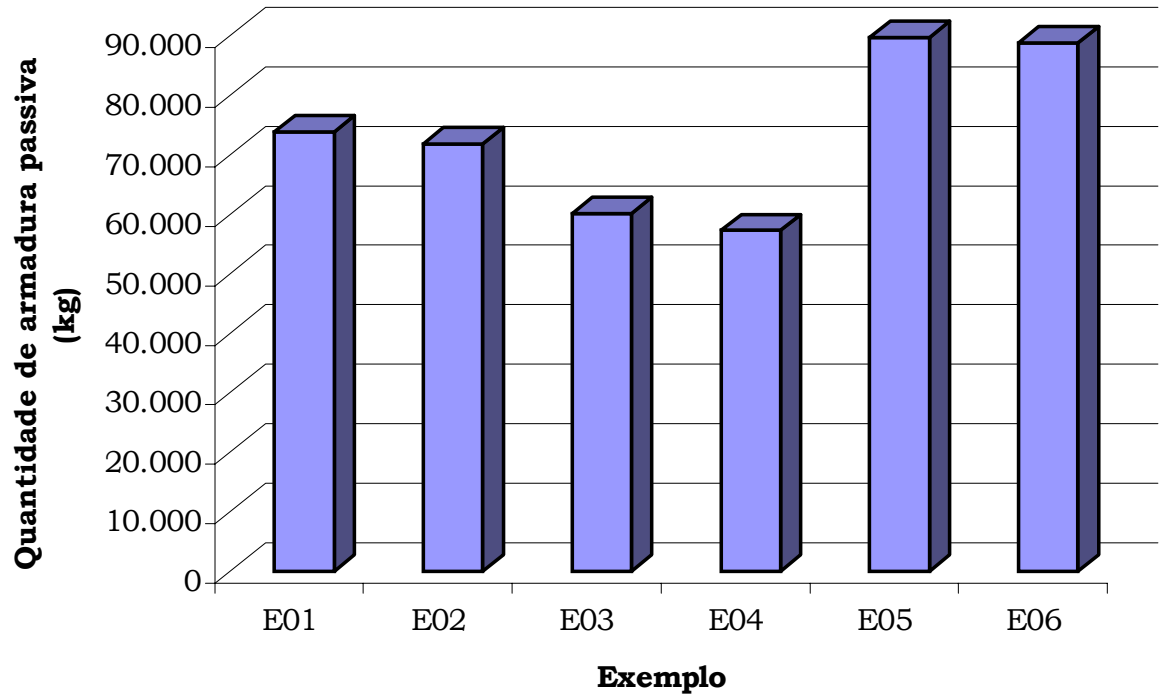

Gráfico 5.5 - Variação da quantidade de armadura passiva para os exemplos.

\subsection{3 - Quantidade de Armadura Ativa}

Vê-se no gráfico 5.6 a variação de armadura passiva para os modelos.

Quantidade total de armadura ativa (kg)

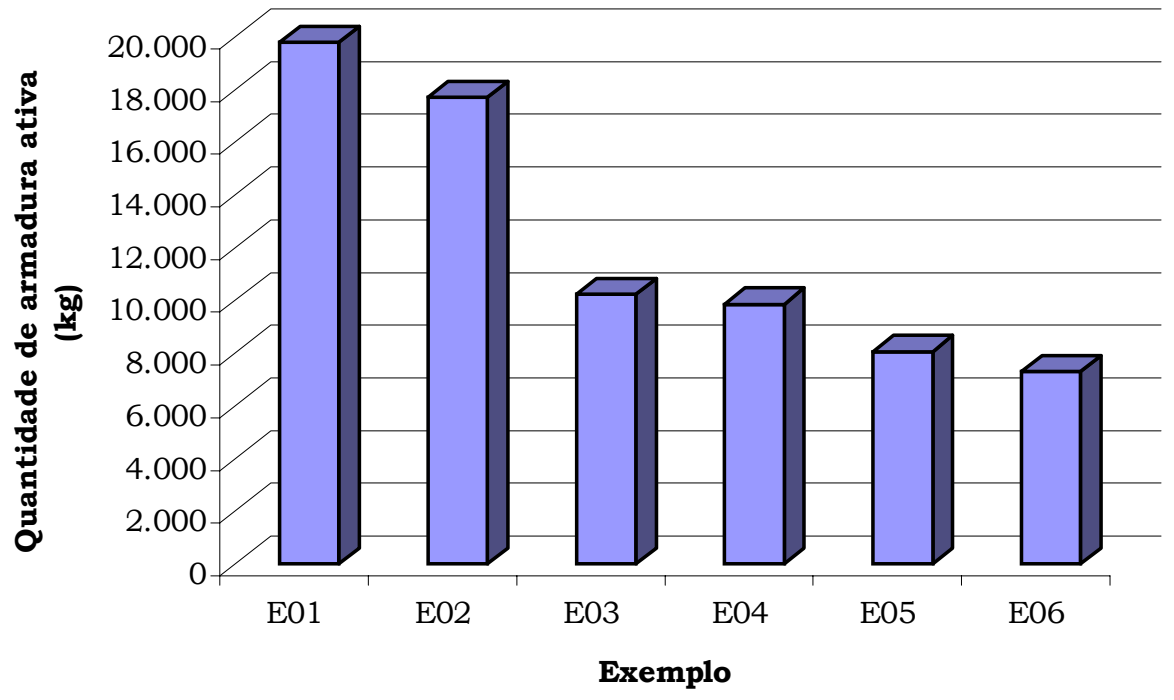

Gráfico 5.6 - Variação da quantidade de armadura ativa para os exemplos.

\subsection{4 - Quantidade da Área de Fôrmas}

Vê-se no gráfico 5.7 a variação da área de fôrmas para os modelos. 
Quantidade total de área de fôrmas (m2)

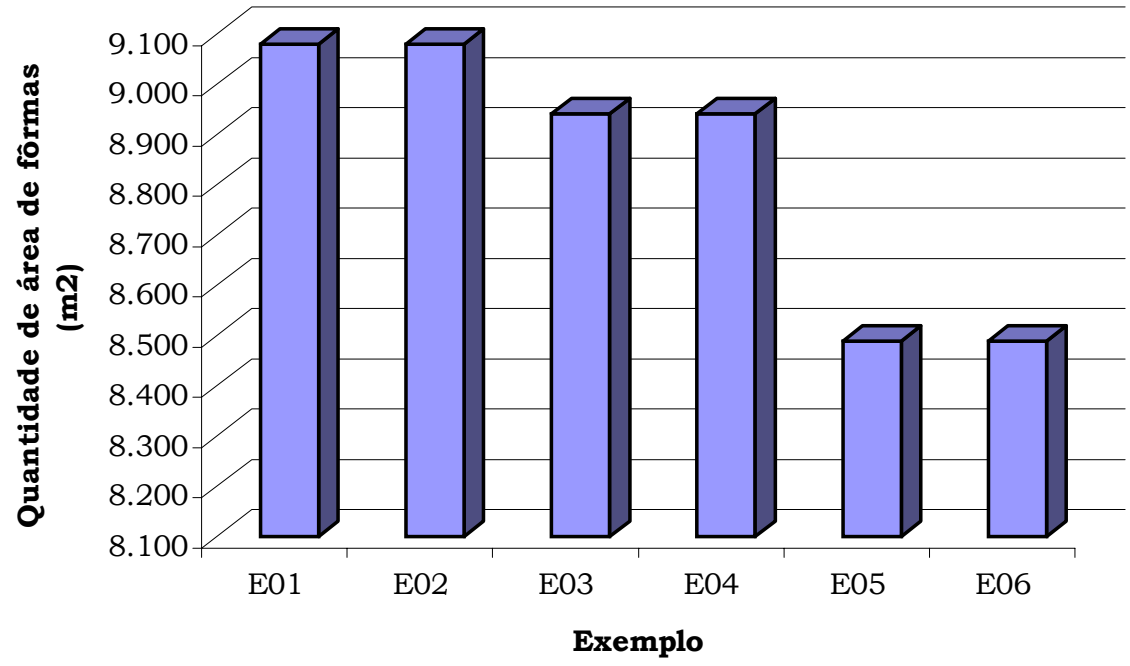

Gráfico 5.7 - Variação da quantidade de armadura ativa para os exemplos.

\subsection{1 - Análise dos Resultados}

Na análise dos resultados, o diferencial dos pavimentos, com protensão aderente ou não aderente, é a quantidade de armadura utilizada, uma vez que os pavimentos apresentaram mesmas características geométricas e propriedades fisicas.

Nos modelos E01 e E02, o consumo de concreto e de fôrmas é o mesmo. Para a armadura ativa, o pavimento com protensão não aderente apresenta um consumo de cordoalhas 10,61\% superior à protensão convencional.

Para a armadura passiva das lajes, houve a confirmação que estruturas com protensão aderente possuem um consumo menor de armadura passiva, com relação ao modelo com protensão não aderente, conforme escrito no item 2.3, que referencia o trabalho de MATTOCK et al. [1971]. Para a laje com protensão não aderente, o consumo de armadura passiva foi de 1.477,20 $\mathrm{kg} /$ pavimento e para a laje com protensão aderente, foi de $1.434,80$ $\mathrm{kg} /$ pavimento, o que resulta numa diferença de $2,87 \%$.

Para as vigas, houve uma diferença de 5,56\% de consumo de armadura, mostrando um menor consumo por parte do modelo E02.

Para os pilares, ambos apresentaram consumo de armadura passiva semelhante. 
Analisando globalmente a estrutura, a solução utilizando a protensão aderente foi ligeiramente econômica, pois, o consumo total de armadura passiva, para todos os elementos, é $2,67 \%$ inferior ao arranjo com protensão não aderente.

Para os modelos E03 e E04, ou seja, os pavimentos com lajes planas nervuradas, o consumo de concreto e fôrmas foi semelhante. O consumo de armadura ativa apresentou uma diferença de 3,71\% sendo que o arranjo mais econômico foi o modelo E04, ou seja, o modelo que utiliza protensão aderente.

O consumo de armadura passiva para o modelo E03 (protensão não aderente), para as lajes, foi de $875,10 \mathrm{~kg} /$ pavimento, enquanto o modelo utilizando a protensão aderente obteve $761,80 \mathrm{~kg} /$ pavimento, o que representa uma diferença de $12,95 \%$.

Para as vigas, assim também como para os pilares, o consumo de armadura passiva foi semelhante.

Analisando globalmente o consumo de armadura passiva da estrutura, obteve-se uma diferença de consumo de armadura de $3,86 \%$, sendo que o pavimento mais econômico foi o arranjo com protensão aderente.

Para os modelos E05 e E06 os consumos de concreto e fôrmas foi semelhante. O consumo de armadura ativa, para o modelo com protensão não aderente, foi $9,42 \%$ superior ao consumo do arranjo com protensão aderente.

O consumo de armadura passiva para o modelo E05 (protensão não aderente), para as lajes, foi de $1.583,10 \mathrm{~kg} /$ pavimento, enquanto o modelo E06 obteve 1.681,7 kg/pavimento, representando uma diferença de 5,86\%.

Para o consumo de armadura passiva para vigas, o modelo E05 obteve um consumo de $1.570,90 \mathrm{~kg} /$ pavimento, enquanto o modelo E06 produziu $1.501,75 \mathrm{~kg} /$ pavimento, mostrando que o modelo E06 é mais econômico $4,40 \%$ que o modelo E05.

Para os pilares, o modelo E05 obteve $1.333,25 \mathrm{~kg} /$ pavimento enquanto que o modelo E06 obteve 1.253,65 kg/pavimento, mostrando que o modelo E06 foi 5,97\% mais econômico que o modelo com protensão não aderente.

A determinação de qual sistema de protensão (aderente ou não aderente) será utilizado dependerá de fatores como: custo da mão-de-obra, dos materiais (no caso, o custo do quilo da protensão aderente e da não aderente), do custo do concreto e das fôrmas e ainda, de outros fatores que fogem da competência do engenheiro de estruturas, tais como a disponibilidade destes 
materiais e de mão-de-obra especializada para a construção civil utilizando a protensão.

$\mathrm{Na}$ análise dos resultados obtidos, verifica-se que os pisos de edifícios que utilizaram concreto armado obtiveram um índice de consumo de materiais inferior aos pavimentos com concreto protendido.

Para a comparação dos modelos, vai-se confrontar os valores dos modelos E01, E02, E03 e E04 (modelos em laje plana maciça e nervurada) com o modelo A03 (laje plana nervurada de concreto armado), e, os modelos E05 e E06 (modelos com vigas faixa protendidas), serão comparados aos modelos A01 e A02 (modelo de laje apoiada sobre vigas). A idéia é comparar os pavimentos com soluções estruturais semelhantes e confrontar seus resultados.

Nos gráficos a seguir, tem-se a comparação dos consumos de materiais para todos os modelos (armados e protendidos), onde o objetivo é mostrar a variação de consumo de materiais para todos os exemplos.

O gráfico 5.8 mostra a variação de consumo de concreto.

Volume total de concreto (m3)

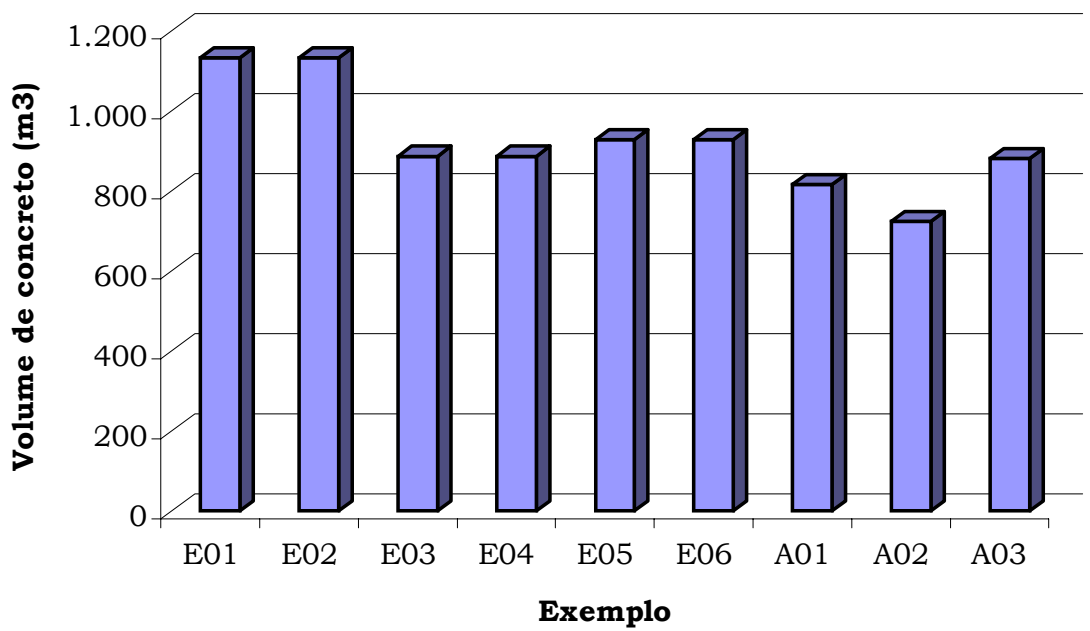

Gráfico 5.8 - Variação do volume de concreto nos modelos

Vê-se no gráfico 5.9 a variação de armadura passiva para os modelos. 
Quantidade total de armadura passiva $(\mathrm{kg})$

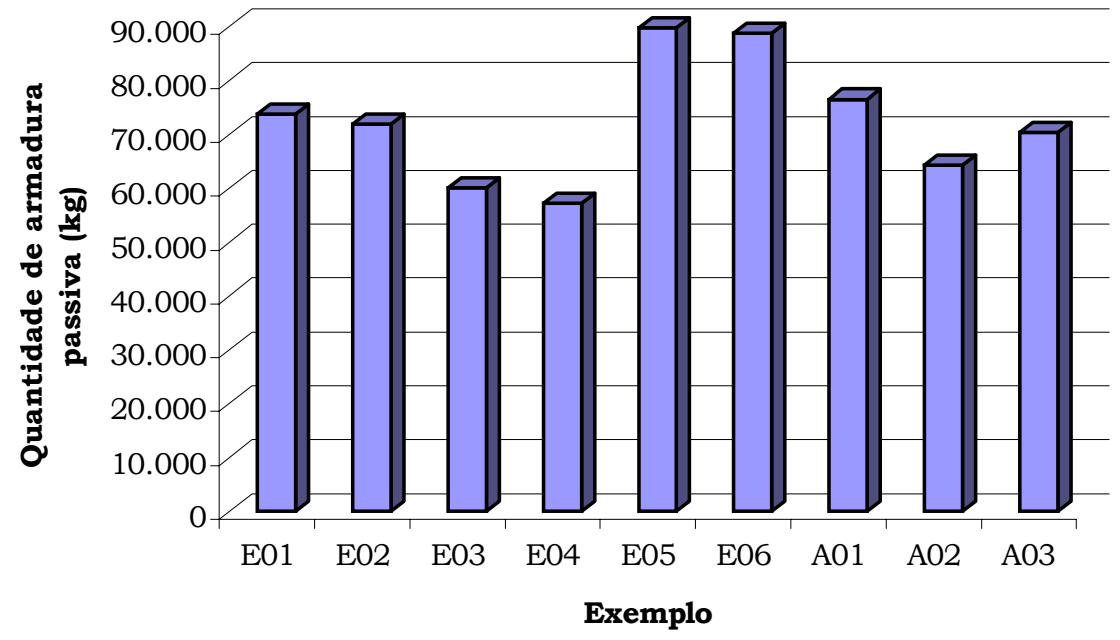

Gráfico 5.9 - Variação da quantidade de armadura passiva para os modelos

Vê-se no gráfico 5.10 a variação da quantidade de fôrmas para os modelos.

Quantidade total de área de fôrmas (m2)

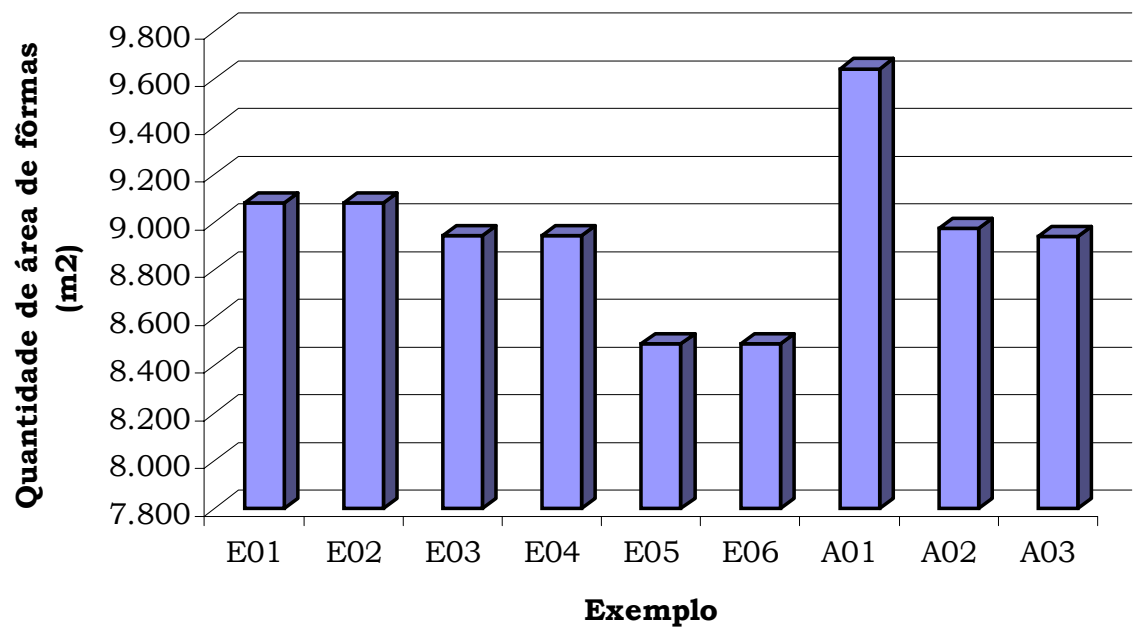

Gráfico 5.10 - Variação da quantidade área de fôrmas para os modelos

Comparando o consumo dos materiais, vai-se iniciar este procedimento com os arranjos em lajes planas, conforme explicado anteriormente, que, no caso, são os modelos E01, E02, E03, E04 e o A03.

O gráfico 5.11 mostra a diferença de consumo de concreto.

Como valor base, foi escolhido o modelo com menor consumo e os demais comparados a este. 


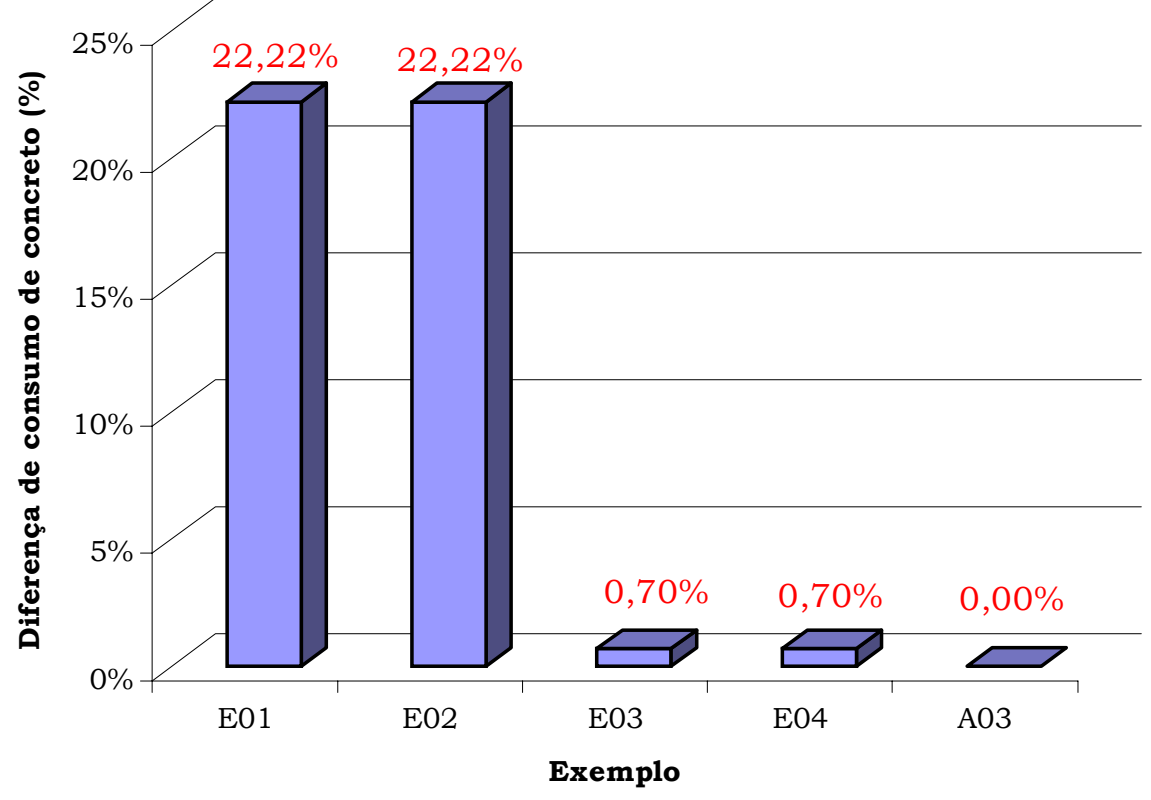

Gráfico 5.11 - Diferença de consumo de concreto

O consumo de concreto foi menor no modelo A03, sendo 22,22\% mais econômico que os modelos E01 e E02 e 0,70\% mais econômico que os modelos E03 e E04.

No quesito de consumo de armadura passiva, o gráfico 5.12 mostra as diferenças obtidas. Vale salientar que não está inclusa a quantidade de armadura ativa.

Como valor base, foi escolhido o modelo com menor consumo e os demais comparados a este. O modelo que obteve menor consumo foi o E04, que possui o sistema de protensão aderente. Note que o valor apresentado não inclui a armadura ativa. 


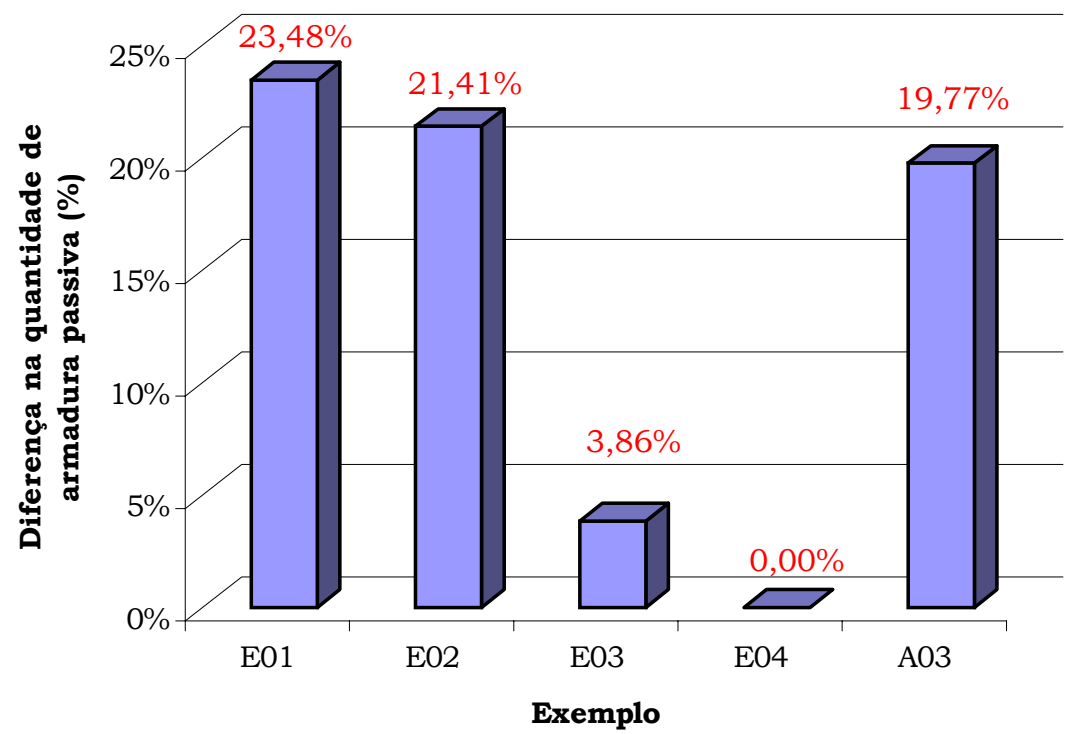

Gráfico 5.12 - Diferença de consumo de armadura passiva

Para o consumo de fôrmas, será feito o mesmo raciocínio. O valor de referência é do A03, pois corresponde menor consumo (embora a diferença seja de apenas $0,03 \%$ com relação aos modelos com laje plana nervurada protendida). Com relação aos modelos com laje plana maciça protendida, a diferença foi de 1,55\%. O gráfico 5.13 mostra a diferença entre o consumo de área de fôrmas. Vale salientar que as diferenças encontradas são muito pequenas, portanto, os modelos apresentam consumos relativamente iguais.

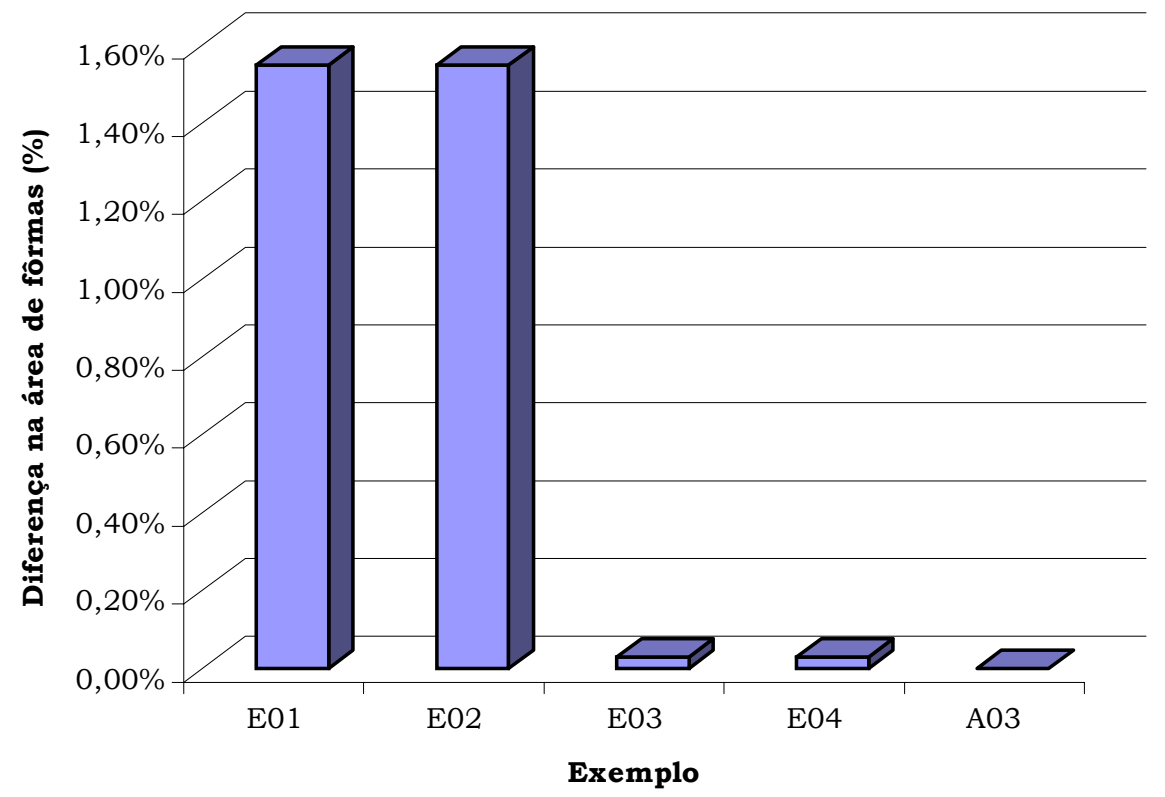

Gráfico 5.13 - Diferença de consumo área de fôrmas $\left(\mathrm{m}^{2}\right)$ 
Comparando-se os modelos de vigas faixa (E05 e E06) com os modelos convencionais (A01 e A02) de ALBUQUERQUE [1998], o gráfico 5.14 mostra a variação de consumo de concreto.

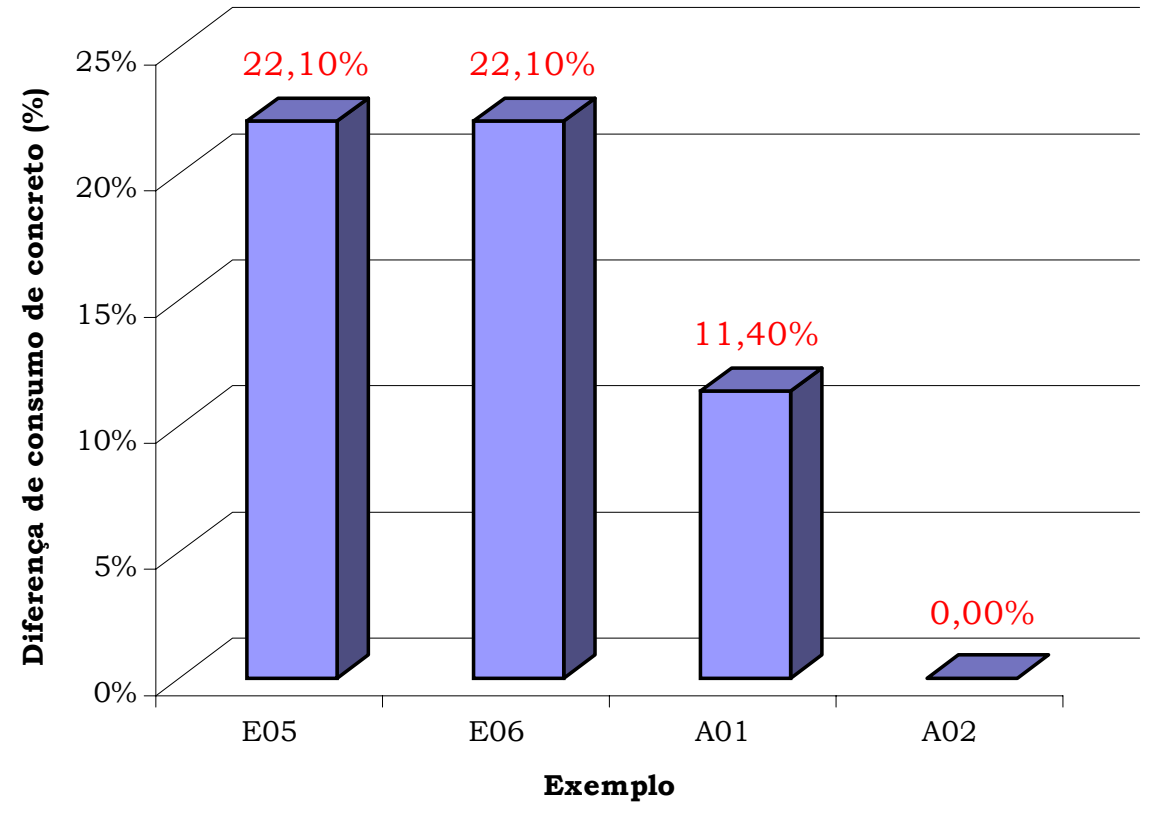

Gráfico 5.14 - Variação no volume de concreto

O modelo A02 foi o que apresentou menor consumo de concreto, mostrando uma economia de $22,10 \%$ com relação aos modelos protendidos e, teve ainda um consumo $11,40 \%$ inferior ao modelo A01.

O gráfico 5.15 mostra a variação da quantidade de armadura passiva nos exemplos. Novamente, a parcela relativa à armadura ativa não está inclusa nesses resultados. 


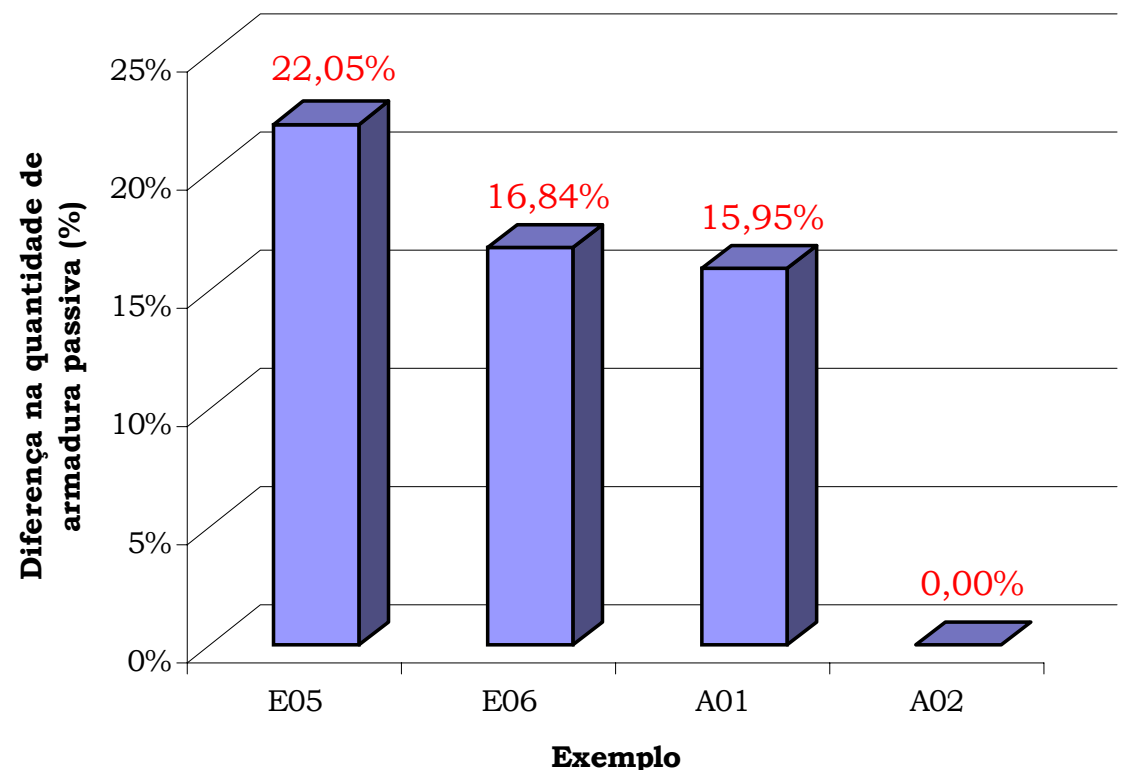

Gráfico 5.15 - Diferença de consumo de armadura passiva

Neste gráfico, o modelo A02 destacou-se na economia de armadura passiva tanto em relação aos modelos com protensão (E05 - 22,05\% e E06 $16,84 \%)$ quanto para o modelo A01 (15,95\%). Pode-se notar que a diferença de consumo entre os modelos E06 e A01 foi de 1,05\%, mostrando que, pavimentos com protensão apresentam uma grande competitividade com relação aos pavimentos convencionais com lajes maciças.

Para o consumo de fôrmas, será feito o mesmo raciocínio. O valor de referência é do A03, por ser o menor. O gráfico 5.16 mostra a diferença de consumo de fôrmas. Percebe-se que, os modelos protendidos obtiveram uma margem de economia de material de $11,04 \%$ com relação ao modelo A01. Ainda, obtiveram uma redução de consumo de fôrmas da ordem de 5,38\% com relação ao modelo A02. 


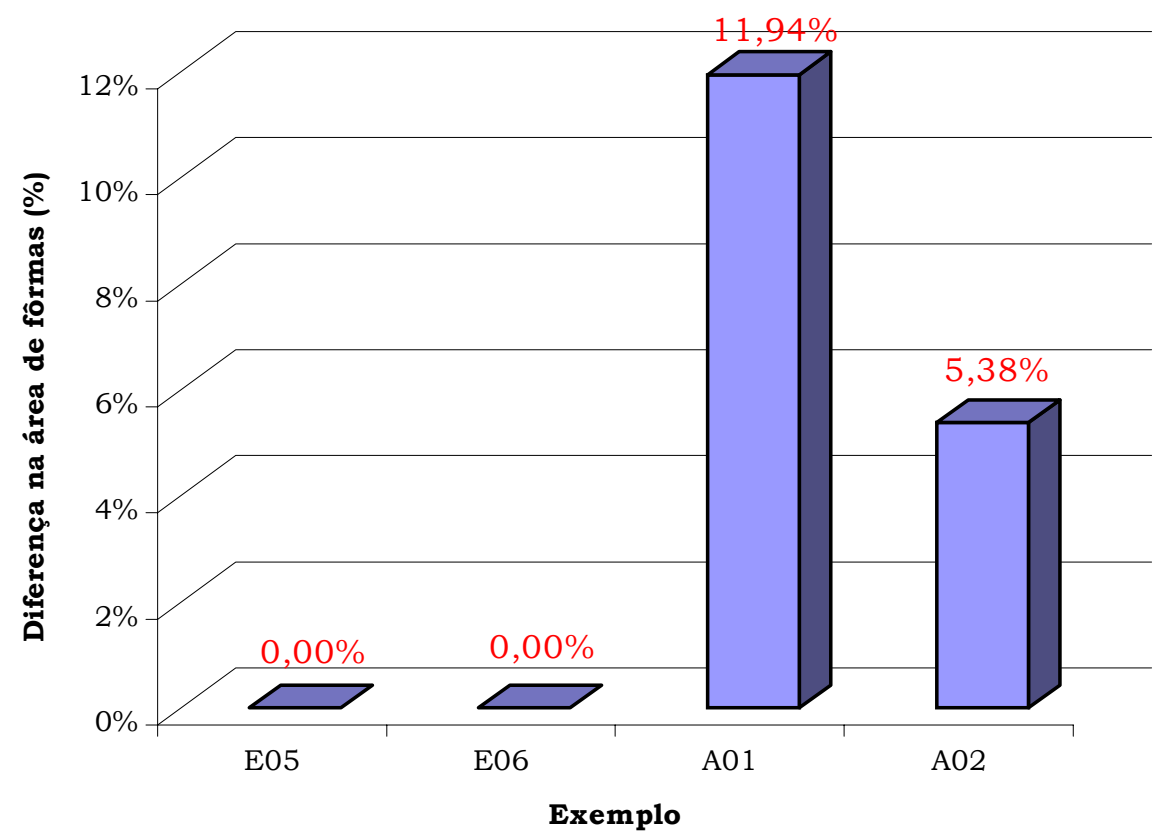

Gráfico 5.16 - Diferença de fôrmas com relação aos modelos protendidos

\subsection{2 - Tempo de Execução}

Neste segmento, será avaliado o tempo de execução dos exemplos estudados, tanto os modelos em concreto armado quanto os modelos em concreto protendido. A idéia é salientar as vantagens da utilização da protensão não aderente comparando os tempos de execução com relação à protensão aderente e a concreto armado.

Para a avaliação do tempo de execução, os critérios que norteiam a escolha de uma estrutura protendida vão mais além do cálculo da estrutura.

Antes de qualquer decisão, é necessário que a solução apresente competitividade econômica com relação às demais soluções existentes.

\subsection{1 - Protensão Aderente x Protensão Não Aderente}

Com relação ao tempo de execução para os cabos aderentes e não aderentes, pode-se comparar dois fatores, que são: tempo de posicionamento dos cabos à fôrma e tempo para executar o devido alongamento do cabo. 
O tempo de posicionamento do cabo, isto é, o tempo que é necessário para que os cabos estejam devidamente executados nas fôrmas, de acordo com o projeto, e prontas para serem concretadas.

De um modo geral, as cordoalhas engraxadas demandam cerca de 20 segundos para serem alongadas. Do mesmo modo, a protensão aderente demanda um tempo reduzido, porém, ocorre perda de tempo para a fixação do macaco às fôrmas, transporte do macaco ao local dos cabos e fixação dos cabos no macaco hidráulico. A vantagem da protensão não aderente está no transporte facilitado do macaco hidráulico, do fácil posicionamento na fôrma e da simples fixação da cordoalha ao macaco, enquanto a protensão aderente precisa de macacos pesados.

Segundo o catálogo da MAC - Sistema Brasileiro de Protensão, um macaco hidráulico para 4 cordoalhas pesa cerca de 70,0 kgf enquanto que o macaco hidráulico para protensão não aderente pesa cerca de 20,0 kgf.

Para efeito de comparação, vai-se resumir o processo de execução de um cabo não aderente e de outro aderente.

Para a protensão não aderente, vai-se considerar que os cabos chegam à obra devidamente cortados, com as ancoragens nas extremidades e prontos para serem somente posicionados às fôrmas, assim que o cabo chega à obra, é necessário apenas que haja o devido transporte do canteiro até o pavimento que está sendo executado e posicionado à fôrma de acordo com as especificações de projeto. Após a concretagem e obtenção da resistência mínima à compressão do concreto (especificação de projeto), é feito o alongamento dos cabos com o transporte do macaco hidráulico até o local e fixação do cabo ao equipamento.

Para a protensão aderente, vai-se considerar que os cabos chegam à obra devidamente cortados, com as ancoragens nas extremidades e prontos para serem somente posicionados às fôrmas. Neste caso, existe um cuidado especial no transporte das bainhas à fôrma, pois não pode haver, em hipótese alguma, a passagem de concreto para dentro da bainha, pois este concreto poderá oferecer obstáculo ao alongamento que o cabo estará sujeito quando no ato da protensão. Outro ponto importante é a injeção da pasta de cimento nas bainhas após a concretagem, sendo este um processo demorado e cuidadoso, pois é necessário que a bainha esteja preenchida de nata de cimento para que haja a devida aderência entre a armadura ativa e o concreto. Após a 
concretagem e que seja atingida a resistência mínima à compressão do concreto (especificação de projeto), é injetada a pasta de cimento na bainha e então é feito o alongamento do cabo com o transporte do macaco hidráulico até o local e fixação do cabo ao equipamento.

Nesta pesquisa foi verificado que, de acordo com a experiência dos engenheiros de obra, pavimentos usuais com protensão não aderente são geralmente mais rápidos que os com protensão aderente cerca de um dia.

\subsection{2 - Concreto Armado x Protensão Aderente e Não Aderente}

As estruturas que demandam mais tempo para se executar são àquelas com maior quantidade de vigas e pilares. Desta forma, tanto as lajes com grandes painéis nervurados, ou com painéis nervurados apoiados em vigas faixas protendidas, quanto às soluções em concreto armado estudadas por Albuquerque, deverão demandar o mesmo tempo de execução ou tempos bastante próximos com relação aos modelos protendidos (cerca de 6 a 7 dias).

De acordo com a pesquisa realizada, as soluções protendidas deveriam levar em média um tempo de execução de 6 a 7 dias (dados estes extraídos de empresas de São Paulo), dependendo das características da equipe de trabalho. Já as soluções em concreto armado demandaram, no mínimo, 7 dias para a devida execução do pavimento. Esses resultados mostram que é possivel a economia de 1 dia/pavimento.

Com relação às lajes planas nervuradas protendidas, estas apresentaram a menor taxa de consumo de materiais por pavimento, sendo uma solução deveras econômica, porém, do ponto de vista de execução do pavimento, esta solução torna-se muito trabalhosa devido à demora no correto posicionamento dos caixotes plásticos e a partir daí, iniciar a execução das ferragens. De acordo com a experiência dos engenheiros de obra, foi visto que as lajes planas nervuradas demandam $20 \%$ a mais de tempo em relação às lajes planas maciças, devido ao posicionamento dos caixotes plásticos e isto representa, em média, a perda de um a um dia e meio, na execução de pavimentos usuais.

Dentre as soluções estudadas, a de vigas faixa protendidas deveria apresentar o menor tempo de execução. Porém, a presença de nervuras nas lajes compensa o tempo ganho na protensão dos cabos nas vigas faixa. Com 
isso, as soluções com lajes planas nervuradas protendidas apresentam o mesmo tempo de execução que o caso das vigas faixa. Do ponto de vista de alongamento dos cabos na estrutura, esta solução é a mais rápida, pois os cabos apresentam-se reunidos nas três vigas faixa existentes no pavimento, o que torna o trabalho de transporte do macaco hidráulico reduzido, aumentando a produtividade da obra.

A solução em laje plana maciça protendida apresenta um tempo de execução compativel com as demais, porém, existe uma parcela de tempo considerável perdida com a execução da armadura passiva e do volume de concreto utilizado, porém, esta apresenta uma execução mais rápida e fácil, do ponto de vista de posicionamento de fôrmas e ferragens e lançamento do concreto, pois a inexistência de caixotes plásticos ou de grandes quantidades de vigas aumenta a produtividade da obra, tornando esta solução novamente competitiva com relação à solução em laje plana nervurada protendida.

Para as soluções em concreto armado, tanto a solução em laje plana nervurada quanto as soluções tradicionais (A01 e A02) apresentam um tempo de execução semelhante, pois a versatilidade que a laje nervurada tradicional (A02) possui com relação ao consumo de materiais é perdida devido ao posicionamento dos caixotes plásticos. A laje maciça tradicional (A01) possui consumos menores que os pavimentos protendidos, mas apresenta grande quantidade de área de fôrmas e diversos recortes, devido à presença de muitas vigas. A solução em laje plana nervurada (A03) é muito interessante devido ao consumo de materiais, porém, apresenta uma grande quantidade de pilares, o que torna o andamento da obra demorado, além de apresentar, do mesmo modo que a solução protendida, a existência de caixotes plásticos.

\subsection{3 - Comentários Finais}

Para a eleição da melhor solução que trará maiores benefícios, deve ser dada prioridade a três fatores:

- Desempenho estrutural;

- Consumo de materiais;

- Tempo de execução. 
A análise do pavimento visando o desempenho estrutural é de grande importância, pois limita os deslocamentos do pavimento, melhorando o conforto do imóvel. Porém não se deve esquecer a economia do arranjo estrutural, pois não seria viável um arranjo que promovesse grande desempenho e tivesse alto custo.

A análise visando a economia do pavimento é um critério eliminador, assim como o desempenho estrutural, de soluções estruturais, pois não adianta possuir um grande projeto estrutural bem organizado se este tiver alto índice de consumo de materiais, tornando a obra inviável.

A idéia é unir o desempenho estrutural com a economia dos materiais.

Para se comparar os deslocamentos encontrados nos modelos, a tabela 5.32 mostra os deslocamentos máximos encontrados. Vale salientar que os deslocamentos referentes aos modelos em concreto armado não estão ilustrados, pois não foi objeto de estudo da pesquisa de ALBUQUERQUE [1998], Assim, são ilustradas apenas as soluções com protensão.

Tabela 5.32 - Deslocamentos dos modelos protendidos (Apêndice B)

\begin{tabular}{||c|c|}
\hline Modelo & Deslocamento (cm) \\
\hline \hline E01 & 2,20 \\
\hline E02 & 1,90 \\
\hline E03 & 1,10 \\
\hline E04 & 0,80 \\
\hline E05 & 1,80 \\
\hline E06 & 1,60 \\
\hline
\end{tabular}

Com os resultados referentes aos deslocamentos, pode-se ver que os modelos com protensão aderente são mais rígidos, promovendo menores deslocamentos, sendo que, o modelo E04 obteve o menor valor. 


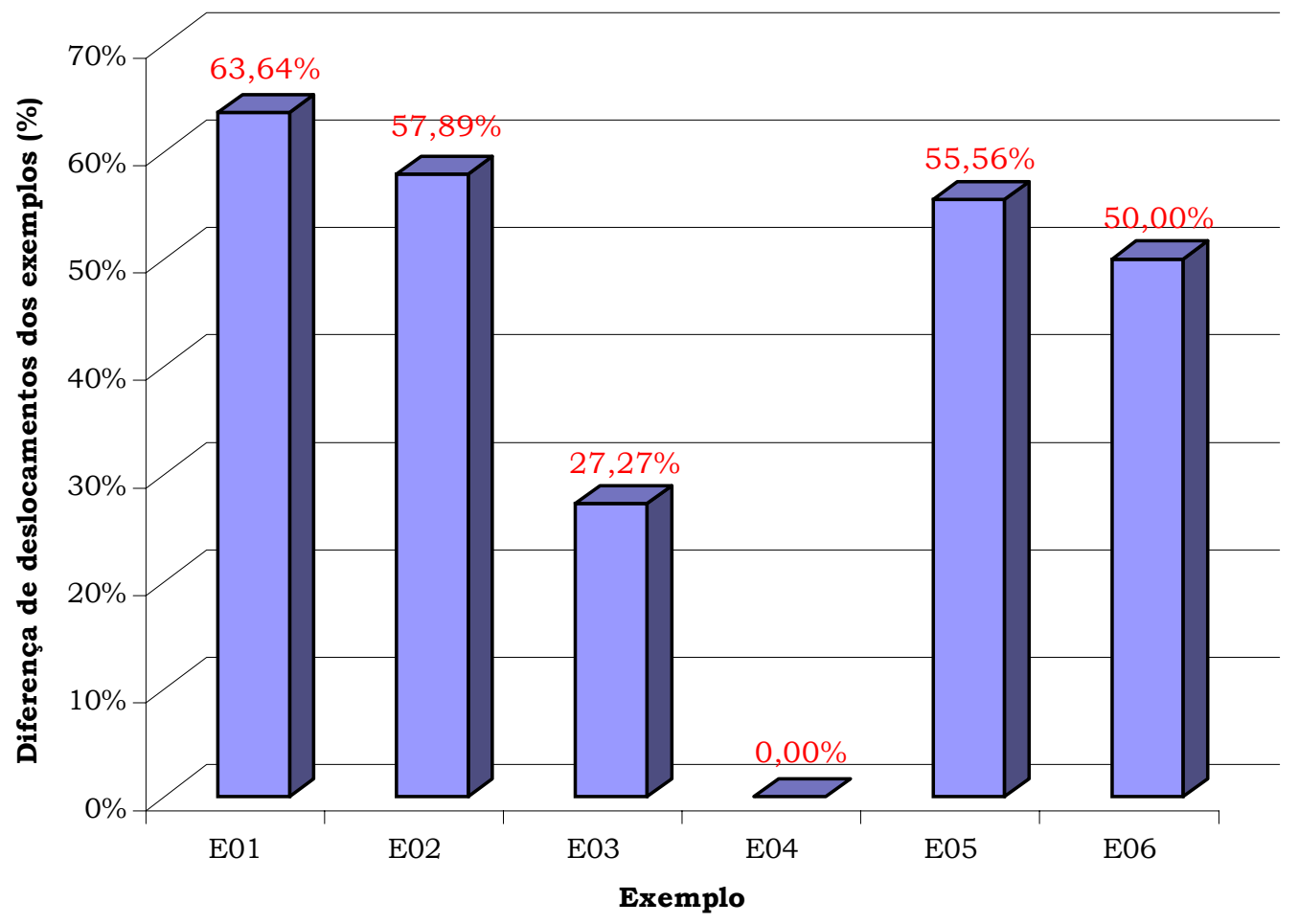

Gráfico 5.19 - Diferença de deslocamentos para os modelos protendidos

De acordo com o gráfico 5.19, pode-se observar que os modelos em laje plana maciça apresentaram maiores deslocamentos, seguidos pelos modelos com vigas faixa protendidas.

Com isso, conclui-se que, do ponto de vista de desempenho estrutural, o modelo E04 (laje plana nervurada com protensão aderente) é a melhor escolha.

Partindo para o consumo de materiais, pode-se observar que, de acordo com os resultados no item 5.10, o modelo E04 foi o mais econômico (com uma pequena diferença em relação ao modelo E03), mostrando assim, que a melhor escolha para este caso, é novamente, o modelo E04.

Agora, falta avaliar o tempo de execução para os modelos e eleger o pavimento mais eficaz. De acordo com o item 5.12, observa-se que os pavimentos com protensão aderente apresentam um gasto maior no tempo de execução, em virtude de fatores anteriormente citados como: posicionamento de bainhas, injeção de pasta de cimento, cuidados no transporte da bainha e no posicionamento do macaco hidráulico. 
Já a solução E03, isto é, a solução em laje plana nervurada com protensão não aderente, promoveria o melhor tempo de execução, juntamente com os modelos E05 e E06 (modelos com vigas faixa protendidas). Logo, podese concluir que a solução mais eficaz é a solução em laje plana nervurada com protensão não aderente (E03).

Os modelos E01 e E02, embora sejam soluções com laje maciça, apresentam alto consumo de concreto, aumentando o tempo de execução.

Verifica-se que, em uma obra, a maior parte do custo deve-se aos custos indiretos, que podem ser a mão-de-obra, aluguel de máquinas, dentre outros. Com isso, o modelo E04 perderia com o tempo de execução, levando a gastos maiores que não são ilustrados nesta pesquisa.

Após todo este procedimento, conclui-se que o modelo com protensão não aderente (E03) será o mais vantajoso, pois unirá da melhor forma os três fatores: desempenho estrutural, consumo de materiais e tempo de execução. 


\section{6 conclusões}

A utilização da protensão não aderente em edifícios residenciais e comerciais vem se tornando cada vez mais freqüente, principalmente, devido às imposições arquitetônicas e à tendência de procura, por parte dos proprietários, de maior conforto e liberdade de possuir um apartamento com divisões à sua escolha, tornando seu imóvel único.

$\mathrm{Na}$ presente pesquisa foi realizado um estudo sobre a utilização da protensão não aderente em pavimentos de edificios residenciais, comparados às soluções com protensão aderente e em concreto armado, com relação aos índices de consumo de materiais e ao tempo de execução.

Foram analisados seis modelos com protensão e, em sua análise, foi visto que a protensão do tipo aderente era a mais econômica, do ponto de vista de consumo de materiais, com relação à protensão não aderente, e esta diferença se fez presente na quantidade de armaduras ativas e passivas.

Nas análises foram confrontados os consumos de materiais, sendo eles: o volume de concreto, área de fôrmas, quantidade de armadura passiva e armadura ativa. Foi também desenvolvida uma análise sobre o tempo de execução de pavimentos com e sem protensão, no sentido de mostrar o grau 
de competitividade dos pavimentos que utilizam a protensão, sendo esta do tipo aderente ou não aderente.

Para que haja competitividade econômica da solução é necessário que o sistema apresente características que unam a execução e o consumo de materiais. Assim, quando se escolhe o processo de laje protendida, sempre se compara com a solução em concreto armado, se esta for possivel pelos critérios técnicos, pela arquitetura ou preferência do cliente.

Daí é necessária uma quantificação de custos, avaliação das facilidades de execução oferecidas pela solução, equipamento e mão-de-obra disponivel, integração com o projeto arquitetônico, interferência com as instalações, durabilidade e qualidade da estrutura, fator tempo e outros.

Só com todas as variáveis envolvidas no processo sendo analisadas é que se pode optar por uma solução. Claro que nunca se pode ter a melhor solução, mas com certeza pode-se chegar o mais próximo dela, pois, quanto mais informações são dadas ao construtor para a avaliação das soluções, provavelmente ter-se-á escolhida uma boa alternativa estrutural.

No consumo de materiais, foi visto que os pavimentos de concreto armado obtiveram um menor índice de consumo de concreto, como escrito anteriormente, devido às imposições do Projeto de Revisão da NBR 6118-2001 com relação à espessura mínima para lajes protendidas maciças $(16,0 \mathrm{~cm})$.

Dentre os modelos analisados pelo programa computacional TQS®, o modelo E04, isto é, o modelo dotado de laje plana nervurada com protensão aderente apresentou os melhores resultados com relação ao consumo de materiais, em especial, o consumo de armadura passiva, de armadura ativa e de volume de concreto, mostrando a grande versatilidade deste sistema. Porém, no quesito de tempo de execução, este modelo estrutural apresenta a deficiência do tempo consumido no posicionamento dos caixotes plásticos que, embora sejam leves e práticos, é necessário que sejam presos de forma adequada, para que não haja defeitos na seção transversal das nervuras.

Ainda, na análise dos modelos, seis da presente pesquisa e três do estudo desenvolvido por ALBUQUERQUE [1998], os exemplos em concreto armado foram mais econômicos em relação aos modelos utilizando protensão, em especial, o modelo A02, isto é, o modelo com laje nervurada apoiada em vigas sobre pilares. Porém, do mesmo modo que o modelo A01, estes exemplos 
apresentam recortes e pilares internos, perdendo a versatilidade do arquiteto de poder trabalhar com o arranjo interno do pavimento mais livre. O modelo A03, que consiste no pavimento com laje plana nervurada de concreto armado apoiada em pilares, é mais econômica do que os similares em concreto protendido, porém, apresenta uma grande quantidade de pilares em seu arranjo (18 no total), reduzindo a produtividade da obra favorecendo o modelo protendido (14 pilares no total).

Para as lajes planas nervuradas protendidas, foi observado uma grande competitividade com relação à solução em concreto armado (A03), pois, além de apresentar pequeno número de pilares, taxa de armadura inferior e menor quantidade de fôrmas, o pavimento apresenta um vão livre médio da ordem de $7,00 \mathrm{~m}$, tornando esta solução ideal para os arquitetos de interiores.

Do mesmo modo que os modelos com laje plana nervurada protendida, os modelos com laje plana maciça apresentaram um consumo superior à solução em concreto armado (A03), porém, existe um ganho no tempo de execução devido à inexistência do posicionamento dos caixotes plásticos e, ainda, o pavimento apresenta um vão livre médio da ordem de $7,00 \mathrm{~m}$, igual aos modelos em laje plana nervurada protendida, tornando esta solução atraente para os arquitetos de interiores.

Então, pode-se concluir satisfatoriamente que a protensão não aderente é uma solução muito vantajosa, do ponto de vista executivo e de consumo de materiais, pois, para pavimentos com maiores dimensões, o concreto armado perderia a versatilidade econômica que possui com a presença de muitos recortes nas fôrmas e da grande quantidade de vigas e pilares, e do ponto de vista executivo, esses recortes e a presença de muitos elementos estruturais atrasariam o andamento da obra. A protensão aderente, embora talvez fosse mais econômica, pois uniria a versatilidade com o consumo de materiais, perderia em produtividade na obra, onde, um dos principais gastos na construção civil é justamente a mão-de-obra empregada. Com essa conclusão, mostra-se que a união entre versatilidade, consumo de materiais e tempo de execução converge para a protensão não aderente como opção viável e adequada.

A figura 6.1 ilustra um fluxograma com as características das soluções estudadas conforme o que foi observado nesta pesquisa. Vale salientar que, cada caso é um caso, e deve ser analisado com todas as alternativas possiveis. 
É claro que as soluções com protensão apresentam um preço um pouco mais elevado que as construções em concreto armado, porém, a versatilidade e a produtividade obtidas com tais soluções tornam esta solução mais apreciada pelos escritórios de arquitetura.
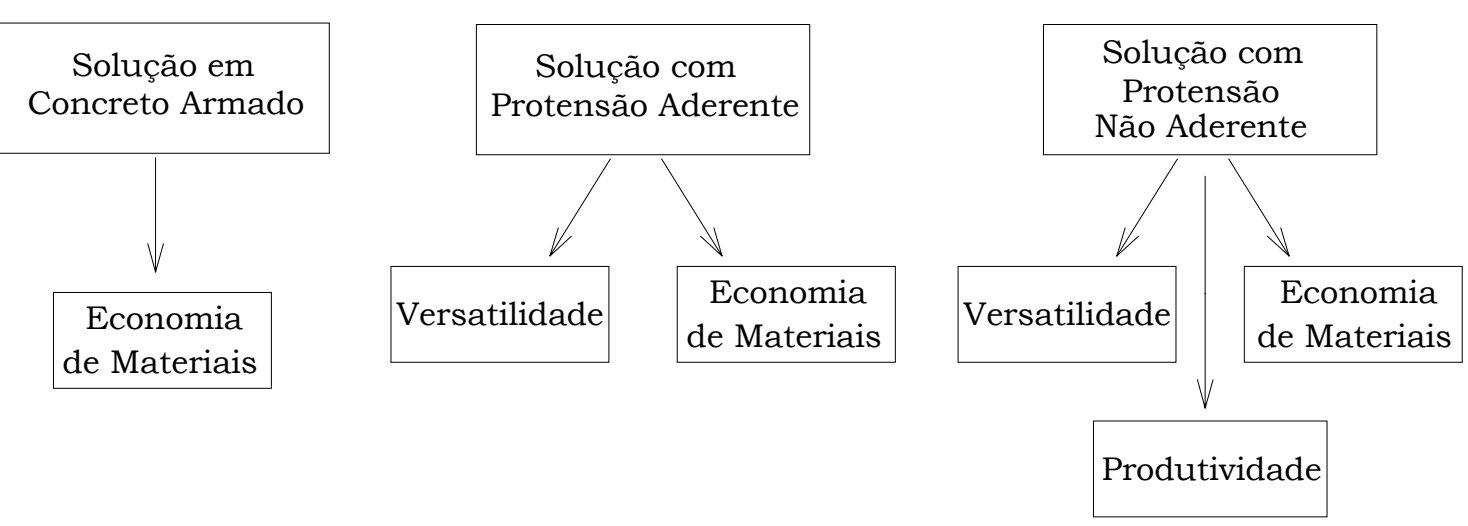

Figura 6.1 - Características das soluções estudadas

\section{Propostas de trabalhos futuros}

De acordo com a atual tendência do mercado que caminha para soluções cada vez mais arrojadas e delgadas, a protensão é a primeira escolha que os imóveis estão sendo sujeitos devido à grande versatilidade propiciada por sua utilização. Existem diversos programas computacionais que desenvolvem soluções cada vez mais próximas da resposta natural da estrutura, sendo estes: Programa de Cálculo Estrutural TQS ${ }^{\circ}$ e o Programa de Análise pelo Método dos Elementos Finitos ANSYS 5.5.1®, sendo que ambos foram utilizados na presente pesquisa.

A utilização do Programa ANSYS ${ }^{\circledR}$ é muito restrita, pois, seu pósprocessador fornece somente esforços e deformações, não executando um dimensionamento da estrutura. Porém, apresentou na análise desenvolvida a melhor aproximação com relação aos deslocamentos do modelo experimental, o que não aconteceu na avaliação dos momentos fletores (ver item 4.5 Capítulo 4). A utilização do Programa do TQS® foi recomendada por causa dos problemas ocorridos com o uso do Programa ANSYS ${ }$. Aquele programa fornece, além de uma boa interface com o operador, uma maior interatividade entre o desenvolvimento do projeto e a avaliação por parte do projetista, 
realizando em seu processamento, o dimensionamento e até do detalhamento da estrutura. Com base nessas informações, um programa que pudesse compatibilizar o processamento da estrutura em elementos finitos e que fornecesse um adequado dimensionamento e detalhamento da estrutura, seria o próximo passo para análises cada vez mais precisas, buscando aprimorar a real resposta da estrutura.

Outro ponto que merece atenção é o caso das perdas de protensão. Atualmente, o Projeto de Revisão da NBR 6118-2001 não trata das perdas progressivas de protensão para o caso de se utilizar a protensão não aderente, pois, apresenta em seu texto (sub-item 9.6.3.3) que: "Os valores parciais e totais das perdas progressivas de protensão, decorrentes da retração e da fluência do concreto e da relaxação do aço de protensão, devem ser determinados considerando-se a interação dessas causas, podendo ser utilizados os processos indicados de 9.6.3.3.1 a 9.6.3.3.4. Nesses processos admite-se que exista aderência entre a armadura e o concreto e que o elemento estrutural permaneça no Estádio I".

Um outro estudo que merece atenção seria o de acabar com a crença que a protensão não aderente não é segura. Diversos pesquisadores (AALAMI [1988-2000], SCORDELIS [1956-1959], NAAMAN [1991a], entre outros presentes na revisão bibliográfica desta pesquisa), realizaram inúmeros ensaios e verificações para avaliar o grau de segurança da estrutura quando se utilizar a protensão não aderente. Um exemplo disso é a pesquisa de MATTOCK et al. [1971] que mostra que a protensão não aderente é tão eficiente quanto a protensão convencional (aderente) se for adicionada uma parcela de armadura passiva para aumentar o momento resistente da seção transversal. Esta pesquisa poderia ser desenvolvida realizando-se estudos de arranjos de lajes (maciças ou nervuradas) com ensaios experimentais e numéricos para então mostrar a segurança que a protensão não aderente fornece. Ainda, poderia ser feita uma ampliação do presente estudo com mais exemplos para tornar as comparações desenvolvidas mais conclusivas. 


\section{REFERÊNCIAS BIBLIOGRÁFICAS}

AALAMI, B. O. [1988]. Innovative Rehabilitation of a Parking Structure.

Concrete International : Design \& Construction, February 1988;

AALAMI, B. O. [1989]. Design of Post-Tensioned Floor Slabs. Concrete International: Design \& Construction, V. 11, No. 6, June 1989, pp. $59-67$;

AALAMI, B. O. [1990a]. Load Balancing: a Comprehensive Solution to PostTensioning. ACI Structural Journal, 1990;

AALAMI, B. O. [1990b]. Developments in Post-Tensioned Floors in Buildings. FIP - XIth International Congress on Prestressed Concrete, Hamburg, 4-9 June, 1990;

AALAMI, B. O. [1993a]. Effective Width and Post-Tensioning. PTI - PostTensioned Institute: Technical Notes, Issue 1, April 1993;

AALAMI, B. O. [1993b]. Developments in Post-Tensioned Building Design. Proceedings, CONCET'93, International Conference on Concrete Engineering and Technology, Kuala Lumpur, Malaysia, 25 - 27 May, 1993, 15 p.;

AALAMI, B. O. [1993c]. One-Way and Two-Way Post-Tensioned Floor Systems. PTI - Post-Tensioned Institute: Technical Notes, Issue 3, October 1993; 
AALAMI, B. O. [1994a]. Strength Evaluation of Existing Post-Tensioned Beams and Slabs - Analytical Approach. PTI - Post-Tensioned Institute: Technical Notes, Issue 4, March 1994;

AALAMI, B. O. [1994b]. Unbonded and Bonded Post-Tensioning Systems in Building Construction - A Design and Performance Review. PTI - PostTensioned Institute: Technical Notes, Issue 5, September 1994;

AALAMI, B. O. [1998a]. Time Dependent Analysis of Post-Tensioned Concrete Structures. Construction Research Communications Limited: Concrete Construction, 1998;

AALAMI, B. O. [1998b]. Hyperstatic (Secondary) Actions in Prestressing and Their Computation. PTI - Post-Tensioned Institute: Technical Notes, October 4, 1998;

AALAMI, B. O. [1998c]. Disposition of Prestressing Tendons and NonPrestressed Reinforcement in Post-Tensioned Floor Systems. PTI Post-Tensioned Institute, October 20, 1998;

AALAMI, B. O. [2000]. Design of Post-Tensioned Buildings. EPUSP - 2000, São Paulo - SP;

AALAMI, B. O. \& BOMMER, A. [1998a]. Basics of Structural Modeling, and Design of Concrete Floor Systems with Particular Reference to PostTensioning. ADAPT - June 01, 1998;

AALAMI, B. O. \& BOMMER, A. [1998b]. Considerations in Design of PostTensioned Floor System. ADAPT - June 01, 1998;

AALAMI, B. O. \& BOMMER, A. [1998c]. Finite Element Method. ADAPT - June 01, 1998;

AALAMI, B. O. \& BOMMER, A. [1998d]. Design Procedure Using Equivalent Frame Method. ADAPT - June 01, 1998;

AALAMI, B. O. \& BOMMER, Allan [1999]. Design Fundamentals of PostTensioned Concrete Floors. PTI - Post-Tensioned Institute, April 1999; AALAMI, B. O. \& CHEGINI, M. [1995]. Structural retrofitting of Cast-in-Place Concrete Parking Structures. Third National Concrete \& Mansory Engineering Conference, San Francisco, California, June 15-17, 1995; ACI Committee 318 [1999]. Building Code Requirements for Structural Concrete and Commentary. Farmington Hills, 391 pp, 1999;

ACI Committee 435 [1995]. Control of Deflection in Concrete Structures. Detroit, 77 pp, 1995; 
ACI - ASCE COMMITTEE 423 [1989]. Recommendations for Concrete Members Prestressed with Unbonded Tendons. ACI Structural Journal, V. 86, No. 3, May - June 1989, pp. 301-318;

ADAPT - Adapt Structural Engineering Consultants. Economics of Post-

Tensioned Concrete Building Structures - Cost Analysis;

ALBUQUeRQue, A. T. [1998]. Análise de Alternativas Estruturais para

Edifícios de Concreto Armado. Dissertação de Mestrado, EESC - USP, São Carlos - SP, 100 p.;

ALlouche, E. N.; CAMPBElL, T. I.; GREEN, M. F.; SOUDKI, K. A. [1998].

Tendons Stress in Continuous Unbonded Prestressed Concrete Members - Part 1: Review of Literature. PCI Journal, NovemberDecember 1998, pp. 86-93;

AMENT J. M.; CHAKRABARTI, P. R.; PUTCHA, C. S. [1997]. Comparative Statistical Study for the Ultimate Stress in Unbonded Post-Tensioning. ACI Structural Journal, Vol. 94, No. 2, March-April 1997, pp. 171-180; ASSOCIAÇÃO BRASILEIRA DE NORMAS TÉCNICAS - ABNT [1989]. Projeto de Estruturas de Concreto Protendido - NBR 7197/89. São Paulo, 1989, 71 p.;

ASSOCIAÇÃO BRASILEIRA DE NORMAS TÉCNICAS - ABNT [2001]. NBR

6118/2001 - Projeto de Revisão e Comentários da NBR 6118/78 -

Projeto e Execução de Estruturas de Concreto Armado. Rio de Janeiro, 180 p.;

BARBOZA, A. S. R. [1992]. Contribuição à Análise Estrutural de Sistemas

Lajes-Vigas de Concreto Armado Mediante Analogia de Grelha.

Dissertação de Mestrado, EESC - USP, São Carlos - SP, 130 p.;

BRANSON, D. E. [1964]. Design Procedures for Computing Deflections. ACI

Journal, Sept. 1968, pp. 730-742;

BRANSON, D. E. [1964]. Compression Steel Effect on Long-Time Deflections.

ACI Journal, Aug. 1971, pp. 555-559;

BRANSON, D. E. [1964]. Time-Dependent Effects in Composite Concrete

Beams. Journal of ACI, Fev. 1964, pp. 213-229;

BURNS, N. H.; HEMAKOM, R. [1977]. Test of Scale Model Post-tensioned Flat Plate. Proceedings, ASCE, ST6, June 1977, pp. 1237 - 1255; 
BURNS, N. H.; HEMAKOM, R. [1985]. Test of Post-Tensioned Flat Plate with Banded Tendons. Proceedings, ASCE, V. 111, No. 9, Sept. 1985, pp. 1899 - 1915;

CANO, M. T.; KLINGNER, R. E. [1988]. Comparison Analysis Procedures for Two-Way Slabs. ACI Structural Journal, November-December 1988, pp. 597-608;

CARDOSO, C. F. F. [2001]. Análise de Lajes com Protensão sem Aderência.

Dissertação de Mestrado. Escola Politécnica de São Paulo - USP. 2001 -

São Paulo, pp. 151;

CARMO, R. M. S. [1995]. Efeitos de Segunda Ordem em Edifícios Usuais de Concreto Armado. São Carlos, 1995. 112 p. Dissertação (Mestrado) Escola de Engenharia de São Carlos, Universidade de São Paulo;

CAUDURO, E. L. [1997]. Em favor da Leveza. Revista Téchne, No. 26, pp. 3033 ;

CAUDURO, E. L; LEME, A. J. H. A Protensão de Edificio sem Vigas: Novas Técnicas Aumentam a Qualidade e Reduzem o Custo Total do Edificio. 14 p.;

CHACOS, G. P. [1988]. Resolution of Field Problems with Unbonded Single

Strand Tendons. Concrete International: Design and Construction, V. 10, No. 2, Fev. 1988, pp. 40-44;

CHACOS, G. P. [1993]. Wedge Forces on Post-Tensioning Strand Anchors. PTI

- Post-Tensioned Institute: Technical Notes, Issue 2, September 1993;

COllins, M. P.; MitChell, D. [1987]. Prestressed Concrete Basics. Canadian Prestressed Concrete Institute, Ottawa;

CONCRETE SOCIETY [1984]. Post-Tensioned Concrete Floors - Design Handbook. Technical Report No. 43;

CORLEY, W. G.; JIRSA, J. O. [1970]. Equivalente Frame Analysis for Slab Design. ACI Journal, V. 67, No. 11, Nov. 1970, pp. 875 - 884;

CORREAA, M R. S. [1991]. Aperfeiçoamento de Modelos Usualmente Empregados no Projeto de Edificios. São Carlos, 2001. Tese (Doutorado) - Escola de Engenharia de São Carlos, Universidade de São Paulo;

CORREAA, G. S.; MELO, G. S. S. A.; MARTINS, P. C. R. [2001]. Comportamento ao Puncionamento em Lajes Cogumelo Protendidas com Cabos Não 
Aderentes.Anais do 43 ongresso Brasileiro do Concreto - IBRACON Foz do Iguaçu, PR, 16 p., ANAIS [CD-ROM];

DUARTE, P. E. [1995]. Projeto e Cálculo de Lajes Planas Protendidas. MAC: Sistema Brasileiro de Protensão LTDA. São Paulo, Nov. 1995, 75 p.;

FALCONER, D. W. [1988a]. Tips for Post-Tensioning. Concrete International:

Design and Construction, V. 10, No. 2, Fev. 1988, pp. 36-39;

FALCONER, D. W.; WILSON, P. W. [1988b]. Inspection of Unbonded Tendons.

Concrete International: Design and Construction, V. 10, No. 2, Fev. 1988, pp. 53-56;

FISCHLI, F.; GRIMM, M.; MARTI, P. [1988]. Cutting Openings in Post-

Tensioned Floor Slabs. Concrete International: Design and

Construction, V. 10, No. 2, Fev. 1988, pp. 45-47;

FOUTCH, D. A.; GAMBLE, W. L.; SUNIDJA, H. [1990]. Tests of Post-tensioned

Concrete Slab-Edge Column Conections. ACI Structural Journal, V.

87, No. 2, Mar. - Apr. 1990, pp. 167-179;

GARDNER, N. J.; KALlAGE, M. R. [1998]. Punching Shear Strength of

Continuous Post-Tensioned Concrete Flat Plates. ACI Materials Journal, Vol. 95, No. 3, May-June 1998, pp. 272-283;

GHALI, A. [1989]. An Efficient Solution to Punching of Slabs. Concrete

International: Design and Construction, June 1989, pp. 50-54;

GILBERT, R. I. [1985]. Deflection Control of Slab Using Allowable Span to depth Ratios. ACI Journal, Proceedings, V. 82, No. 1, JanuaryFebruary 1985, pp. 67-72;

GILBERT, R. I. [1989]. Determination os Slab Thickness in Suspended Post-

Tensioned Floor Systems. ACI Structural Journal, V. 86, no. 5, September-October 1989, pp. 602-607;

GRAZIANO, F. P. [2000]. Lajes Protendidas com Cordoalhas Engraxadas -

Parte 1. Revista Téchne, No. 48, pp. 82-86;

GRAZIANO, F. P. [2001]. Lajes Protendidas com Cordoalhas Engraxadas -

Parte 2. Revista Téchne, No. 52, pp. 69-72;

HANAI, J. B. [1998]. Fundamentos do Concreto Protendido. São Carlos SP, março, 1998, 74 p.;

HANAI, J. B. [2000]. Perdas de Protensão por Atrito nos Cabos. Publicação SET, 17 p.: 
HAWKINS, N. M. [1981]. Lateral Load Resistence of Unbonded Post-tensioned Flat Plate Construction. Journal of PCI, Jan. - Fev. 1981, pp. 94-116; HONDROS, G.; SMITH, G. C. [1969]. Model and Theoretical Analysis of a PostTensioned Diagrid Flat Plate. Journal of PCI, Vol. 14, No. 2, April 1969, pp. 63 - 87;

HAMBLY, E. C. [1976]. Bridge Deck Behavior. London, Chapman and Hall; KENNY, A. R.; SONG, J. W. [1988]. Post-Tensioning Alternative Reduces Construction Time. Concrete International: Design and Construction, V. 10, No. 2, Fev. 1988, pp. 48-52;

KISS, P. [1999]. Os Leves Puxam o Mercado. Revista Téchne, No. 41, pp. 5256 ;

KORETSKY, A. V.; PRITCHARD, R. W. [1982]. Assessment of Relaxation Loss Estimates for Strands. ASCE Journal, ST12, December 1982, pp. 2819 $-2836$

KOSUT, G. M.; BURNS, N. H.; WINTER, C. V. [1985]. Test of Four-Panel PostTensioned Flat Plate. Proceedings, ASCE, V. 111, No. 9, Sept. 1985, pp. 1916 - 1929;

LEONHAndT, F. [1983]. Construções de Concreto - Concreto Protendido. Vol. 5, Editora Interciência Ltda., Rio de Janeiro, RJ, 316 p.;

LIGHTFOOT, E.; SAWKO, F. [1959]. Structural Frame Analysis by Electronic Computer: Grid Frameworks resolved by Generalized Slope Deflection. Engineering, 187, pp. 18-20;

LIMA, J. S. [2001]. Verificações da Punção e da Estabilidade Global em Edificios de Concreto: Desenvolvimento e Aplicação de Recomendações Normativas. São Carlos, 2001. 225 p. Dissertação (Mestrado) - Escola de Engenharia de São Carlos, Universidade de São Paulo;

LIN, T. Y. [1963]. Load-Balancing Method for Design and Analysis of Prestressed Concrete Structures. ACI Proceedings, V. 60, No. 6, June 1963, pp.719-741;

LIN, T. Y.; BURNS, N. H. [1981]. Design of Prestressed Concrete Structures. $3^{\text {th }}$ Edition, John Wiley \& Sons, New York, 646 pp.;

LONG, A. E.; CLELAND, D. J. [1993]. Post-Tensioned Concrete Flat Slabs at Edge Columns. ACI Materials Journal, May - June 1993, pp. 207 213; 
MATTACCHIONE, A. [1992]. Unbonded P-T Slabs: An Economical Alternative.

Concrete International: Design and Construction, V. 14, No. 2, Fev. 1992, pp. 41-45;

MATTOCK, A. H.; YAMAZAKI, J.; KATTUKA, B. T. [1971]. Comparative Study of Prestressed Concrete Beams, with and without Bond. ACI Journal, Fev. 1971, pp. 116 - 125;

Melges, J. L. P. [1995]. Punção em Lajes: Exemplos de Cálculo e Análise

Teórico-Experimental. São Carlos, 1995. 217 p. Dissertação (Mestrado) - Escola de Engenharia de São Carlos, Universidade de São Paulo;

Melges, J. L. P. [2001]. Análise Experimental da Punção em Lajes de Concreto Armado e Protendido. São Carlos, 2001. Tese (Doutorado) Escola de Engenharia de São Carlos, Universidade de São Paulo;

MEYERS, B. L.; BRANSON, D. E. [1972]. Design Aid for Predicting Creep and Shrinkage Properties of Concrete. ACI Journal, Sept. 1972, pp. 551555 ;

MORDECAI, V. S. [1984]. The Progress of Post-Tensioning Concrete. Journal of the Concrete Society, V. 18, No. 10, Oct. 1984, pp. $9-12$;

MUSPRATT, M. A. [1969]. Behavior of a Prestressed Concrete Waffle Slab with

Unbonded Tendons. ACI Journal, Proceedings, December 1969, pp. 1001 - 1004;

NAAMAN, A. E. [1992]. Unified Design Recommendations for Reinforced,

Prestressed, and Partially Prestressed Concrete Bending and Compression Members. ACI Structural Journal, Vol. 89, No. 2, MarchApril 1992, pp. 200-210;

NAWY, E. G. [1996]. Prestressed Concrete - A Fundamental Approach. 2 ${ }^{\text {nd }}$ Edition, Prentice Hall International Series in Civil Engineering and Engineering Mechanics, New Jersey, 789 pp.;

O’BRIEN, E. J.; DIXON, A. S. [1995]. Reinforced and Prestressed Concretre

Design - The Complete Process. Longman Scientific \& Technical, Dublin, 492 pp.;

PCI JOURNAL - PRESTRESSED CONCRETE INSTITUTE [1985]. Specification For Unbonded Single Strand Tendons. Journal of the Prestressed Concrete Institute, Vol. 30, No. 2, March/April 1985; 
PTI - Post-Tensioned Institute [1983]. Post-Tensioned Commercial and Industrial Floors. Phoenix, 35 pp., 1983;

PTI - Post-Tensioned Institute [1987].Design of Post-Tensioned Slabs. 2nd Edition, $2^{\text {nd }}$ Printing, 1987, 54 p.;

PTI - POST-TENSIONING INSTITUTE [1994]. Field Procedures Manual for

Unbonded Single Strand Tendons. $2^{\text {nd }}$ Edition. July 1994. U.S.A.;

PTI - POST-TENSIONING INSTITUTE [1998]. Construction and Maintenance

Procedures Manual for Post-Tensioned Slabs-on-Ground. 2nd Edition.

September 1998. U.S.A.;

REGAN, P. E. [1985]. The Punching Resistance of Prestressed Concrete Slabs.

Proceedings of the Institution of Civil Engineers, Part 2, 1985, Vol.

79, December, pp. 657 - 680;

ROZVANY, G.; WOODS, J. [1969]. Sudden Collapse of Unbonded Prestressed

Structures. ACI Journal, Proceedings, V. 66, No. 2, Feb. 1969, pp. 129135 ;

SCHMID, M. T. [1993]. Lajes Planas Protendidas. Publicação Técnica, Rudloff

- VSL Industrial Ltda. São Paulo, Brasil, 1993, 22 p.;

SCORDELIS, A. C.; PISTER, K. S.; LIN, T. Y. [1956]. Strength of a Concrete

Slab Prestressed in Two Directions. ACI Journal, V. 28, No. 3, Sept. 1956 (Proceedings V. 53), pp. 241-256;

SCORDELIS, A. C.; LIN, T. Y.; ITAYA, R. [1959]. Behavior of a Continuous Slab

Prestressed in Two Directions. ACI Journal, December 1959, pp. 441459;

SILVA, R. L. [1998]. Projeto de Lajes Maciças Protendidas de Edifícios.

Dissertação de Mestrado. Escola Politécnica de São Paulo. 1998 - São Paulo, pp. 151;

SOUZA, V. C. M.; CUNHA, A. J. P. [1994]. Lajes em Concreto Armado e Protendido. Niterói, EDUFF - 1994, 584p.;

TAKEYA et al. [1985]. Recomendações para o Projeto e a Execução da Estrutura de Lajes Cogumelo Pertencentes as UBS do Plano Metropolitano de Saúde. Relatório Técnico, São Carlos - EESC, 1985, 31 p.;

VANDERBILT, M. D.; CORLEY, W. G. [1983]. Frame Analysis of Concrete Buildings. Concrete International: Design and Construction, Dec. 1983, pp. 33-43; 


\section{APÊNDICE A}

\section{CRITÉRIOS ADOTADOS DE PROJETO \\ PARA O PROGRAMA DE CÁLCULO ESTRUTURAL TQS®}

\section{A.1 - Resistência à Compressão do Concreto $\left(f_{\text {ck }}\right)$}

Foi adotada uma resistência à compressão do concreto usual no mercado da construção civil.

Foi visto que a maioria dos escritórios de cálculo estrutural adotam valores da ordem de 20 a $30 \mathrm{MPa}$ para estruturas de concreto armado e de 25 a $35 \mathrm{MPa}$ para estruturas de concreto protendido. Com isso, foi determinado um valor de $35 \mathrm{MPa}$ para a resistência à compressão do concreto para todos os elementos estruturais, sendo eles, lajes, vigas e pilares.

\section{A.2 - Módulo de Elasticidade Longitudinal do Concreto $\left(E_{c}\right)$}

Com base no valor de $35 \mathrm{MPa}$ para resistência à compressão do concreto, foi utilizada a formulação fornecida pelo Projeto de Revisão da NBR 6118-2001, que consiste em:

$$
\mathrm{E}_{\mathrm{c}}=5600 \cdot \sqrt{\mathrm{f}_{\mathrm{ck}}}
$$

Substituindo o valor de $\mathrm{f}_{\mathrm{ck}}$ na equação A.1, tem-se que:

$$
\mathrm{E}_{\mathrm{c}}=33130,05 \mathrm{MPa} \text { ou } \mathrm{E}_{\mathrm{c}}=3.313 .004,68 \mathrm{tf} / \mathrm{m}^{2}
$$

Logo, o valor adotado foi de 3.300.000,0 tf $/ \mathrm{m}^{2}$ para o módulo de elasticidade tangente e, para o módulo de elasticidade secante 2.800.000,0 $\mathrm{tf} / \mathrm{m}^{2}$.

\section{A.3 - Módulo de Elasticidade Transversal do Concreto $\left(\mathbf{G}_{c}\right)$}

Seguindo as recomendações de TAKEYA et al. [1985], pode-se adotar é igual a $15 \%$ do valor do módulo de elasticidade longitudinal do concreto, já com a consideração aproximada da fissuração por cisalhamento.

Logo, $G_{c}=496.950,70 \mathrm{tf} / \mathrm{m}^{2}$ ou, simplificando, $G_{c}=490.000 \mathrm{tf} / \mathrm{m}^{2}$ 


\section{A.4 - Critérios Adotados para a Modelagem por Grelha}

O programa de cálculo TQS ${ }$ faz a geração automática do modelo de grelha a partir dos dados da fôrma do pavimento, tanto para lajes maciças quanto para lajes nervuradas.

O desenho da grelha obedece as fôrmas do pavimento e só pode ser alterado se a planta de fôrmas for modificada.

As barras da grelha possuem características geométricas e físicas correspondentes ao estabelecido na planta de fôrmas, sendo assim, é considerado, para as lajes nervuradas, que as nervuras são calculadas como seção T com a incorporação das capas como mesas. Do mesmo modo são as lajes maciças, com seções retangulares.

$\mathrm{Na}$ discretização das barras, pode ser considerada uma parcela da inércia à torção (que foi desprezada nos modelos) e uma outra parcela referente à flexão.

Os carregamentos aplicados à grelha, no caso das alvenarias, são admitidos como carga pontual aplicada nos nós da grelha.

Para o apoio da grelha, foi adotada a técnica do apoio elástico independente. Este processo considera uma parcela da seção transversal do pilar referente à posição da barra que nela chega. A seção transversal de cada pilar é igual a que se encontra $\mathrm{n}$ meio da distância entre pavimentos adjacentes. Com isso, compara a largura do pilar com a largura da viga e determina a influência da ligação da viga no pilar, determinado assim, uma mola representativa do apoio.

$\mathrm{Na}$ zona de engrossamento das ligações laje-pilar, as barras a grelha que chegam a esta zona modificam suas caracteristicas geométricas, assumindo propriedades inerentes à nova geometria existente. No caso das lajes nervuradas, ocorre o mesmo procedimento, onde as barras das nervuras que chegam à zona de engrossamento, mudam suas características de seção T para assumir as características do capitel.

A figura A.1 ilustra a discretização da grelha para o caso de laje plana nervurada. 


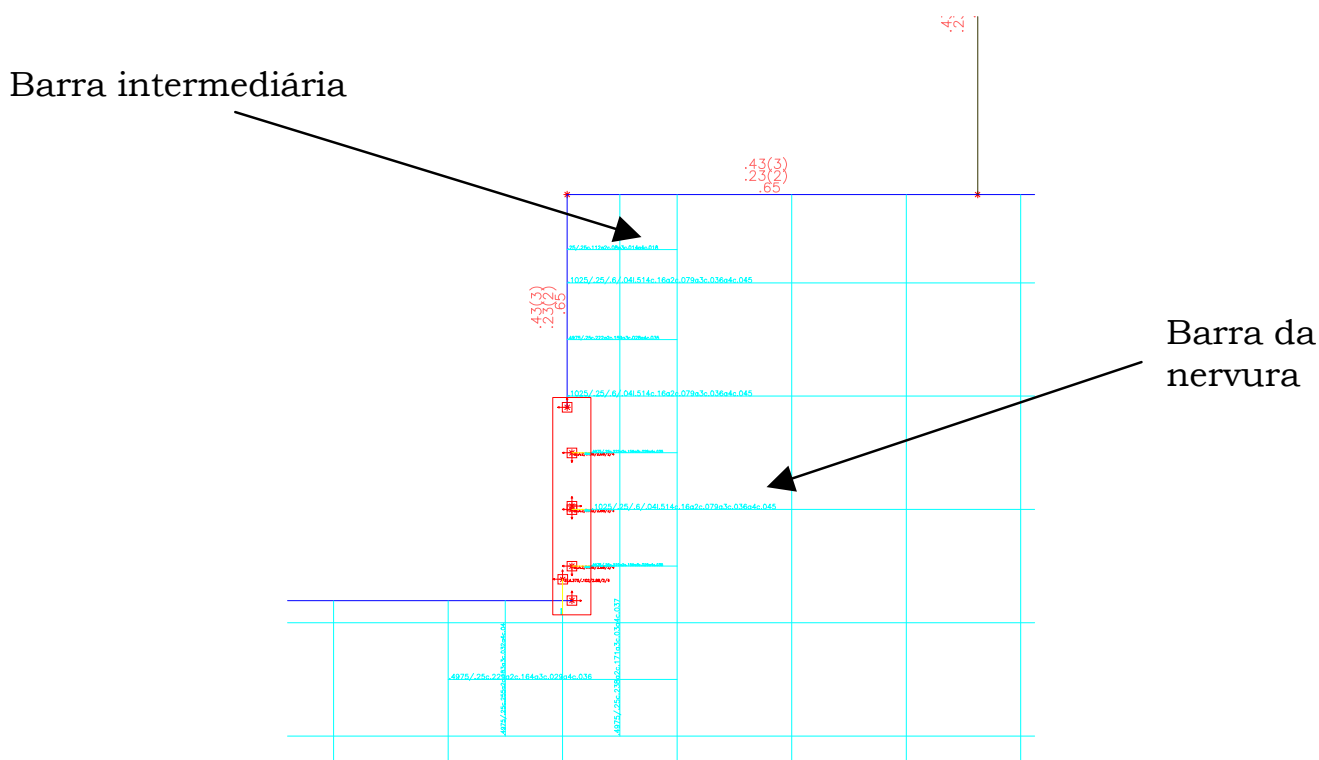

Figura A.1 - Detalhe das barras na zona de engrossamento da laje nervurada

O programa gera na zona de engrossamento uma série de barras intermediárias. Estas barras intermediárias possuem propriedades geométricas referentes ao engrossamento. No dimensionamento dos esforços, pode-se determinar no programa a distribuição do momento fletor encontrado na capa ou concentrado nas nervuras. Pode-se ainda definir valores para cada um deles para trabalharem em conjunto, ou seja, pode-se atribuir uma porcentagem de participação maior para as nervuras, por exemplo, e o restante sendo distribuído para a capa de concreto.

Dentre outros critérios adotados para o cálculo da grelha, tem-se que:

- Os espaçamentos, tanto para a direção X quanto para a Y foi de $40,0 \mathrm{~cm}$ entre barras para os modelos com lajes planas maciças;

- Na zona de engrossamento da laje plana nervurada são consideradas barras adicionais para determinar os momentos fletores atuantes, assumindo as características geométricas desta região.

Pode-se ver na figura A.2, a discretização do pavimento-tipo do edificio modelo, no caso da laje plana maciça. 


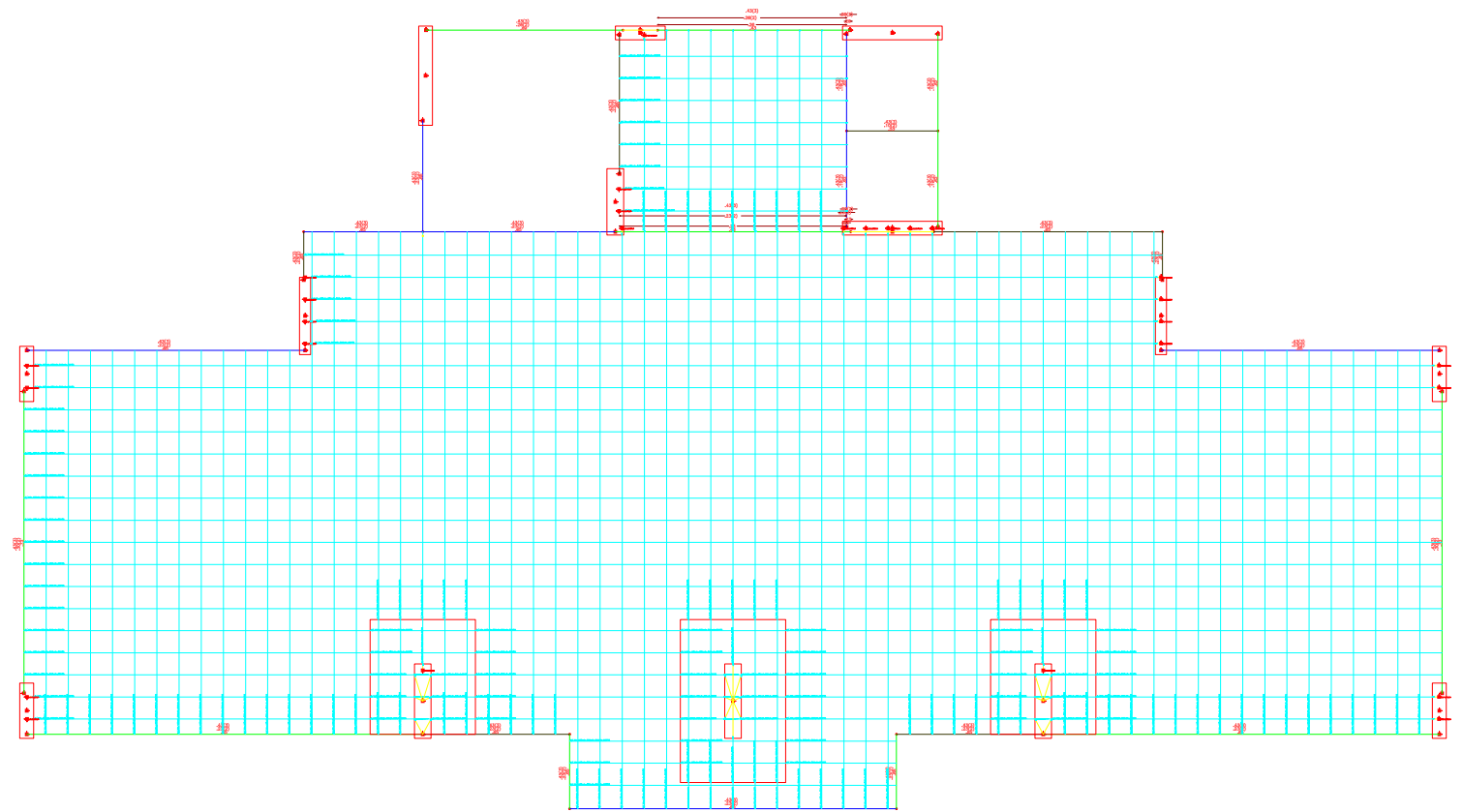

Figura A.2 - Pavimento-tipo de laje plana maciça discretizado

Para as lajes nervuradas, é mostrado na figura A.3 e A.4 a estruturação do pavimento-tipo em barras, tanto para o modelo de laje plana nervurada quanto o modelo de laje apoiada sobre vigas faixa.

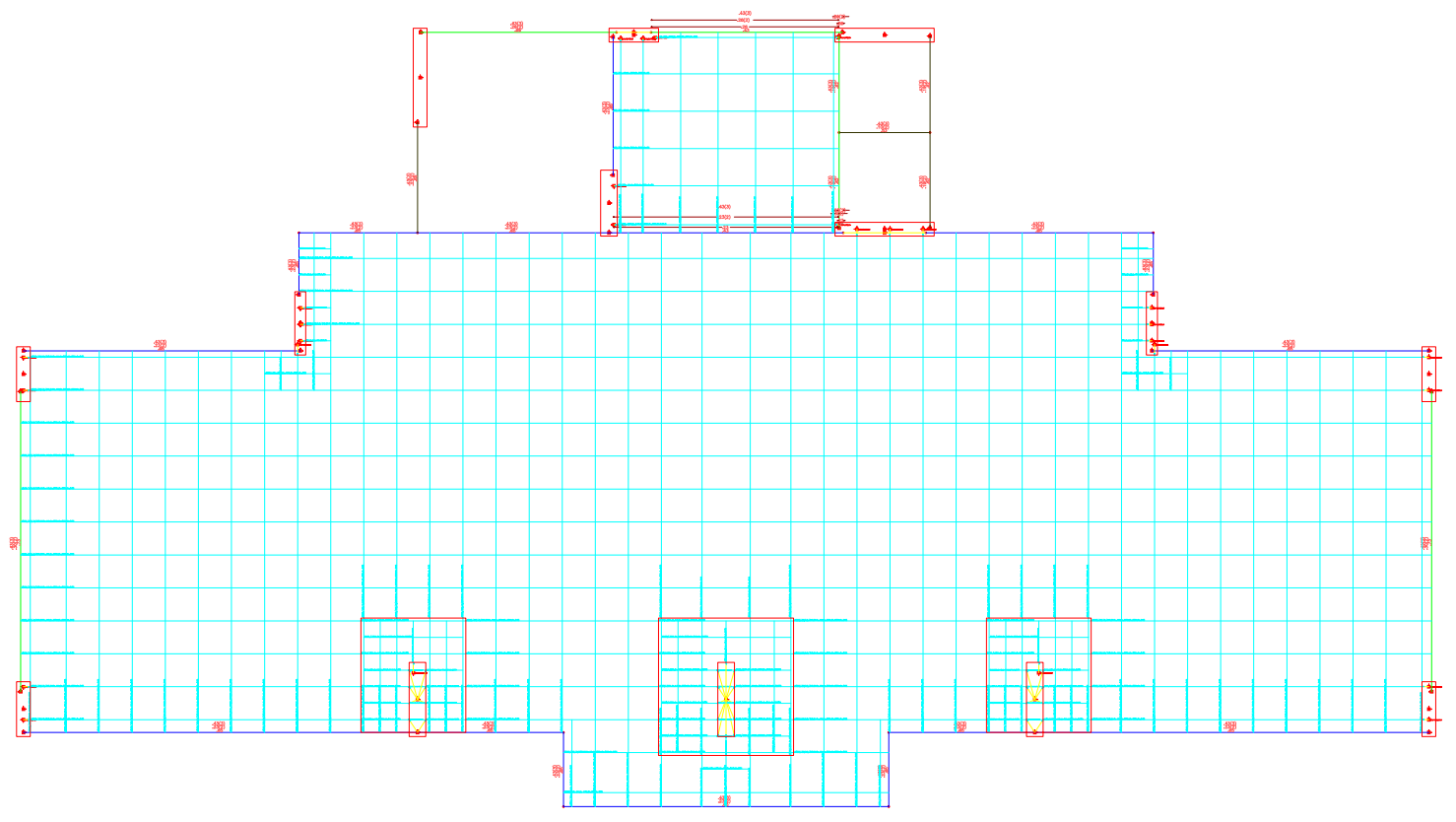

Figura A.3 - Discretização em grelha dos modelos de laje plana nervurada 


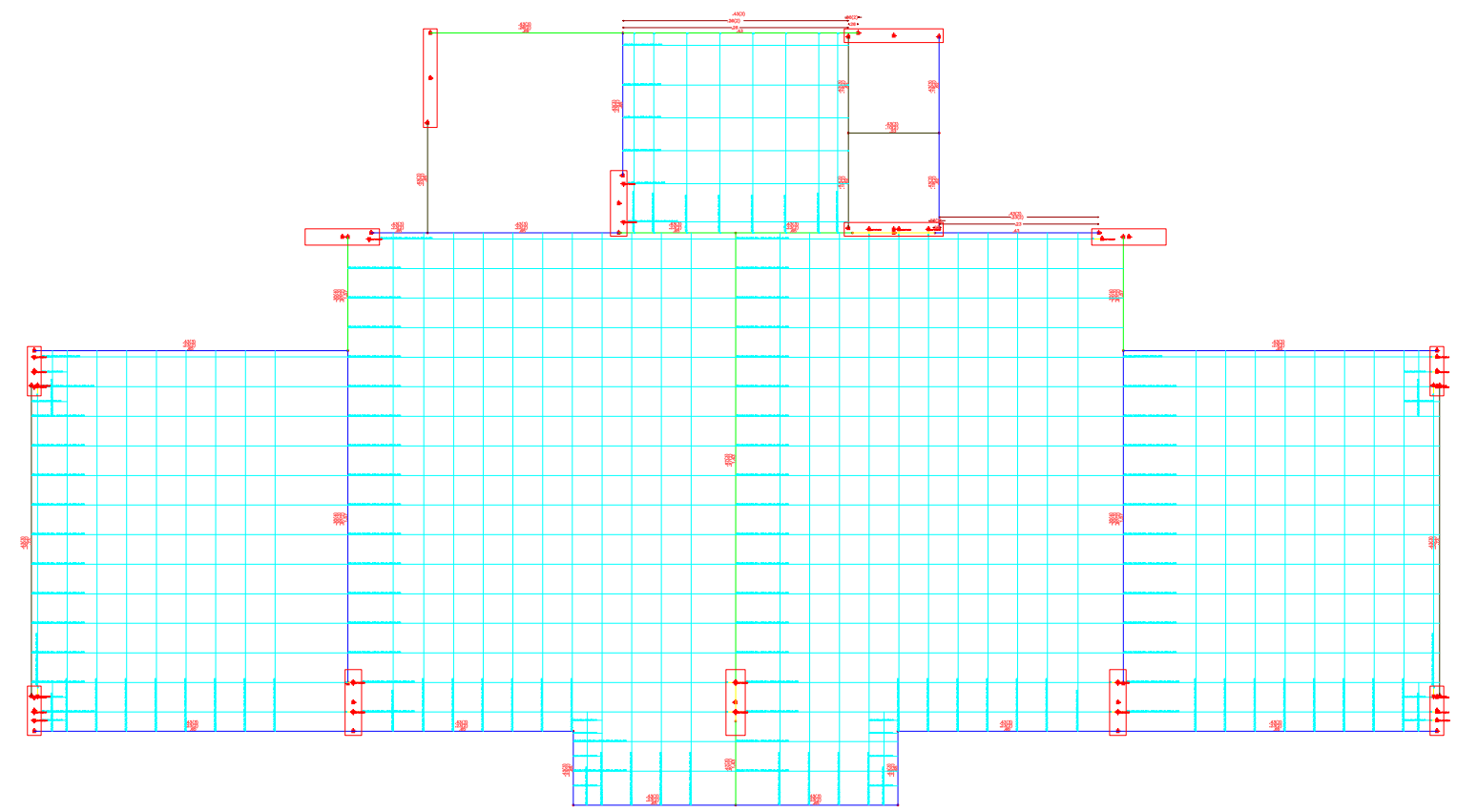

Figura A.4 - Discretização em grelha dos modelos de laje plana nervurada

\section{A.5 - Critérios Adotados para Lajes Protendidas}

Neste segmento, serão mostrados os parâmetros utilizados para o cálculo de lajes com protensão aderente e não aderente.

Os dois tipos de protensão apresentam características distintas e por isso, serão tratados separadamente.

Porém, alguns critérios são semelhantes, como a resistência à compressão do concreto; Módulo de elasticidade Longitudinal e transversal e a resistência à tração do concreto.

\section{i) Lajes com Protensão Aderente}

Nas lajes com protensão com aderência, ou seja, o pavimento é protendido com o sistema convencional de protensão que consiste na utilização de uma cordoalha imersa em uma nata de cimento dentro de uma bainha metálica de aço.

Neste sistema, serão utilizados diversos tipos de bainhas, sendo que o número de cordoalhas em seu interior varia de 1 a 4 . 
Na tabela A.1, tem-se as dimensões das bainhas utilizadas no cálculo do pavimento-tipo.

Tabela A.1 - Dimensões usuais para bainhas metálicas (medidas em centímetros)

\begin{tabular}{|c|c|c|c|c|c|c|c|c|}
\hline \multirow{2}{*}{$\begin{array}{l}\text { Bitola } \\
\text { (mm) }\end{array}$} & \multicolumn{2}{|c|}{1 Cordoalha } & \multicolumn{2}{|c|}{2 Cordoalhas } & \multicolumn{2}{|c|}{3 Cordoalhas } & \multicolumn{2}{|c|}{4 Cordoalhas } \\
\hline & Base & Altura & Base & Altura & Base & Altura & Base & Altura \\
\hline 12,7 & 3,50 & 2,10 & 3,50 & 2,10 & 6,60 & 2,10 & 6,60 & 2,10 \\
\hline 15,2 & 4,00 & 2,10 & 4,00 & 2,10 & 7,00 & 2,10 & 7,00 & 2,10 \\
\hline
\end{tabular}

Fonte: TQS Informática

Em se tratando de perdas de protensão, foi adotado um valor para o coeficiente de perdas por atrito igual a 0,2 e para o coeficiente para perdas devido às curvas não intencionais igual a 0,01, de acordo com o Projeto de Revisão da NBR 6118-2001.

Para os cobrimentos, foi adotada uma espessura única igual a $3,50 \mathrm{~cm}$ ao redor da cordoalha.

No detalhamento dos cabos, a extremidade da cordoalha termina no centro de gravidade da seção transversal da laje.

Os detalhes das características dos cabos podem ser vistas na tabela A.2.

Tabela A.2 - Características das cordoalhas para protensão aderente

\begin{tabular}{|c|c|c|c|c|c|c|c|c|c|}
\hline $\begin{array}{c}\phi \\
(\mathbf{m m})\end{array}$ & $\begin{array}{c}P_{\text {inicial }} \\
\text { (tf) }\end{array}$ & $\begin{array}{c}P_{t}=0 \\
(t f)\end{array}$ & $\begin{array}{l}\mathbf{P}_{\mathbf{i}_{\infty}} \\
\text { (tf) }\end{array}$ & $\begin{array}{l}P_{\text {rup }} \\
\text { (tf) }\end{array}$ & $\begin{array}{c}\text { Pescda } \\
\text { (tf) }\end{array}$ & $\begin{array}{c}\% \\
\text { Perda }\end{array}$ & $\begin{array}{c}F_{p y k} \\
\left(\mathrm{kgf}_{\left./ \mathrm{cm}^{2}\right)}\right.\end{array}$ & $\begin{array}{c}F_{\text {ptk }} \\
\left(\mathrm{kgf} / \mathrm{cm}^{2}\right)\end{array}$ & $\begin{array}{c}\mathrm{dw}^{*} \\
(\mathrm{~mm})\end{array}$ \\
\hline 12,7 & 15 & 13,95 & 12,14 & 18,70 & 16,83 & 13 & 17100 & 19000 & 6,0 \\
\hline 15,2 & 20 & 18,73 & 16,30 & 26,60 & 23,92 & 13 & 17100 & 19000 & 6,0 \\
\hline
\end{tabular}

Fonte: TQS Informática

* corresponde à acomodação da cordoalha na ancoragem.

Para a armadura passiva, o programa do TQS ${ }^{\circledR}$ fornece a opção de três tipos de cálculo para a armadura passiva mínima, sendo elas:

- Critério de armadura mínima do Projeto de Revisão da NBR 6118-2001 onde, $A_{\text {Smin }}=0,15-0,5 \cdot \rho_{\mathrm{p}} \geq 0,05 \%$; 
- Outro critério onde $A_{\text {Smin }}=0,03 \cdot \frac{f_{c k}}{f_{y k}}$;

- E o terceiro critério que pode ser definido pelo projetista.

Nos modelos com protensão aderente foi utilizado o primeiro critério.

\section{ii) Lajes com Protensão Não Aderente}

Do mesmo modo que na protensão aderente, os critérios para a protensão não aderente seguem os mesmos parâmetros com algumas mudanças.

A quantidade de cordoalhas por feixe varia de 1 a 4 .

Para as perdas de protensão, foi adotado um valor para o coeficiente de perdas por atrito igual a 0,05 e para o coeficiente para perdas devido às curvas não intencionais igual a 0,0035, de acordo com os critérios do Projeto de Revisão da NBR 6118-2001.

Para os cobrimentos foi adotada uma espessura única igual a $3,50 \mathrm{~cm}$ ao redor da cordoalha.

Os detalhes das características das cordoalhas são as mesmas da tabela A.2.

No detalhamento das cordoalhas, foi adotado um comprimento de cabo reto nas extremidades igual a 50,0 cm com a extremidade do cabo terminando no centro de gravidade da seção transversal da laje.

Para a armadura passiva, o programa do TQS ${ }^{\circledR}$ fornece a opção de três tipos de cálculo para a armadura passiva mínima, sendo elas:

- Critério de armadura minima da Norma onde, $\mathrm{A}_{\mathrm{Smin}}=0,5-0,2 . \rho_{\mathrm{p}} \geq 0,05 \%$;

- Outro critério onde $A_{\text {Smin }}=0,03 \cdot \frac{f_{c k}}{f_{y k}}$;

- E o terceiro critério que é de responsabilidade do projetista.

Nos modelos com protensão não aderente foi utilizado o primeiro critério. 


\section{A.6 - Critérios Adotados para Análise Estrutural do Edificio}

Para a análise global da estrutural, foi utilizado o modelo de pórtico tridimensional onde os esforços horizontais e verticais foram utilizados para dimensionar vigas e pilares.

A versão do programa TQS ${ }^{\circledR}$ utilizado, conta com a inovação da flexibilização dos nós da estrutura que torna o comportamento desta mais próximo da realidade.

Neste processo, cada ligação viga-pilar contém, em sua rigidez, uma mola que faz com que a estrutura seja mais deslocável, levando a resultados mais realistas. Para maiores detalhes, consultar o manual da TQS ${ }^{\circledR}$ à respeito deste modelo.

Os comportamentos dos pórticos tridimensionais podem ser vistos no apêndice $B$.

No modelo de pórtico tridimensional foi adotado um critério de duas faixas de análise para os pavimentos, isto é, no processamento, o edificio foi dividido em duas partes, sendo a primeira do $1^{0}$ ao $10^{\circ}$ andar, e a segunda, do $11^{\circ}$ ao $20^{\circ}$ andar. A justificativa é que tal disposição fornece um consumo reduzido de armadura passiva nas vigas, pois, todas as vigas foram dimensionadas com base nos efeitos das cargas verticais e horizontais e, do ponto de vista executivo, a adoção deste critério também traz apenas dois arranjos diferentes de armadura para as vigas, facilitando assim, os trabalhos no canteiro de obras.

Note que é possível fazer a divisão do edificio em várias faixas e quanto maior a divisão, maior seria a economia, porém, com isso, seria mais trabalhoso e consumiria mais tempo de execução no canteiro de obras, pois a armadura das vigas iria variar nos pavimentos de cada faixa. 


\section{APÊNDICE B}

\section{DIAGRAMAS DE MOMENTO FLETOR E DESLOCAMENTOS DOS PAVIMENTOS}

O objetivo deste apêndice é mostrar os valores obtidos na modelagem desenvolvida no programa de cálculo TQS® .

\section{B.1 - Modelo E01}

Trata-se do modelo laje plana maciça com protensão não aderente (E01). A figura B.1 ilustra a distribuição de armadura ativa no pavimento para o modelo.

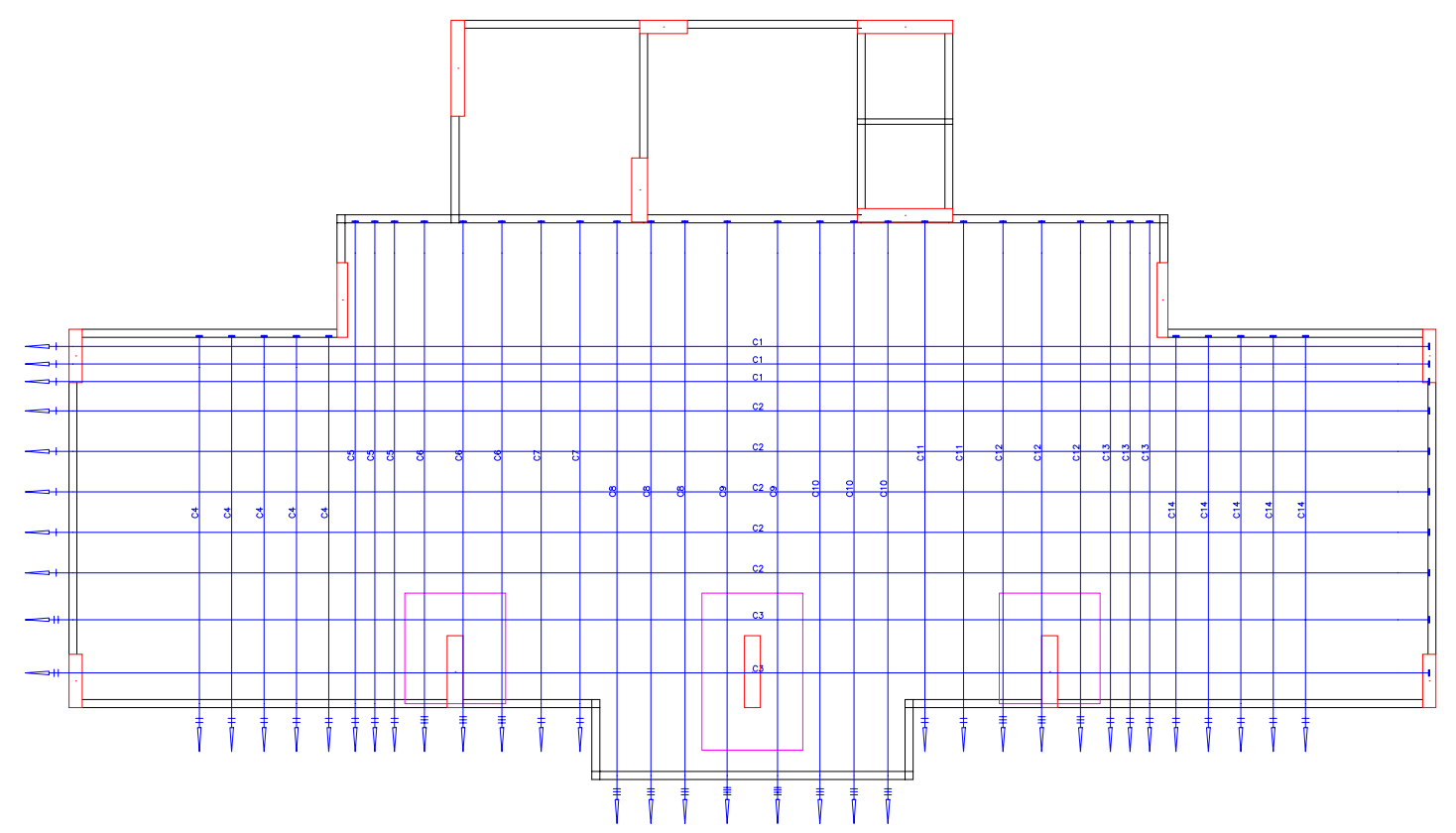

Figura B.1 - Distribuição de armadura ativa no pavimento (E01)

A figura B.1 mostra que o tipo de disposição de cabos, para este caso foi do tipo distribuído nas duas direções, resultado em um consumo de armadura ativa de $990,0 \mathrm{~kg} /$ pavimento.

Na figura B.2 tem-se os deslocamentos no pavimento sem a presença da protensão. Pode-se ver que o deslocamento é superior ao limite estabelecido 
pela Proposta de Revisão da NBR 6118-2001 que, para deslocamentos é de $1 / 300$.

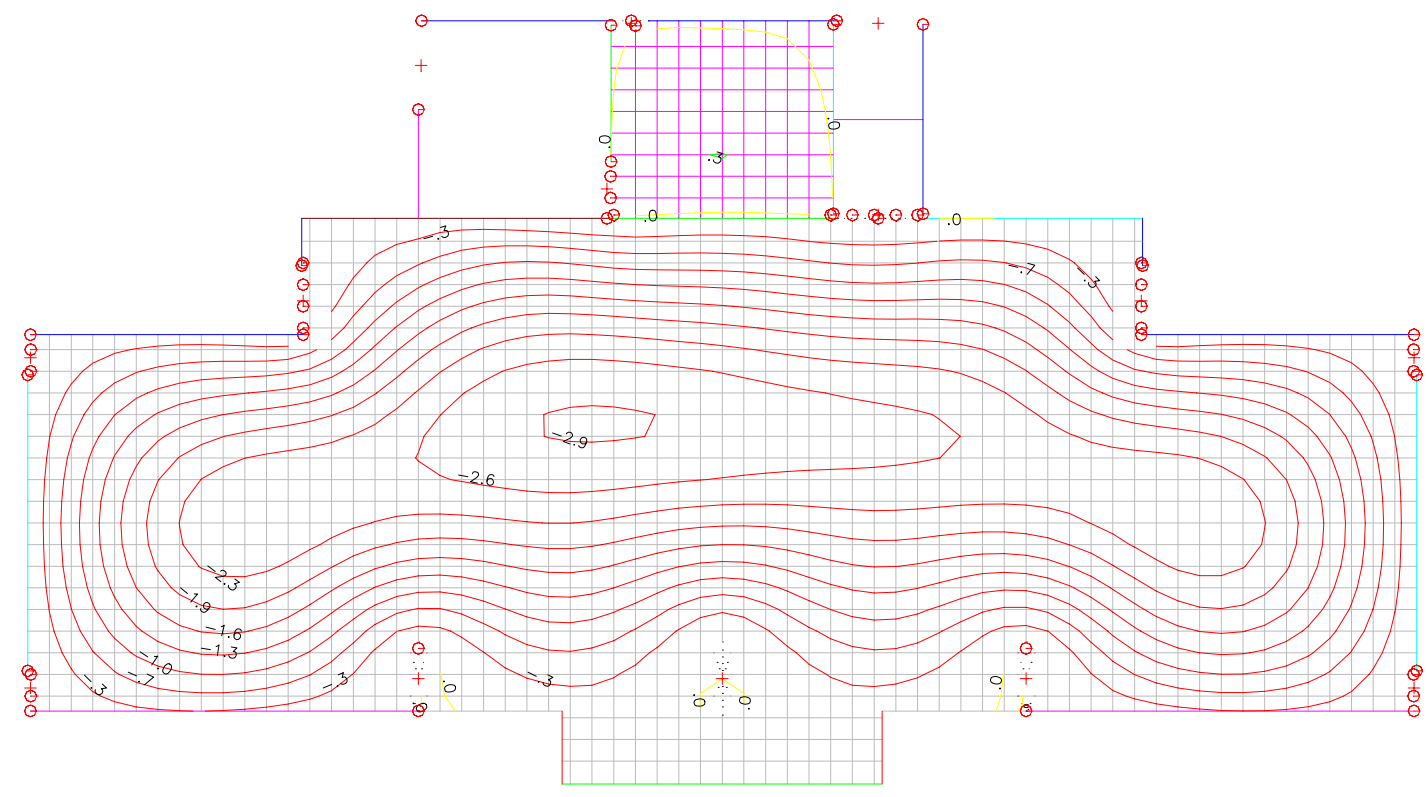

Figura B.2 - Diagrama de isolinhas de deslocamentos no pavimento sem a presença da protensão

Na figura B.3 é ilustrado o deslocamento do pavimento após a aplicação da protensão. O deslocamento consiste na deformação imediata somada da deformação lenta.

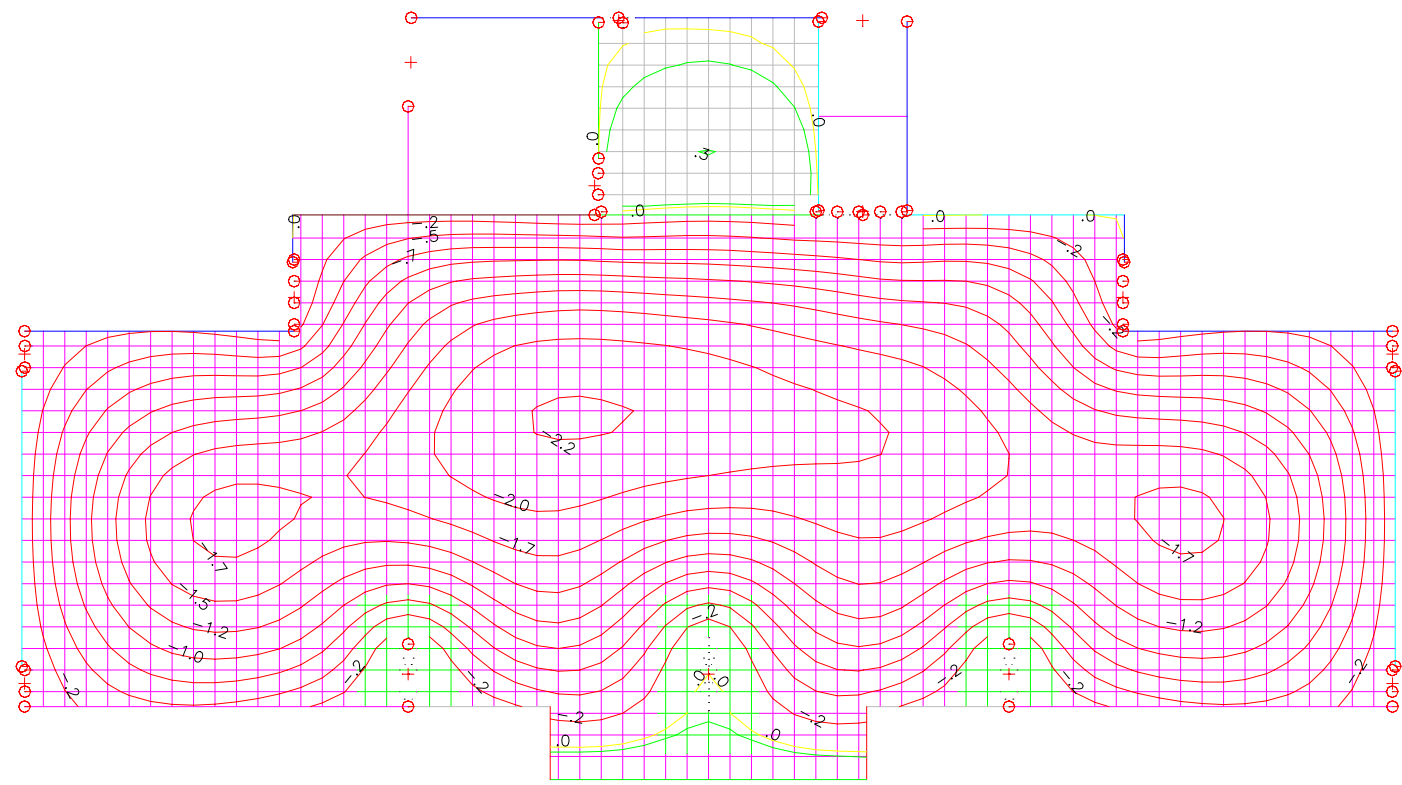

Figura B.3 - Diagrama de isolinhas de deslocamentos no pavimento com a presença da protensão 
O deslocamento máximo encontrado é de 2,20 cm, portanto, inferior ao limite estabelecido de $1 / 300$.

Nas figuras B.4 e B.5, tem-se os diagramas de momento fletor para o pavimento nas direções $\mathrm{X}$ e $\mathrm{Y}$, para o caso de deslocamentos para tempo infinito (deformação imediata + deformação lenta).

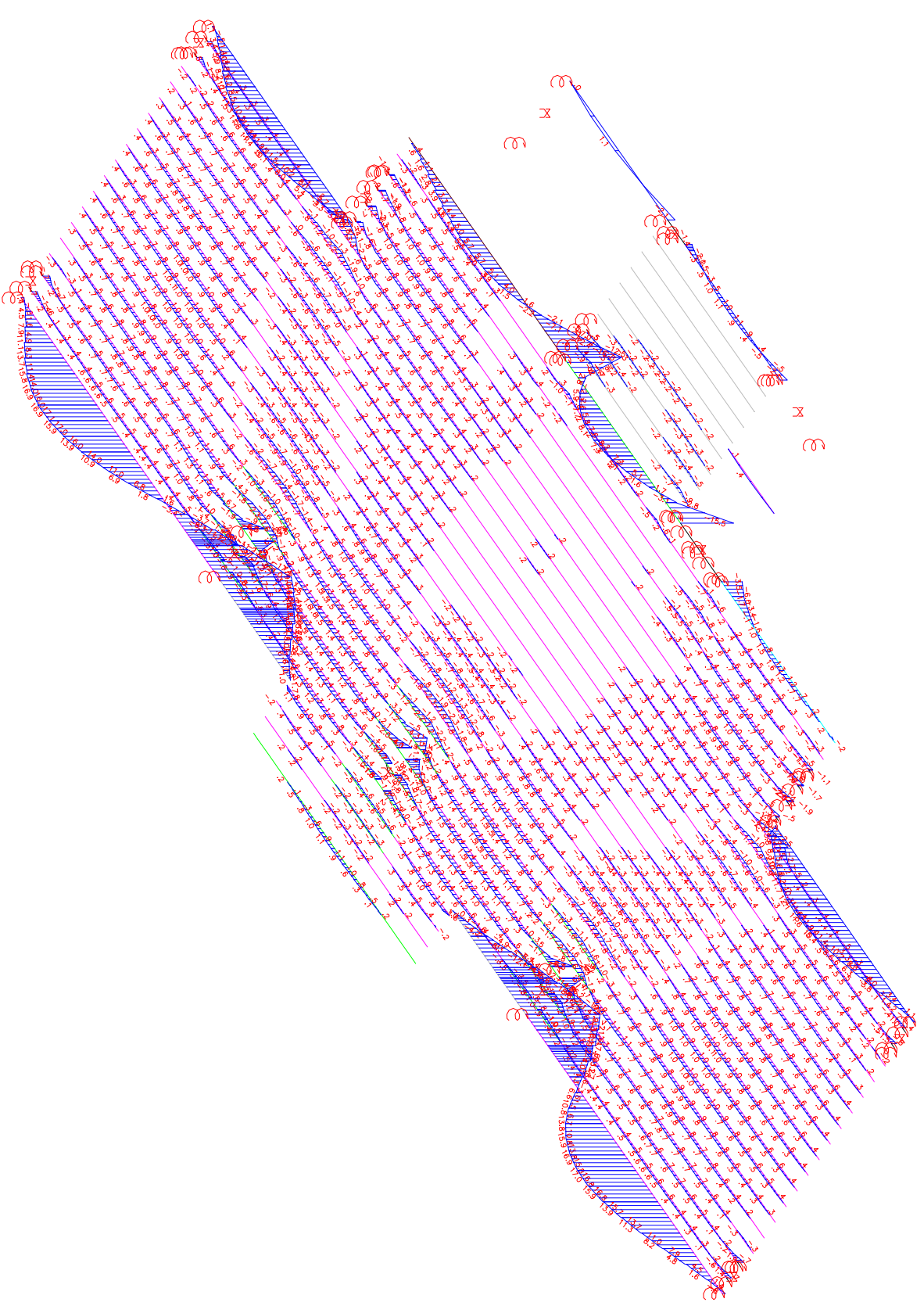

Figura B.4 - Momentos fletores na direção X com a presença da protensão para deslocamentos com tempo infinito 


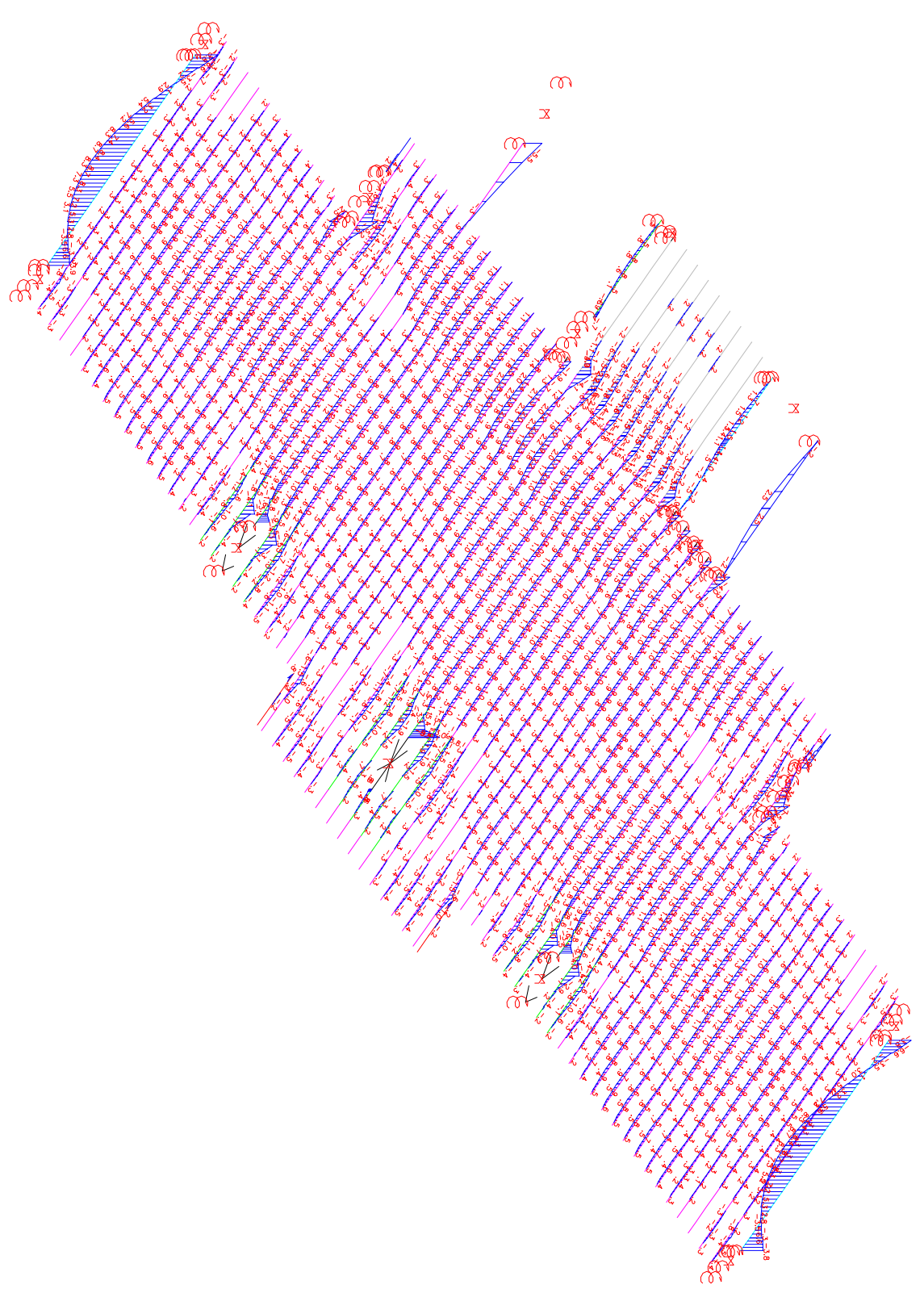

Figura B.5 - Momentos fletores na direção Y com a presença da protensão para deslocamentos para tempo infinito

\section{B.2 - Modelo E02}

Trata-se do modelo de pavimento de laje plana maciça com a utilização da protensão aderente.

Na figura B.6 tem-se a distribuição de cabos no piso para o modelo. 


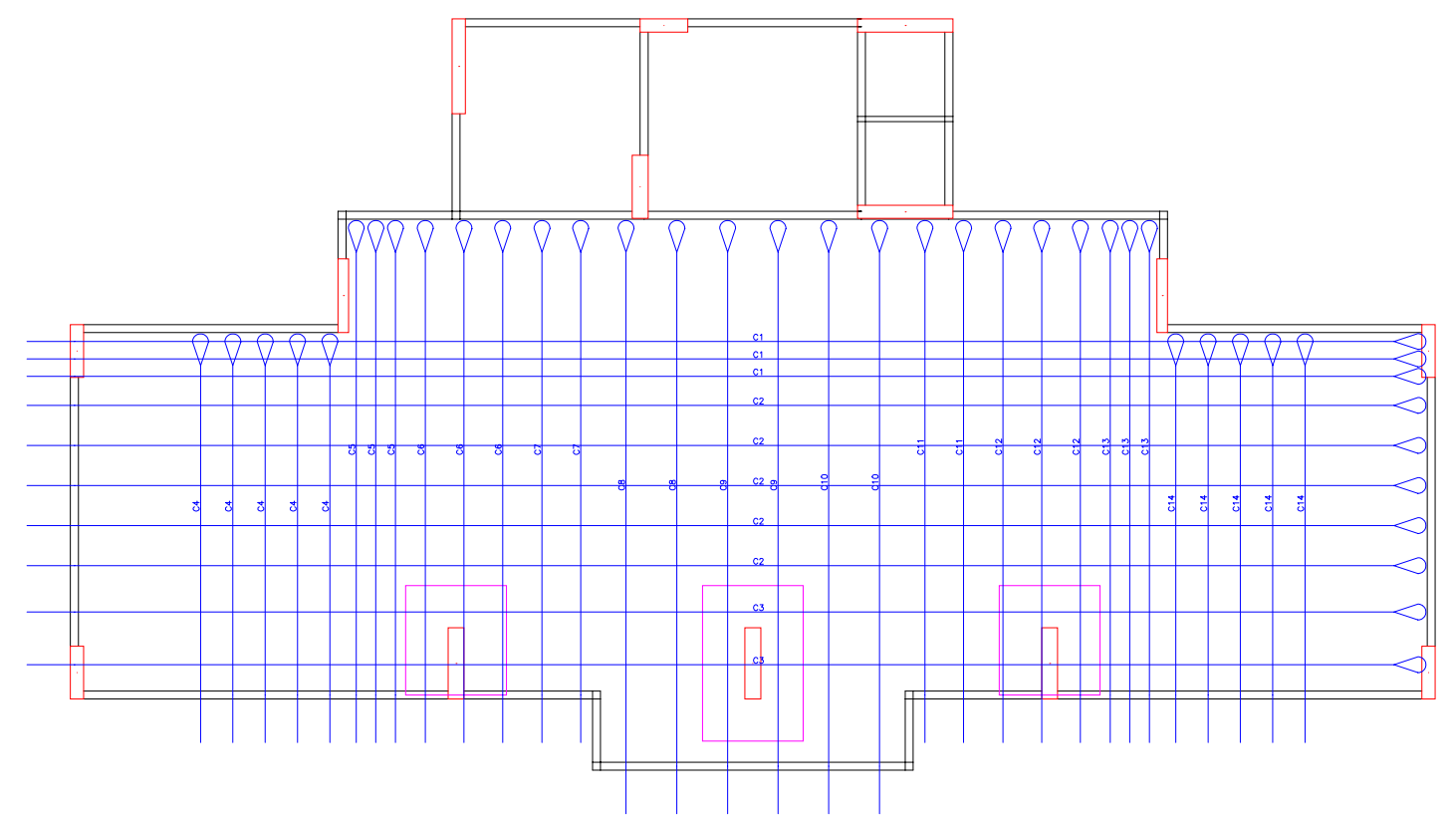

Figura B.6 - Distribuição de armadura ativa no pavimento (E02)

Na figura B.7 tem-se o diagrama de isolinhas de deslocamento com a inclusão da protensão.

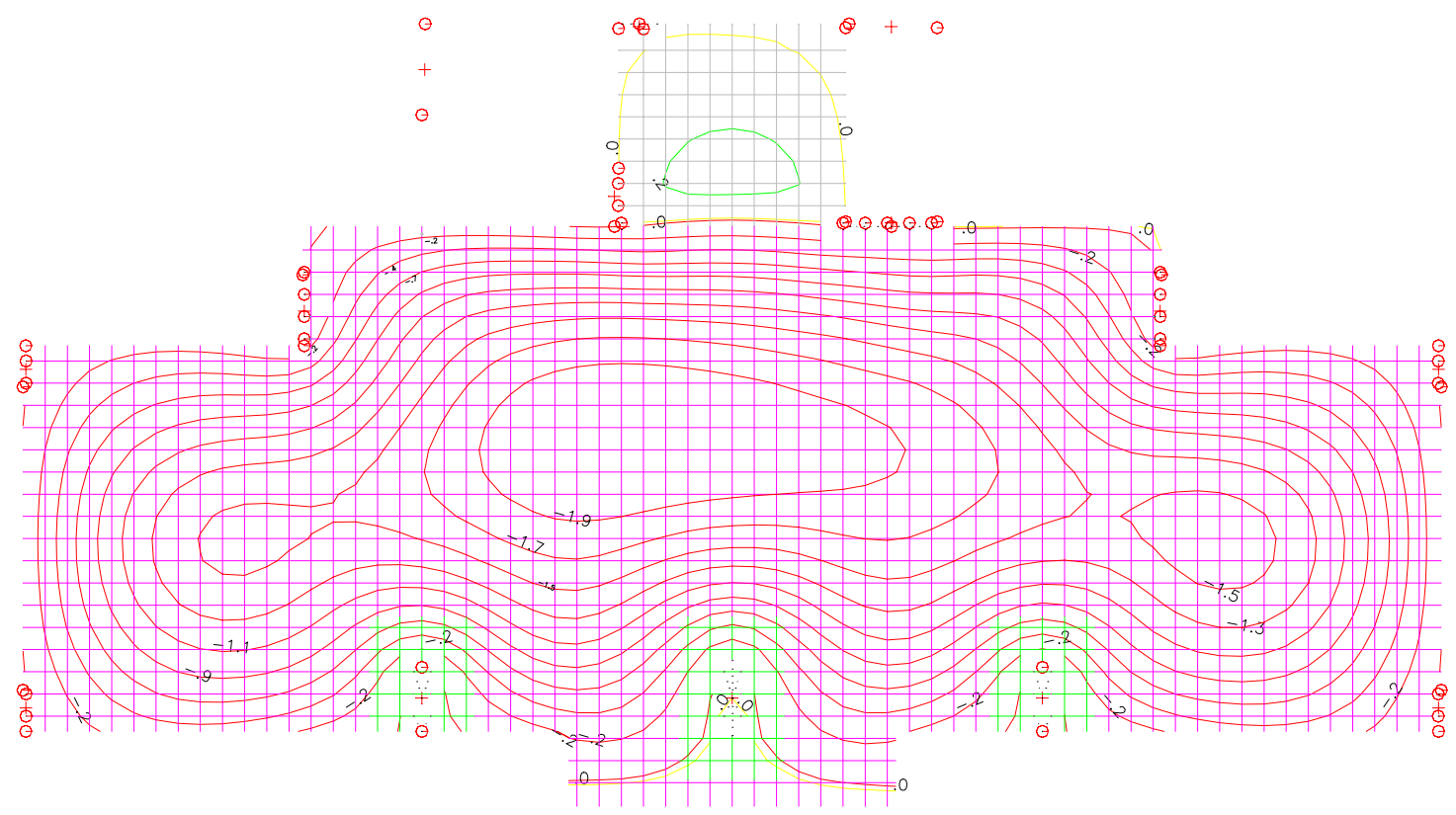

Figura B.7 - Diagrama de isolinhas de deslocamento no pavimento com a presença da protensão 
O deslocamento máximo encontrado foi de $1,90 \mathrm{~cm}$, portanto, inferior aos limites estabelecidos pela Proposta da Revisão da NBR 6118-2001 de $1 / 300$.

Nas figuras B.8 e B.9, tem-se os diagramas de momento fletor para o pavimento nas direções $\mathrm{X}$ e $\mathrm{Y}$, para o caso de deslocamentos para tempo infinito (deformação imediata + deformação lenta).

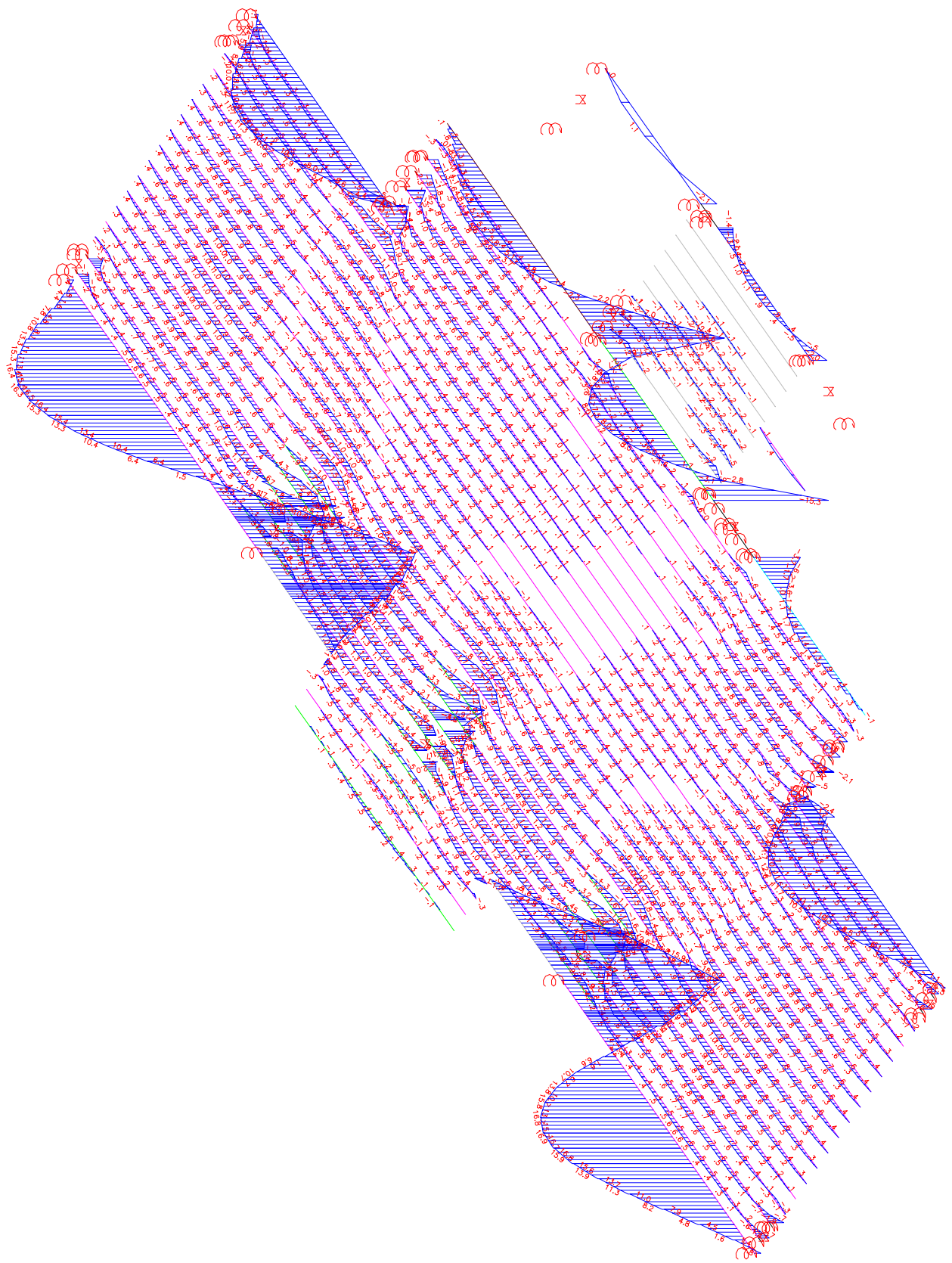

Figura B.8 - Momentos fletores na direção X com a presença da protensão para deslocamentos com tempo infinito 


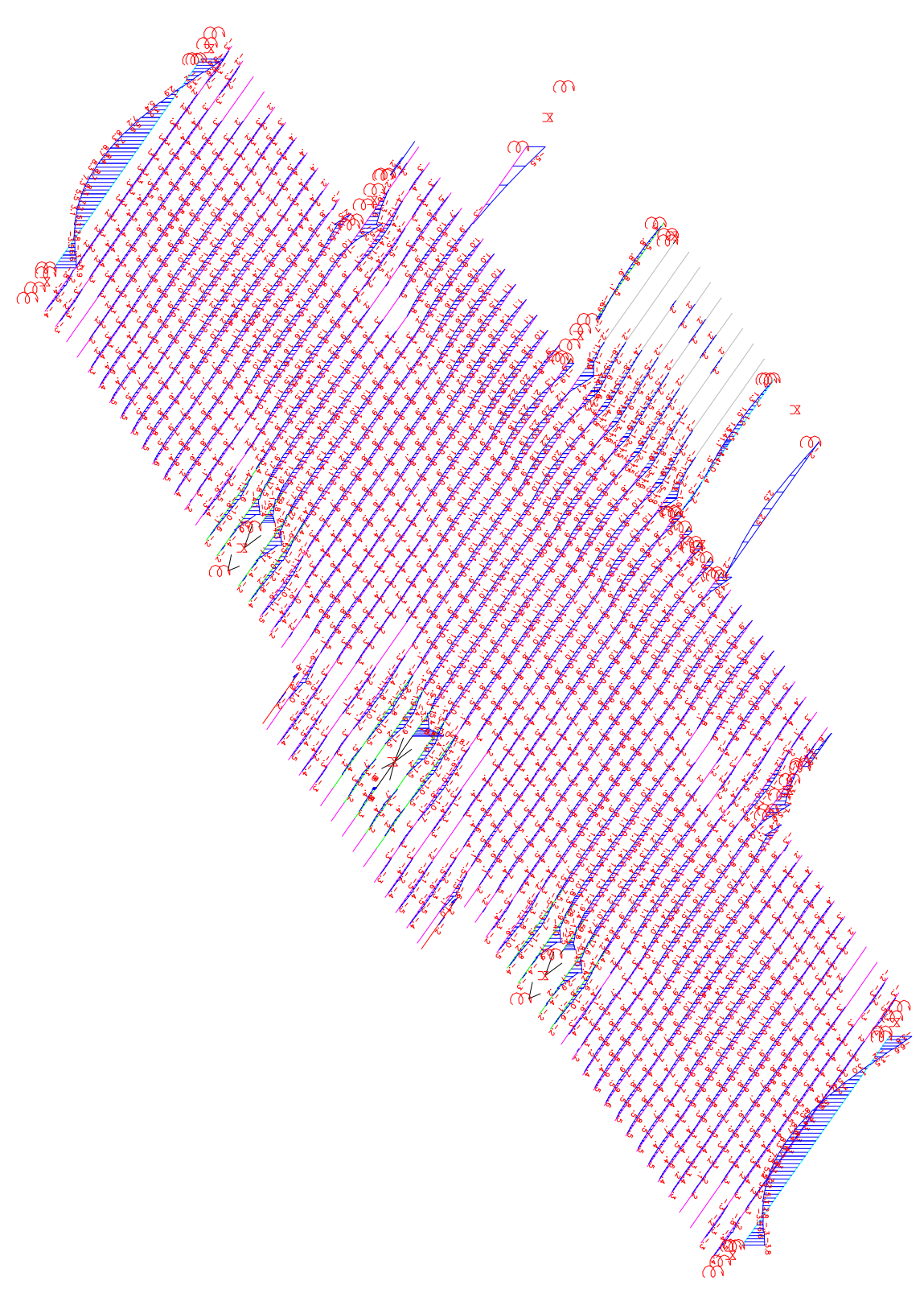

Figura B.9 - Momentos fletores na direção Y com a presença da protensão para deslocamentos para tempo infinito

\section{B.3 - Modelo E03}

Trata-se modelo de laje plana nervurada com protensão não aderente.

A figura B.11 ilustra a disposição dos cabos. Do mesmo modo que no caso da laje plana maciça, os cabos foram distribuídos ao longo da laje. 


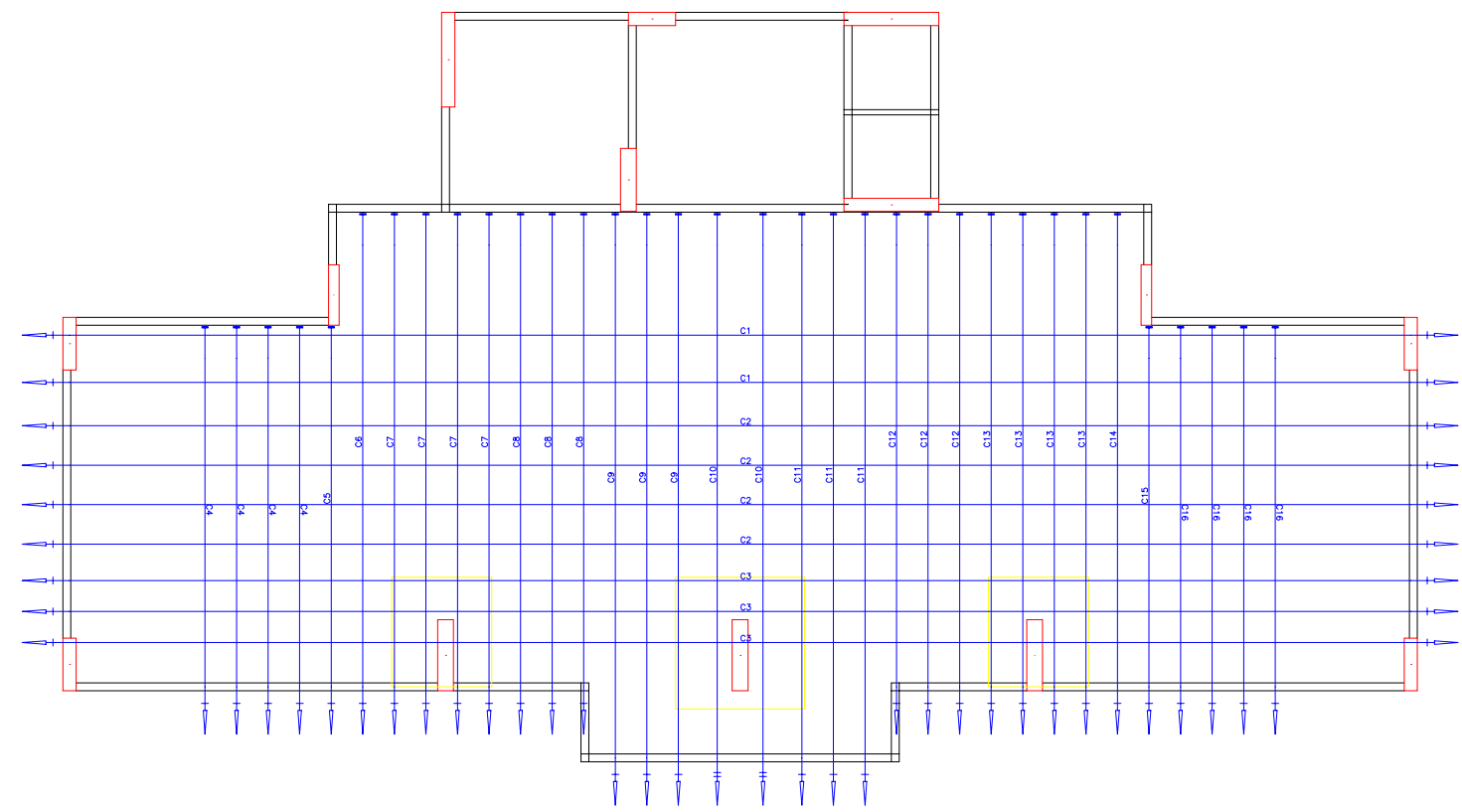

Figura B.11 - Distribuição de armadura ativa no pavimento (E03)

$\mathrm{Na}$ figura B.12, tem-se os deslocamentos referentes à deformação do piso, incluindo o valor da deformação lenta, obtendo valores dentro dos limites estabelecidos pelo Projeto de Revisão da NBR 6118-2001.

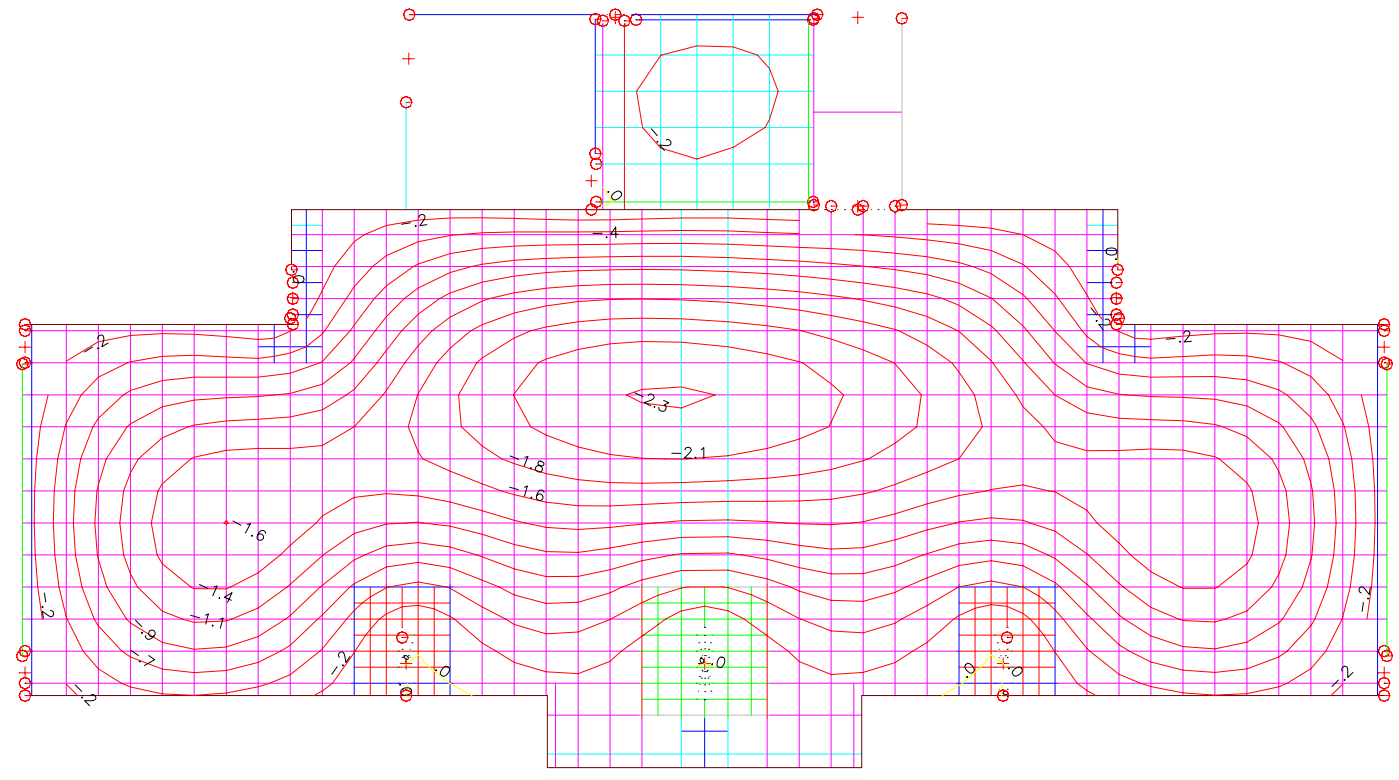

Figura B.12 - Diagrama de isolinhas de deslocamentos no pavimento sem a presença da protensão

Neste caso o pavimento nervurado apresentou um deslocamento incluindo a deformação lenta de $2,30 \mathrm{~cm}$, o que está dentro dos limites 
estabelecidos pelo Projeto de Revisão da NBR 6118-2001, porém, a protensão não tem função apenas como redutora de flechas, podendo também ser utilizada como medida redutora de armadura passiva, o que foi bem observado nos modelos com protensão aderente e não aderente.

A figura B.13 ilustra os deslocamentos no pavimento após a influência da protensão.

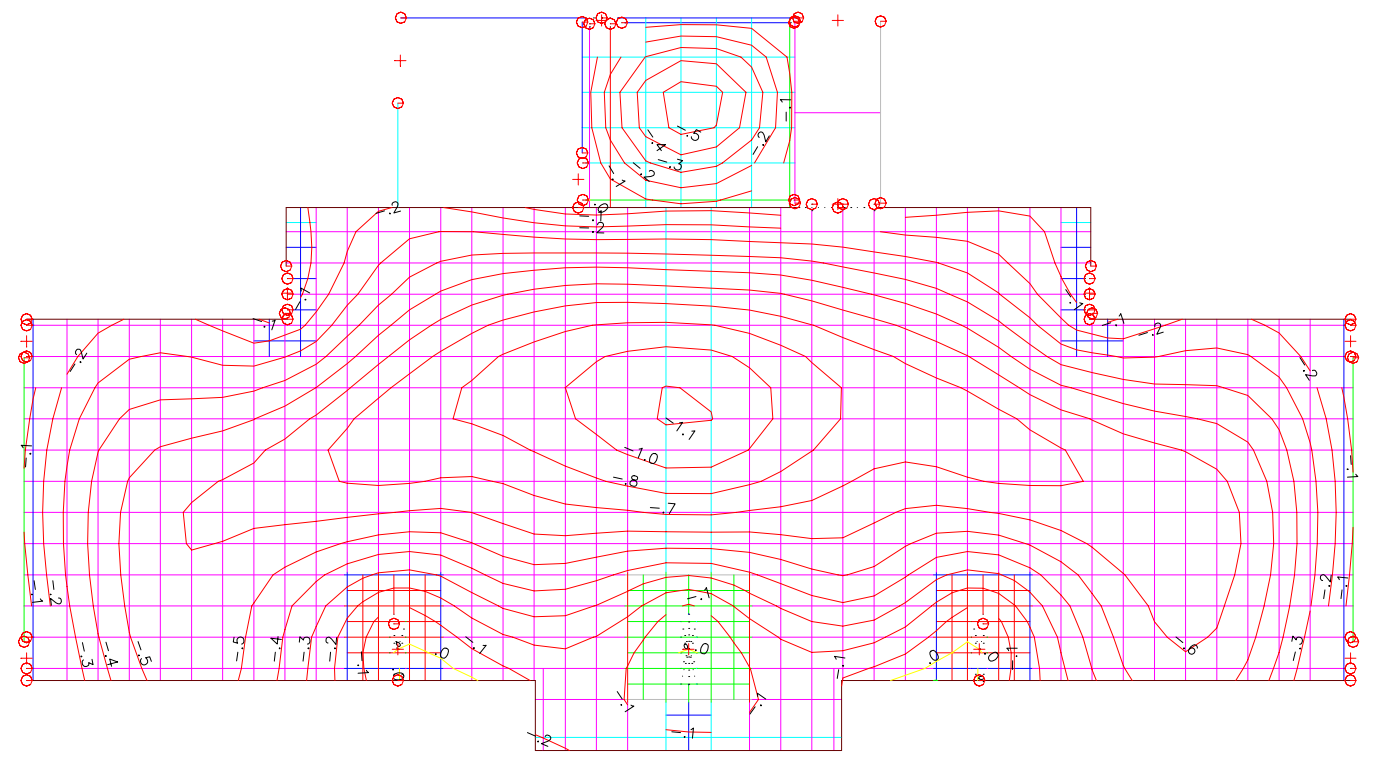

Figura B.13 - Diagrama de isolinhas de deslocamentos no pavimento com a presença da protensão

O deslocamento máximo obtido no pavimento, após a inclusão da protensão, é de $1,10 \mathrm{~cm}$, dentro dos limites estabelecidos pelo Projeto de Revisão da NBR 6118-2001.

Para os momentos fletores, as figuras B.14 e B.15 mostram o comportamento do pavimento para as direções $\mathrm{X}$ e $\mathrm{Y}$, respectivamente. 


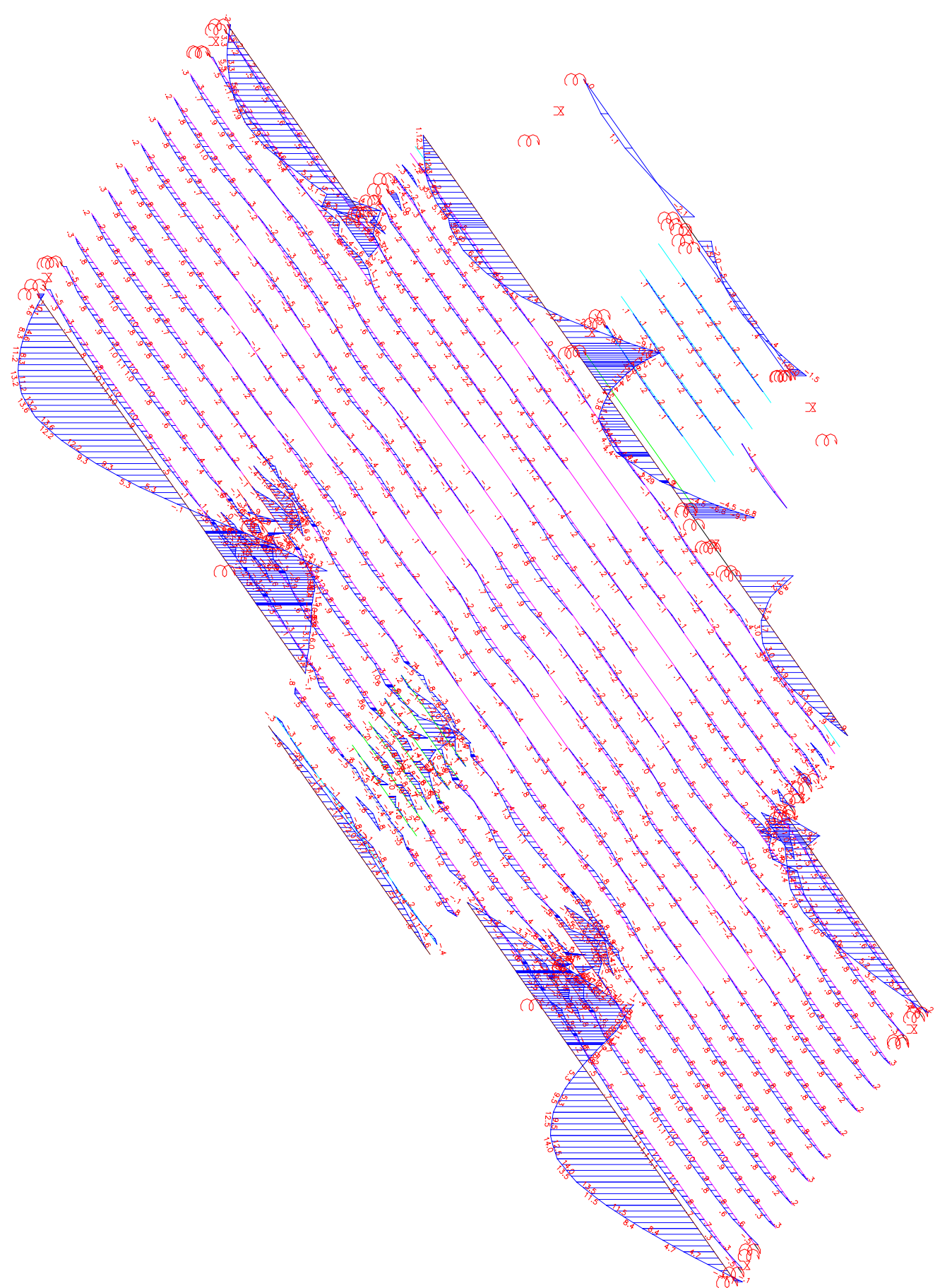

Figura B.14 - Momentos fletores na direção X com a presença da protensão para deslocamentos para tempo infinito 


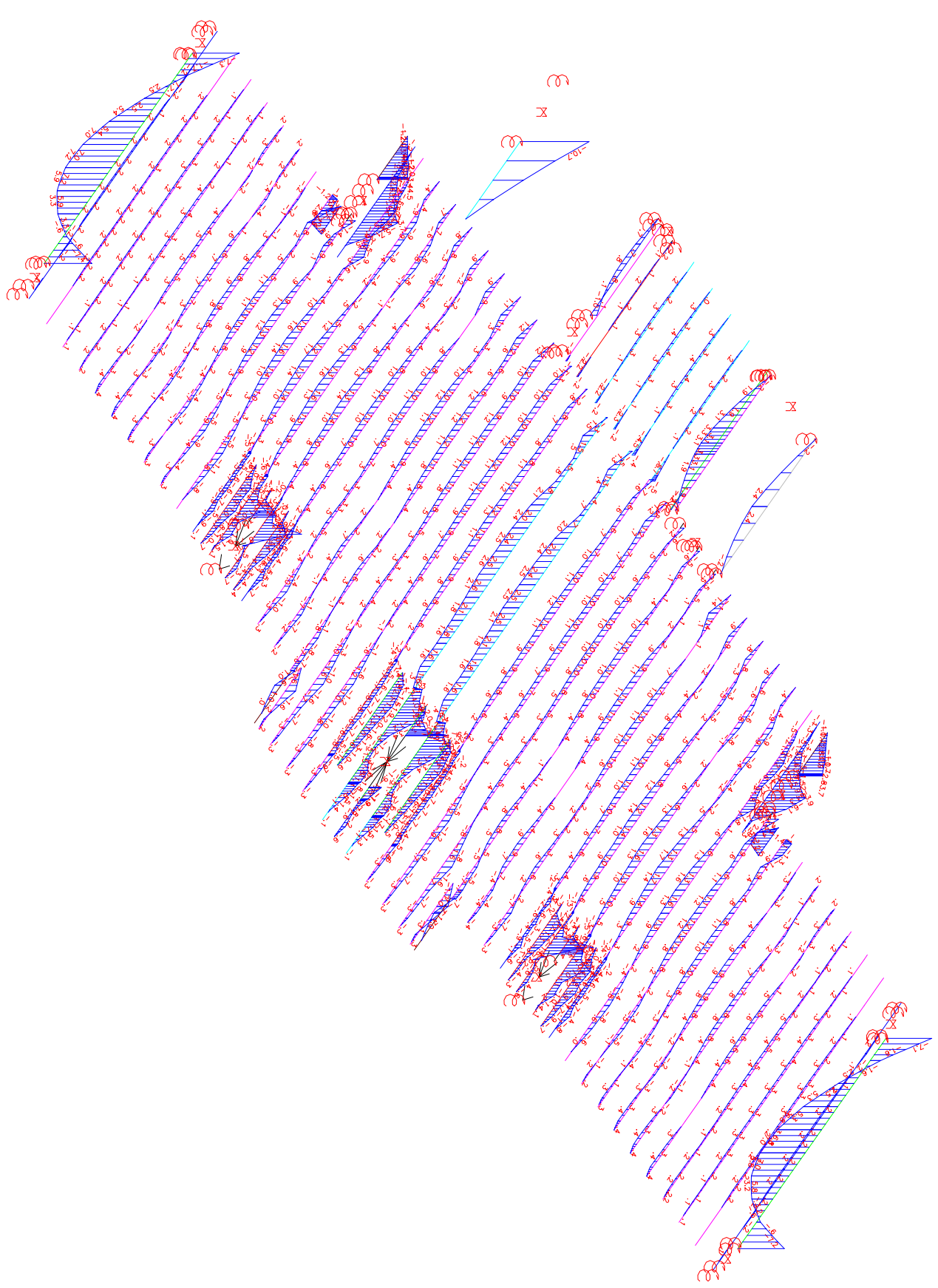

Figura B.15 - Momentos fletores na direção Y com a presença da protensão para deslocamentos para tempo infinito

\section{B.4 - Modelo E04}

Trata-se modelo de laje plana nervurada com protensão não aderente.

A figura B.16 ilustra a disposição dos cabos. Do mesmo modo que no caso da laje plana maciça, os cabos foram distribuídos ao longo da laje. 


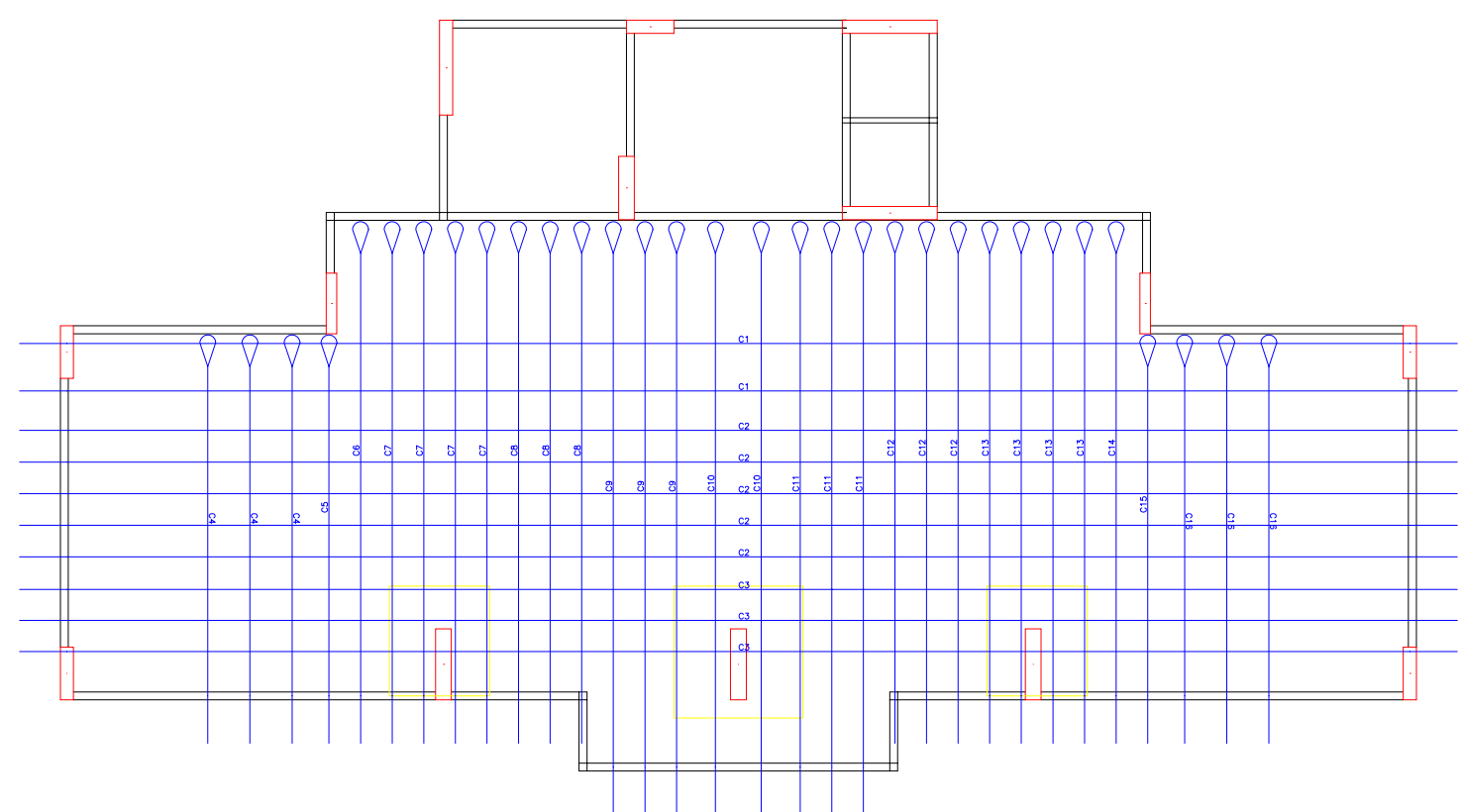

Figura B.16 - Distribuição de armadura ativa no pavimento (E04)

A figura B.17 ilustra os deslocamentos no pavimento após a influência da protensão.

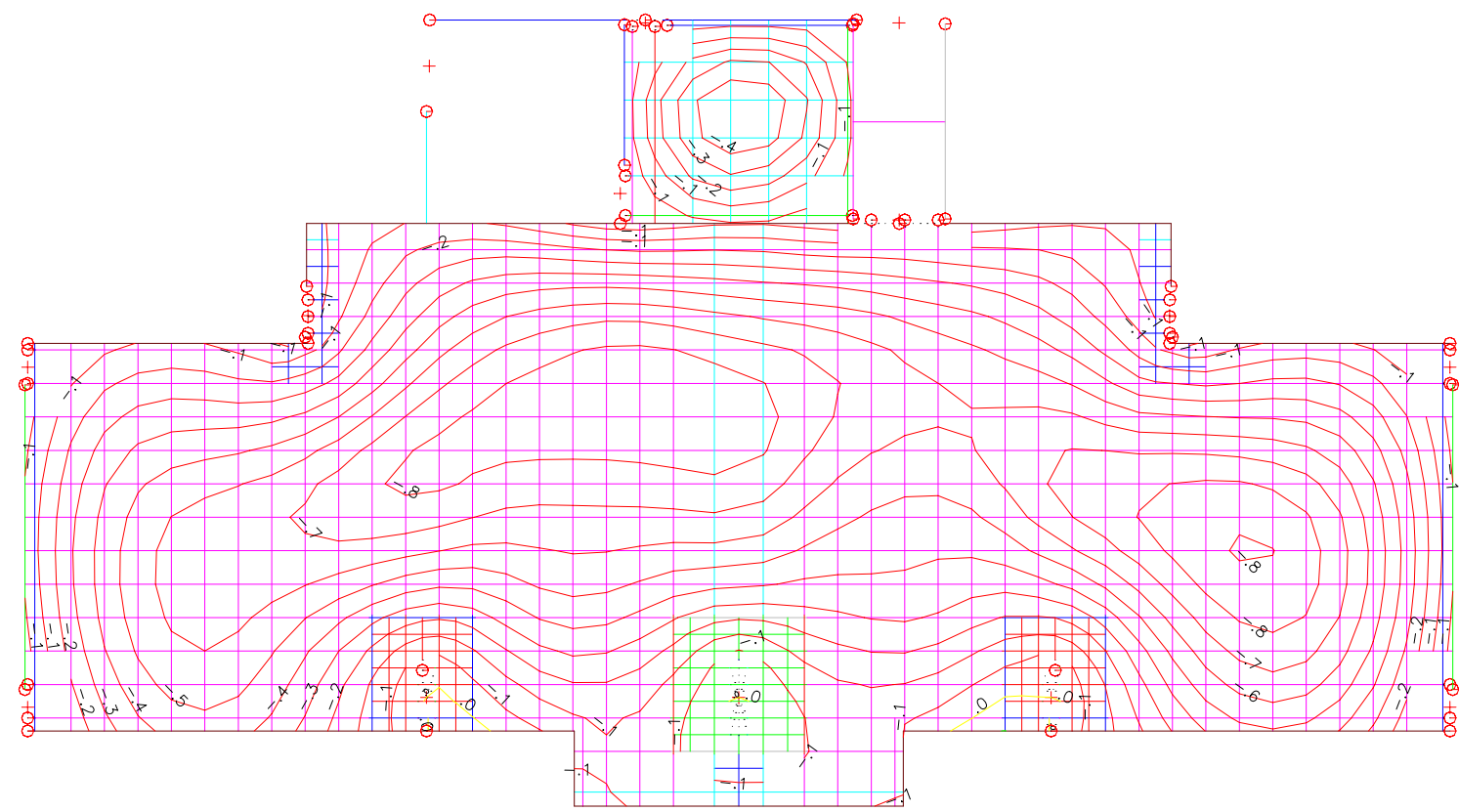

Figura B.17 - Diagrama de isolinhas de deslocamentos no pavimento com a presença da protensão 
O deslocamento máximo obtido no pavimento, após a inclusão da protensão, é de $0,80 \mathrm{~cm}$, dentro dos limites estabelecidos pelo Projeto de Revisão da NBR 6118-2001.

Para os momentos fletores, as figuras B.18 e B.19 mostram o comportamento do pavimento para as direções X e Y, respectivamente.

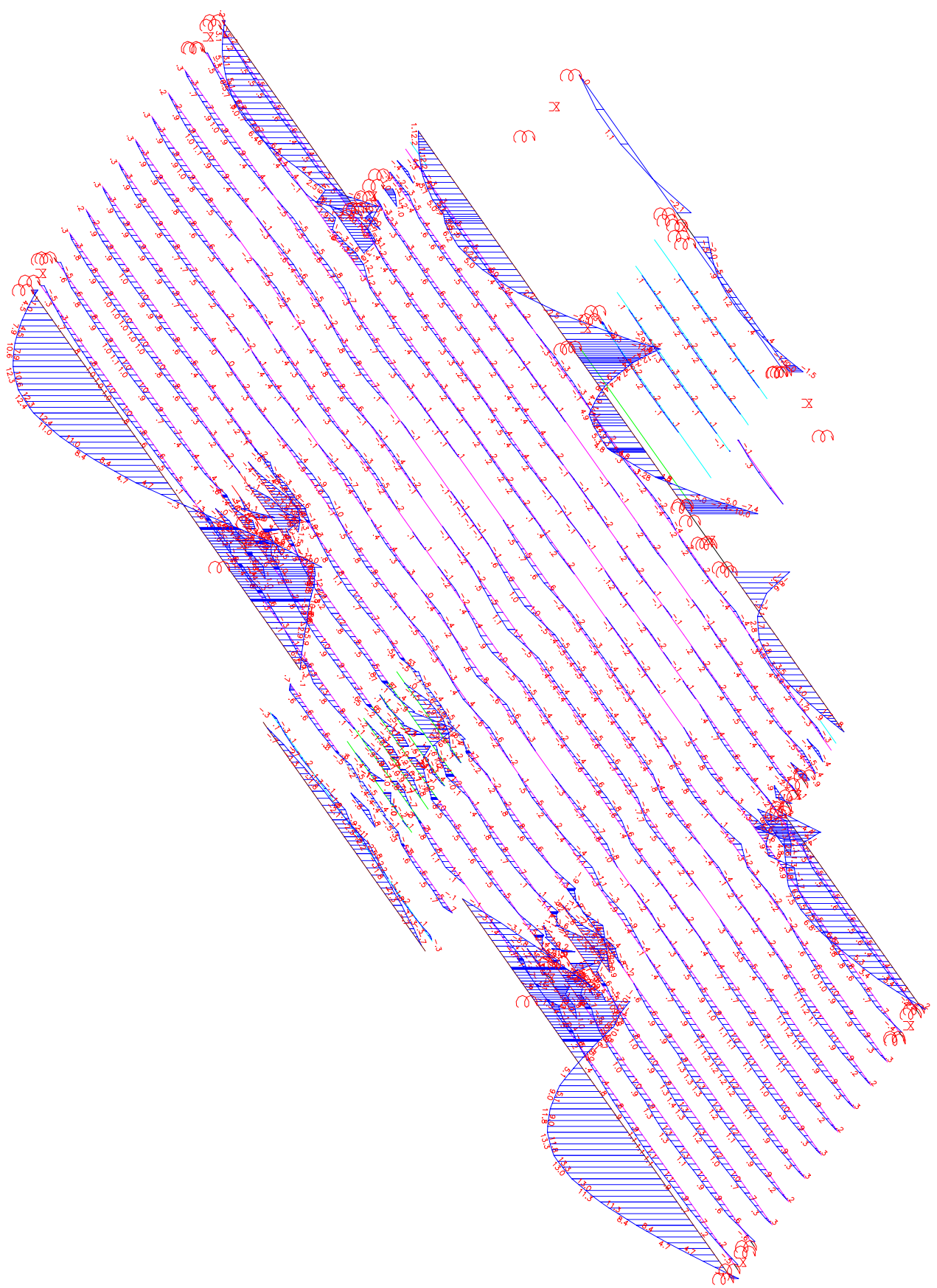

Figura B.18 - Momentos fletores na direção X com a presença da protensão para deslocamentos para tempo infinito 


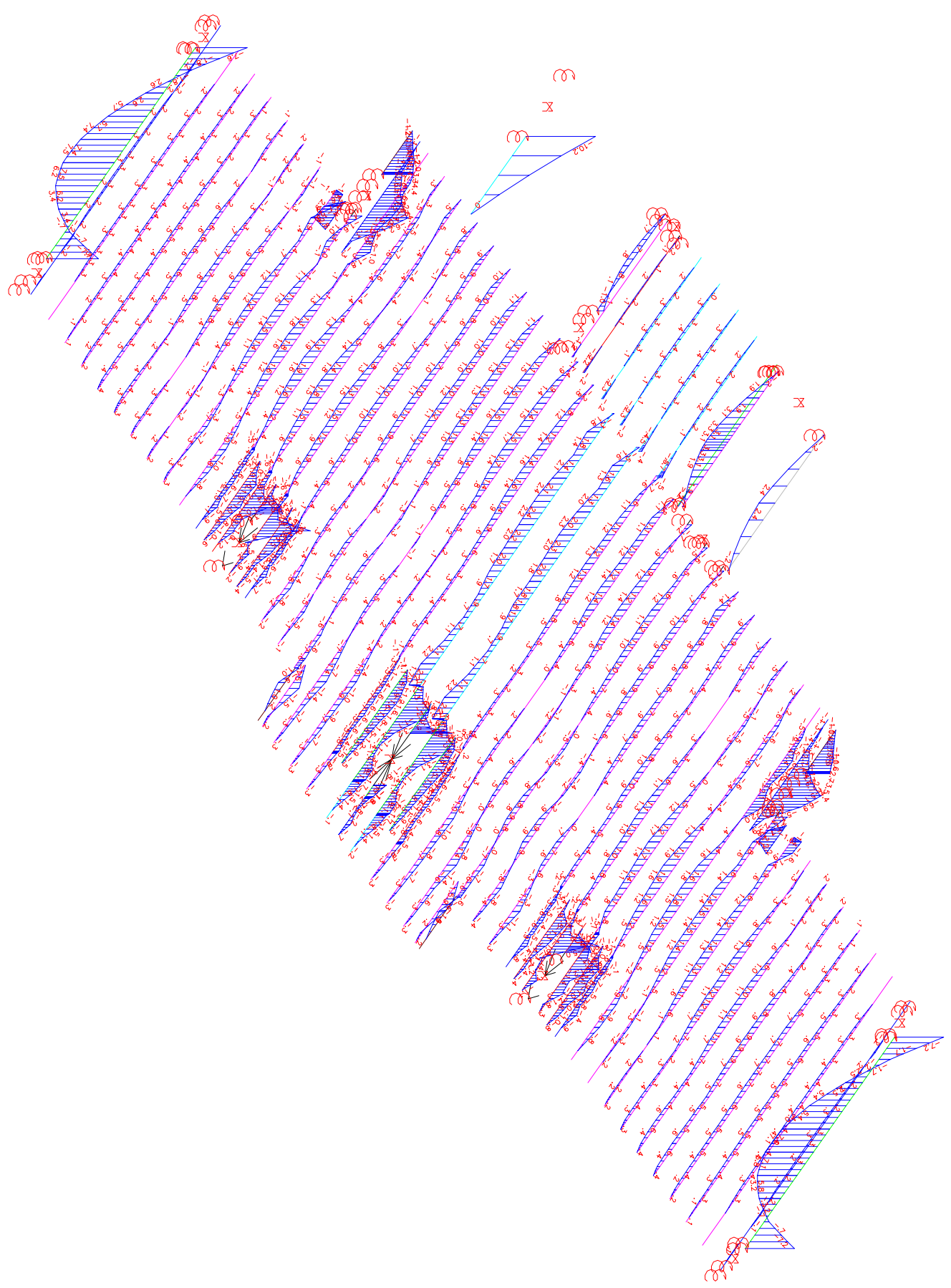

Figura B.19 - Momentos fletores na direção Y com a presença da protensão para deslocamentos para tempo infinito 


\section{B.5 - Modelo E05}

Trata-se do modelo de laje nervurada apoiada sobre vigas faixa com protensão não aderente.

A figura B.20 ilustra a disposição dos cabos no pavimento.

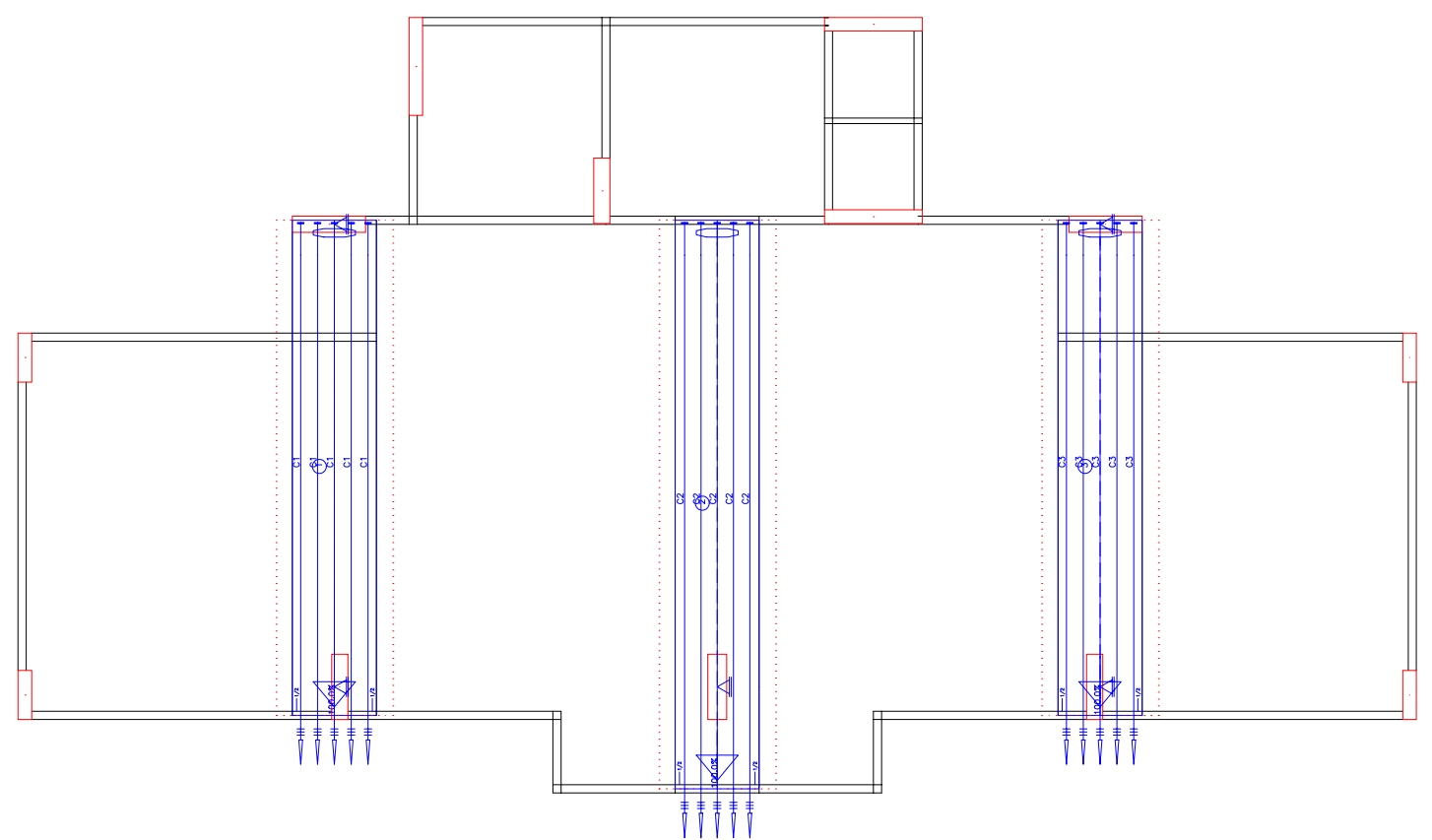

Figura B.20 - Disposição da armadura ativa no modelo E05

Na figura B.21, tem-se os deslocamentos referentes à deformação do piso, incluindo a deformação lenta, obtendo valores fora dos limites estabelecidos pelo Projeto de Revisão da NBR 6118-2001. 


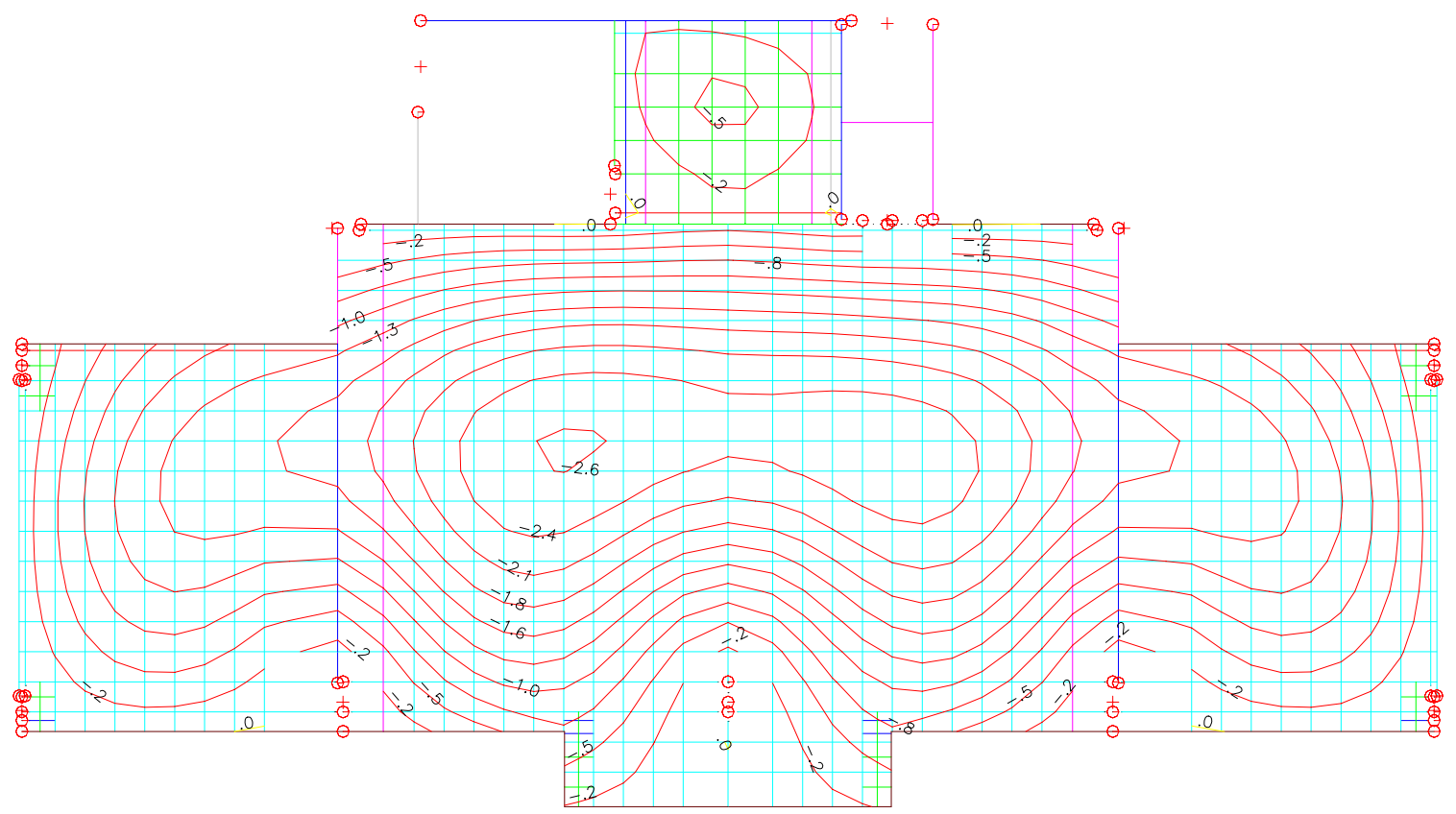

Figura B.21 - Diagrama de isolinhas de deslocamentos no pavimento sem a presença da protensão

A figura B.21 mostra o diagrama de isolinhas de deslocamento do pavimento com a inclusão da protensão não aderente.

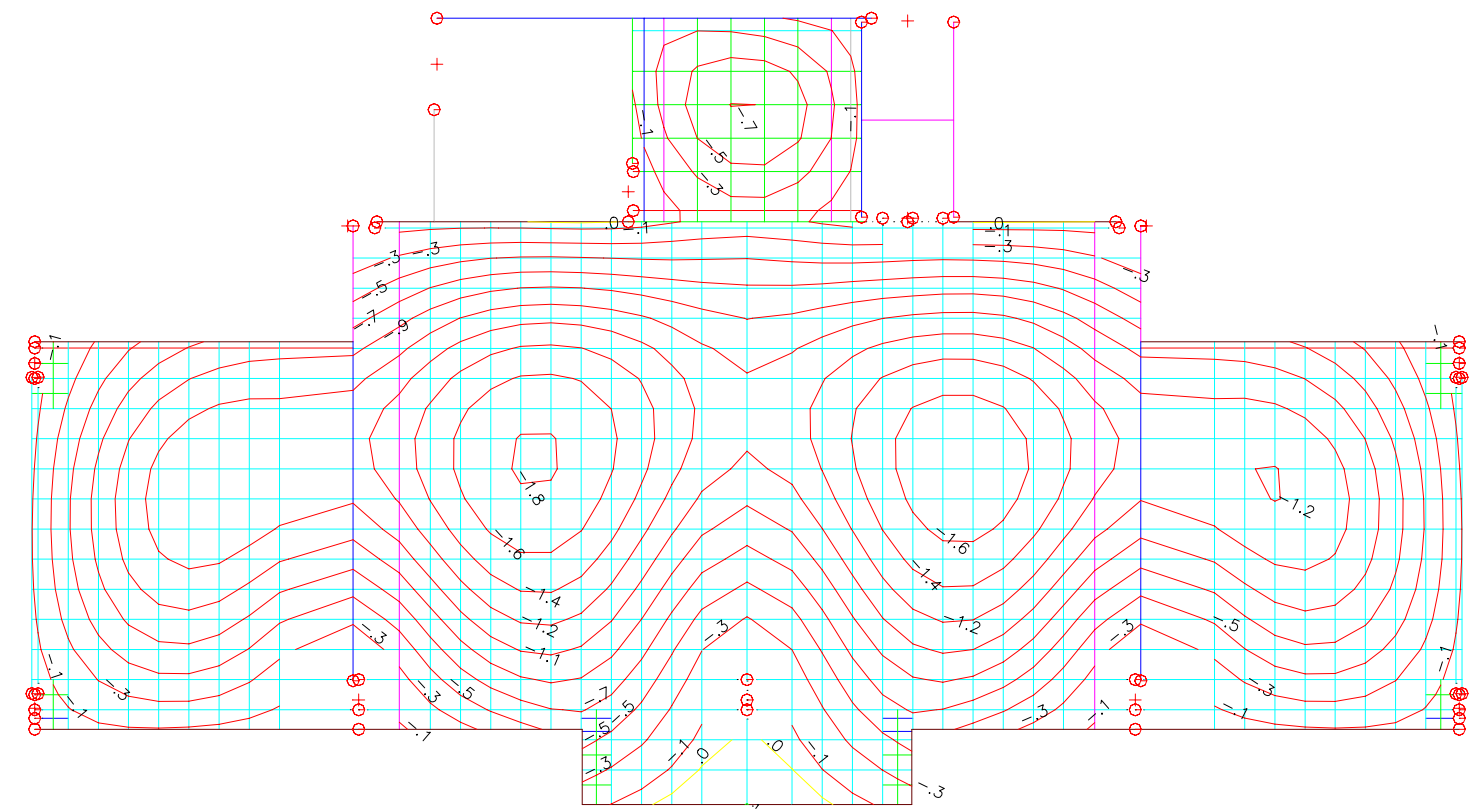

Figura B.22 - Diagrama de isolinhas de deslocamentos no pavimento com a presença da protensão

$\mathrm{Na}$ figura B.22, pode-se ver que o deslocamento máximo obtido no pavimento com a influência da protensão é de $1,80 \mathrm{~cm}$, o que está dentro dos limites estabelecidos pelo Projeto de Revisão da NBR 6118-2001. 
Para os momentos fletores, as figuras B.23 e B.24 mostram o comportamento do pavimento para as direções $\mathrm{X}$ e $\mathrm{Y}$, respectivamente.

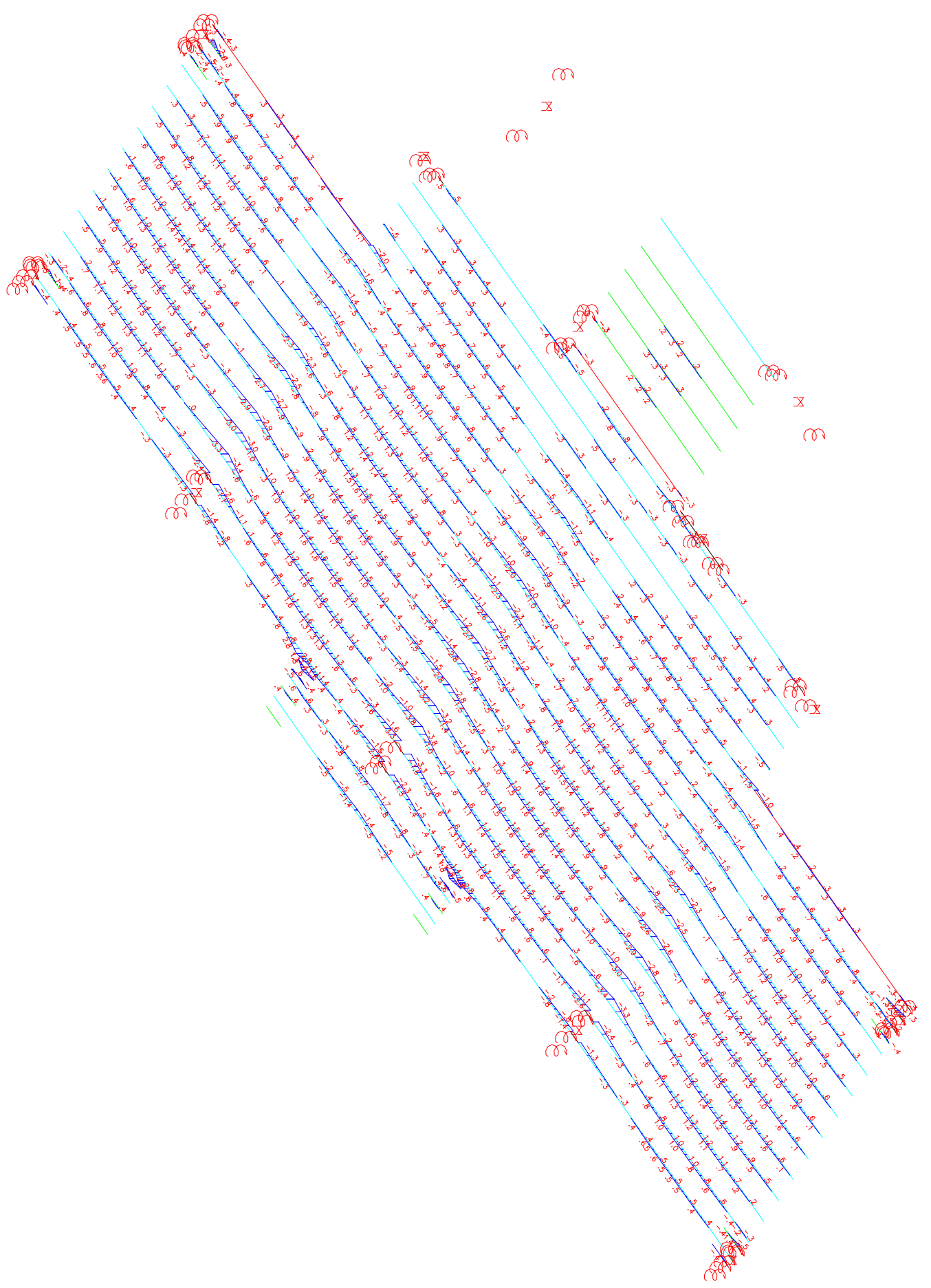

Figura B.23 - Momentos fletores na direção X com a presença da protensão para deslocamentos para tempo infinito 


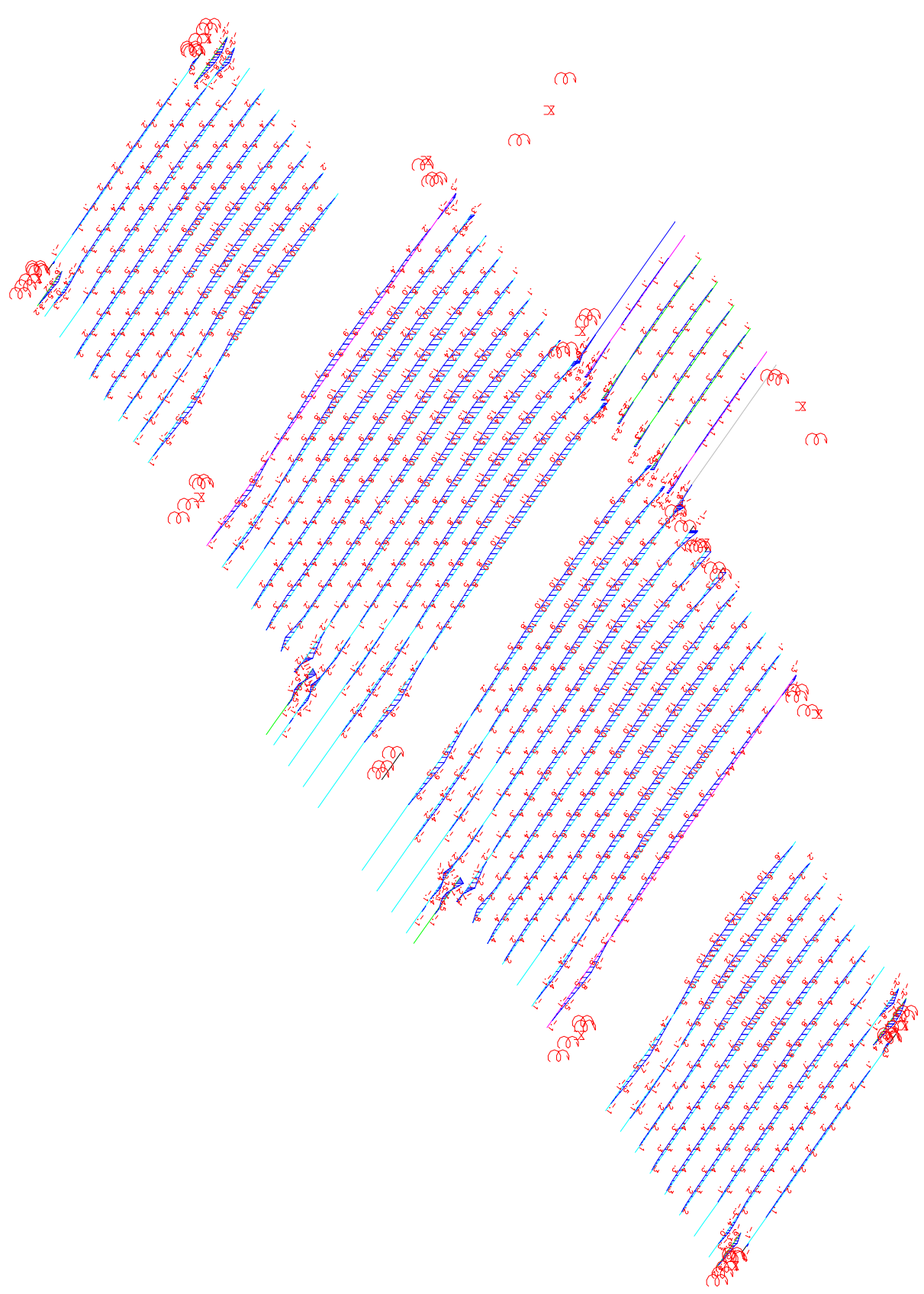

Figura B.24 - Momentos fletores na direção Y com a presença da protensão para deslocamentos para tempo infinito

Na figura B.25, é mostrado, para facilitar a visualização, os diagramas de momento fletores para as vigas do pavimento. 


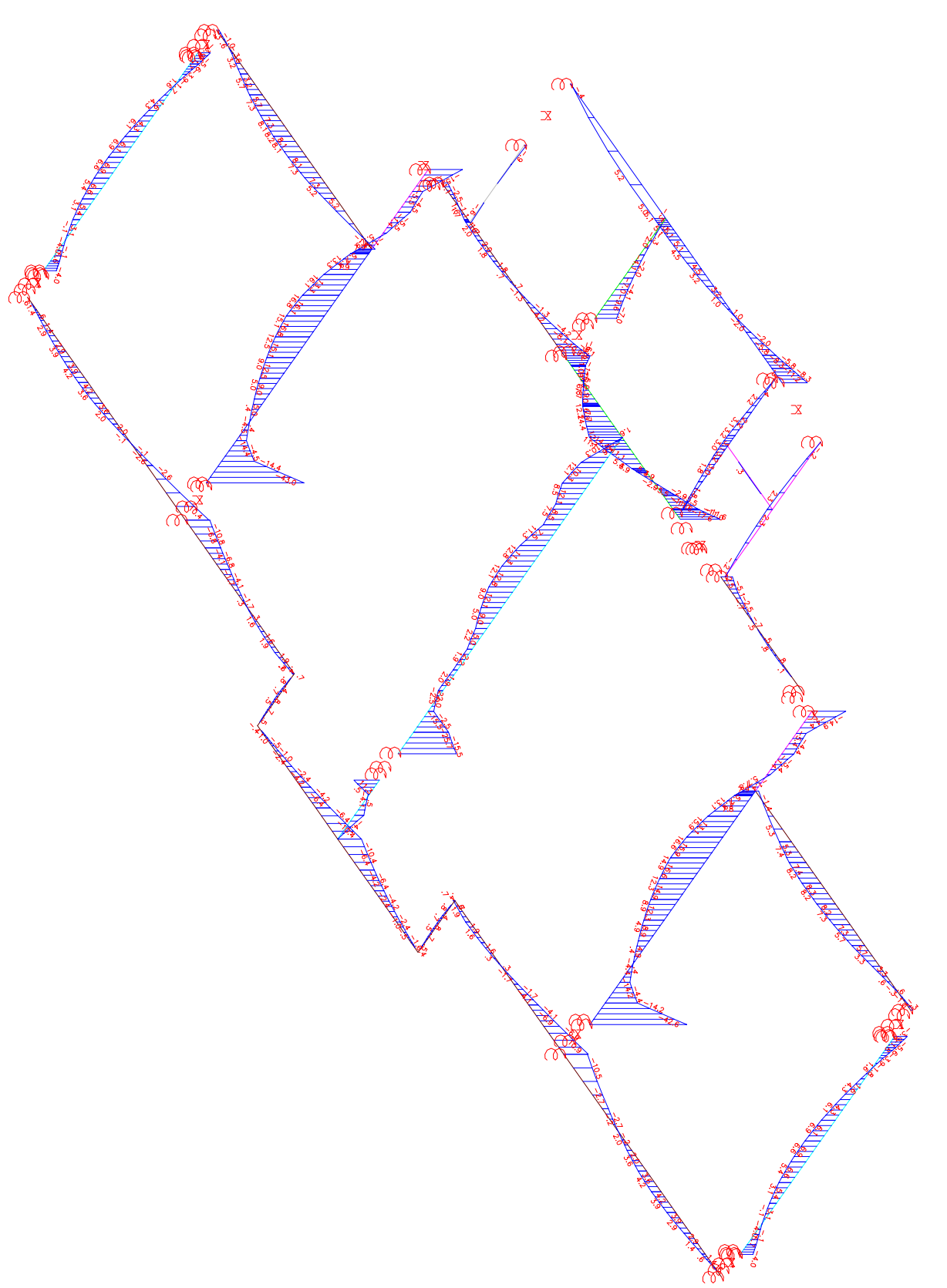

Figura B.25 - Diagrama de momento fletor para as vigas do pavimento do modelo E05

\section{B.6 - Modelo E06}

Trata-se do modelo de laje nervurada apoiada sobre vigas faixa com protensão não aderente.

A figura B.26 ilustra a disposição dos cabos no pavimento. 


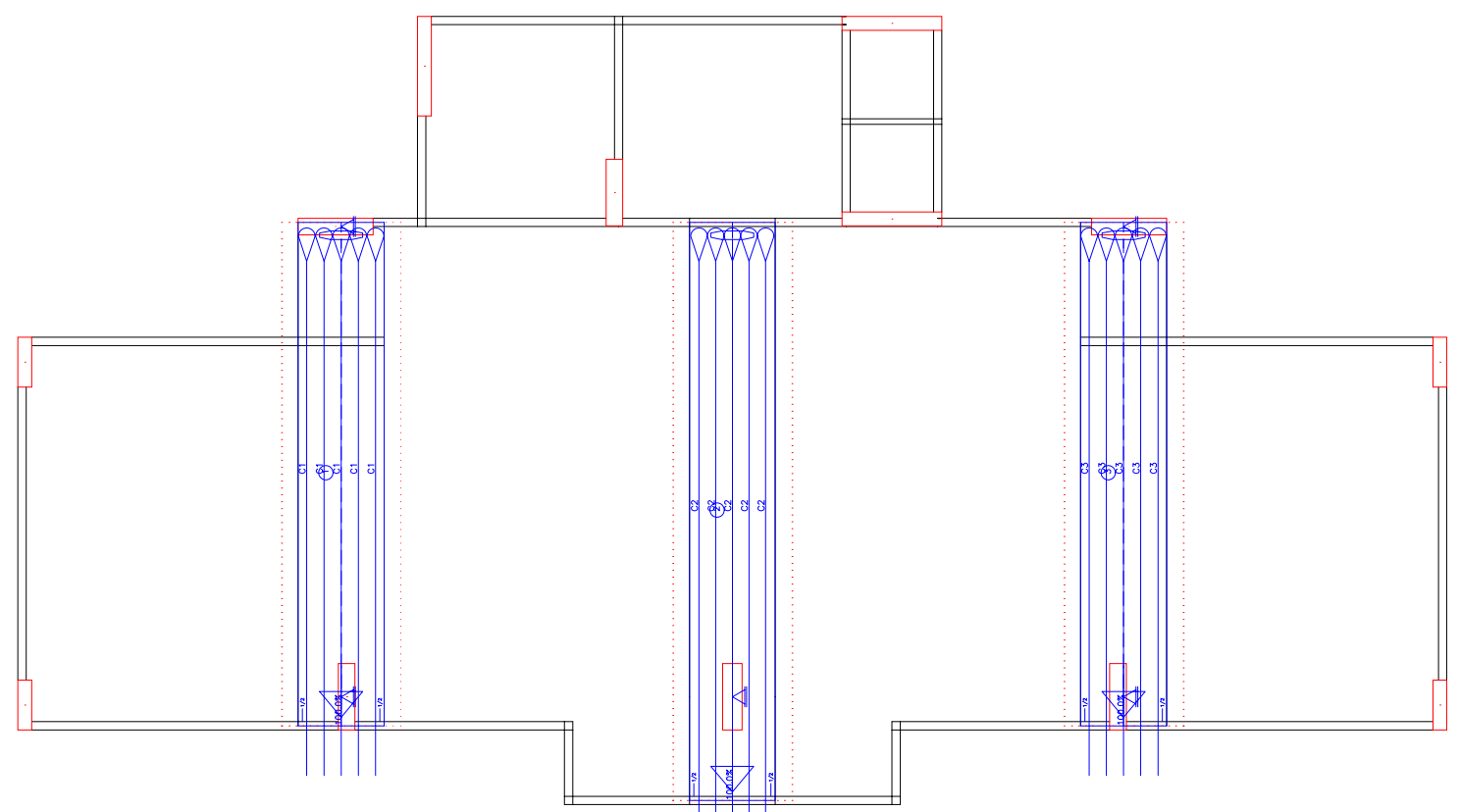

Figura B.26 - Disposição da armadura ativa no modelo E06

A figura B.27 mostra o diagrama de isolinhas de deslocamento do pavimento com a inclusão da protensão aderente.

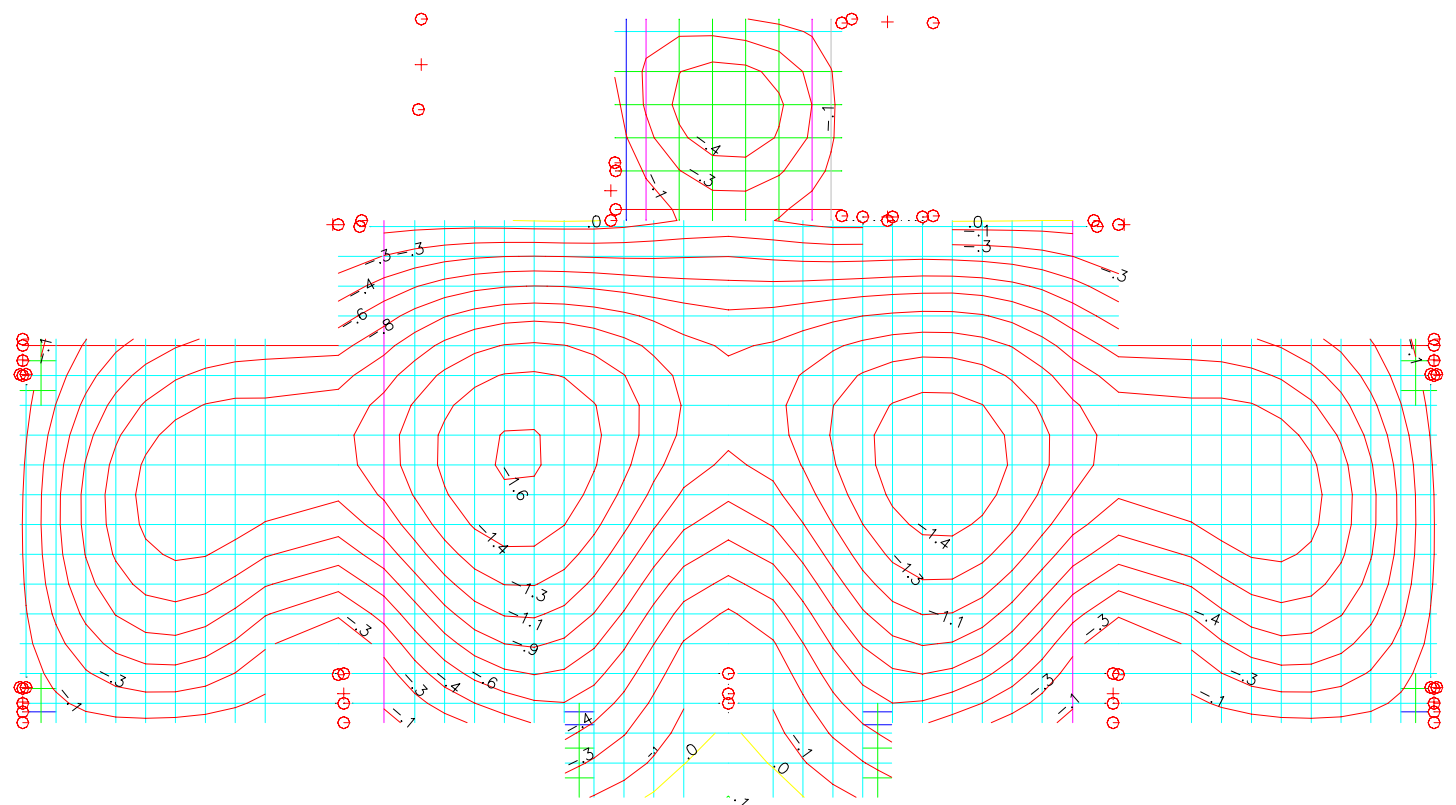

Figura B.27 - Diagrama de isolinhas de deslocamentos no pavimento com a presença da protensão 
$\mathrm{Na}$ figura B.27, pode-se ver que, o deslocamento máximo obtido no pavimento com a influência da protensão é de 1,60 cm, o que está dentro dos limites estabelecidos pelo Projeto de Revisão da NBR 6118-2001.

Para os momentos fletores, as figuras B.28 e B.29 mostram o comportamento do pavimento para as direções X e Y, respectivamente.

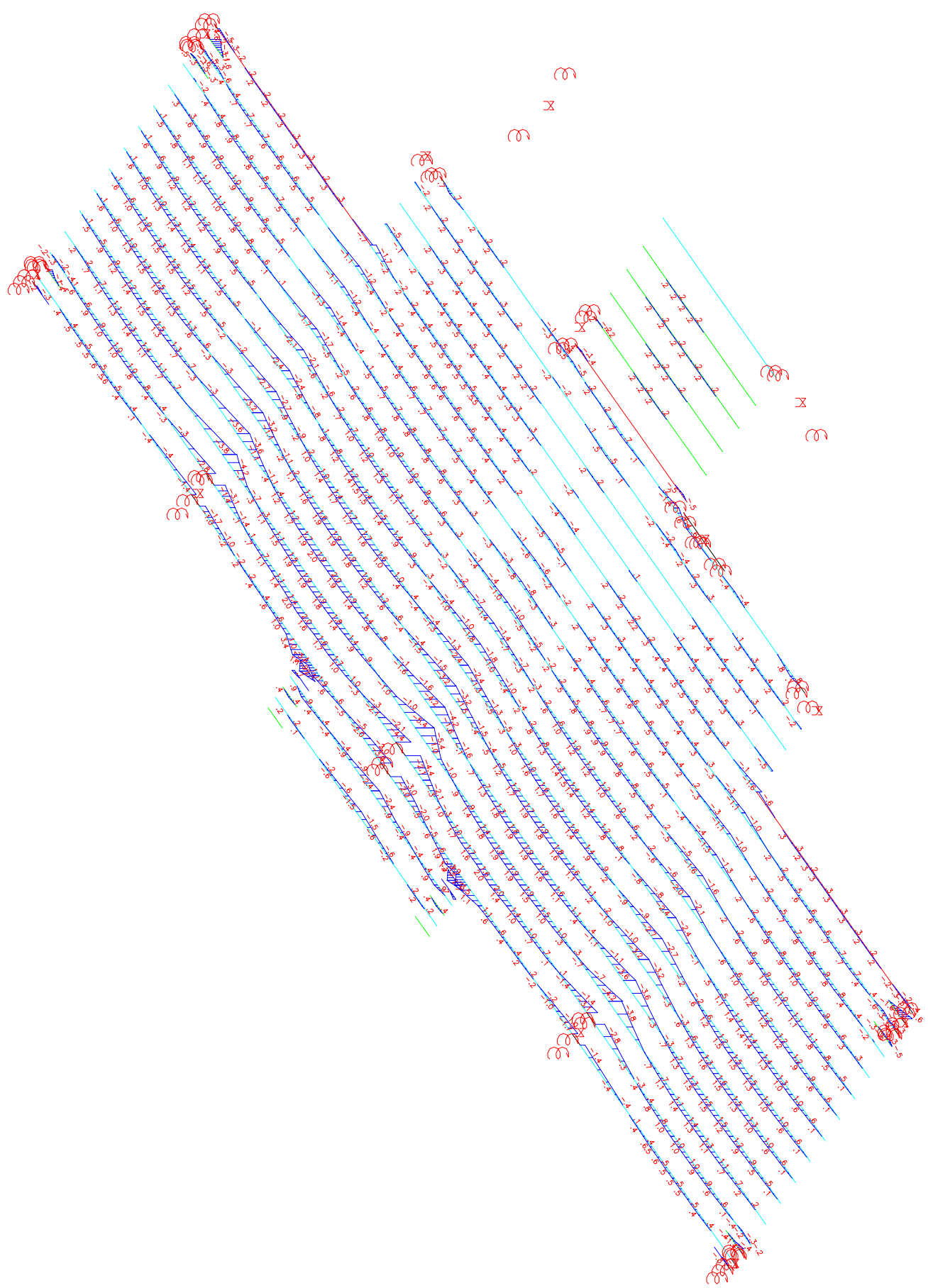

Figura B.28 - Momentos fletores na direção X com a presença da protensão para deslocamentos para tempo infinito 


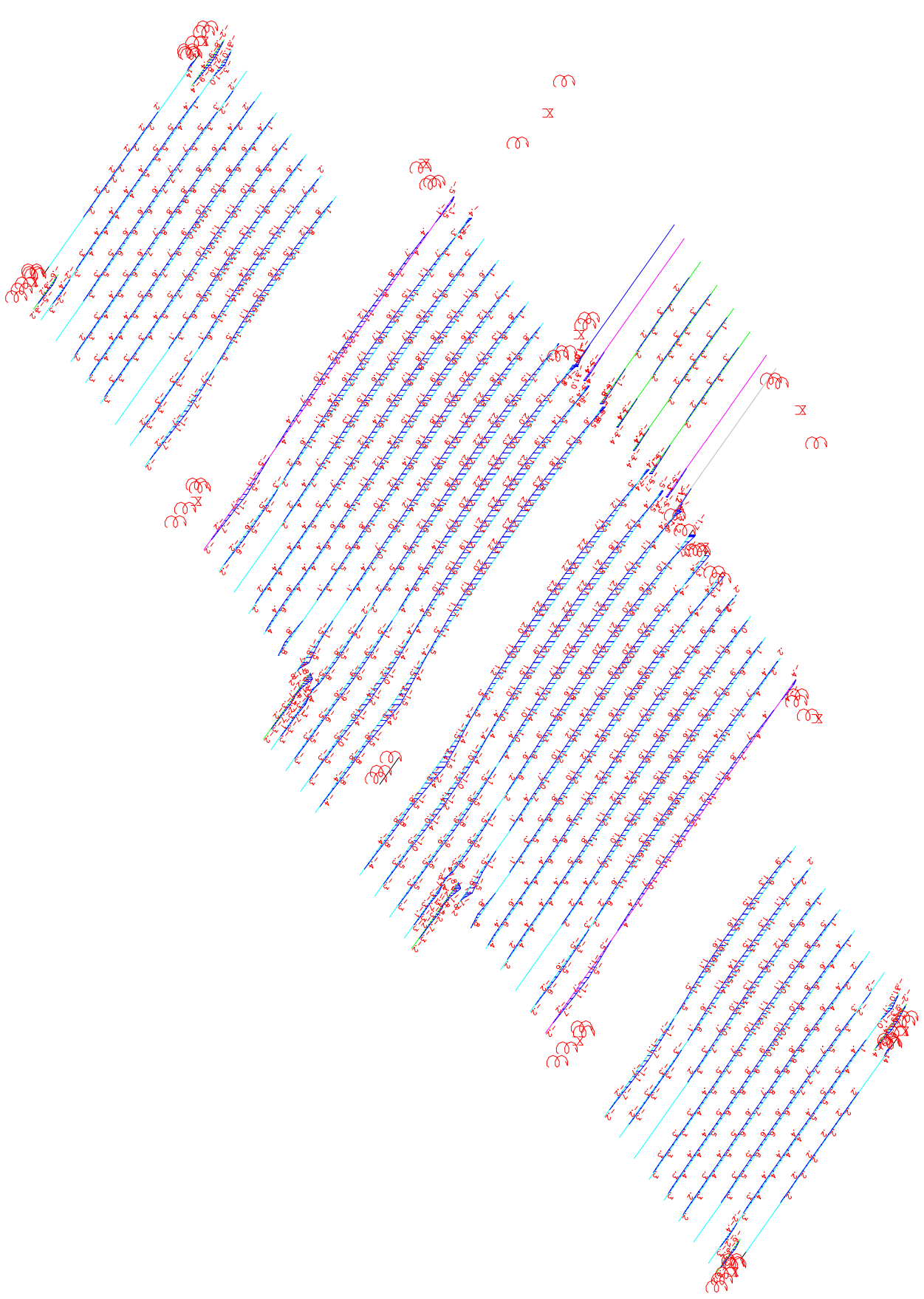

Figura B.29 - Momentos fletores na direção Y com a presença da protensão para deslocamentos para tempo infinito

Na figura B.30, é mostrado, para facilitar a visualização, os diagramas de momento fletores para as vigas do pavimento. 


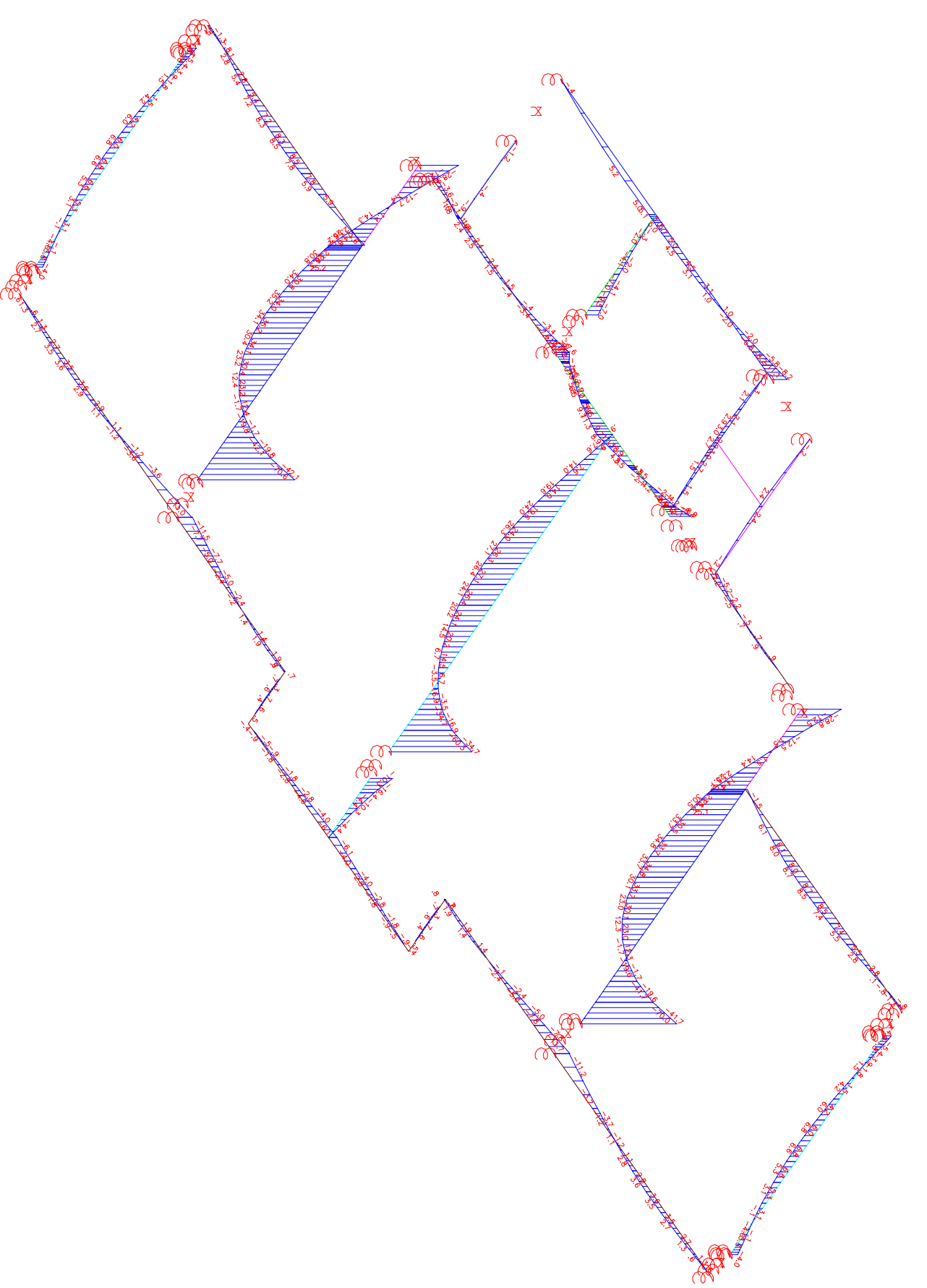

Figura B.30 - Diagrama de momento fletor para as vigas do pavimento do modelo E06 


\section{APÊNDICE C}

\section{ANÁlISE DOS PÓRTICOS TRIDIMENSIONAIS DOS MODELOS}

Para a análise dos pórticos tridimensionais, serão feitas as seguintes considerações para a análise dos efeitos de segunda ordem:

- Os pilares apresentarão as mesmas seções transversais ao longo da altura do edifício;

- Será considerado que o pavimento, tanto maciço quanto o nervurado, não têm participação na rigidez do edifício para avaliação da instabilidade da estrutura ( $\alpha$ e $\left.\gamma_{z}\right)$;

- Para o cálculo dos parâmetros de instabilidade ( $\alpha$ e $\left.\gamma_{z}\right)$, serão seguidas as considerações de acordo com o subitem 6 do Capítulo 5;

Para a verificação dos efeitos de segunda ordem, serão admitidas as mesmas características da pesquisa desenvolvida por Albuquerque, onde, as ações devidas ao vento foram avaliadas de acordo com a NBR 6123 [1987].

Para o cálculo do efeito da ação do vento na estrutura, foi adotado:

- Local da estrutura: Fortaleza - CE;

- Velocidade Básica $\left(\mathrm{V}_{0}\right)$, de acordo com as isopletas presentes na NBR 6123 [1987], igual a $30,0 \mathrm{~m} / \mathrm{s}$;

- Fator topográfico $S_{1}=1,0$ (terreno plano ou fracamente acidentado);

- Rugosidade do terreno $\mathrm{S}_{2}=0,92$ (Admitindo-se centro de cidade grande, categoria de edificação V, e classe C, pois a estrutura apresenta altura superior a $50,0 \mathrm{~m})$;

- Fator estatístico $\mathrm{S}_{3}=1,0$ (admitindo-se grupo 2: Edificações para hotéis e residências);

- Coeficiente de arrasto $\left(\mathrm{C}_{\mathrm{a}}\right)$ para a direção Y igual a 1,20 e para a direção $\mathrm{X}$ igual a 1,00 (adotando altura da edificação igual a 57,60 m e lados da estrutura iguais a $1_{\mathrm{x}}=25,70 \mathrm{~m}$ e $1_{\mathrm{y}}=14,05 \mathrm{~m}$, conforme a figura C. 1 ). 
$\mathrm{Na}$ avaliação dos pórticos tridimensionais, serão comparados os deslocamentos máximos com relação aos modelos desenvolvidos por ALBUQUERQUE [1998] e com os modelos protendidos.

O objetivo é avaliar o desempenho estrutural dos exemplos e determinar o mais eficiente. Essa comparação será feita confrontando-se os valores referentes aos deslocamentos da estrutura (direções X e Y) e à análise dos parâmetros de instabilidade ( $\alpha$ e $\left.\gamma_{z}\right)$.

Vale salientar que nos modelos das estruturas protendidas, nos pórticos tridimensionais, o parâmetro de instabilidade $\gamma_{Z}$ é determinado adotando-se a modelagem com nós semi-rígidos. Esse cálculo utiliza a técnica dos nós semirígidos tornando assim a ligação viga-pilar mais flexível, causando um aumento do valor do $\gamma_{z}$ (o resultado é um comportamento mais realista da estrutura).

\section{C.1 - Pórticos tridimensionais dos Modelos Protendidos}

A seguir, são ilustrados os pórticos tridimensionais desenvolvidos na pesquisa para cada arranjo estrutural.

Nestes, são ilustrados os valores médios encontrados de deslocamento no topo da edificação.

$\mathrm{Na}$ figura C.1, tem-se as direções $\mathrm{X}$ e $\mathrm{Y}$ (vento lateral e frontal, respectivamente) para os modelos.

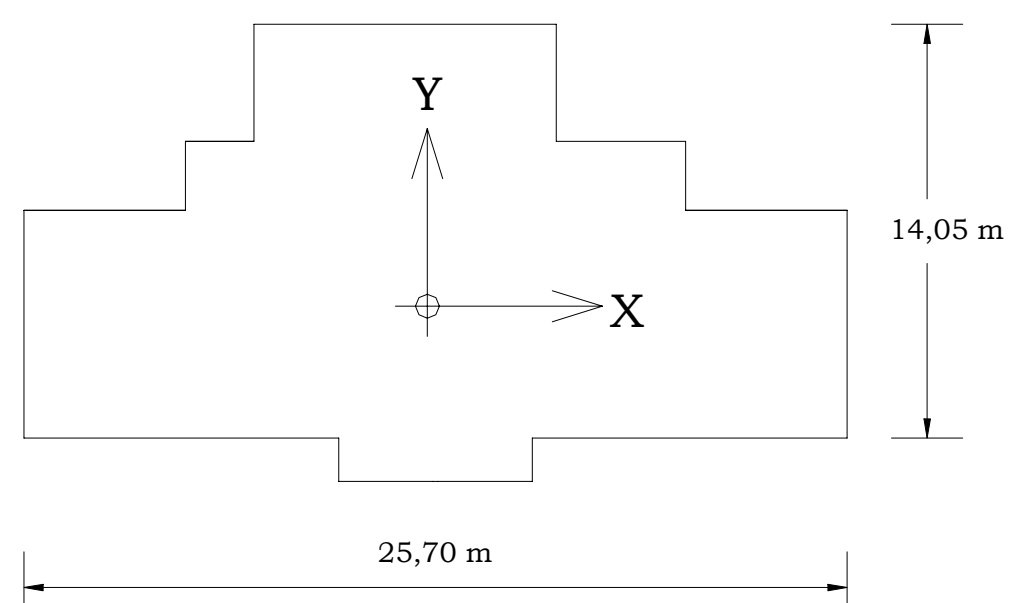

Figura C.1 - Direção da ação do vento 


\section{C.1.1 - Modelos E01 e E02}

$\mathrm{Na}$ análise do pórtico tridimensional, os deslocamentos alcançados no topo da edificação foram iguais para ambos os modelos e, atingiram um valor médio igual a $5,32 \mathrm{~cm}$ para o deslocamento na direção frontal de aplicação do vento, e de $2,80 \mathrm{~cm}$ para o deslocamento na direção dos esforços agindo na lateral da edificação (ver figura C.2).

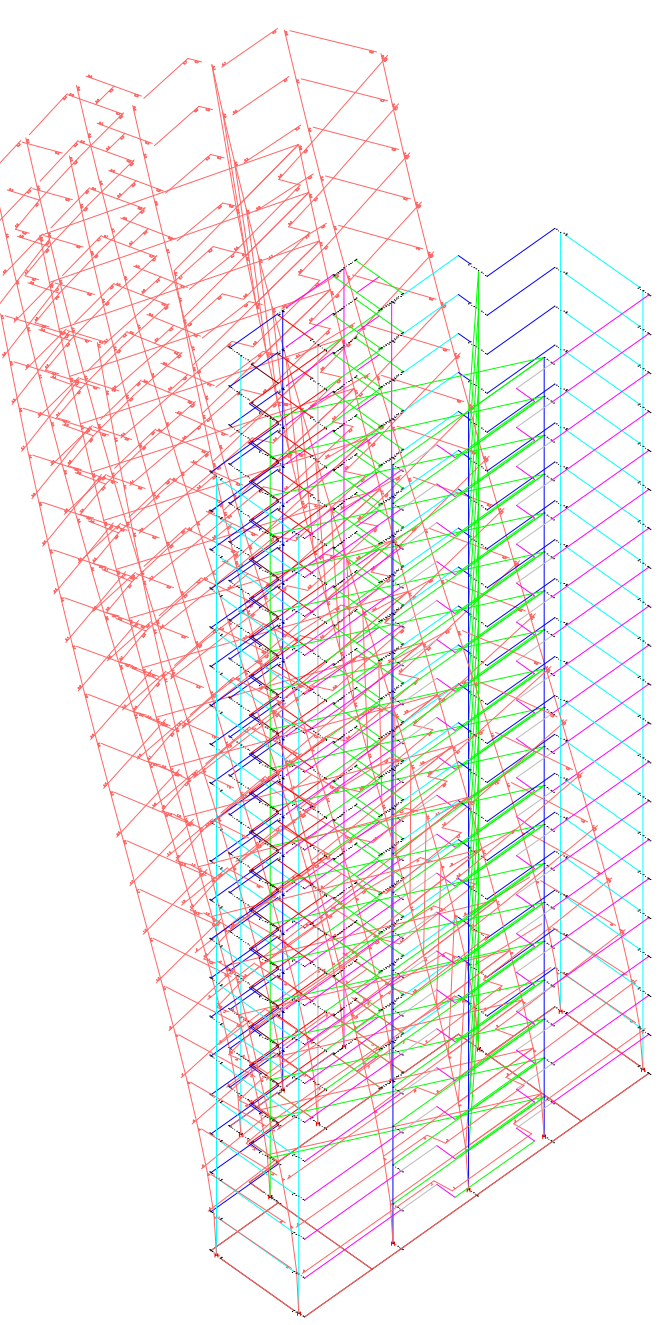

(direção frontal Y)

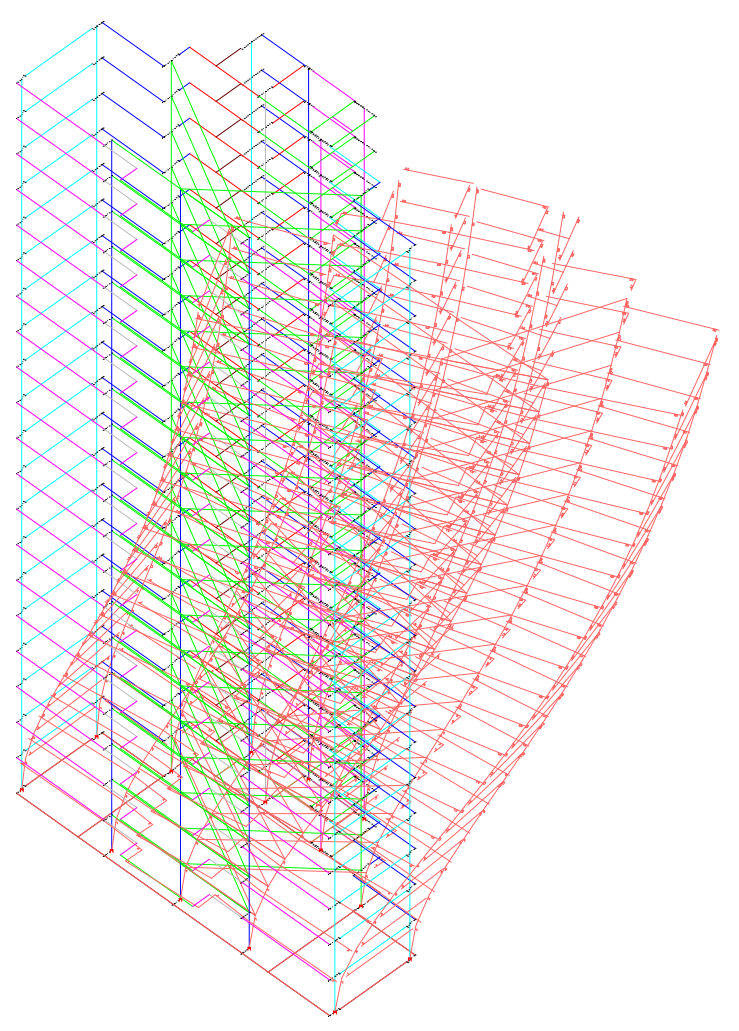

(direção lateral X)

Figura C.2 - Aspecto da deformada do pórtico espacial para os modelos E01 e E02 


\section{C.1.2. - Modelos E03 e E04}

$\mathrm{Na}$ análise do pórtico tridimensional, os deslocamentos alcançados no topo da edificação foram iguais para ambos os modelos e, atingiram um valor médio igual a $5,93 \mathrm{~cm}$ para o deslocamento na direção frontal de aplicação do vento, e de $3,04 \mathrm{~cm}$ para o deslocamento na direção dos esforços agindo na lateral da edificação (ver figura C.3).

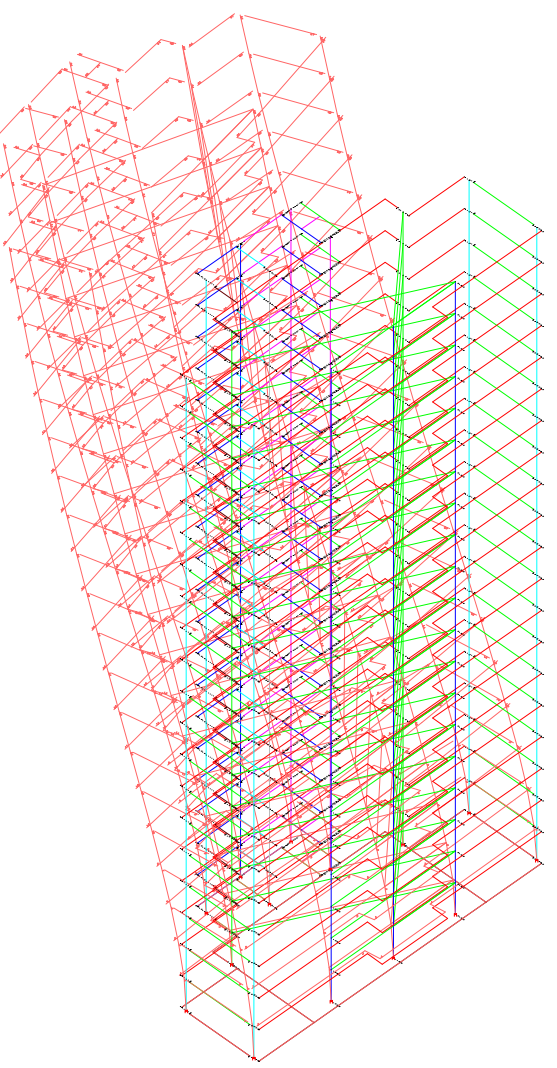

(direção frontal Y)

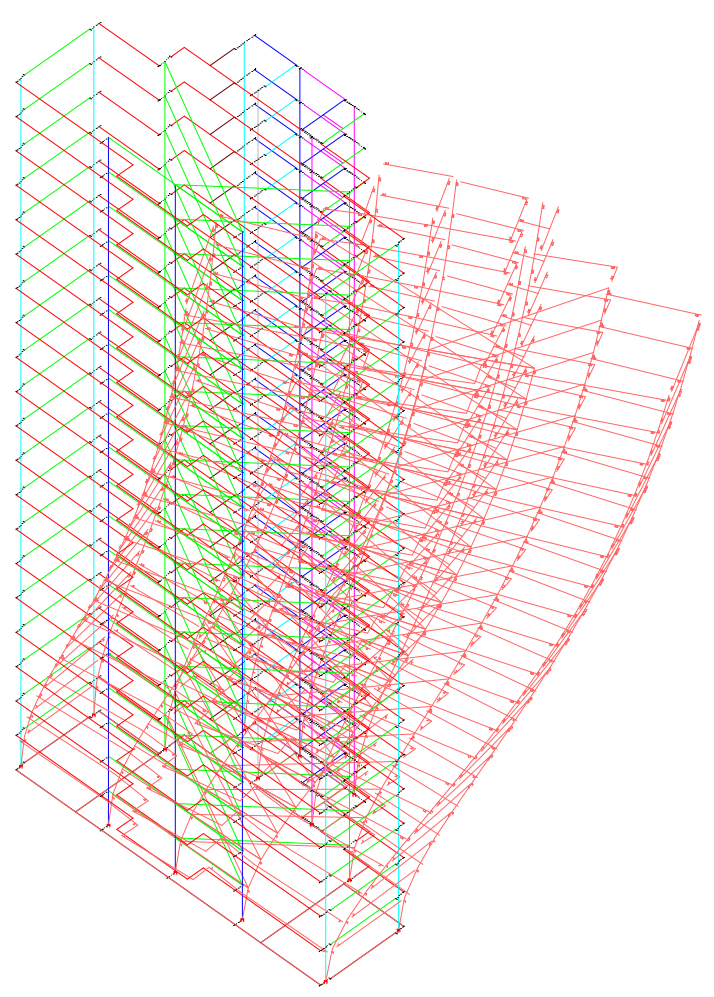

(direção lateral X)

Figura C.3 - Aspecto da deformada do pórtico espacial para os modelos E03 e E04

\section{C.1.3. - Modelos E05 e E06}

$\mathrm{Na}$ análise do pórtico tridimensional, os deslocamentos alcançados no topo da edificação foram iguais para ambos os modelos e, atingiram um valor médio igual a $5,37 \mathrm{~cm}$ para o deslocamento na direção frontal de aplicação do 
vento, e de 2,56 cm para o deslocamento na direção dos esforços agindo na lateral da edificação (ver figura C.4).

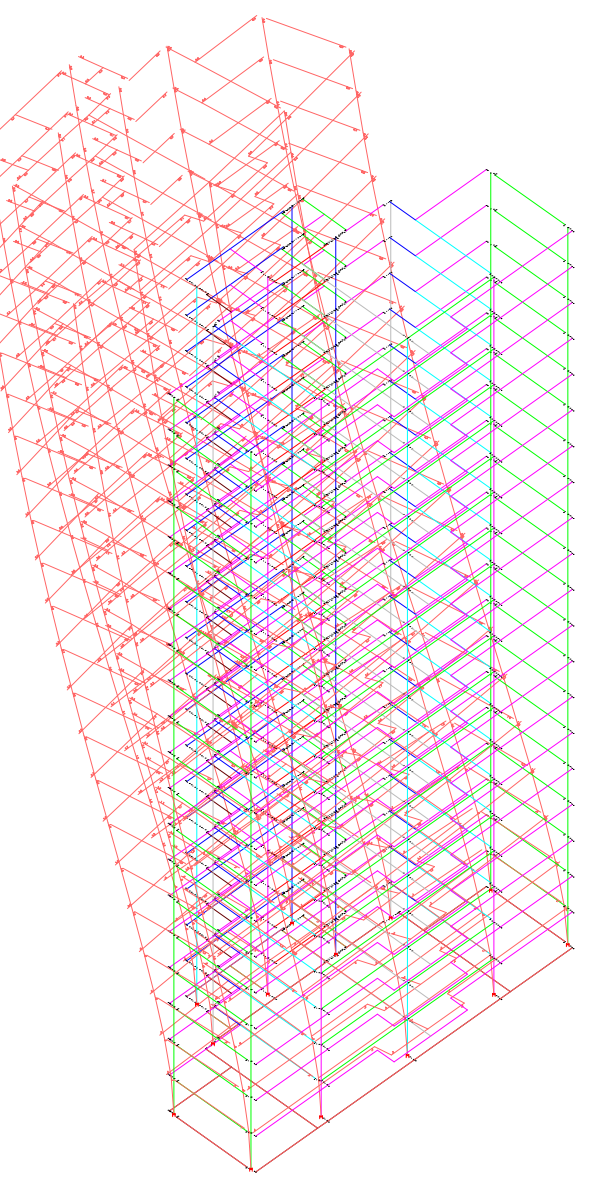

(direção frontal Y)

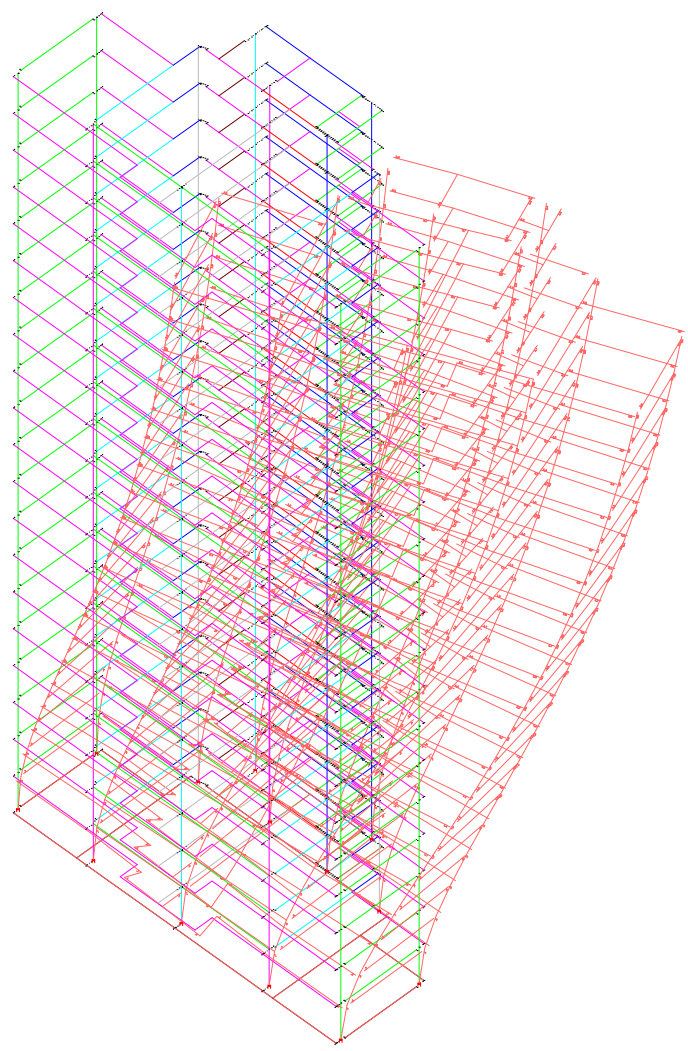

(direção lateral X)

Figura C.3 - Aspecto da deformada do pórtico espacial para os modelos E05 e E06

\section{C.2 - Comentários Finais}

Segundo a pesquisa de Albuquerque, os deslocamentos encontrados e os parâmetros de instabilidade obtidos, podem ser vistos na tabela C.1.

Serão comparados, conforme mencionado anteriormente, as diferenças de deslocamento para as duas direções X e Y e assim, será eleito o arranjo estrutural mais eficiente, do ponto de vista de desempenho estrutural. 
Tabela C.1 - Deslocamentos e parâmetros de instabilidade dos exemplos

\begin{tabular}{||c|c|c|c|c|c|c||}
\hline Modelo & $\begin{array}{c}\text { Deslocamento. } \\
\text { na direção Xeslocamento }\end{array}$ & $\begin{array}{c}\alpha \\
\text { na direção } \mathbf{Y}\end{array}$ & $\begin{array}{c}\alpha \\
\text { (dir. X) }\end{array}$ & $\begin{array}{c}\gamma_{\mathbf{Z}} \\
\text { (dir. Y) }\end{array}$ & $\begin{array}{c}\gamma_{\mathbf{Z}} \\
\text { (dir. } \mathbf{X} \text { ) }\end{array}$ & (dir. Y) \\
\hline \hline $\mathbf{A 0 1}$ & 2,82 & 5,60 & 0,64 & 0,57 & 1,07 & 1,06 \\
\hline $\mathbf{A 0 2}$ & 3,26 & 5,60 & 0,66 & 0,56 & 1,08 & 1,05 \\
\hline $\mathbf{A 0 3}$ & 2,23 & 10,62 & 0,55 & 0,75 & 1,05 & 1,09 \\
\hline $\mathbf{E 0 1}$ & 2,80 & 5,32 & 0,83 & 0,77 & 1,17 & 1,12 \\
\hline $\mathbf{E 0 2}$ & 2,80 & 5,32 & 0,83 & 0,77 & 1,17 & 1,12 \\
\hline E03 & 3,04 & 5,93 & 0,83 & 0,78 & 1,17 & 1,13 \\
\hline E04 & 3,04 & 5,93 & 0,83 & 0,78 & 1,17 & 1,13 \\
\hline E05 & 2,56 & 5,37 & 0,76 & 0,75 & 1,14 & 1,12 \\
\hline E06 & 2,56 & 5,37 & 0,77 & 0,72 & 1,14 & 1,12 \\
\hline
\end{tabular}

No gráfico C.1 têm-se as diferenças de deslocamentos para a direção X.

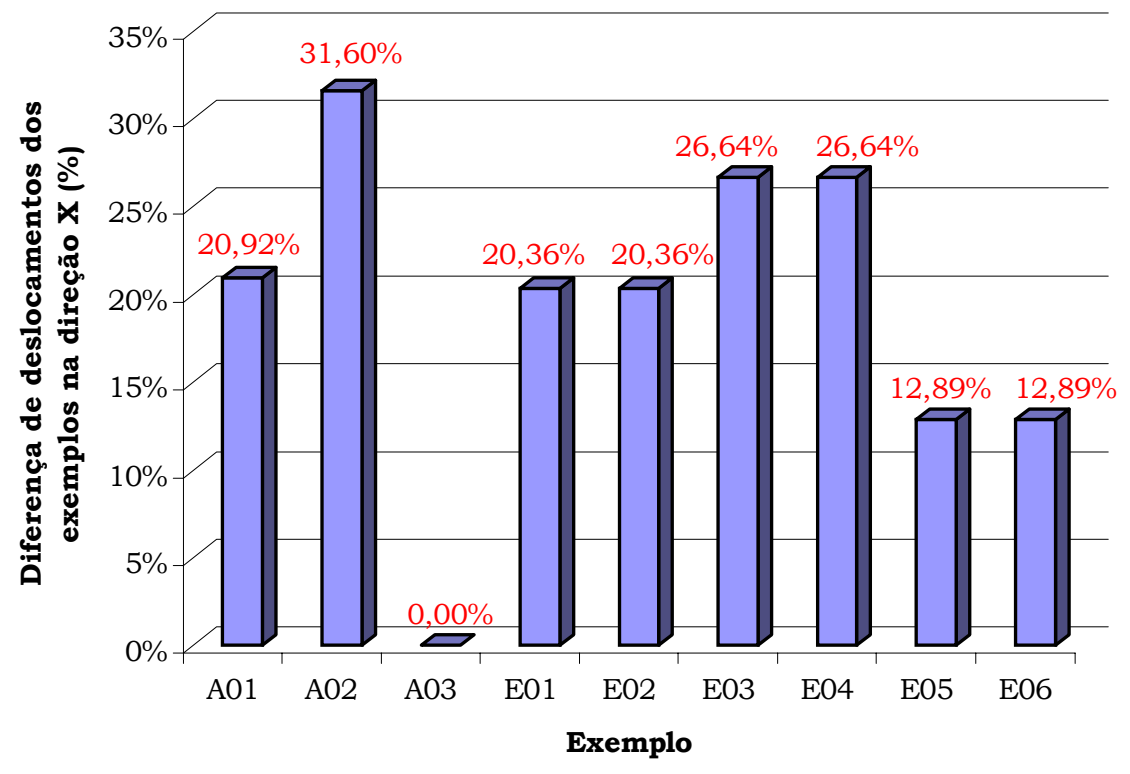

Gráfico C.1 - Variação dos deslocamentos da estrutura global dos exemplos na direção $\mathrm{X}$

Pode-se concluir que o modelo A03 foi o mais rígido na direção X. Isso se deve à grande quantidade de pilares presentes na estrutura (18 no total).

No gráfico C.2, vêm-se as diferenças de deslocamentos para a direção Y. 


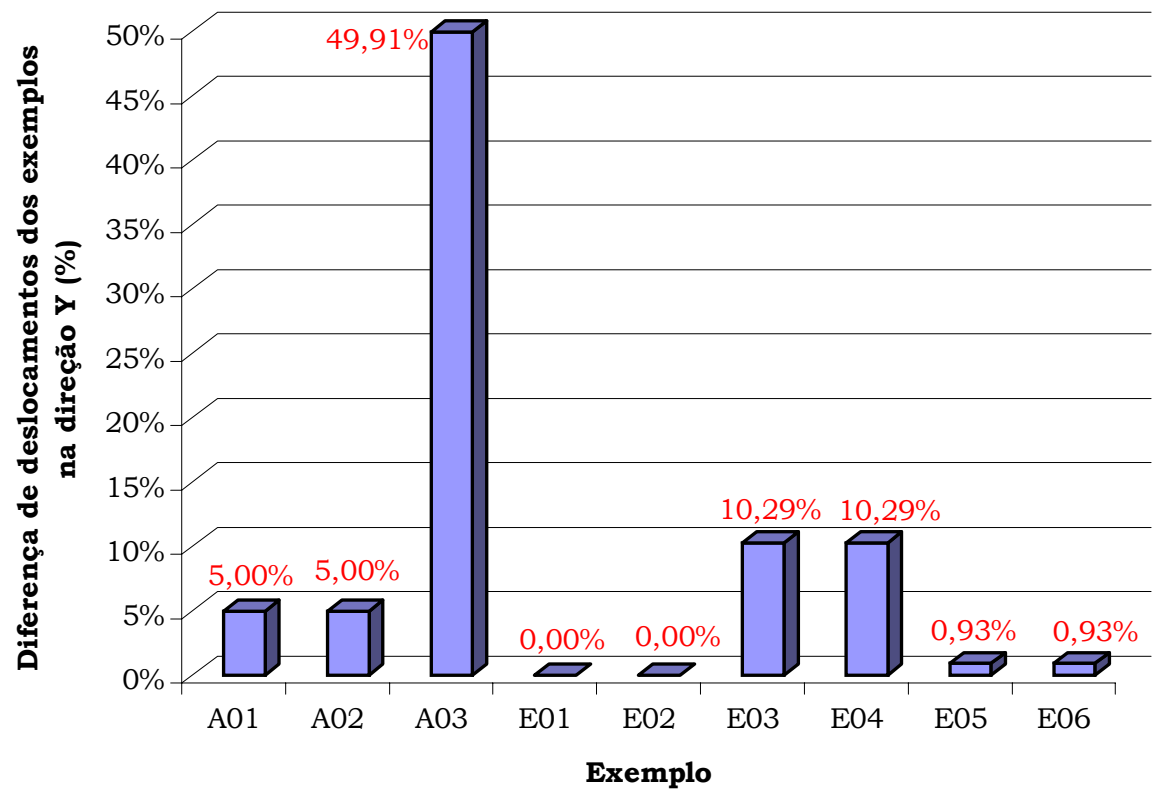

Gráfico C.2 - Variação dos deslocamentos da estrutura global dos exemplos na direção Y

Pode-se concluir que os modelos com laje plana maciça (E01 e E02) apresentaram os menores deslocamentos, sendo as estruturas mais rígidas. Entretanto, o modelo A03, que antes havia sido o modelo mais rígido na direção $\mathrm{X}$, agora, para a direção $\mathrm{Y}$, é o mais flexível tendo uma diferença de deslocamento, em relação aos modelos E01 e E02, de 49,91\%.

Com isso, após a verificação desses dois gráficos, percebe-se que existe um bom comportamento dos pórticos (com exceção do deslocamento na direção Y para o modelo A03) fornecendo assim, um bom desempenho estrutural.

Agora, vai-se analisar os deslocamentos encontrados em todos os modelos e compará-los com o deslocamento limite. Esses valores são utilizados para a verificação do Estado Limite de Deformações Excessivas das estruturas. De acordo com CARMO [1995], as limitações à inclinação lateral, especificadas como frações da altura total da edificação pelos diversos regulamentos, códigos e trabalhos de pesquisa, variam desde $\mathrm{H} / 200$ a $\mathrm{H} / 1200$. Segundo a referida autora, o valor limite mais indicado pelos regulamentos citados em sua pesquisa converge para H/500 (que é também recomendado pelo ACI 435.3R-68 [1984], e que será utilizado nesta pesquisa). 
Analisando os deslocamentos com relação aos limites estabelecidos pela expressão H/500, onde $\mathrm{H}$ é a altura da edificação, o gráfico C.3 ilustra a diferença nos deslocamentos para os modelos na direção X.

A altura da edificação é igual a $57,60 \mathrm{~m}$, com isso, substituindo na expressão, o valor limite para inclinação lateral é de $11,52 \mathrm{~cm}$, que será tomado como base para comparar os demais resultados para as direções X e Y.

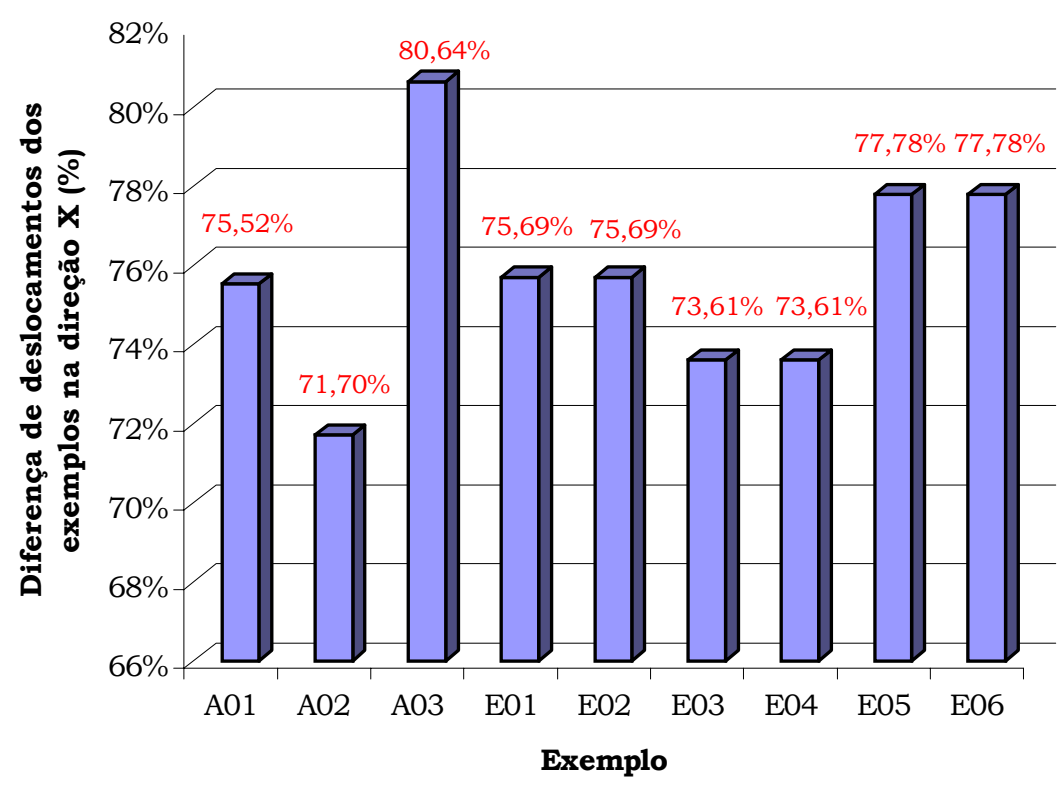

Gráfico C.3 - Diferença de deslocamento entre os modelos para a direção X

O gráfico C.3 mostra que houve um bom comportamento das estruturas, do ponto de vista de deslocamento lateral, apresentando diferença de deslocamento superior a 70\%. Vale salientar que o modelo A03 foi o mais rígido nesta direção, apresentando uma diferença de $80,64 \%$ em relação ao limite de $\mathrm{H} / 500$.

O gráfico C.4 ilustra a diferença nos deslocamentos para os modelos na direção Y. 


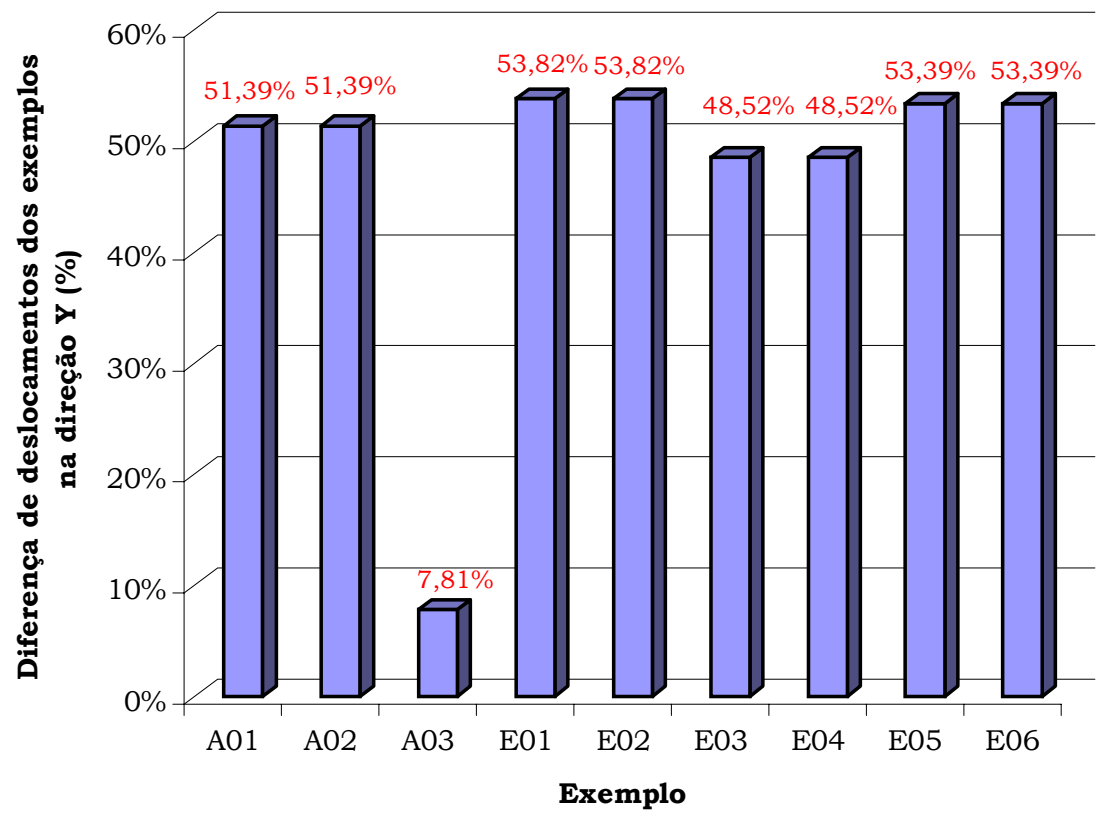

Gráfico C.4 - Diferença de deslocamento entre os modelos para a direção Y

Com isso, verifica-se que, de acordo com o gráfico C.4, o modelo A03 apresentou deslocamentos dentro dos limites de inclinação lateral (H/500), porém apresentou resultados muito inferiores aos demais exemplos, tornando esta solução pouco viável, em relação às demais soluções.

Embora a pesquisa de Albuquerque não apresente uma análise sobre a variação dos momentos fletores e do esforço normal para seus exemplos, serão ilustradas essas variações.

Para esta análise, foram escolhidos os painéis da estrutura mais solicitados, que podem ser visualizados na figura C.4.

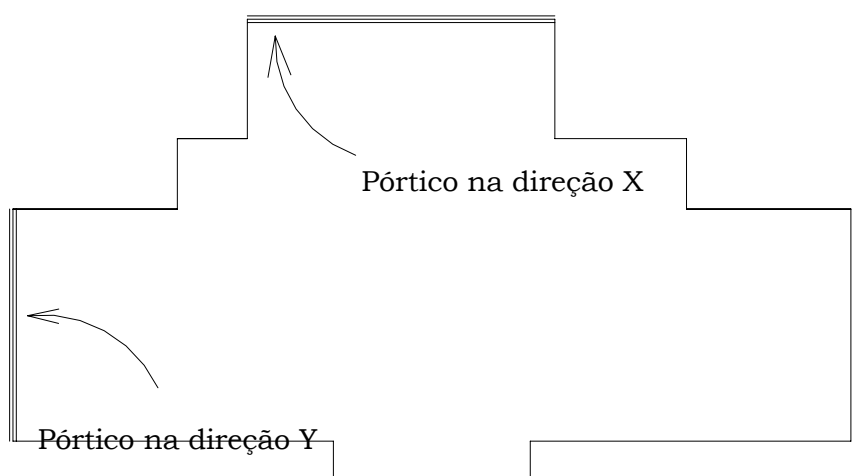

Figura C.4 - Posição dos pórticos analisados 
O gráfico C.5 mostra a variação do momento fletor, no pilar mais solicitado, nos pórticos.

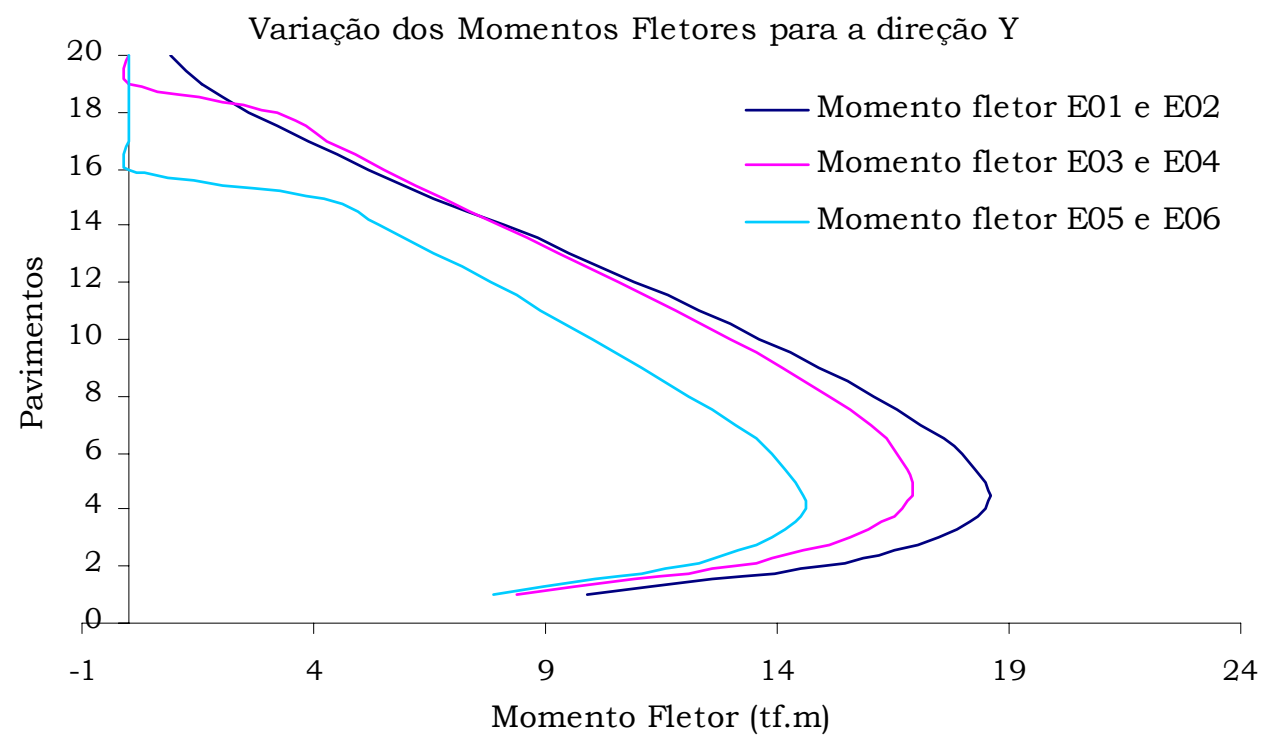

Gráfico C.5 - Variação do momento fletor para a aplicação do vento na direção Y

O gráfico C.6 ilustra a variação de momento para a direção X.

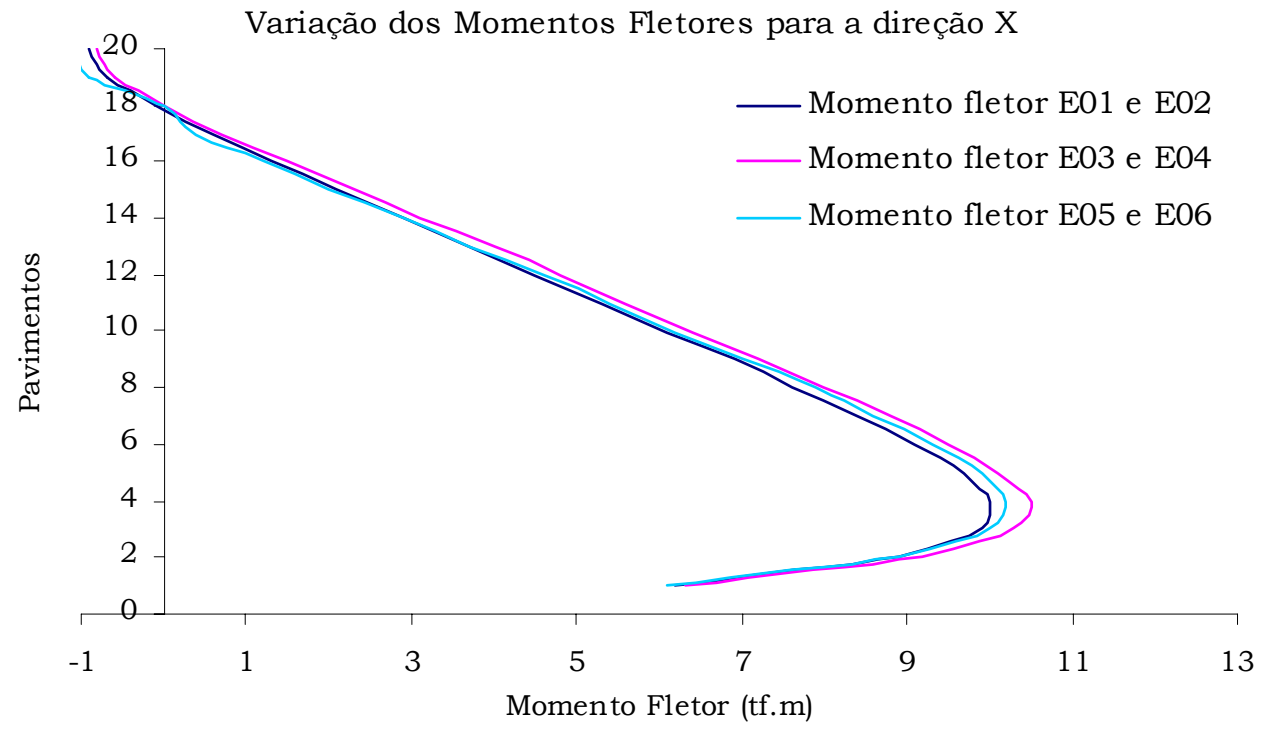

Gráfico C.6 - Variação do momento fletor para a aplicação do vento na direção X

Pode-se concluir que os pavimentos mais solicitados, para todos os modelos protendidos, foram o $4^{0}$ e o $5^{\circ}$. 
O gráfico C.7 ilustra a variação do esforço cortante nos pilares. Para este caso, foi escolhido o pilar mais solicitado e comparado com os demais (Ver figura C.6).

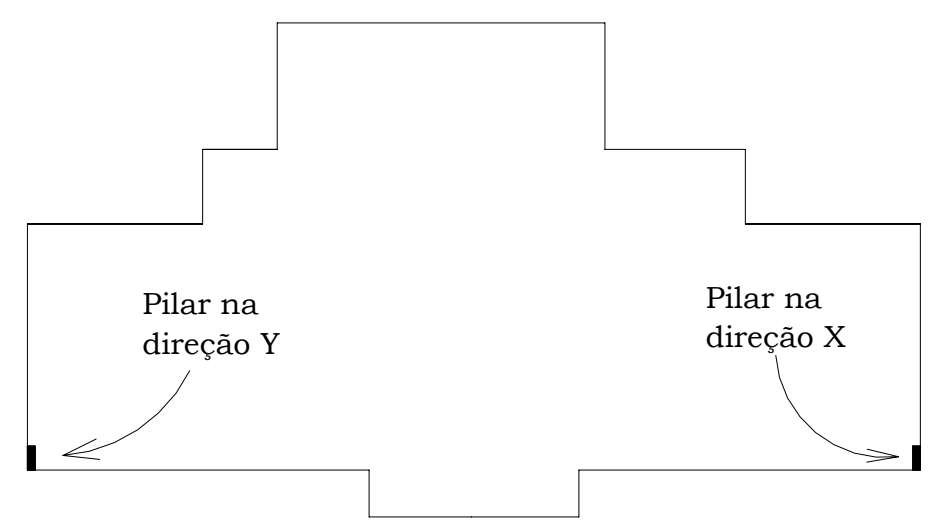

Figura C.6 - Localização dos pilares mais solicitados

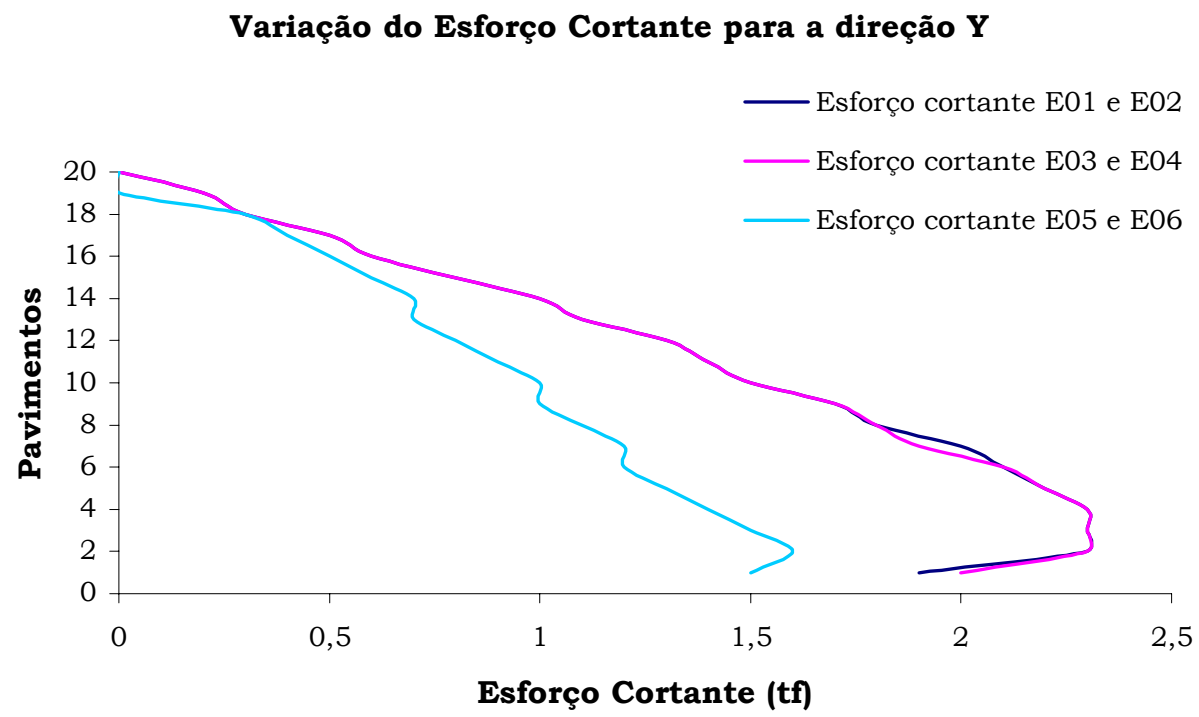

Gráfico C.7 - Variação do esforço cortante para a aplicação do vento na direção Y

O gráfico C.8 ilustra variação do esforço cortante em um pilar, ao longo do edifício, para a direção X. 


\section{Variação do Esforço Cortante para a direção X}

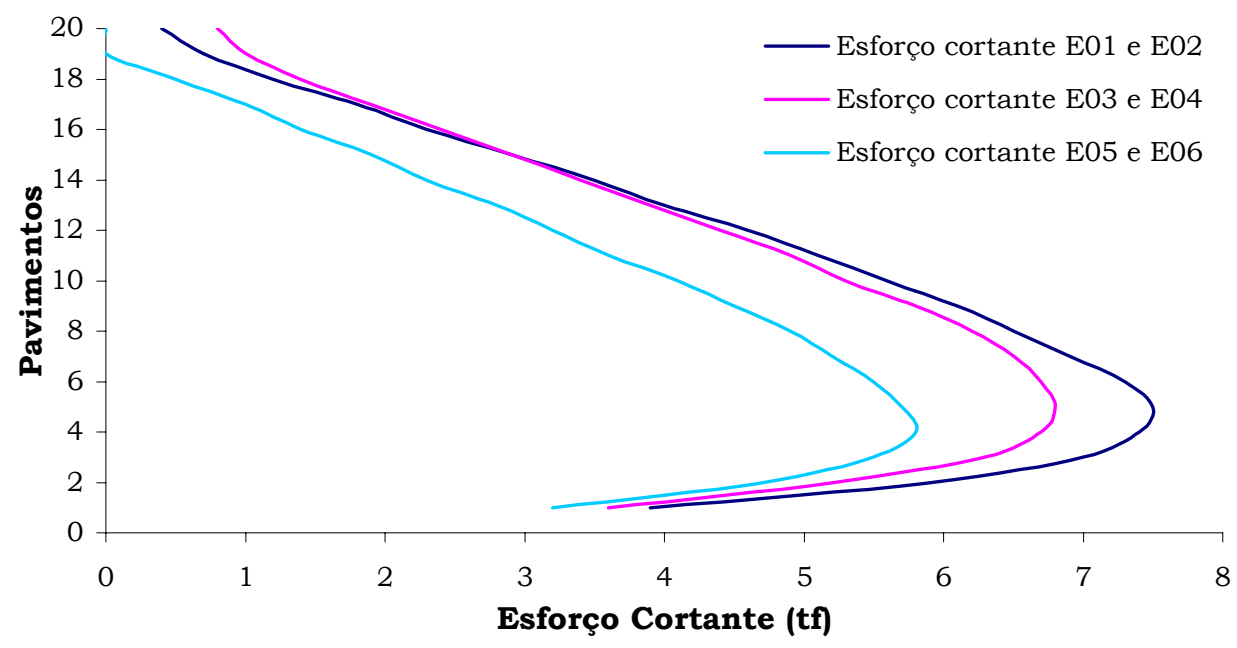

Gráfico C.8 - Variação do esforço cortante para a aplicação do vento na direção X

Pode-se ver que, para todos os modelos protendidos, o comportamento dos modelos foi semelhante.

Com os gráficos C.7 e C.8, pode-se ver que os maiores esforços ocorreram nos pavimentos inferiores, mais precisamente, no quinto pavimento.

Com isso, pode-se concluir que os modelos das estruturas protendidas apresentaram bons resultados e ainda, embora não tenha sido realizada uma comparação com os modelos em concreto armado quanto aos esforços internos, os modelos de Albuquerque foram menos rígidos (com relação aos deslocamentos), mostrando que as estruturas protendidas são mais rígidas, tornando essas soluções mais interessantes para edificios residenciais e comerciais.

Partindo para uma análise entre os modelos de estruturas protendidas, os modelo que apresentou menores valores para momento fletor nas vigas e esforço cortante nos pilares, foram os modelos dotados de vigas faixa protendidas. Isso se deve ao acréscimo de rigidez no pavimento dado pelas vigas faixa, pois, adotou-se que o pavimento plano, maciço ou nervurado, não contribui na rigidez lateral do edificio. 


\section{ANEXO A}

\section{Prescrições do Projeto de Revisão da NBR 6118-2001}

De acordo com a NBR 6118 - 2001, o concreto protendido consiste em uma peça no qual ocorre um sistema de forças permanentemente aplicadas tal que, em condições de serviço, a protensão provoca o impedimento ou a limitação da formação de fissuras no concreto quando a peça for submetida às ações pré-determinadas que ocorrerem na sua vida útil desta.

\section{A.1 - Tipos de Protensão}

A protensão pode ser realizada de três formas:

i) Protensão aderente com pré-tração:

Este tipo de protensão é utilizado principalmente em estruturas prémoldadas, onde o sistema tem mais eficiência.

Consiste no estiramento da armadura (aplicação da força de protensão) utilizando apoios independentes da peça antes do lançamento do concreto. A ancoragem é realizada somente pela aderência da cordoalha com o concreto da peça, após atingir uma resistência mínima préestabelecida.

ii) Protensão aderente com pós-tração:

Como o próprio nome diz, após o a idade em que o concreto atinge a resistência mínima determinada pelo projetista, é que é realizado o estiramento da armadura utilizando apoios (ou ancoragens) na própria peça aonde a aderência com o concreto se dá posteriormente com a injeção da nata de cimento nas bainhas. 
iii) Protensão não aderente:

É tratado da mesma maneira que a protensão aderente com póstração, porém, após o estiramento da armadura, não existe mais a aderência do cabo com o concreto, ficando a cordoalha ligada à peça somente nas extremidades do cabo onde se localizam as ancoragens ativa e passiva.

\section{A.2 - Grau de protensão}

O grau de protensão, de acordo com a NBR 7197/89, é determinado em função dos Estados Limites de Serviço, em especial a fissuração.

Para a determinação do valor da força de protensão necessária para a peça de concerto protendido, é importante classificar inicialmente o grau de agressividade no local da estrutura e, com isso, verificar a durabilidade da peça (ver tabela A.1).

Tabela A.1 - Determinação do tipo de protensão

\begin{tabular}{|c|c|}
\hline $\begin{array}{c}\text { Nivel de Agressividade do } \\
\text { Ambiente }\end{array}$ & $\begin{array}{c}\text { Exigências Minimas Quanto ao } \\
\text { Tipo de Protensão }\end{array}$ \\
\hline \hline Muito Agressivo & Protensão Completa \\
\hline Pouco Agressivo & Protensão Limitada \\
\hline Não Agressivo & Protensão Parcial \\
\hline
\end{tabular}

Fonte: Projeto de Revisão da NBR 6118-2001.

Pode-se ver na Tabela A.2 e A.3, os graus de agressividade para o concreto protendido sugeridos pelo Projeto de Revisão da NBR 6118 - 2001. 
Tabela A.2 - Determinação da Classe de Agressividade do Ambiente

\begin{tabular}{|c|c|}
\hline Classe da Agressividade Ambiental & Grau de Agressividade \\
\hline \hline I & Fraca \\
\hline II & Média \\
\hline III & Forte \\
\hline IV & Muito Forte \\
\hline
\end{tabular}

Fonte: Projeto de Revisão da NBR 6118-2001

Tabela A.3 - Classes de Agressividade Ambiental e Exigências Relativas à Fissuração Excessiva

\begin{tabular}{|c|c|c|c|c|}
\hline \multirow{2}{*}{$\begin{array}{l}\text { Tipo de } \\
\text { Protensão }\end{array}$} & \multicolumn{2}{|c|}{$\begin{array}{c}\text { Classe de Agressividade } \\
\text { Ambiental }\end{array}$} & \multirow{2}{*}{$\begin{array}{c}\text { Exigências } \\
\text { com Relação } \\
\text { ao E.L. de } \\
\text { Fissuração } \\
\text { Excessiva } \\
\end{array}$} & \multirow{2}{*}{$\begin{array}{c}\text { Combinações } \\
\text { de Ações a } \\
\text { Considerar }\end{array}$} \\
\hline & Pré-tração & Pós-tração & & \\
\hline \multirow{2}{*}{$\begin{array}{l}\text { Protensão } \\
\text { Parcial }\end{array}$} & \multirow{2}{*}{ I } & \multirow{2}{*}{ I e II } & $\begin{array}{c}\text { ELS }-\mathrm{W} \\
\left(\mathrm{w}_{\mathrm{k}} \leq 0,2 \mathrm{~mm}\right)\end{array}$ & Freqüente \\
\hline & & & ELS - F & $\begin{array}{c}\text { Quase } \\
\text { permanente }\end{array}$ \\
\hline \multirow[b]{2}{*}{$\begin{array}{l}\text { Protensão } \\
\text { Limitada }\end{array}$} & \multirow[b]{2}{*}{ II } & \multirow[b]{2}{*}{ III e IV } & $\overline{E L S}-\mathrm{F}$ & Freqüente \\
\hline & & & ELS - D & $\begin{array}{c}\text { Quase } \\
\text { permanente }\end{array}$ \\
\hline \multirow{2}{*}{$\begin{array}{l}\text { Protensão } \\
\text { Completa }\end{array}$} & \multirow{2}{*}{ III e IV } & \multirow{2}{*}{ - } & $\overline{E L S}-\mathrm{F}$ & Rara \\
\hline & & & $\overline{E L S}-\mathrm{D}$ & Freqüente \\
\hline
\end{tabular}

Fonte: Projeto de Revisão da NBR 6118-2001

A NBR 7197/89 permite o emprego do concreto protendido sem aderência desde que este tipo de protensão fosse do tipo completa, o que tornou o emprego da protensão não aderente inviável. Porém, o Projeto de Revisão da NBR 6118-2001 permite a utilização da protensão não aderente desde que sejam respeitados os estados limites de serviço e último (protensão limitada e parcial).

A atual revisão da NBR 6118 - 2001 promove um enorme aprimoramento das diretrizes que visam a durabilidade das estruturas, para isso, melhorando os cobrimentos e qualidade do concreto utilizado. 
Pode-se ver na tabela A.4, os cobrimentos estabelecidos de acordo com os graus de agressividade do ambiente.

Tabela A.4 - Classe de Agressividade, Qualidade do Concreto e Cobrimento nominal

\begin{tabular}{|c|c|c||}
\hline $\begin{array}{c}\text { Classe de } \\
\text { Agressividade }\end{array}$ & $\begin{array}{c}\text { Qualidade do } \\
\text { Concreto }\end{array}$ & $\begin{array}{c}\text { Cobrimento } \\
\text { Nominal }\end{array}$ \\
\hline \hline I & $\geq \mathrm{C} 25$ & $\geq 30 \mathrm{~mm}$ \\
\hline II & $\geq \mathrm{C} 30$ & $\geq 35 \mathrm{~mm}$ \\
\hline III & $\geq \mathrm{C} 35$ & $\geq 45 \mathrm{~mm}$ \\
\hline IV & $\geq \mathrm{C} 40$ & $\geq 55 \mathrm{~mm}$ \\
\hline
\end{tabular}

Fonte: Projeto de Revisão da NBR 6118-2001.

Com isso, vê-se que a utilização de protensão não aderente para peças de concreto protendido pode ser feita tanto para a protensão parcial quanto para a protensão limitada.

\section{A.3 - Estados Limites de Serviço}

Os Estados Limites de Serviço visam promover um nível de desempenho adequado para o qual a estrutura foi projetada. Abrangem a fissuração (formação de fissuras e fissuração inaceitável), deformação excessiva, a descompressão da seção e a compressão excessiva da seção.

Para melhor exemplificar estes Estados Limites, vai-se utilizar como exemplo, a ilustração da figura A.1, onde as tensões nos estados limites, ilustrados nas figuras A.2 a A.6, são para as seções transversais mais solicitadas.

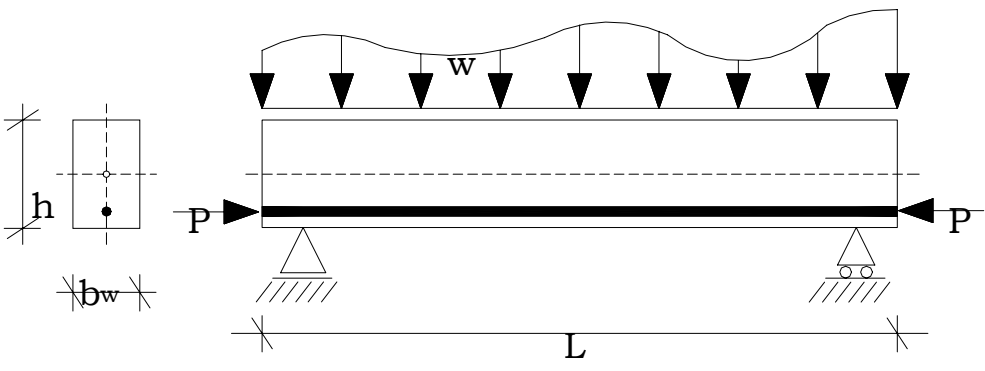

Figura A.1 - Exemplo de seção transversal 


\section{i) Estado Limite de Compressão Excessiva (ELS - CE)}

Este estado visa garantir a segurança para que as tensões normais nas seções transversais de concreto protendido não superem o limite convencional de 0,7 $\mathrm{f}_{\mathrm{ck}}$ (Figura A.2). Esta verificação deve ser feita somente na fase de aplicação da protensão com o concreto no regime elástico-linear.

Deve-se atentar ao fato que, quando uma grande força de protensão for aplicada, além de respeitar limite de 0,7 $\mathrm{f}_{\mathrm{ck}}$, deve-se também avaliar a contra-flecha e a fissuração que poderão ocorrer na estrutura produzidas pela da força de protensão.

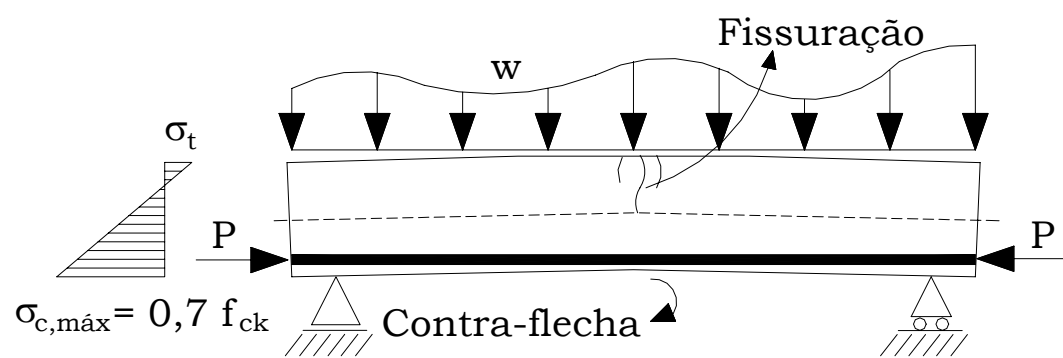

Figura A.2 - Estado Limite de Compressão Excessiva

\section{ii) Estado Limite de Descompressão (ELS - D)}

Considerando uma seção transversal típica de concreto protendido, portanto pré-comprimida, quando é submetida à ação de outros carregamentos externos, vai se descomprimindo aos poucos até atingir uma situação que um ou mais pontos da seção transversal, a tensão normal é nula (Figura A.3), fazendo com que, qualquer outro carregamento maior que o carregamento que provoca a descompressão do concreto $\left(\mathrm{W}_{\mathrm{D}}\right)$ origine tensões de tração na borda inferior da estrutura.

Esta verificação é feita no Estádio Ia (material elástico-linear). 


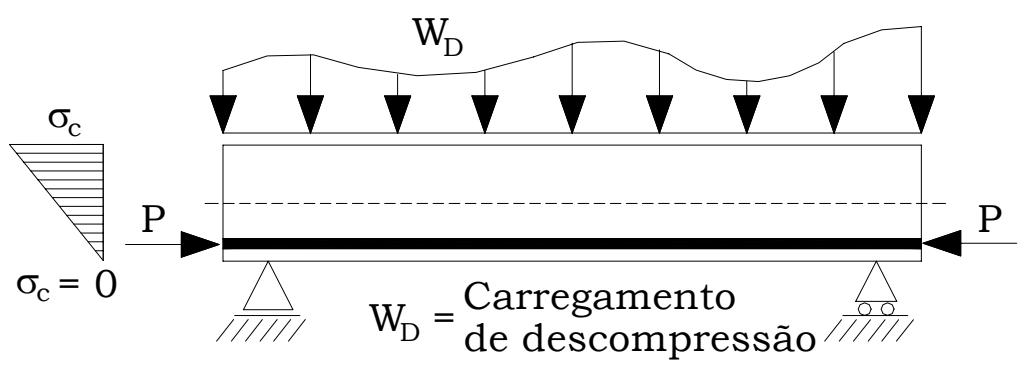

Figura A.3 - Estado Limite de Descompressão

\section{iii) Estado Limite de Formação de Fissuras (ELS - F)}

Este Estado Limite de Serviço trata de determinar o valor das forças externas aplicadas na estrutura de modo que se tenha uma grande probabilidade de formação de fissuras perpendiculares à armadura longitudinal (Figura A.4).

Este cálculo pode ser feito no Estádio Ib (de acordo com a NB -1/78) ou no Estádio Ia (simplificadamente), onde o concreto encontra-se em um estado não-fissurado e elástico-linear. Neste caso, a razão entre os módulos de deformação para combinações de ações quase-permanentes e freqüentes é de $\alpha_{\mathrm{e}}=15$ e para combinações raras de ações $\alpha_{\mathrm{e}}=10$.

Efetuando-se os cálculos no Estádio Ia, toma-se como valores limites para as tensões de tração no concreto $\mathrm{f}_{\mathrm{ctm}}=1,2 . \mathrm{f}_{\mathrm{ctk}}$ para seções transversais $\mathrm{T}$ ou duplo $\mathrm{T}$ e $\mathrm{f}_{\mathrm{ctm}}=1,5 . \mathrm{f}_{\mathrm{ctk}}$ para seções transversais retangulares.

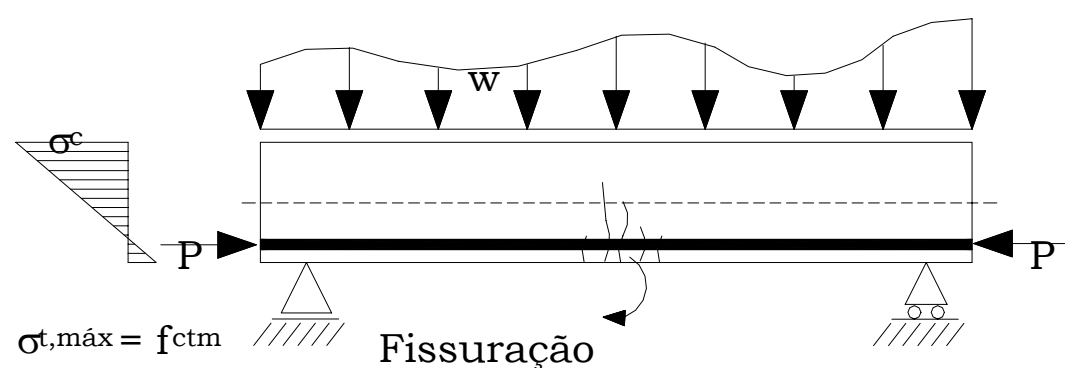

Figura A.4 - Estado Limite de Formação de Fissuras

\section{iv) Estado Limite de Abertura de Fissuras (ELS - W)}

Esta verificação é feita calculando-se as tensões nas barras da armadura de tração no concreto fissurado (Estádio II) com comportamento 
elástico-linear dos materiais, adotando uma relação entre os módulos de elasticidade do aço e do concreto $\left(\alpha_{\mathrm{e}}\right)$ igual a 15 (Figura A.5 (b)).

Para tal, de cada armadura, seja ela passiva ou ativa (desde que esta armadura ativa não esteja dentro de bainhas), será estimada uma área de influência $\left(A_{c r}\right)$ de concreto que envolve a barra (Figura A.5 (a)) que corresponde a um retângulo cujos lados não distam mais de 7,5.申 do contorno da barra.

Deve ser respeitado o valor limite para abertura de fissuras, de acordo com o Projeto de Revisão da NBR 6118-2001, em $\mathrm{w}_{\mathrm{k}} \leq 0,2 \mathrm{~mm}$.

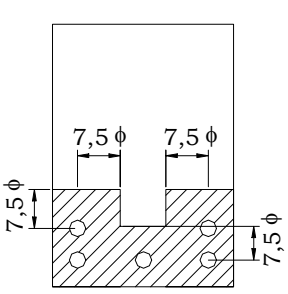

(a)

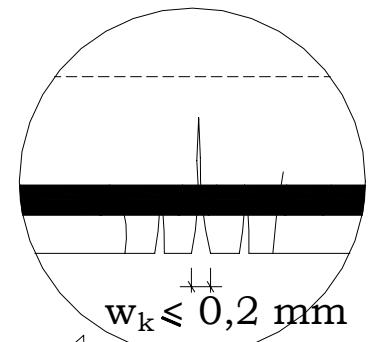

$\mathrm{w}_{\mathrm{k}} \leqslant 0,2 \mathrm{~mm}$

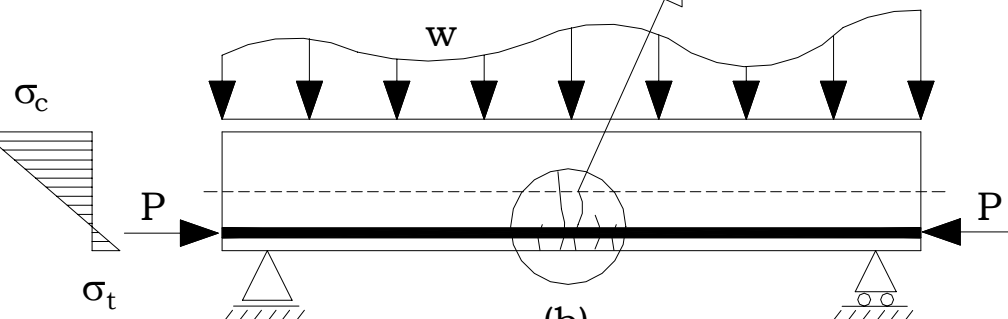

(b)

Figura A.5 - Estado Limite de Abertura de Fissuras

\section{v) Estado Limite de Deformações Excessivas (ELS - DEF)}

A verificação da segurança deve ser feita no Estádio I ou II, adotando $\alpha_{\mathrm{e}}=15$ e considerando, ainda, a deformação lenta do concreto (Figura A.6).

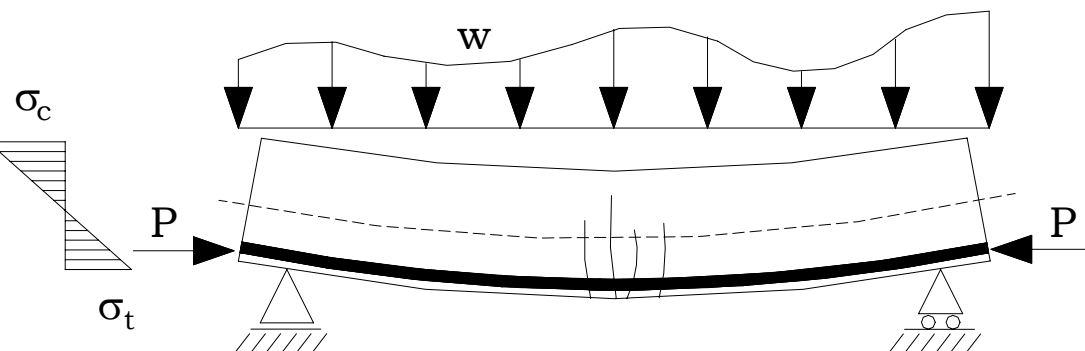

Figura A.6 - Estado Limite de Deformações Excessivas 


\section{vi) Estado Limite de Vibrações Excessivas (ELS - VE)}

Este Estado Limite visa limitar os deslocamentos oscilatórios (vibrações) em estruturas de tal modo a manter um nível de funcionabilidade adequado para a utilização da estrutura.

Este Estado Limite é analisado em situações em que ações dinâmicas atuam sobre a estrutura (caso das pontes) e não será considerada neste trabalho.

\section{A.4 - Estado Limite Último: Solicitações Normais}

Os procedimentos de cálculo são os mesmos utilizados para o caso do concreto armado, onde a única diferença reside no fato da armadura de protensão possuir um alongamento prévio antes de se considerarem as ações externas.

A influência da aderência é de grande importância no comportamento resistente tanto para o Estado Limite Último como com relação à fissuração em serviço. De acordo com LEONHARDT, em ensaios de vigas protendidas com aderência posterior e sem aderência [1950], a viga com aderência sofre menores deslocamentos para grandes cargas de ruptura $(900 \mathrm{kN})$, enquanto, a viga protendida sem aderência rompeu na zona comprimida sobre uma carga de $600 \mathrm{kN}$. Pode-se ver com isso que a falta de aderência provoca uma diminuição da carga limite em 30\%. Logo, para o caso de protensão sem aderência, que é objeto do presente estudo, deve-se promover um acréscimo de armadura passiva que seja suficiente para garantir segurança à estrutura, impedindo a progressão das fissuras, uma vez que não existe a parcela de deformação conjunta da armadura ativa com o concreto.

Para a verificação à flexão no Estado Limite Último, toma-se o concreto no Estádio IIb, portanto fissurado, e estando ambos os materiais, aço e concreto, no regime plástico. A verificação das seções transversais tem por objetivo determinar o momento resistente último e avaliar a capacidade de resistir ao momento de cálculo. Para se determinar este valor, deve-se inicialmente arbitrar um valor para a tensão na armadura $\left(\sigma_{\mathrm{cp}, \text { arb. }}\right)$, que em geral está situando entre $f_{\text {pyd }}$ e $f_{\text {ptd }}$ como primeira tentativa. 


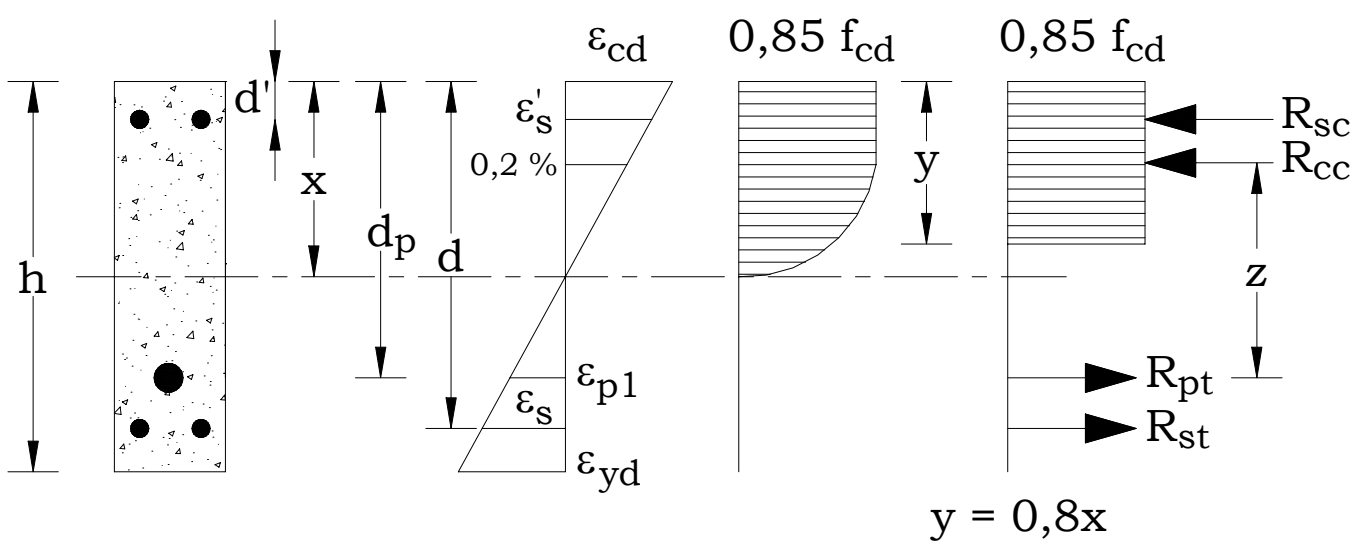

Figura A.7 - Análise de uma seção de concreto protendido

Determina-se a deformação adicional correspondente às deformações posteriores ao estado de neutralização ${ }^{1}\left(\sigma_{\mathrm{p} 1}\right)$ que depende da altura da linha neutra e das condições de equilíbrio da seção (Ver figura A.7).

Fazendo o equilíbrio da seção, tem-se:

$$
\begin{aligned}
\sum \mathrm{F}_{\mathrm{X}}=0 \rightarrow \mathrm{R}_{\mathrm{CC}} & +\mathrm{R}_{\mathrm{Sc}}-\mathrm{R}_{\mathrm{pt}}-\mathrm{R}_{\mathrm{st}}=0 \rightarrow \\
& \rightarrow \mathrm{A}_{\mathrm{cc}} \mathrm{0}, 85 \mathrm{f}_{\mathrm{cd}}+\mathrm{A}_{\mathrm{Sc}} \mathrm{f}_{\mathrm{yd}}-\mathrm{A}_{\mathrm{p}_{\mathrm{pyd}}}-\mathrm{A}_{\mathrm{st}} \mathrm{f}_{\mathrm{yd}}=0
\end{aligned}
$$

Com isso, chega-se a um valor para a profundidade da linha neutra e, com a Hipótese de Bernoulli, encontra-se:

$$
\varepsilon_{\mathrm{p} 1}=\varepsilon_{\mathrm{cd}} \frac{\mathrm{d}_{\mathrm{p}}-\mathrm{x}}{\mathrm{x}}
$$

Deve-se, então, calcular o valor do pré-alongamento da armadura de protensão, ou seja, o alongamento necessário para provocar um estado de neutralização na seção transversal de concreto.

$$
\varepsilon_{\mathrm{cp}}=\frac{\sigma_{\mathrm{cp}}}{\mathrm{E}_{\mathrm{c}}} \quad ; \quad \Delta \varepsilon_{\mathrm{p}}=-\varepsilon_{\mathrm{cp}}=-\frac{\sigma_{\mathrm{cp}}}{\mathrm{E}_{\mathrm{c}}} \quad ; \quad \mathrm{P}_{\mathrm{n}}=\mathrm{P}+\Delta \mathrm{P}
$$

Onde,

$\mathrm{P}_{\mathrm{n}} \quad$ é a força necessária para provocar o pré-alongamento da estrutura.

$\Delta \sigma_{p}=\Delta \varepsilon_{p} \cdot E_{p}=-\sigma_{c p} \cdot \frac{E_{p}}{E_{c}}=-\sigma_{c p} \cdot \alpha_{p}$

${ }^{1}$ Corresponde ao pré-alongamento que consiste na deformação na armadura ativa, no seu centro de gravidade, onde a tensão no concreto neste ponto é igual a zero. 
$\Delta \mathrm{P}=\mathrm{A}_{\mathrm{p}} \cdot \Delta \sigma_{\mathrm{p}}=-\alpha_{\mathrm{p}} \cdot \mathrm{A}_{\mathrm{p}} \cdot \sigma_{\mathrm{cp}} \quad$ (Acréscimo para o pré-alongamento)

$\mathrm{P}_{\mathrm{n}}=\mathrm{P}+\Delta \mathrm{P} \rightarrow \mathrm{P}_{\mathrm{n}}=\mathrm{P}+\alpha_{\mathrm{p}} \cdot \mathrm{A}_{\mathrm{p}} \cdot\left|\sigma_{\mathrm{cp}}\right|$

Daí tem-se:

$$
\varepsilon_{\mathrm{pn}}=\frac{\mathrm{P}_{\mathrm{n}}}{\mathrm{A}_{\mathrm{p}} \cdot \mathrm{E}_{\mathrm{p}}}
$$

Partindo para valores de cálculo, ou seja, adotando coeficientes de segurança, tem-se:

$\gamma_{\mathrm{f}}=0,9 \quad$ (armadura no banzo tracionado)

$\gamma_{\mathrm{f}}=1,2 \quad$ (armadura no banzo comprimido)

$$
\varepsilon_{\text {pnd }}=\frac{\gamma_{f} \cdot\left(P+\alpha_{p} \cdot A_{p} \cdot\left|\sigma_{c p}\right|\right)}{A_{p} \cdot E_{p}}
$$

Logo, a deformação total será igual a:

$$
\varepsilon_{\mathrm{pd}}=\varepsilon_{\mathrm{p} 1 \mathrm{~d}}+\varepsilon_{\mathrm{pnd}}
$$

E com isso, determina-se a tensão no aço:

$$
\sigma_{\mathrm{pd}}=\mathrm{E}_{\mathrm{p}} \cdot \varepsilon_{\mathrm{pd}}
$$

Uma vez determinado o valor da tensão na armadura de protensão, deve-se verificar se ele é suficientemente próximo do valor arbitrado ( $\left.\sigma_{\mathrm{cp}, \text { arb. }}\right)$.

Faz-se, então, a verificação do momento (Ver figura A.7):

$$
\begin{aligned}
M_{d}=R_{c d} \cdot\left(x-\frac{y}{2}\right)+R_{s t} \cdot(d-x)+R_{p d} \cdot\left(d_{p}-x\right)- \\
R_{s c} \cdot\left(x-d^{\prime}\right)-R_{p d^{\prime}} \cdot\left(x-d_{p^{\prime}}\right)
\end{aligned}
$$

Note que a fórmula possui a parcela referente à protensão no banzo comprimido.

Não havendo presença de armadura ativa no banzo superior, a equação pode ser reescrita da seguinte forma: 


$$
M_{d}=R_{c d} \cdot\left(x-\frac{y}{2}\right)+R_{s t} \cdot(d-x)+R_{p d} \cdot\left(d_{p}-x\right)-R_{s c} \cdot\left(x-d^{\prime}\right)
$$

Onde,

$$
\begin{array}{ll}
\mathrm{R}_{\mathrm{cd}}=0,68 \cdot \mathrm{b}_{\mathrm{w}} \cdot \mathrm{x} \cdot \mathrm{f}_{\mathrm{cd}} & \text { Eq. (A.8) } \\
\mathrm{R}_{\mathrm{pd}}=\mathrm{A}_{\mathrm{pd}} \cdot \sigma_{\mathrm{pd}} & \text { Eq. (A.9) } \\
\mathrm{R}_{\mathrm{pd}}=\mathrm{A}_{\mathrm{pd}} \cdot \sigma_{\mathrm{pd}^{\prime}} & \text { Eq. (A.10) } \\
\mathrm{R}_{\mathrm{st}}=\mathrm{A}_{\mathrm{st}} \cdot \sigma_{\mathrm{st}} & \text { Eq. (A.11) } \\
\mathrm{R}_{\mathrm{sc}}=\mathrm{A}_{\mathrm{sc}} \cdot \sigma_{\mathrm{sc}} & \text { Eq. (A.12) }
\end{array}
$$

A segurança estará garantida se a condição abaixo for satisfeita:

$$
\mathrm{M}_{\mathrm{ud}} \geq \gamma_{\mathrm{f}} \cdot \mathrm{M}_{\mathrm{k}}
$$

Onde: $\gamma_{\mathrm{f}}=1,4$

Cabe observar que esse equacionamento é válido para o caso da protensão aderente.

Para peças com protensão não aderente, a tensão no cabo, no Estado Limite Último, é aproximadamente igual à protensão efetiva quando, a taxa de armadura passiva aumentar. Contudo, seções superarmadas não são recomendadas.

De acordo com NAAMAN [1992], a análise de 143 modelos experimentais de vigas com protensão não aderente e com razões vão/espessura variando de 8 a 45, mostra que a equação A.12 fornece valores conservativos em $94 \%$ dos casos levando, geralmente, a resultados a favor da segurança.

Segundo NAAMAN [1992], para peças submetidas à protensão não aderente, o momento último da seção pode ser escrita do mesmo modo que o equacionamento da protensão com aderência (ver eq. A.13), mas, o valor da tensão na armadura ativa na seção considerada, deve ser igual a:

$$
\mathrm{f}_{\mathrm{ps}}=\mathrm{f}_{\mathrm{pe}}+105(\mathrm{em} \mathrm{MPa})
$$

Onde, 
$\mathrm{f}_{\mathrm{pe}} \quad$ é a tensão efetiva na armadura ativa na seção transversal, após a consideração de todas as perdas de protensão;

$\mathrm{f}_{\mathrm{ps}}$ é o valor da tensão na armadura ativa na seção considerada, para o carregamento e no instante considerados;

$\mathrm{M}_{\mathrm{d}}=\mathrm{A}_{\mathrm{pd}} \cdot \mathrm{f}_{\mathrm{ps}} \cdot\left(\mathrm{d}_{\mathrm{p}}-\mathrm{y} / 2\right)+\mathrm{A}_{\mathrm{s}} \cdot \mathrm{f}_{\mathrm{y}} \cdot(\mathrm{d}-\mathrm{y} / 2)-\mathrm{A}_{\mathrm{s}} \cdot \mathrm{f}_{\mathrm{y}} \cdot\left(\mathrm{d}^{\prime}-\mathrm{y} / 2\right) \quad$ Eq. (A.13)

Observe que, na equação anterior, nesta equação, o equilíbrio é feito na altura da força $R_{c c}$ referente à parcela do concreto comprimido.

\section{i) Valores Minimos para Armadura Passiva Aderente}

Esses valores visam garantir à estrutura desempenho e ductilidade satisfatórios, assim como controlar a fissuração. Essa armadura dever ser constituída preferencialmente por barras de alta aderência ou por telas soldadas.

$\mathrm{Na}$ tabela abaixo estão mostrados os valores mínimos para armaduras passivas aderentes.

Tabela A.5 - Valores minimos para armaduras passivas aderentes

\begin{tabular}{|c|c|}
\hline Armadura & Protensão não aderente \\
\hline Armaduras Negativas & $\rho_{\mathrm{s}} \geq \rho_{\text {min }}-0,2 . \rho_{\mathrm{p}} \geq 0,67 . \rho_{\min }$ \\
\hline Armadura Positiva (bidirecionais) & $\rho_{\mathrm{s}} \geq \rho_{\min }-0,2 . \rho_{\mathrm{p}} \geq \rho_{\min }$ \\
\hline Armadura Positiva (Unidirecionais) & $\rho_{\mathrm{s}} \geq \rho_{\text {min }}-0,2 . \rho_{\mathrm{p}} \geq 0,5 . \rho_{\text {min }}$ \\
\hline
\end{tabular}

Fonte: Projeto de Revisão da NBR 6118-2001.

Onde,

$\rho_{\mathrm{S}}=\frac{A_{\mathrm{S}}}{\mathrm{b}_{\mathrm{h}}} \quad$ taxa de armadura passiva aderente;

$\rho_{\text {min }} \quad$ é o valor para armadura mínima para cada tipo de concreto;

O valor da armadura passiva negativa sobre os apoios para lajes lisas assume o valor mínimo de: 


$$
A_{S}=0,00075 \cdot h .1
$$

Com,

h sendo a altura da laje;

1 o vão médio da laje, medido na direção da armadura a ser colocada.

\section{A.5 - Estado Limite Último: Solicitações Tangenciais}

\section{A.5.1 - Cisalhamento}

A protensão introduz tensões de compressão que contribuem na redução das tensões de tração principais, tornando-as mais inclinadas em relação ao eixo da peça, de modo que as fissuras possuem menor inclinação do que no caso do concreto armado. Estas inclinações variam entre $15^{\circ}$ a $35^{\circ}$, exceto no caso de cargas concentradas, em que assumem até $45^{\circ}$ de inclinação.

De acordo com LEONHARDT, à medida que se aumenta o grau de protensão, menores são os esforços de cisalhamento, fazendo com que as forças de tração nos estribos se situem abaixo de sua tensão de escoamento até a ruína da peça.

De acordo com o Projeto de Revisão da NBR 6118-2001 o dimensionamento é baseado na analogia do modelo de treliça de banzos paralelos associados a mecanismos resistentes (parcela $V_{c}$ ). No concreto protendido, a força $\mathrm{V}_{\mathrm{sd}}$ de cálculo sofre uma redução devida ao efeito da força de protensão aplicada. Com isso, a tensão nos estribos reduz devido à inclinação das bielas comprimidas.

De acordo com o Projeto de Revisão da NBR 6118 - 2001, tem-se:

\section{i) Vigas Protendidas}

Verifica-se que ocorre uma redução da força cortante $\left(\mathrm{V}_{\mathrm{sd}}\right)$ por efeito do perfil do cabo na viga. Além disso, ocorre a redução da tensão nos estribos devido à inclinação das bielas comprimidas. A Proposta de Revisão da NBR 6118 - 2001 prescreve dois modelos de cálculo: o Modelo I, que admite a inclinação das bielas fixada em $\theta=45^{\circ}$ e o valor de $V_{c}$ constante; e 
o Modelo II, que admite uma inclinação variável entre $30^{\circ} \leq \theta \leq 45^{\circ}$ e o valor de $V_{c}$ reduzido. Mais adiante serão detalhados esses dois modelos.

De acordo com a Proposta de Revisão da Norma NBR 6118-2001, devem ser atendidas as seguintes condições:

a) A taxa geométrica para armadura transversal mínima com estribos para todos os elementos (com exceção de lajes, vigas-parede, consolos curtos e elementos de volume) deve ser:

$$
\rho_{\text {sw }}=\frac{A_{\text {sw }}}{b_{w} \cdot \operatorname{sisen} \alpha} \geq 0,2 \cdot \frac{f_{c t m}}{f_{y w k}}
$$

Onde:

$\mathrm{A}_{\mathrm{sw}} \quad$ é a área da seção transversal dos estribos;

s é o espaçamento segundo o eixo longitudinal do elemento;

$\alpha \quad$ é o ângulo em relação ao mesmo eixo;

$b_{\mathrm{w}} \quad$ é a largura media da alma do elemento;

$\mathrm{f}_{\mathrm{ctm}}$ é a resistência do concreto à tração direta média;

$\mathrm{f}_{\mathrm{ywk}}$ é a resistência característica ao escoamento da armadura transversal.

b) No valor de $V_{\text {sd }}$ deve ser considerado o efeito da força de protensão na sua direção e, quando este efeito for favorável, a armadura longitudinal de tração junto à face tracionada por flexão deve satisfazer à seguinte condição:

$$
A_{p} \cdot f_{\text {pyd }}+A_{s} \cdot f_{y d} \geq V_{s d}
$$

Onde:

$\mathrm{A}_{\mathrm{p}} \quad$ é a área da seção transversal da armadura ativa;

$\mathrm{f}_{\text {pyd }}$ é a resistência de escoamento do aço de armadura ativa de cálculo;

$A_{s} \quad$ é a área da seção transversal da armadura passiva

$\mathrm{f}_{\mathrm{yd}}$ é a resistência de escoamento do aço de armadura passiva de cálculo;

$\mathrm{V}_{\text {sd }} \quad$ é a força cortante solicitante. 
c) Resistência

A resistência de uma viga ao esforço cortante é garantida quando as seguintes condições são verificadas simultaneamente:

- Quando a força solicitante de cálculo $\left(\mathrm{V}_{\mathrm{sd}}\right)$ for inferior a força cortante resistente de cálculo relativo ao esmagamento das diagonais comprimidas do concreto $\left(\mathrm{V}_{\mathrm{Rd} 2}\right)$;

$$
\mathrm{V}_{\text {sd }}<\mathrm{V}_{\mathrm{Rd} 2}
$$

- A força solicitante de cálculo $\left(\mathrm{V}_{\mathrm{sd}}\right)$ for inferior à força resistente de cálculo relativa à tração diagonal do concreto $\left(\mathrm{V}_{\mathrm{Rd} 3}\right)$ que é a soma das forças resistidas pelos mecanismos complementares ao de treliça $\left(V_{C}\right)$ e pela parcela absorvida pela armadura transversal ( $\left.\mathrm{V}_{\mathrm{Sw}}\right)$;

$$
\mathrm{V}_{\mathrm{sd}}<\mathrm{V}_{\mathrm{Rd} 3}=\mathrm{V}_{\mathrm{c}}+\mathrm{V}_{\mathrm{sw}}
$$

\section{i.1) Modelo de Cálculo I}

Neste modelo, a compressão diagonal é assegurada pela verificação da seguinte equação:

$$
\mathrm{V}_{\mathrm{Rd} 2}=0,27 \cdot \alpha_{\mathrm{v}} \cdot \mathrm{f}_{\mathrm{cd}} \cdot \mathrm{b}_{\mathrm{w}} \cdot \mathrm{d}
$$

Onde:

$\alpha_{\mathrm{v}}=\left(1-\frac{\mathrm{f}_{\mathrm{ck}}}{250}\right)$ com $\mathrm{f}_{\mathrm{ck}}$ em MPa.

E a segurança contra a ruína pela tração diagonal é determinada pelo cálculo da armadura transversal:

$$
V_{\mathrm{Sw}}=\left(\frac{\mathrm{A}_{\mathrm{sw}}}{\mathrm{s}}\right) \cdot 0,9 \cdot \mathrm{d} \cdot \mathrm{f}_{\mathrm{ywd}} \cdot(\operatorname{sen} \alpha+\cos \alpha)
$$

Onde:

$\mathrm{A}_{\mathrm{sw}}$ é a armadura transversal para resistir à ruína por tração diagonal;

s é o espaçamento entre os elementos de armadura transversal;

$\alpha \quad$ é o ângulo de inclinação da armadura transversal em relação ao eixo longitudinal do elemento, podendo variar de $45^{\circ}$ a $90^{\circ}$;

$\mathrm{f}_{\mathrm{ywd}}$ é a tensão na armadura transversal passiva, não tomando valor superior a $435 \mathrm{MPa}$; 
d é a altura útil da seção transversal.

$\mathrm{V}_{\mathrm{C}}=0 \quad$ na flexo-tração com linha neutra fora da seção;

$\mathrm{V}_{\mathrm{C}}=\mathrm{V}_{\mathrm{Co}} \quad$ na flexão simples e na flexo-tração com linha neutra na seção;

$\mathrm{V}_{\mathrm{C}}=\mathrm{V}_{\mathrm{co}} \cdot\left(1+\frac{\mathrm{M}_{\mathrm{o}}}{\mathrm{M}_{\mathrm{d}}}\right) \leq 2 \cdot \mathrm{V}_{\text {co }}$ na flexo-compressão.

Com,

$\mathrm{v}_{\mathrm{co}}=0,6 . \mathrm{f}_{\mathrm{ctd}} \cdot \mathrm{b}_{\mathrm{w}} \cdot \mathrm{d} \quad \mathrm{e}, \quad \mathrm{f}_{\mathrm{ctd}}=\frac{\mathrm{f}_{\mathrm{ctk}, \mathrm{inf}}}{\gamma_{\mathrm{c}}}$

Onde:

$\mathrm{f}_{\mathrm{ctd}} \quad$ é a resistência de cálculo do concreto à tração;

$\mathrm{M}_{\mathrm{d}} \quad$ corresponde ao momento fletor máximo aplicado na seção;

$\mathrm{M}_{\mathrm{o}}$ é o momento fletor que anula a tensão normal de compressão na borda da seção tracionada, com o valor de $\gamma_{p}=0,9$;

$$
\mathrm{M}_{\mathrm{O}}=\gamma_{\mathrm{p}} \cdot \mathrm{P}_{\infty} \cdot\left(\frac{\mathrm{W}_{1}}{\mathrm{~A}_{\mathrm{c}}}+\mathrm{e}_{\mathrm{p}}\right)
$$

$\mathrm{W}_{1}$ é o módulo resistente da seção transversal de concreto com relação à borda inferior;

$\mathrm{A}_{\mathrm{c}} \quad$ é a área da seção transversal de concreto;

$\mathrm{e}_{\mathrm{p}} \quad$ é a excentricidade da armadura ativa na seção transversal;

$\mathrm{P}_{\infty} \quad$ é a força de protensão após as perdas progressivas.

\section{i.2) Modelo de Cálculo II}

A segurança da compressão diagonal da biela comprimida é garantida pela seguinte expressão:

$\mathrm{V}_{\mathrm{Rd} 2}=0,54 \cdot \alpha_{\mathrm{V}} \cdot \mathrm{f}_{\mathrm{cd}} \cdot \mathrm{b}_{\mathrm{w}} \cdot \mathrm{d} \cdot \operatorname{sen}^{2} \theta \cdot(\operatorname{cotg} \alpha+\operatorname{cotg} \theta)$

Eq. (A.22)

Onde:

$\theta \quad$ é o ângulo de inclinação das bielas comprimidas. 
E o valor da armadura transversal é dado por:

$$
\mathrm{V}_{\mathrm{Sw}}=\left(\frac{\mathrm{A}_{\mathrm{Sw}}}{\mathrm{s}}\right) \cdot 0,9 \cdot \mathrm{d} \cdot \mathrm{f}_{\mathrm{ywd}} \cdot(\operatorname{cotg} \alpha+\operatorname{cotg} \theta) \cdot \operatorname{sen} \alpha
$$

Com,

$\mathrm{V}_{\mathrm{C}}=0 \quad$ na flexo-tração com linha neutra fora da seção;

$\mathrm{V}_{\mathrm{C}}=\mathrm{V}_{\mathrm{c} 1} \quad$ na flexão simples e na flexo-tração com linha neutra na seção;

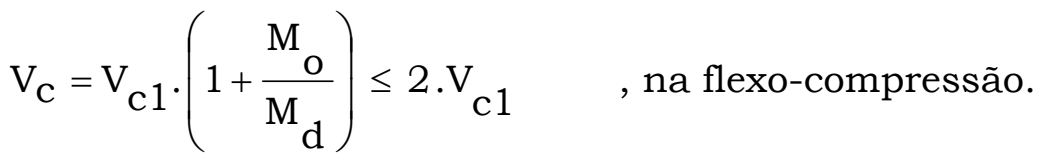

E ainda,

$\mathrm{V}_{\mathrm{c} 1}=\mathrm{V}_{\mathrm{co}} \quad$, quando $\mathrm{V}_{\mathrm{d}} \leq \mathrm{V}_{\mathrm{co}}$

$\mathrm{V}_{\mathrm{c} 1}=0 \quad$, quando $\mathrm{V}_{\mathrm{d}}=\mathrm{V}_{\mathrm{Rd} 2}$.

Interpolando-se linearmente para valores intermediários.

\section{ii) Lajes sem armadura para força cortante}

Deve-se verificar a seguinte condição:

$$
\tau_{\mathrm{Rd} 1} \geq \frac{\mathrm{V}_{\mathrm{sd}}}{\mathrm{b}_{\mathrm{w}} \cdot \mathrm{d}}
$$

Onde:

$\mathrm{V}_{\text {sd }}$ é a força cortante de cálculo com consideração da componente vertical da força de protensão;

$$
\tau_{\operatorname{Rd} 1}=\sqrt[3]{f_{c k}} \cdot\left(1+50 \cdot \rho_{l}\right) \cdot(1,6-d) \cdot \alpha_{q}
$$

Onde:

$\alpha_{\mathrm{q}} \quad$ varia de acordo com o tipo de carregamento;

$\alpha_{\mathrm{q}}=\frac{0,14}{\left(1-3 \cdot \frac{\mathrm{d}}{1}\right)} \quad$ para cargas distribuídas, podendo-se adotar um valor de 0,17 quando $\mathrm{d} \leq \frac{1}{20}$, sendo 1 o menor vão teórico das 
lajes apoiadas ou o dobro do comprimento teórico do balanço;

$(1,6-d) \geq 1 \quad$ com d sendo a altura útil da seção em metros;

$\left(1+50 . \rho_{l}\right) \leq 2 \quad$ onde $\rho_{l}$ é a taxa geométrica de armadura longitudinal aderente a uma distância $2 \mathrm{~d}$ da face do apoio.

\section{iii) Lajes com armadura para força cortante}

Aplicam-se os mesmos critérios estabelecidos no item i).

Quando a laje apresentar espessura superior a $35 \mathrm{~cm}$, a resistência dos estribos pode ser adotada como $\mathrm{f}_{\mathrm{ywd}} \leq 435 \mathrm{Mpa}$ e, se apresentar espessura até $15 \mathrm{~cm}$, a resistência dos estribos é limitada em $250 \mathrm{MPa}$, podendo-se interpolar linearmente entre esses dois valores.

\section{A.5.2 - Punção}

O fenômeno da punção ocorre em lajes apoiadas diretamente sobre os pilares, sem a presença de vigas.

A Projeto de Revisão da NBR 6118-2001, basicamente uma adaptação do Código Modelo CEB/90, estabelece a formação de três perimetros criticos a serem analisados, para se obterem níveis seguros de utilização e de ruptura, que serão vistos posteriormente.

Para lajes sem armadura de punção, são necessárias duas verificações em duas superficies críticas, sendo uma, na face do pilar e a outra, a uma distância $2 \mathrm{~d}$ da sua face.

Para lajes com armadura de punção, devem ser feitas as duas verificações nas superfícies críticas e ainda, deve se analisado um outro perímetro crítico, localizado além da região armada para o combate à punção.

A punção varia de acordo com vários fatores como: geometria da laje e dos pilares, disposição dos pilares, tipo de carregamento, sistema de cargas unidirecional ou bidirecional, dentre outras.

Existe três tipos de ligação de pilares em pavimentos de laje lisa: pilar interno, pilar de borda e pilar de extremidade (Ver figura A.8). 


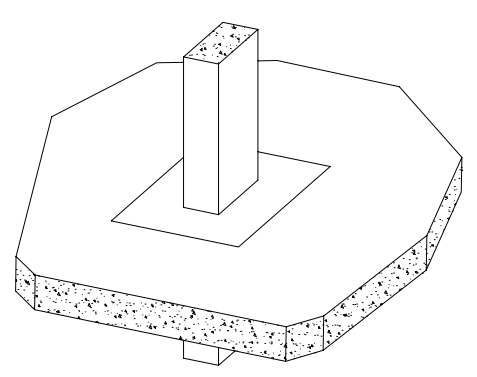

Pilar interno

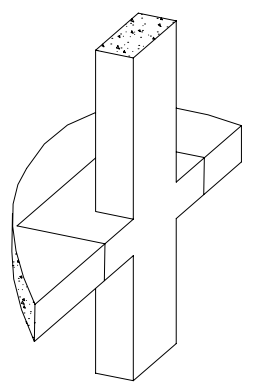

Pilar de borda

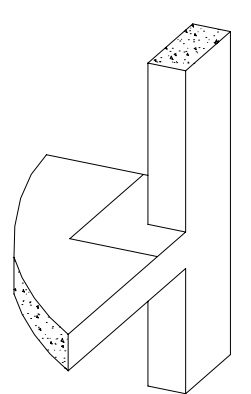

Pilar de extremidade

Figura A.8 - Tipos de ligação de pilar com a laje

Cada uma destas ligações possui características próprias com sua geometria e tipo de ruptura.

A figura A.9 ilustra os perímetros críticos e sua verificação nos vários tipos de ligação laje-pilar.

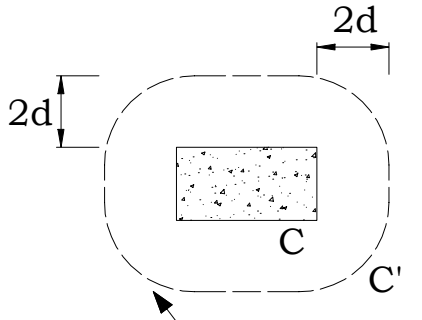

Perimetro crítico

(Pilar interno)

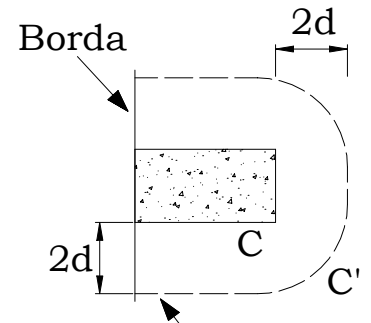

Perímetro crítico

(Pilar de borda)

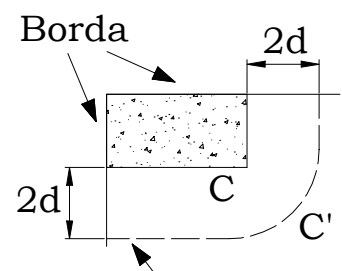

Perímetro crítico

(Pilar de canto)

Figura A.9 - Perímetros críticos

\section{i) Verificação da tensão na superficie critica na face do pilar}

Este cálculo, realizado para o Estado Limite Último, é associado à compressão da biela comprimida de concreto, e visa, quantificar a máxima resistência que a ligação pode apresentar.

A tensão resistente de cálculo é dada pela seguinte expressão:

$$
{ }^{\tau_{R d} 2}=0,27 \cdot \alpha_{\mathrm{v}} \cdot f_{\mathrm{cd}}
$$

Onde:

$\alpha_{\mathrm{V}}=\left(1-\frac{\mathrm{f}_{\mathrm{ck}}}{250}\right) \operatorname{com} \mathrm{f}_{\mathrm{ck}}$ em MPa. 


\section{ii) Verificação da tensão na superficie crítica a $2 \mathrm{~d}$ da face do pilar}

Neste caso, deve-se tomar uma distância igual a $2 \mathrm{~d}$ da face do pilar, verificando se há ou não a presença de armadura de punção.

Para lajes sem armadura de punção:

$$
\tau_{\mathrm{Rd}}=0,13 \cdot(1+\sqrt{20 / \mathrm{d}}) \cdot \sqrt[3]{100 \cdot \rho \cdot \mathrm{f}_{\mathrm{ck}}}
$$

Para lajes com armadura de punção:

$$
\begin{aligned}
\tau_{\mathrm{Rd}}= & 0,10 \cdot(1+\sqrt{20 / \mathrm{d}}) \cdot \sqrt[3]{100 \cdot \rho \cdot \mathrm{f}_{\mathrm{ck}}}+ \\
& 1,5 \cdot\left(\mathrm{d} / \mathrm{s}_{\mathrm{r}}\right) \cdot\left(\frac{\mathrm{A}_{\mathrm{sw}} \cdot \mathrm{f}_{\mathrm{ywd}} \cdot \operatorname{sen} \alpha}{\mathrm{u}_{1} \cdot \mathrm{d}}\right)
\end{aligned}
$$

Onde,

d é a altura útil da laje, em $\mathrm{cm}$;

A corresponde a área de armadura de punção localizada num contorno paralelo ao perímetro crítico adotado;

$\mathrm{s}_{\mathrm{r}} \quad$ é o espaçamento radial, sendo adotados valores inferiores $0,75 \mathrm{~d}$;

$\alpha \quad$ é o ângulo entre a armadura e o plano médio da laje (em geral, $\alpha=$ 90);

$f_{\text {ywd }}$ corresponde a resistência de cálculo da armadura de punção, sendo adotados valores não superires a $300 \mathrm{MPa}$ para conectores e 250 MPa para estribos (para lajes com espessura até 15,0 cm). Para lajes com espessura superior a $35,0 \mathrm{~cm}$, pode ser utilizada a resistência para estribos $\leq 435 \mathrm{MPa}$, permitindo-se, a interpolação linear para casos em que se tenham espessuras entre esses valores;

$\rho \quad$ é a taxa geométrica de armadura de flexão aderente (armadura não aderente deve ser desprezada). $\rho=\sqrt{\rho_{\mathrm{x}} \cdot \rho_{\mathrm{y}}}$;

$\mathrm{f}_{\mathrm{ck}} \quad$ é a resistência característica à compressão do concreto. 


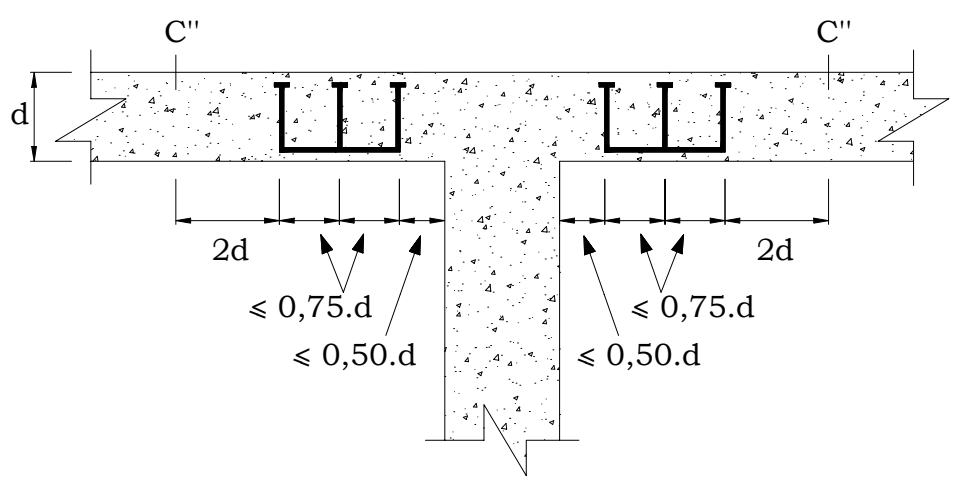

Figura A.10 - Disposição da armadura de punção (adaptado do Projeto de Revisão da NBR 6118-2001)

\section{a) Pilar Interno}

Quando o carregamento for considerado simétrico, tem-se que a tensão no contorno C' (região compreendida entre o perímetro C e distante 2 d deste contorno) é:

$$
\tau_{\mathrm{Sd}}=\frac{\mathrm{F}_{\mathrm{Sd}}}{\text { u.d }}
$$

Onde,

$\tau_{\mathrm{Sd}} \quad$ é a tensão atuante de cálculo;

u é o perímetro crítico do contorno C';

d é a altura útil da laje ao longo do contorno crítico C' que equivale à média das alturas úteis nas duas direções $\mathrm{X}$ e $\mathrm{Y}$;

$$
\mathrm{d}=\frac{\mathrm{d}_{\mathrm{x}}+\mathrm{d}_{\mathrm{y}}}{2}
$$

$\mathrm{F}_{\mathrm{Sd}} \quad$ corresponde a força aplicada (ou reação) de cálculo.

No caso de haver transferência de momento da laje para o pilar em uma direção, tem-se:

$$
\tau_{\text {Sd }}=\frac{\mathrm{F}_{\mathrm{Sd}}}{\text { u.d }}+\frac{\mathrm{K} \cdot \mathrm{M}_{\mathrm{Sd}}}{\mathrm{W}_{\mathrm{p}} \cdot \mathrm{d}}
$$

Onde, 
$\mathrm{K}$ é o coeficiente que fornece a parcela do $\mathrm{M}_{\mathrm{Sd}}$ transmitida ao pilar por cisalhamento, dependendo da relação $\mathrm{c}_{1} / \mathrm{c}_{2}$, onde, $\mathrm{c}_{1}$ é a dimensão do pilar paralela à excentricidade da força e $c_{2}$ é a dimensão do pilar perpendicular à excentricidade.

Tabela A.6 - Valores de K

\begin{tabular}{|c||c|c|c|c||}
\hline $\mathrm{c}_{1} / \mathrm{c}_{2}$ & $\mathbf{0 , 5}$ & $\mathbf{1 , 0}$ & $\mathbf{2 , 0}$ & $\mathbf{3 , 0}$ \\
\hline $\mathrm{K}$ & 0,45 & 0,60 & 0,70 & 0,80 \\
\hline
\end{tabular}

Fonte: Projeto de Revisão da NBR 6118-2001.

$\mathrm{M}_{\mathrm{Sd}}$ é o momento de cálculo transferido da laje para o pilar;

$\mathrm{W}_{\mathrm{p}} \quad$ é o parâmetro referente ao perímetro crítico $\mathrm{u}$, definido como módulo de resistência plástica do perímetro crítico, onde, para o caso de pilares retangulares e circulares vale:

Pilar retangular: $\quad \mathrm{w}_{\mathrm{p}}=\frac{\mathrm{c}_{1}{ }^{2}}{2}+\mathrm{c}_{1} \cdot \mathrm{c}_{2}+4 \cdot \mathrm{c}_{2} \cdot \mathrm{d}+16 \cdot \mathrm{d}^{2}+2 \cdot \pi \cdot \mathrm{d} \cdot \mathrm{c}_{1}$

Pilar circular: $\quad \mathrm{W}_{\mathrm{p}}=(\mathrm{D}+4 . \mathrm{d})^{2}$

Onde,

D é o diâmetro do pilar.

No caso em que a força aplicada apresenta excentricidade nas duas direções, isto é, ocorre transferência de momento da ligação laje-pilar nas duas direções, tem-se:

$$
\tau_{\text {Sd }}=\frac{F_{S d}}{\text { u.d }}+\frac{K_{1} \cdot M_{S d 1}}{W_{p 1} \cdot d}+\frac{K_{2} \cdot M_{S d 2}}{W_{p 2} \cdot d}
$$




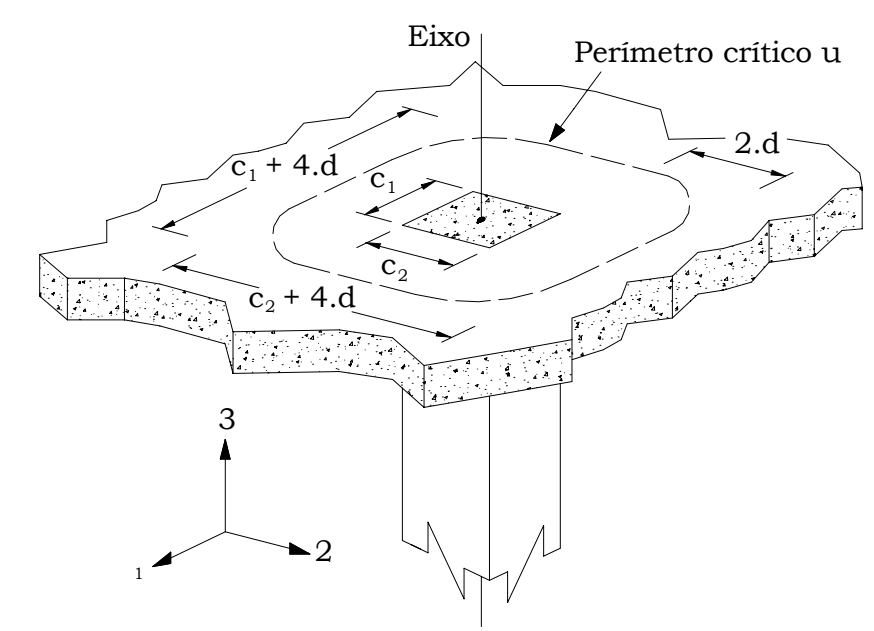

Figura A.11 - Características do pilar interno

\section{b) Pilar de Borda}

Quando, sobre a ligação, não agir momento no plano paralelo à borda livre, tem-se:

$$
\tau_{\mathrm{Sd}}=\frac{\mathrm{F}_{\mathrm{Sd}}}{\mathrm{u} \cdot \mathrm{d}}+\frac{\mathrm{K}_{1} \cdot \mathrm{M}_{\mathrm{Sd}}}{\mathrm{W}_{\mathrm{p} 1} \cdot \mathrm{d}}
$$

Onde,

$\mathrm{W}_{\mathrm{p} 1}$ é o módulo de resistência plástica perpendicular à borda livre, calculado para o perímetro $\mathrm{u}$;

$\mathrm{W}_{\mathrm{p} 1}=\frac{\mathrm{c}_{1}{ }^{2}}{2}+\frac{\mathrm{c}_{1} \cdot \mathrm{c}_{2}}{2}+2 \cdot \mathrm{c}_{2} \cdot \mathrm{d}+8 \cdot \mathrm{d}^{2}+\pi \cdot d \cdot \mathrm{c}_{1}$

$\mathrm{M}_{\mathrm{Sd}}=\left(\mathrm{M}_{\mathrm{Sd} 1}-\mathrm{M}_{\mathrm{Sd}}{ }^{*}\right) \geq 0 ; \quad \operatorname{com}, \mathrm{M}_{\mathrm{Sd}}{ }^{*}=\mathrm{F}_{\mathrm{Sd}} \cdot \mathrm{e}^{*}$

Onde,

$\mathrm{e}^{*} \quad$ é a excentricidade do perímetro crítico reduzido;

$\mathrm{e}^{*}=\frac{\mathrm{c}_{1} \mathrm{a}-\mathrm{a}^{2}+\frac{\mathrm{c}_{1} \cdot \mathrm{c}_{2}}{2}+2 \cdot d \cdot \mathrm{c}_{2}+8 \cdot \mathrm{d}^{2}+\pi \cdot d \cdot \mathrm{c}_{1}}{2 \cdot \mathrm{a}+\mathrm{c}_{2}+2 \cdot \pi \mathrm{d}}$

Eq. (A.37) 


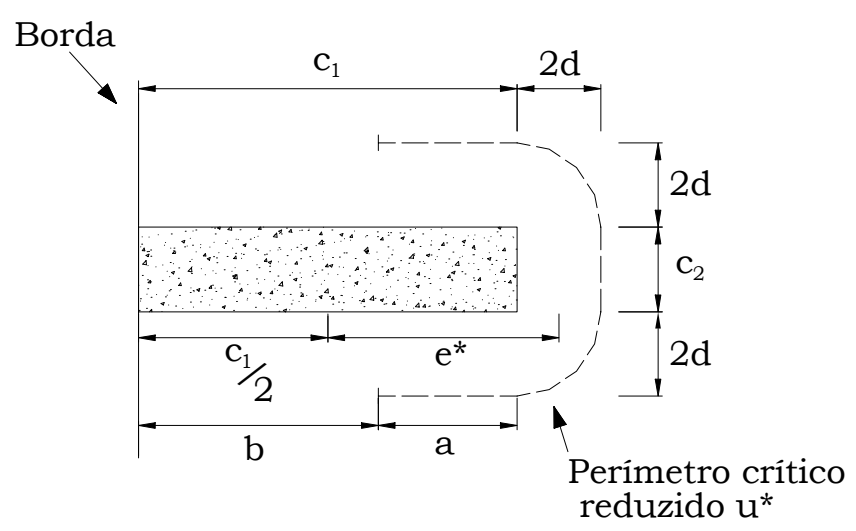

Figura A.12 - Excentricidade do perimetro crítico reduzido

(adaptado do Projeto de Revisão da NBR 6118-2001)

$\mathrm{M}_{\mathrm{Sd}^{*}}{ }^{*}$ é o momento de cálculo resultante da excentricidade do perímetro crítico reduzido $\mathrm{u}^{*}$ em relação ao centro do pilar;

$\mathrm{M}_{\mathrm{Sd} 1}$ é o momento de cálculo perpendicular à borda livre;

$\mathrm{K}_{1} \quad$ varia de acordo com a tabela A.6.

Do mesmo modo, quando houver momento atuante nas duas direções, tem-se:

$$
\tau_{\mathrm{Sd}}=\frac{\mathrm{F}_{\mathrm{Sd}}}{\mathrm{u}^{*} \cdot \mathrm{d}}+\frac{\mathrm{K}_{1} \cdot \mathrm{M}_{\mathrm{Sd}}}{\mathrm{W}_{\mathrm{p} 1} \cdot \mathrm{d}}+\frac{\mathrm{K}_{2} \cdot \mathrm{M}_{\mathrm{Sd} 2}}{\mathrm{~W}_{\mathrm{p} 2} \cdot \mathrm{d}}
$$

Onde,

$\mathrm{M}_{\mathrm{Sd} 2}$ é o momento de cálculo no plano paralelo à borda livre;

$\mathrm{W}_{\mathrm{p} 2}$ é o módulo de resistência plástica, paralelo à borda livre, calculado para o perímetro $\mathrm{u}$;

$\mathrm{w}_{\mathrm{p} 2}=\frac{\mathrm{c}_{2}{ }^{2}}{4}+\mathrm{c}_{1} \cdot \mathrm{c}_{2}+4 \cdot \mathrm{c}_{1} \cdot \mathrm{d}+8 \cdot \mathrm{d}^{2}+\pi \cdot \mathrm{d} \cdot \mathrm{c}_{2}$

$\mathrm{K}_{1}$ varia conforme a tabela A.6, porém, deve-se substituir a relação $\mathrm{c}_{1} / \mathrm{c}_{2}$ por $\mathrm{c}_{2} / 2 \mathrm{c}_{1}$. 

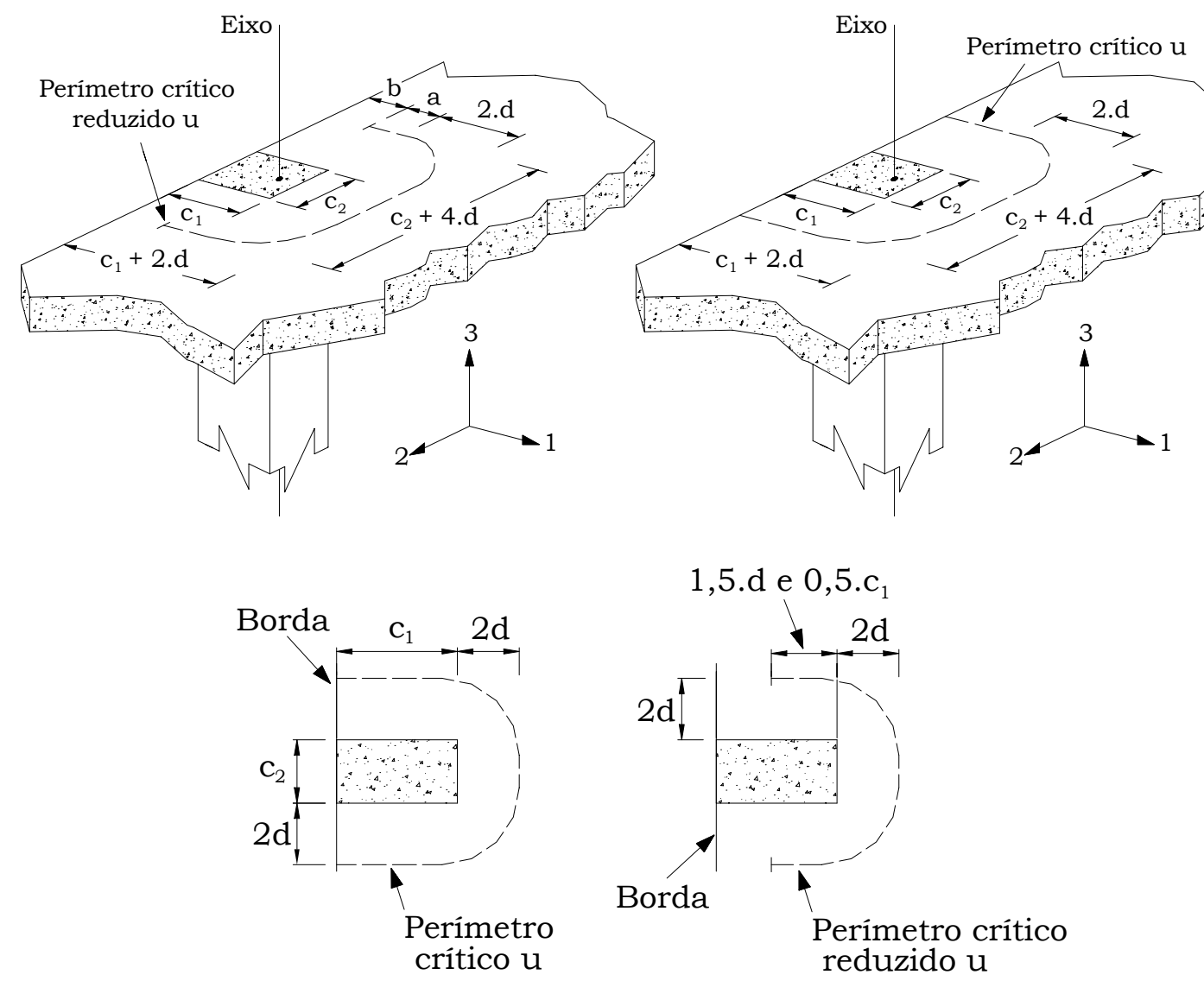

Figura A.13 - Características do pilar de borda

(adaptado do Projeto de Revisão da NBR 6118-2001)

\section{c) Pilar de canto}

O pilar de canto ou de extremidade apresenta duas bordas livres e, nesse caso, faz-se a verificação separada de cada uma delas, considerando o momento fletor perpendicular à borda livre adotada.

Neste caso, $K$ deve ser calculado em função da relação $c_{1} / \mathrm{c}_{2}$ que são os mesmos da tabela A.6.

A tensão é calculada pela seguinte expressão:

$$
\tau_{\text {Sd }}=\frac{F_{S d}}{u . d}+\frac{K_{1} \cdot M_{S d}}{W_{p 1} \cdot d}
$$

Onde, 


$$
\begin{aligned}
& \mathrm{W}_{\mathrm{p} 1}=\frac{\mathrm{c}_{1}{ }^{2}}{4}+\frac{\mathrm{c}_{1} \cdot \mathrm{c}_{2}}{2}+2 \cdot \mathrm{c}_{2} \cdot \mathrm{d}+4 \cdot \mathrm{d}^{2}+\frac{\pi \cdot d \cdot \mathrm{c}_{1}}{2} \\
& \mathrm{M}_{\mathrm{Sd}}=\left(\mathrm{M}_{\mathrm{Sd} 1}-\mathrm{M}_{\mathrm{Sd}}{ }^{*}\right) \geq 0 ; \quad \mathrm{com}, \mathrm{M}_{\mathrm{Sd}}{ }^{*}=\mathrm{F}_{\mathrm{Sd}} \cdot \mathrm{e}^{*} \\
& \mathrm{e}^{*}=\frac{\mathrm{c}_{1} \mathrm{a}_{1}-\mathrm{a}_{1}{ }^{2}+\mathrm{c}_{1} \mathrm{a}_{2}+4 \cdot d \cdot \mathrm{a}_{2}+8 \cdot \mathrm{d}^{2}+\pi \cdot d \cdot \mathrm{c}_{1}}{2 \cdot\left(\mathrm{a}_{1}+\mathrm{a}_{2}+\pi \cdot d\right)}
\end{aligned}
$$

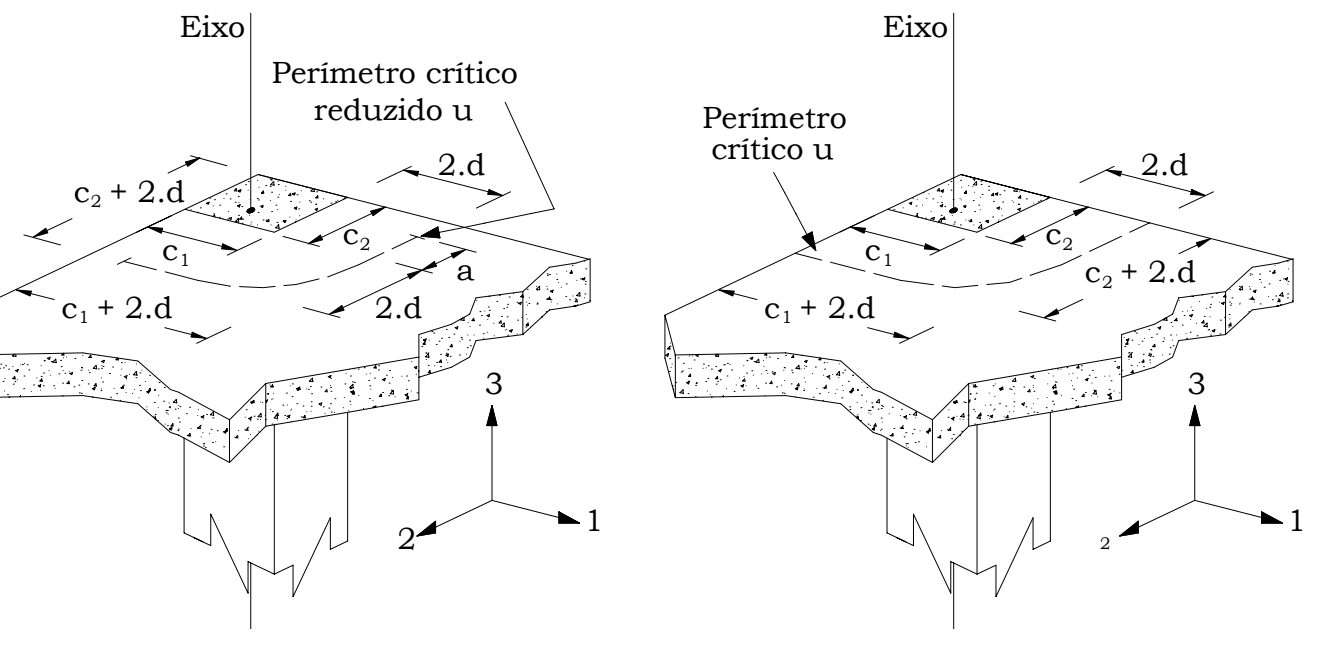

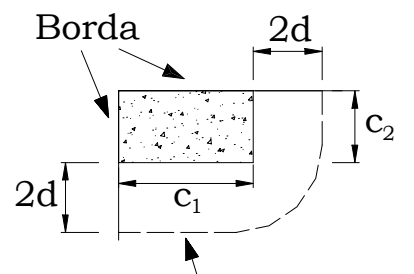

Perímetro crítico u

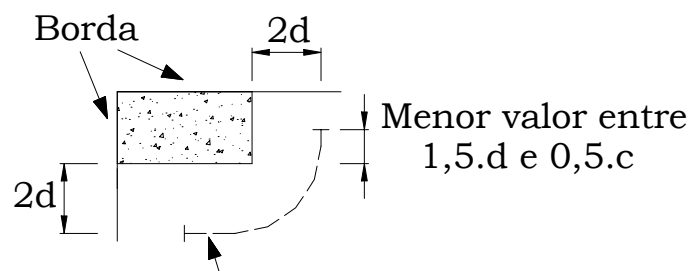

Perimetro crítico reduzido u

Figura A.14 - Características do pilar de extremidade (adaptado do Projeto de Revisão da NBR 6118-2001)

\section{iii) Consideração da força de protensão}

Neste caso, é feito um equilíbrio entre a tensão de cisalhamento na superfície crítica a 2.d da face do pilar com a tensão devida ao efeito dos cabos inclinados que atravessam a superficie crítica e passam a menos de d/2 da face do pilar.

$$
{ }^{\tau} \text { Sd,ef. }{ }^{=}{ }_{\mathrm{Sd}}{ }^{-\tau} \mathrm{Pd}
$$


$\mathrm{Na}$ última expressão $\tau_{\mathrm{Pd}}$ é a tensão devida ao efeito dos cabos de protensão inclinados que atravessam o contorno considerado e passam a menos de d/2 da face do pilar. Essa tensão pode ser estimada por:

$$
\tau_{\mathrm{Pd}}=\frac{\sum \mathrm{P}_{\text {kinf }, \mathrm{i}} \cdot \operatorname{sen} \alpha_{\mathrm{i}}}{\text { u.d }}
$$

Onde,

$\Sigma \mathrm{P}_{\text {kinf,i }}$ é a força de protensão no cabo i;

$\alpha_{\mathrm{i}} \quad$ é a inclinação do cabo i em relação ao plano da laje no contorno considerado;

u é o perimetro crítico do contorno considerado, em que se determinam os valores de $\tau_{\mathrm{Sd} \text {,ef. }}$ e $\tau_{\mathrm{Sd}}$;

d é a altura útil da laje no contorno considerado.

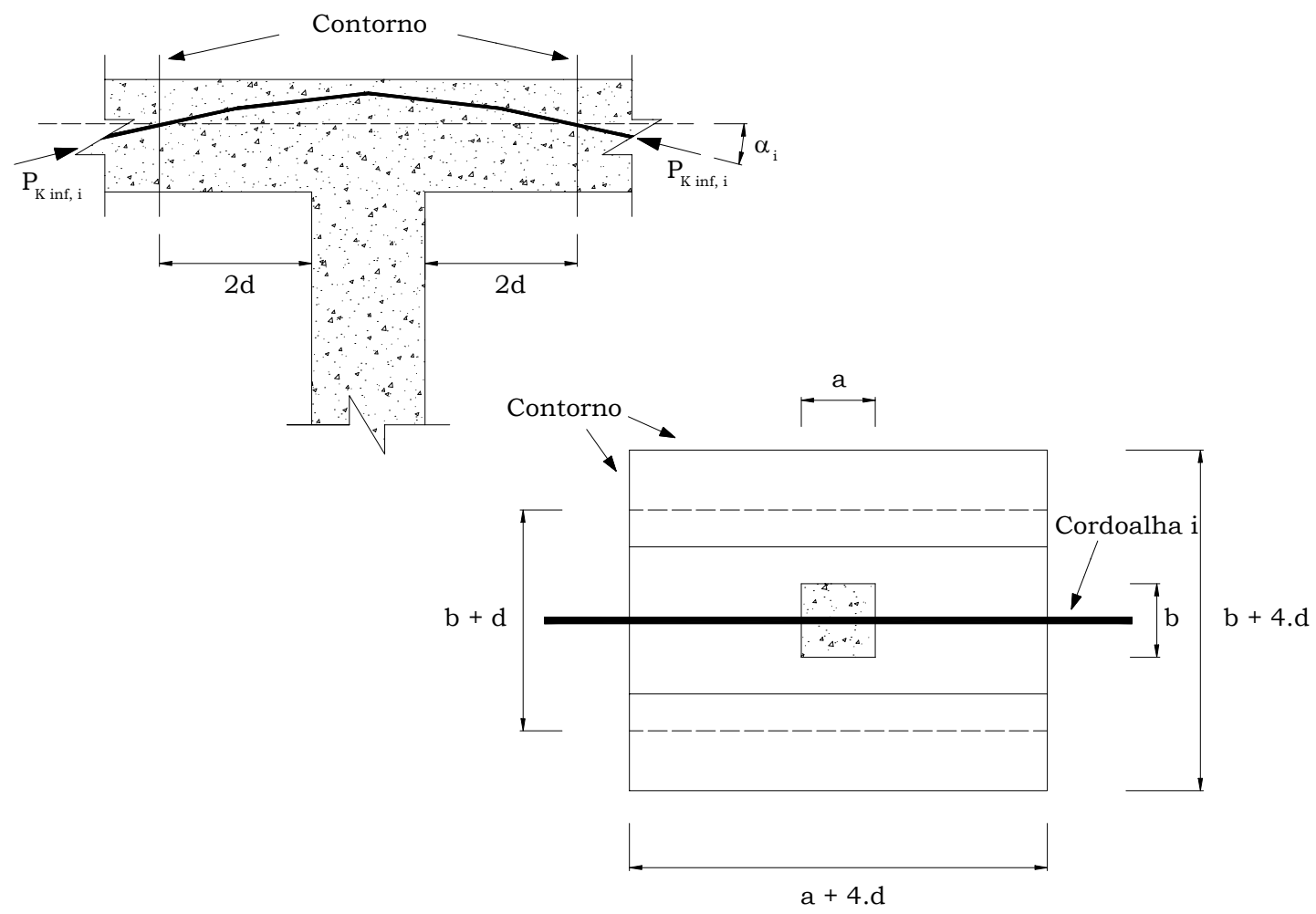

Figura A.15 - Efeito favorável da inclinação dos cabos (adaptado do Projeto de Revisão da NBR 6118-2001) 


\section{ANEXO B \\ Prescrições do ACI 423-89 e do ACI 318-99}

O ACI 423-89 determina que devem ser atendidos os requisitos do ACI 318-99 para Estado Limite de Serviço de acordo com a análise elástica da estrutura, considerando as reações, momentos, esforços cortantes, forças axiais devidas à protensão, deformação lenta, retração, mudança de temperatura, deformação axial entre outras.

As combinações de ação para os estados limites adotados são:

- Para o Estado Limite de Serviço:

$$
\text { 1.DL + 1.LL + 1.PT }
$$

- Para o Estado Limite Último:

$$
1,4 \cdot \mathrm{DL}+1,7 \cdot \mathrm{LL}+1 . \mathrm{HYP}
$$

Onde:

DL é a carga permanente (dead load);

LL é a carga acidental (live load);

PT é a carga de protensão (post-tensioning);

HYP é a parcela referente aos hiperestáticos da protensão.

Para projeto [AALAMI (2000)], a pré-compressão mínima para lajes é de 1,0 MPa.

De acordo com o ACI 423-89, o pavimento é dividido em duas categorias, a seguir apresentados.

\section{B.1 - Sistemas Unidirecionais (One-Way System)}

Baseia-se onde existe um caminho de carga, predominante, que transfere as forças aplicadas ao pavimento aos apoios. 


\section{i) Armadura Passiva Minima}

Do mesmo modo que na NBR 6118-2001, esta quantidade mínima de armadura visa garantir a segurança da estrutura contra uma ruptura frágil e controle de fissuração para elementos com protensão não aderente. A inclusão dessa armadura visa melhorar as condições de serviço e promover um caminho alternativo para as cargas neste sistema unidirecional.

$$
A_{s}=0,004 . A
$$

Onde:

As é a área de armadura não protendida;

A é a área compreendida entre a face com tensão de tração e o centro de gravidade da seção bruta.

Esta quantidade de armadura leva a um nível de tensões no concreto variando de $0,75 \cdot \sqrt{f_{c k}}(e m \mathrm{MPa})$ até $1,0 \cdot \sqrt{\mathrm{f}_{\mathrm{ck}}}(\mathrm{em} \mathrm{MPa})$.

\section{ii) Espaçamento das cordoalhas}

Para lajes unidirecionais, a tabela B.1 mostra as disposições mais utilizadas (para barras de 12,7 mm de diâmetro).

Tabela B.1 - Espaçamentos Recomendados pelo ACI 423-89 para armadura passiva aderente

\begin{tabular}{||c|c|c||}
\hline Espessura (cm) & Momento Positivo & Momento Negativo \\
\hline \hline 11,4 & $53,30 \mathrm{~cm}$ & $53,30 \mathrm{~cm}$ \\
\hline 20,3 & $30,50 \mathrm{~cm}$ & $30,50 \mathrm{~cm}$ \\
\hline
\end{tabular}

No caso de cordoalhas não aderentes, o espaçamento máximo é da ordem de seis a oito vezes a espessura da laje. 


\section{B.2 - Sistemas Bidirecionais (Two-Way System)}

Baseia-se no arranjo onde existem dois caminhos de carga que transferem a força aplicada ao pavimento aos apoios.

\section{i) Armadura Passiva Minima}

O ACI 423-89 estabelece que a quantidade mínima de armadura para regiões de momento negativo é dada por:

$$
A_{S}=0,00075 \cdot h .1
$$

Onde:

1 é o vão na direção paralela ao da armadura determinada;

h é a espessura da laje.

A armadura passiva é necessária em regiões de momentos positivos quando a tensão no concreto, ultrapassar um valor de serviço de $0,17 \cdot \sqrt{f_{c k}}$ (em MPa). A quantidade de armadura necessária é dada pela equação a seguir:

$$
A_{s}=\frac{N_{c}}{0,5 \cdot f_{y}}
$$

Onde:

$\mathrm{N}_{\mathrm{C}}$ é a força no concreto devida à carga permanente mais a carga acidental;

$\mathrm{f}_{\mathrm{y}}$ é a tensão de escoamento da armadura passiva que não deve ultrapassar o valor limite de $414 \mathrm{MPa}$.

\section{ii) Espaçamento e Distribuição das Cordoalhas e da Armadura Passiva}

A quantidade e a disposição das cordoalhas juntamente com a localização da armadura aderente aumentam a capacidade resistente de lajes protendidas bidirecionais tanto para a flexão quanto para o cisalhamento. 
O espaçamento máximo permitido para cordoalhas isoladas ou em grupos é de 8 vezes a espessura da laje ou o valor máximo de 1,52 m. Além disso, as cordoalhas devem garantir um nível mínimo de tensões no concreto da ordem de 0,862 MPa.

A disposição de cordoalhas mais usual e mais recomendada é a distribuição em faixas. É um processo muito interessante, pois é mais econômico e ainda simplifica a execução da cordoalha na obra.

De acordo com o ACI 423-89, é necessário que pelo menos dois cabos passem pela seção crítica do pilar em cada direção (devido ao esforço cortante).

Outras recomendações são dadas:

- Para ligações laje-pilar, deve-se ter pelo menos quatro barras em cada direção em regiões de momento negativo;

- Armadura aderente deve ser colocada a uma distância de no máximo 1,5.h das faces do pilar, onde o máximo espaçamento, neste caso, é de $30,50 \mathrm{~cm}$;

- O comprimento mínimo para barras para combater o momento negativo é de no mínimo 1/6 do vão livre de cada lado do apoio;

- A armadura passiva positiva deve ter pelo menos $1 / 3$ do comprimento do vão livre com as barras concentradas na região de momento positivo;

\section{B.3 - Força Cortante e Punção}

O ACI 318-99 prescreve que, para o sistema bidirecional, deve-se estabelecer um perímetro crítico $b_{0}$ que consiste em uma linha contínua ao longo da laje a cerca de $\mathrm{d} / 2$ a partir de: faces dos pilares, de locais com cargas concentradas e zonas de mudança de espessura nas lajes, tais como capitéis ou drop panels.

A figura B.1, mostra a ruptura provocada pelo esforço cortante em um pavimento típico com laje plana. 


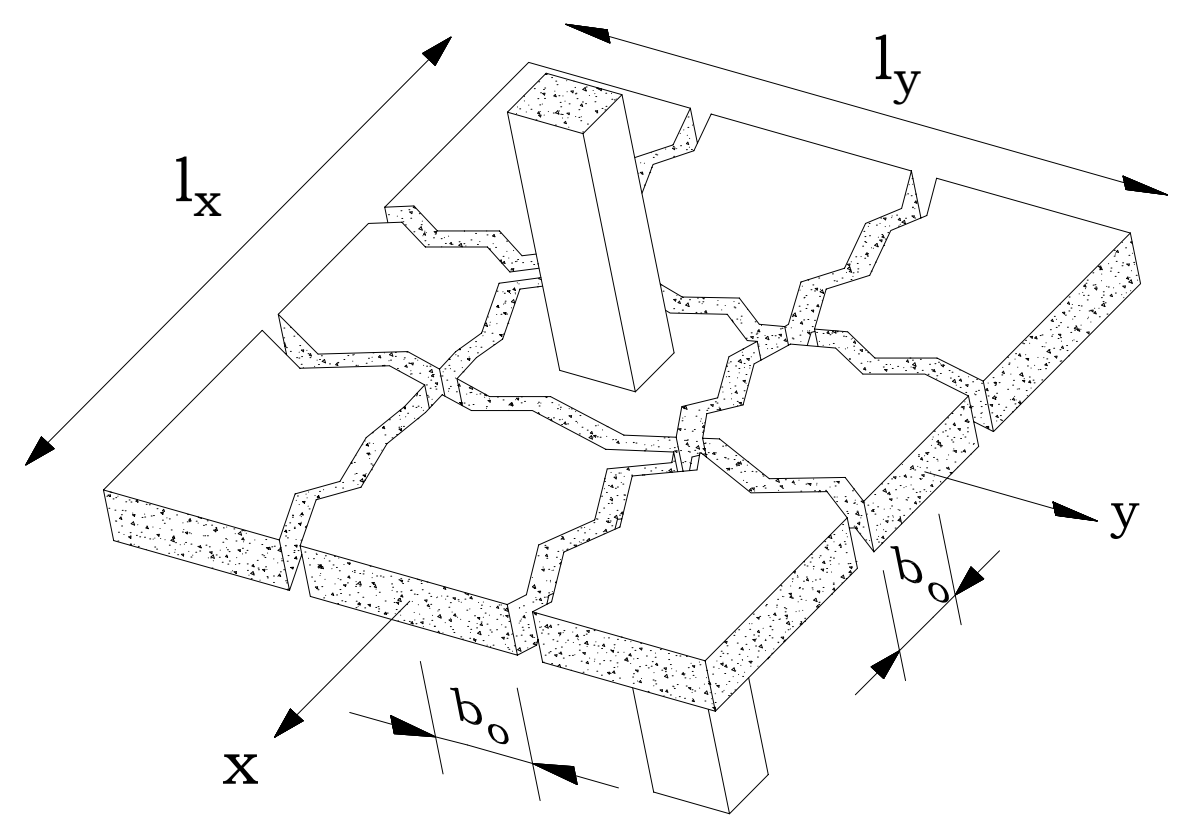

Figura B.1 - Cisalhamento global em lajes a $b_{o}=d / 2$ das faces do pilar de acordo com ACI 318-99 e ACI 423-89

Para lajes sem protensão temos:

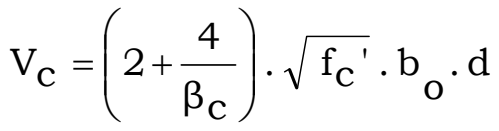

Onde,

$\beta_{c} \quad$ é a razão entre os lados do pilar (figura B.2);

$V_{C}=\left(2+\frac{\alpha_{S} \cdot d}{b_{O}}\right) \cdot \sqrt{f_{c^{\prime}}} \cdot b_{O} \cdot d$

Com,

$\mathrm{V}_{\mathrm{c}}$ é resistência nominal do concreto ao esforço cortante;

$\mathrm{f}_{\mathrm{c}} \quad$ é a resistência à compressão do concreto;

d é a altura útil da seção transversal da peça;

$\alpha_{S} \quad$ igual 40 para pilares internos, 30 para pilares de borda e 20 para pilares de canto.

Para lajes protendidas tem-se:

$$
V_{c}=\left(\beta_{p} \cdot \sqrt{f_{c}{ }^{\prime}}+0,3 \cdot f_{p c}\right) \cdot b_{o} \cdot d+V_{p}
$$




$$
V_{C}=\left(0,29 \cdot \sqrt{f_{c}{ }^{\prime}}+0,3 \cdot f_{p c}\right) \cdot b_{o} \cdot d+V_{p}
$$

Onde:

$$
\beta_{p} \leq\left[\begin{array}{c}
3,5 \\
\text { ou } \\
\frac{\alpha_{\mathrm{s}} \cdot \mathrm{d}}{\mathrm{b}_{\mathrm{o}}}+1,5
\end{array}\right)
$$

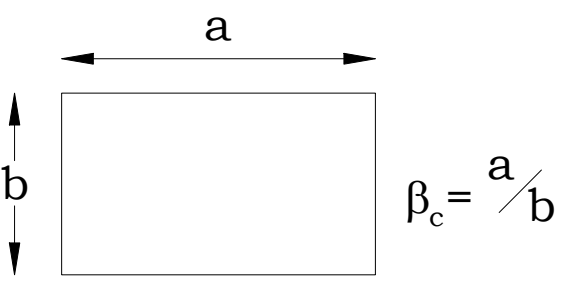

Figura B.2 - Relação $\beta_{c}$

$\mathrm{b}_{0} \quad$ perimetro crítico;

$\mathrm{f}_{\mathrm{pc}} \quad$ é o valor médio da tensão de compressão no concreto devido à força de protensão (após todas as perdas de protensão aplicadas) nas duas direções;

$\mathrm{V}_{\mathrm{p}} \quad$ é a componente vertical das forças de protensão na seção transversal.

Vale ressaltar que o valor de $\mathrm{f}_{\mathrm{c}}$ ' não deve ser superior a 34,473 $\mathrm{MPa}$ e que para $f_{p c}$ em cada direção não deve tomar valores menores que 0,862 MPa e nem maiores que 3,447 MPa.

Para tensões de protensão inferiores a 0,862 $\mathrm{MPa}$, o ACI 423-89 estabelece que a estrutura seja tratada como não protendida, devendo-se deve-se utilizar a equação a seguir:

$$
V_{c}=\left(2+\frac{\alpha_{S} \cdot d}{b_{o}}\right) \cdot \sqrt{f_{c^{\prime}} \cdot b_{o} \cdot d}
$$

Para a punção, admiti-se a distribuição uniforme das tensões em seu perímetro crítico, quando houver apenas a transferência de força normal ao pilar. Porém, quando da aplicação do momento, as tensões de cisalhamento se diferenciam ao longo do perímetro como ilustrado na figura B.3.

$\mathrm{Na}$ figura abaixo, tem-se a representação esquemática da variação destas tensões produzida pelo momento aplicado. 

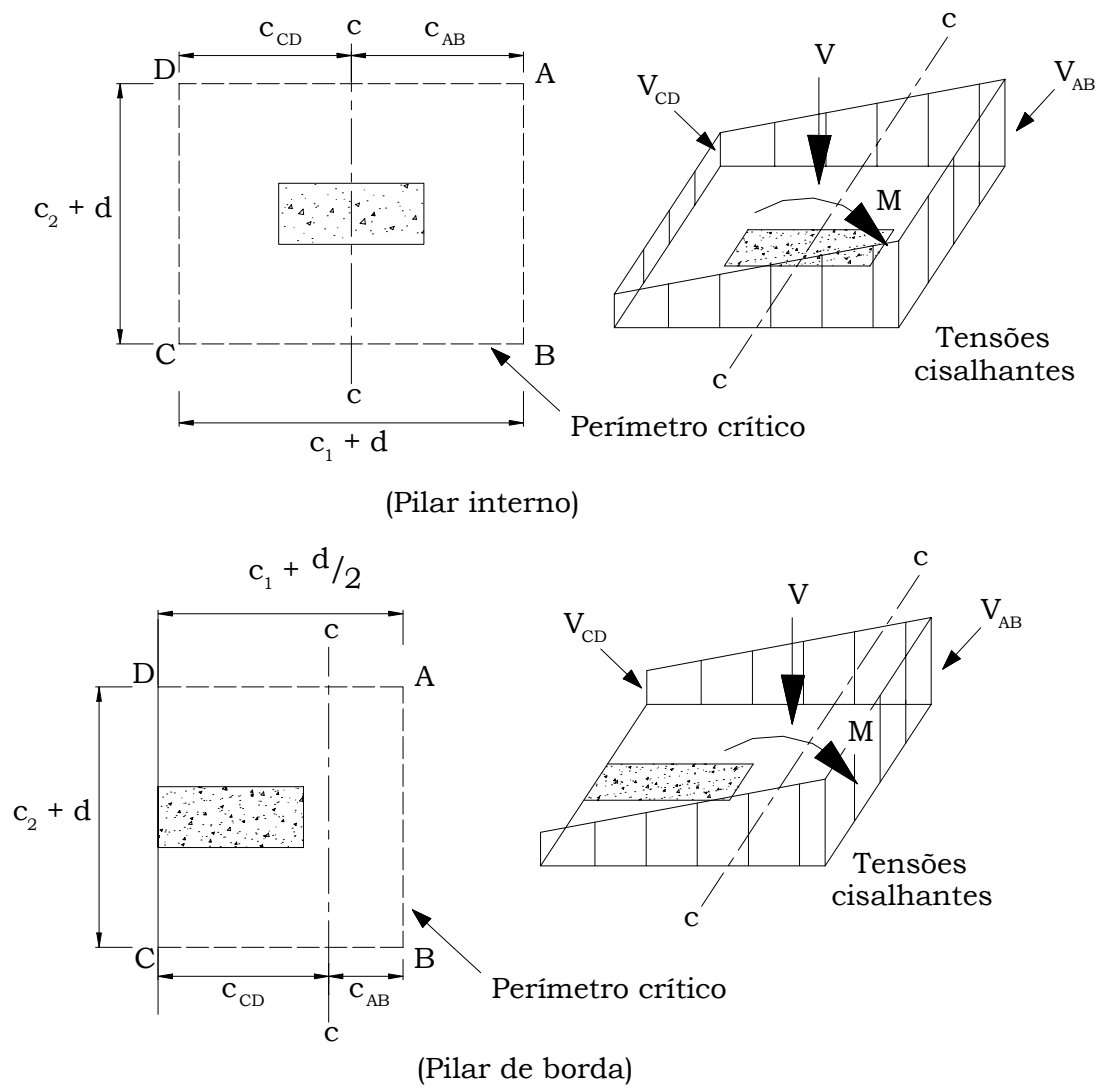

Figura B.3 - Tensões tangenciais nos perímetros críticos dos pilares internos e de borda, adaptado do ACI 318-99

Como se pode ver, ocorre um acréscimo de tensões de cisalhamento no perímetro crítico com uma distribuição não uniforme.

A distribuição de tensões de cisalhamento resultante é dada soma da tensão uniforme com a tensão variável pela transferência de momento para o pilar.

$$
\begin{aligned}
& \mathrm{V}_{\mathrm{u}}(\mathrm{AB})=\frac{\mathrm{V}_{\mathrm{u}}}{\mathrm{A}_{\mathrm{c}}} \pm \frac{\gamma_{\mathrm{v}} \cdot \mathrm{M}_{\mathrm{u}} \cdot \mathrm{c}_{\mathrm{AB}}}{\mathrm{J}_{\mathrm{C}}} \\
& \mathrm{V}_{\mathrm{u}}(\mathrm{CD})=\frac{\mathrm{V}_{\mathrm{u}}}{\mathrm{A}_{\mathrm{c}}} \pm \frac{\gamma_{\mathrm{v}} \cdot \mathrm{M}_{\mathrm{u}} \cdot \mathrm{c}_{\mathrm{CD}}}{\mathrm{J}_{\mathrm{c}}}
\end{aligned}
$$

Com,

$\mathrm{A}_{\mathrm{c}} \quad$ sendo a área do perímetro crítico considerado, para pilar interno;

$A_{c}=2 \cdot d \cdot\left(c_{1}+c_{2}+2 \cdot d\right)$

Eq. (B.11) 
$\mathrm{J}_{\mathrm{c}} \quad$ sendo o momento de inércia polar do perímetro crítico considerado, para pilares de borda;

$J_{C}=\frac{d \cdot\left(c_{1}+d\right)^{3}}{6}+\frac{\left(c_{1}+d\right) \cdot d^{3}}{6}+\frac{d \cdot\left(c_{2}+d\right) \cdot\left(c_{1}+d\right)^{2}}{2}$

$\gamma_{\mathrm{v}} \quad$ é a parcela de momento a ser transferida por esforço cortante;

$\gamma_{\mathrm{v}}=1-\gamma_{\mathrm{f}}$

$\gamma_{\mathrm{f}} \quad$ é a parcela de momento a ser transferida por flexão.

$\gamma_{\mathrm{f}}=\frac{1}{1+\left(\frac{2}{3}\right) \cdot \sqrt{\frac{\mathrm{b}_{1}}{\mathrm{~b}_{2}}}}$

$\mathrm{b}_{1}$ sendo a largura do perímetro crítico na direção do vão em que o momento é considerado;

$\mathrm{b}_{2}$ é a largura do perímetro crítico na direção perpendicular a $b_{1}$.

$\mathrm{Na}$ ocorrência de momento em ambas as direções, a máxima tensão é calculada superpondo-se todos os efeitos. Logo, para um caso genérico, tem-se:

$$
\mathrm{V}_{\mathrm{u}}=\frac{\mathrm{V}_{\mathrm{u}}}{\mathrm{A}}+\frac{\gamma_{\mathrm{vx}} \cdot \mathrm{M}_{\mathrm{ux}} \cdot \mathrm{c}_{\mathrm{x}}}{\mathrm{J}_{\mathrm{cx}}}+\frac{\gamma_{\mathrm{vy}} \cdot \mathrm{M}_{\mathrm{uy}} \cdot \mathrm{c}_{\mathrm{y}}}{\mathrm{J}_{\mathrm{cy}}}
$$

Segundo CARDOSO [2001], carregamentos desiguais em painéis de laje adjacentes, espaçamentos desiguais entre pilares, existência de pilares de borda e de canto, e solicitações diferentes em pilares devidas a recalques diferenciais podem provocar transferência de momento não equilibrado pela laje para o pilar, sendo que, parte desse momento é transferida por flexão e o restante é transferido devido à excentricidade da força cortante em relação ao centro de gravidade do perímetro crítico.

A seguir, tem-se as propriedades geométricas dos perimetros críticos para as situações de pilares internos (figuras B.4), de borda (figuras B.5) e de canto (figuras B.6), de acordo com o Código do ACI 318-99. 


\section{a) Pilar interno}

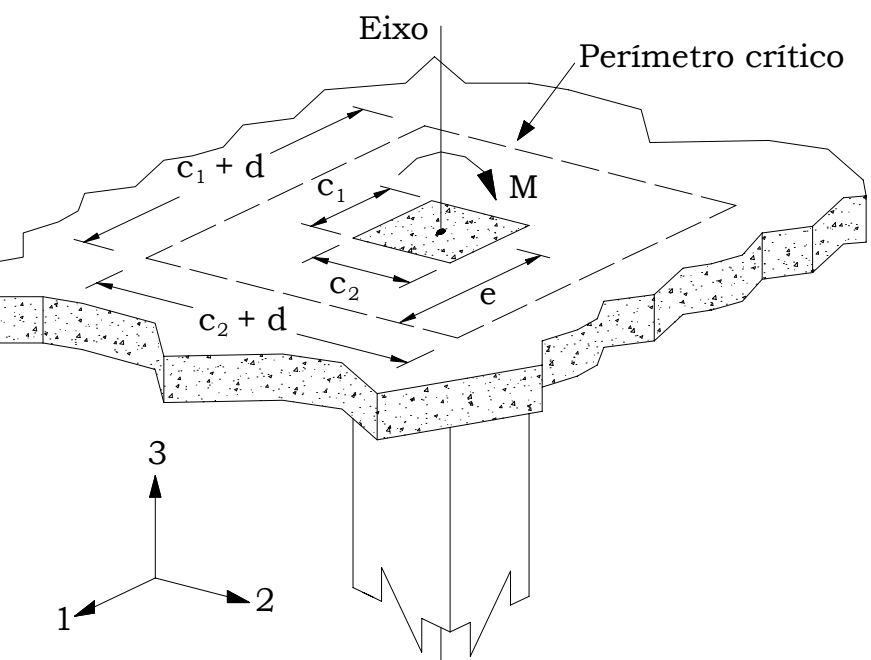

Figura B.4 - Propriedades geométricas para os pilares internos

$$
\begin{aligned}
& \mathrm{A}_{\mathrm{c}}=2 \cdot \mathrm{d} \cdot\left(\mathrm{c}_{1}+\mathrm{c}_{2}+2 \cdot \mathrm{d}\right) \\
& \mathrm{J}_{\mathrm{c}}=\frac{\mathrm{d} \cdot\left(\mathrm{c}_{2}+\mathrm{d}\right)^{3}}{6}+\frac{\left(\mathrm{c}_{2}+\mathrm{d}\right) \cdot \mathrm{d}^{3}}{6}+\frac{\mathrm{d} \cdot\left(\mathrm{c}_{1}+\mathrm{d}\right) \cdot\left(\mathrm{c}_{2}+\mathrm{d}\right)^{2}}{2} \\
& \mathrm{e}=\frac{\mathrm{c}_{1}+\mathrm{d}}{2} \\
& \gamma_{\mathrm{f}}=1-\frac{1}{1+\left(\frac{2}{3}\right) \cdot \sqrt{\frac{\mathrm{b}_{1}+\mathrm{d}}{\mathrm{b}_{2}+\mathrm{d}}}}
\end{aligned}
$$




\section{b) Pilar de borda}

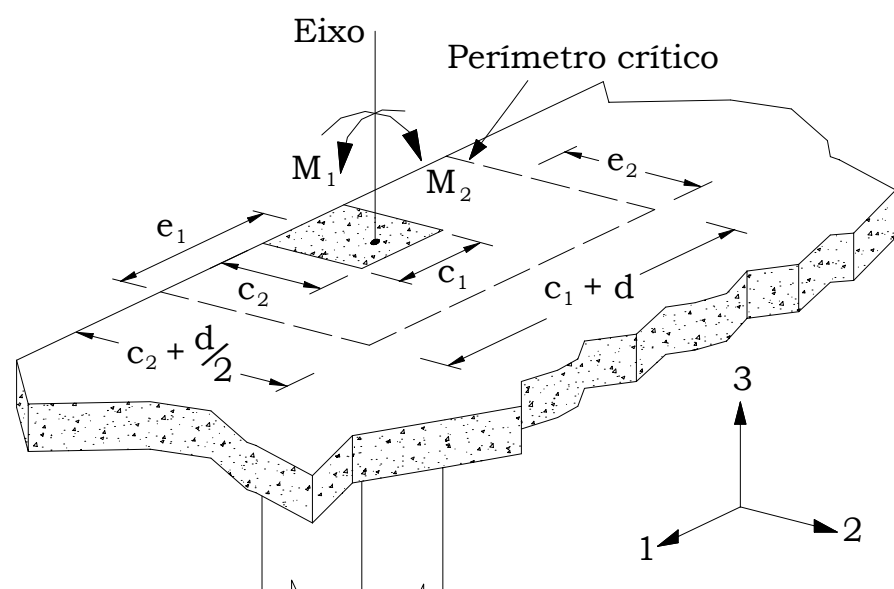

Figura 3.33 - Propriedades geométricas para os pilares de borda

$$
A_{c}=2 \cdot d \cdot\left(c_{1}+c_{2}+2 \cdot d\right)
$$

$e_{1}=\frac{\left(c_{1}+d / 2\right)^{2}}{\left(2 . c_{1}+c_{2}+2 . d\right)}$

$\mathrm{e}_{2}=\frac{\mathrm{c}_{2}+\mathrm{d}}{2}$

$\mathrm{J}_{\mathrm{c} 1}=\frac{\left[\left(\mathrm{c}_{1}+\mathrm{d} / 2\right) \cdot \mathrm{d}^{3}+\left(\mathrm{c}_{1}+\mathrm{d} / 2\right)^{3} \cdot \mathrm{d}\right]}{6}+\left(\mathrm{c}_{2}+\mathrm{d}\right) \cdot \mathrm{d} \cdot \mathrm{e}_{1}{ }^{2}+$

$$
\text { 2.d. }\left(c_{1}+d / 2\right) \cdot\left[\frac{\left(c_{1}+d / 2\right)}{2-e_{1}}\right]^{2}
$$

$$
J_{c 2}=\frac{\left\lfloor\left(c_{2}+d\right) \cdot d^{3}+d \cdot\left(c_{2}+d\right)^{3}\right\rfloor}{12}+2 \cdot d \cdot e_{2}^{2} \cdot\left(c_{1}+\frac{d}{2}\right)
$$

$$
\mathrm{v}_{\mathrm{v} 1}=1-\frac{1}{1+\left(\frac{2}{3}\right) \cdot \sqrt{\frac{\mathrm{c}_{1}+\mathrm{d} / 2}{\mathrm{c}_{2}+\mathrm{d}}}}
$$




$$
\mathrm{\gamma}_{\mathrm{v} 2}=1-\frac{1}{1+\left(\frac{2}{3}\right) \cdot \sqrt{\frac{\mathrm{c}_{2}+\mathrm{d}}{\mathrm{c}_{1}+\mathrm{d} / 2}}}
$$

\section{c) Pilar de borda}

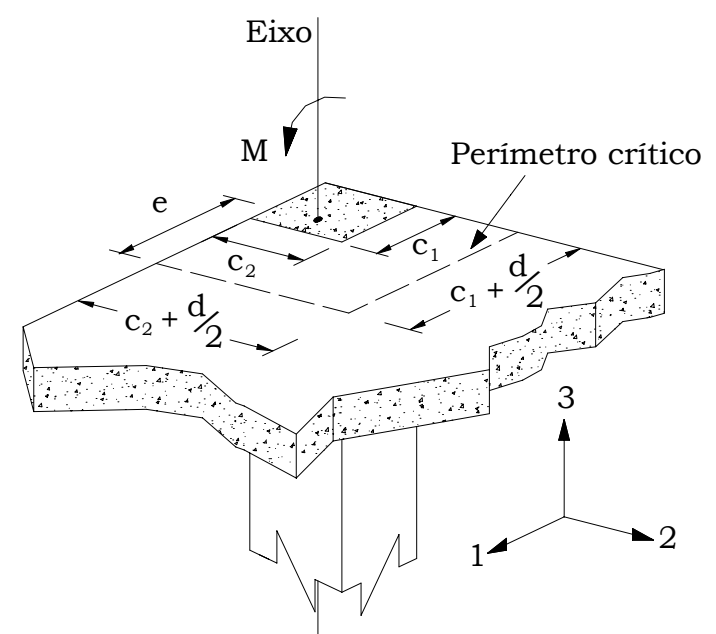

Figura 3.34 - Propriedades geométricas para os pilares de borda

$$
\begin{aligned}
& \mathrm{A}_{\mathrm{c}}=\mathrm{d} \cdot\left(\mathrm{c}_{1}+\mathrm{c}_{2}+\mathrm{d}\right) \\
& \mathrm{e}_{1}=\frac{\left(\mathrm{c}_{1}+\mathrm{d} / 2\right)^{2}}{2 \cdot\left(\mathrm{c}_{1}+\mathrm{c}_{2}+\mathrm{d}\right)} \\
& \mathrm{J}_{\mathrm{C}}=\frac{\left[\left(\mathrm{c}_{1}+\mathrm{d} / 2\right) \cdot \mathrm{d}^{3}+\left(\mathrm{c}_{1}+\mathrm{d} / 2\right)^{3} \cdot \mathrm{d}\right]}{\left.\left.\mathrm{d} \cdot\left(\mathrm{c}_{1}+\mathrm{d} / 2\right) \cdot\left[\frac{12}{2-\mathrm{c}} \mathrm{c}_{1}+\mathrm{d} / 2\right)\right]_{2}+\mathrm{d} / 2\right) \cdot \mathrm{d} \cdot \mathrm{e}^{2}+} \\
& \mathrm{\gamma}_{\mathrm{V}}=1-\frac{1}{1+\left(\frac{2}{3}\right) \cdot \sqrt{\frac{\mathrm{c}_{1}+\mathrm{d} / 2}{\mathrm{c}_{2}+\mathrm{d} / 2}}}
\end{aligned}
$$




\section{B.4 - Tensão no Cabo em Serviço}

Para ambos os casos, sistemas unidirecionais e bidirecionais, o cálculo para a tensão no cabo em serviço é dado pelas seguintes expressões:

Para valores de $1 / \mathrm{h} \leq 35$ :

$$
\mathrm{f}_{\mathrm{ps}}=\mathrm{f}_{\mathrm{se}}+70+\frac{\mathrm{f}_{\mathrm{c}}{ }^{\prime}}{100 \cdot \rho_{\mathrm{p}}}(\mathrm{em} \mathrm{MPa})
$$

Há comprovação experimental ${ }^{1}$ que a equação [Eq. (B.31)] superestima a quantidade do aumento da tensão nas cordoalhas engraxadas em lajes unidirecionais, lajes planas bidirecionais e lajes planas com relações vão/espessura superiores a 35.

Para lajes unidirecionais, lajes planas bidirecionais e lajes protendidas com cordoalhas não aderentes, a seguinte fórmula é válida (Para valores de $1 / \mathrm{h}^{>35)}$ :

$$
\mathrm{f}_{\mathrm{ps}}=\mathrm{f}_{\mathrm{se}}+70+\frac{\mathrm{f}_{\mathrm{c}}{ }^{\prime}}{300 \cdot \rho_{\mathrm{p}}}(\mathrm{em} \mathrm{MPa})
$$

Onde:

$\mathrm{f}_{\mathrm{se}}$ é a tensão efetiva da armadura protendida após a aplicação das perdas de protensão;

$\rho_{\mathrm{p}} \quad$ é a taxa de armadura de protensão $\left(\rho_{\mathrm{p}}=\frac{\mathrm{A}_{\mathrm{ps}}}{\mathrm{b} \cdot \mathrm{d}_{\mathrm{p}}}\right)$;

b é a espessura da face comprimida.

Deve-se levar em conta que o valor de $\mathrm{f}_{\mathrm{ps}}$ não deverá ser maior que $\mathrm{f}_{\mathrm{py}}$ ou maior que $\left(f_{\mathrm{se}}+414\right)$ em MPa.

1 MOJTAHEDI, S.; GAMBLE, W. L. [1978]. Ultimate Steel Stress in Unbonded Prestresed Concrete. Proceedings, ASCE, Vol. 104, ST7, july 1978, pp. 1159-1165. 